\title{
TITLE:
}

\section{Summary of mollusk data}

$\operatorname{AUTHOR}(\mathrm{S})$ :

OHGAKI, SHUN-ICHI; KOMEMOTO, KEN-ICHI; FUNAYAMA, NOBUTAKA

\section{CITATION:}

OHGAKI, SHUN-ICHI ...[et al]. 5. Summary of mollusk data. Publications of the Seto Marine Biological Laboratory. Special Publication Series 2011, 11: 31-166

ISSUE DATE:

2011

URL:

http://hdl.handle.net/2433/159495

RIGHT: 
5-1. Summary of mollusk data

Inter-annual variation in the distribution of 100 common species

Figure 2.

Yearly fluctuations in the distribution of 100 common species of the study area from 1985 to 2010. Species with an order of abundance (CQ in Table 2) of 1 to 100 were selected, and their distribution depicted. A numeral attached to a species name corresponds to the species code in the List of recorded species (Section 2). A filled square indicates a quadrat in which each species occurred. 


\section{Ischnochiton comptus}

ウスヒザラガイ
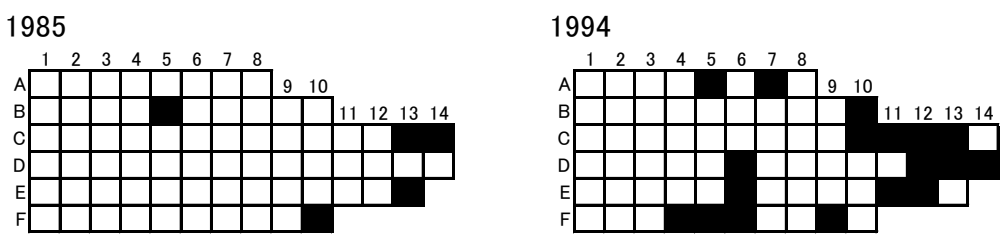

1986

1995
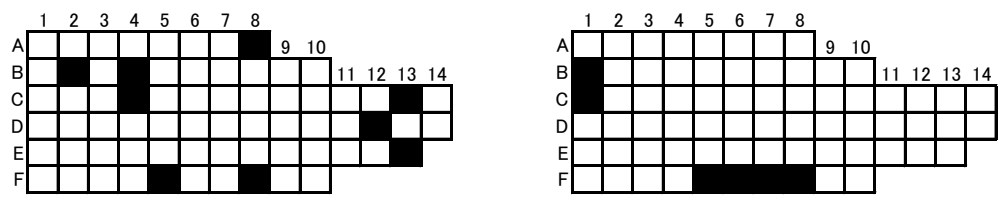

1987

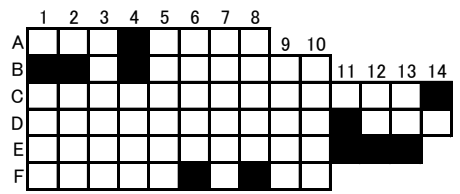

1996

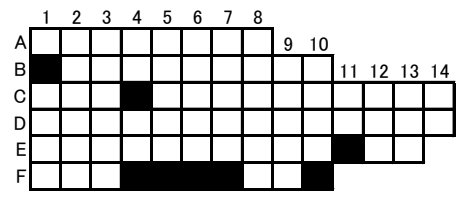

1988

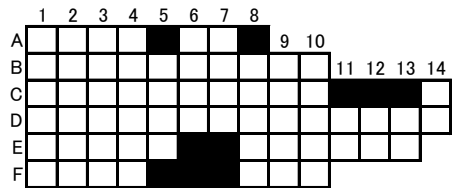

1997

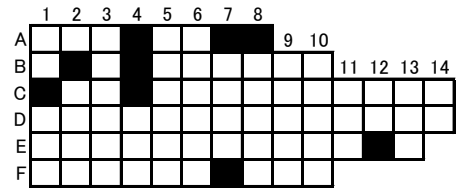

1989

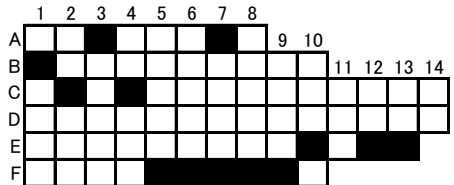

1998

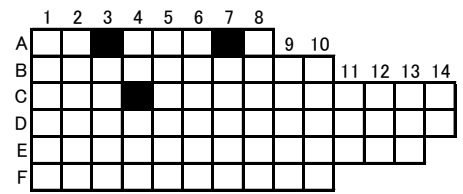

1990

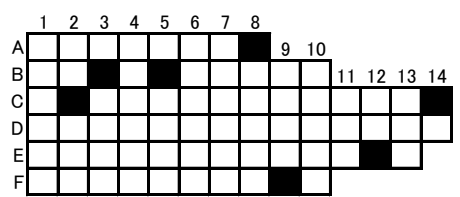

1999

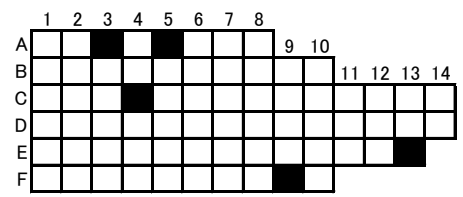

1991

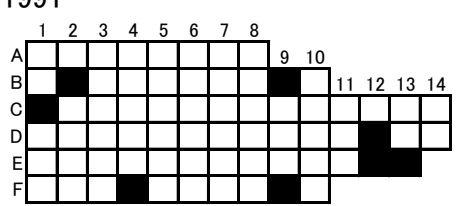

2000

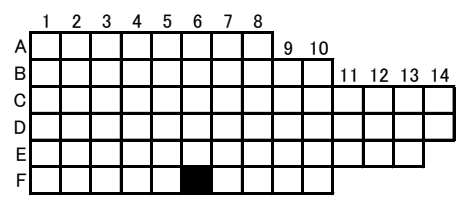

1992

2001

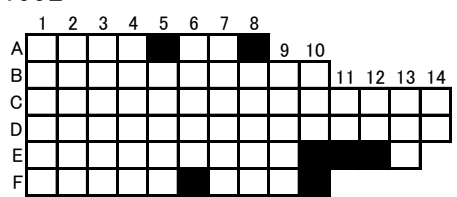

1993

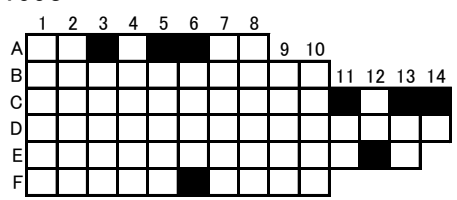

2003

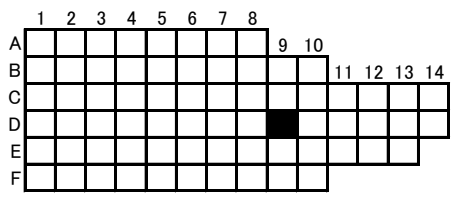

2004

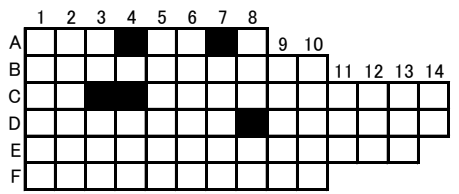

2005

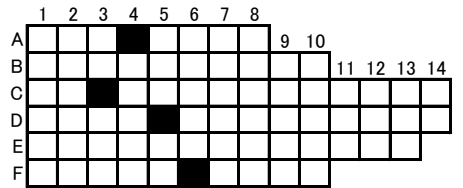

2006

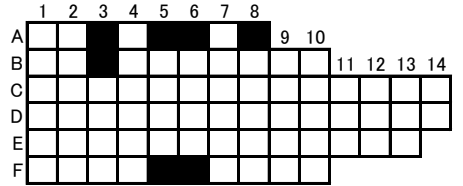

2007

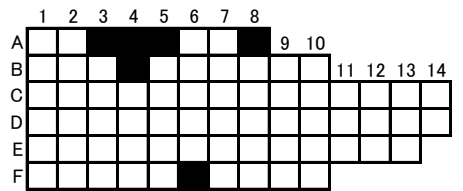

2008

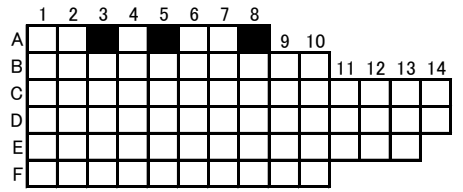

2009

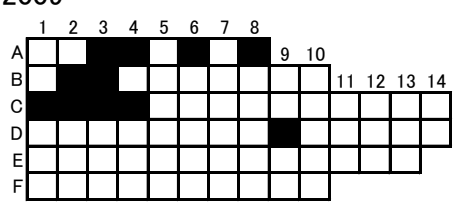

2010

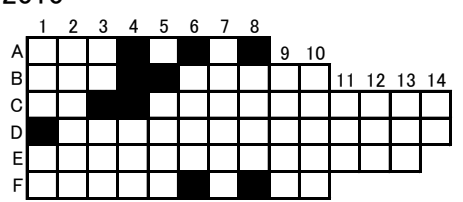

2002

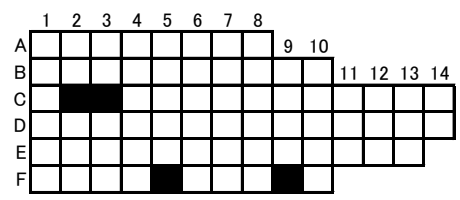



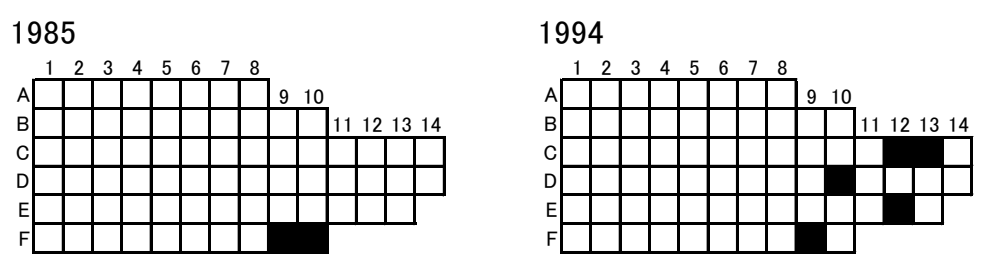

2003

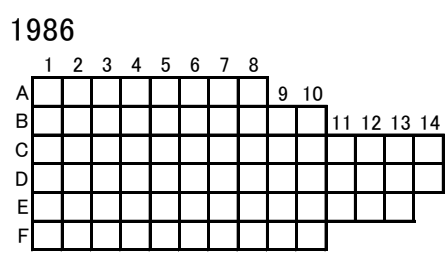

1995

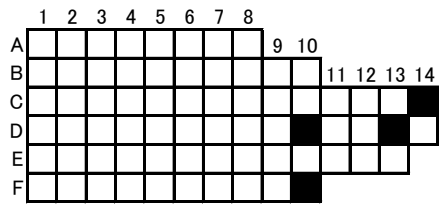

1987

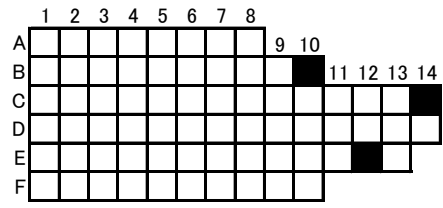

1996
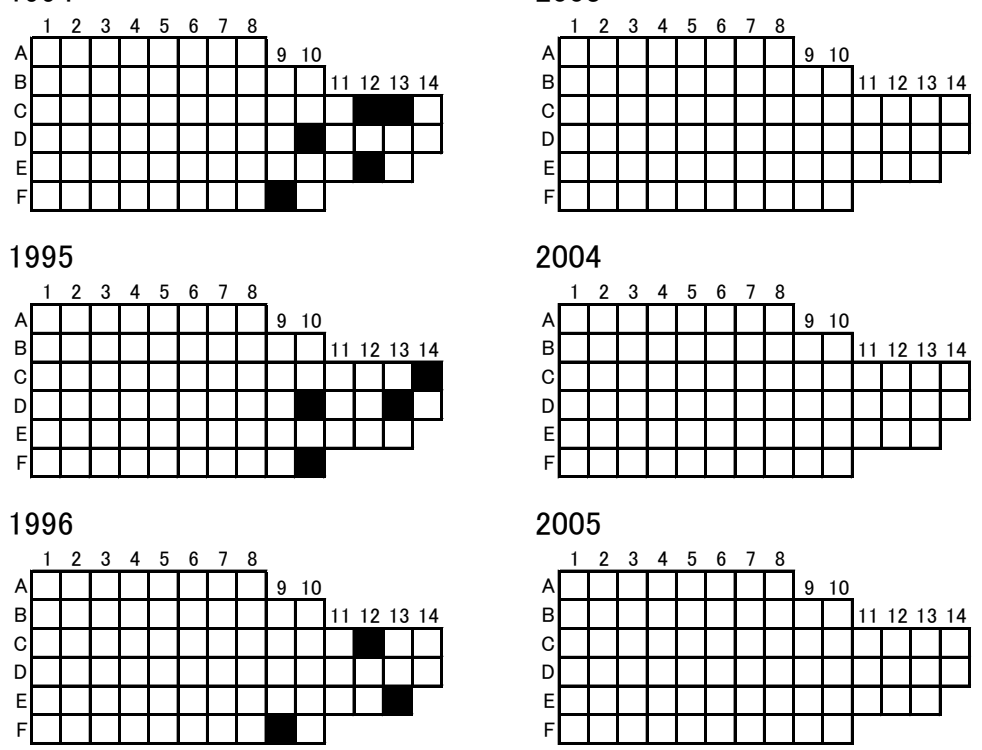

2004

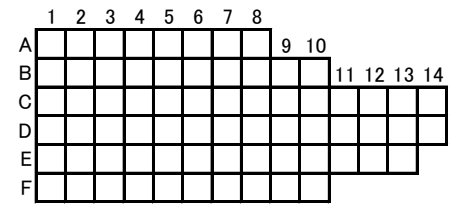

2005

1988

1997
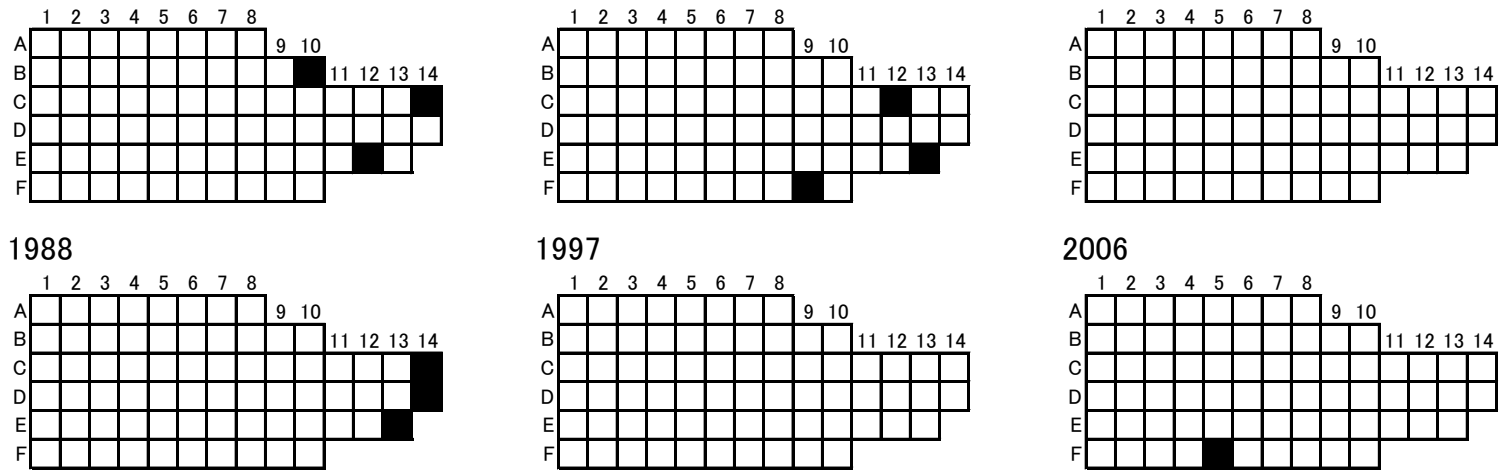

2006

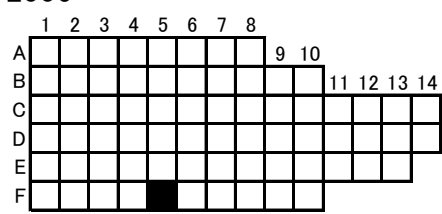

1989

1998
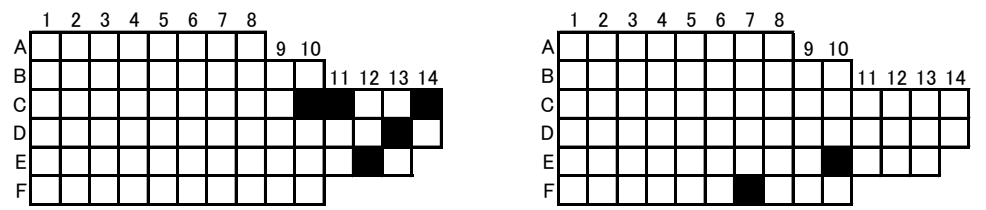

2007
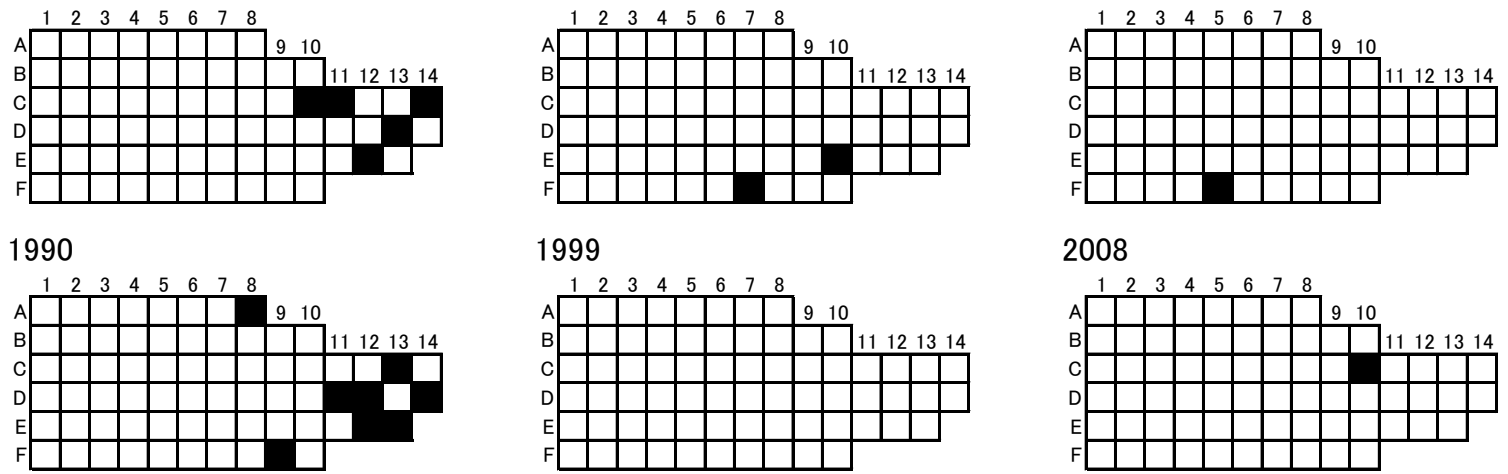

1999

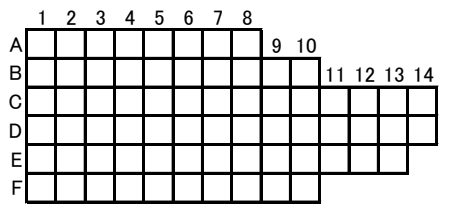

2008

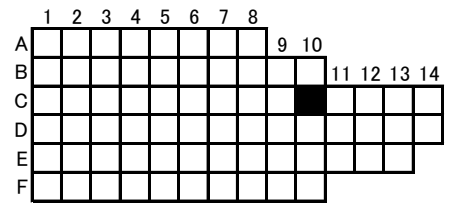

1991

2000
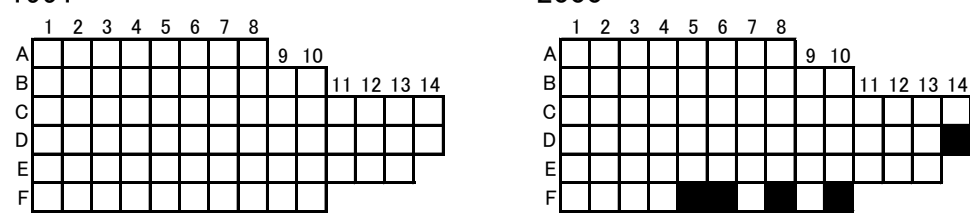

2009

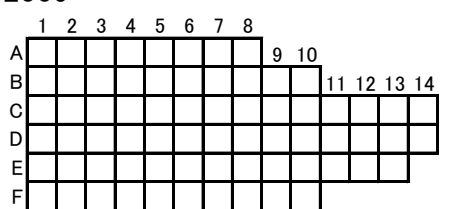

1992

2001
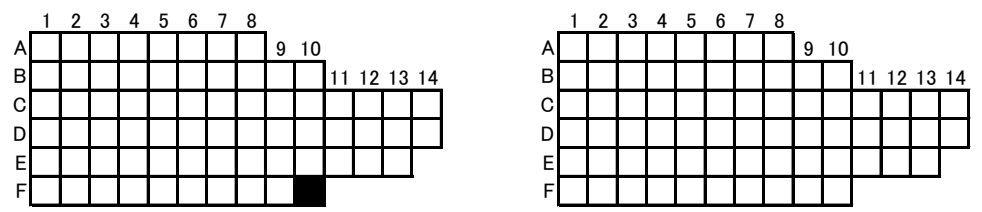

2010

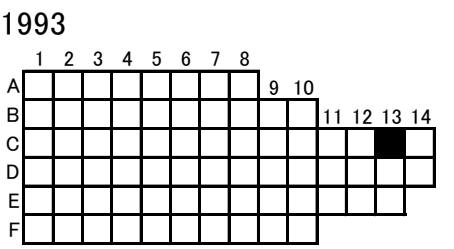

2002

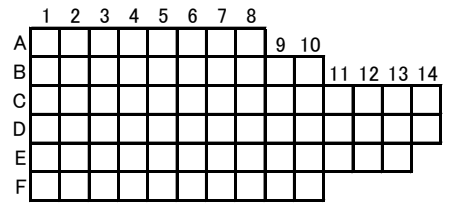

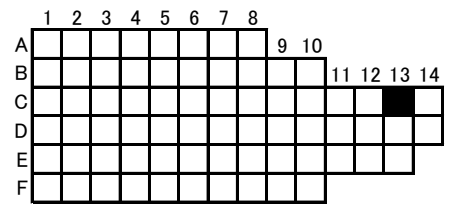


4 Acanthopleura japonica ヒザラガイ

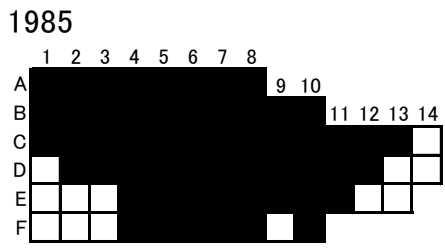

1994

2003
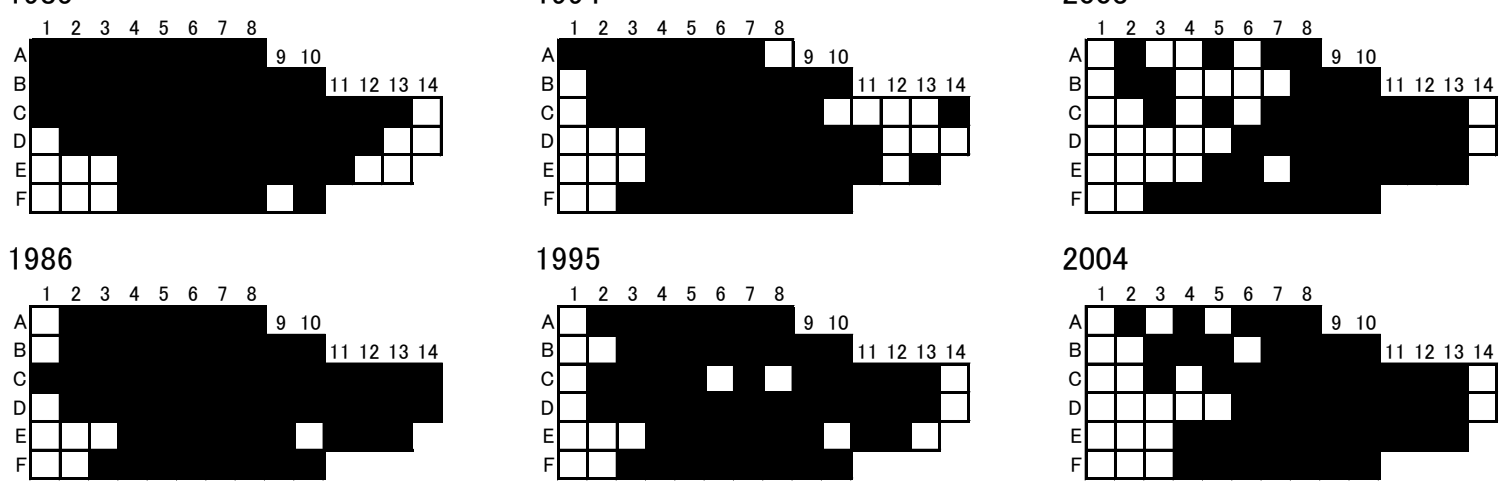

1995

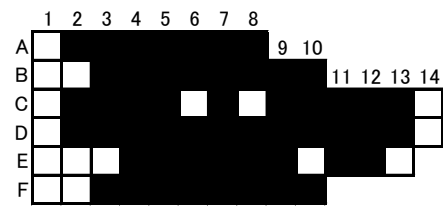

2004

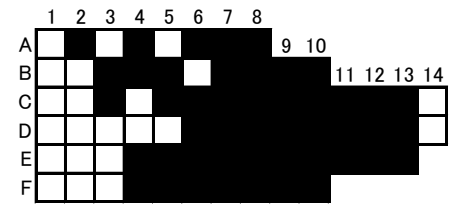

1987

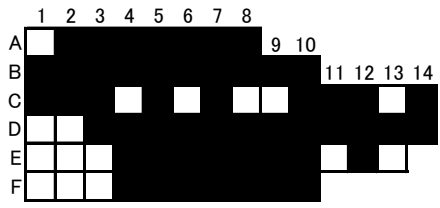

1996

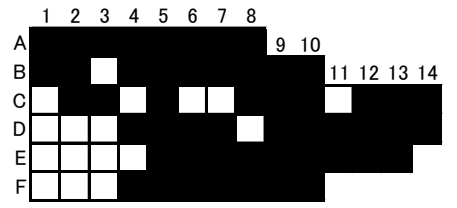

2005

1997
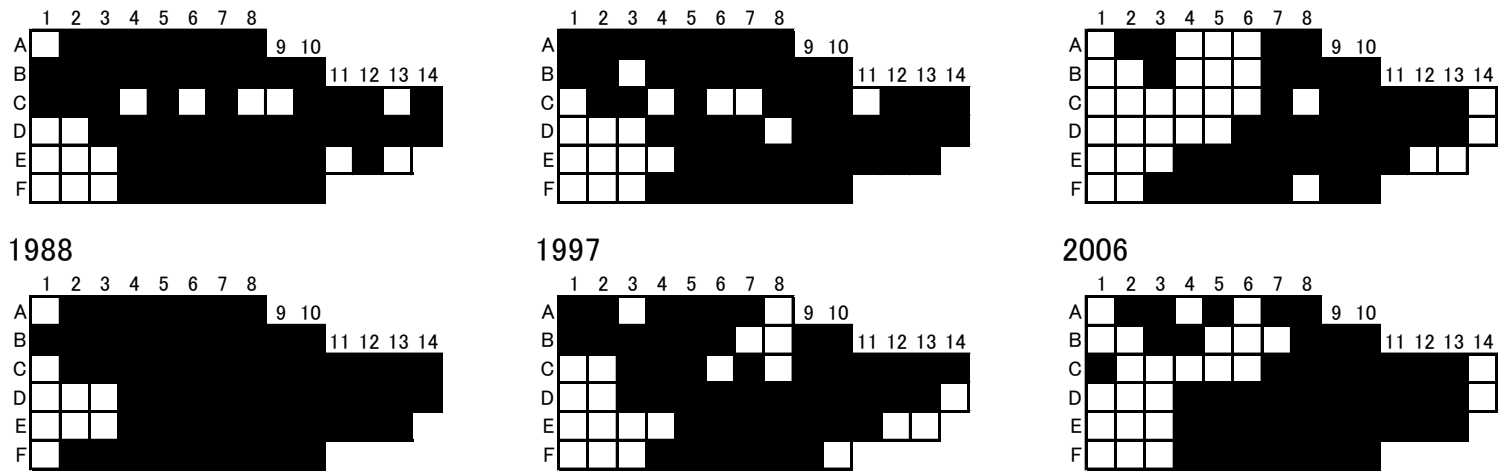

2006

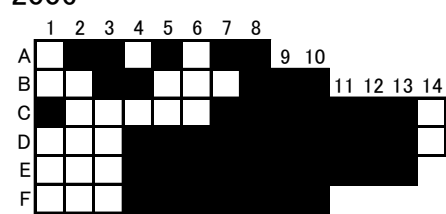

1989

1998
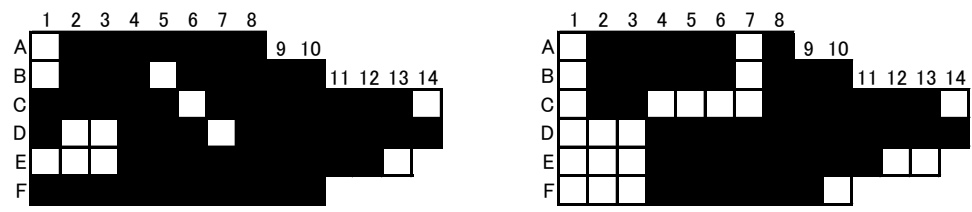

2007
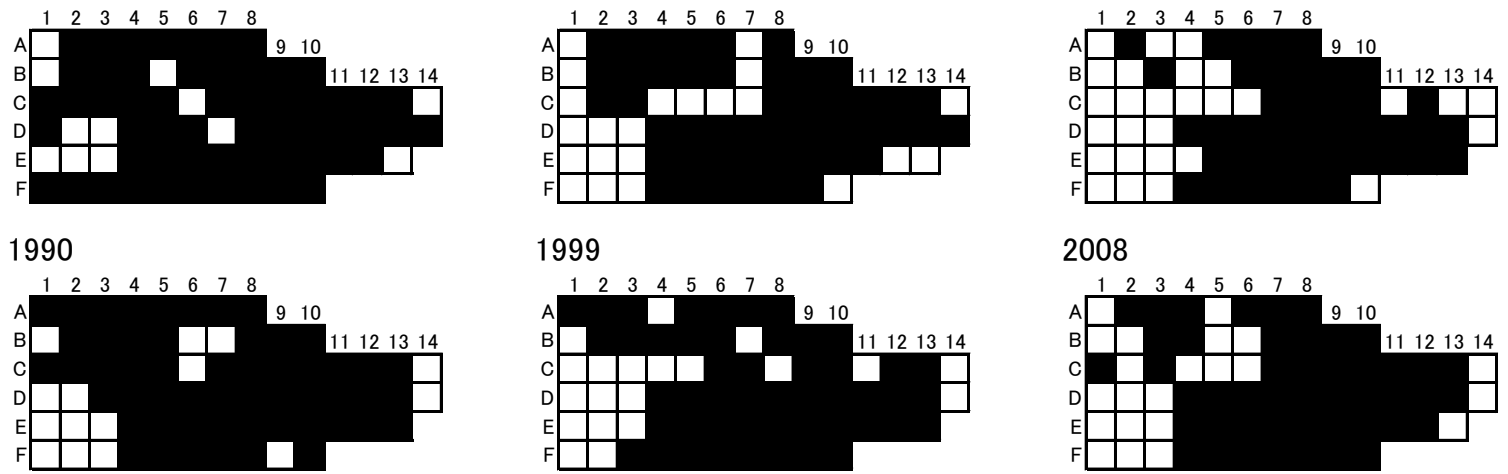

1999

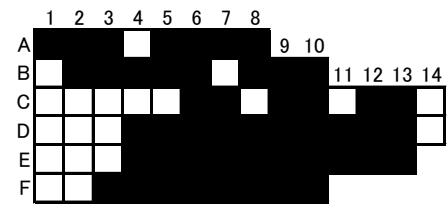

2008

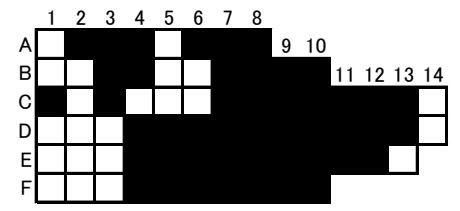

1991

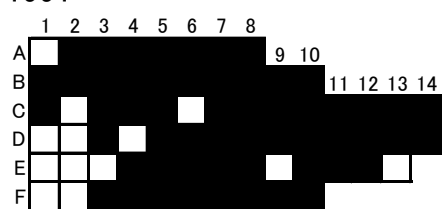

2000

2009
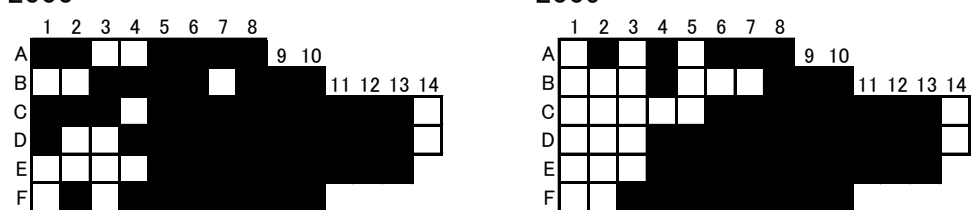

1992

2001
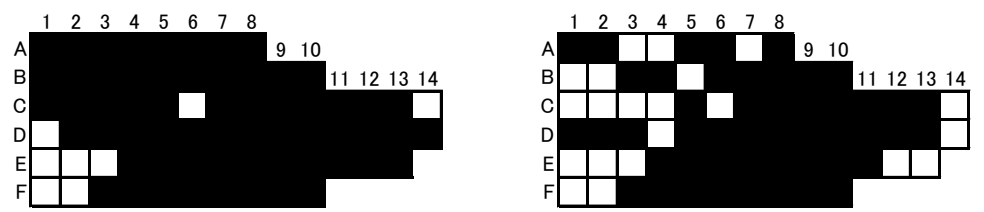

2010

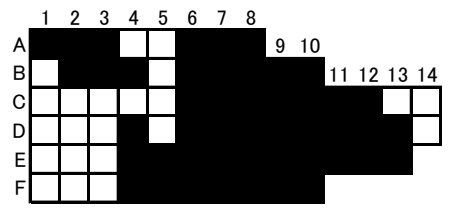

1993

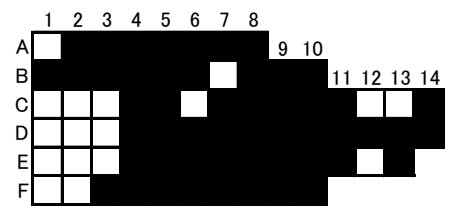

2002

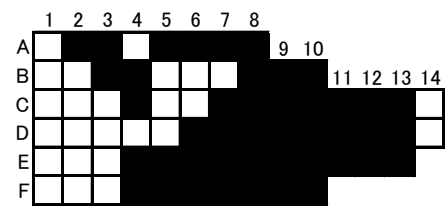


1985

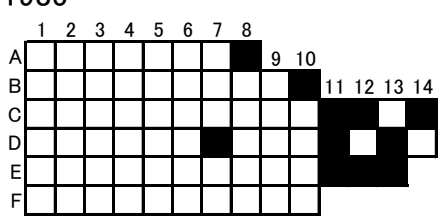

1986

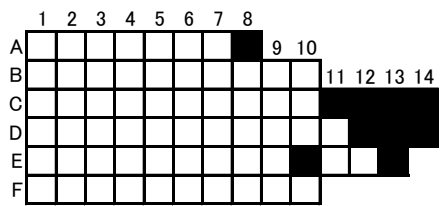

1987

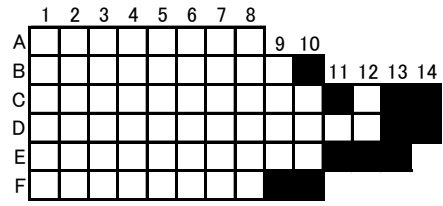

1988

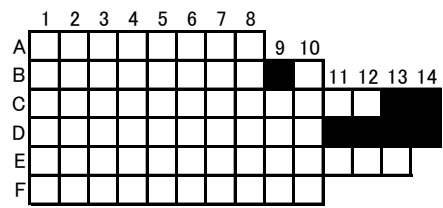

1989

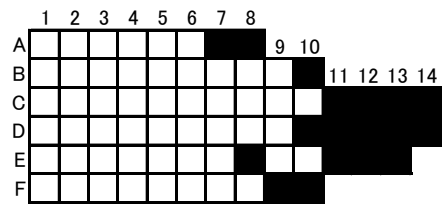

1990

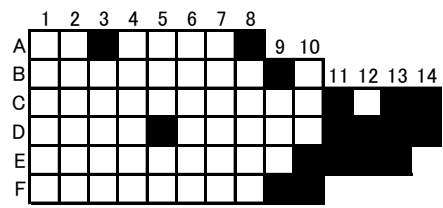

1991

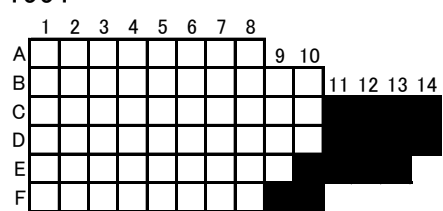

1992

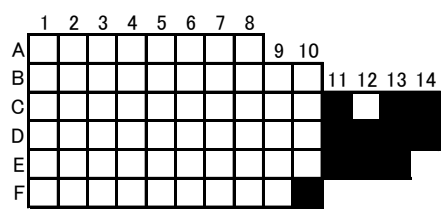

1993

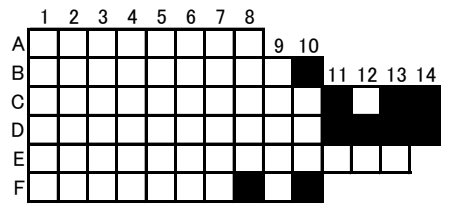

1994

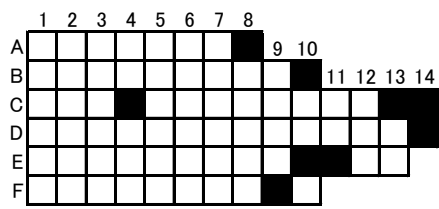

1995

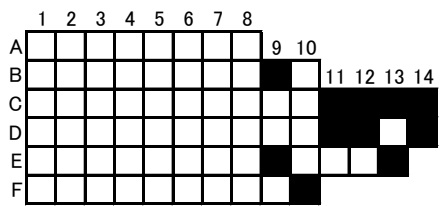

1996

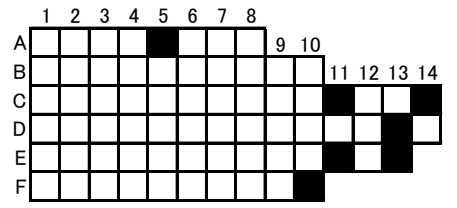

1997

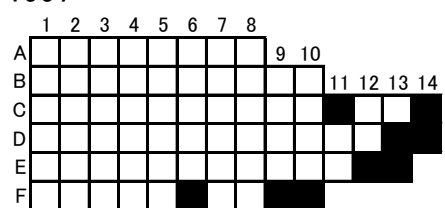

1998

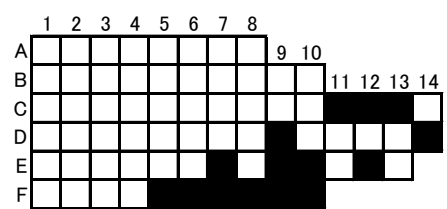

1999

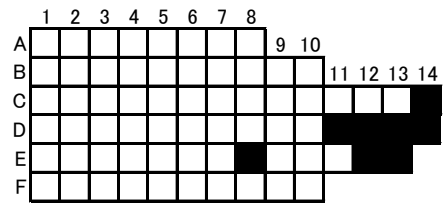

2000

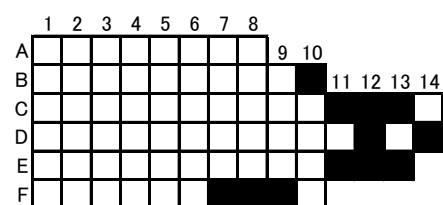

2001

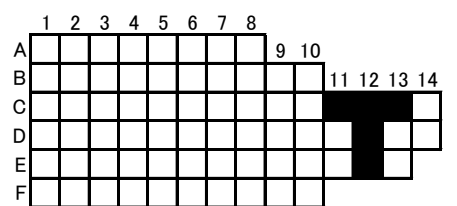

2002

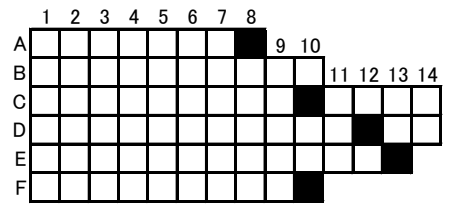

2003

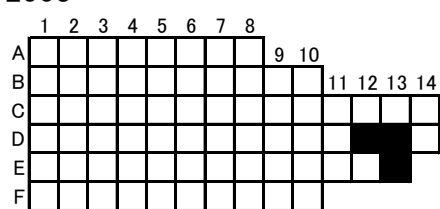

2004

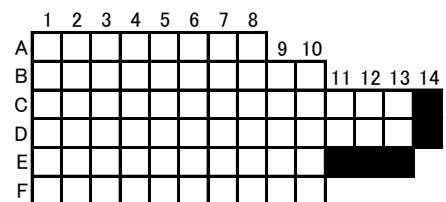

2005

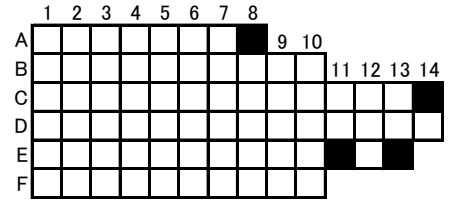

2006

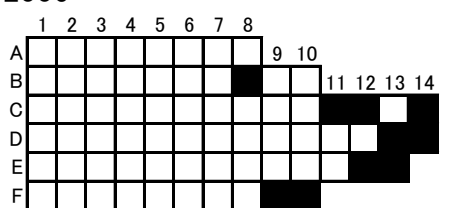

2007

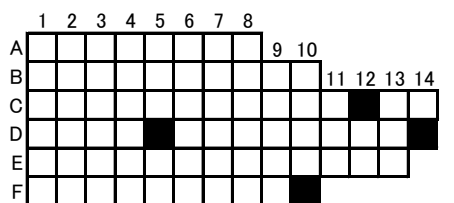

2008

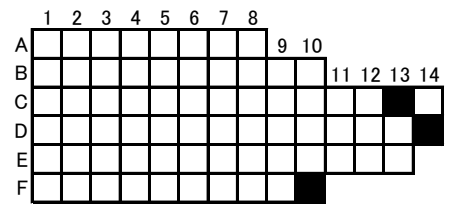

2009

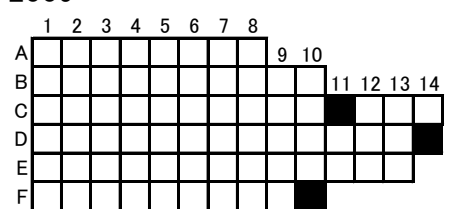

2010

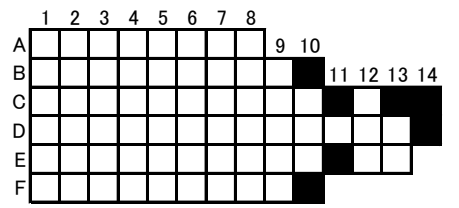


7 Acanthochitona achates ヒメケハダヒザラガイ

1985

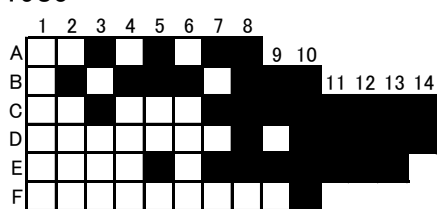

1986

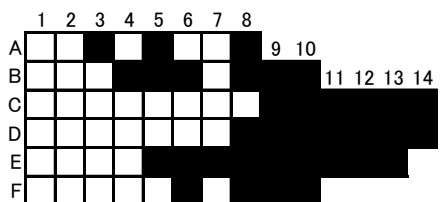

1987

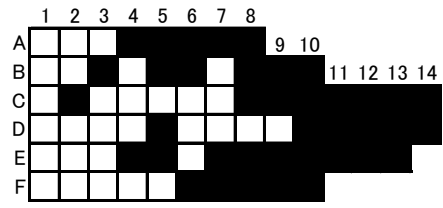

1988

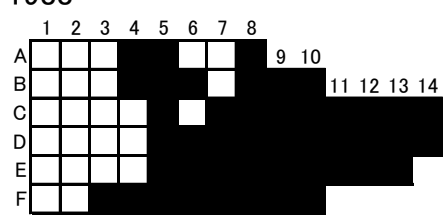

1989

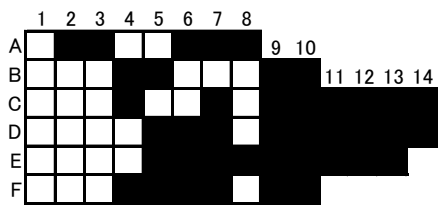

1990

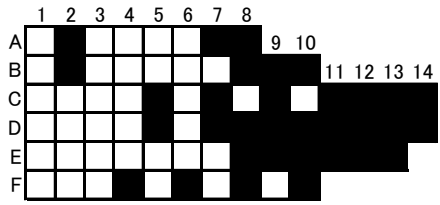

1991

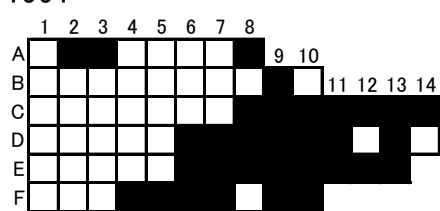

1992

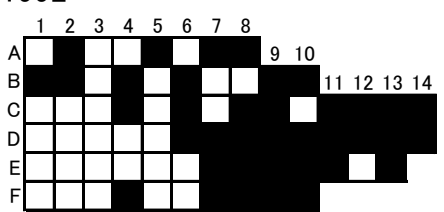

1993

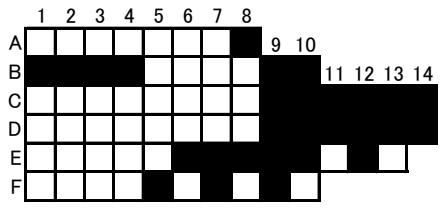

1994

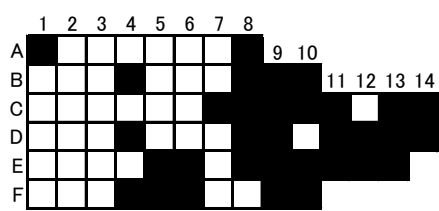

1995

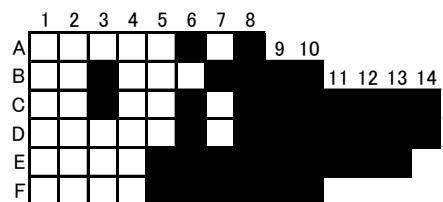

1996

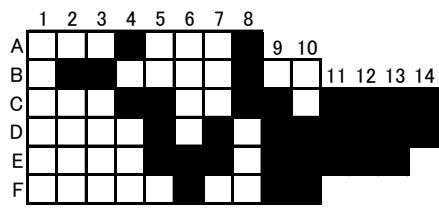

1997

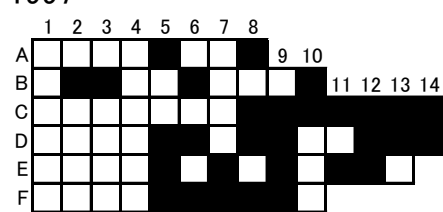

1998

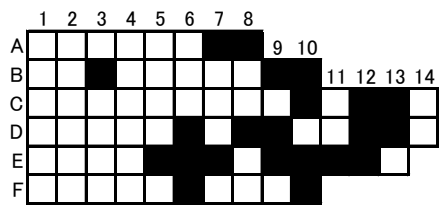

1999

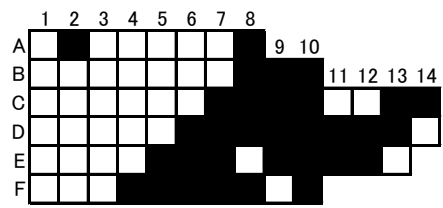

2000

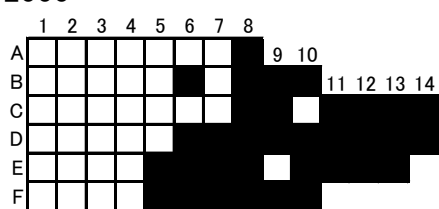

2001

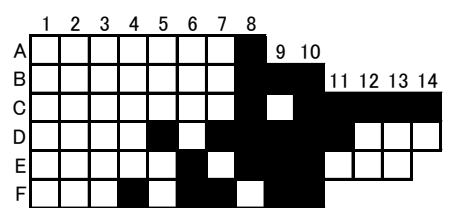

2002

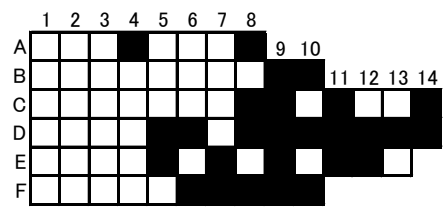

2003

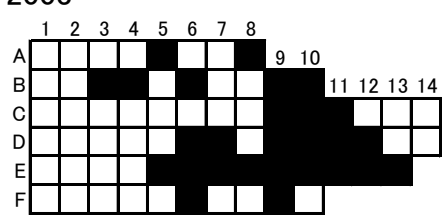

2004

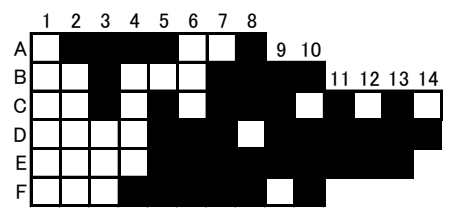

2005

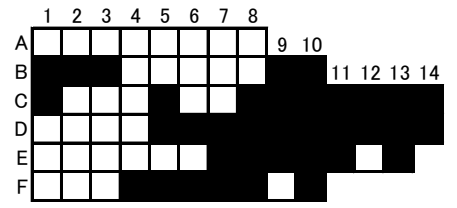

2006

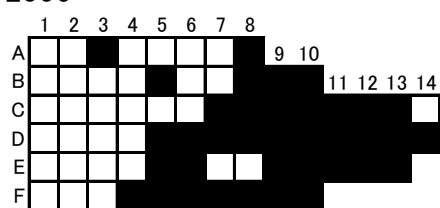

2007

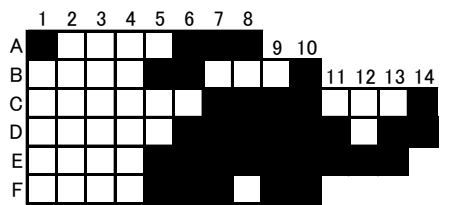

2008

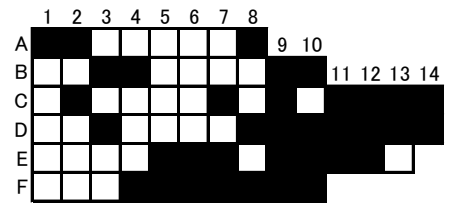

2009

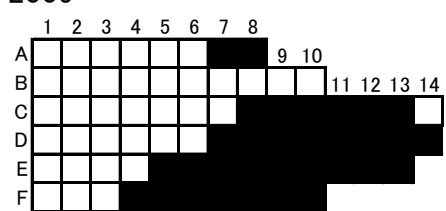

2010

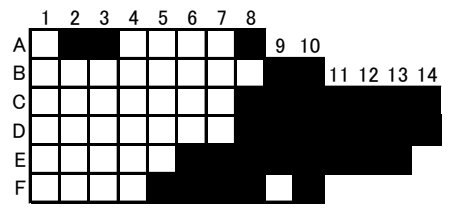


8 Acanthochitona dissimilis ビロウドヒザラガイ
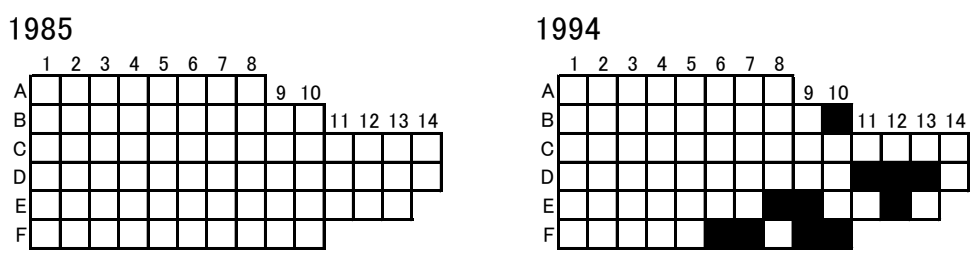

2003

1986

1995
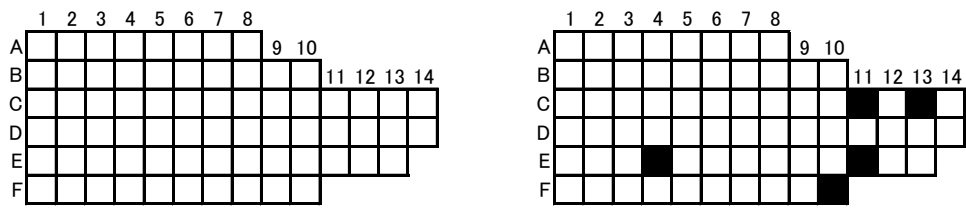

1987

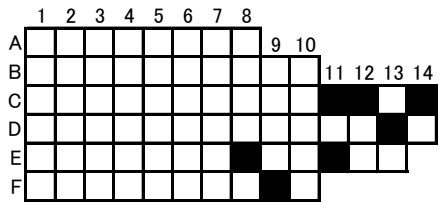

1996

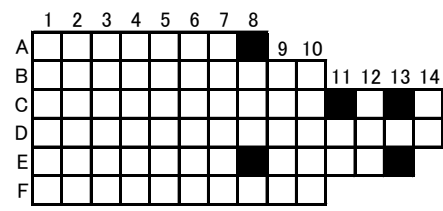

1988

1997
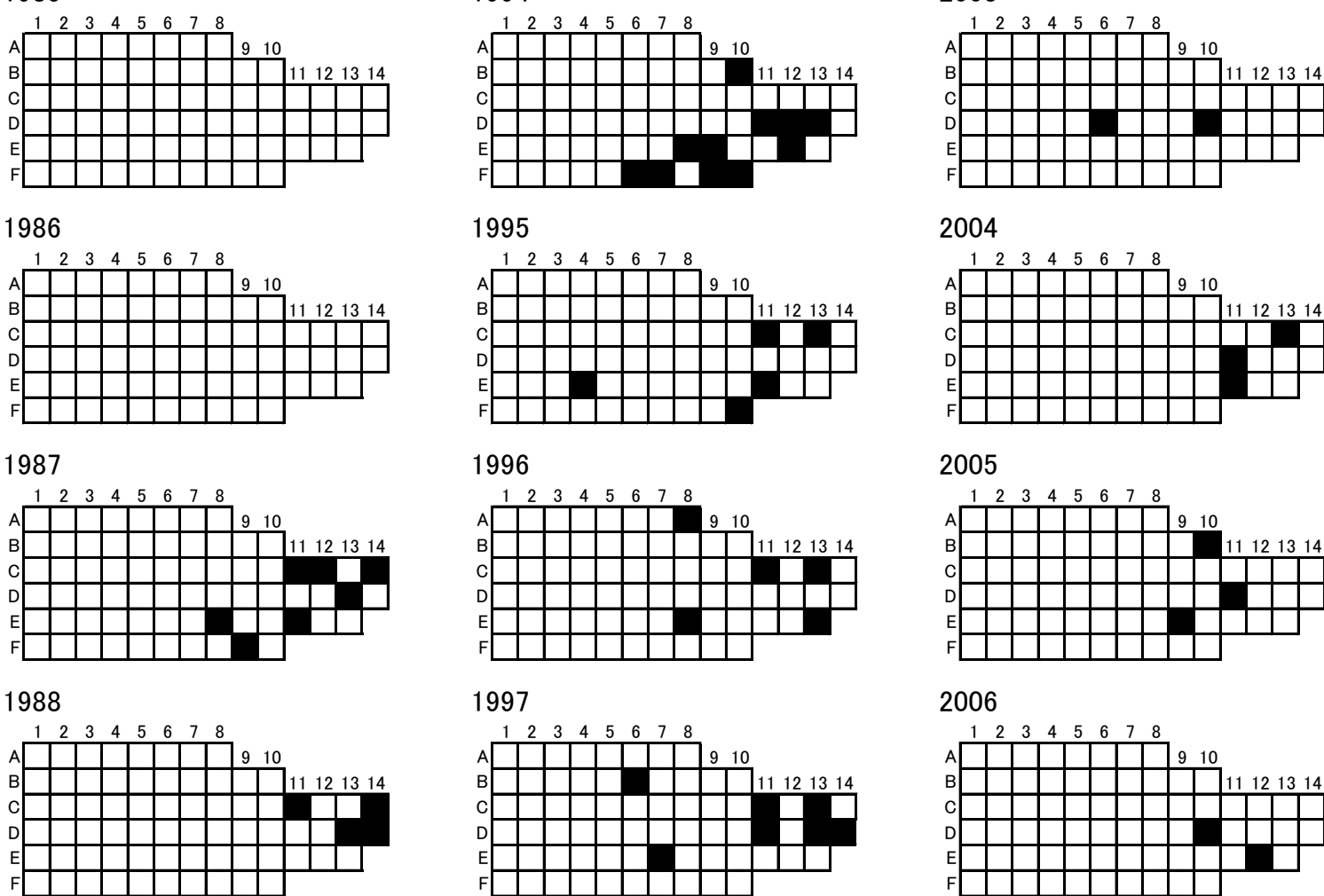

2004

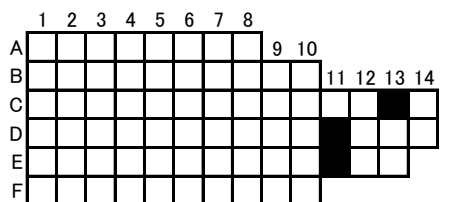

2005

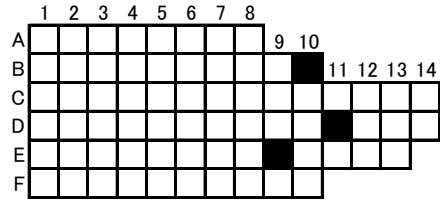

2006

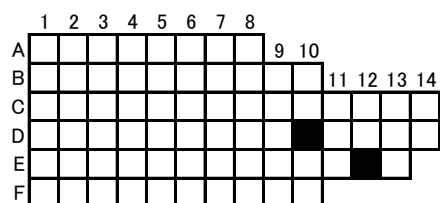

1989

1998
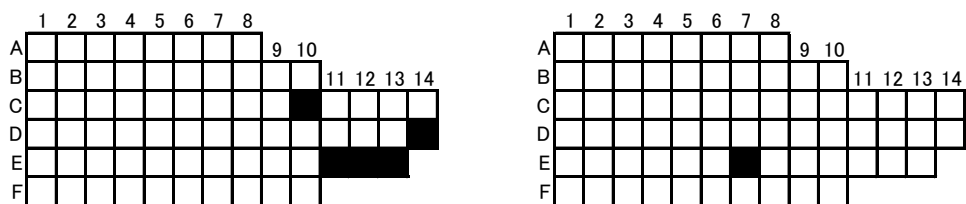

2007
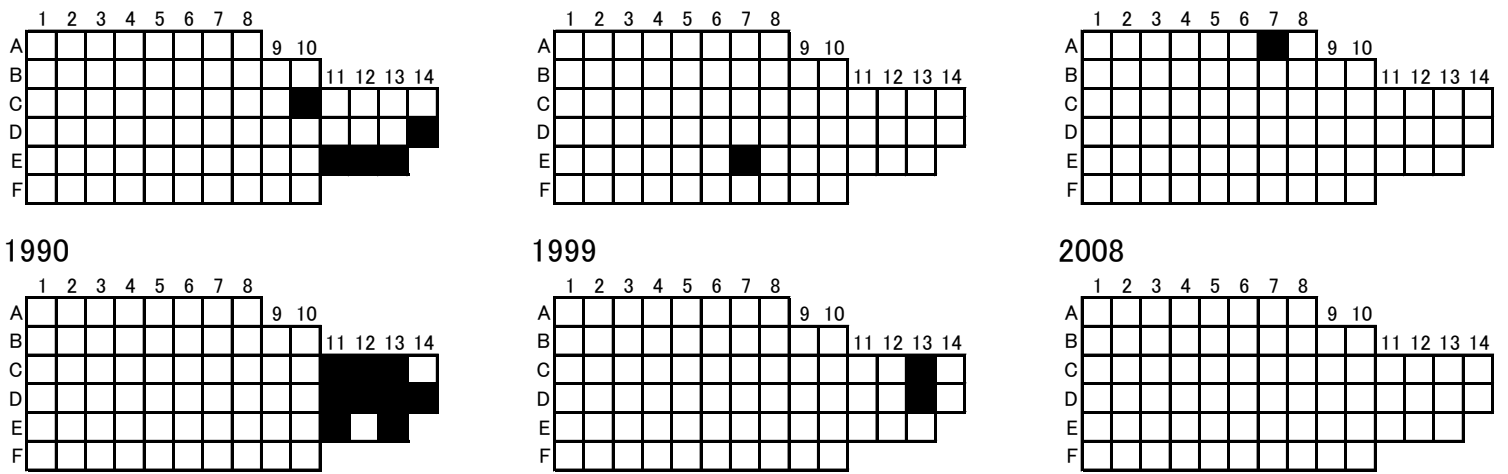

1999

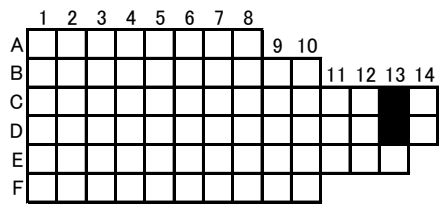

2008

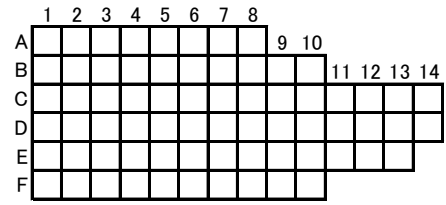

1991

2000
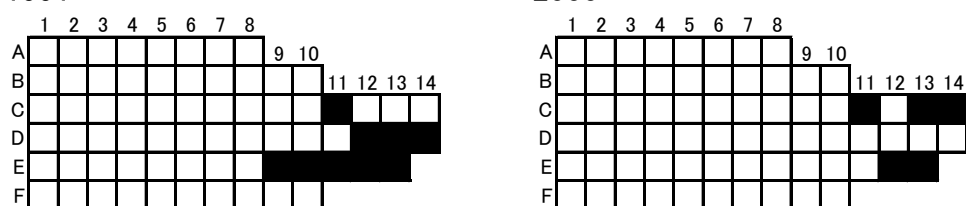

2009

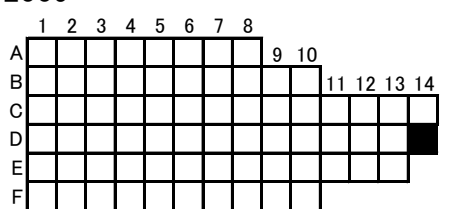

1992

2001
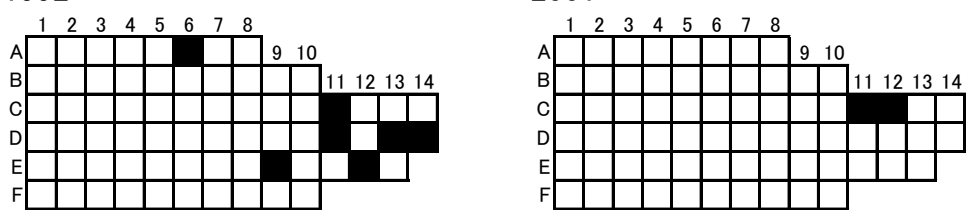

2010

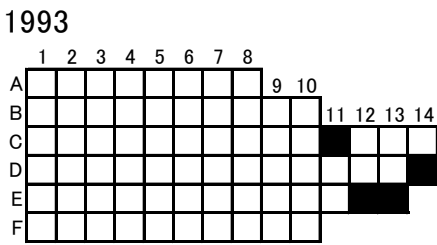

2002

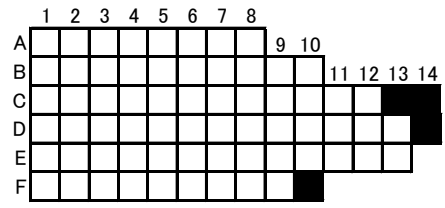

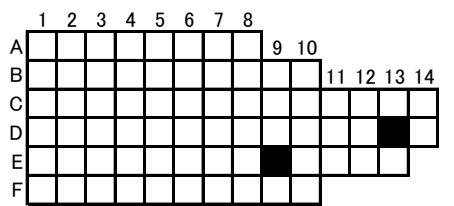



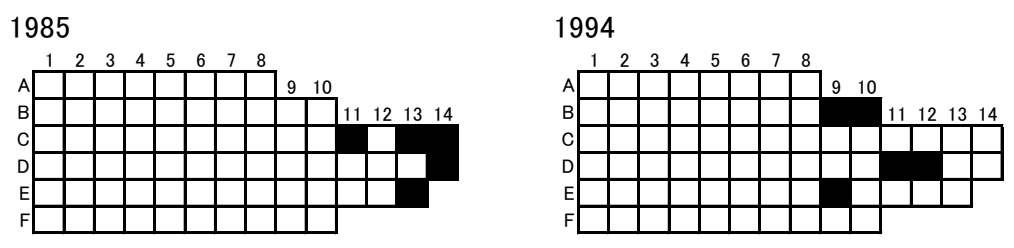

2003

1986

1995
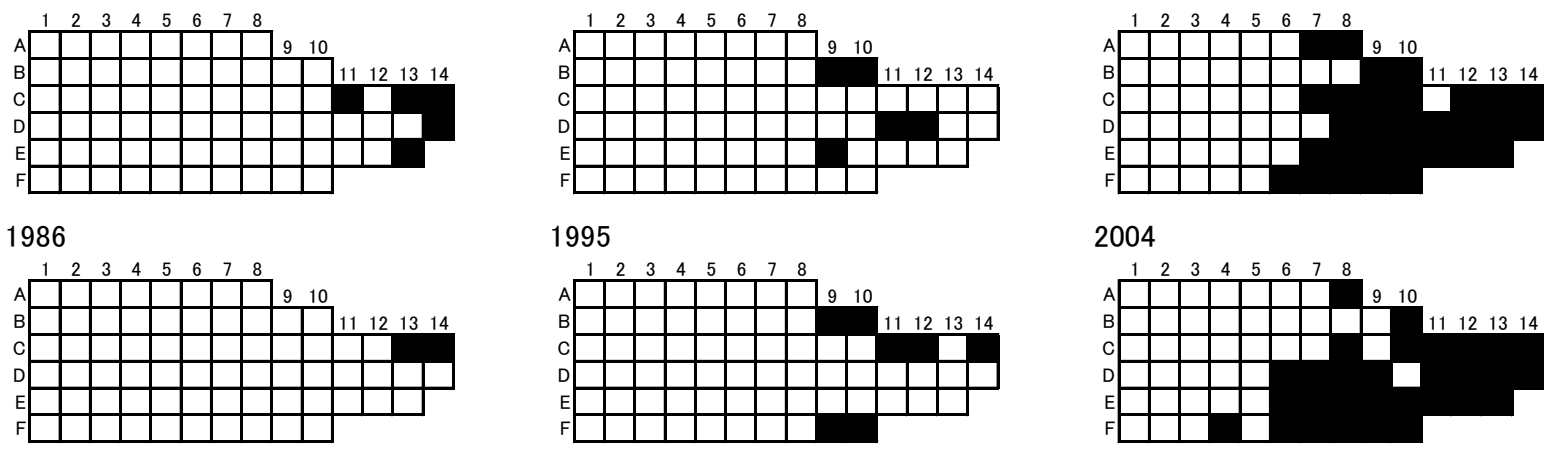

2004

1987

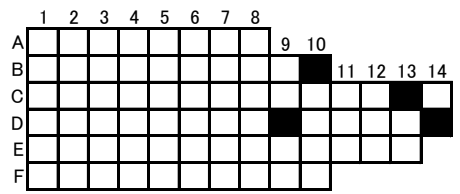

1996
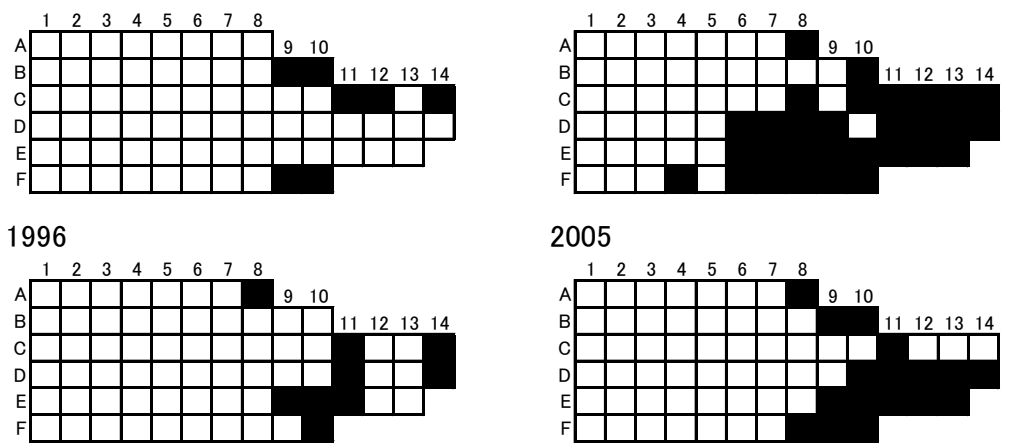

2005

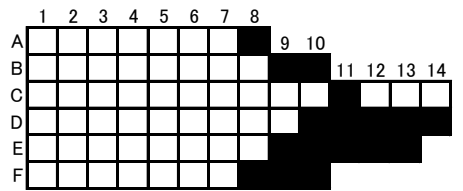

1988

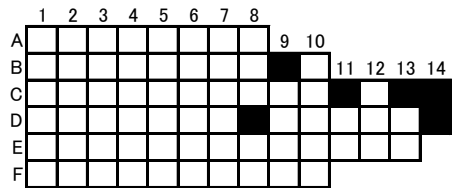

1997

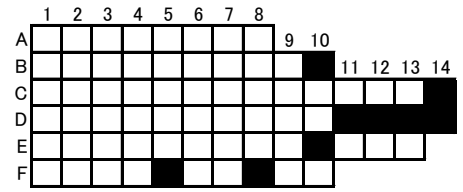

2006

1989

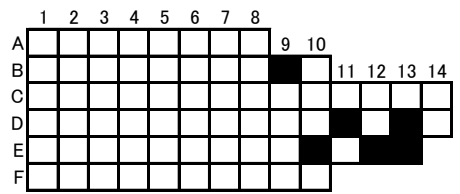

1998
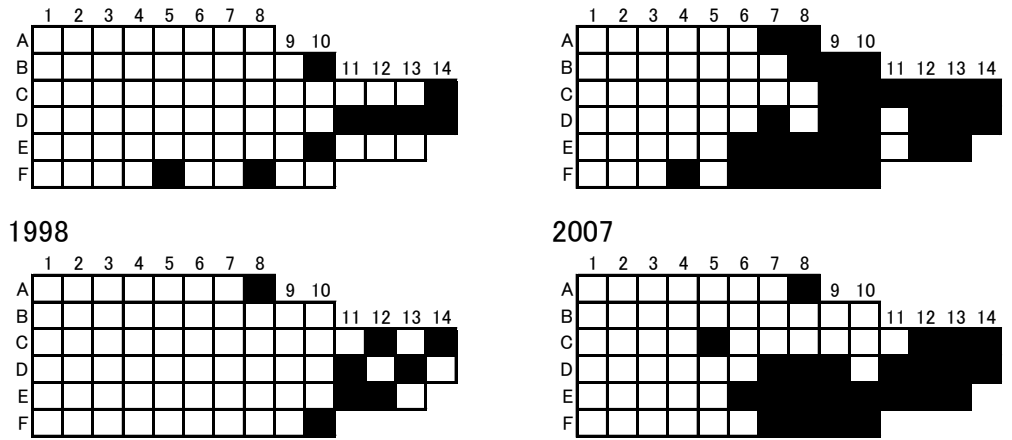

2007

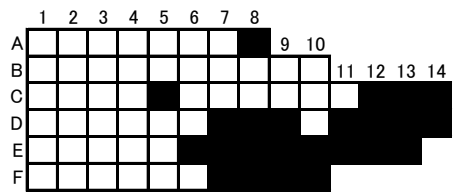

1999
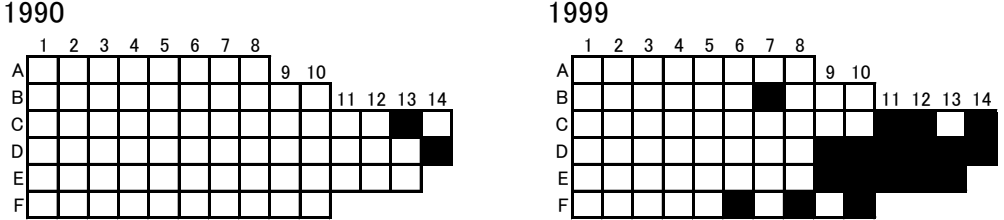

2008

1991

2000
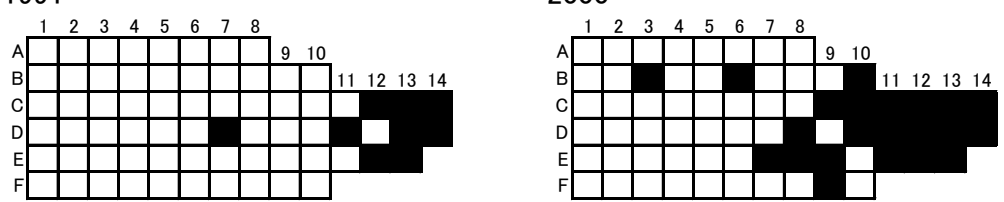

1992

2001
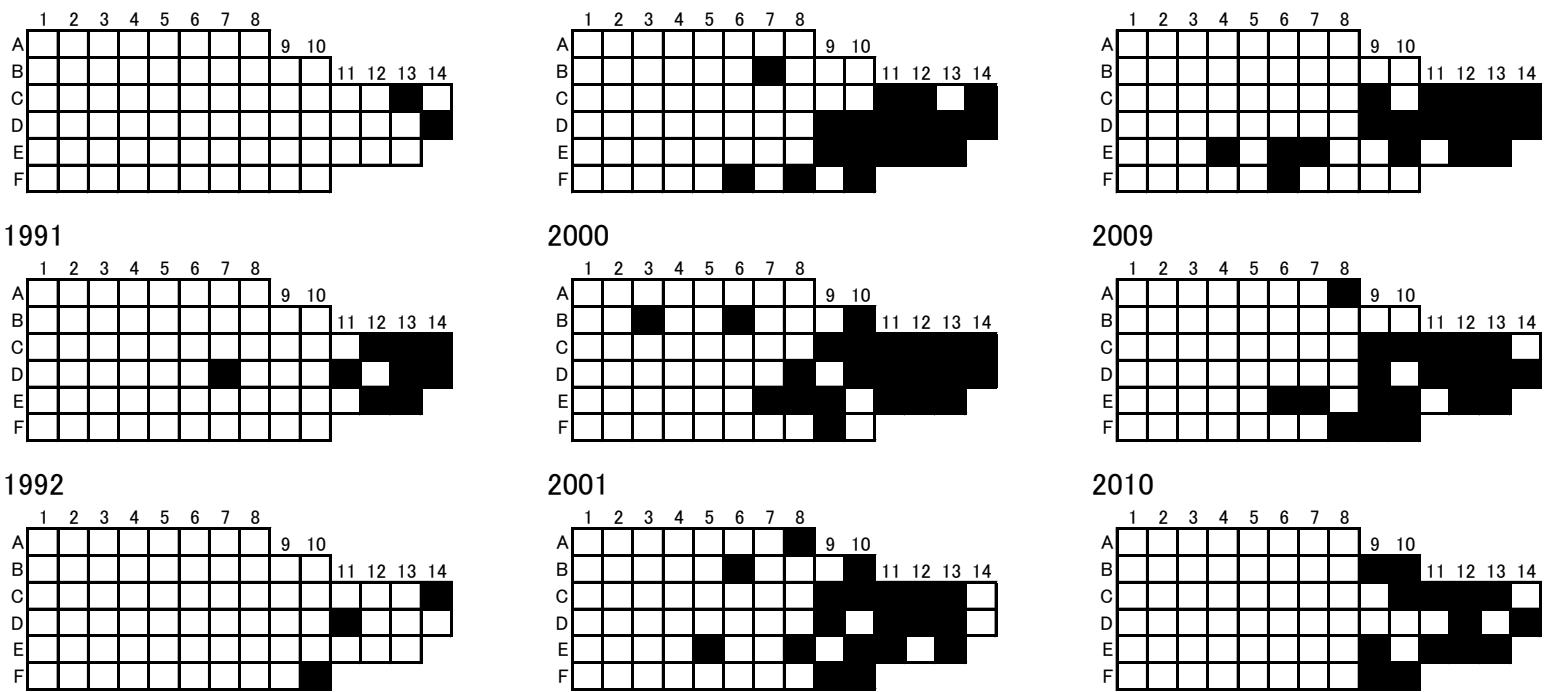

2009

1993

2002
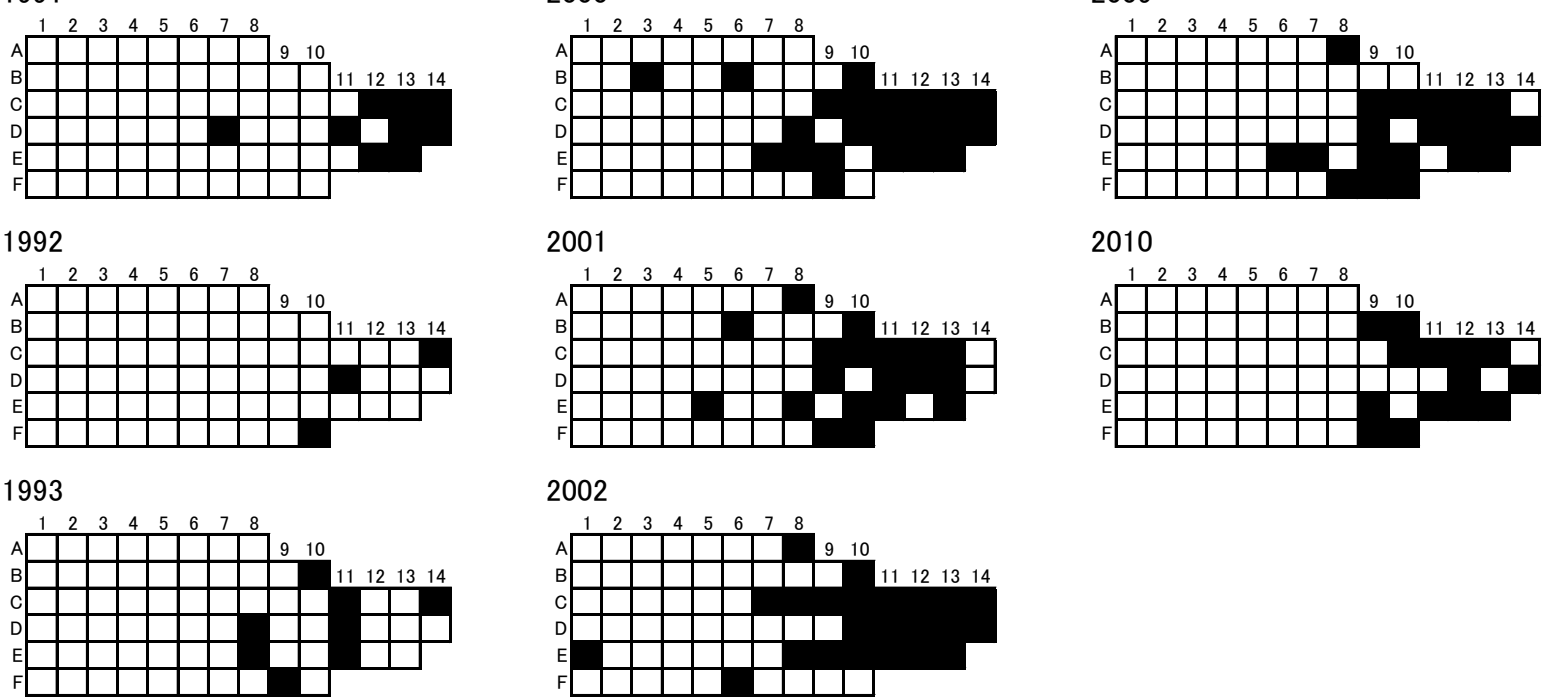

2010

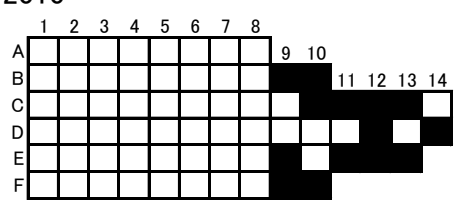


ベッコウガサ

1985

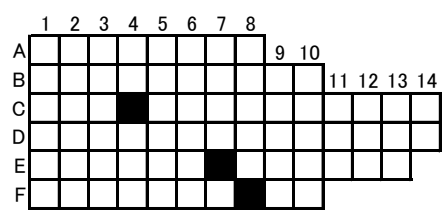

1986

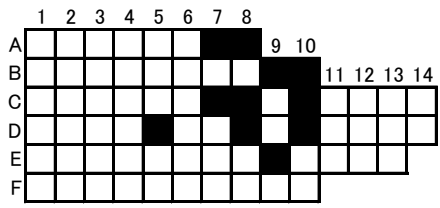

1987

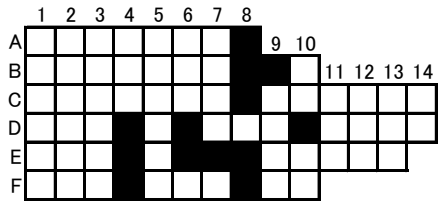

1988

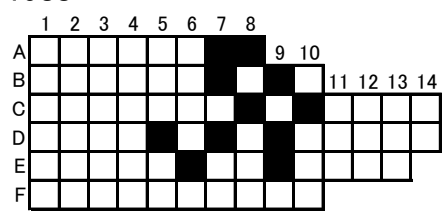

1989

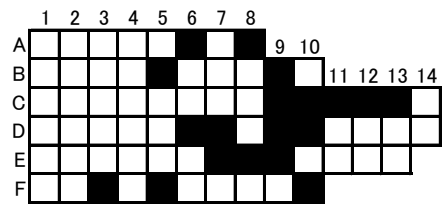

1990

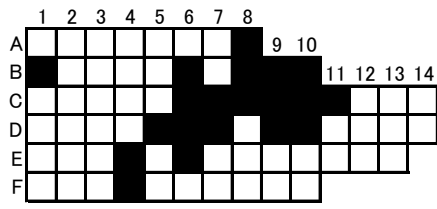

1991

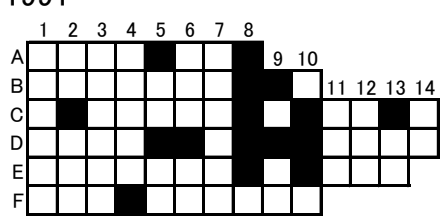

1992

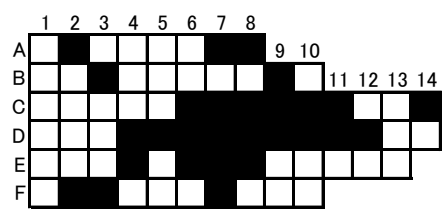

1993

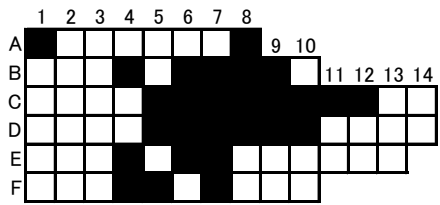

1994

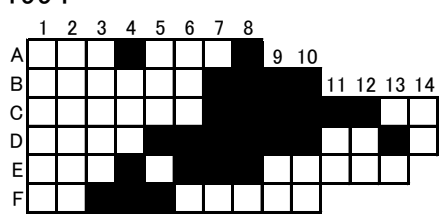

1995

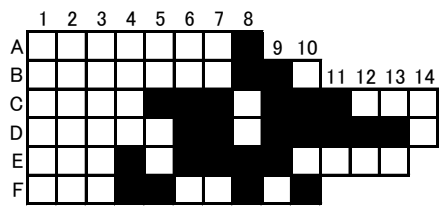

1996

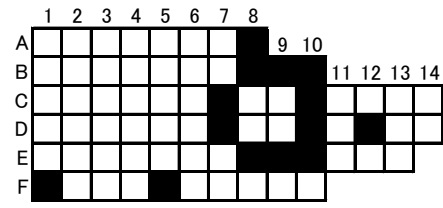

1997

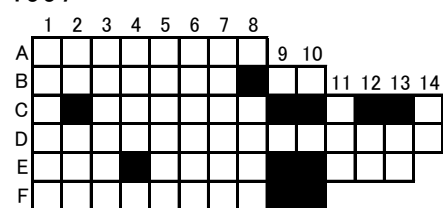

1998

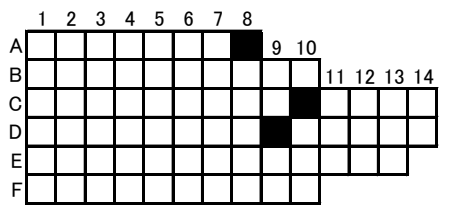

1999

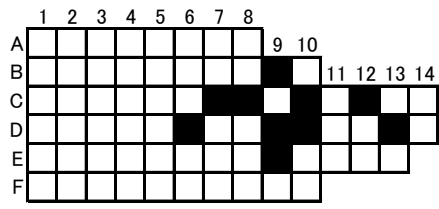

2000

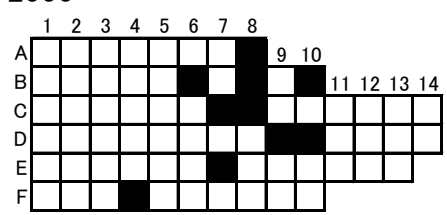

2001

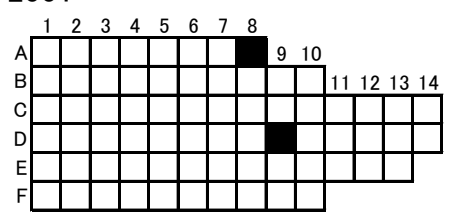

2002

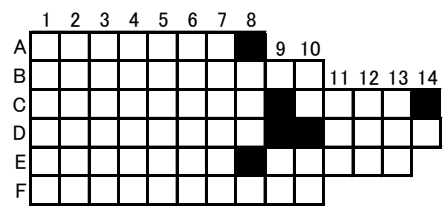

2003

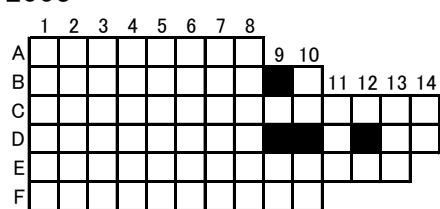

2004

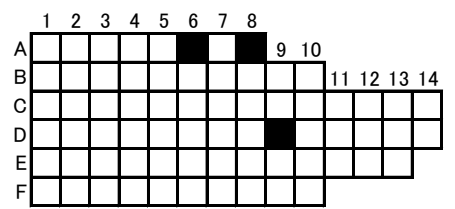

2005

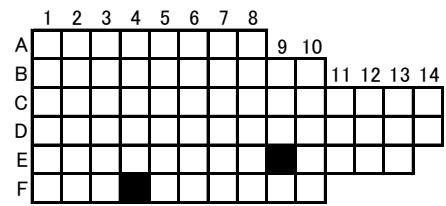

2006

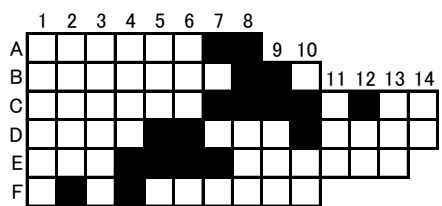

2007

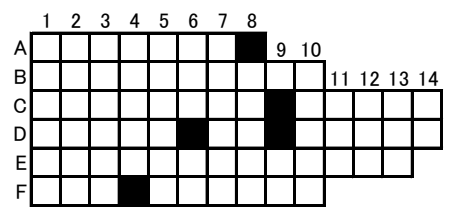

2008

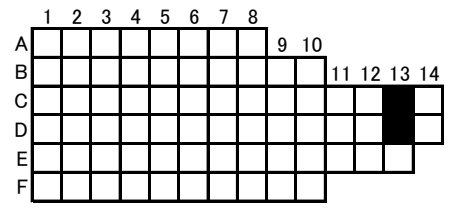

2009

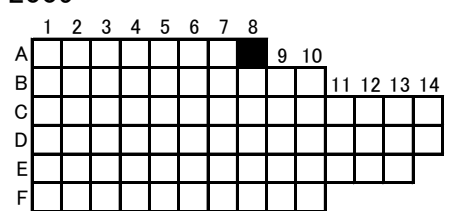

2010

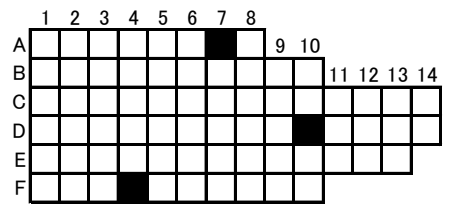


12 Cellana nigrolineata マツバガイ
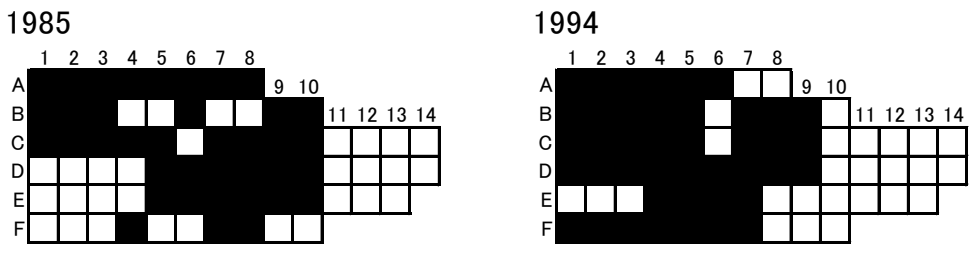

2003

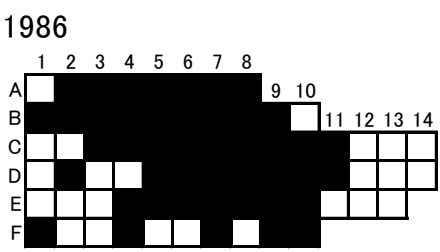

1995
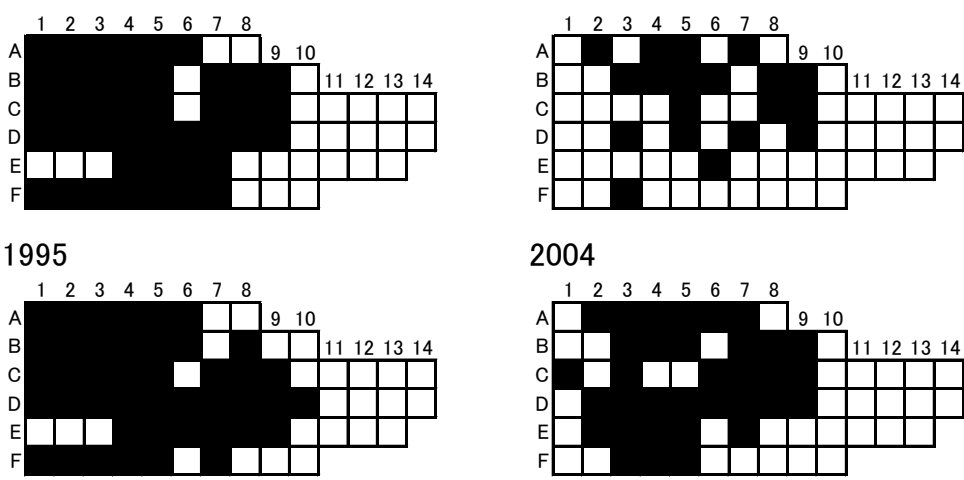

2004

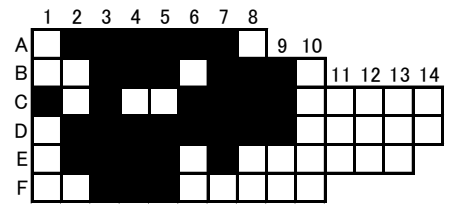

1987

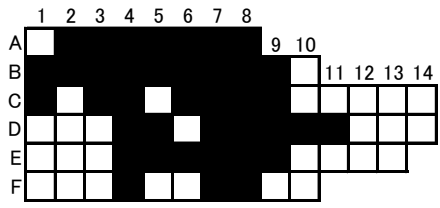

1996

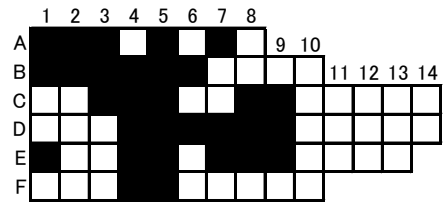

2005

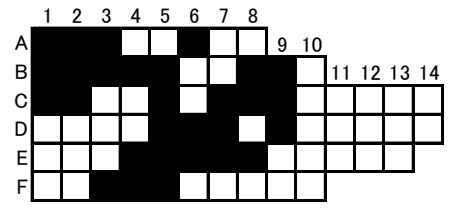

1988

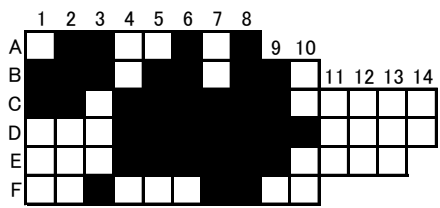

1997

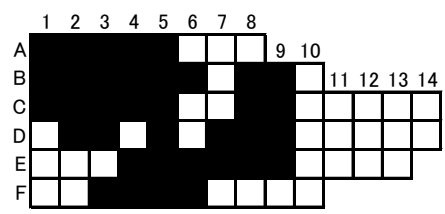

2006

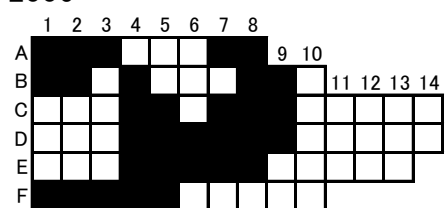

1989

1998
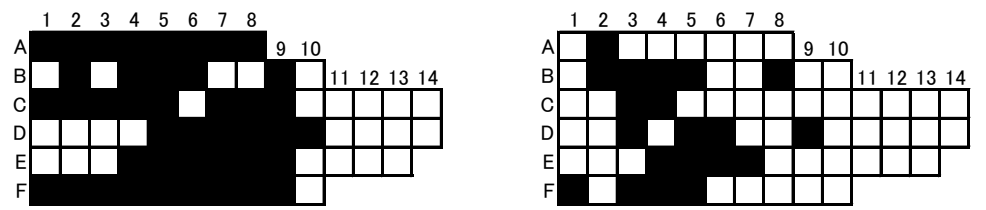

2007
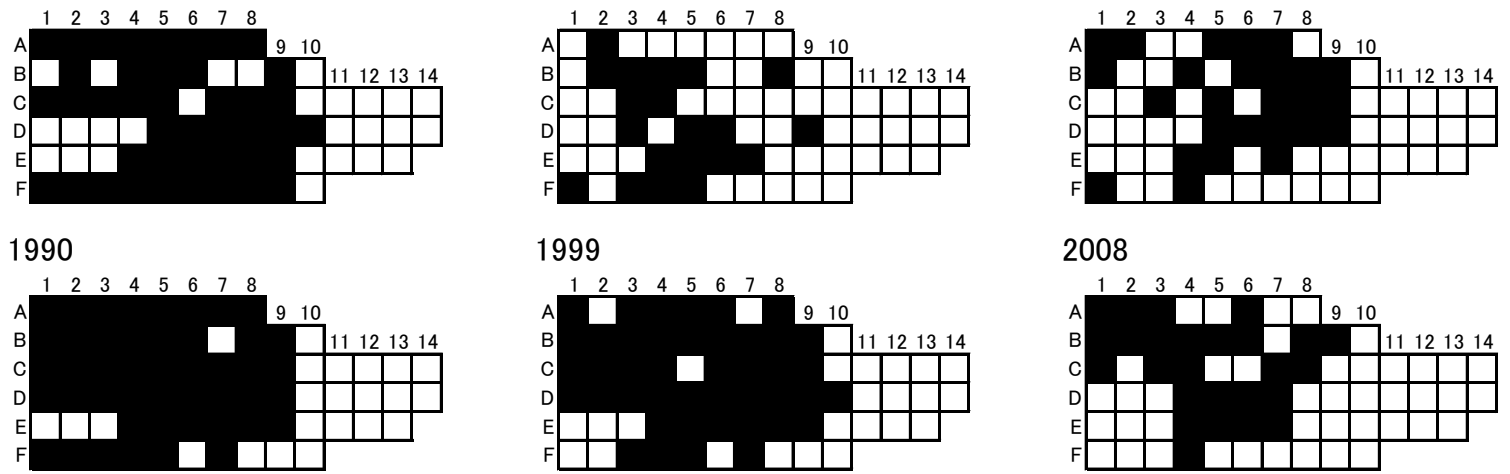

1999

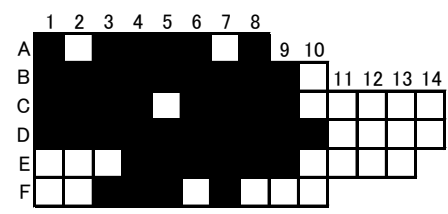

2008

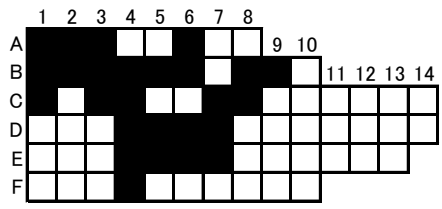

1991

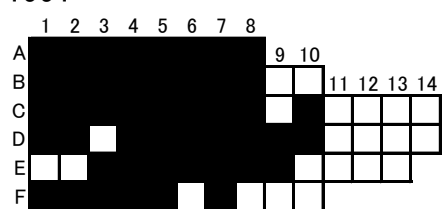

2000

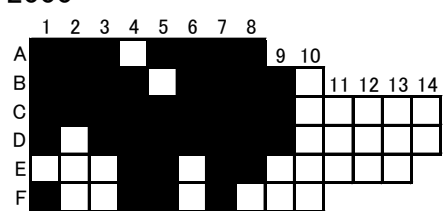

2009

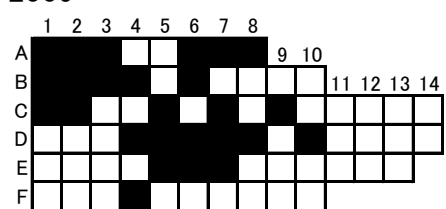

1992

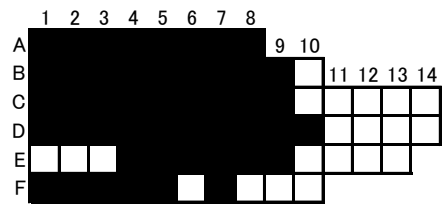

2001

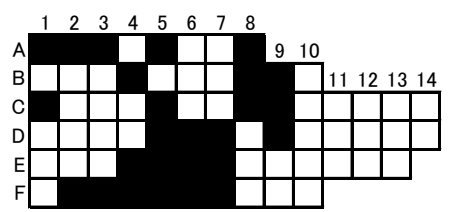

2010

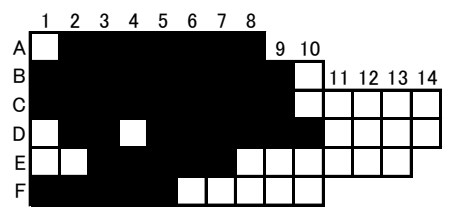

1993

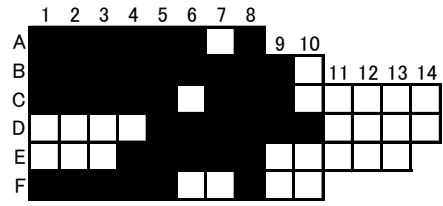

2002

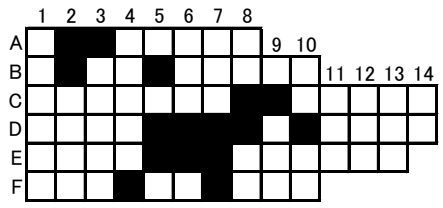


ヨメガカサ

1985

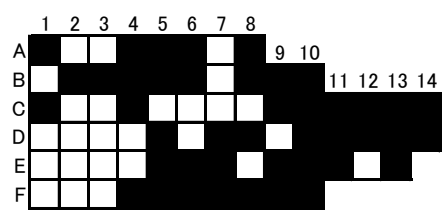

1986

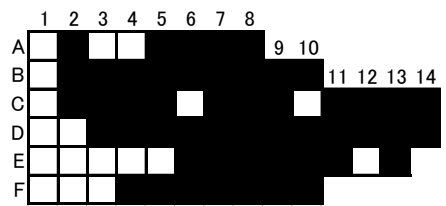

1987

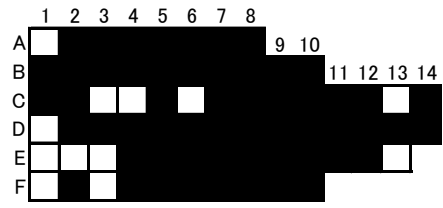

1988
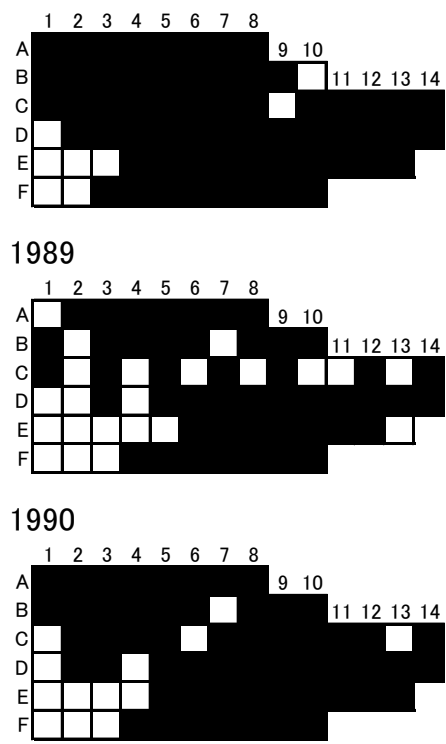

1991

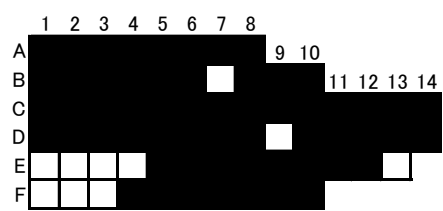

1992

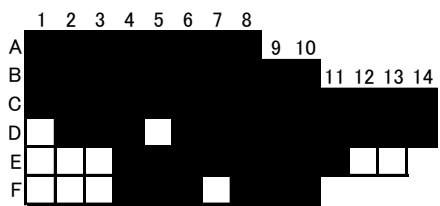

1993

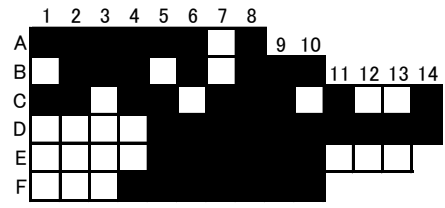

1994

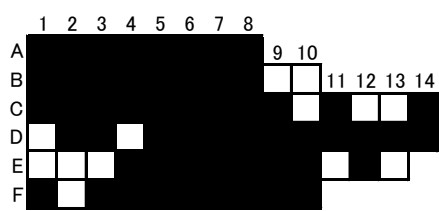

1995

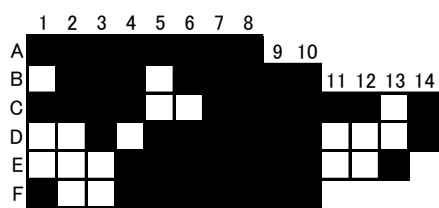

1996

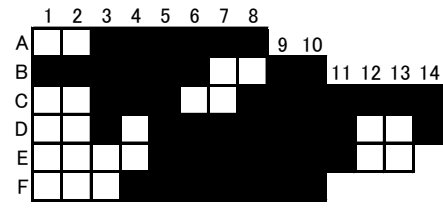

1997

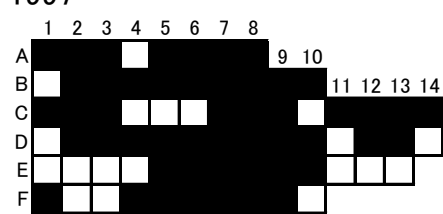

1998

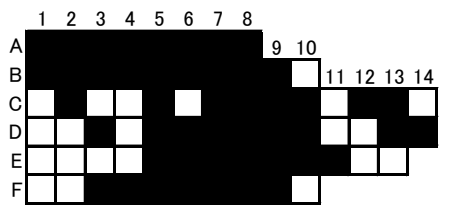

1999

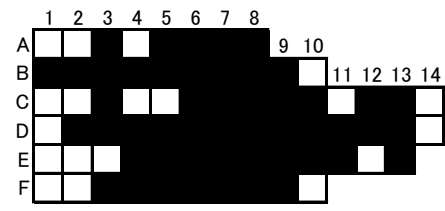

2000

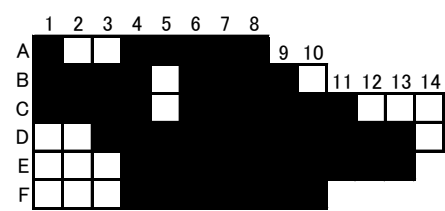

2001

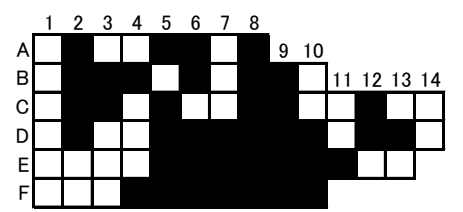

2002

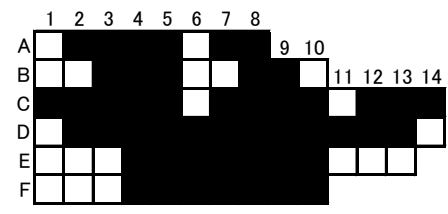

2003

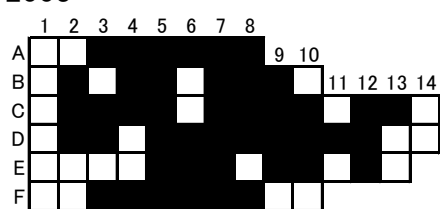

2004

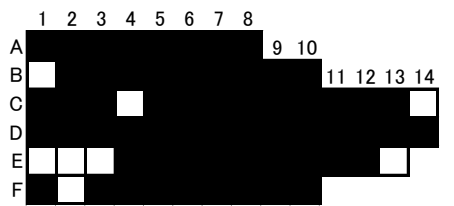

2005

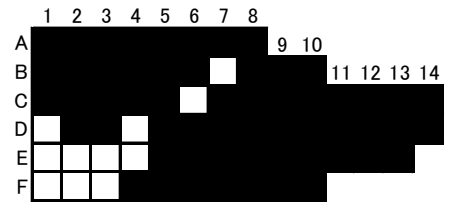

2006

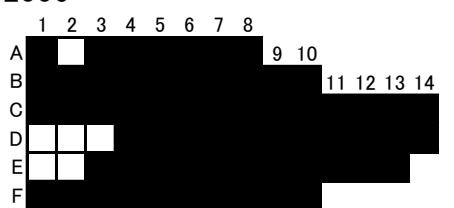

2007

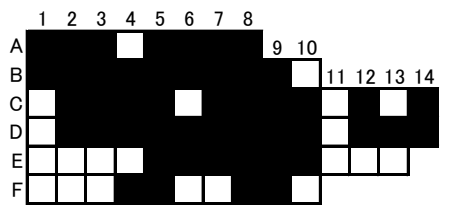

2008

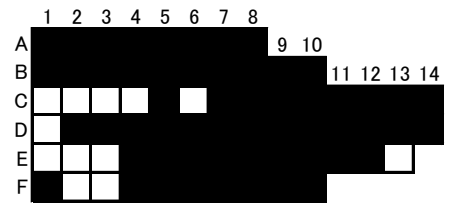

2009

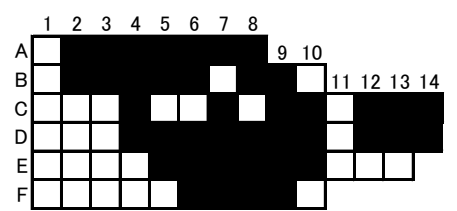

2010

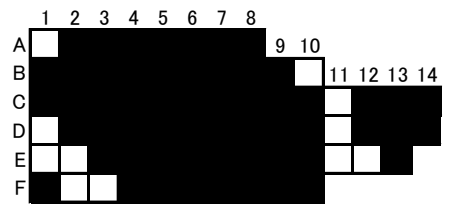


14 Patelloida pygmaea heroldi ヒメコザラ
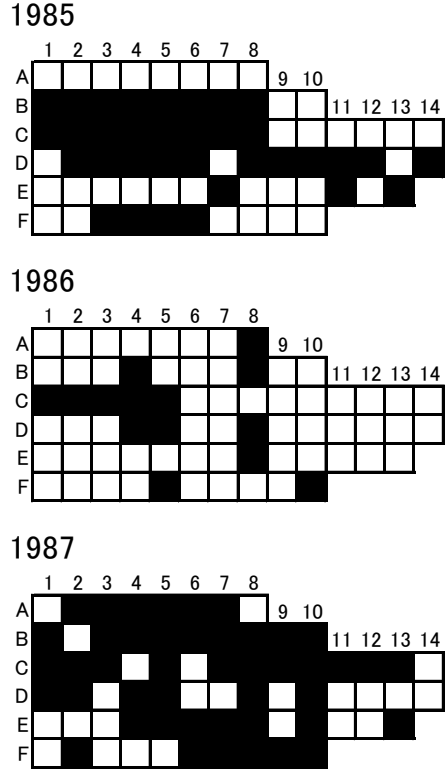

1988

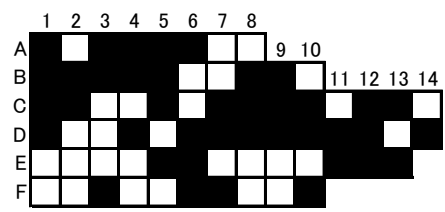

1989

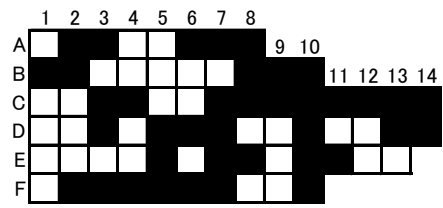

1990

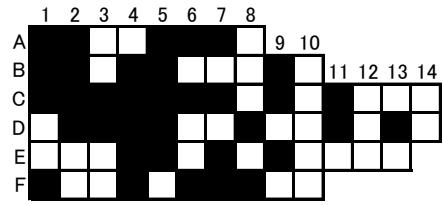

1991

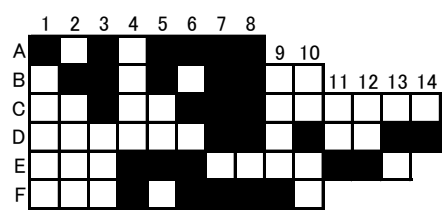

1992

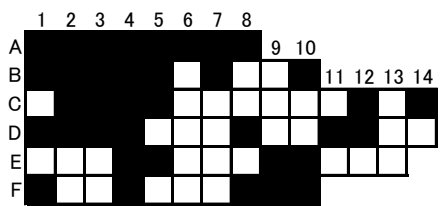

1993

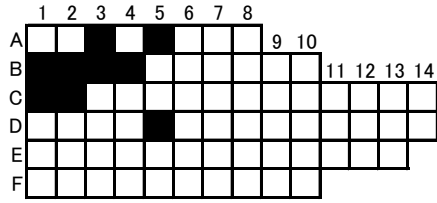

1994

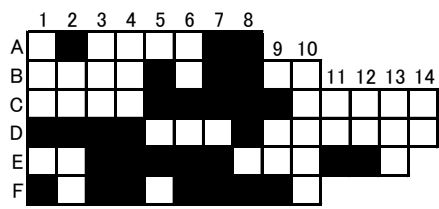

1995

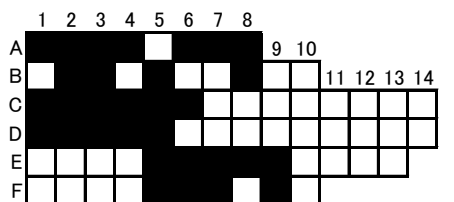

1996

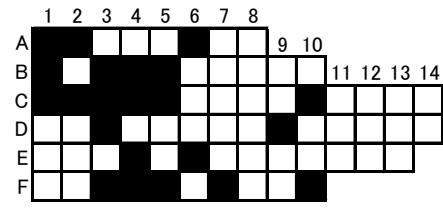

1997

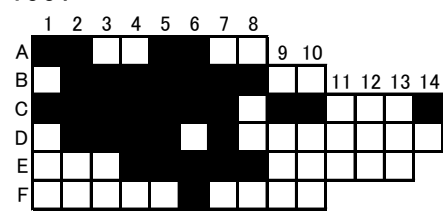

1998

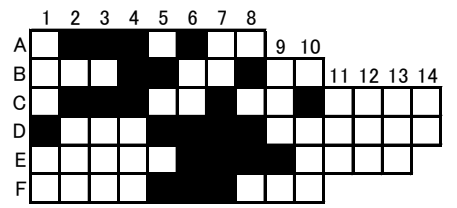

1999

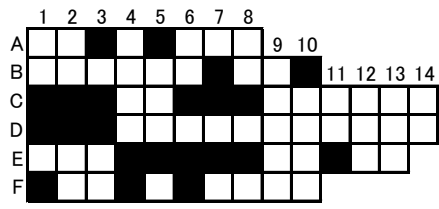

2000

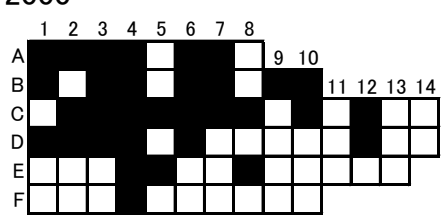

2001

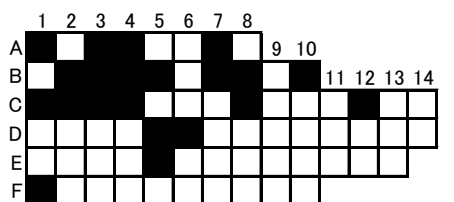

2002

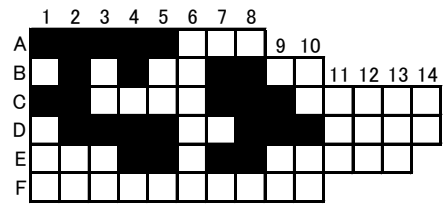

2003

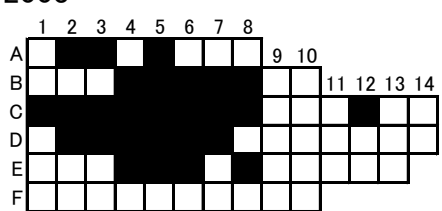

2004

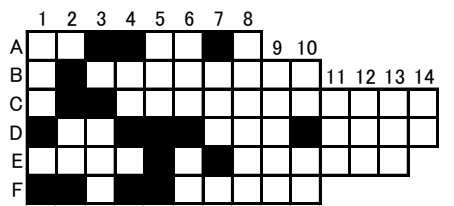

2005

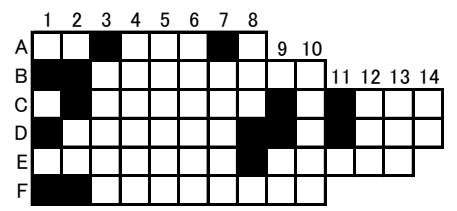

2006

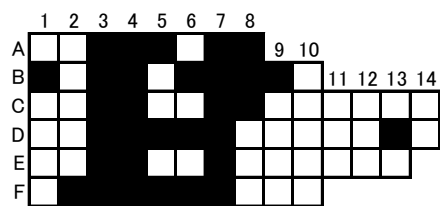

2007

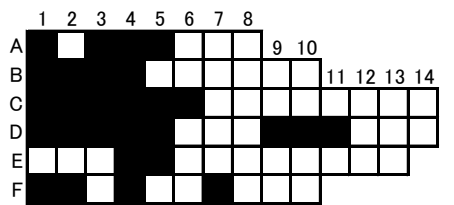

2008

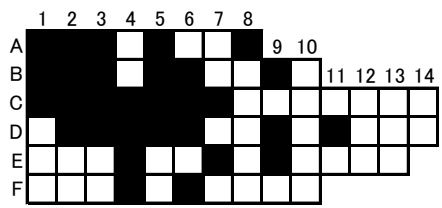

2009

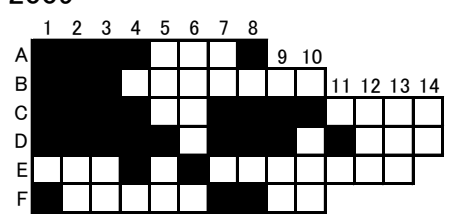

2010

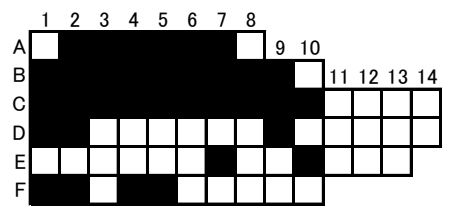



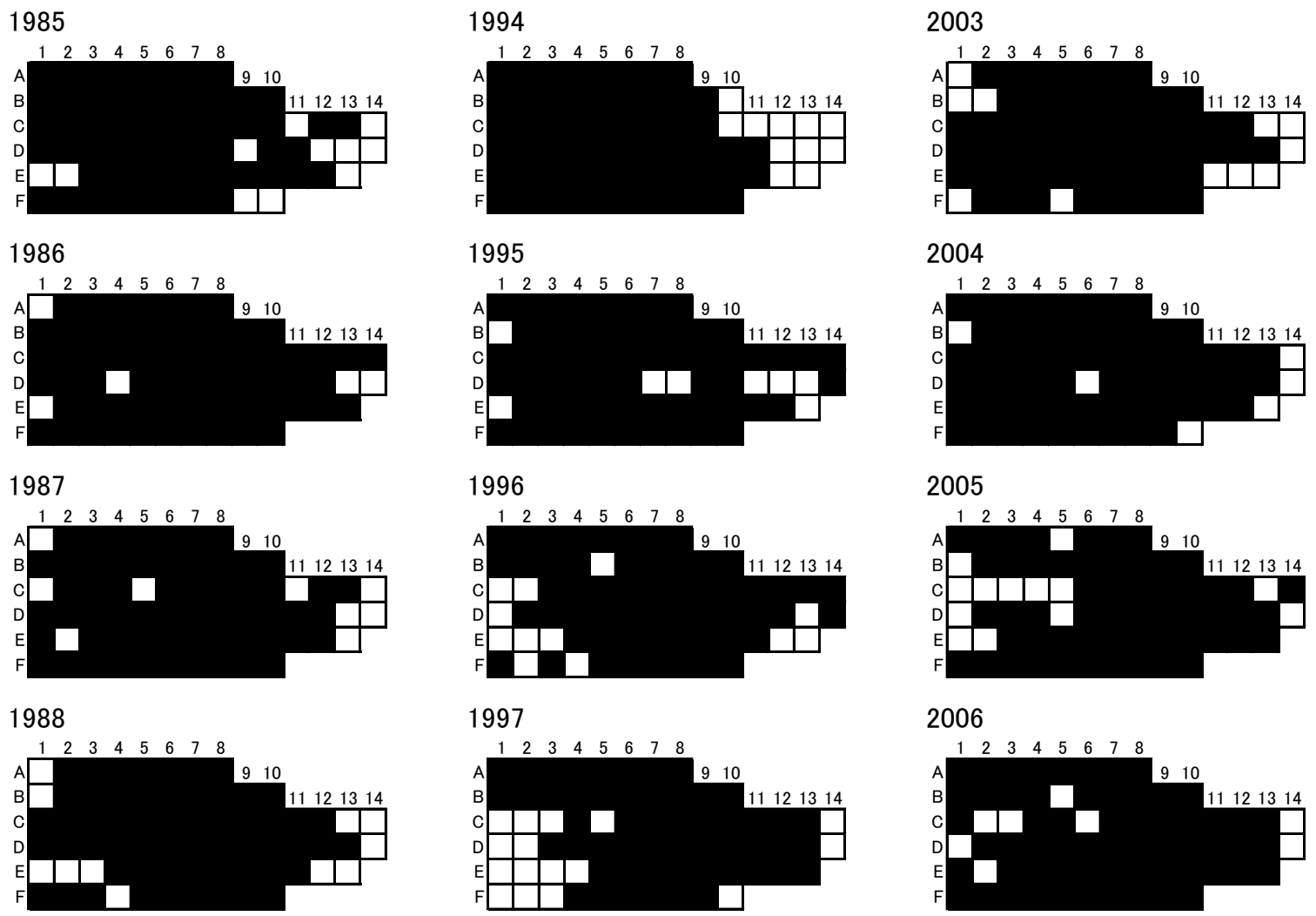

1997

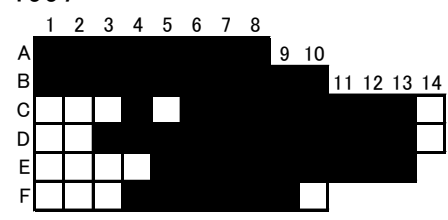

2006
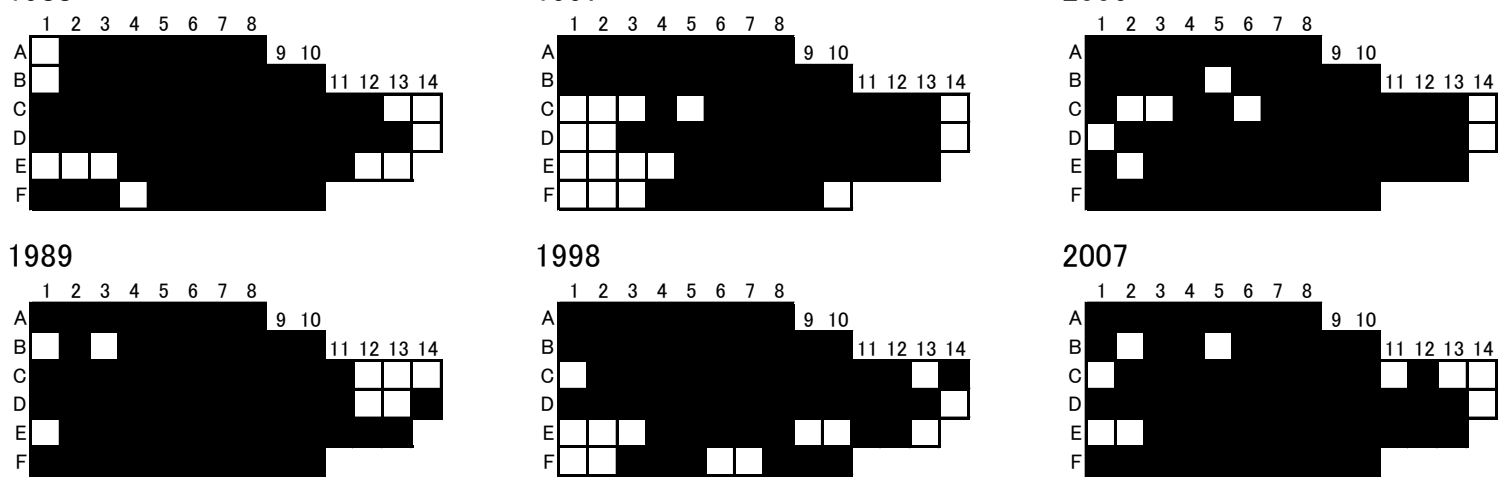

1998

2007
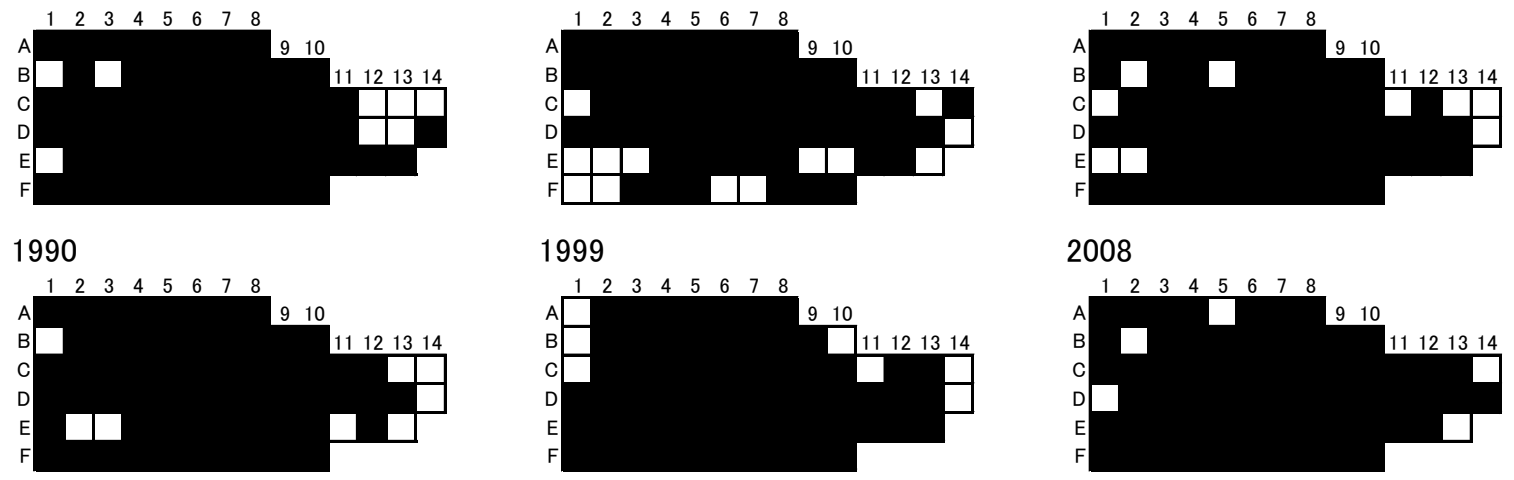

2008
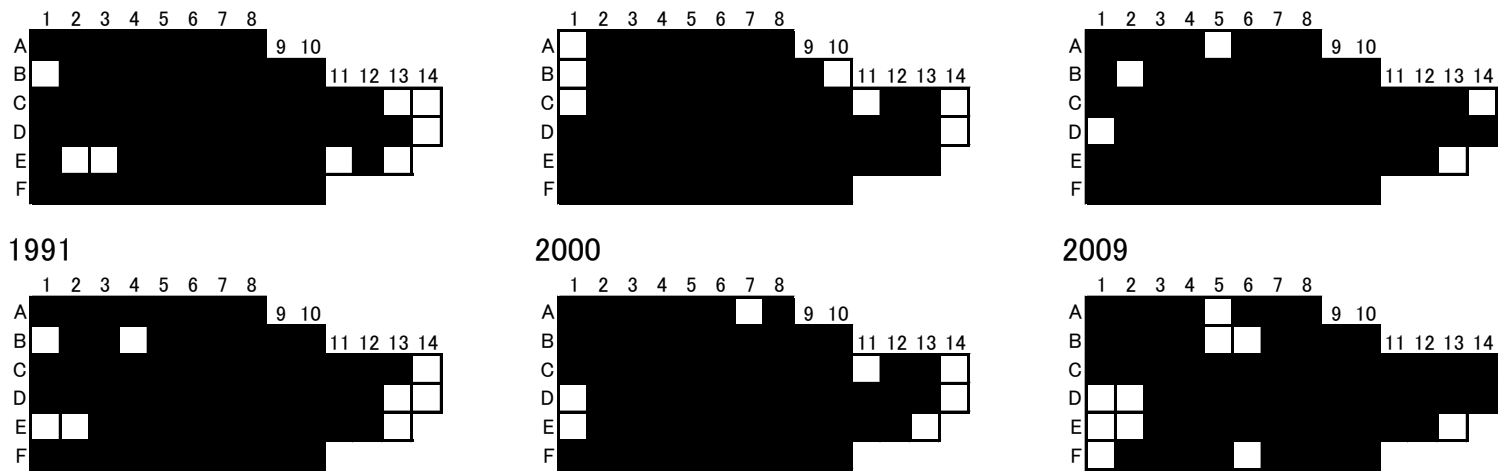

2000

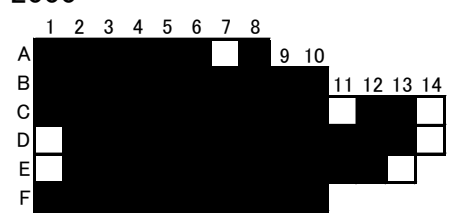

2009
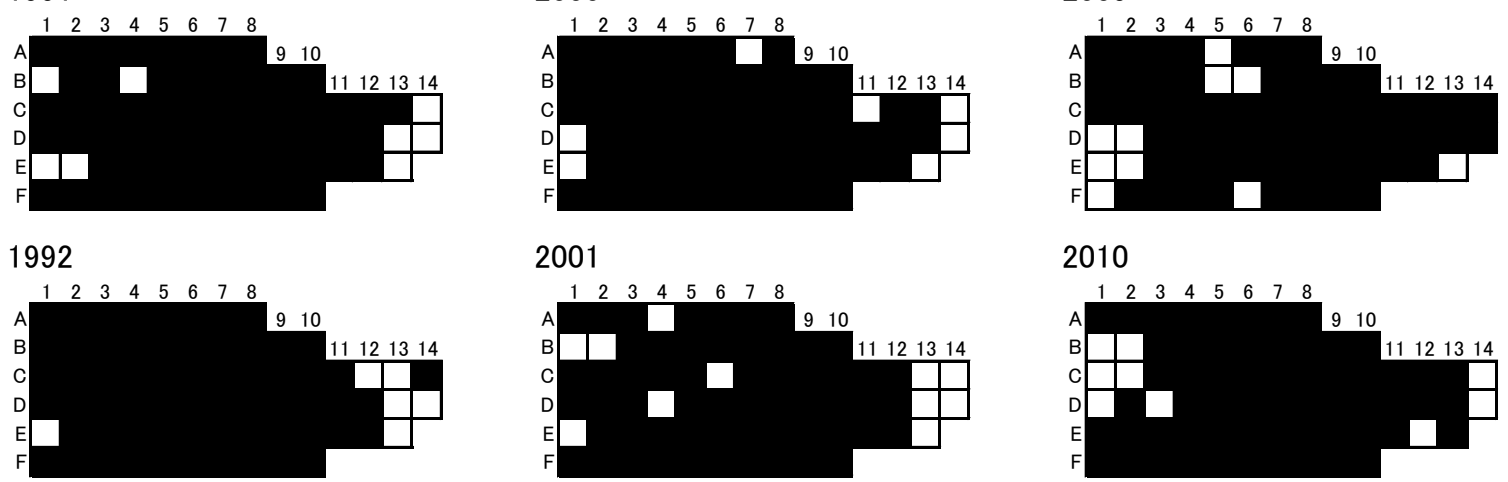

2001

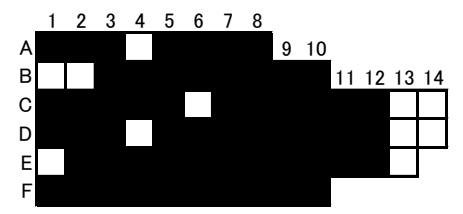

2010
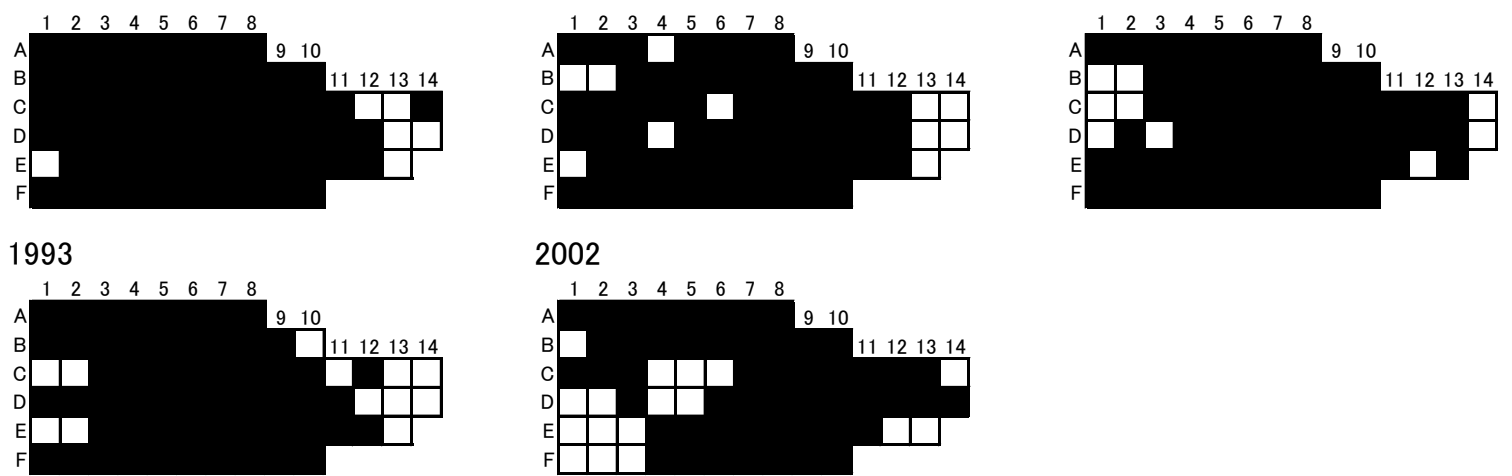

2002

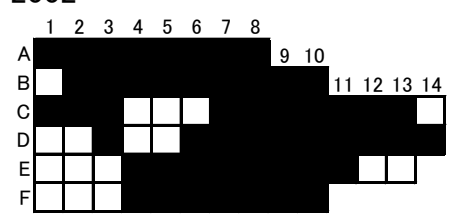


1985

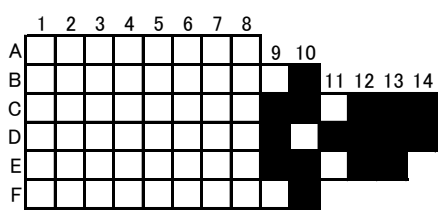

1986

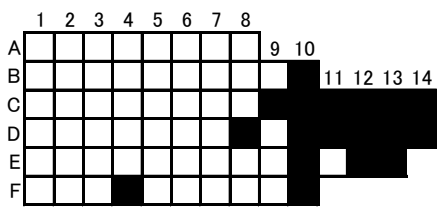

1987

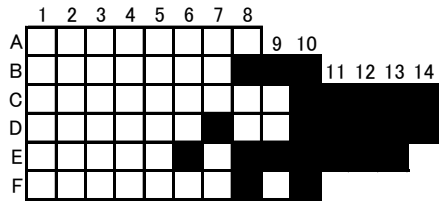

1988

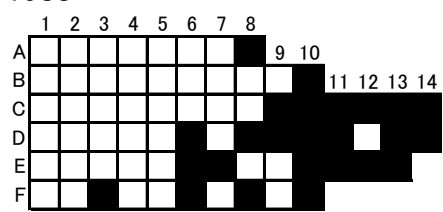

1989

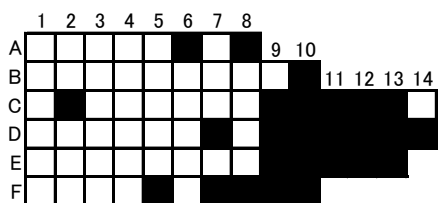

1990

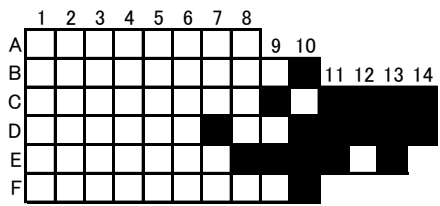

1991

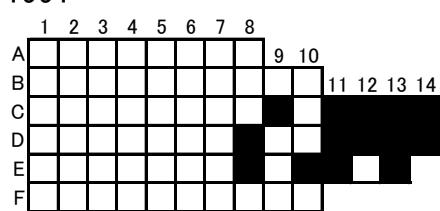

1992

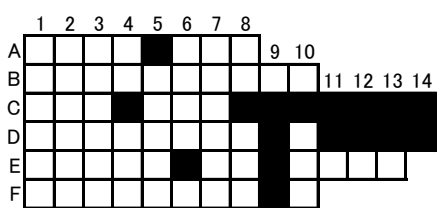

1993

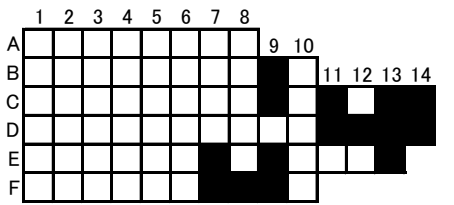

1994

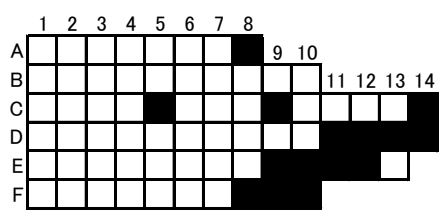

1995

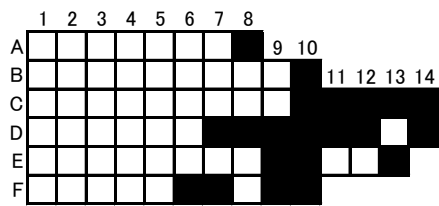

1996

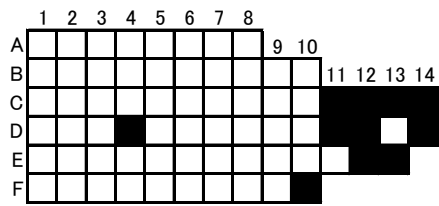

1997

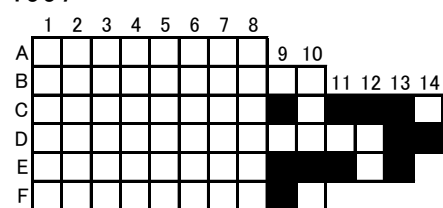

1998

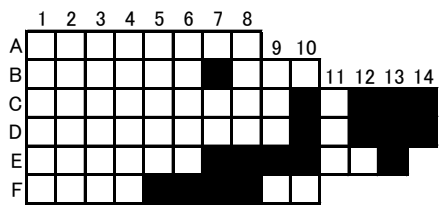

1999

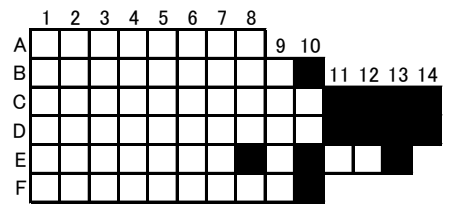

2000

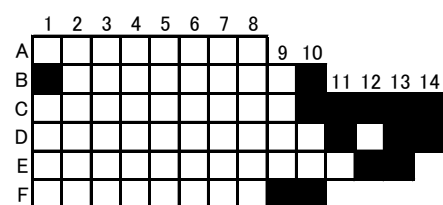

2001

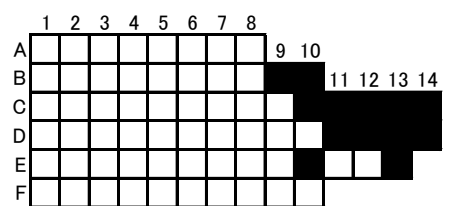

2002

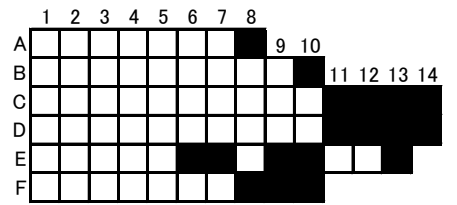

2003

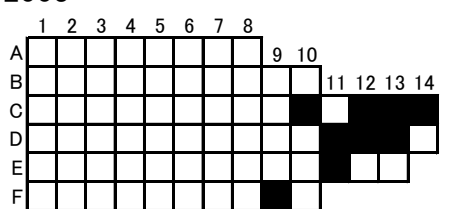

2004

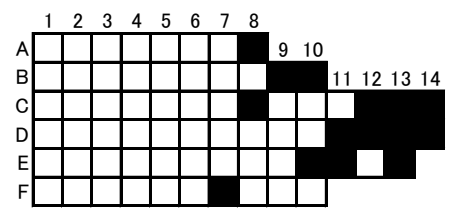

2005

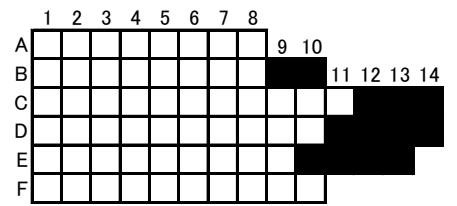

2006

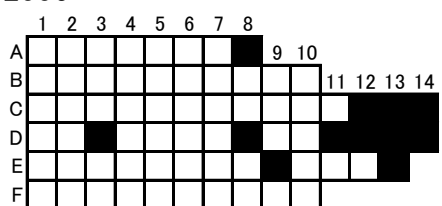

2007

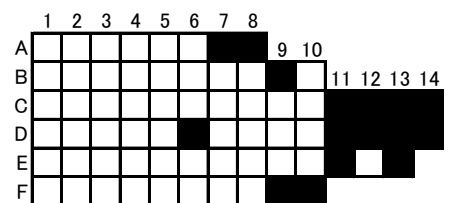

2008

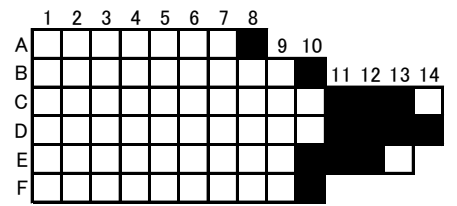

2009

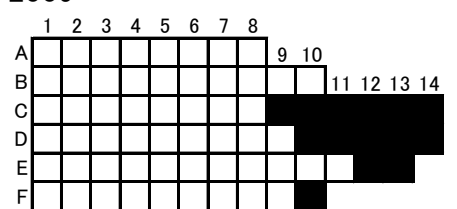

2010

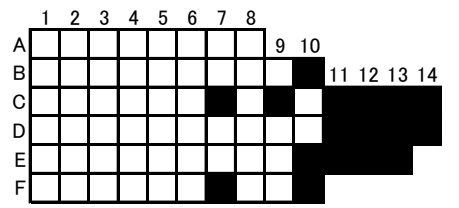




\section{Lottia kogamogai コガモガイ}
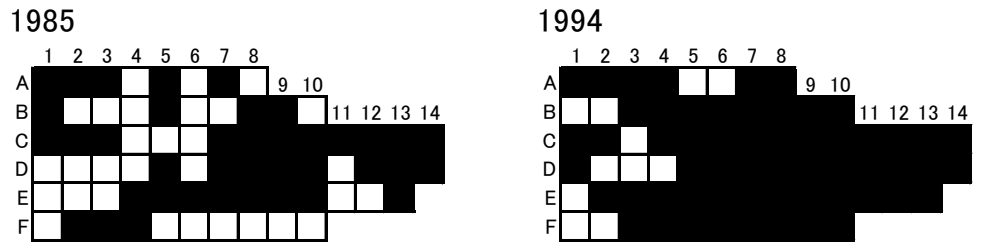

2003

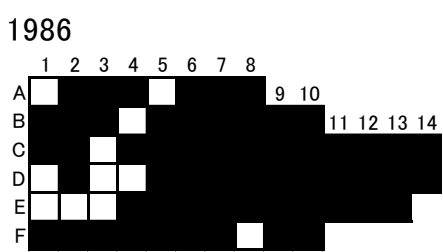

1995
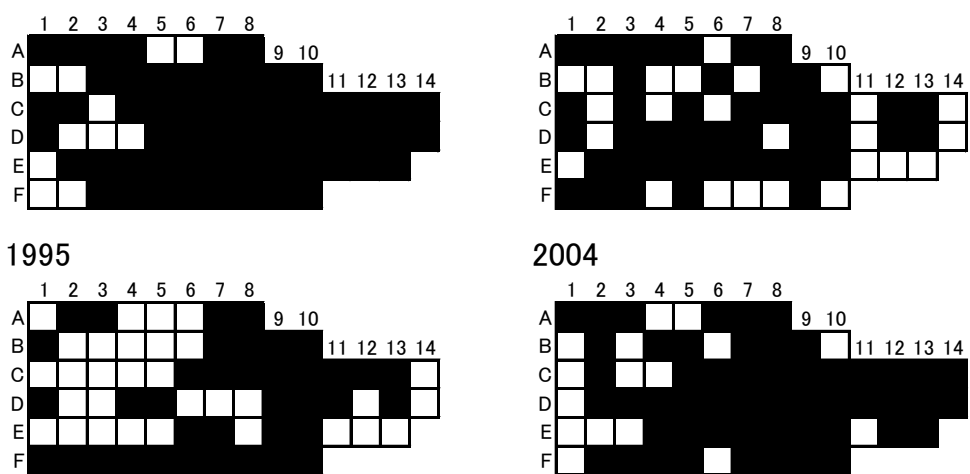

2004
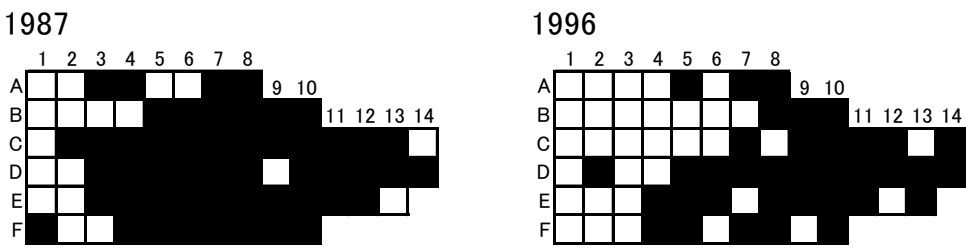

1988

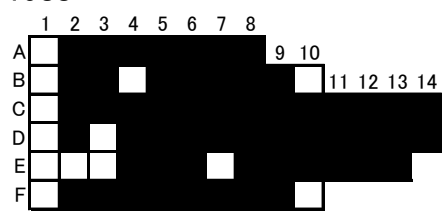

1997
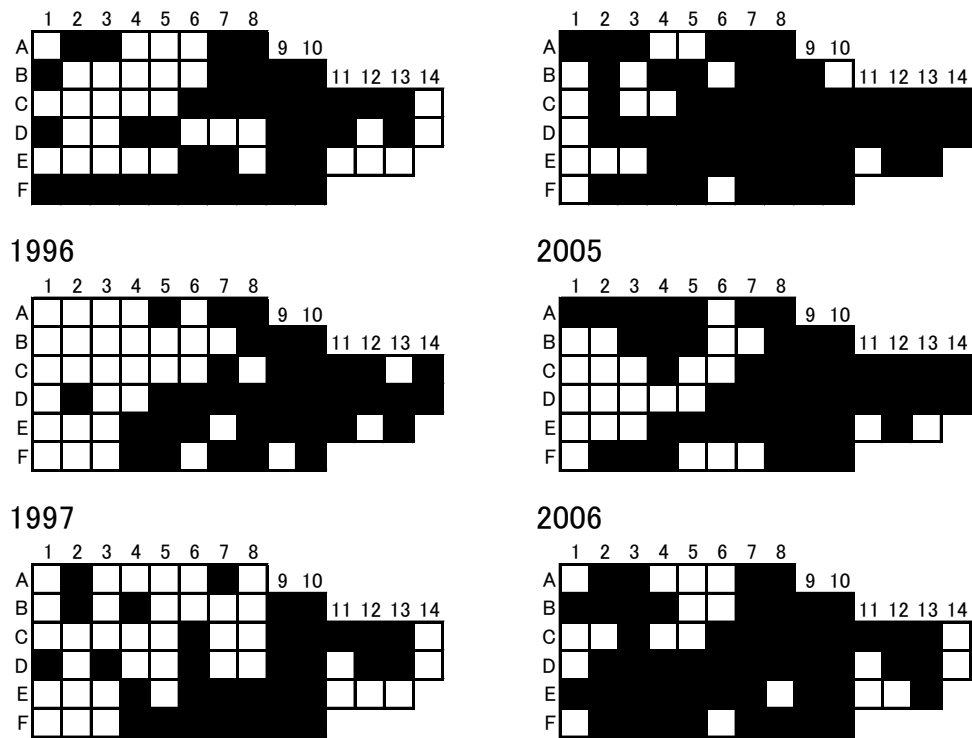

2005

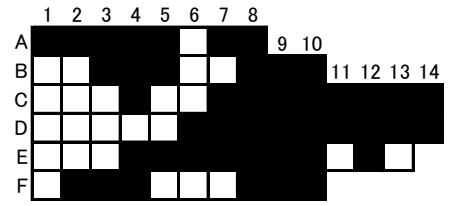

2006

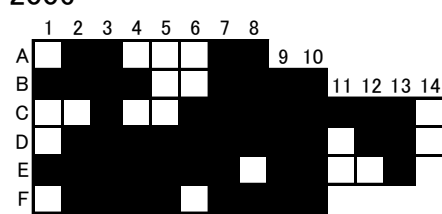

1998
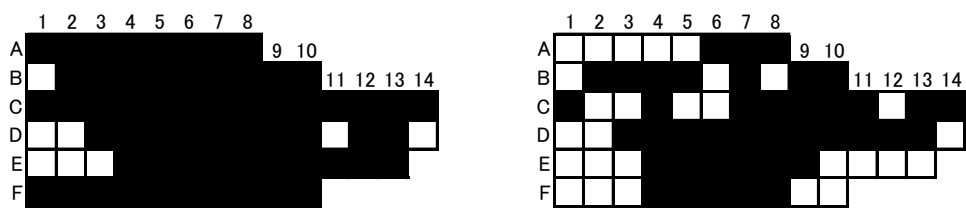

2007

1990

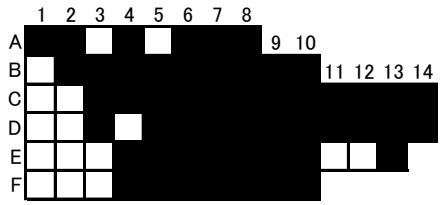

1999
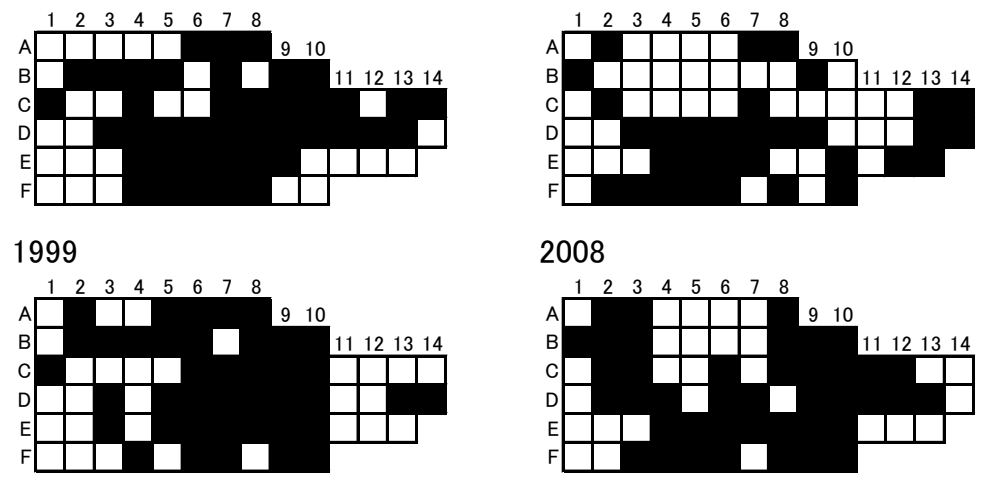

2008

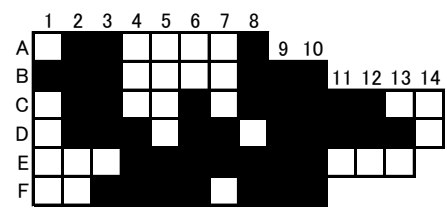

1991

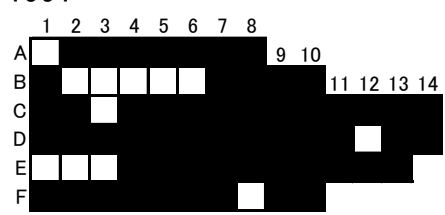

2000

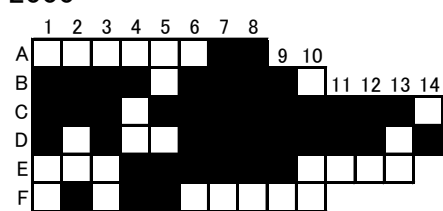

2009

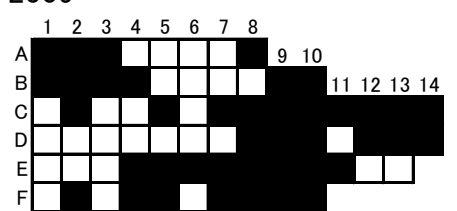

1992

2001

2010
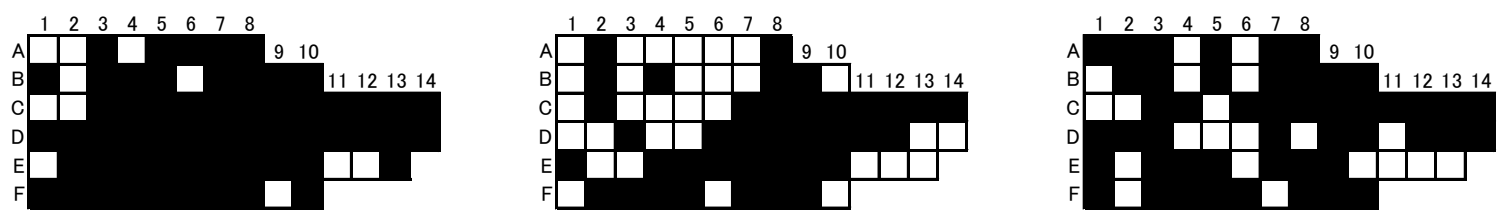

1993

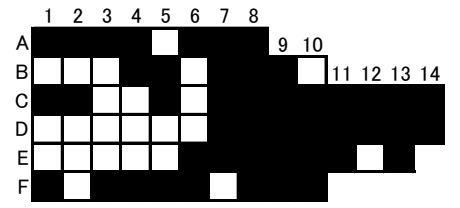

2002

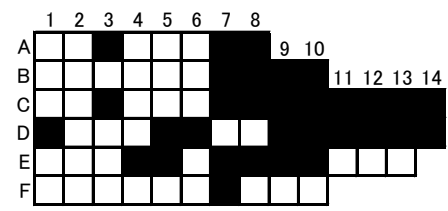




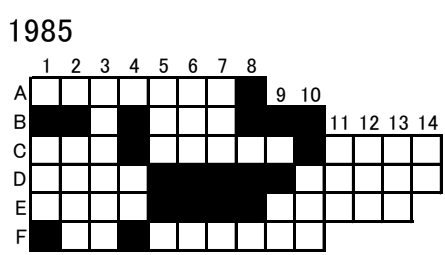

1986

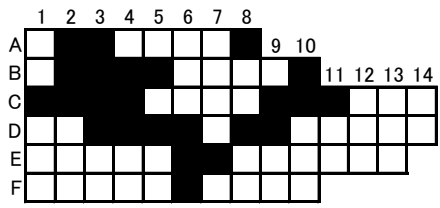

1987

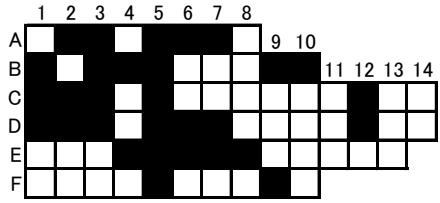

1988

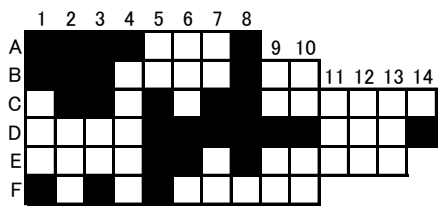

1989

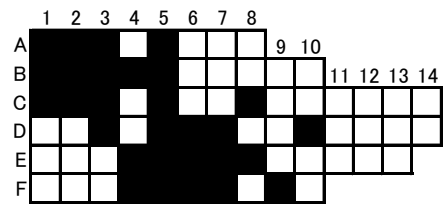

1990

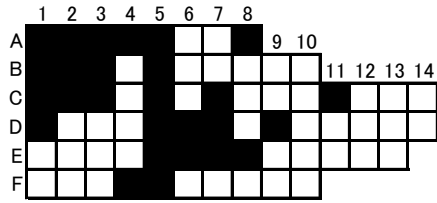

1991

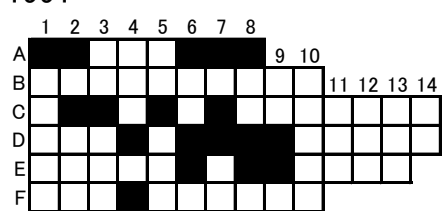

1992

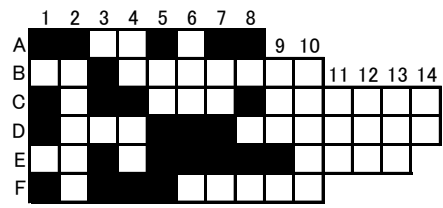

1993

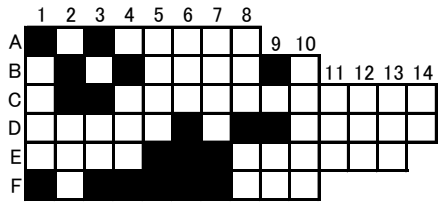

1994

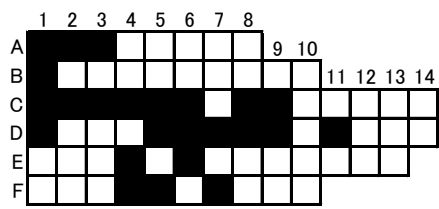

1995

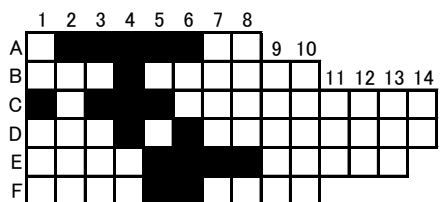

1996

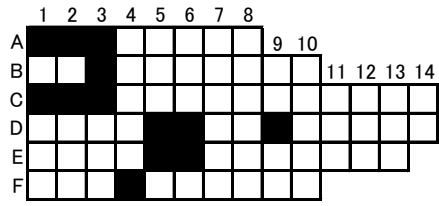

1997

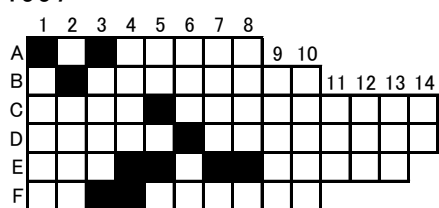

1998

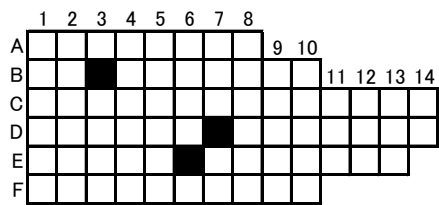

1999

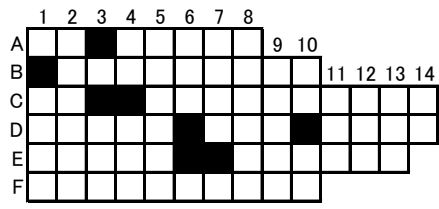

2000

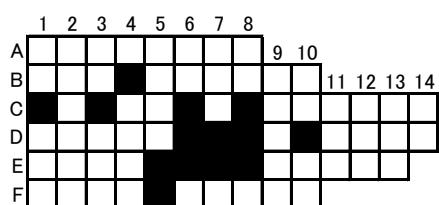

2001

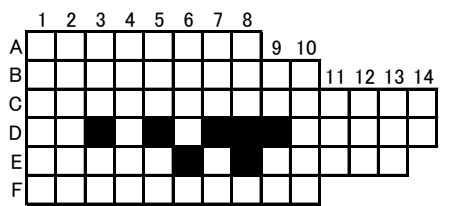

2002

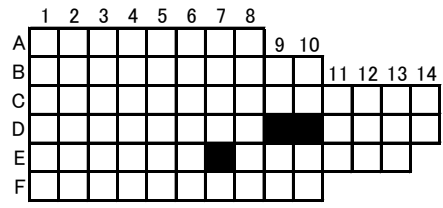

2003

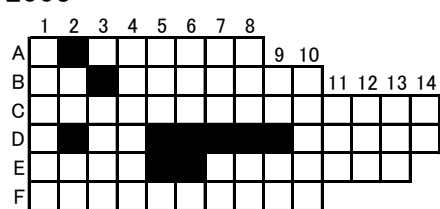

2004

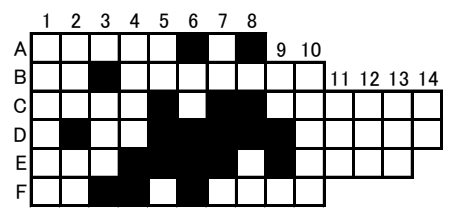

2005

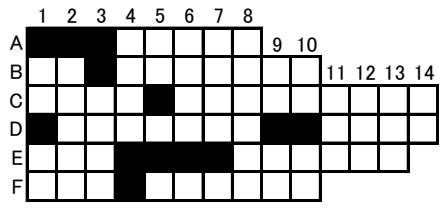

2006

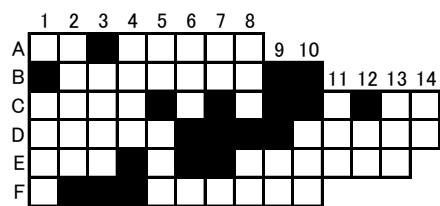

2007

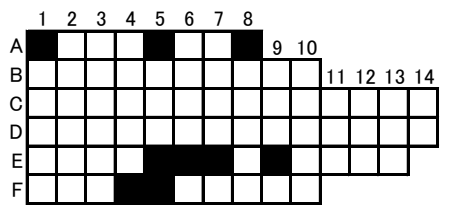

2008

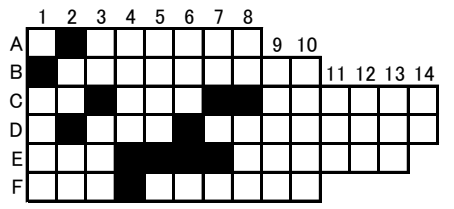

2009

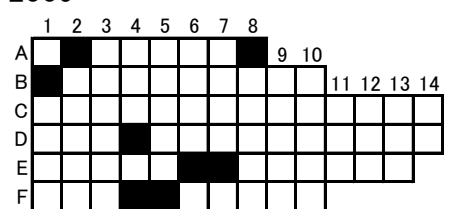

2010

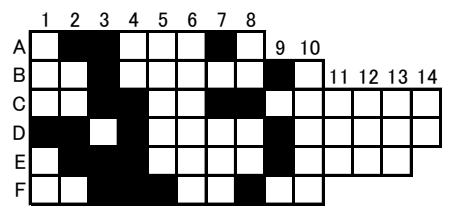


21 Nipponacmea gloriosa サクラアオガイ
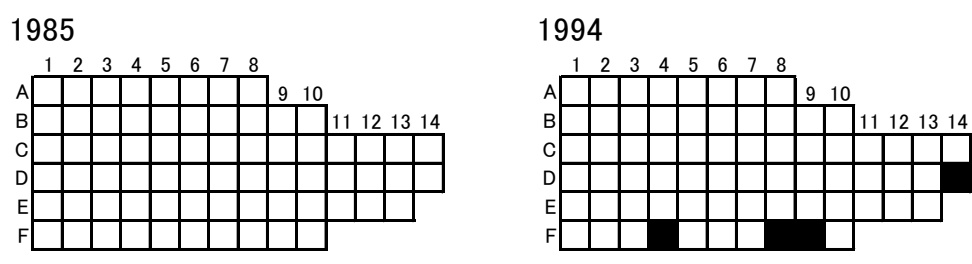

2003

1986

1995
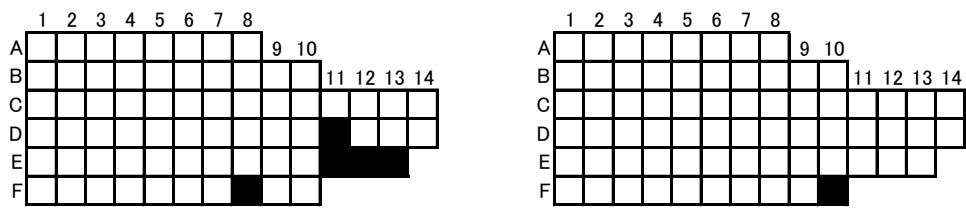

1987

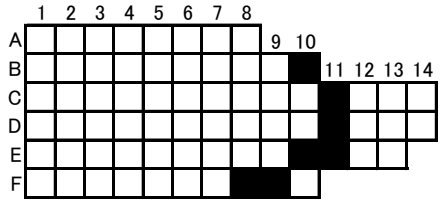

1996
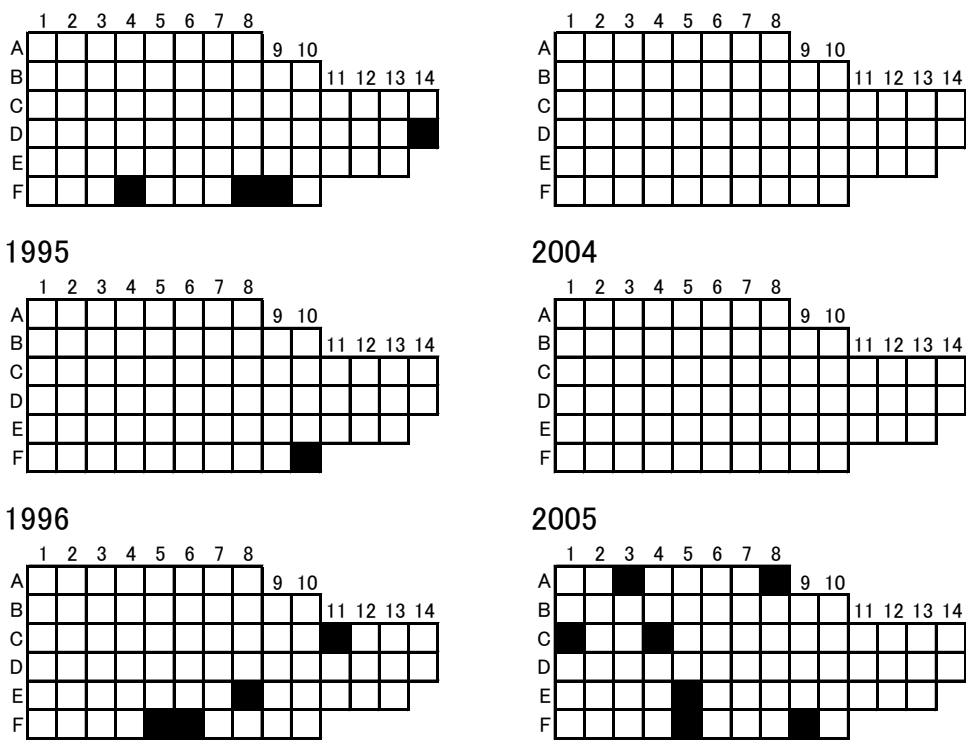

2004

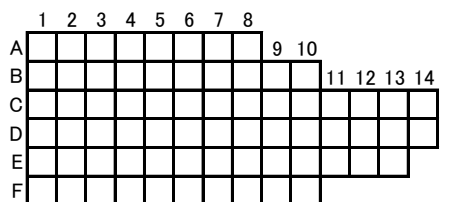

2005

1988

1997
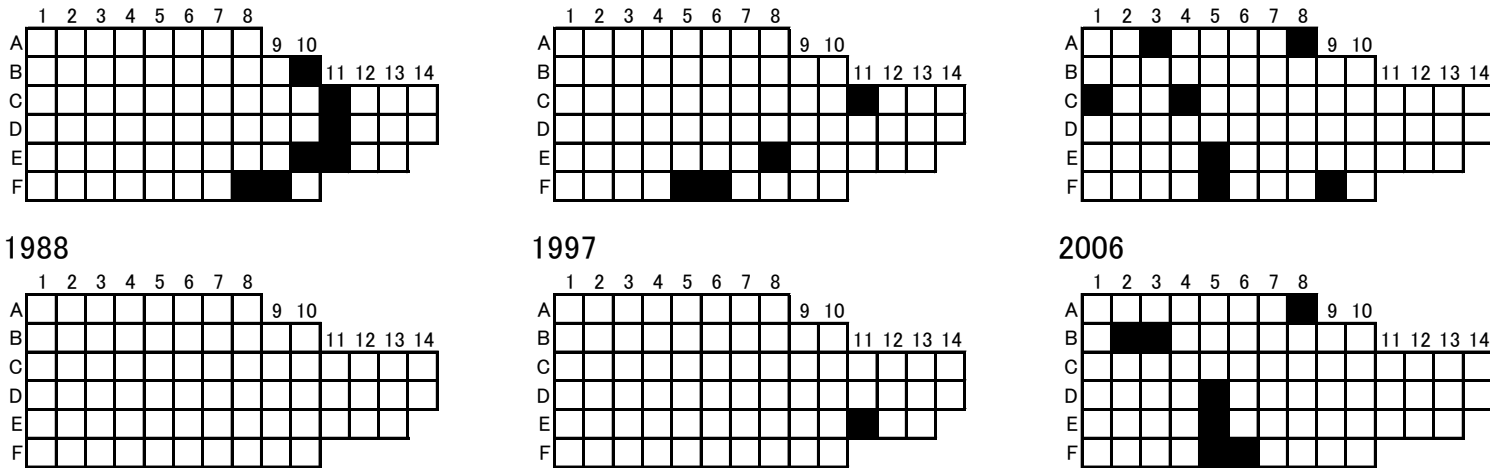

2006

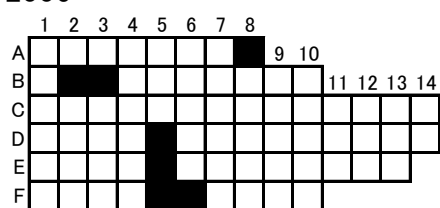

1989

1998
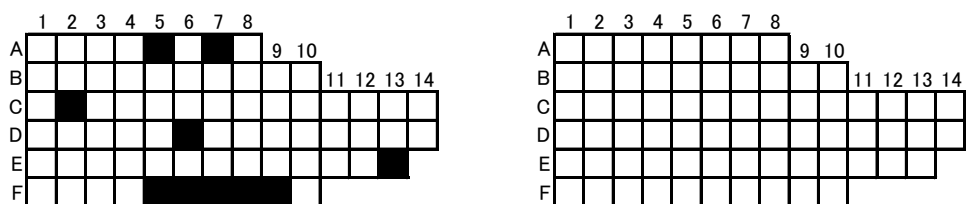

2007
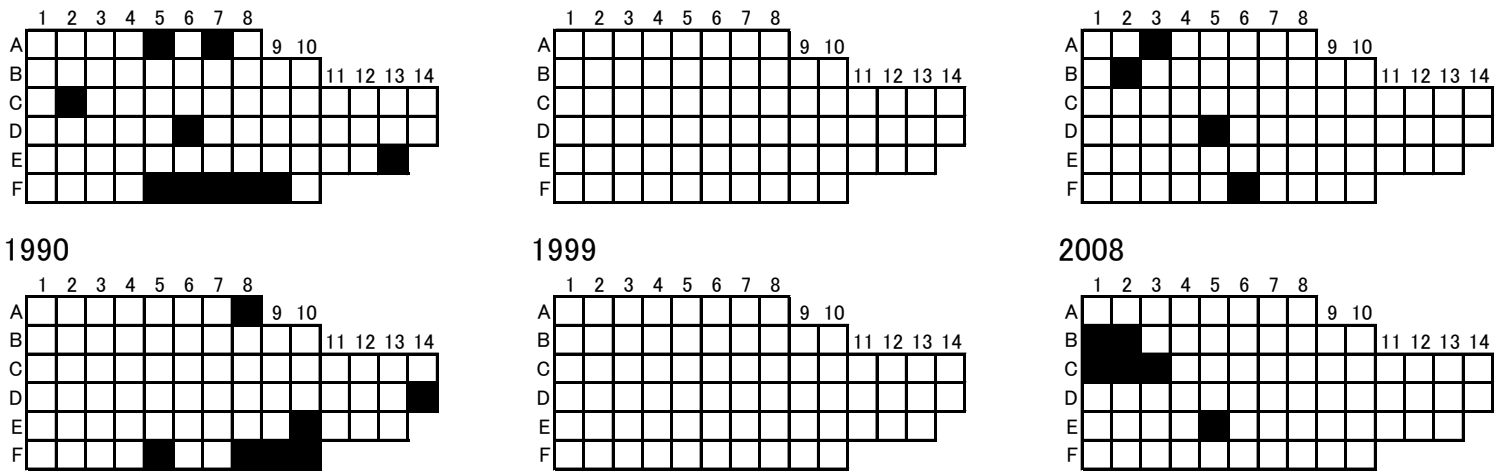

1999

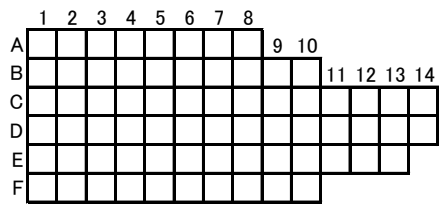

2008

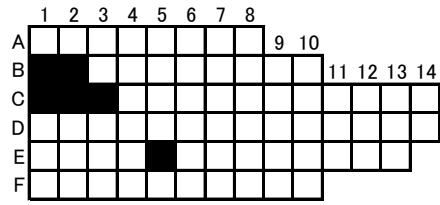

1991

2000
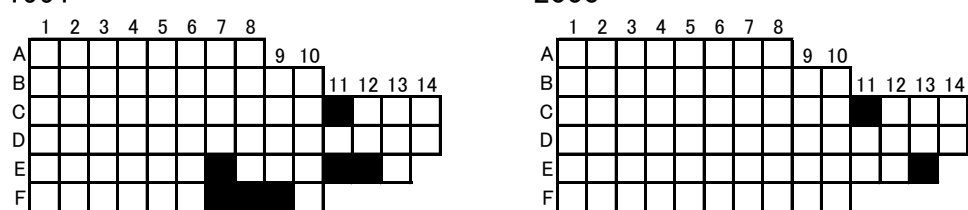

2009

1992

2001
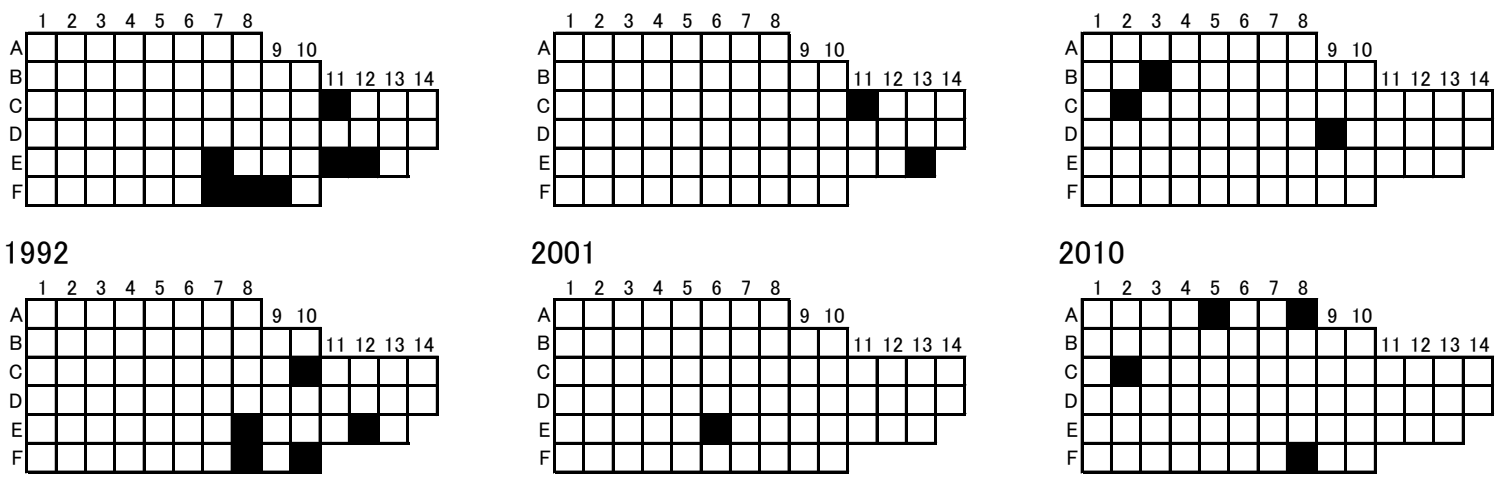

2010

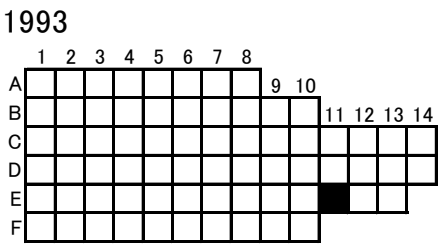

2002
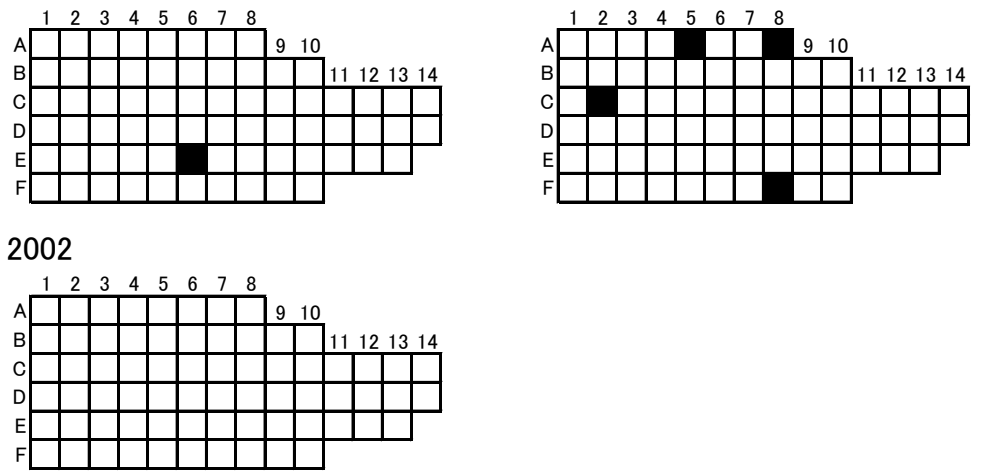


\section{Nipponacmea nigrans クモリアオガイ}

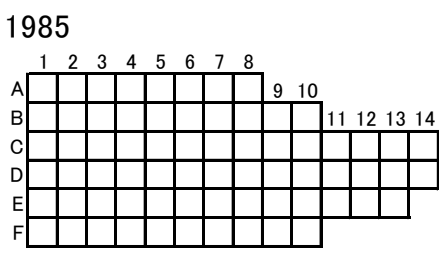

1986

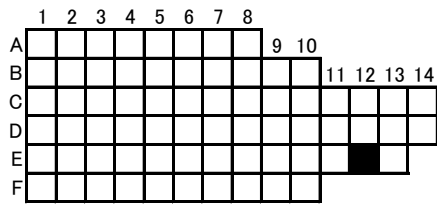

1987

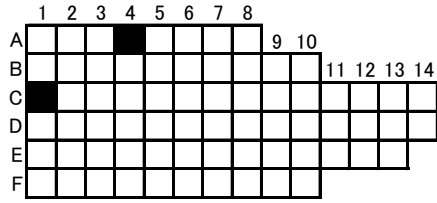

1988

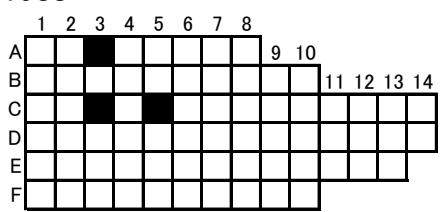

1989

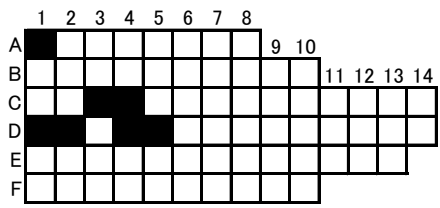

1990

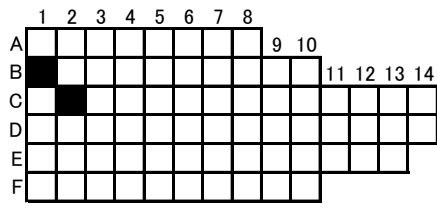

1991

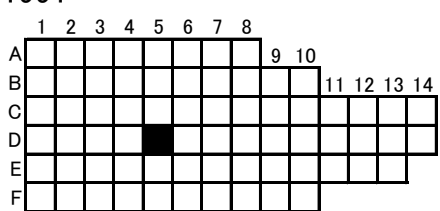

1992

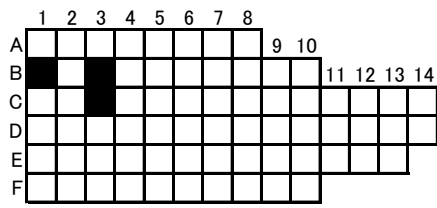

1993

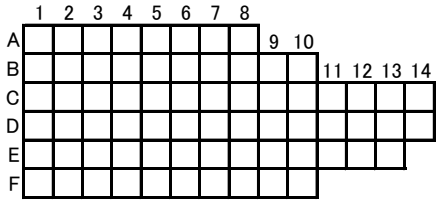

1994

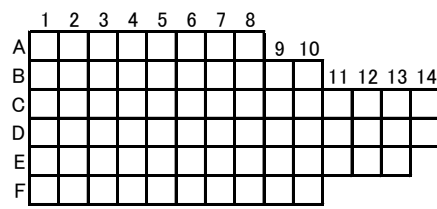

1995

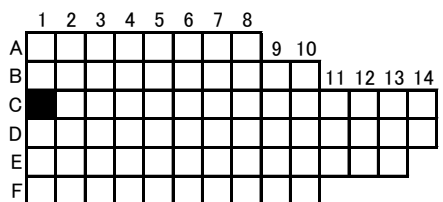

1996

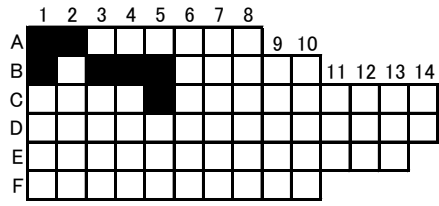

1997

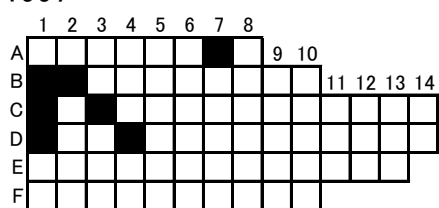

1998

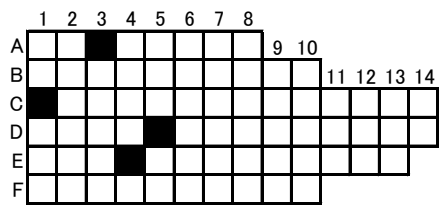

1999

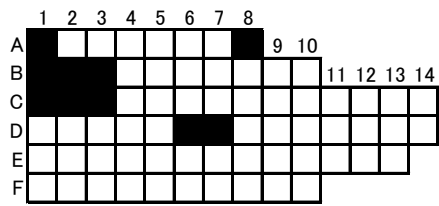

2000

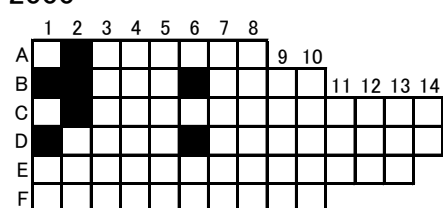

2001

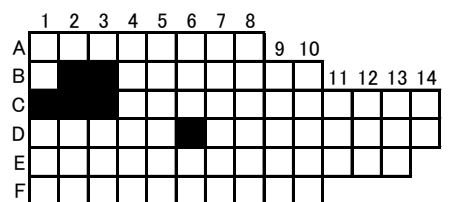

2002

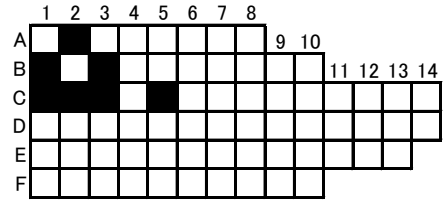

2003

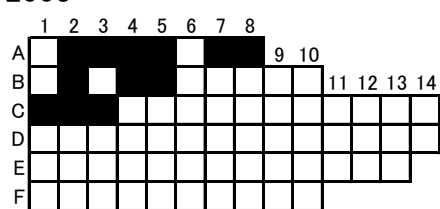

2004

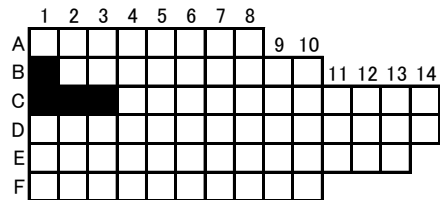

2005

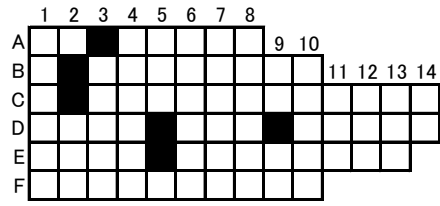

2006

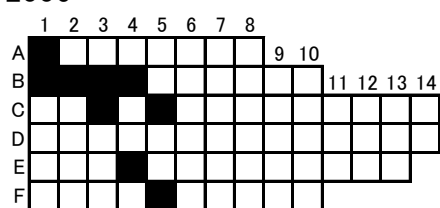

2007

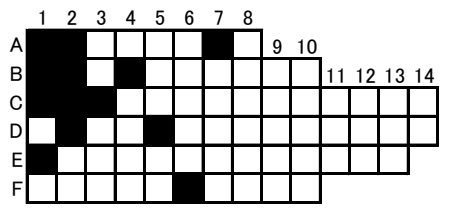

2008

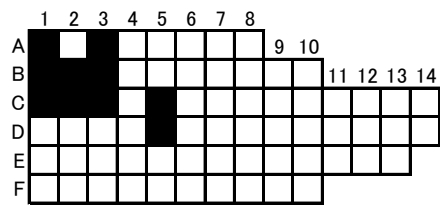

2009

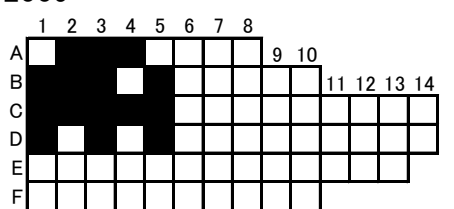

2010

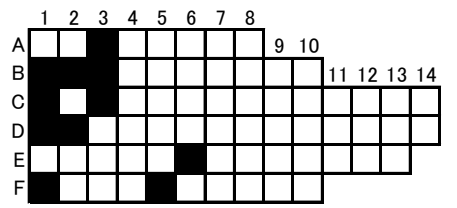




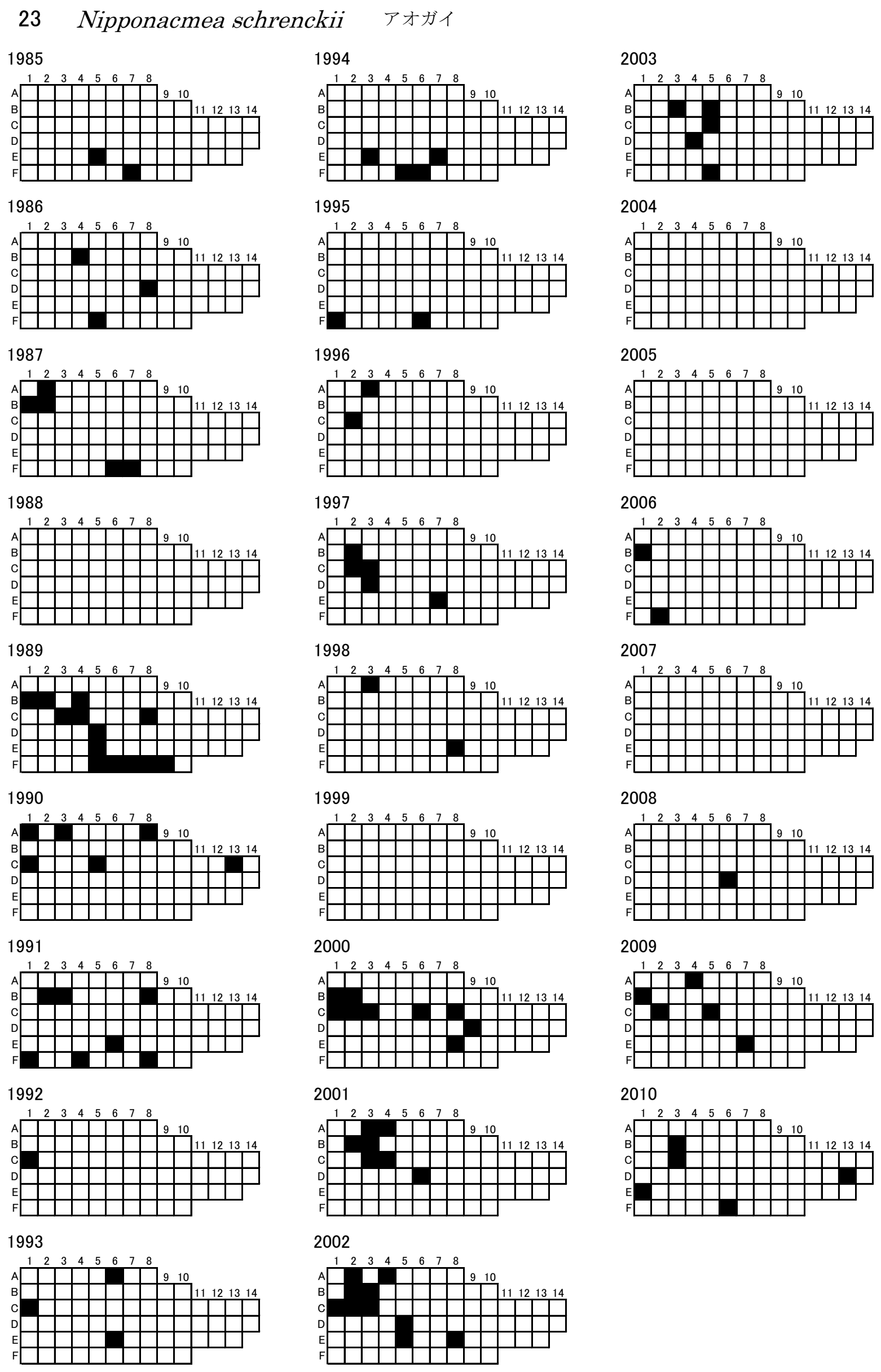


Haliotis varia イボアナゴ
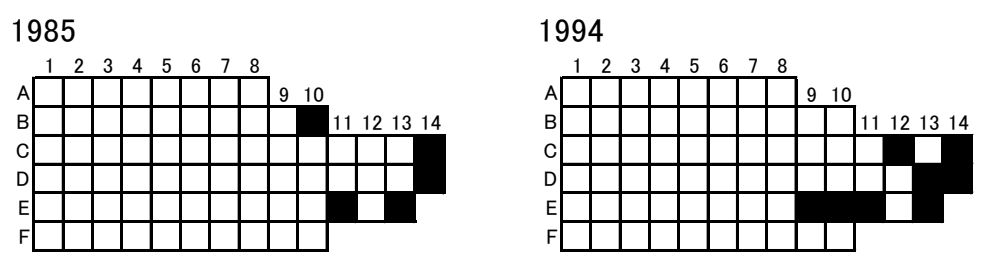

2003

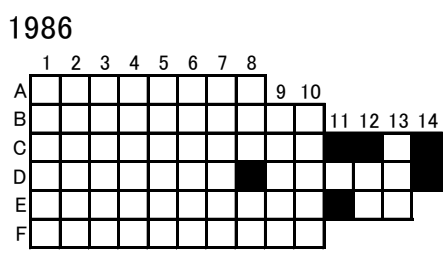

1995
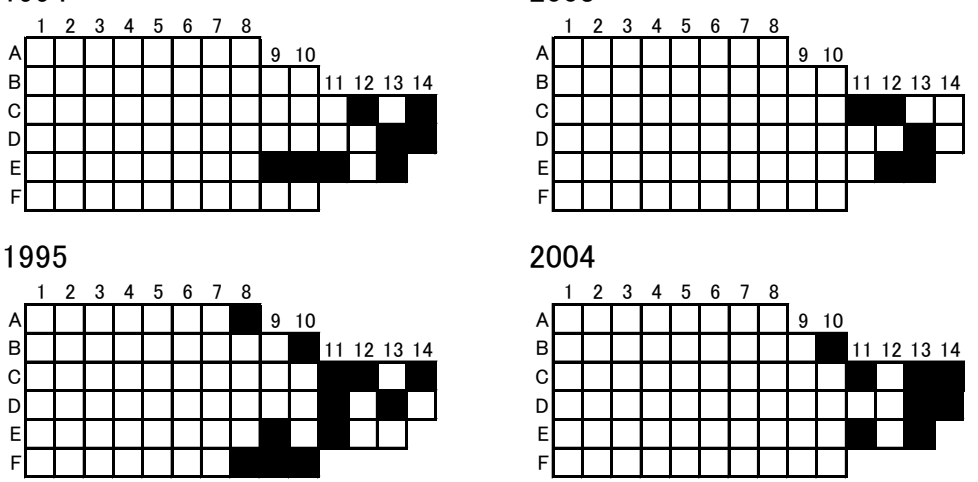

2004

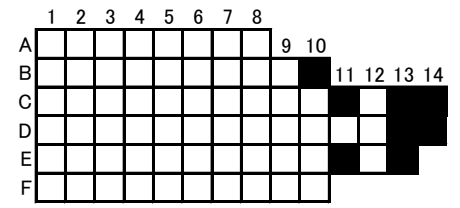
1987

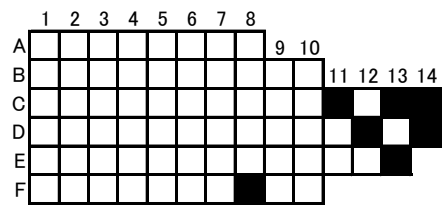

1996

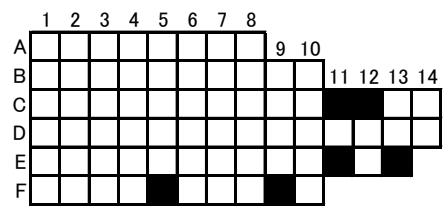

2005

1988

1997
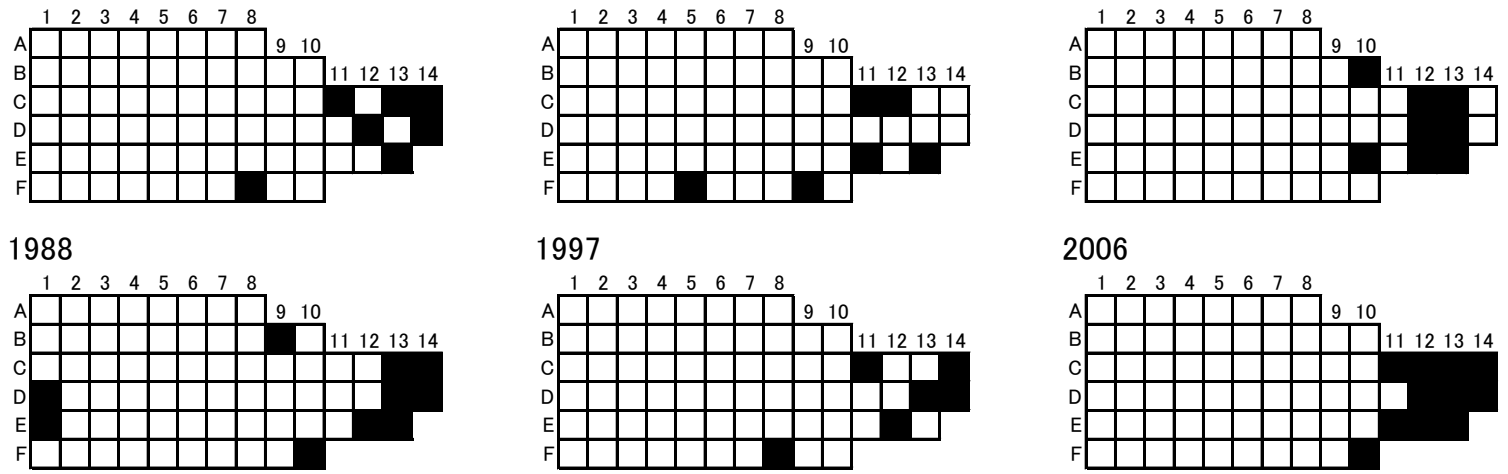

2006

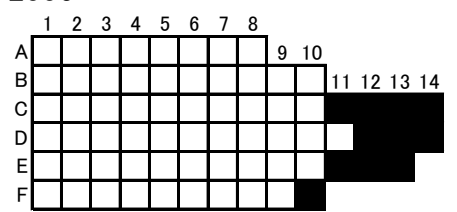
1989

1998
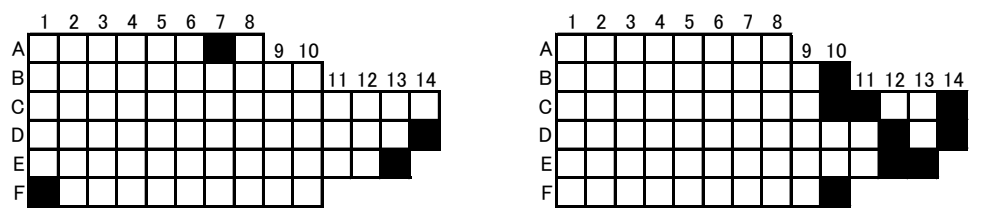

2007
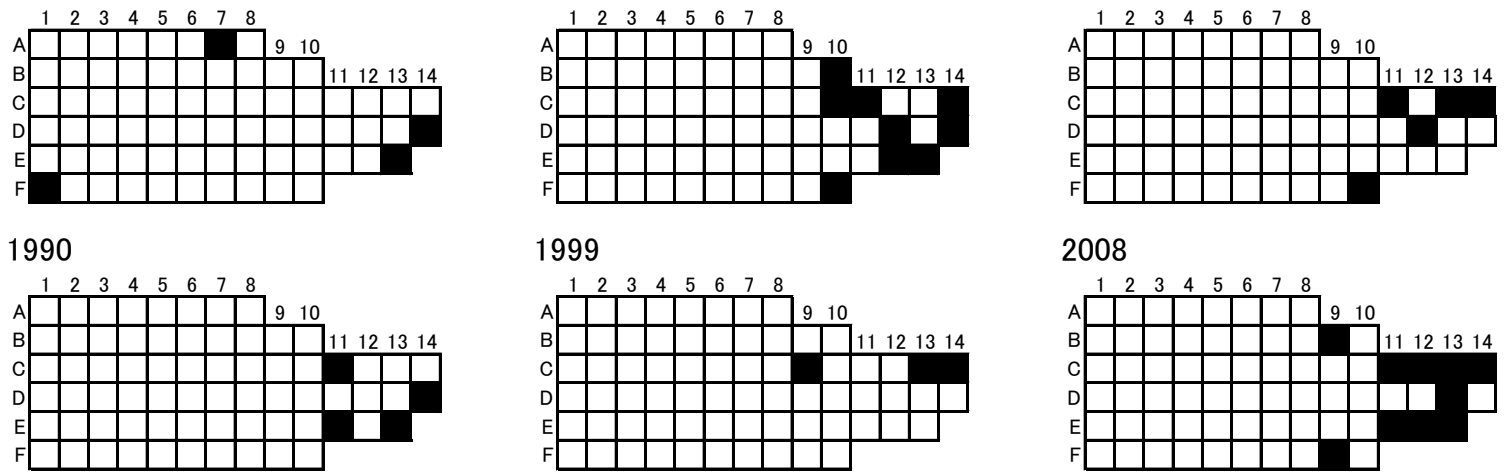

1999

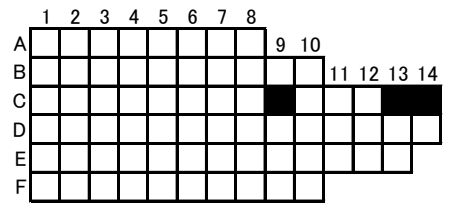

2008

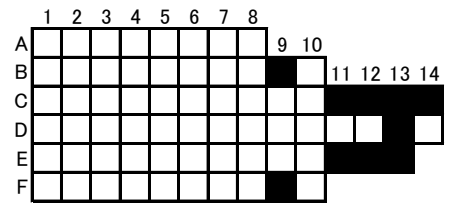
1991

2000
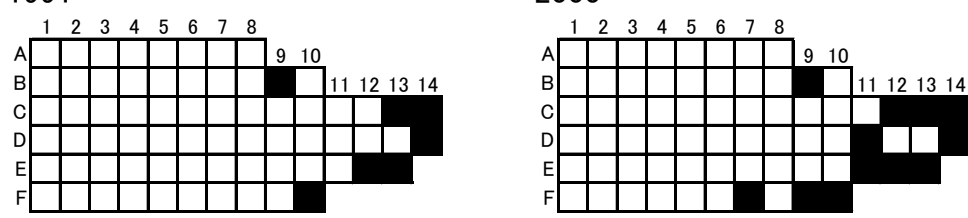

2009

1992

2001
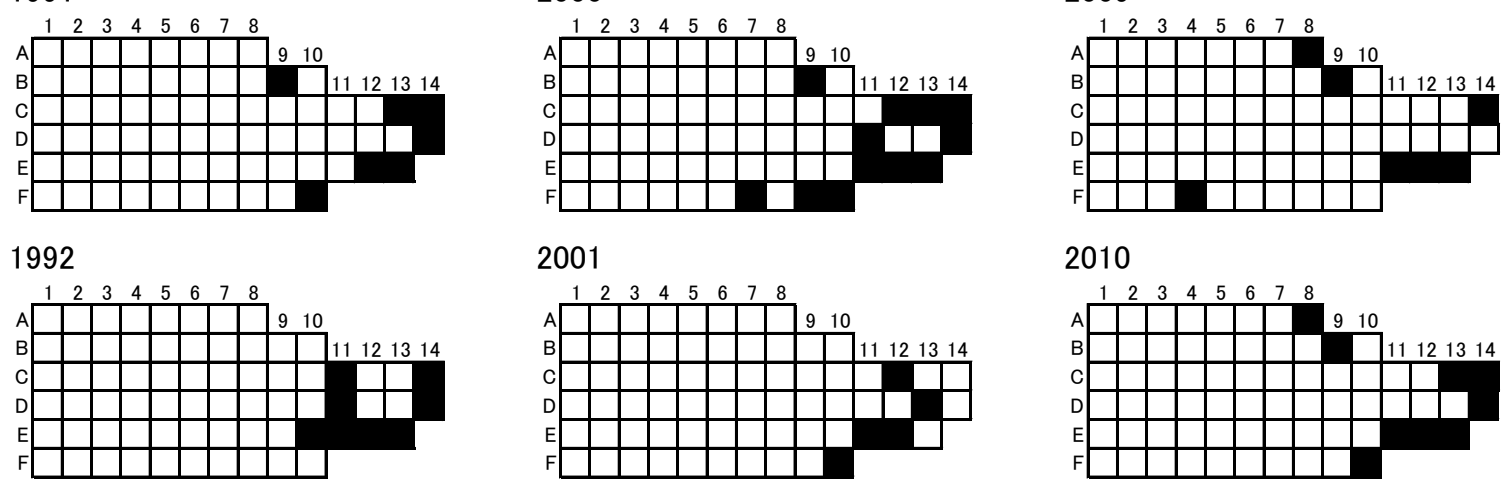

2010
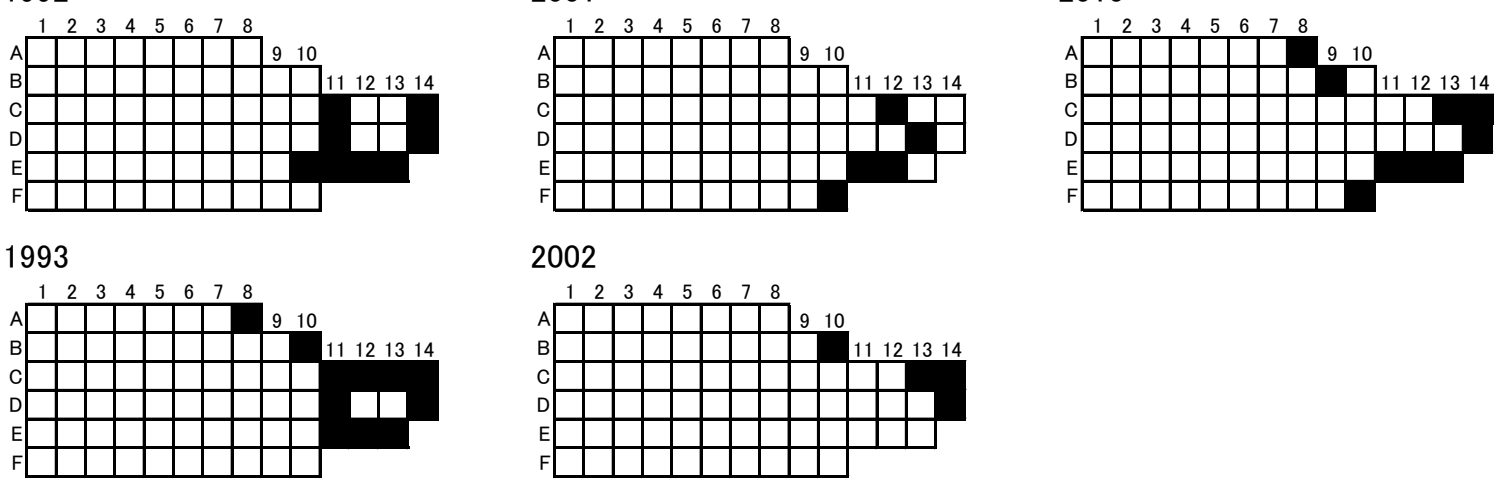


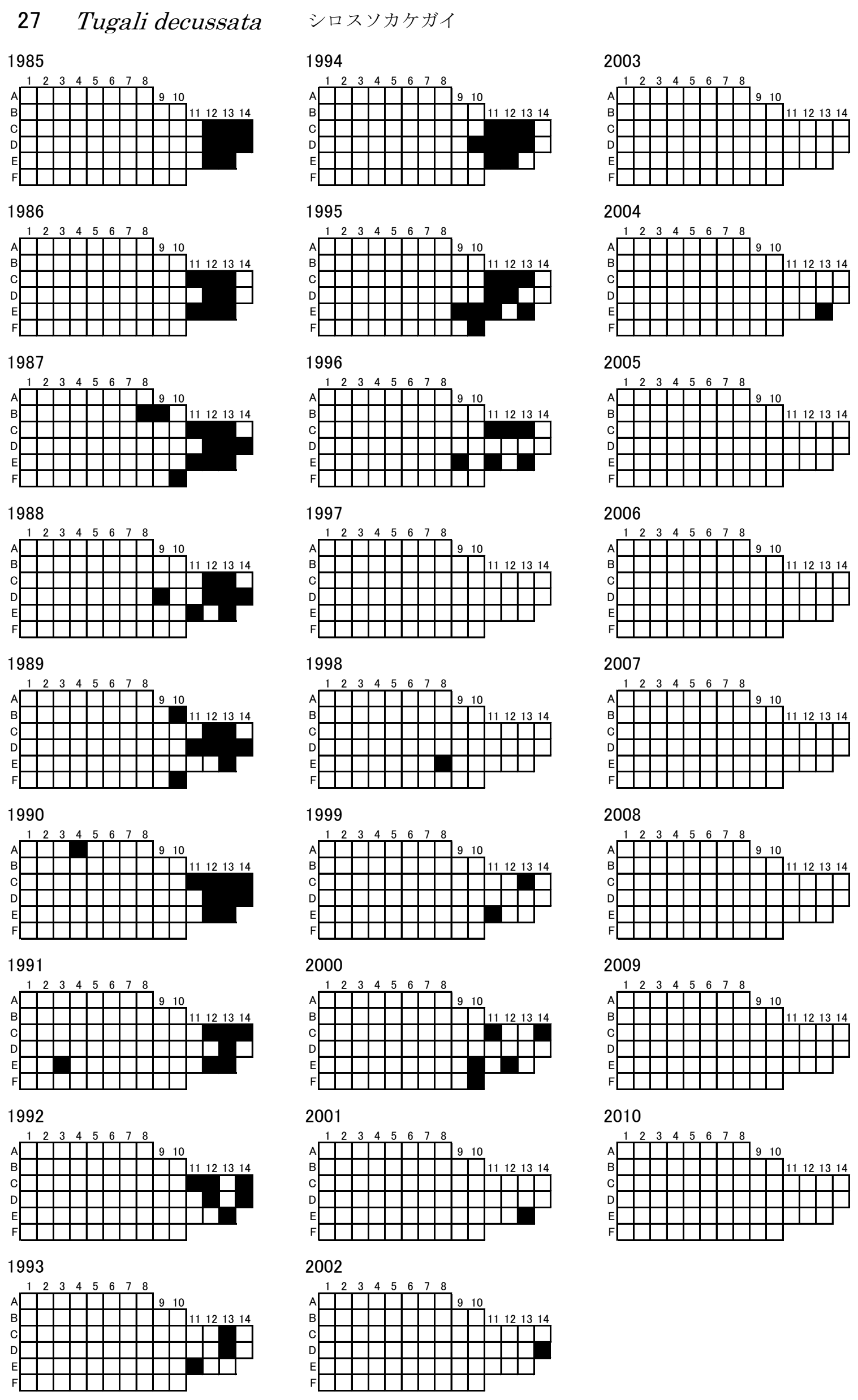


28

Montfortula picta

1985

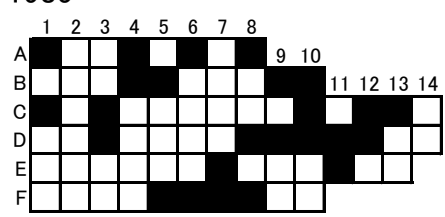

1986

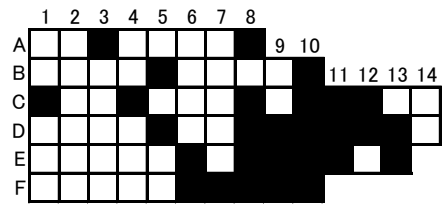

1987

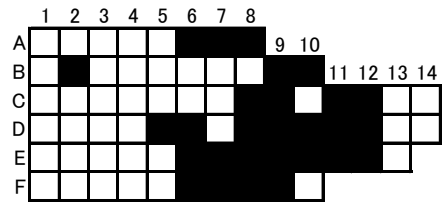

1988

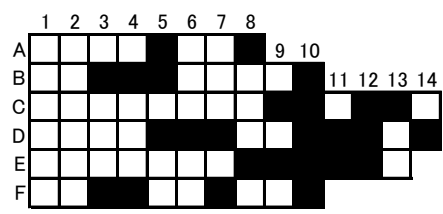

1989

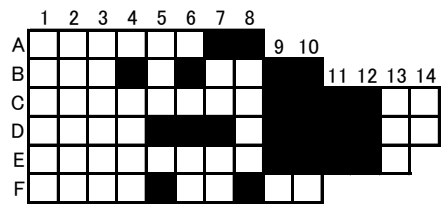

1990

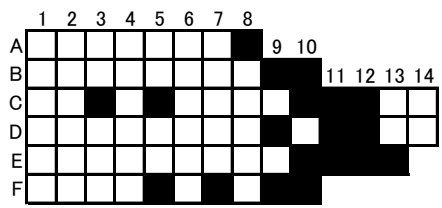

1991

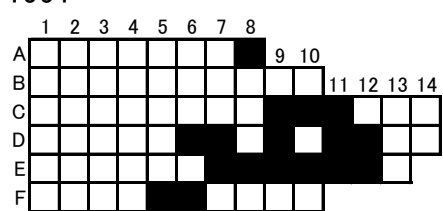

1992

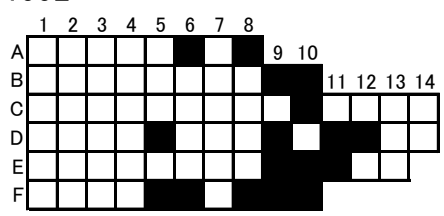

1993

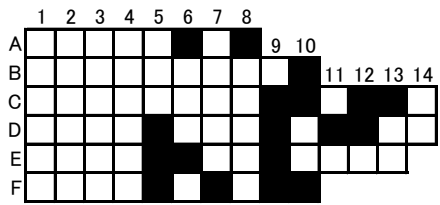

1994

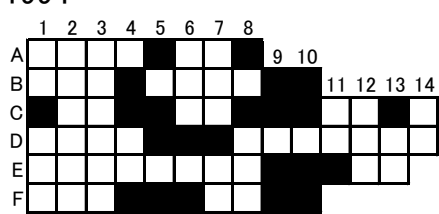

1995

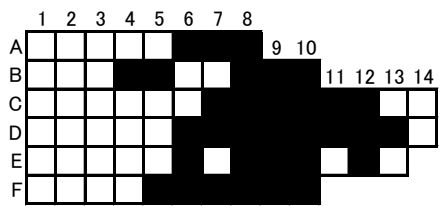

1996

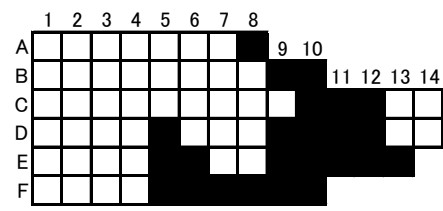

1997

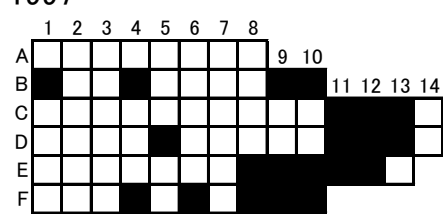

1998

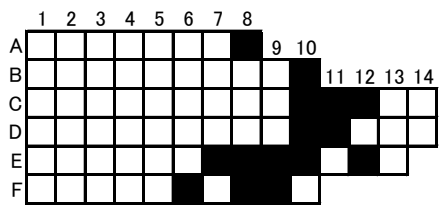

1999

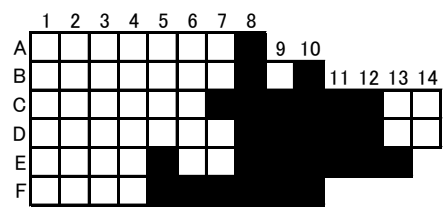

2000

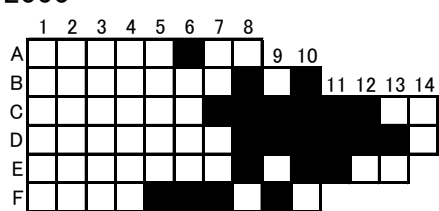

2001

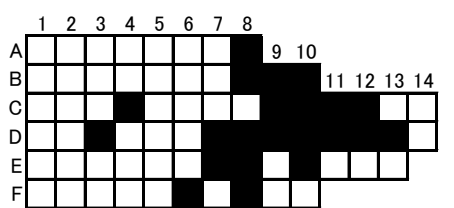

2002

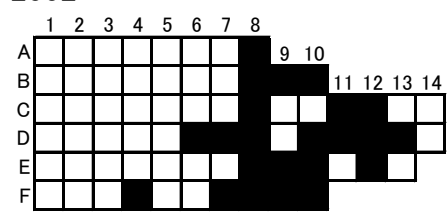

2003

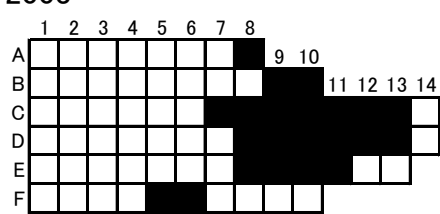

2004

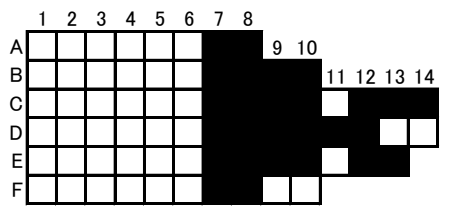

2005

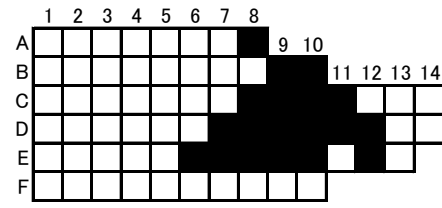

2006

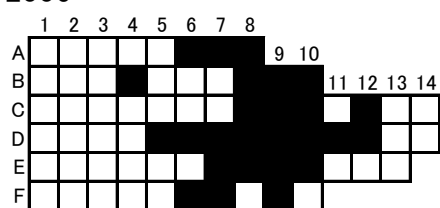

2007

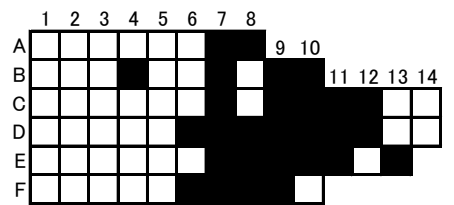

2008

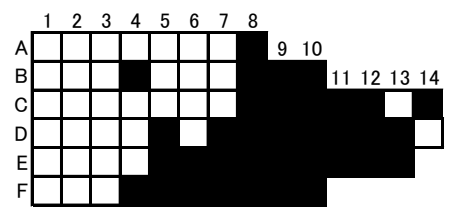

2009

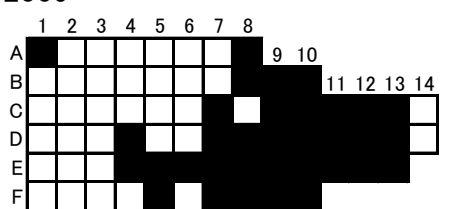

2010

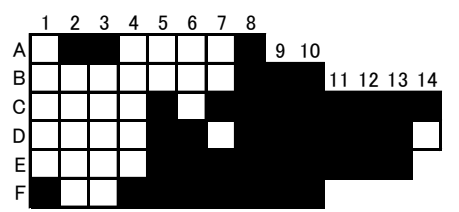


29 Macroschisma dilatatum ヒラスカシガイ

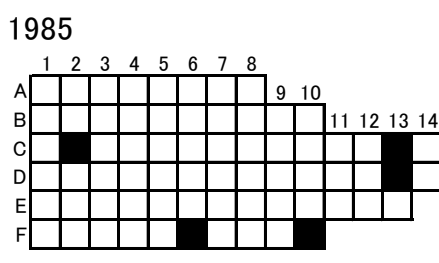

1994

2003

1986
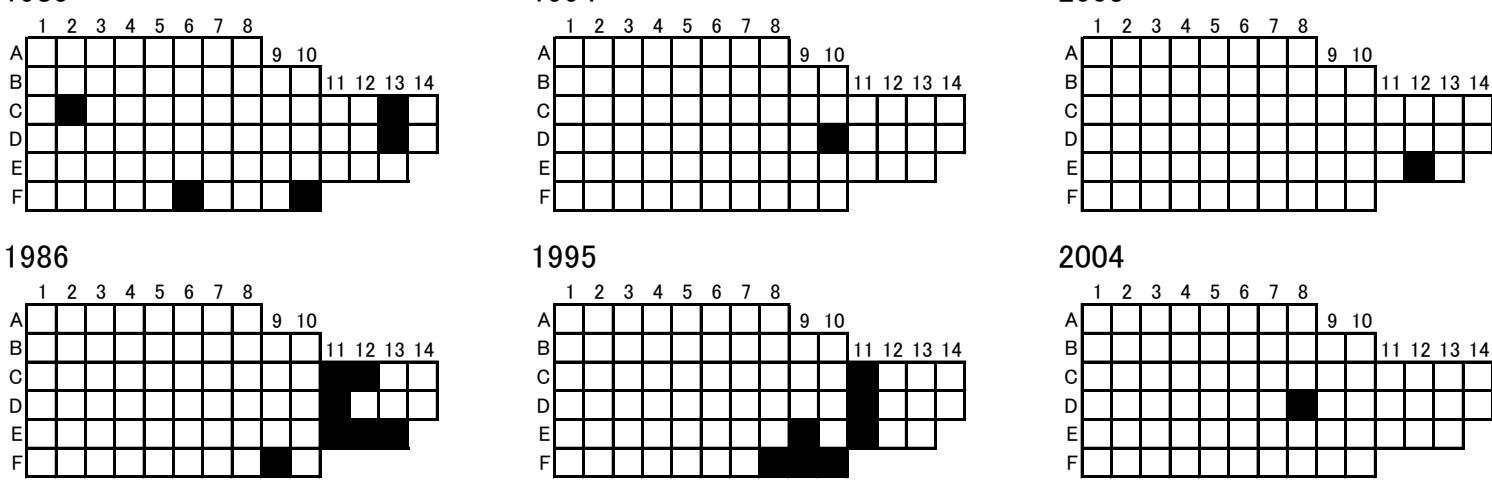

1995

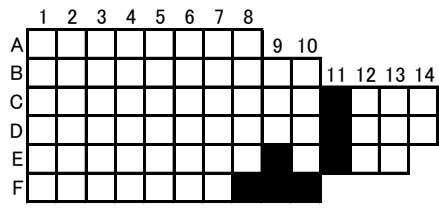

2004

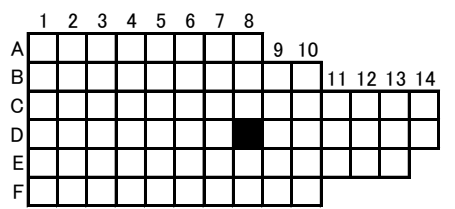

1987

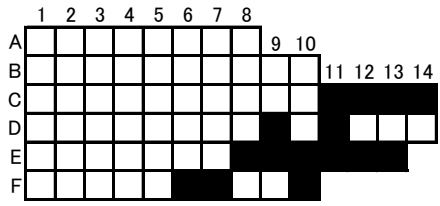

1996

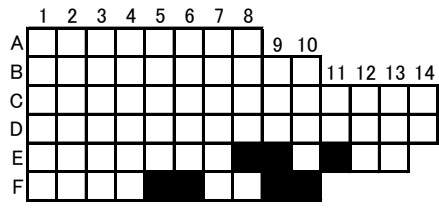

2005

1988

1997
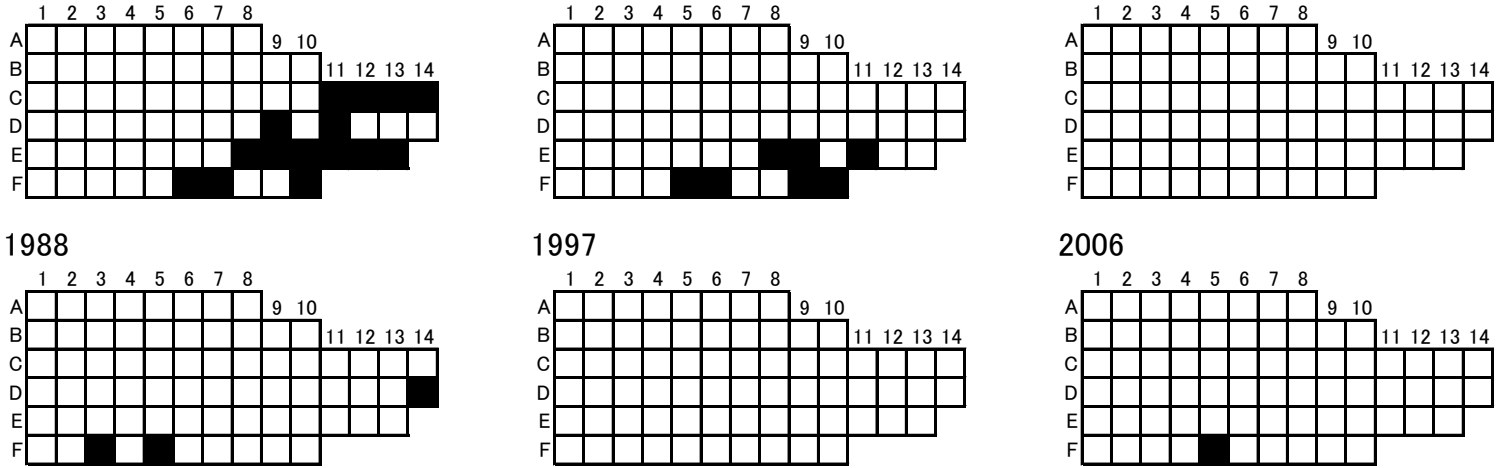

2006

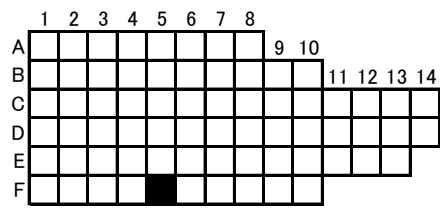

1989

1998
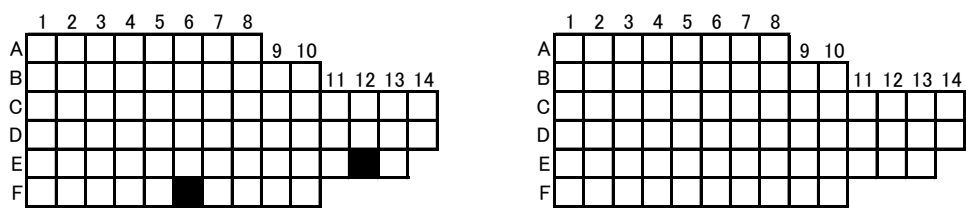

2007
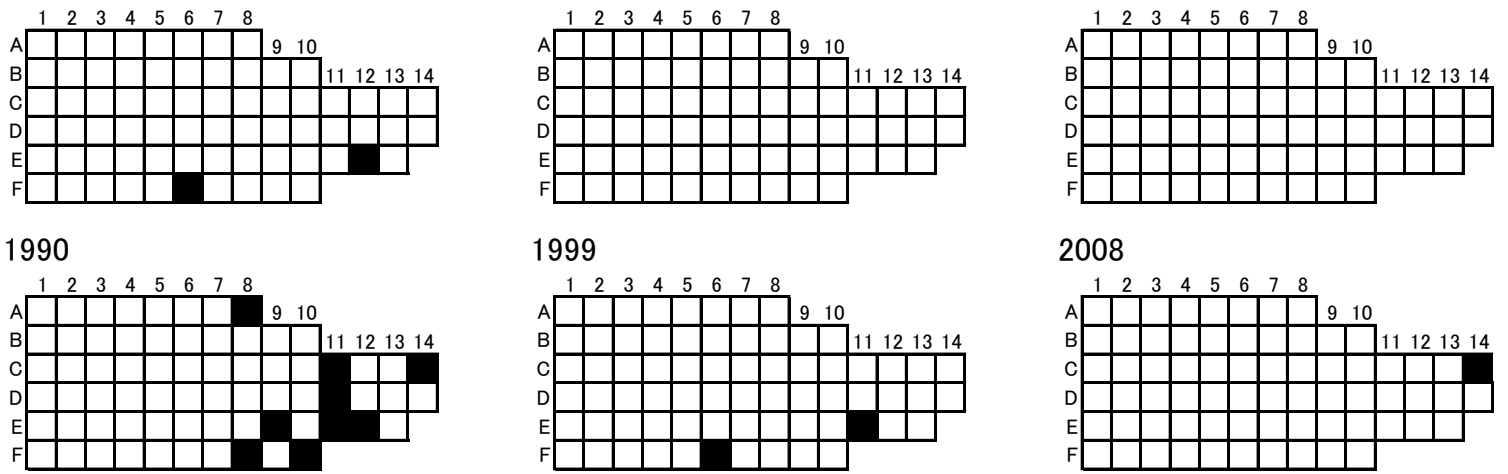

1999

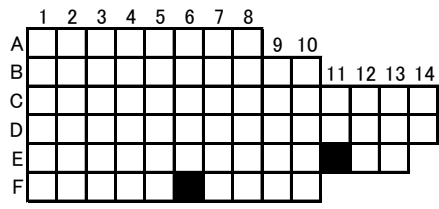

2008

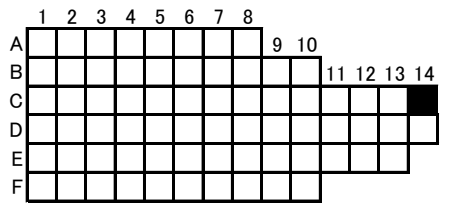

1991

2000
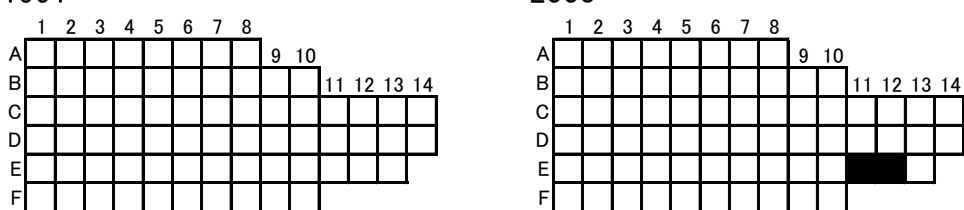

2009

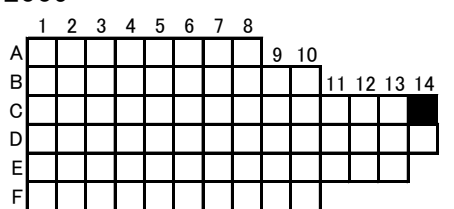

1992

2001
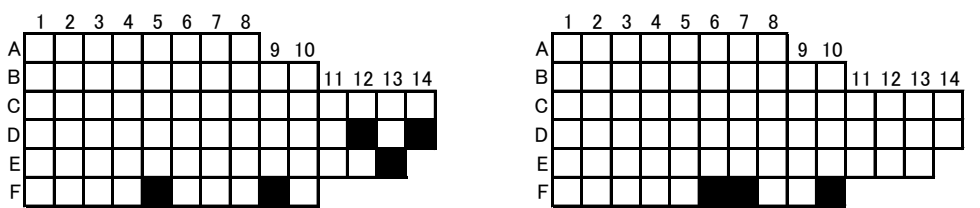

2010

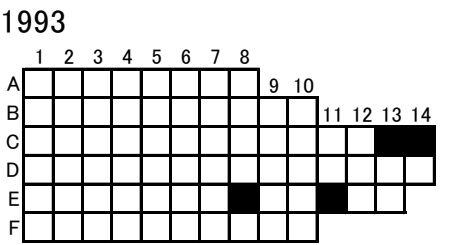

2002

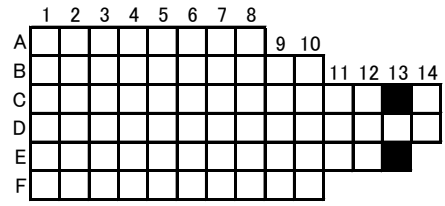

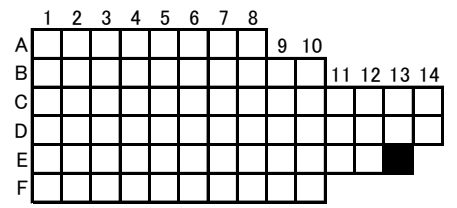




\section{Chlorostoma xanthostigma クマノコガイ}

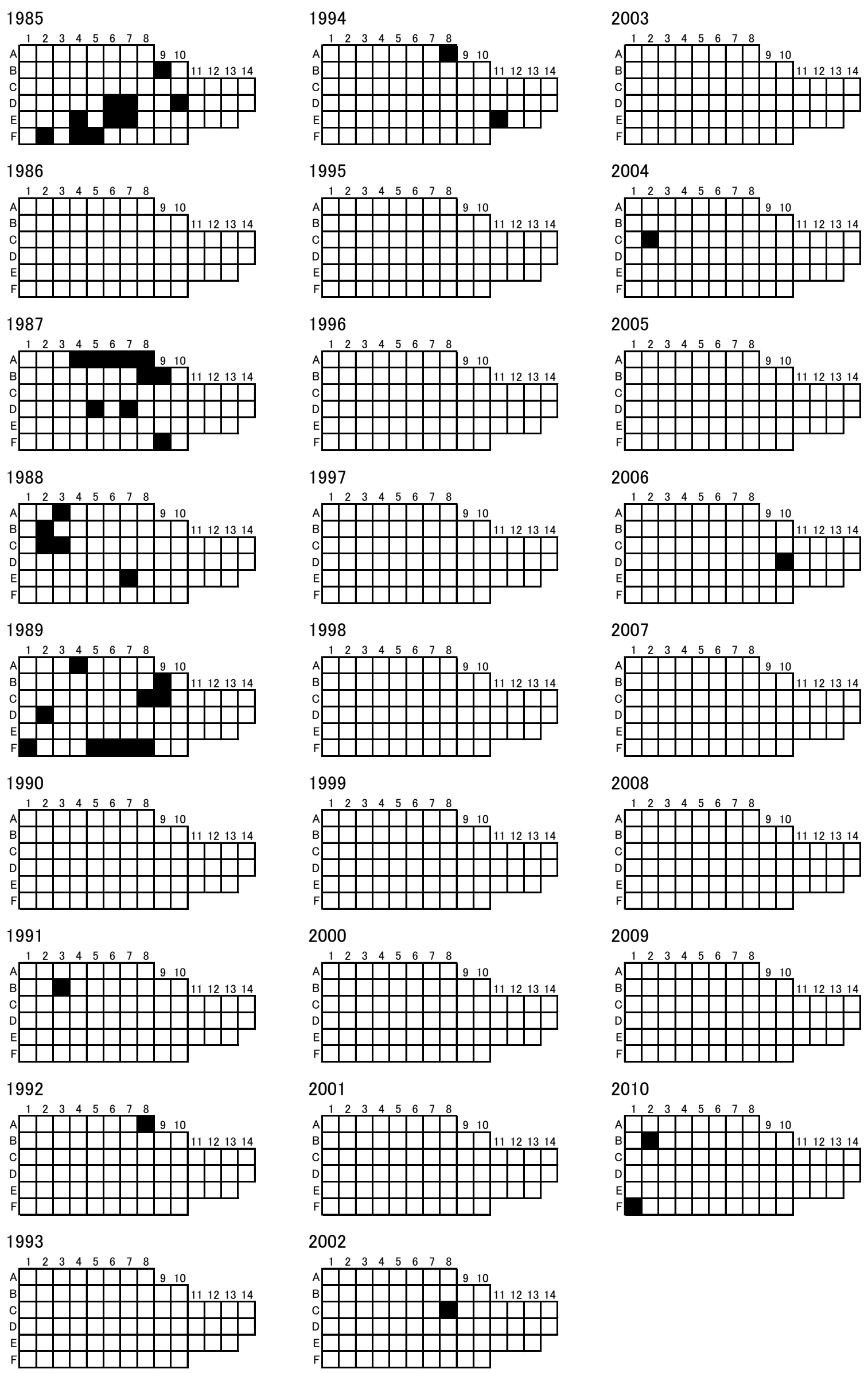


Trochus maculatus ニシキウズ
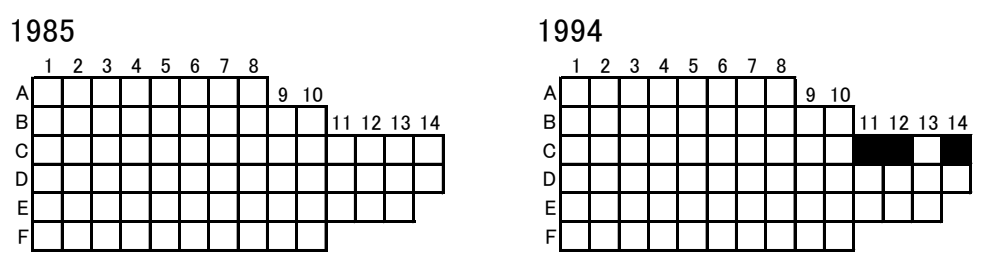

2003

1986

1995
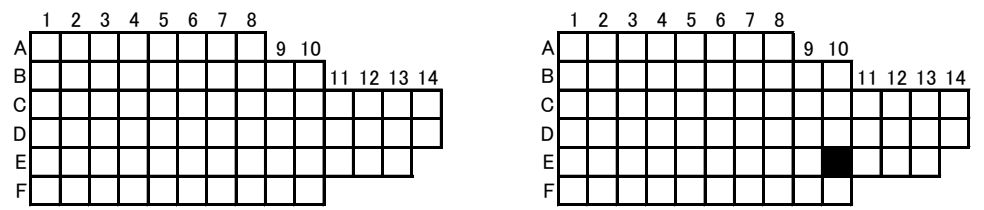

1987

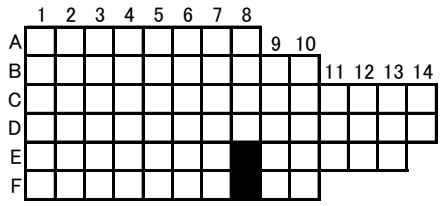

1996
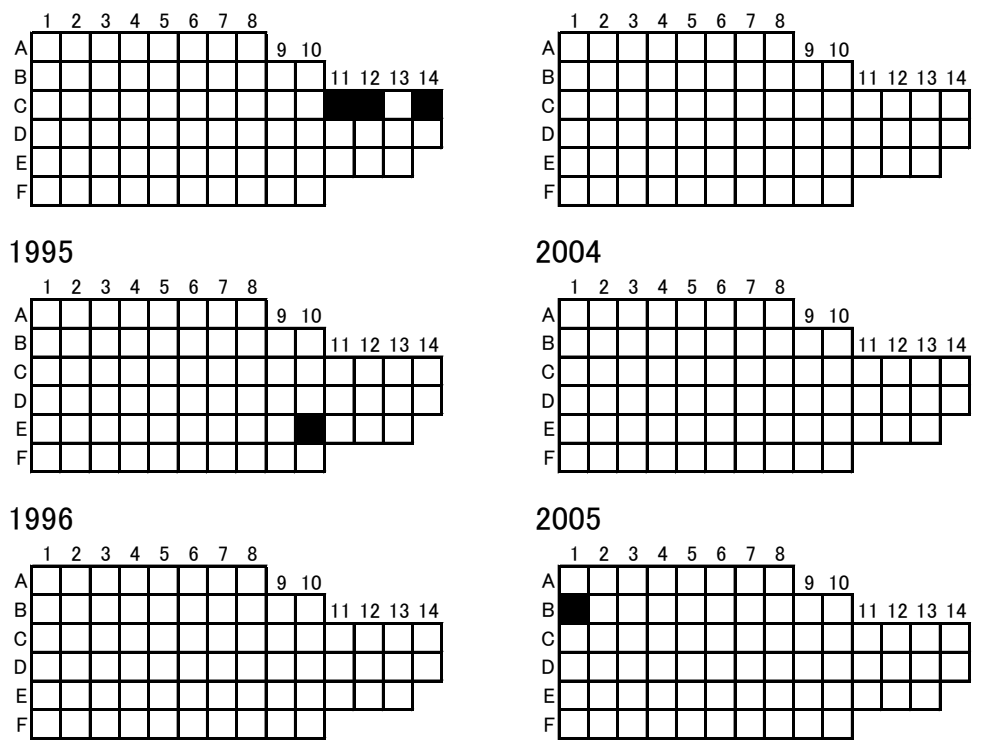

2004

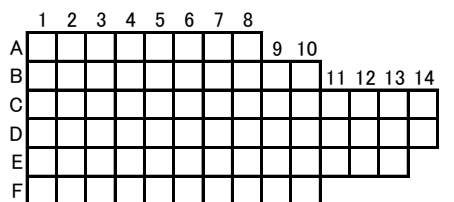

2005

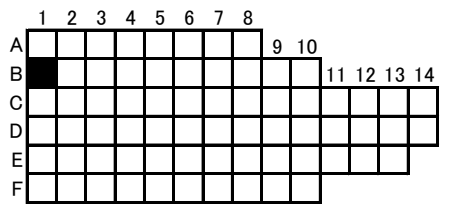

1988

1997
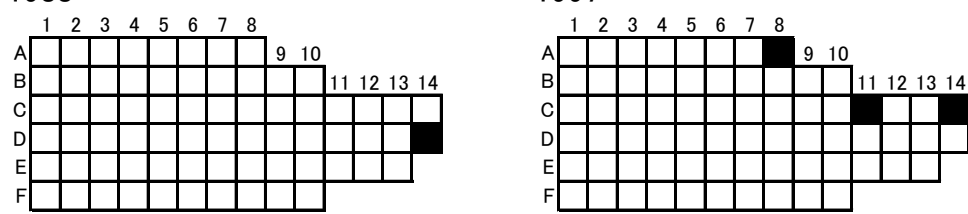

2006

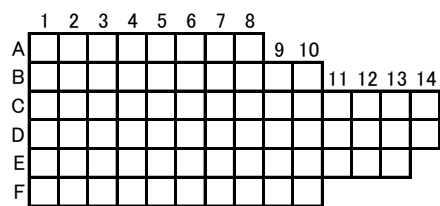

1989

1998
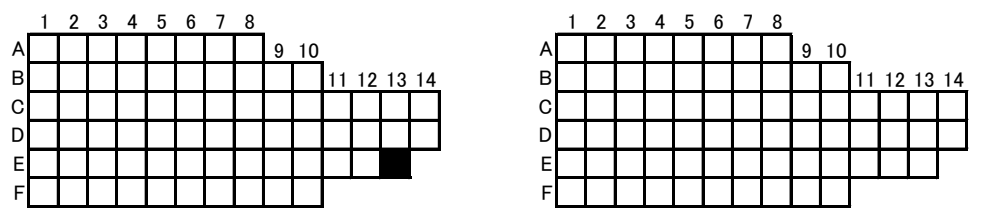

2007
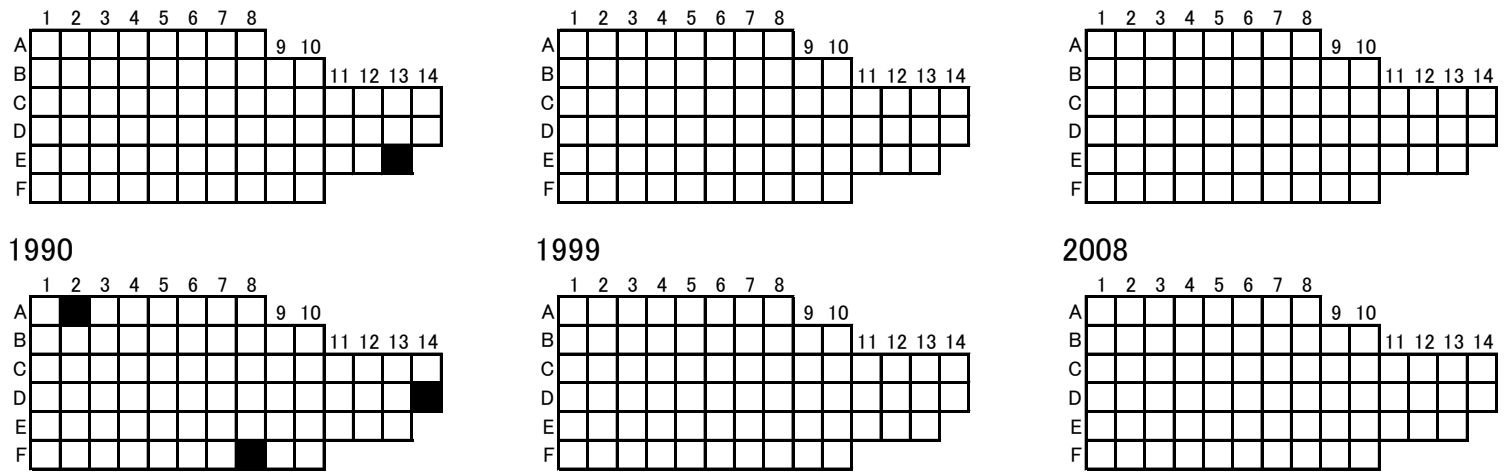

1999

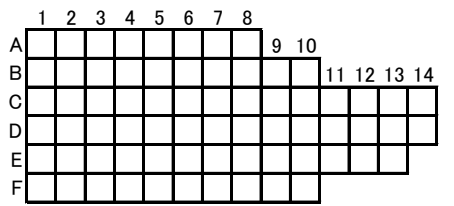

2008

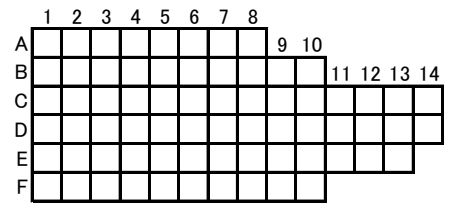

1991

2000
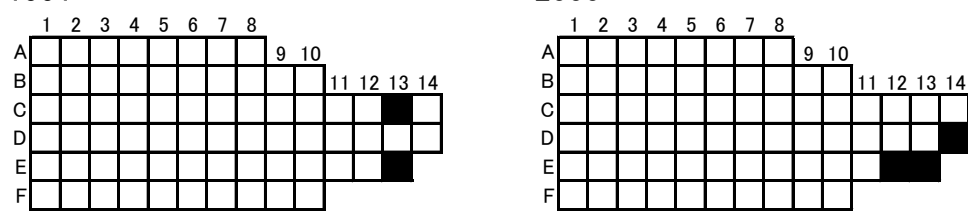

2009

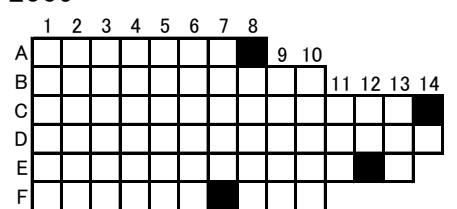

1992

2001
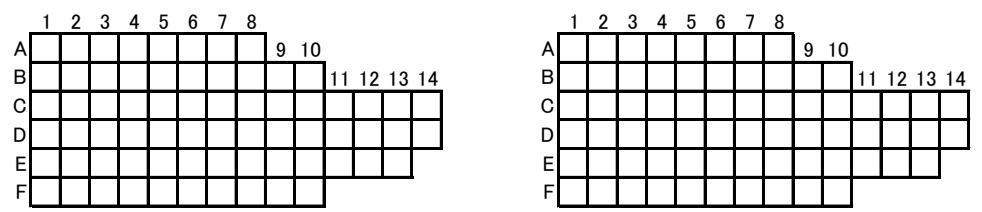

2010
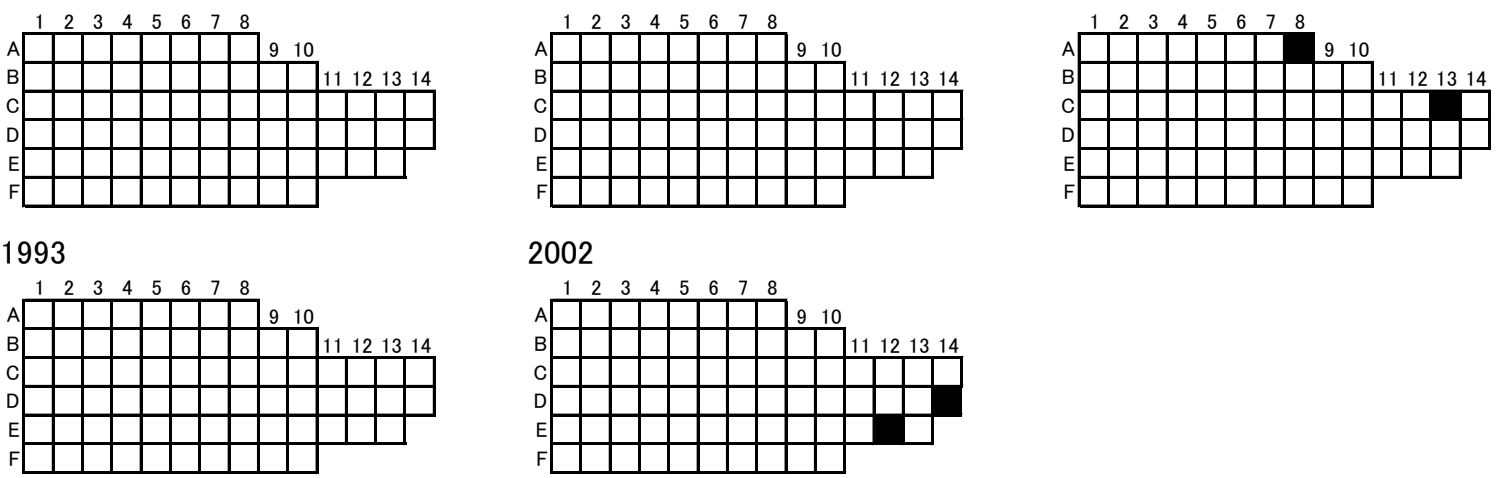
Trochus rota ウズイチモンジ

1985

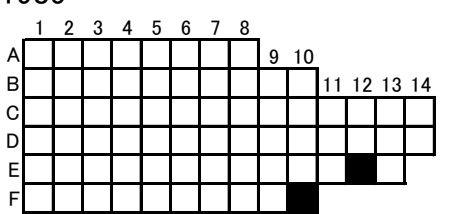

1986

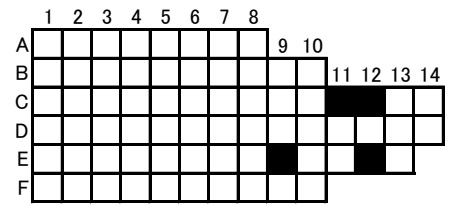

1987

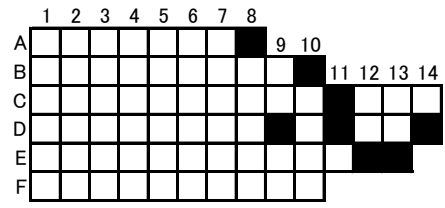

1988

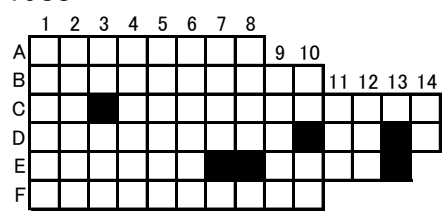

1989

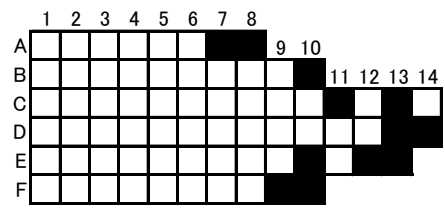

1990

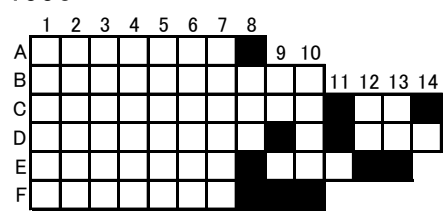

1991

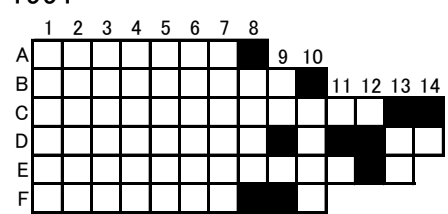

1992

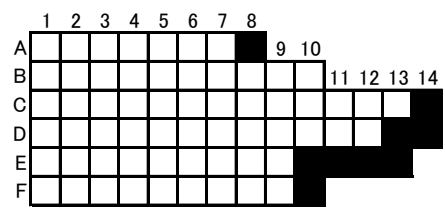

1993

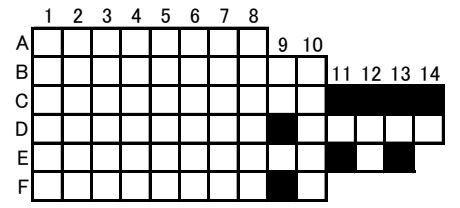

1994

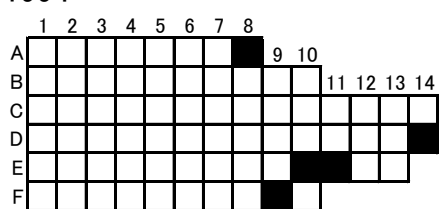

1995

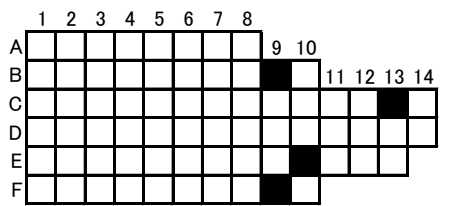

1996

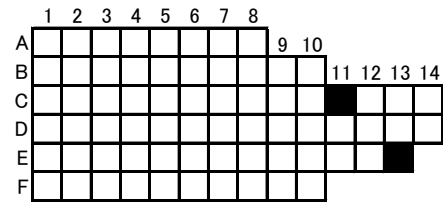

1997

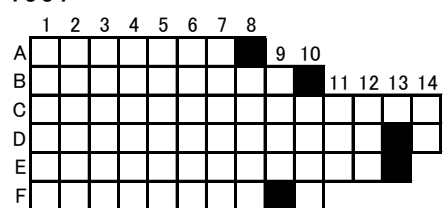

1998

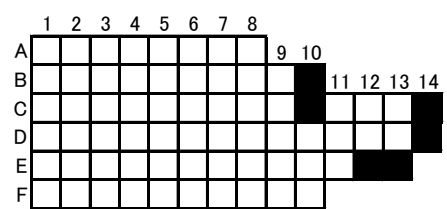

1999

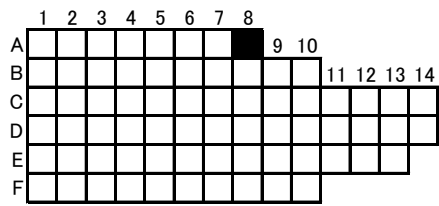

2000

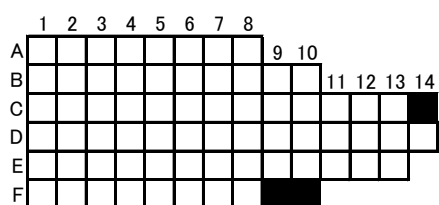

2001

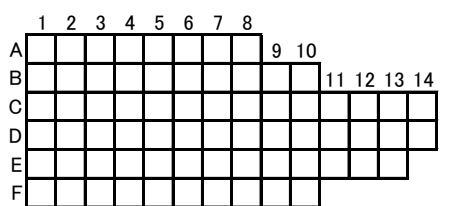

2002

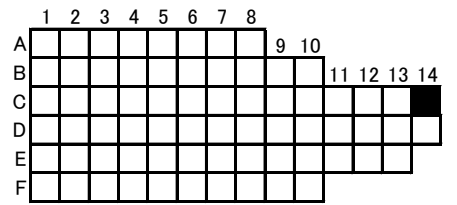

2003

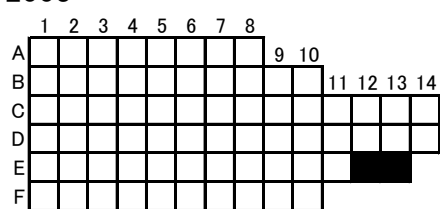

2004

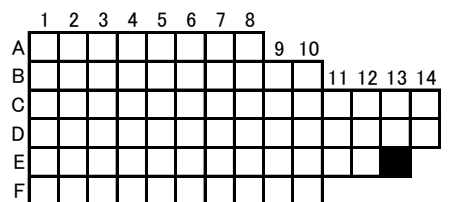

2005

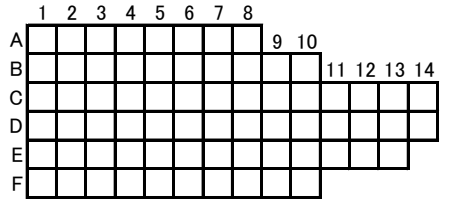

2006

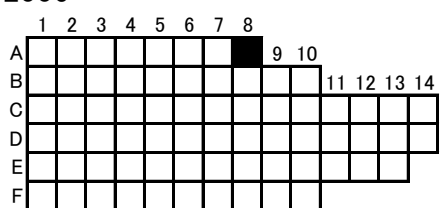

2007

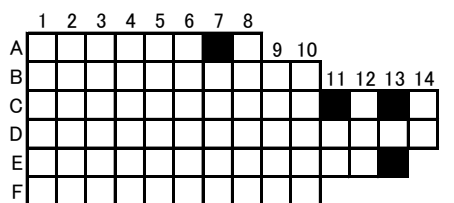

2008

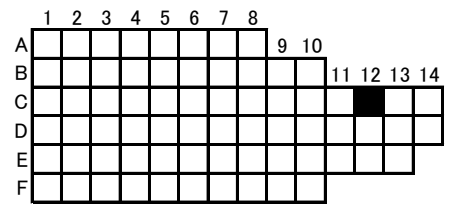

2009

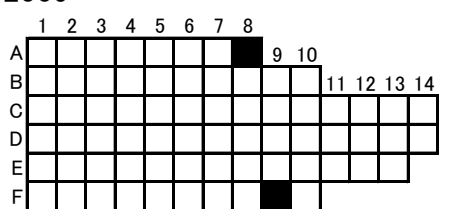

2010

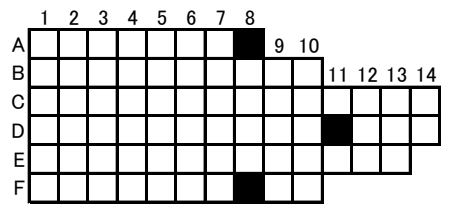




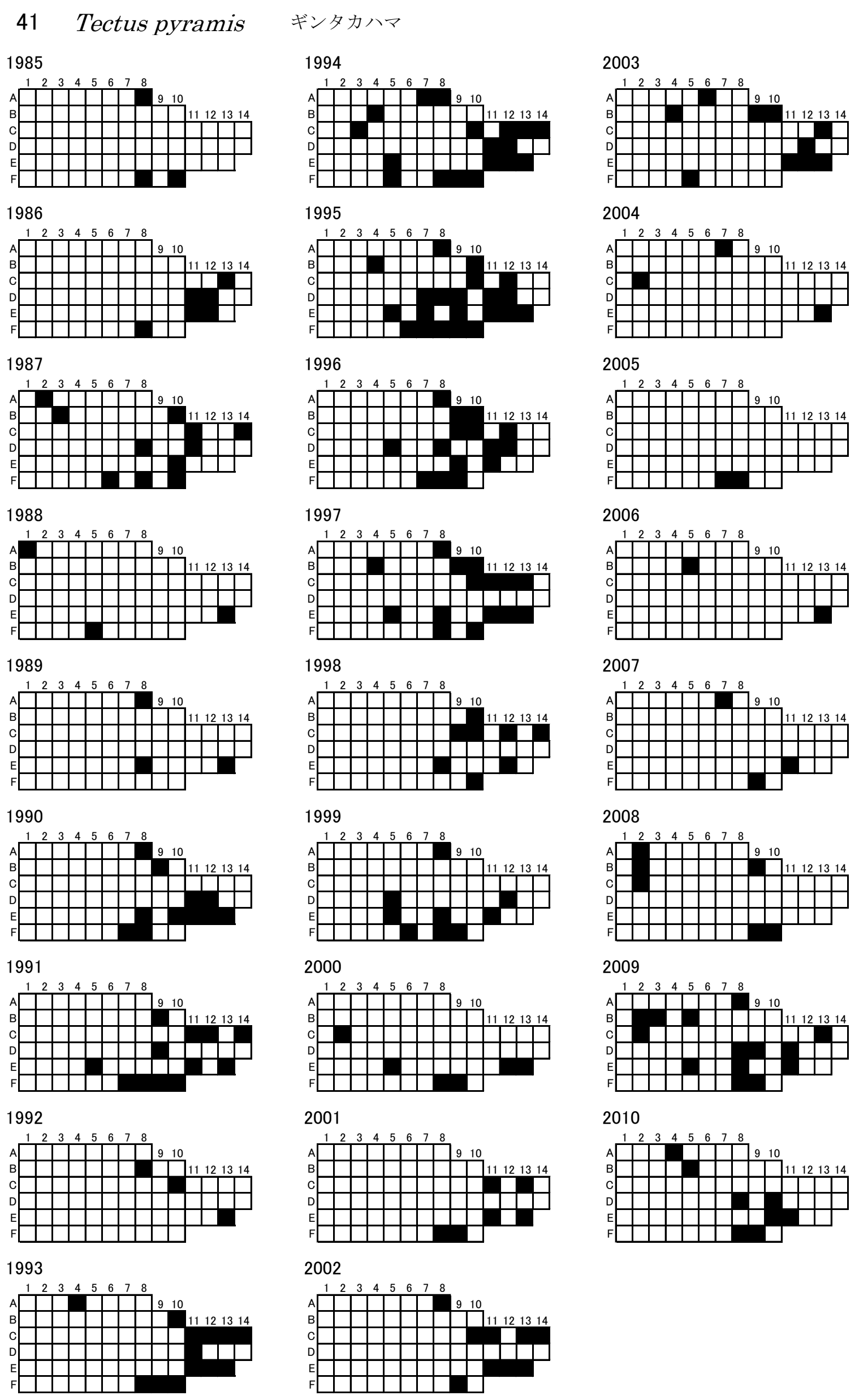


1985

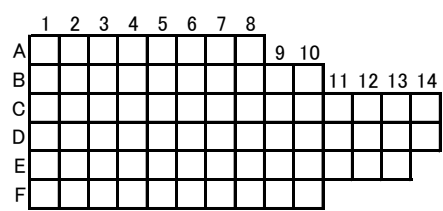

1986

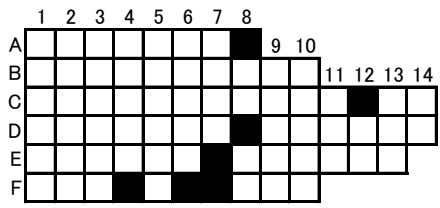

1987

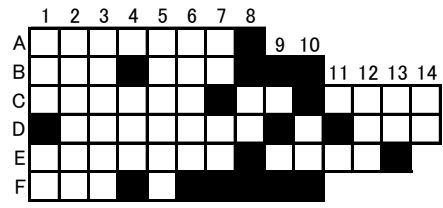

1988

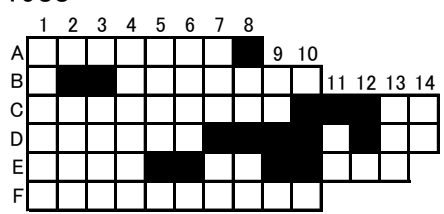

1989

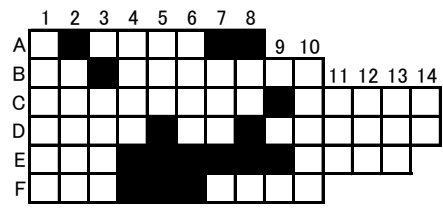

1990

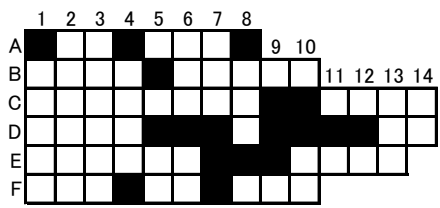

1991

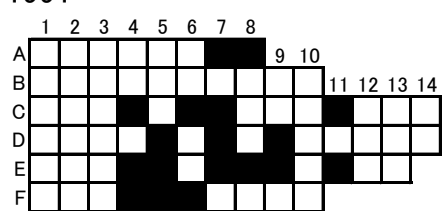

1992

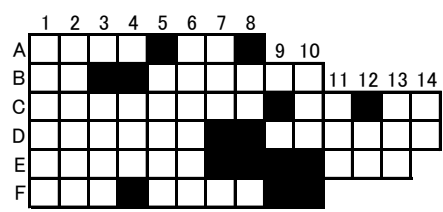

1993

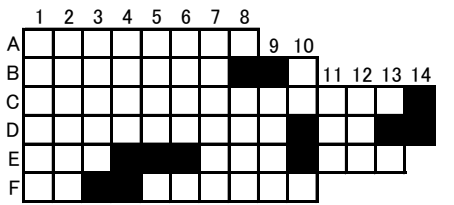

1994

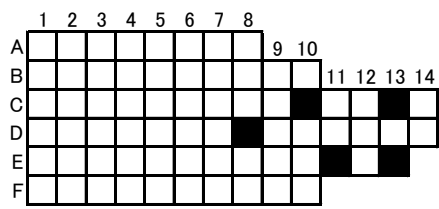

1995

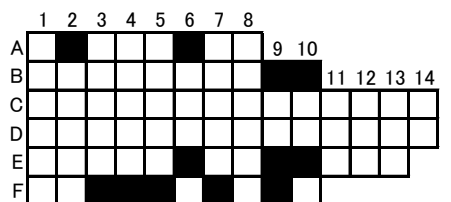

1996

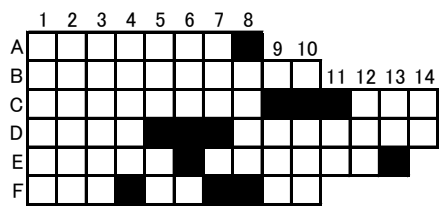

1997

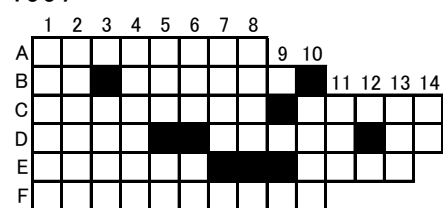

1998

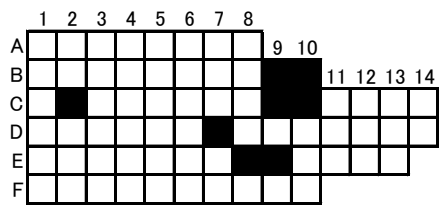

1999

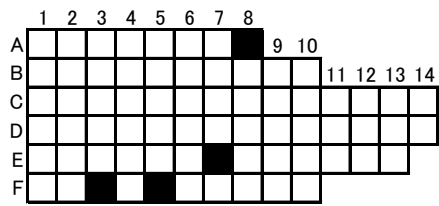

2000

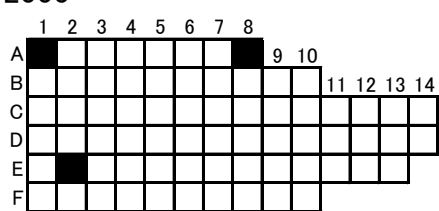

2001

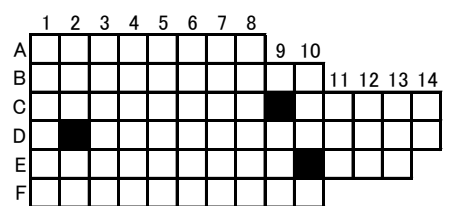

2002

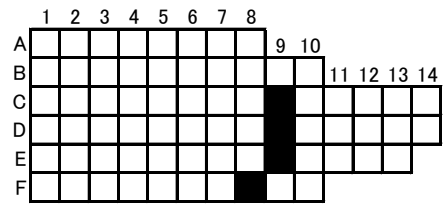

2003

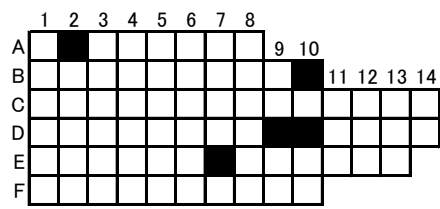

2004

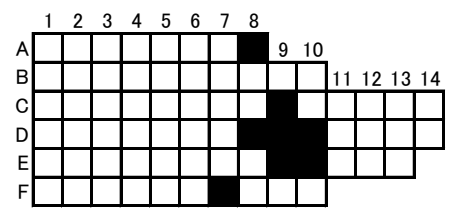

2005

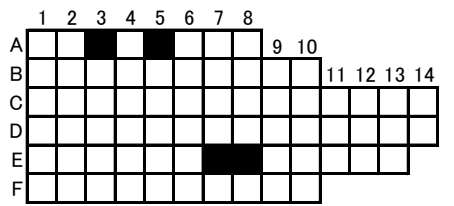

2006

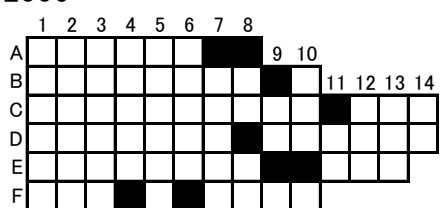

2007

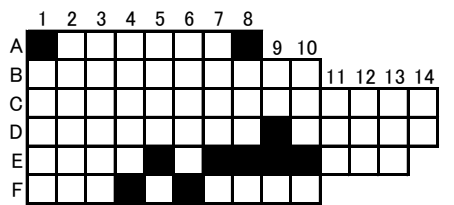

2008

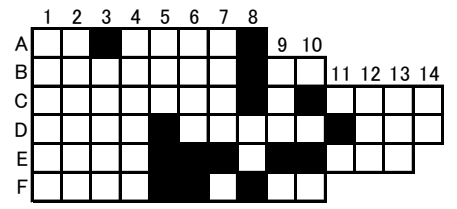

2009

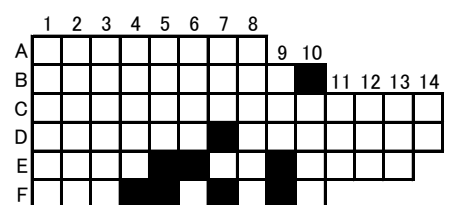

2010

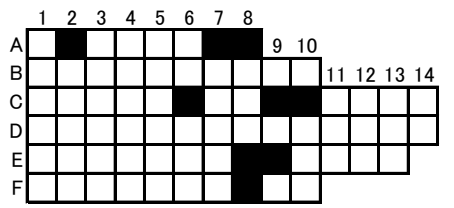


44 Monodonta labio confusa イシダタミ
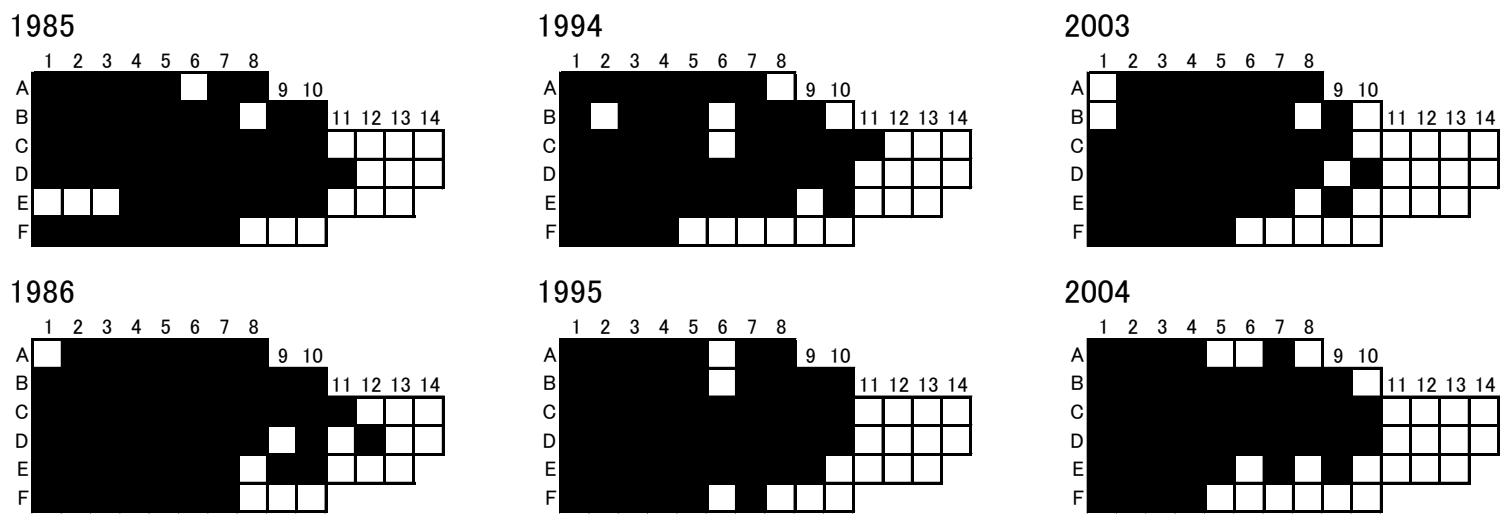

1995

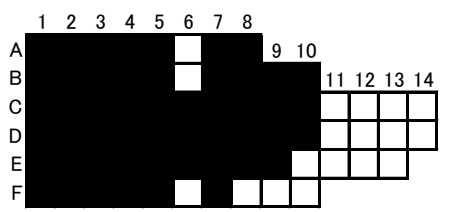

2004
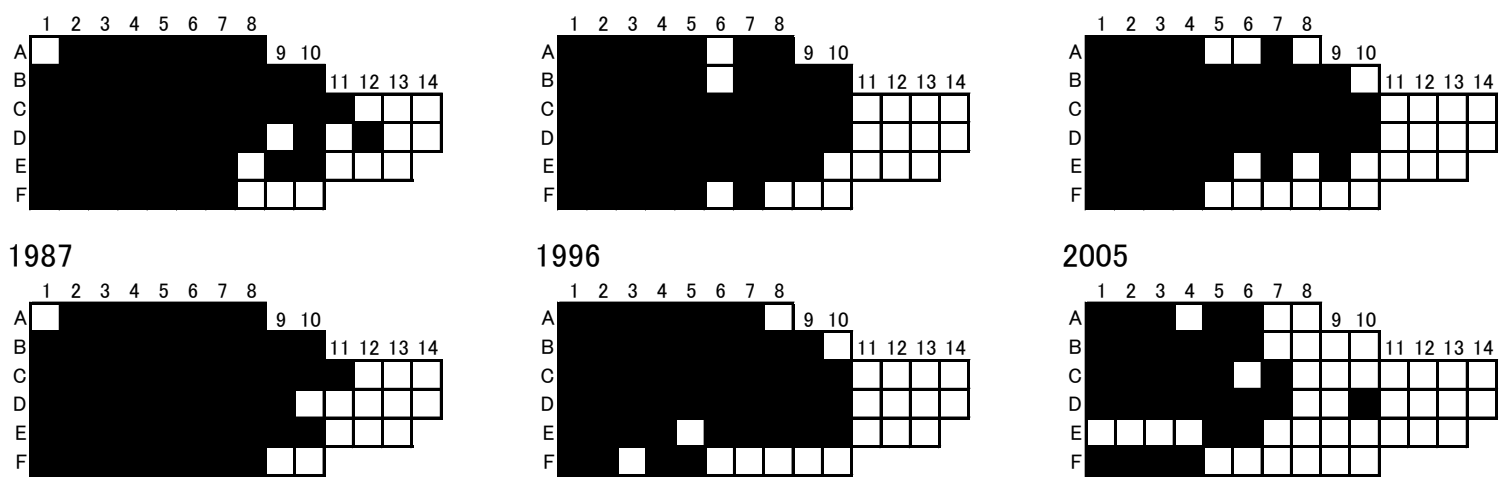

2005
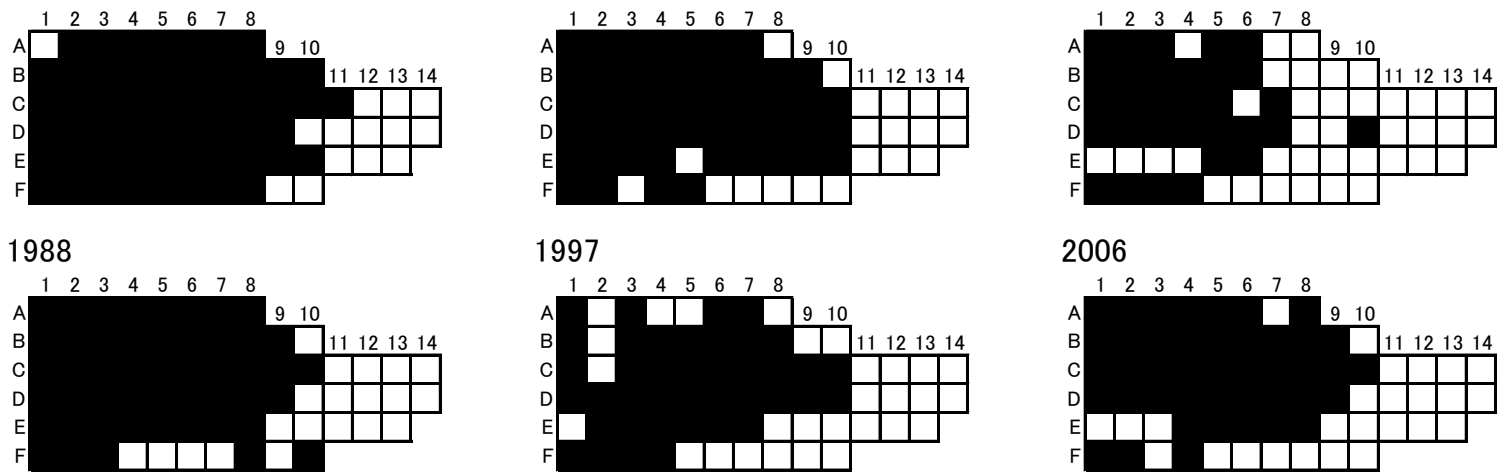

1997

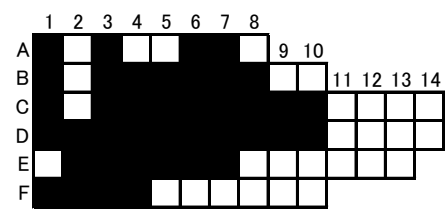

2006

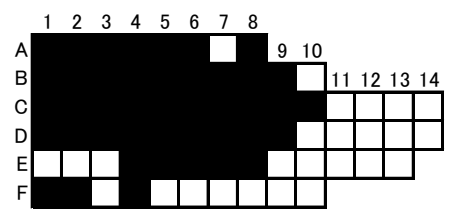

1989

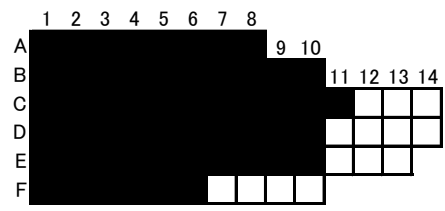

1998

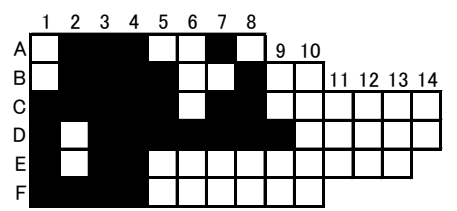

2007
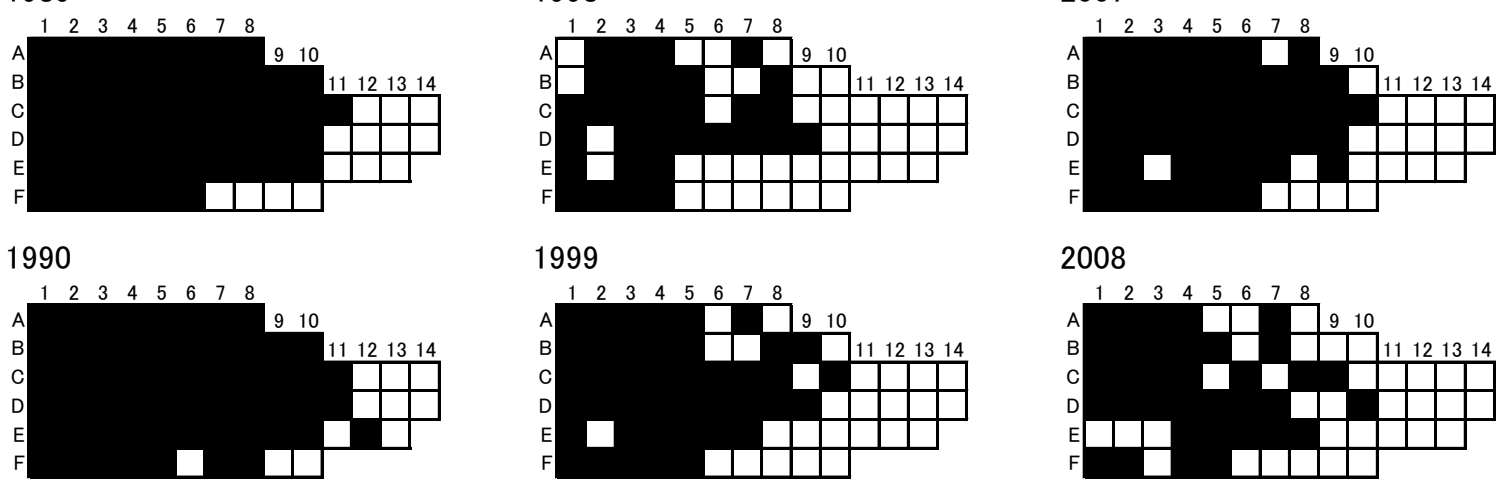

1999

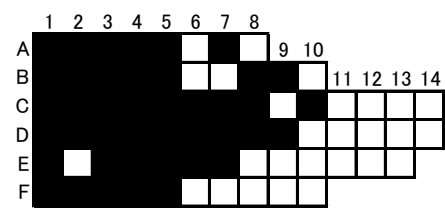

2008

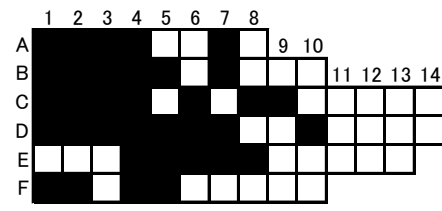

1991

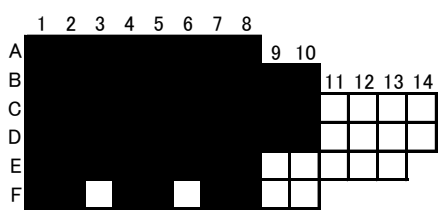

2000

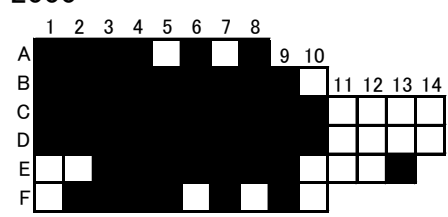

2009

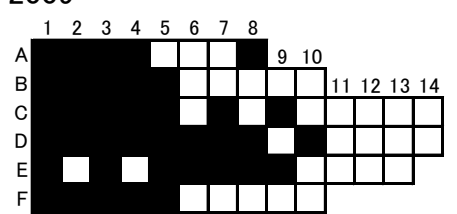

1992

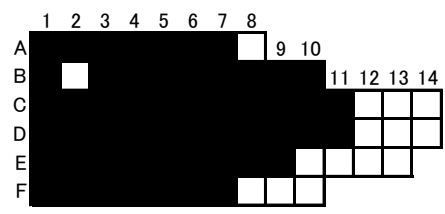

2001

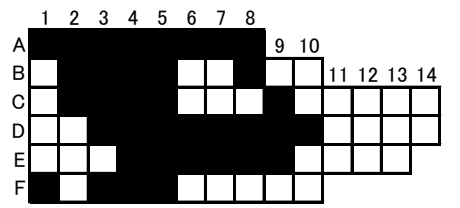

2010
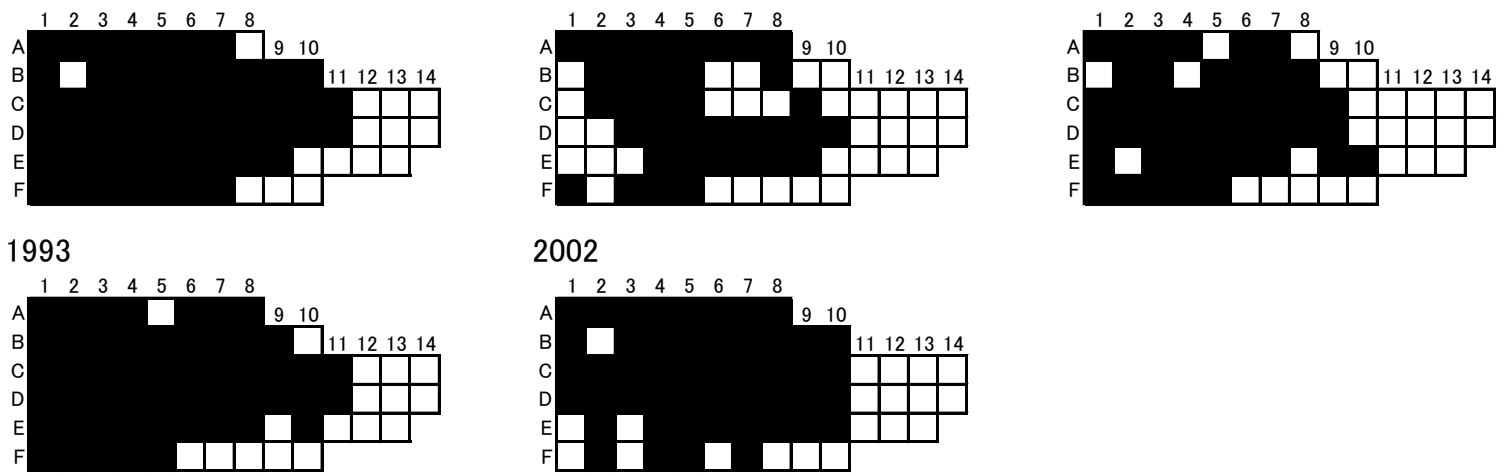

2002

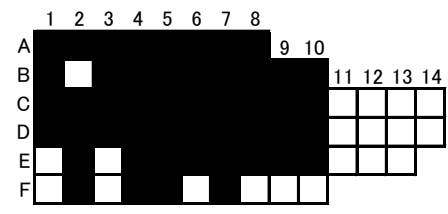


Diloma suavis メクラガイ

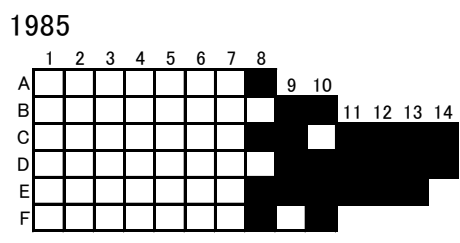

1986

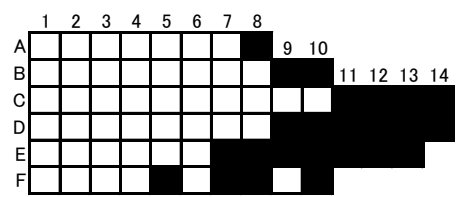

1987

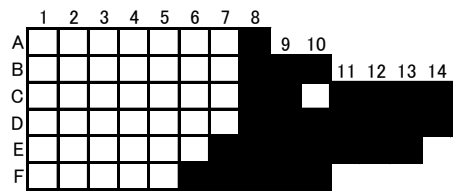

1988

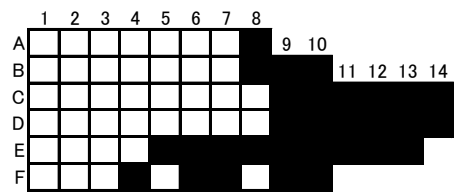

1989

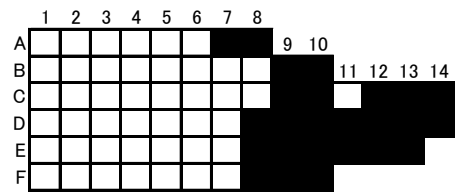

1990

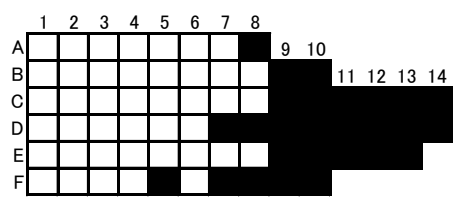

1991

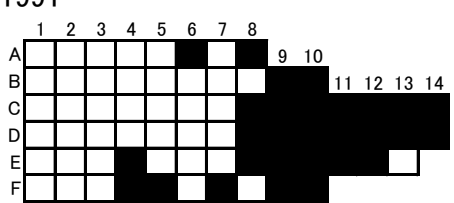

1992

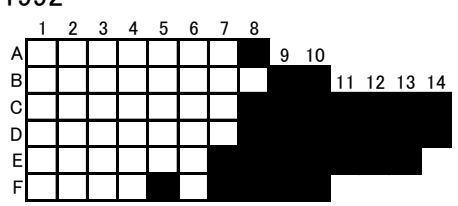

1993

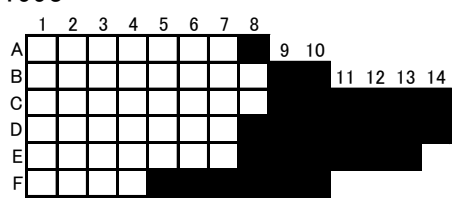

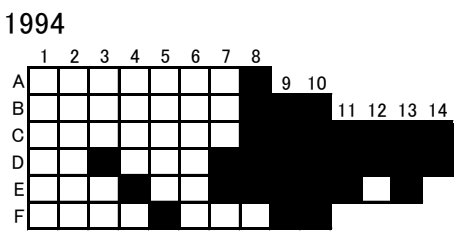

1995

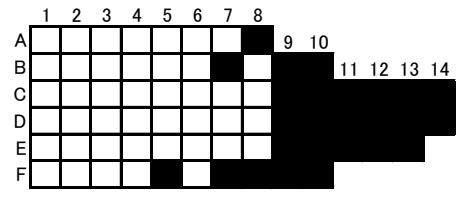

1996

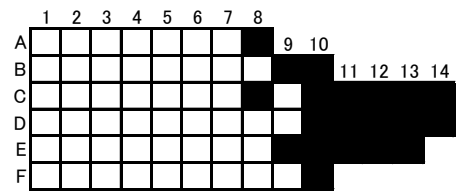

1997

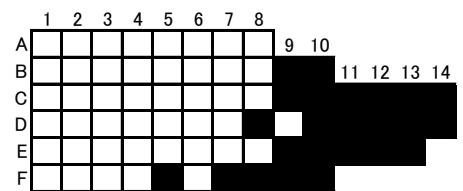

1998

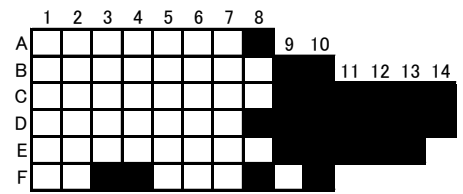

1999

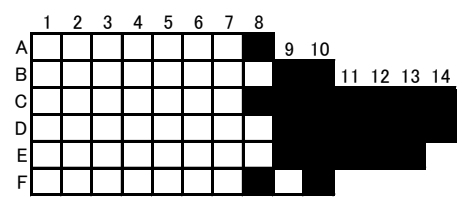

2000

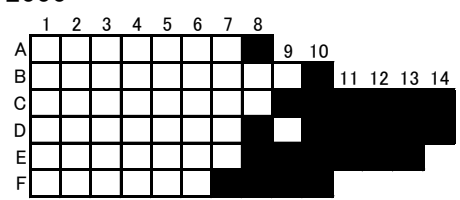

2001

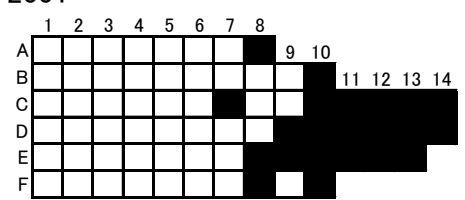

2002

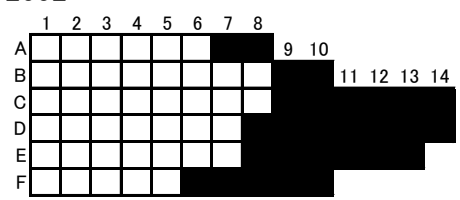

2003

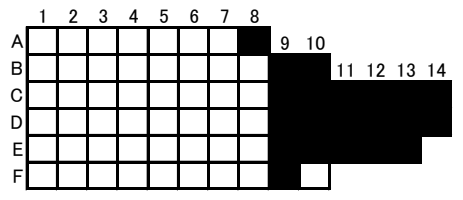

2004

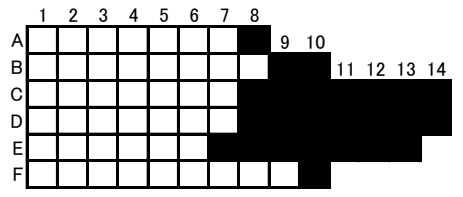

2005

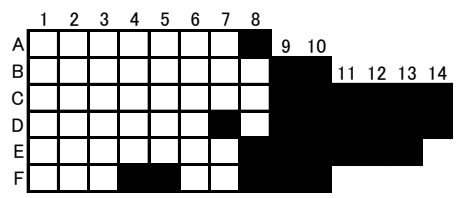

2006

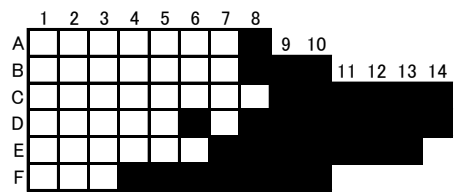

2007

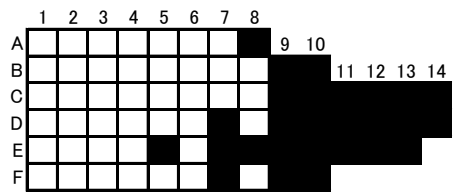

2008

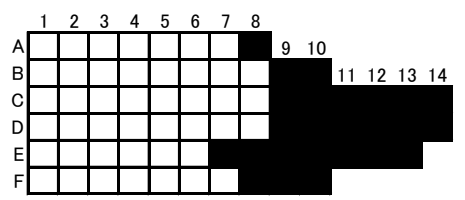

2009

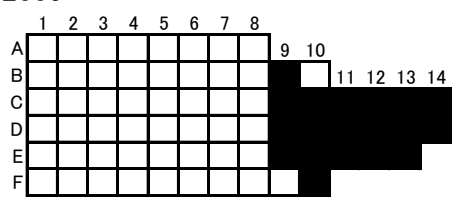

2010

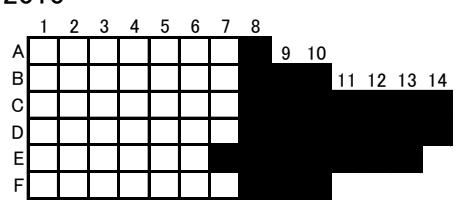


1985

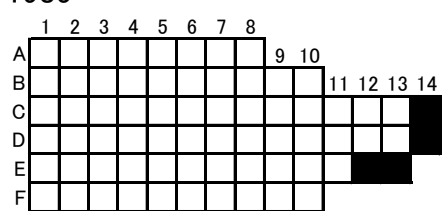

1986

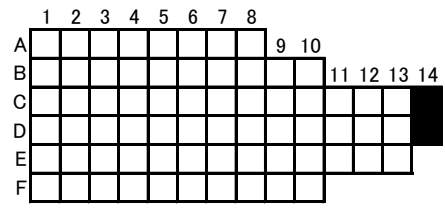

1987

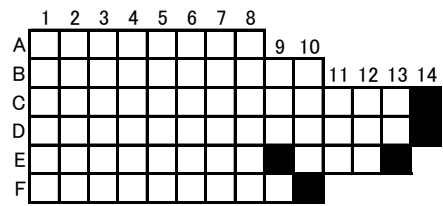

1988

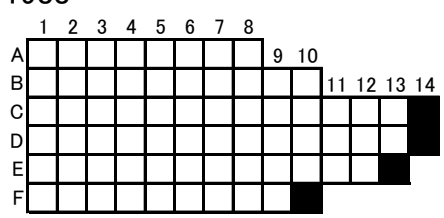

1989

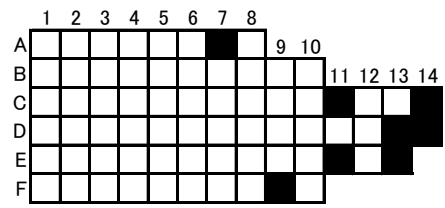

1990

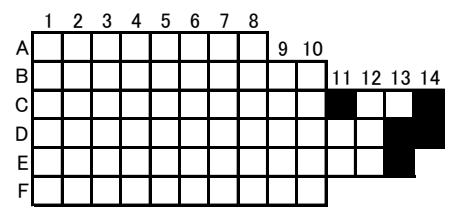

1991

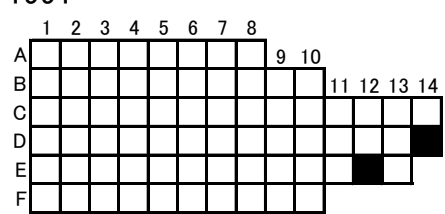

1992

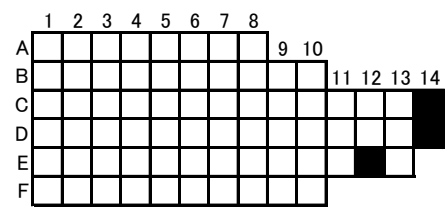

1993

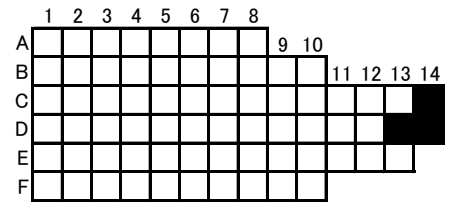

1994

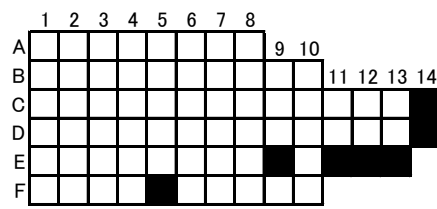

1995

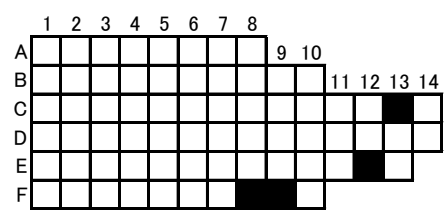

1996

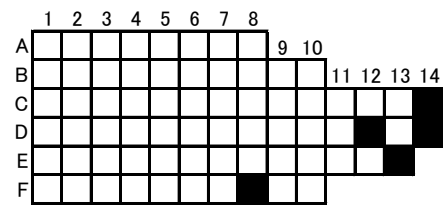

1997

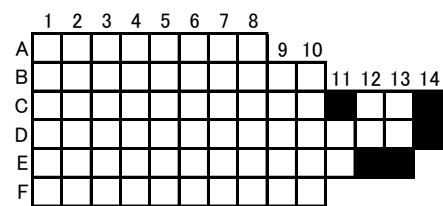

1998

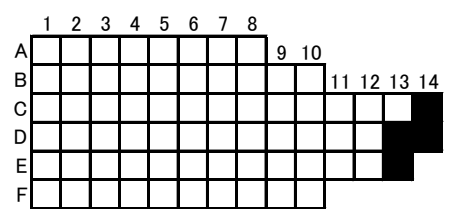

1999

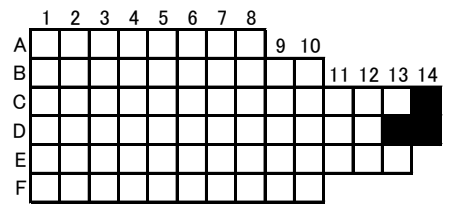

2000

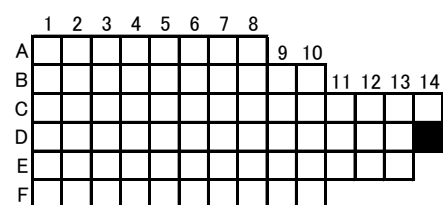

2001

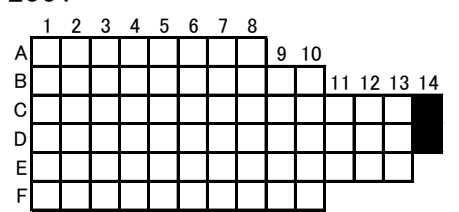

2002

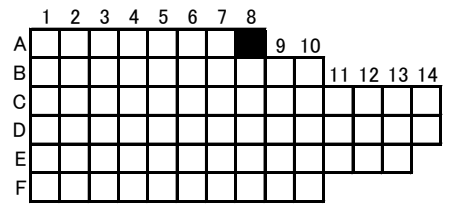

2003

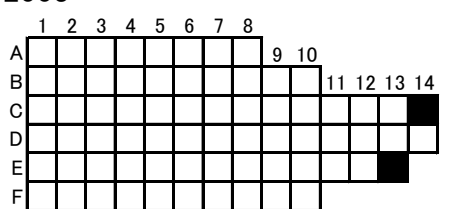

2004

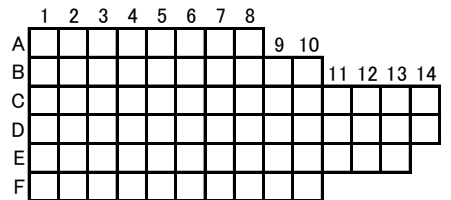

2005

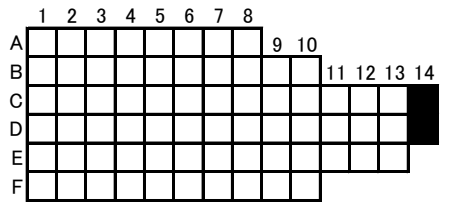

2006

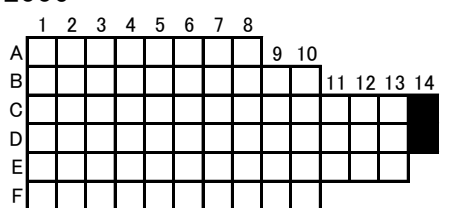

2007

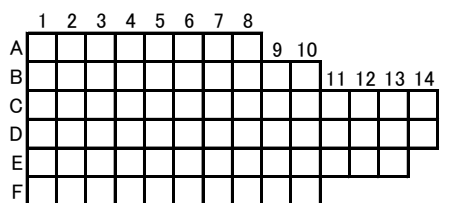

2008

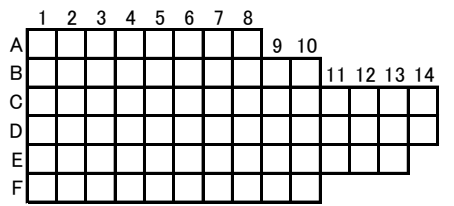

2009

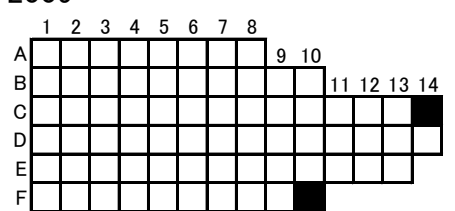

2010

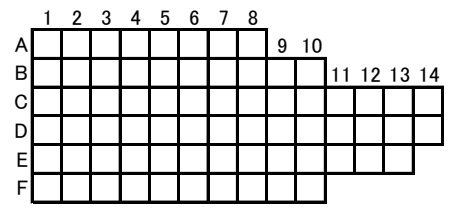


53 Conotalopia mustelina アワジチグサ
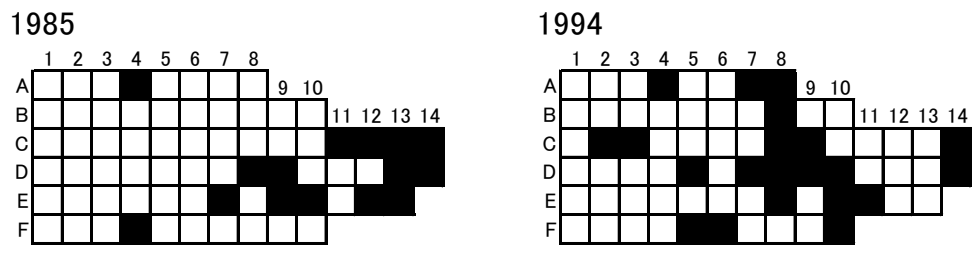

2003

1986

1995
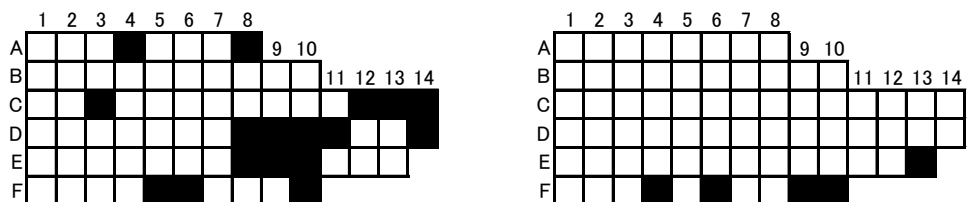

1987

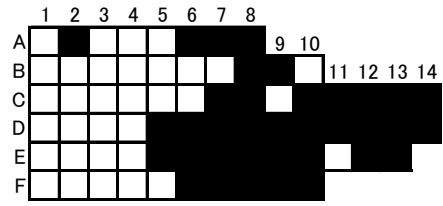

1996
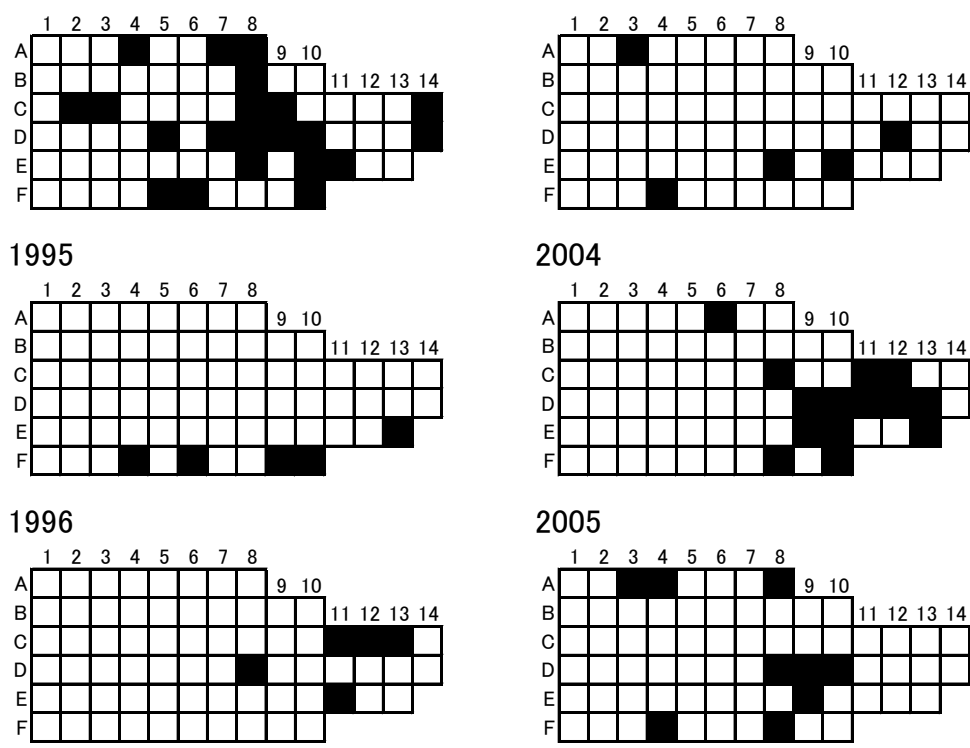

2004

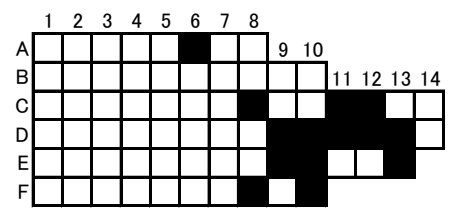

2005

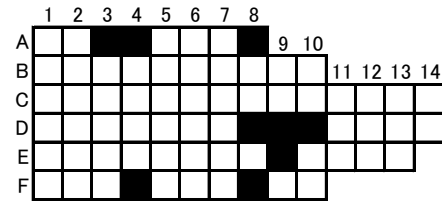

1988

1997

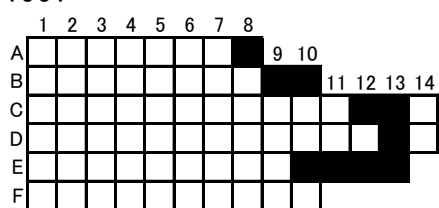

2006

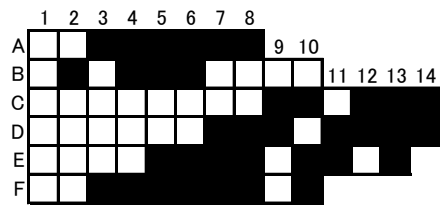

1998

1989
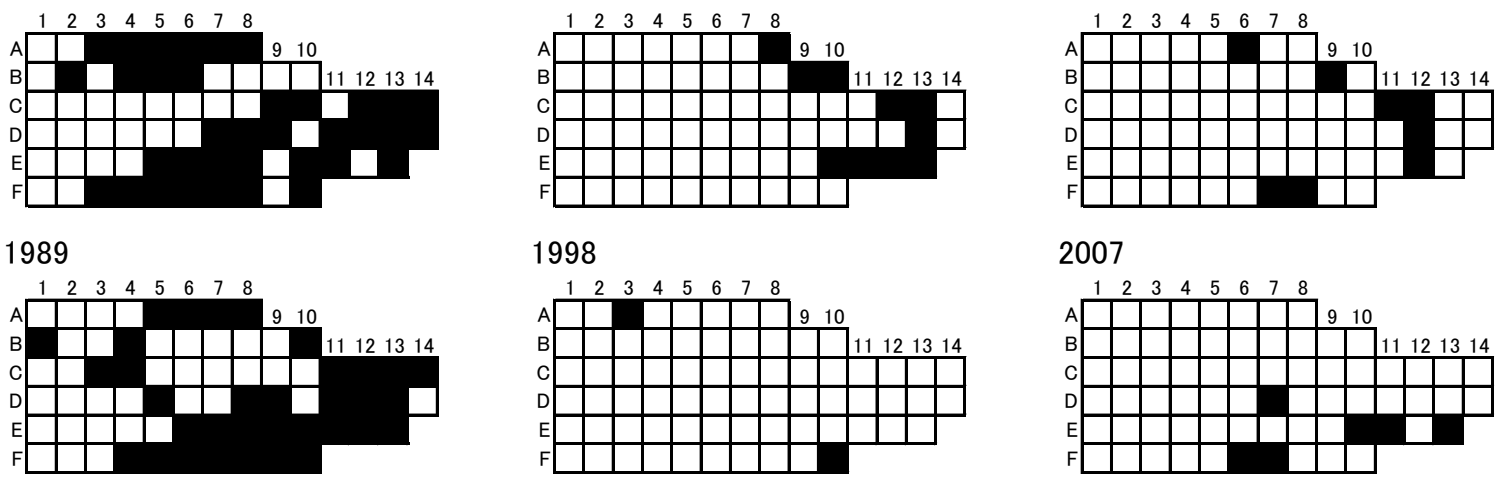

1999
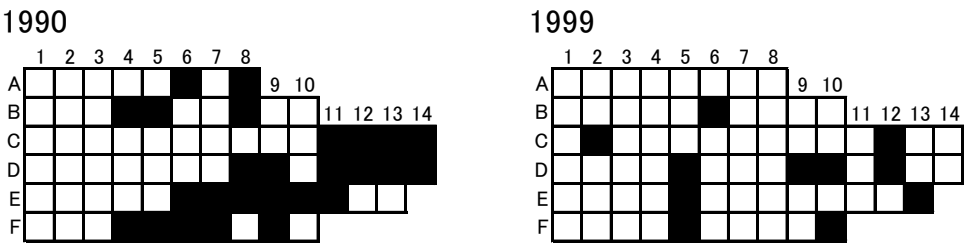

2007

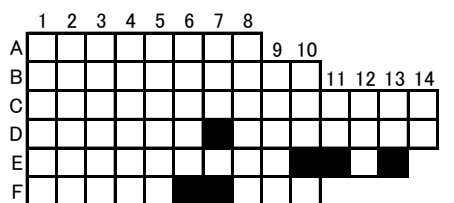

2008

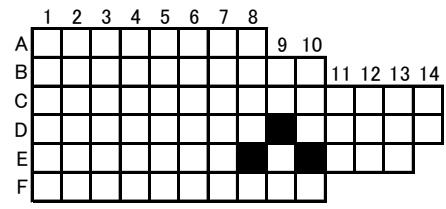

1991

2000
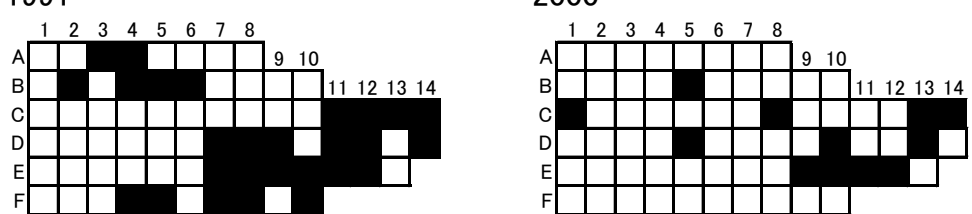

2009

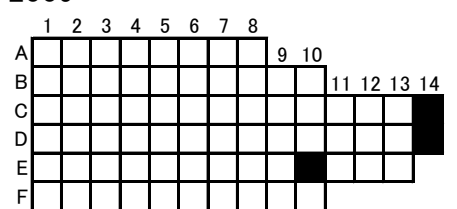

1992

2001
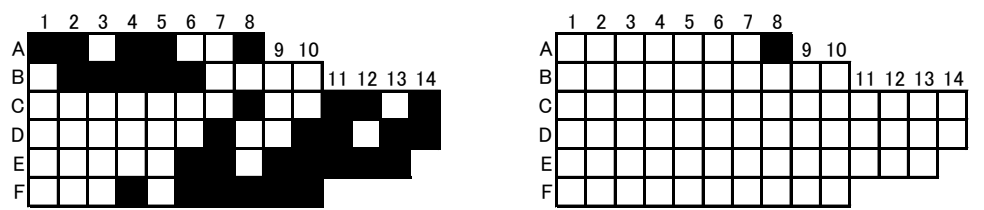

2010

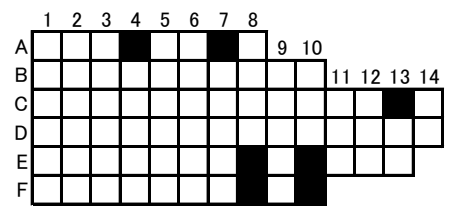

1993

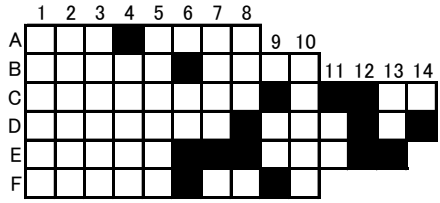

2002

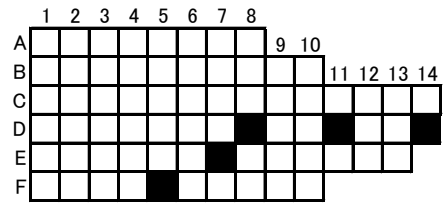


54 Angaria neglecta カタバガイ
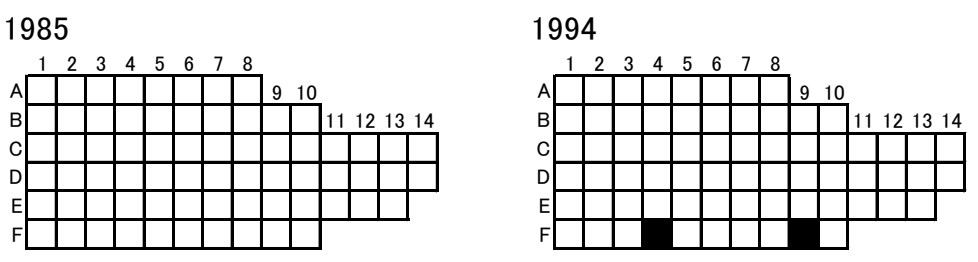

2003

1986

1995
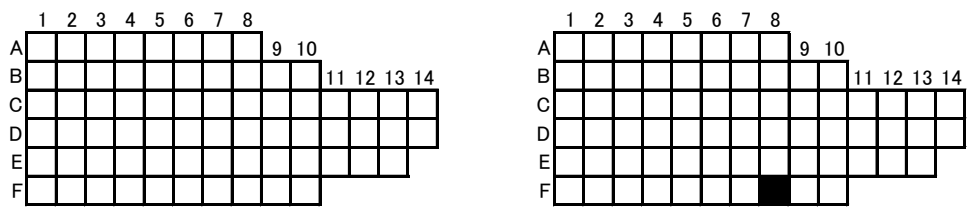

1987

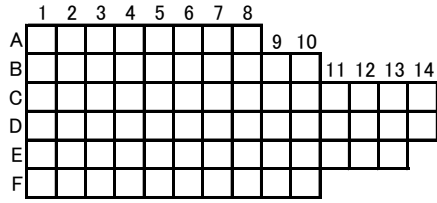

1996
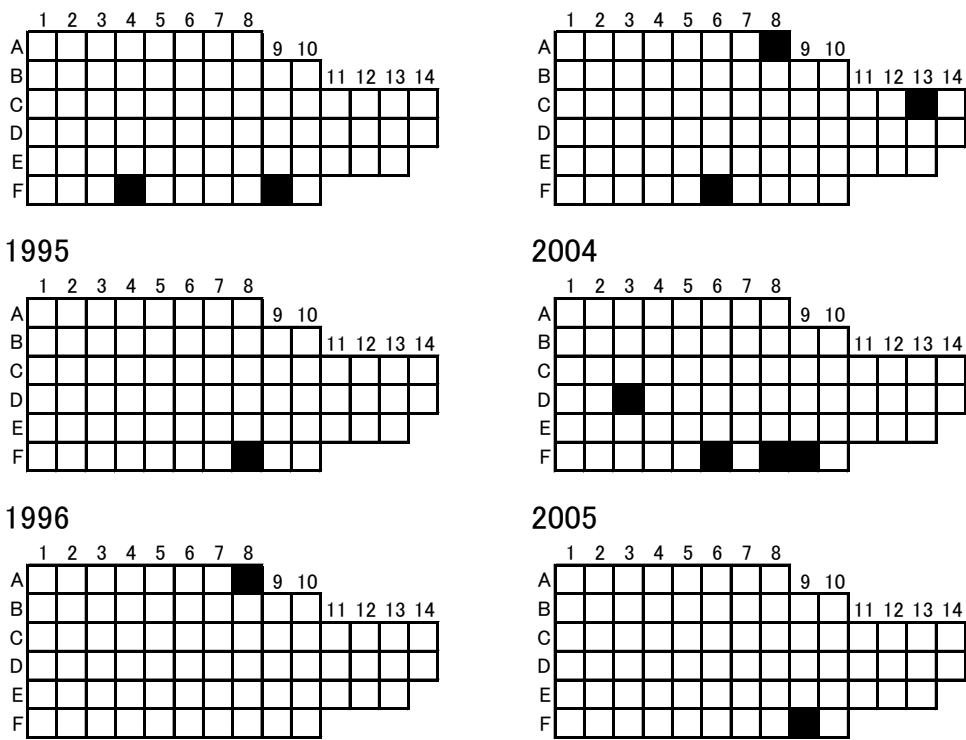

2004

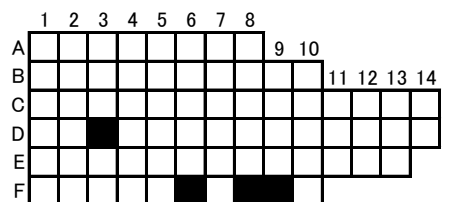

1988

1997
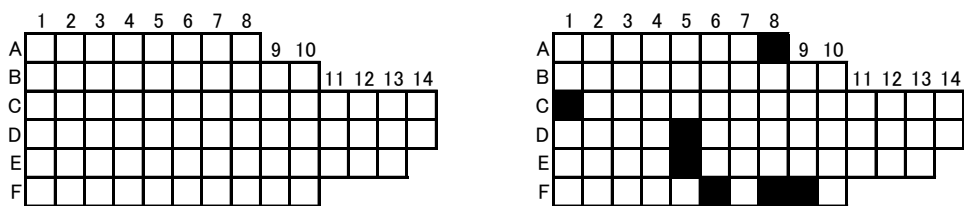

2005

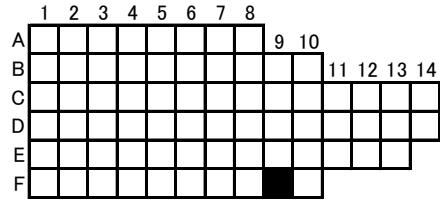

2006

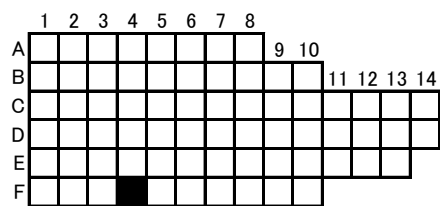

1989

1998
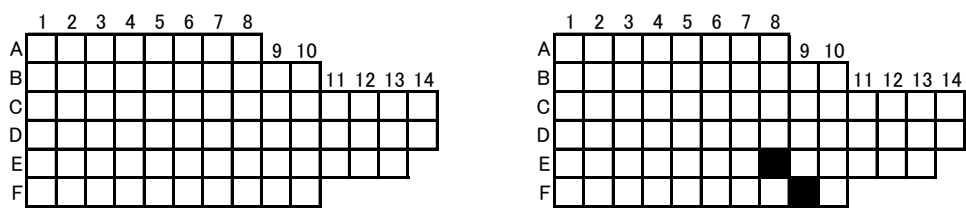

2007
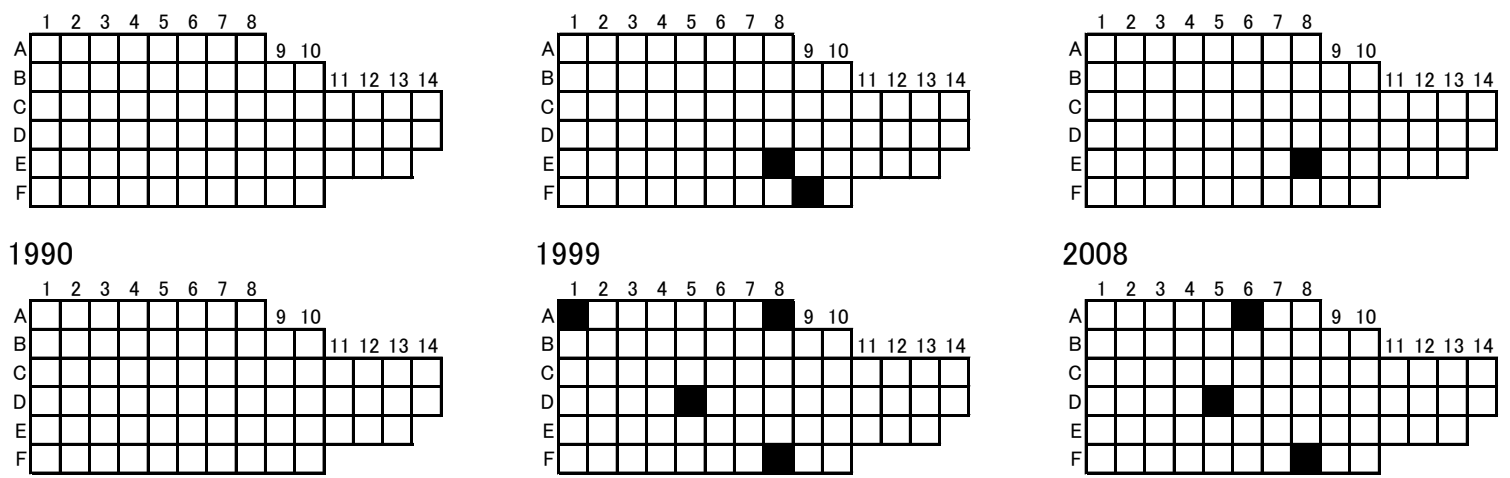

1999

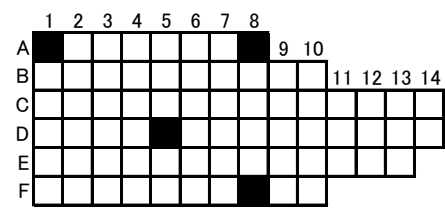

2008

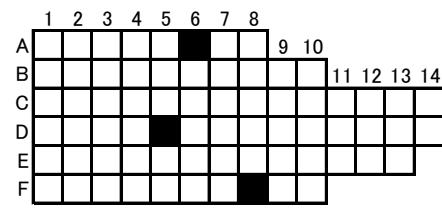

1991

2000
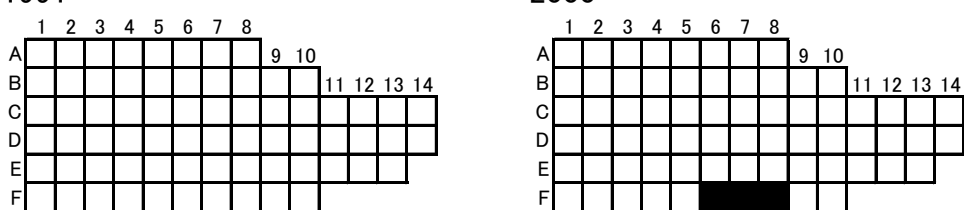

2009

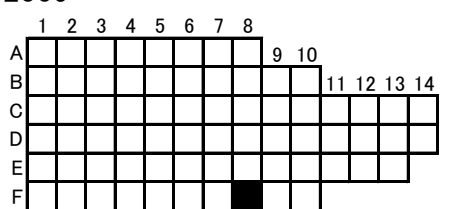

1992

2001
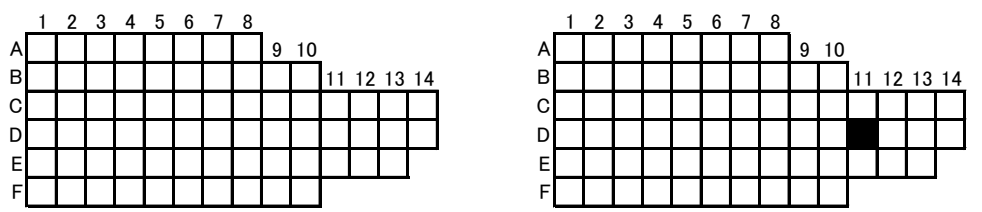

2010

1993

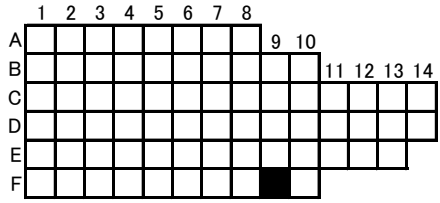

2002

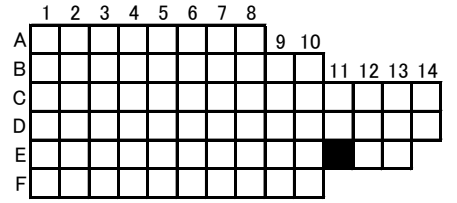

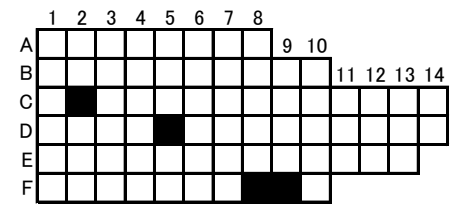


57 Bothropoma pilulum サンショウスガイ
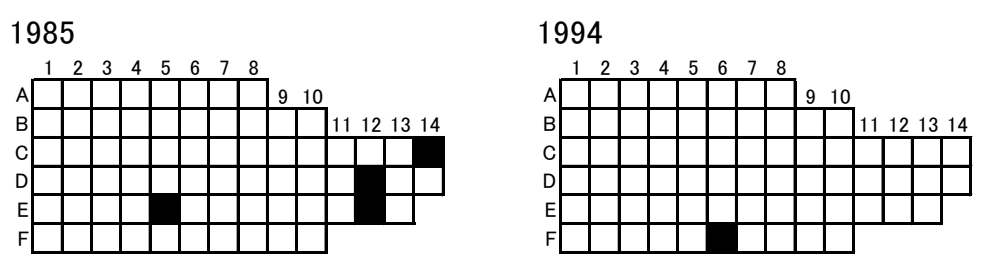

2003

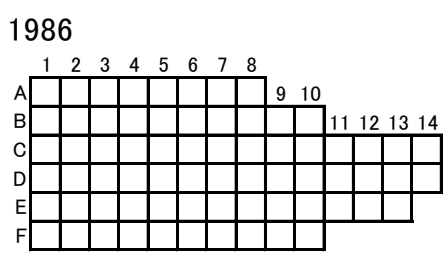

1995
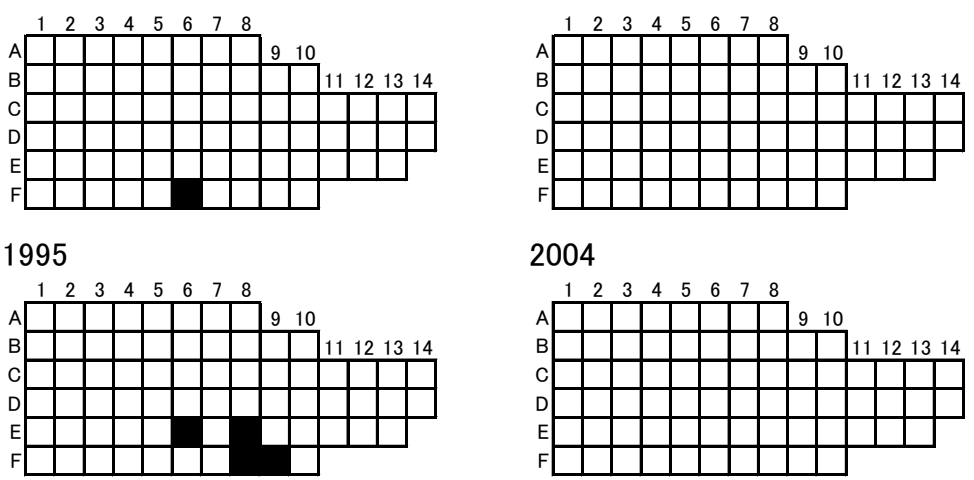

2004

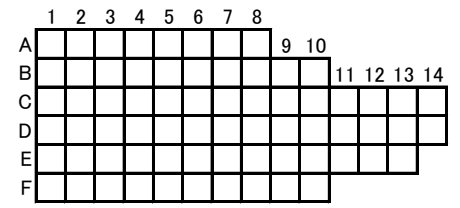

1987

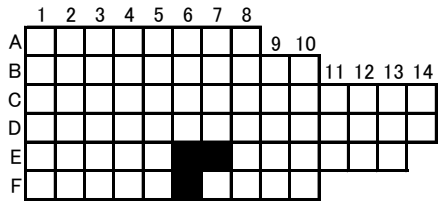

1996

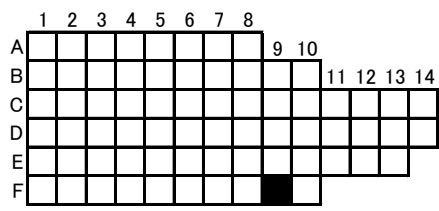

2005

1988

1997
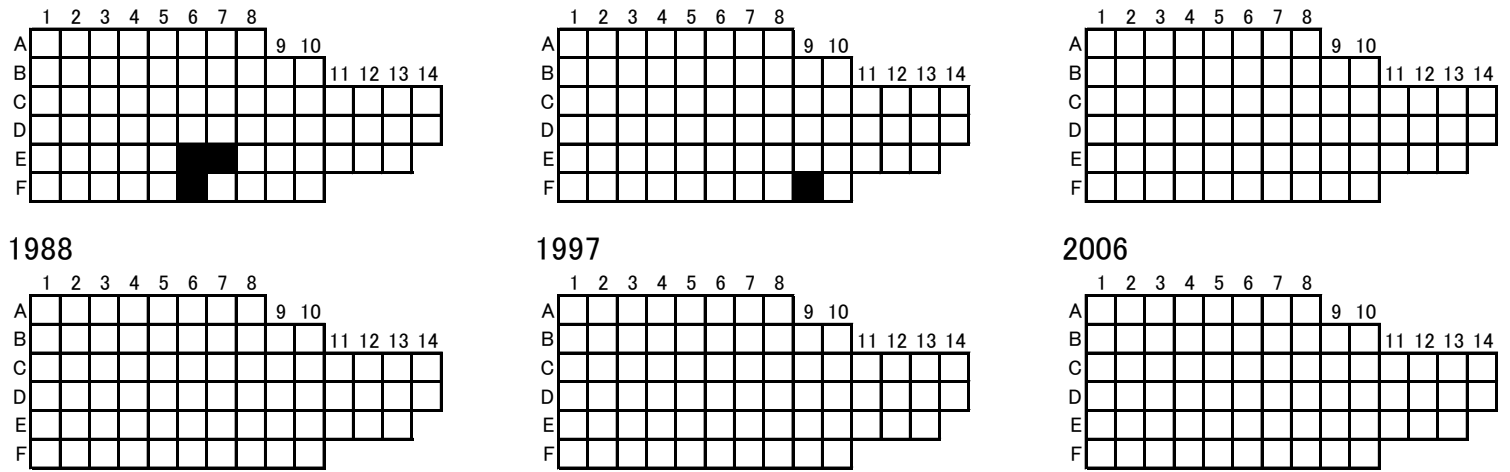

2006

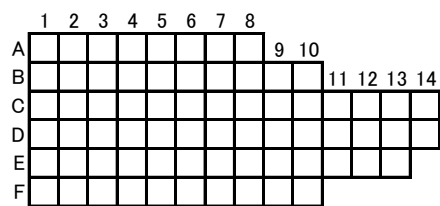

1989

1998
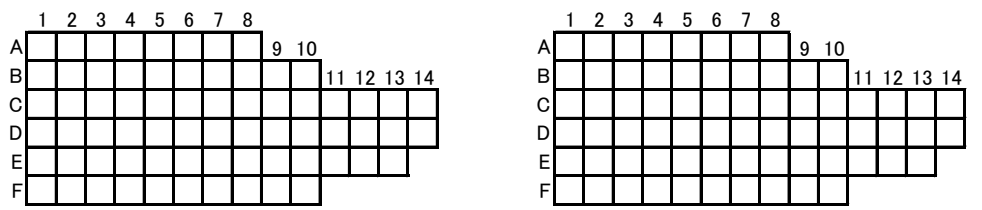

2007
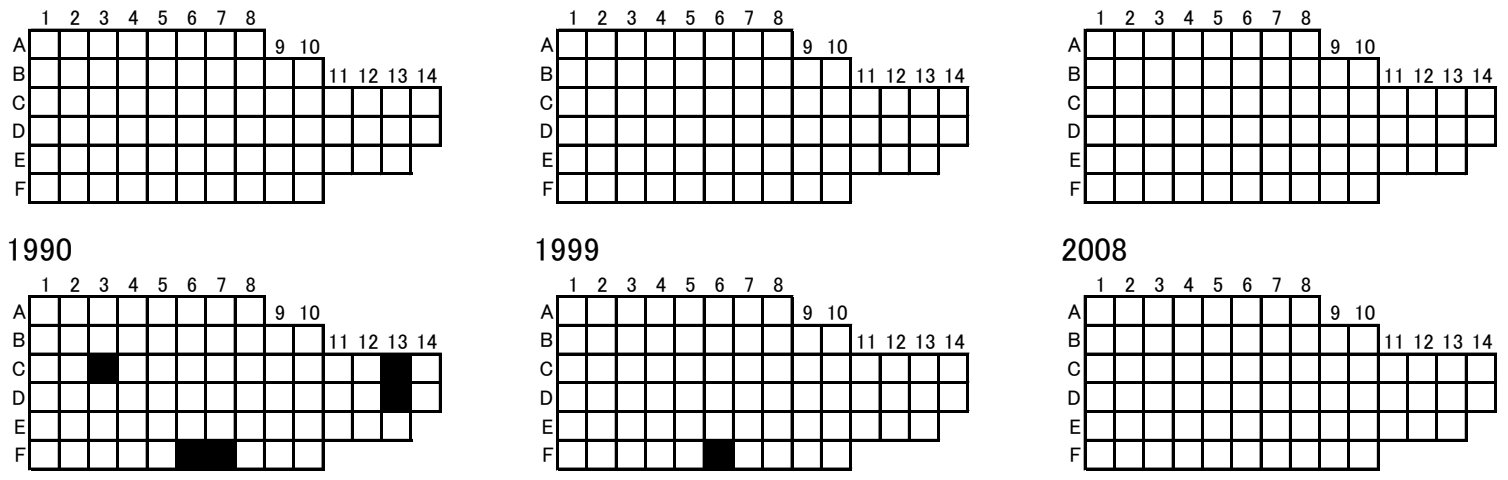

1999

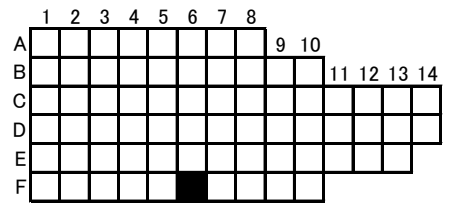

2008

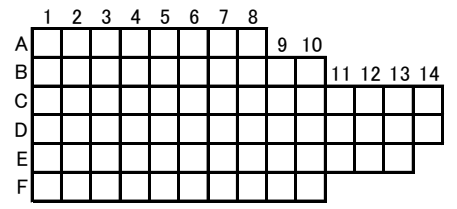

1991

2000
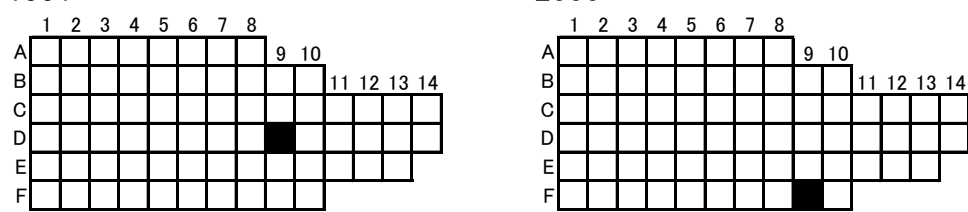

2009

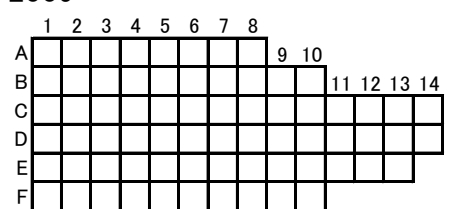

1992

2001
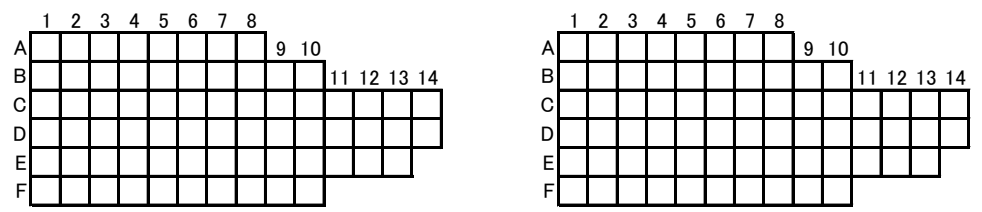

2010
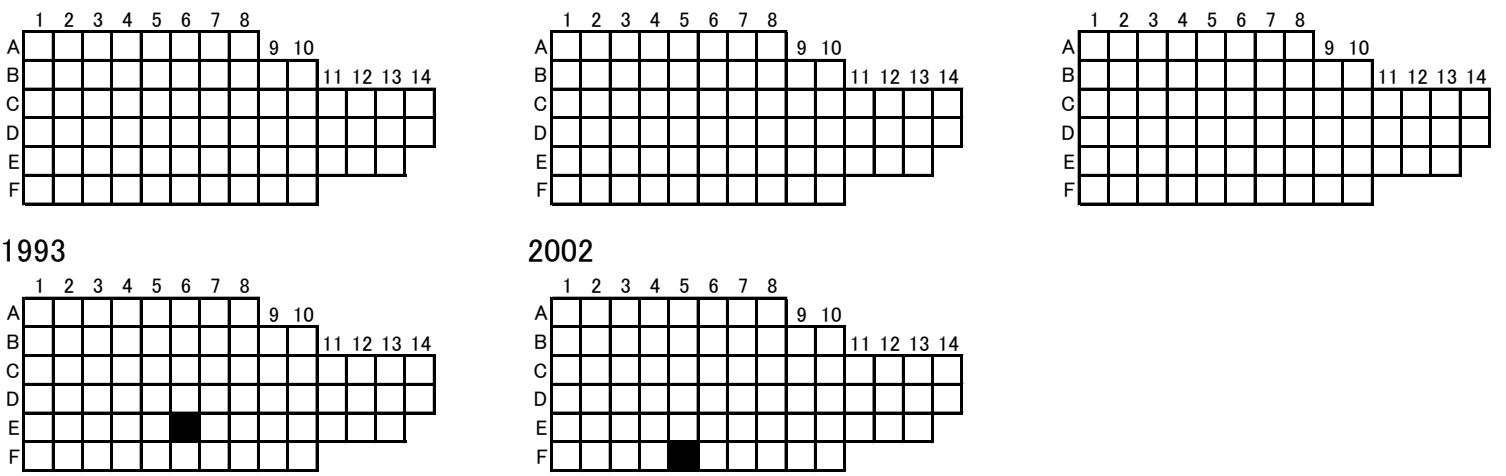


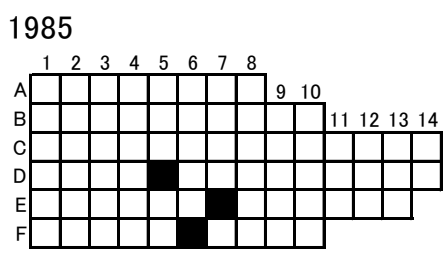

1986

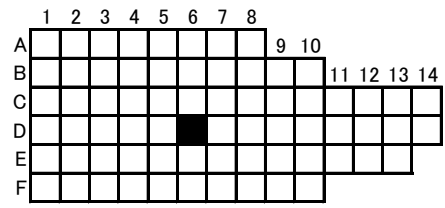

1987

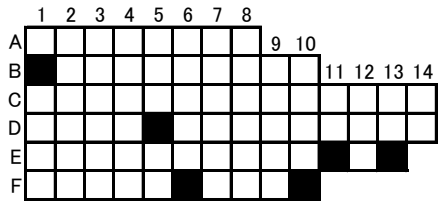

1988

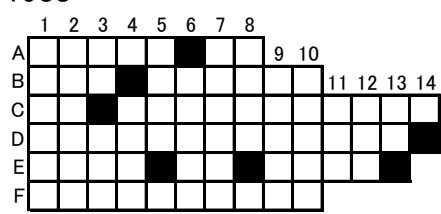

1989

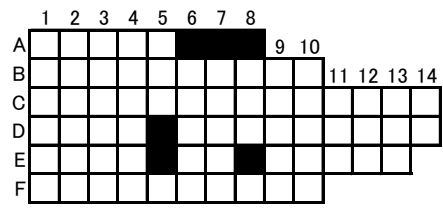

1990

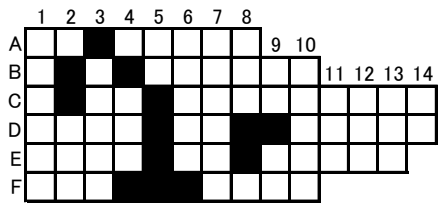

1991

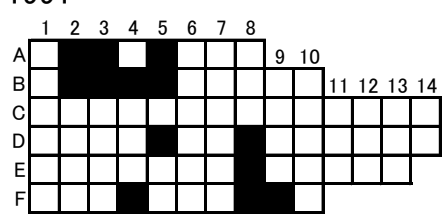

1992

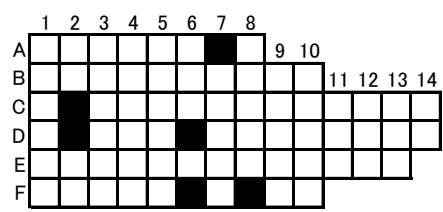

1993

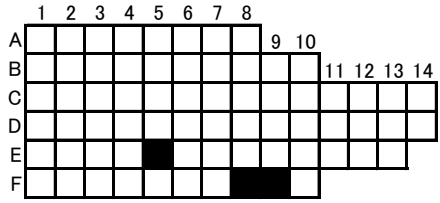

1994

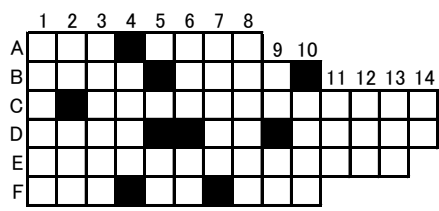

1995

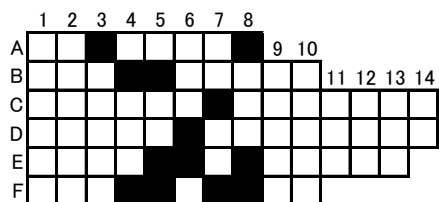

1996

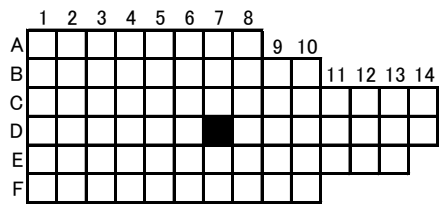

1997

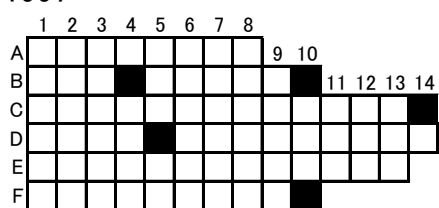

1998

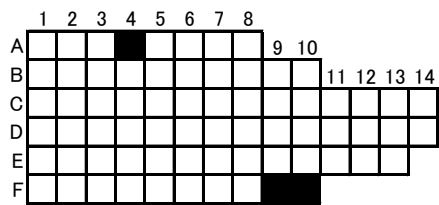

1999

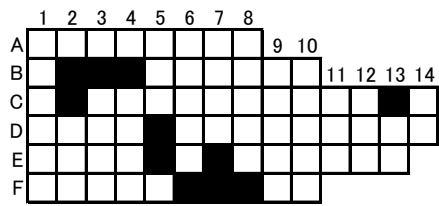

2000

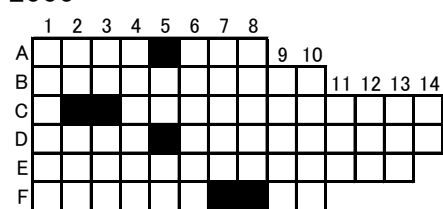

2001

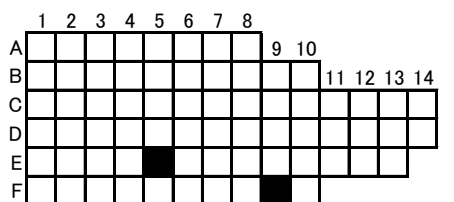

2002

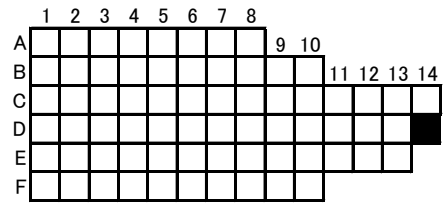

2003

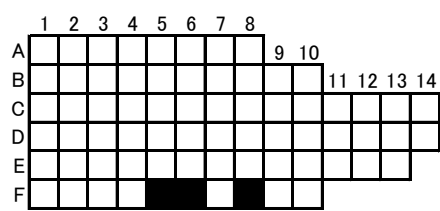

2004

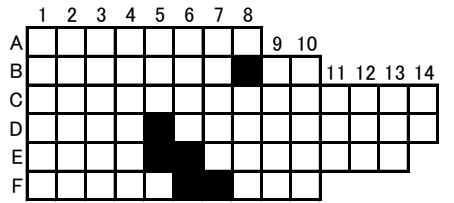

2005

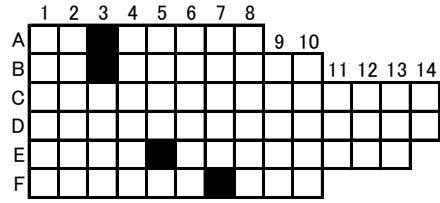

2006

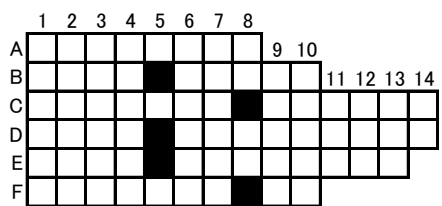

2007

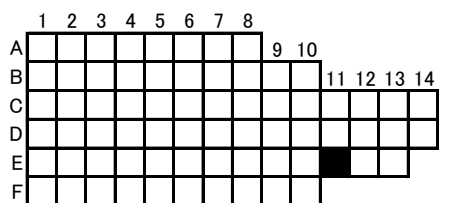

2008

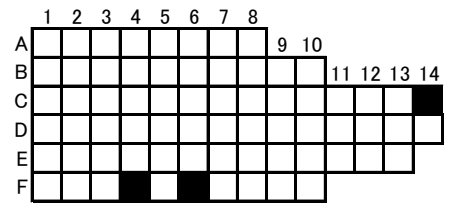

2009

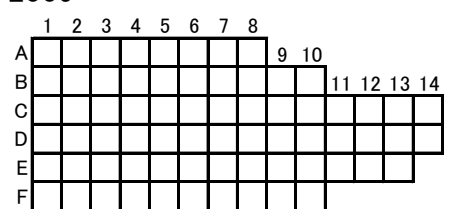

2010

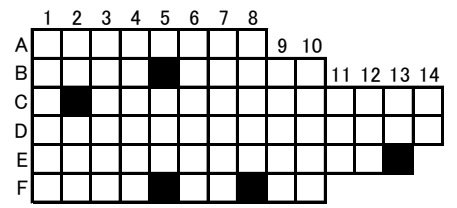




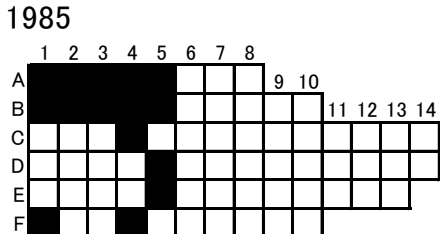

1986

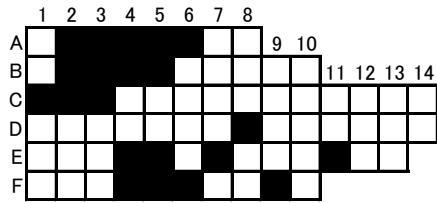

1987

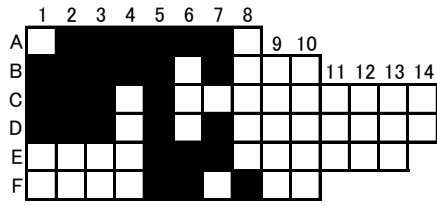

1988

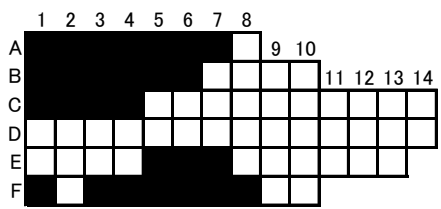

1989

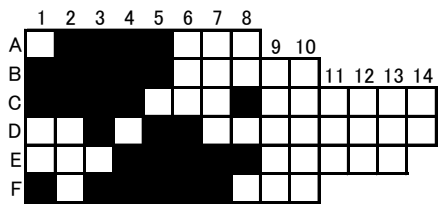

1990

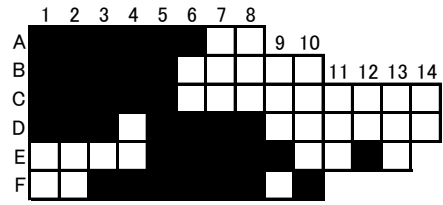

1991

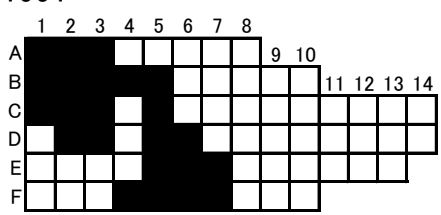

1992

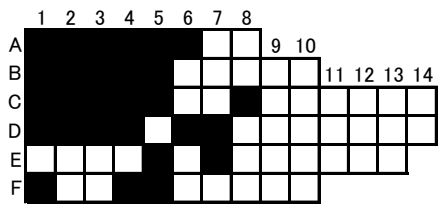

1993

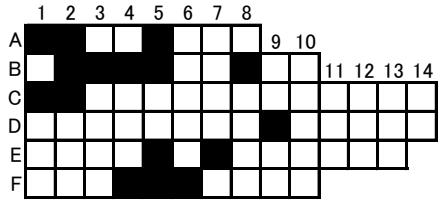

1994

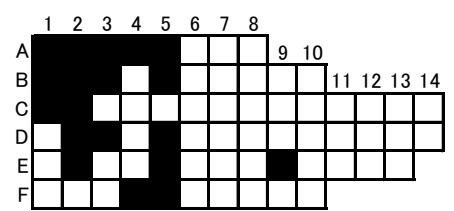

1995

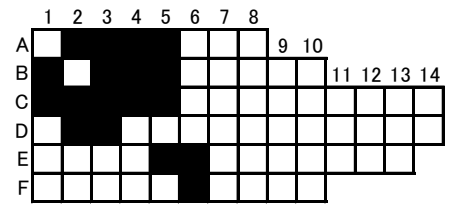

1996

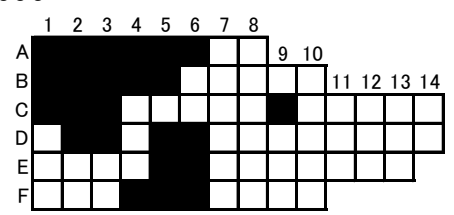

1997

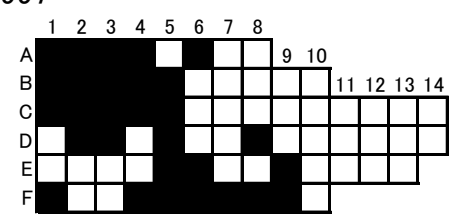

1998

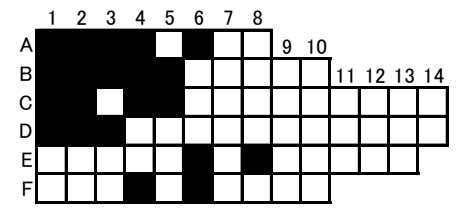

1999

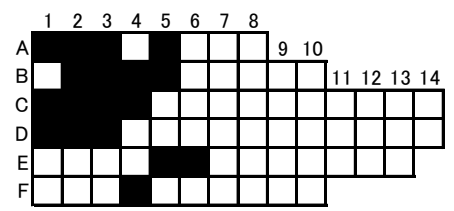

2000

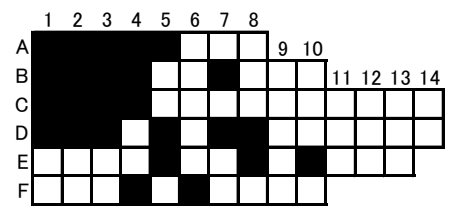

2001

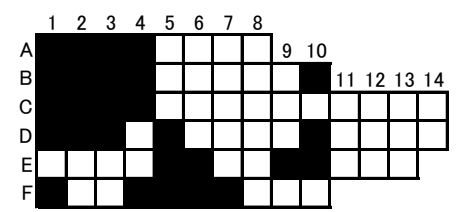

2002

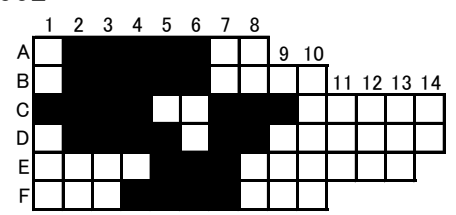

2003

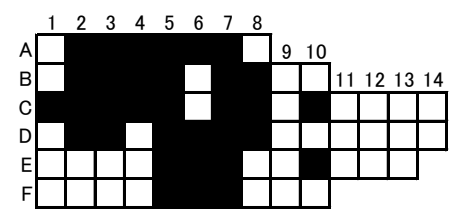

2004

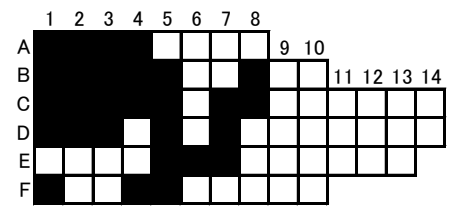

2005

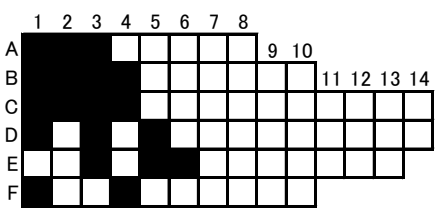

2006

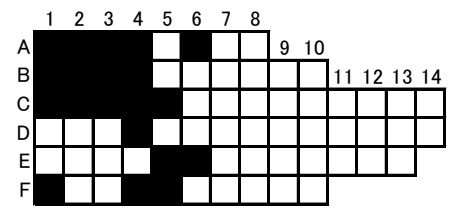

2007

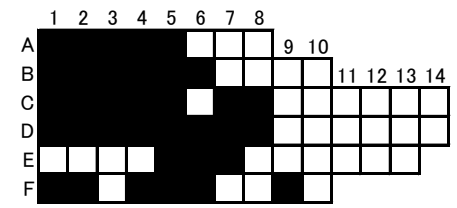

2008

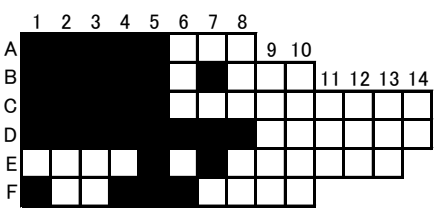

2009

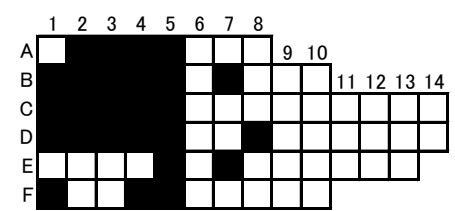

2010

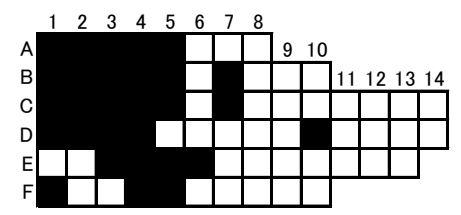


61 Turbo stenogyrus

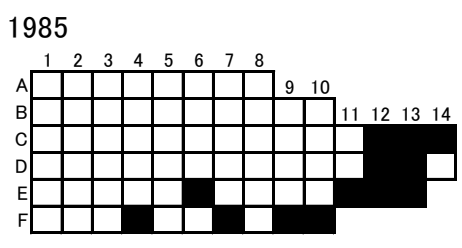

1986

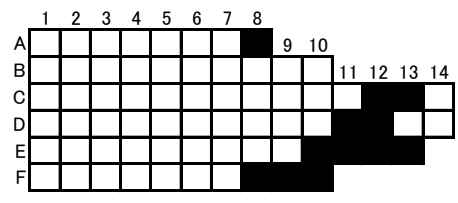

1987

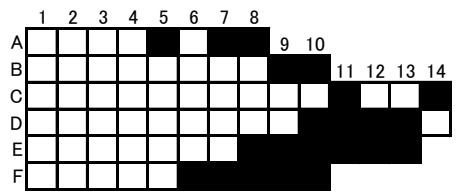

1988

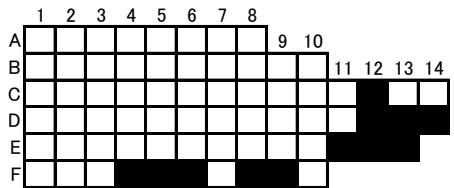

1989

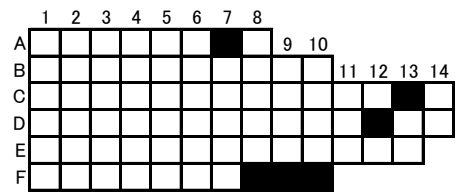

1990

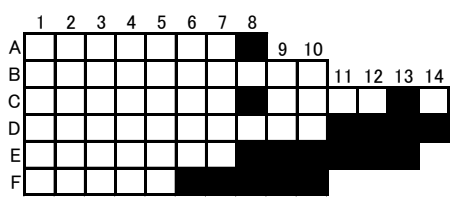

1991

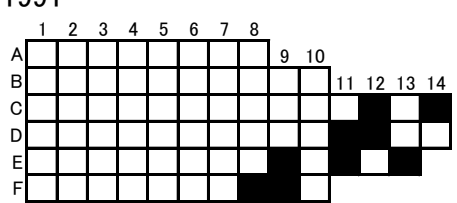

1992

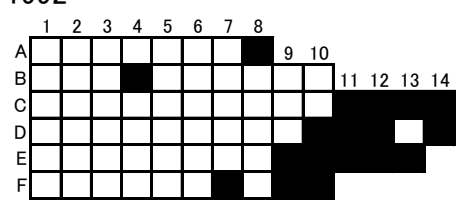

1993

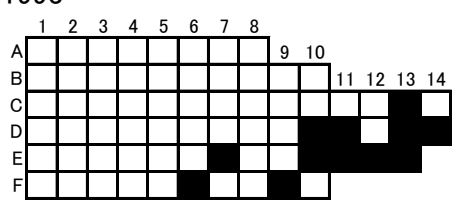

コシダカサザエ

1994

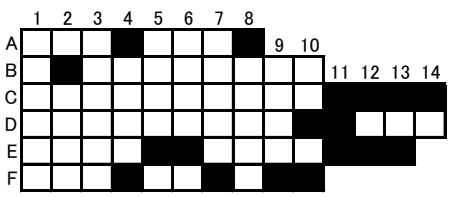

1995

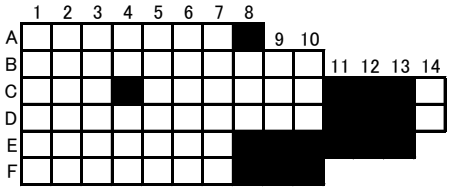

1996

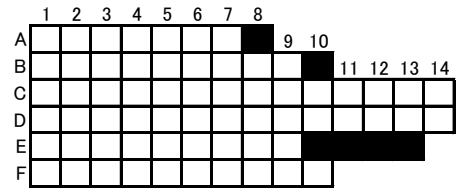

1997

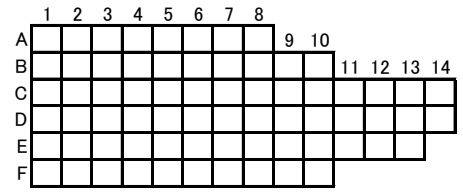

1998

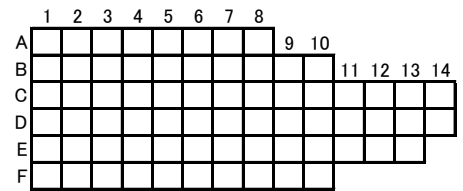

1999

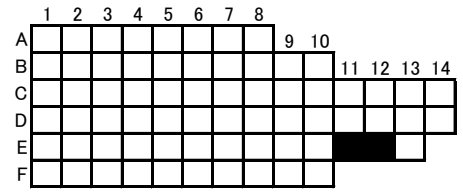

2000

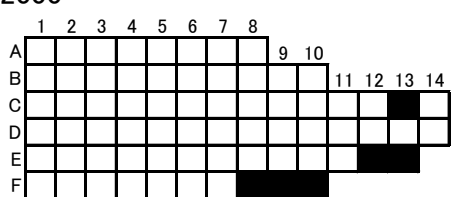

2001

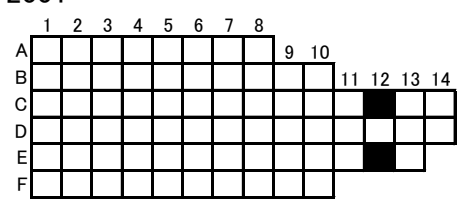

2002

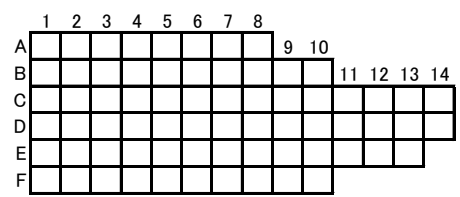

2003

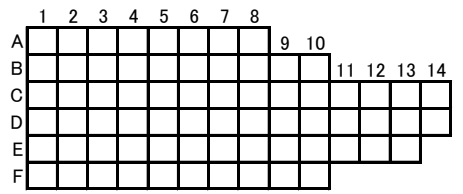

2004

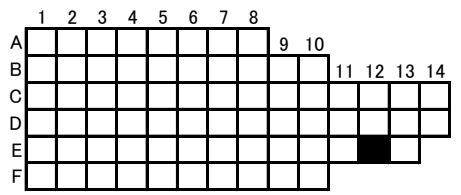

2005

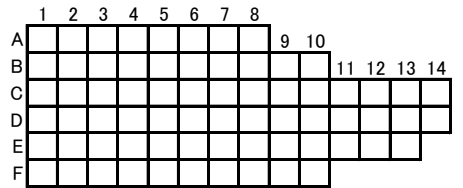

2006

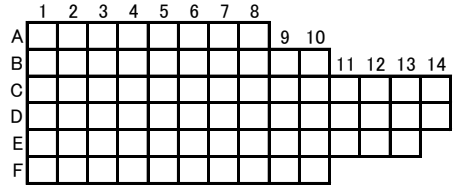

2007

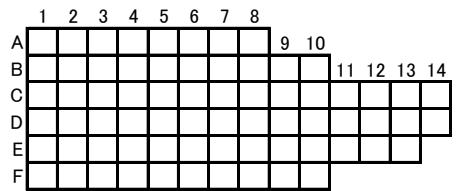

2008

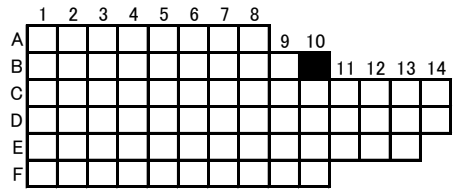

2009

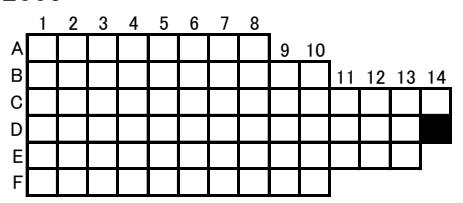

2010

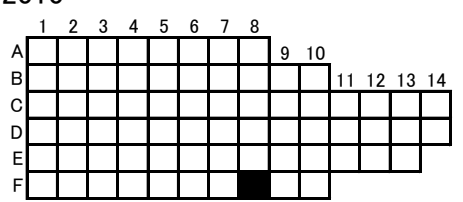


Phasianella solidaサラサバイ

1985

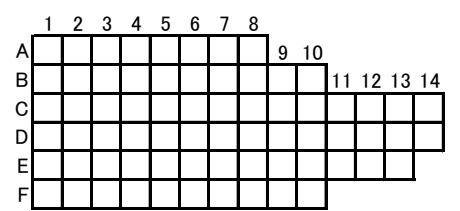

1986

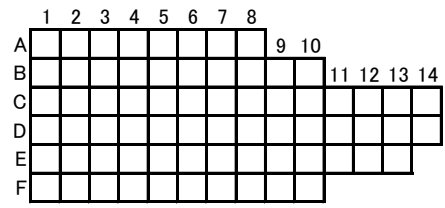

1987

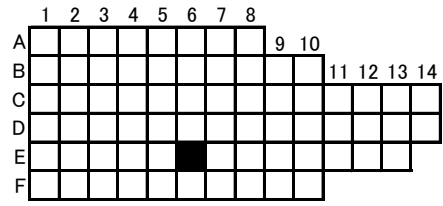

1988

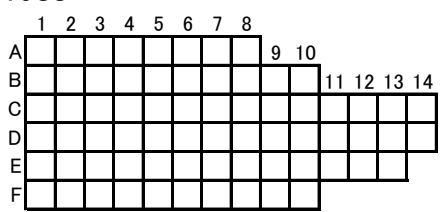

1989

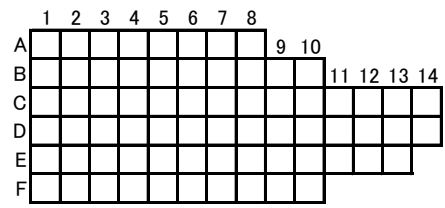

1990

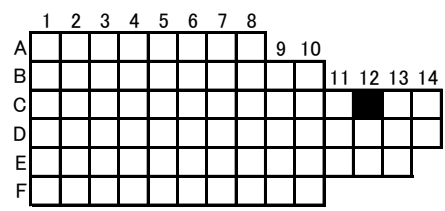

1991

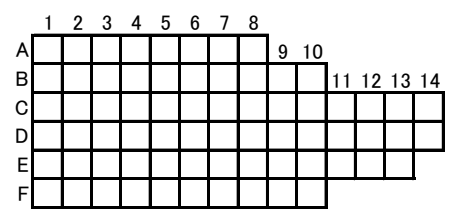

1992

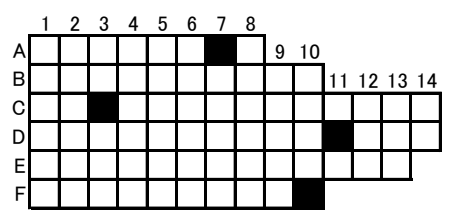

1993

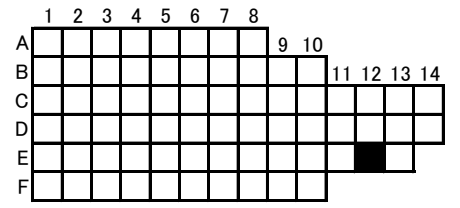

1994

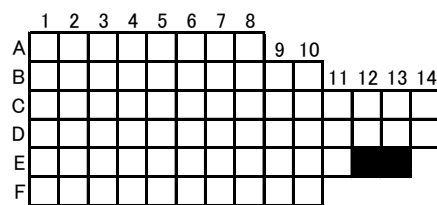

1995

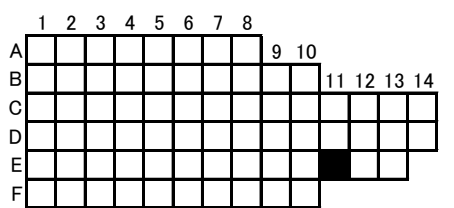

1996

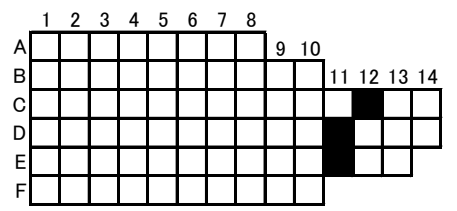

1997

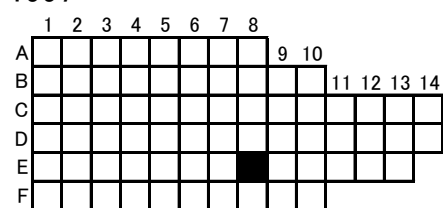

1998

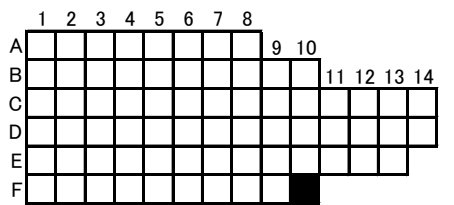

1999

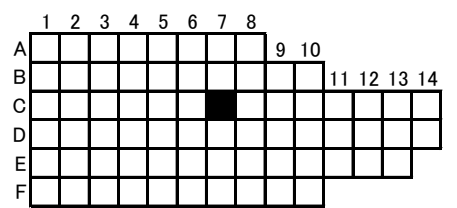

2000

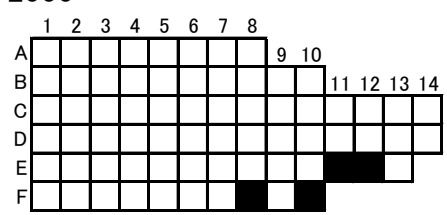

2001

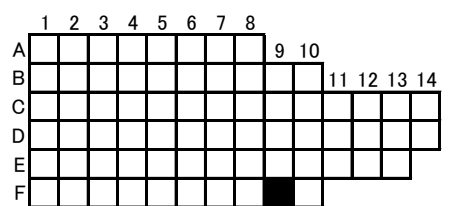

2002

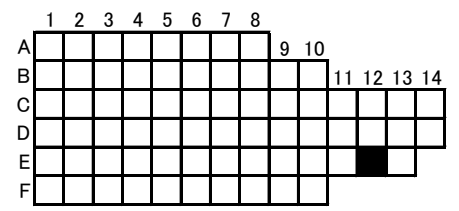

2003

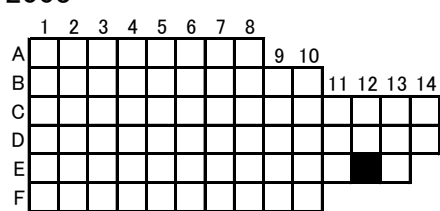

2004

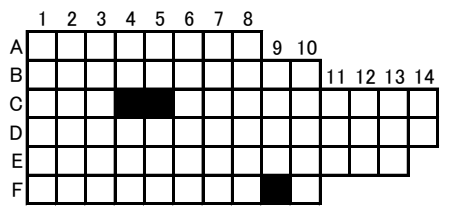

2005

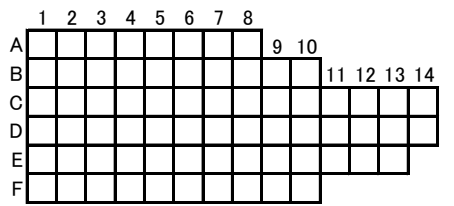

2006

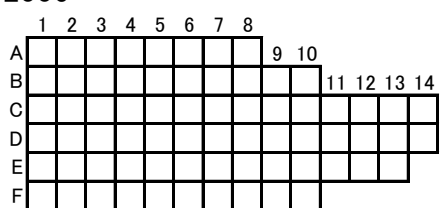

2007

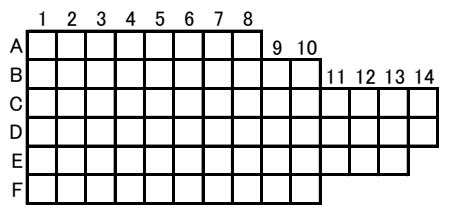

2008

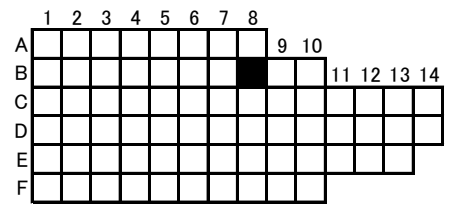

2009

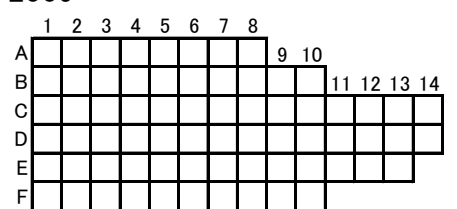

2010

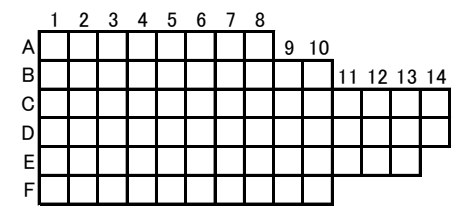


Nerita albicilla～アマオブネガイ

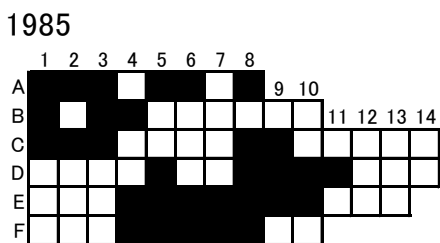

1986

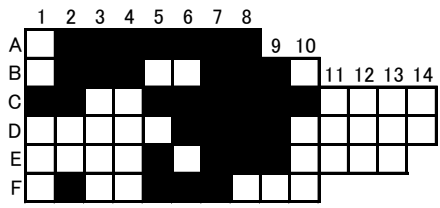

1987

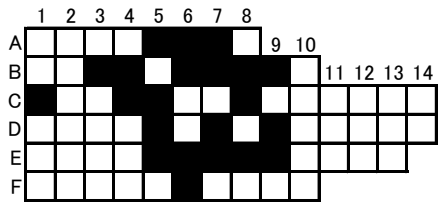

1988

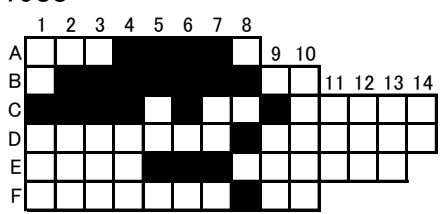

1989

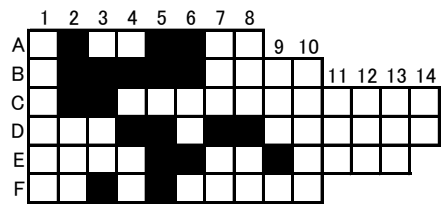

1990

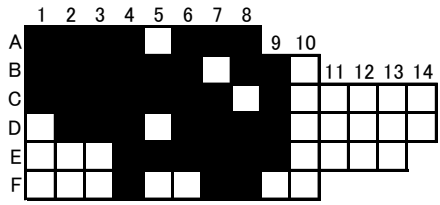

1991

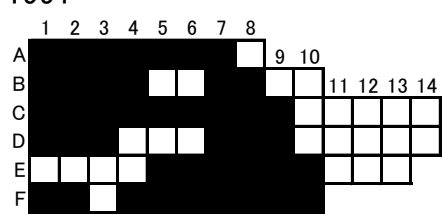

1992

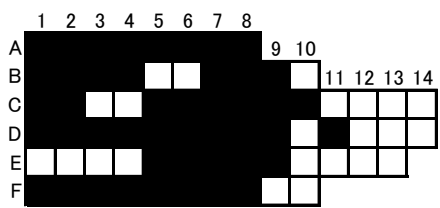

1993

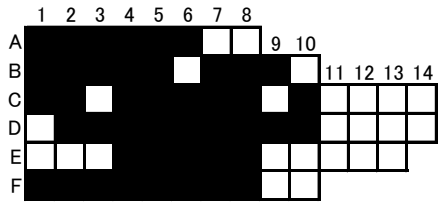

1994

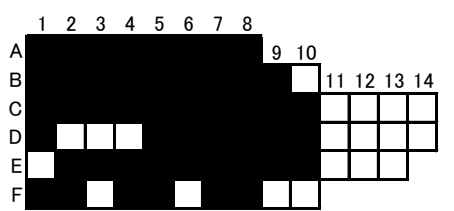

1995

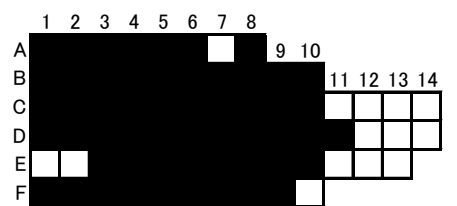

1996

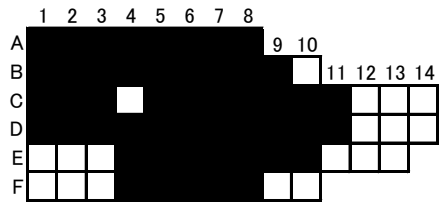

1997

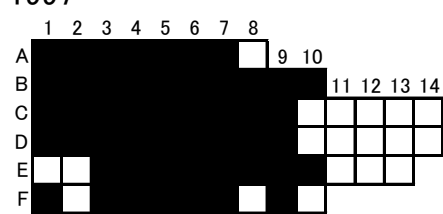

1998

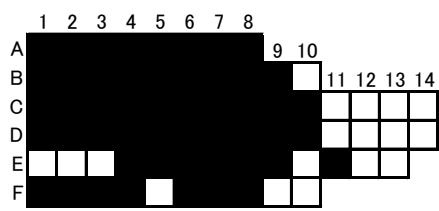

1999

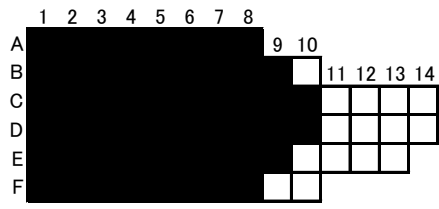

2000

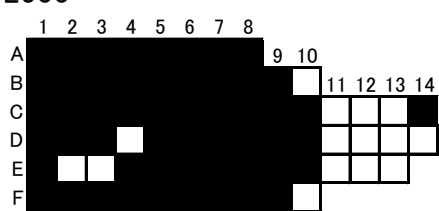

2001

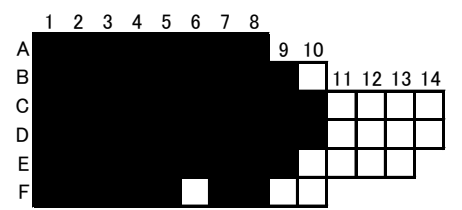

2002

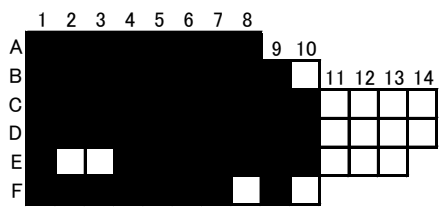

2003

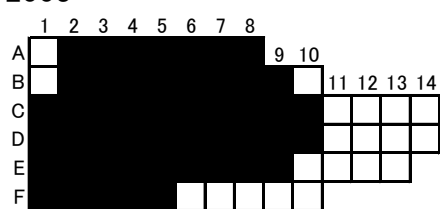

2004

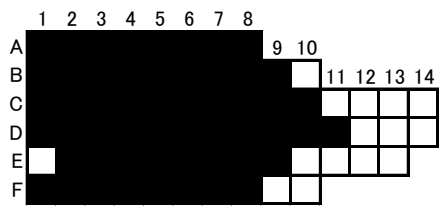

2005

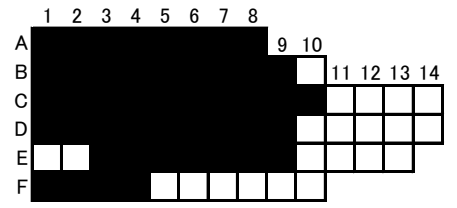

2006

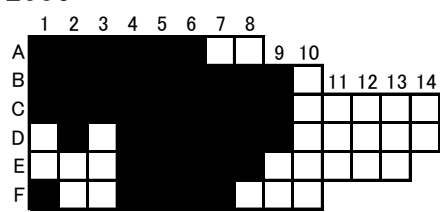

2007

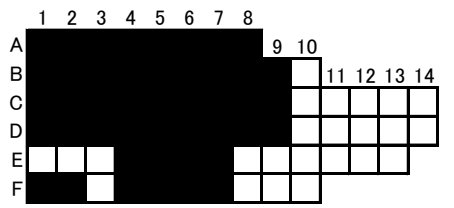

2008

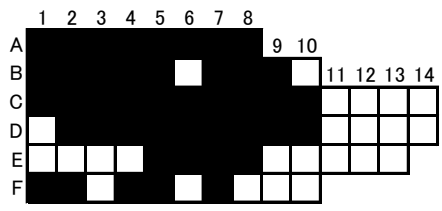

2009

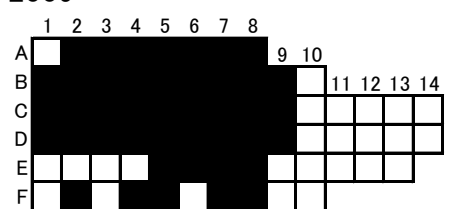

2010

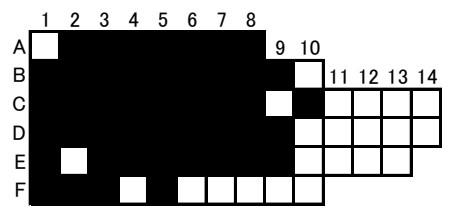


64 Neritajaponica アマガイ
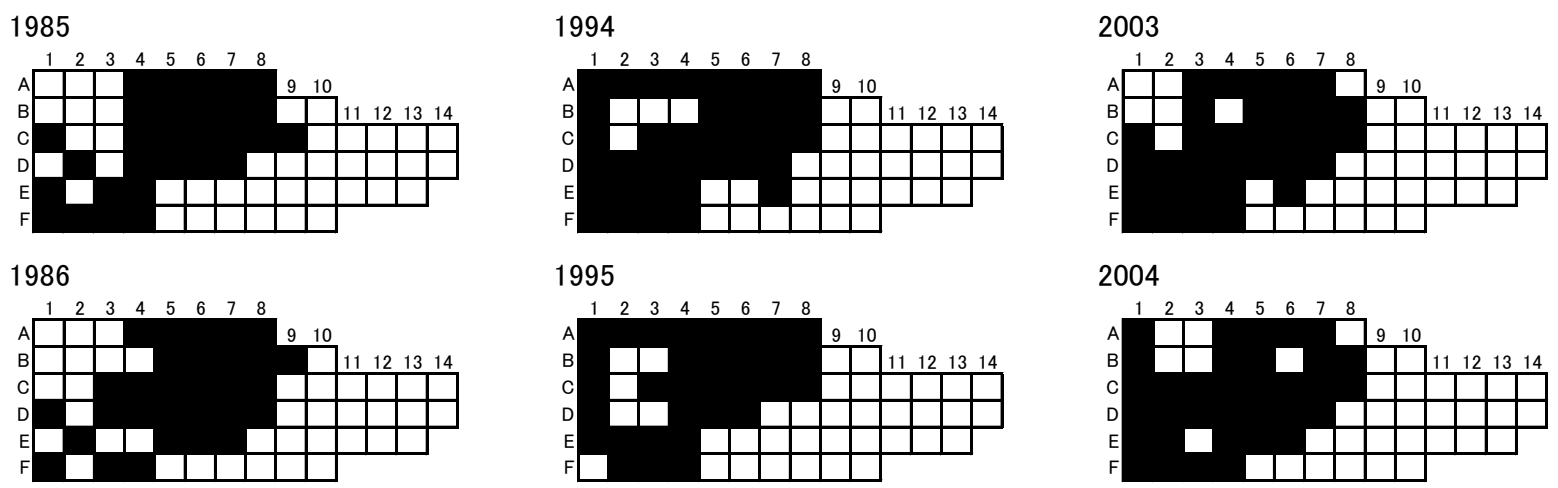

1995

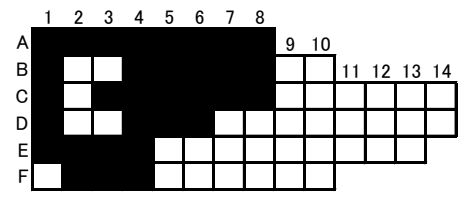

2004

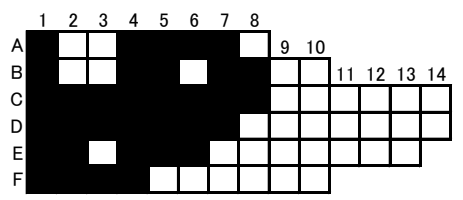

1987

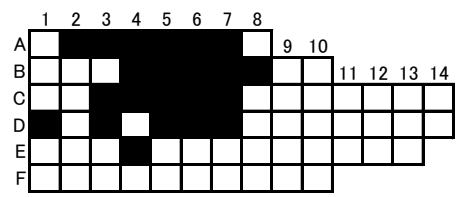

1996

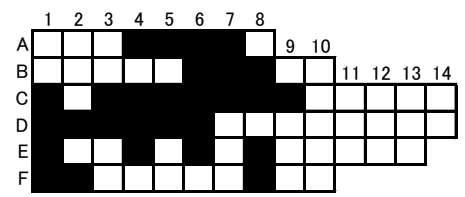

2005

1988

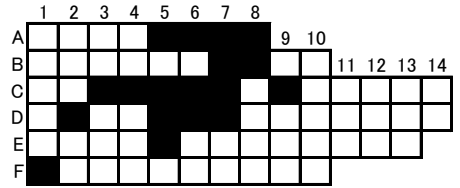

1997
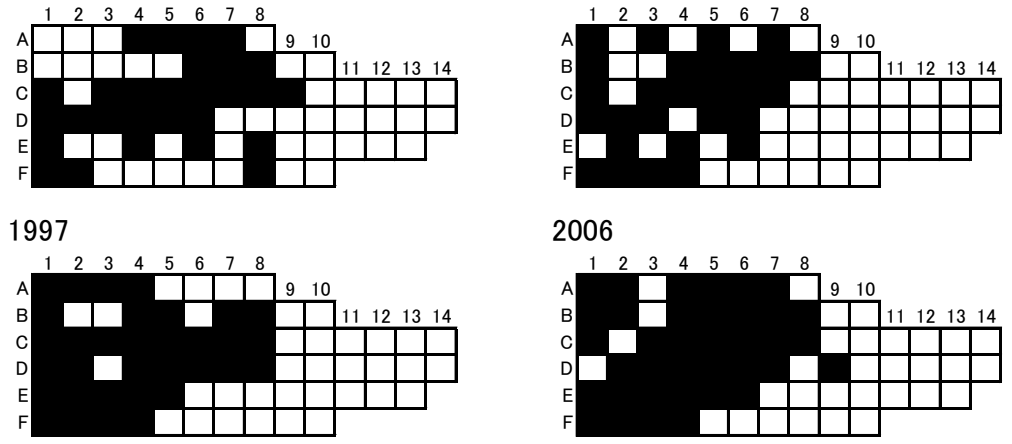

2006

1989

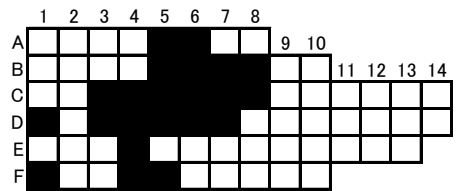

1998
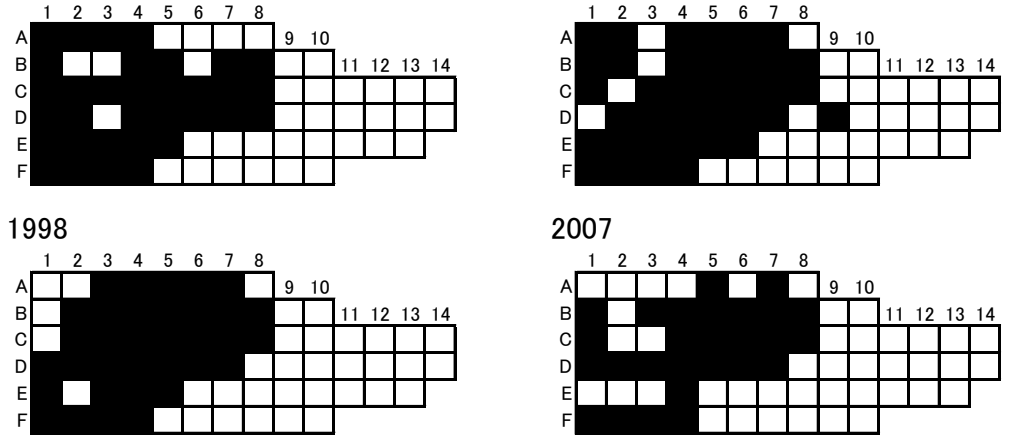

2007

1990

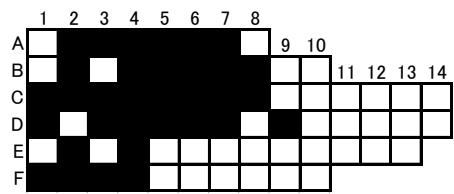

1999
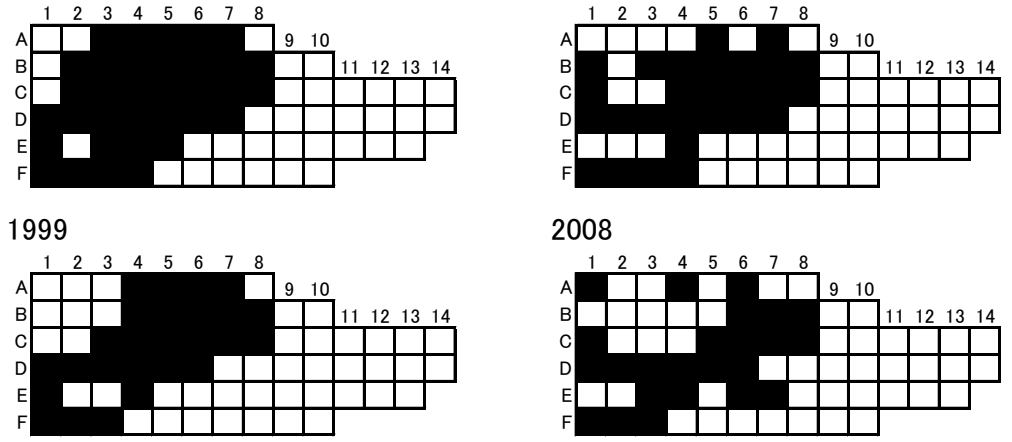

2008

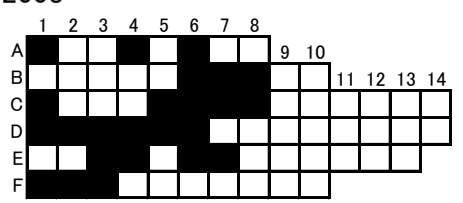

1991

2000
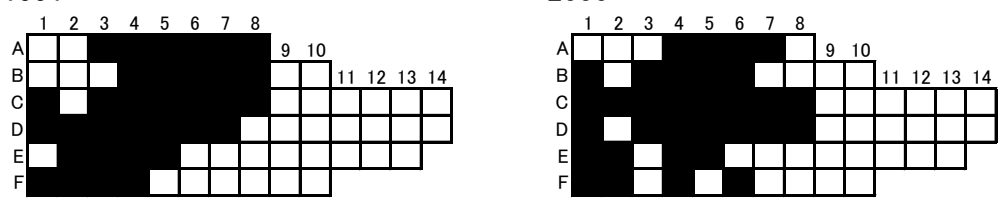

2009

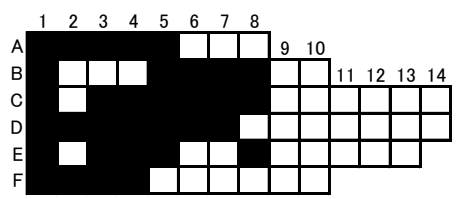

1992

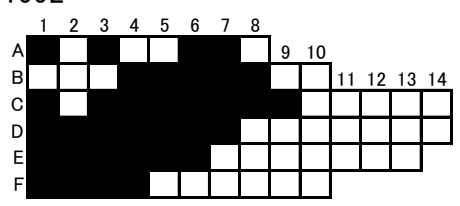

2001

2010
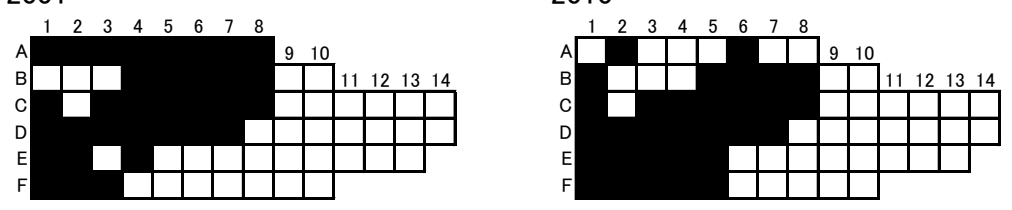

1993

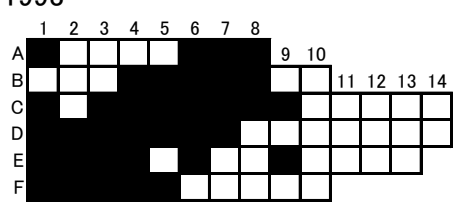

2002

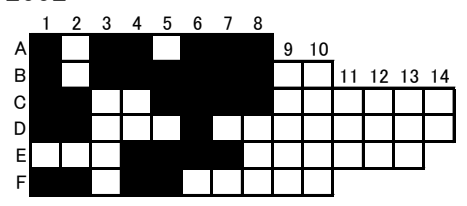



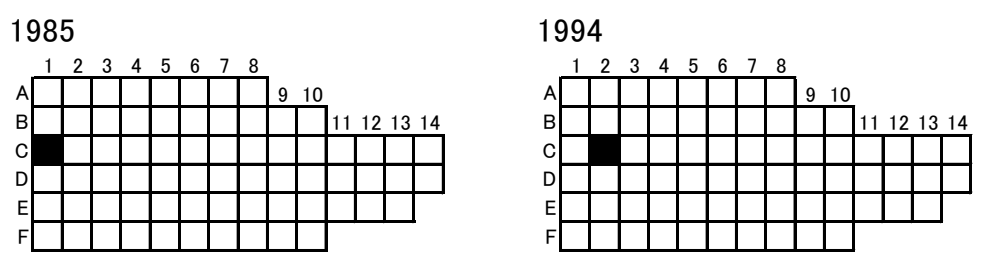

2003

1986

1995
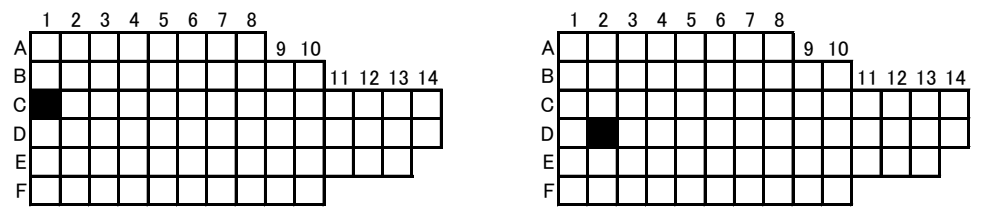

1987

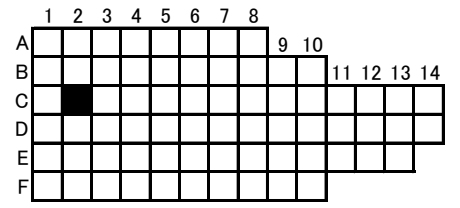

1996
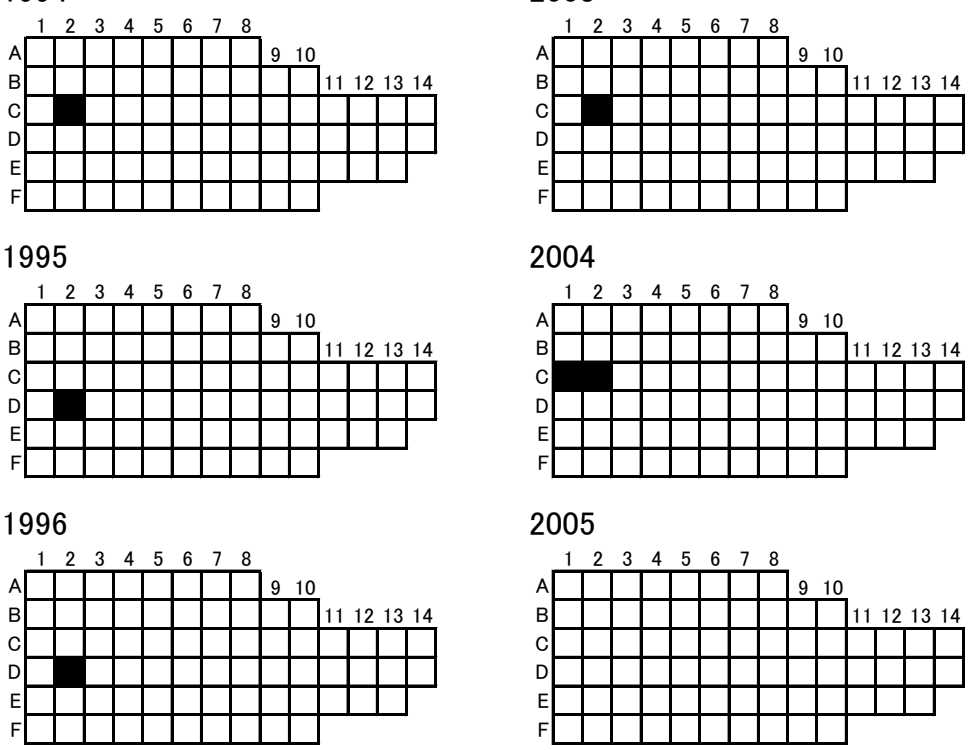

2004

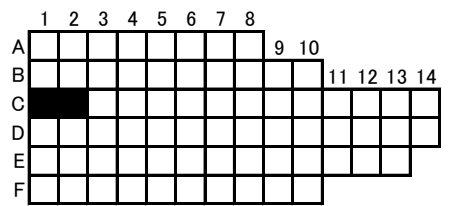

2005

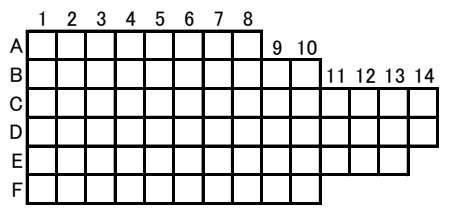

1988

1997
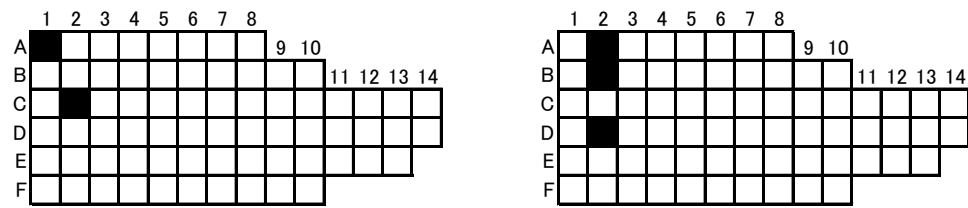

2006

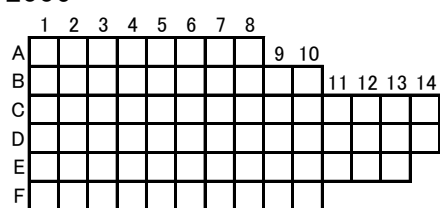

1989

1998
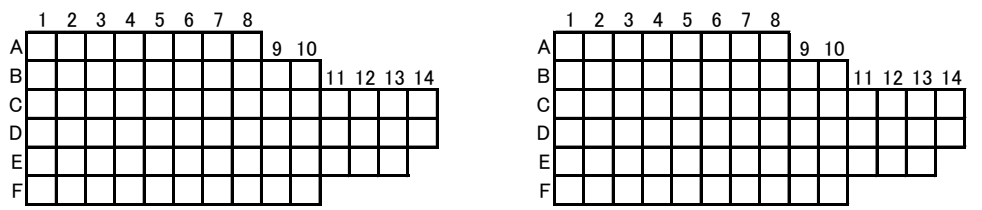

2007
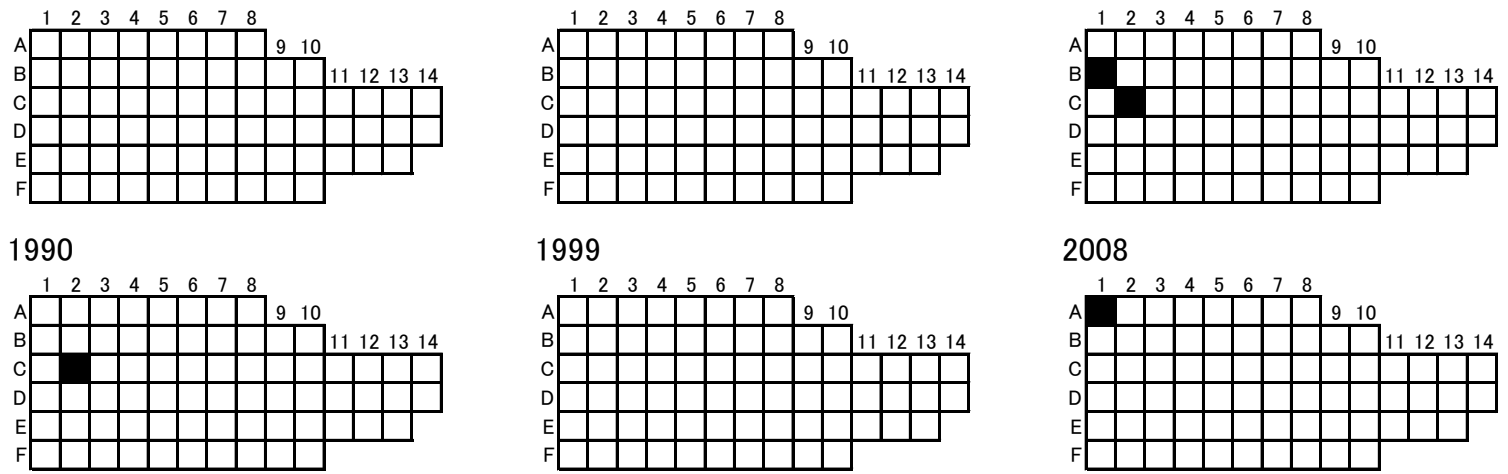

1999

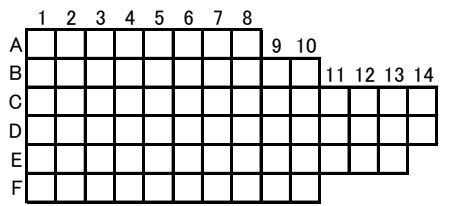

2008

1991

2000
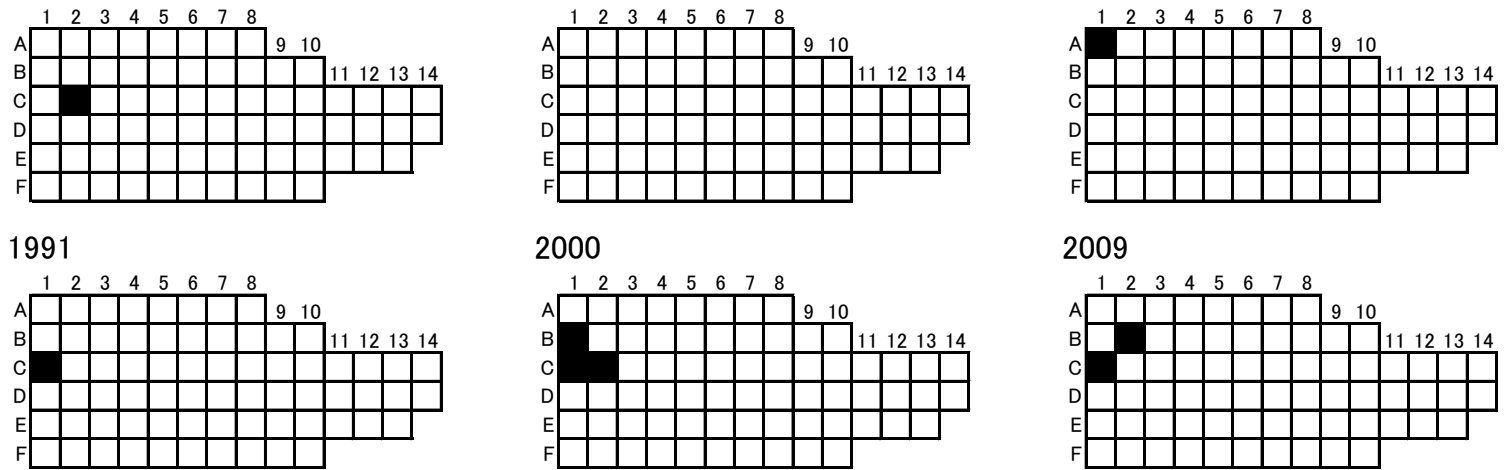

2009

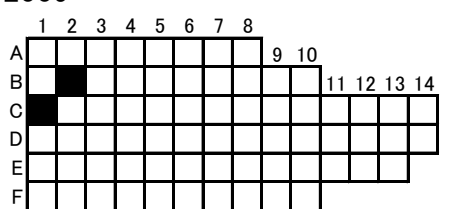

1992

2001
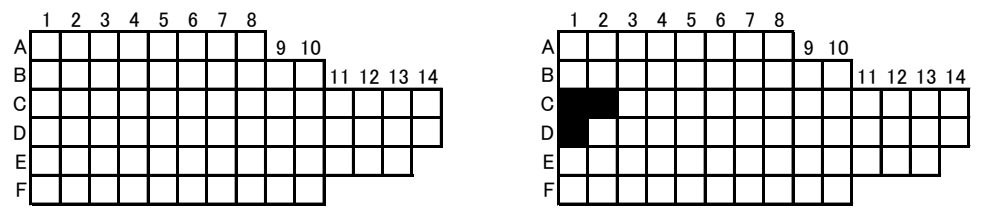

2010

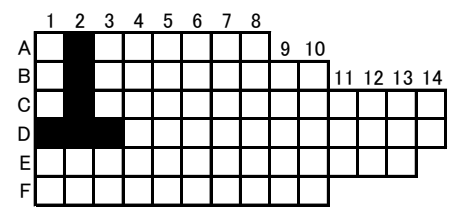
1993

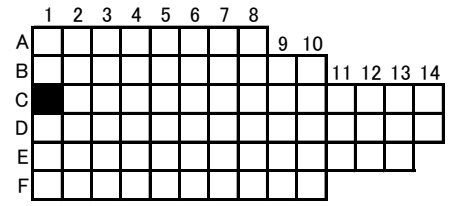

2002

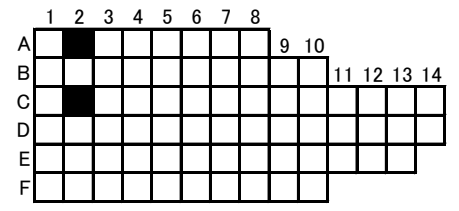




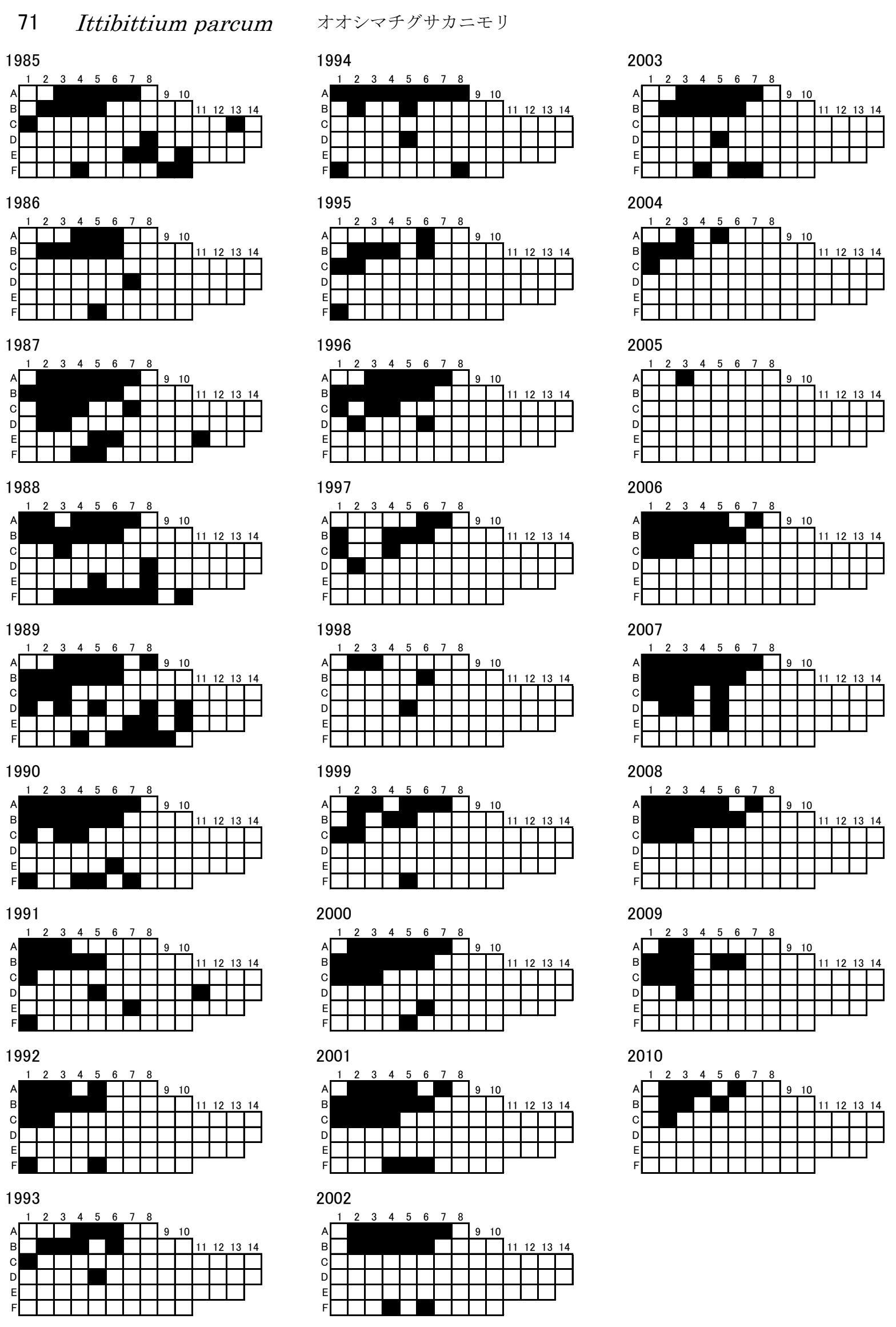




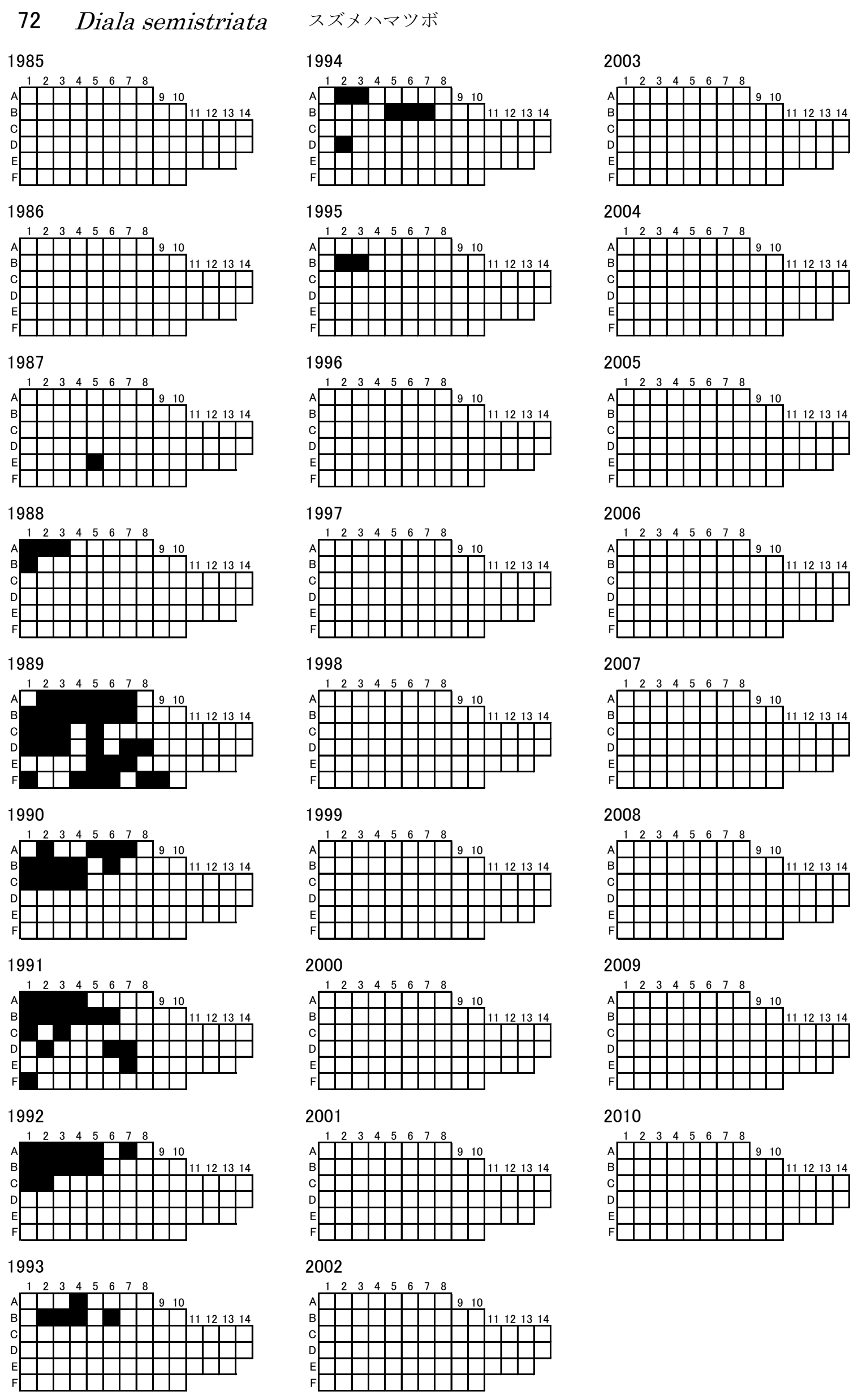


1985

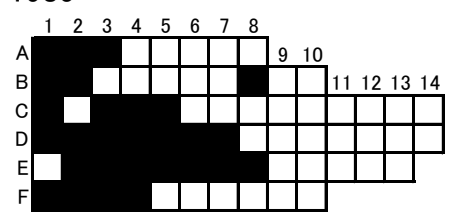

1986

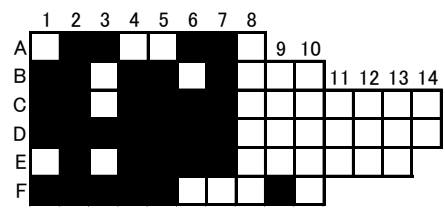

1987

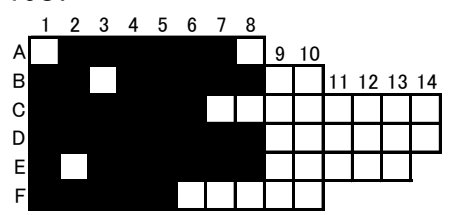

1988

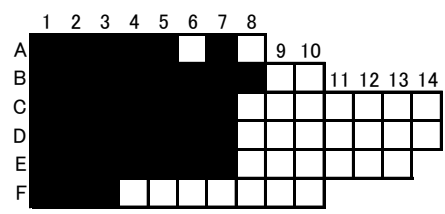

1989

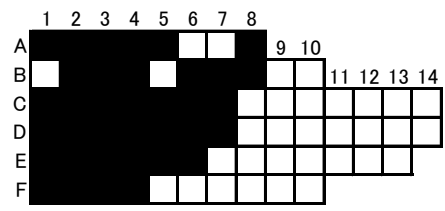

1990

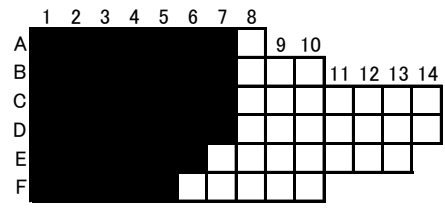

1991

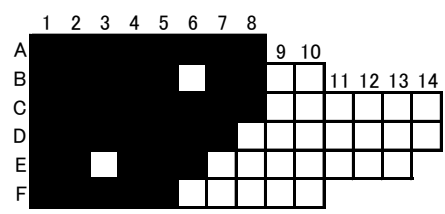

1992

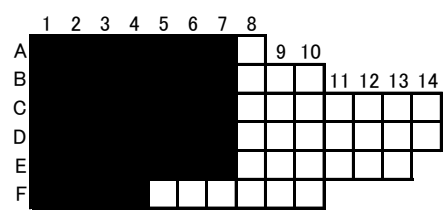

1993

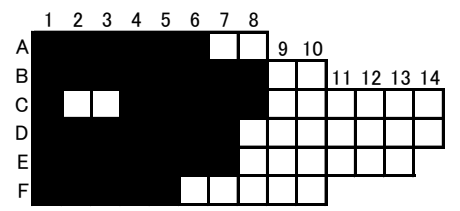

1994

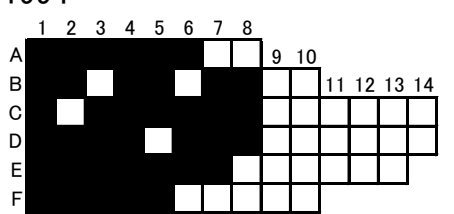

1995

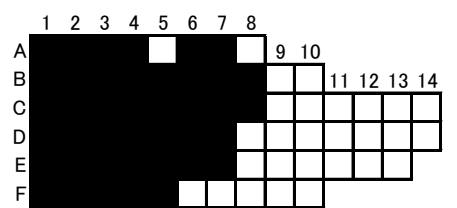

1996

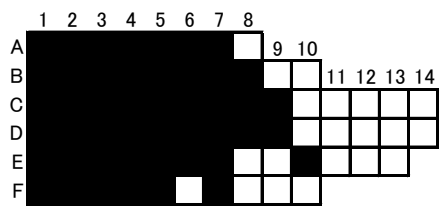

1997

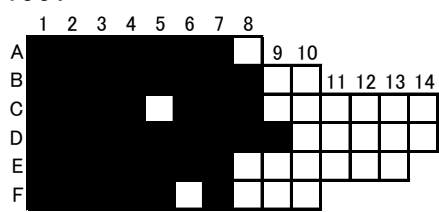

1998

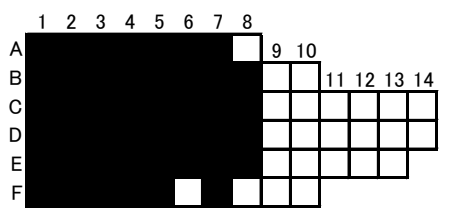

1999

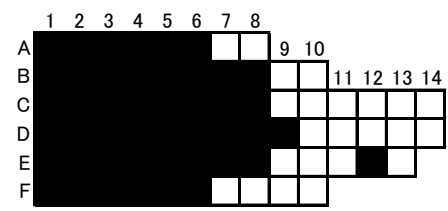

2000

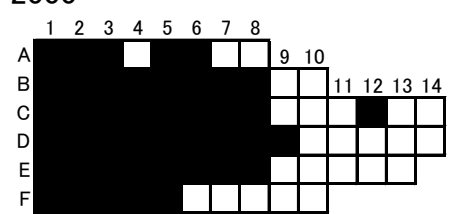

2001

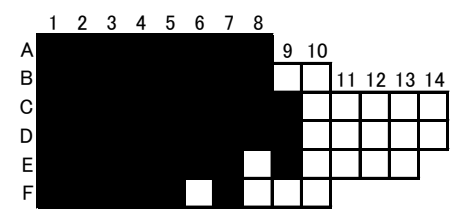

2002

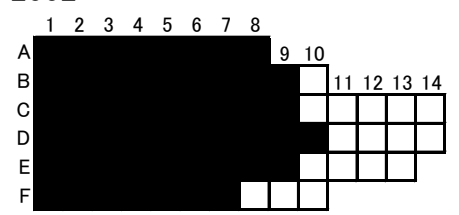

2003

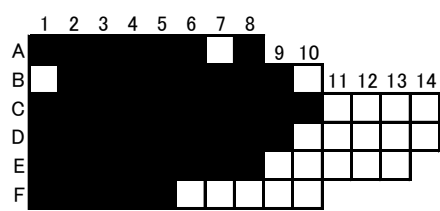

2004

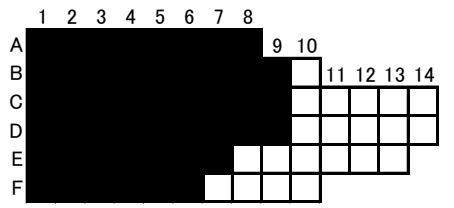

2005

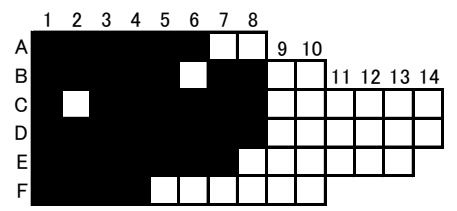

2006

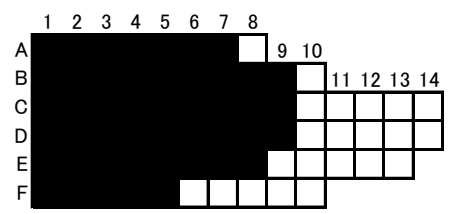

2007

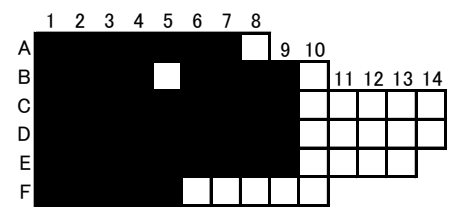

2008

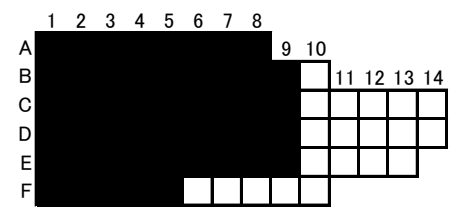

2009

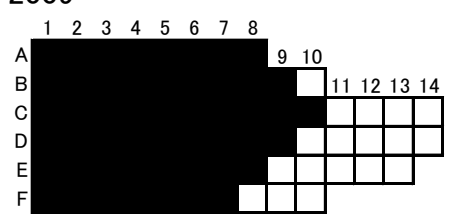

2010

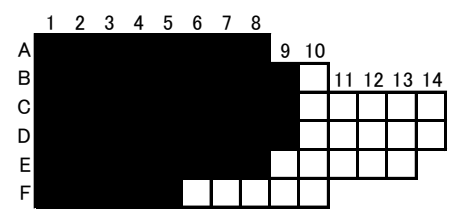


77 Peasiella habei コビトウラウズガイ

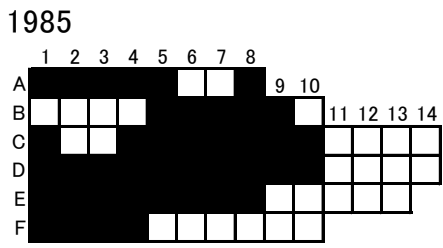

1994

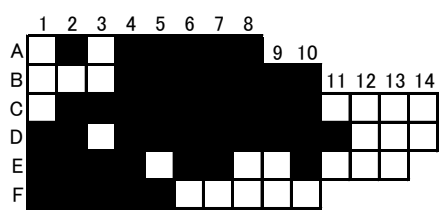

1986

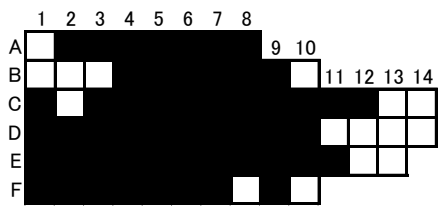

1987

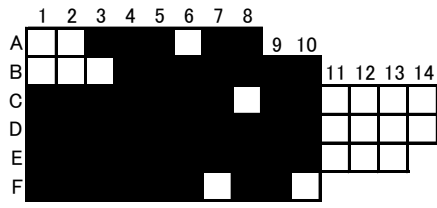

1988

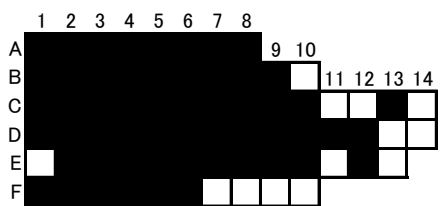

1989

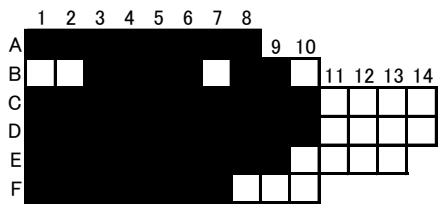

1990

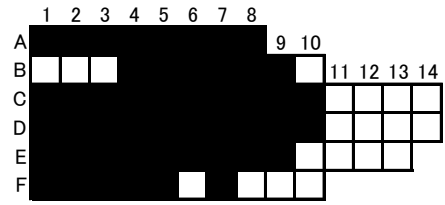

1991

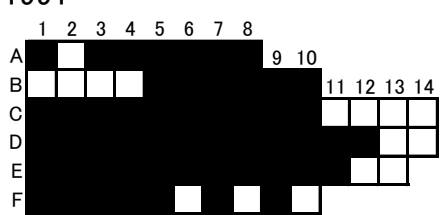

1992

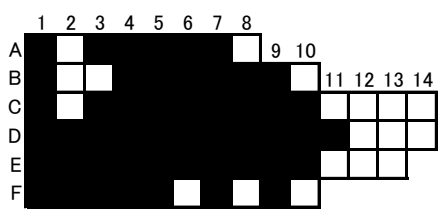

1993

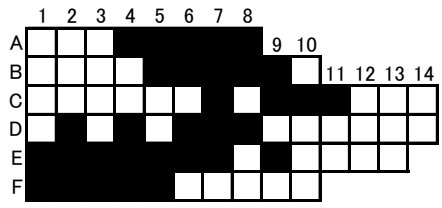

1995

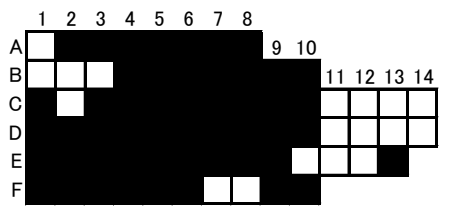

1996

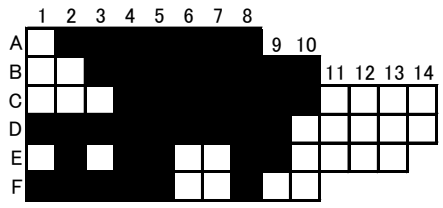

1997

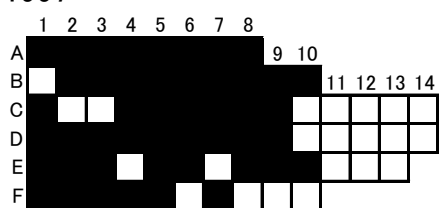

1998

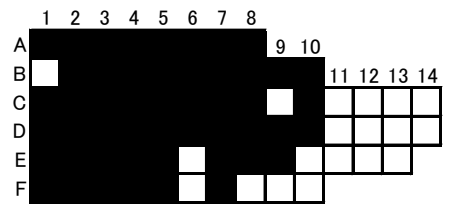

1999

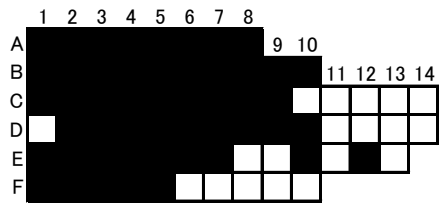

2000

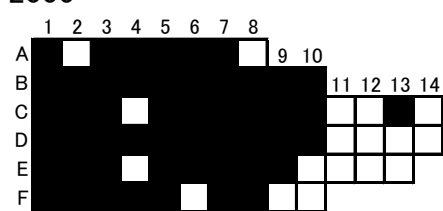

2001

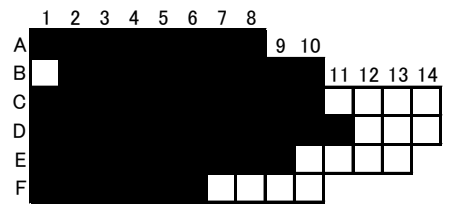

2002

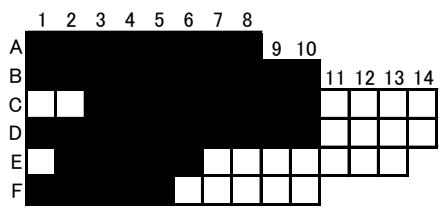

2003

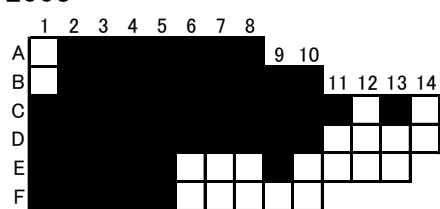

2004

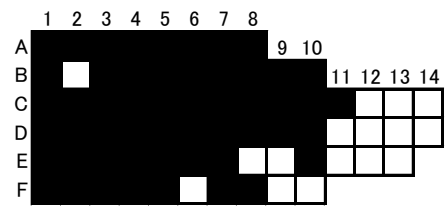

2005

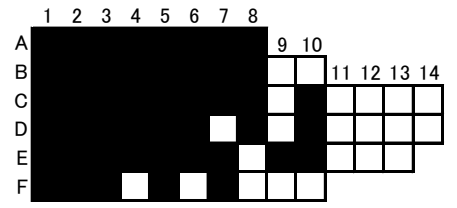

2006

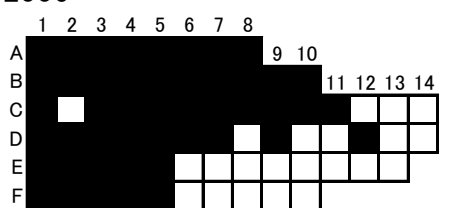

2007

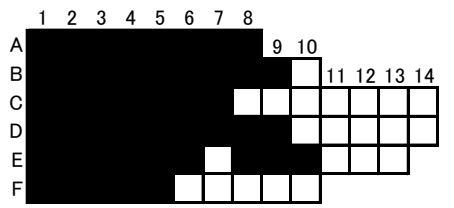

2008

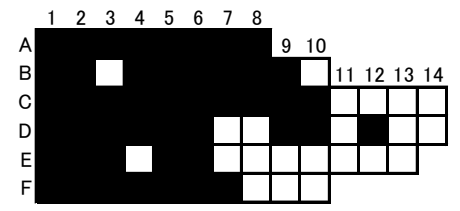

2009

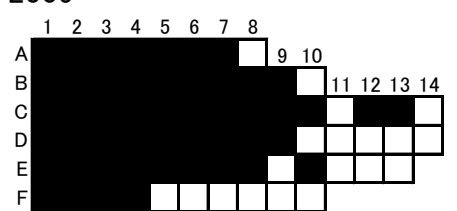

2010

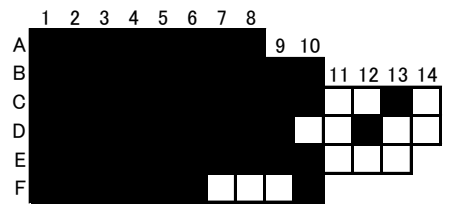


78 Nodilittorina radiata アラレタマキビ
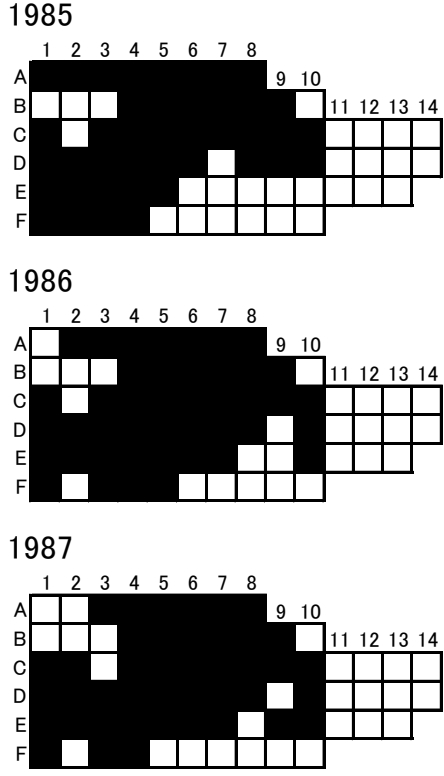

1988

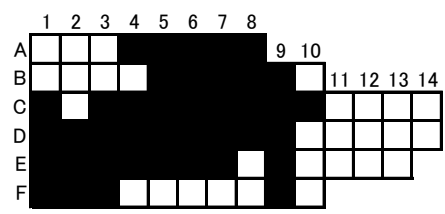

1989
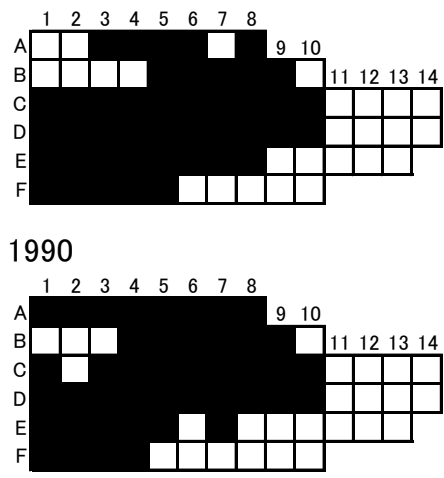

1991

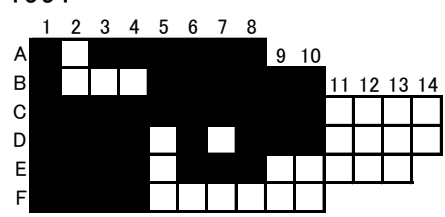

1992

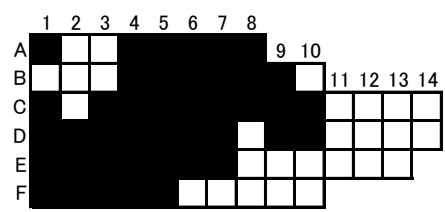

1993

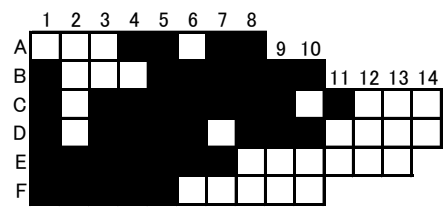

1994

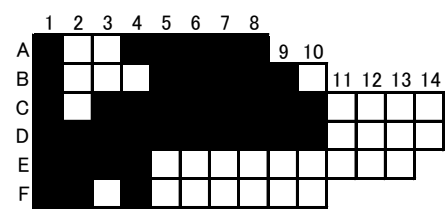

1995

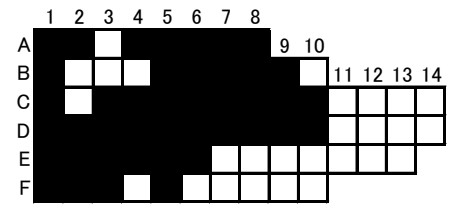

1996

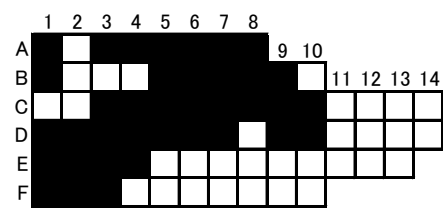

1997

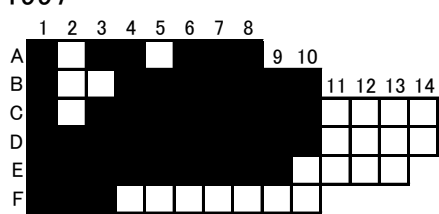

1998

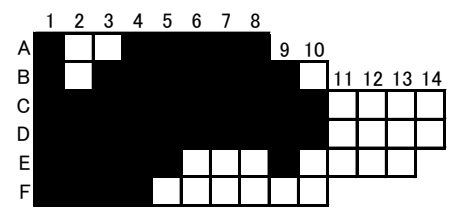

1999

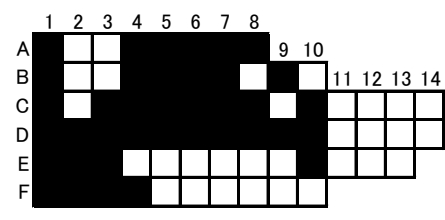

2000

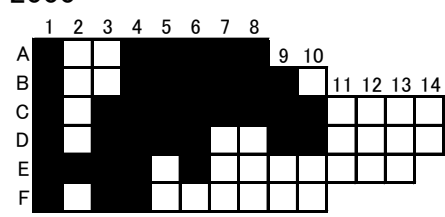

2001

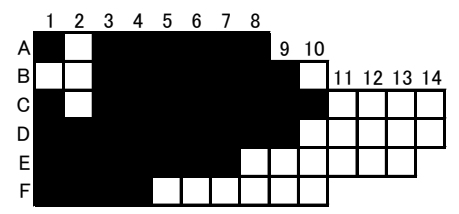

2002

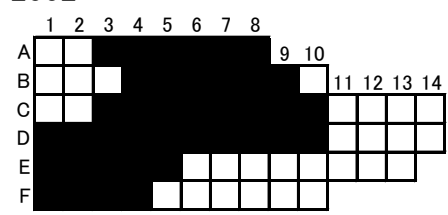

2003

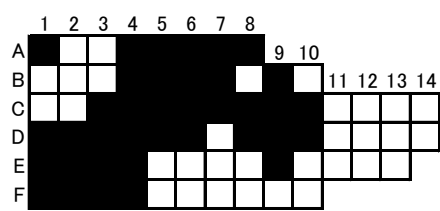

2004

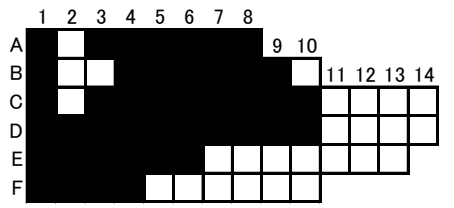

2005

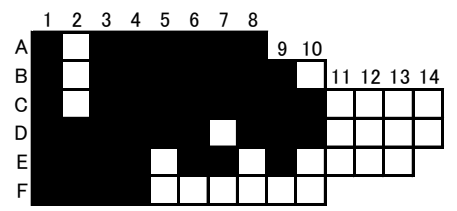

2006

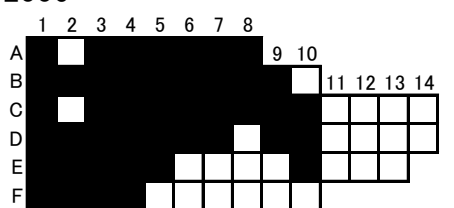

2007

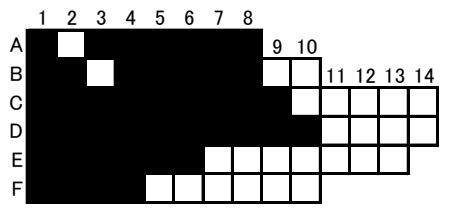

2008

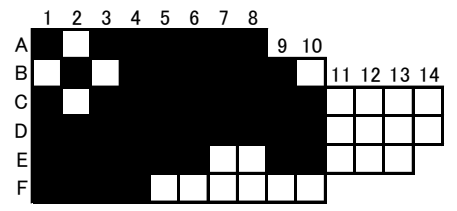

2009

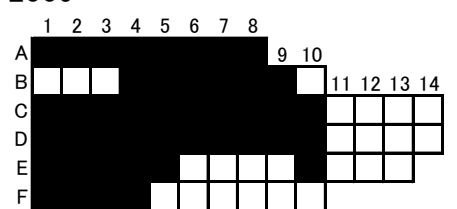

2010

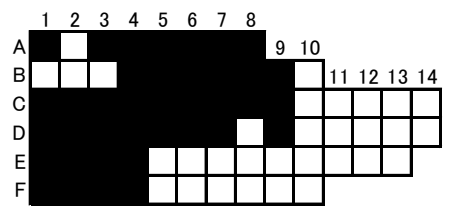




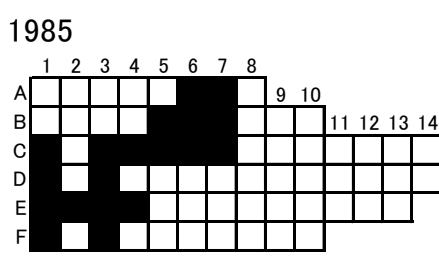

1986

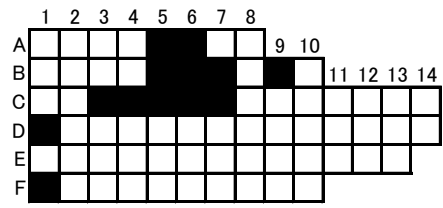

1987

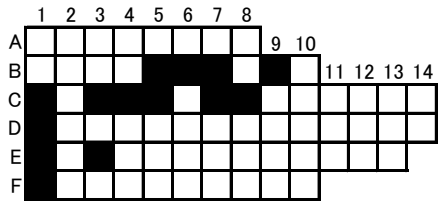

1988

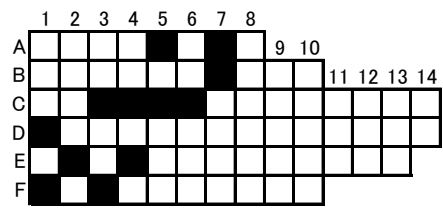

1989

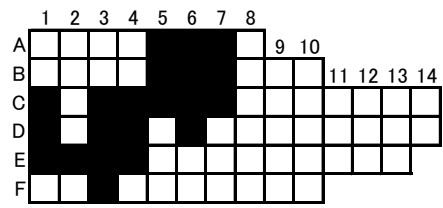

1990

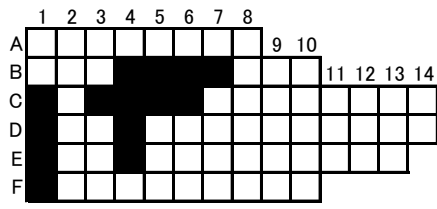

1991

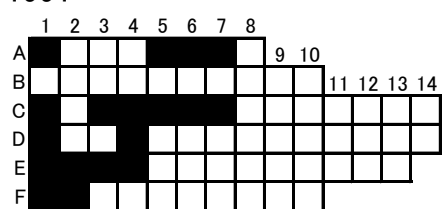

1992

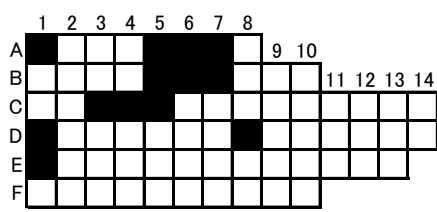

1993

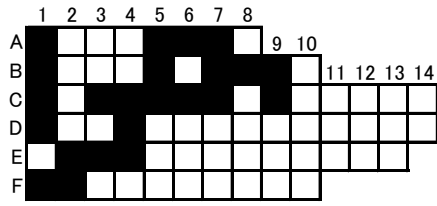

1994

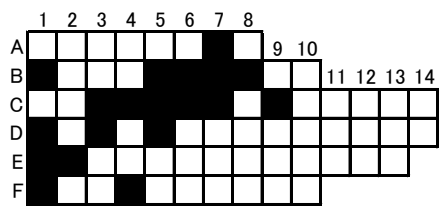

1995

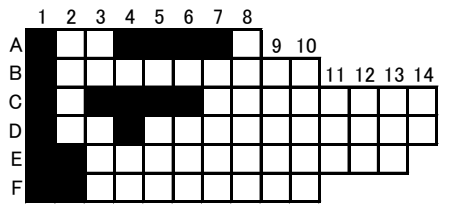

1996

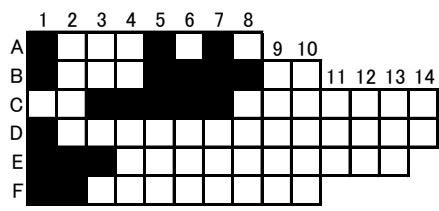

1997

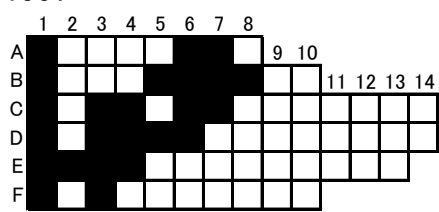

1998

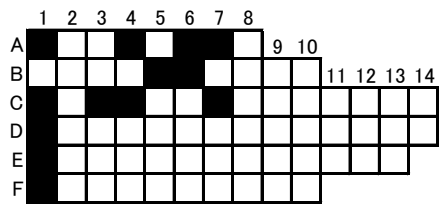

1999

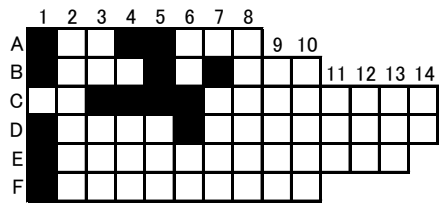

2000

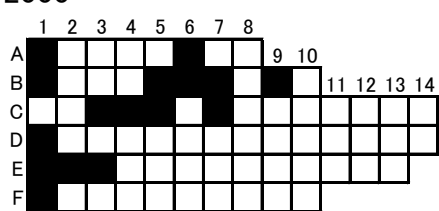

2001

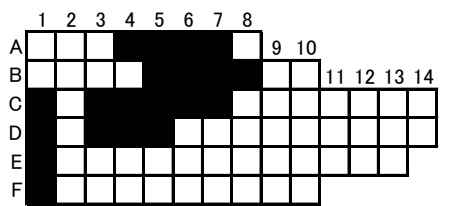

2002

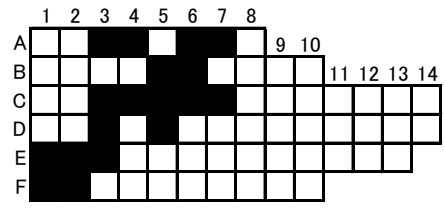

2003

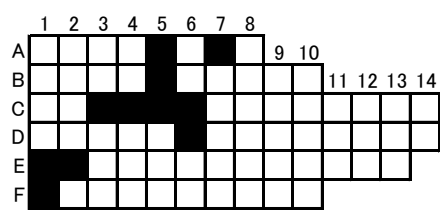

2004

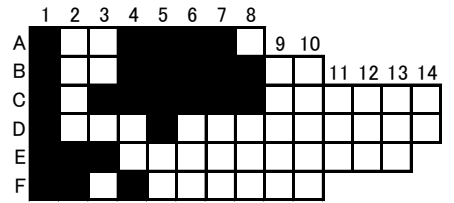

2005

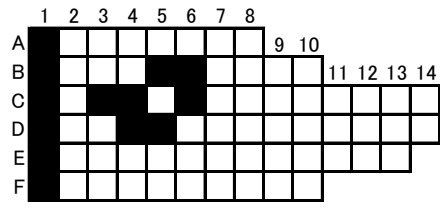

2006

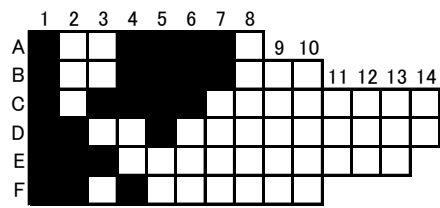

2007

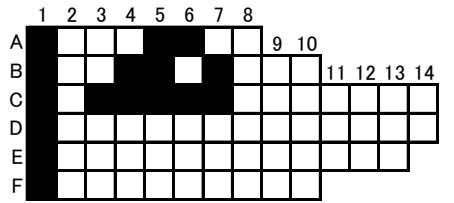

2008

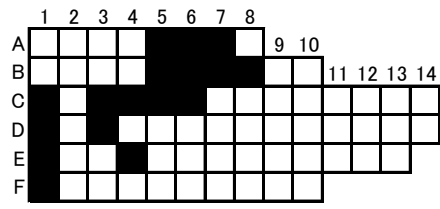

2009

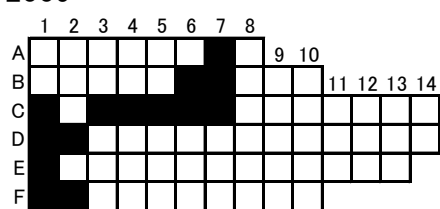

2010

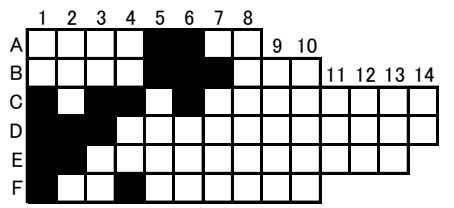


Nodilittorina vidua タイワンタマキビ

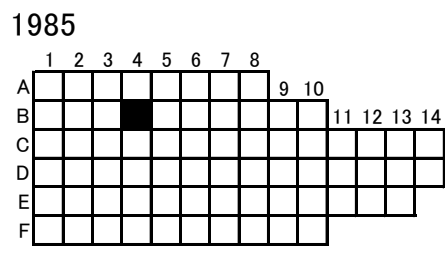

1986

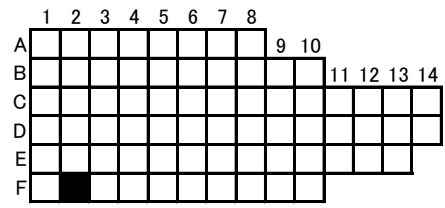

1994

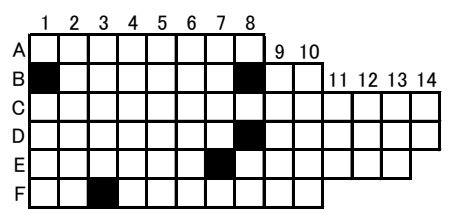

2003

1987

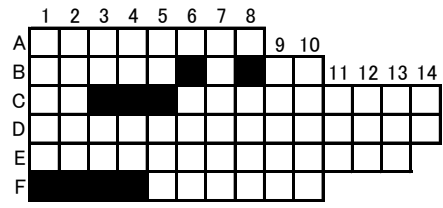

1995
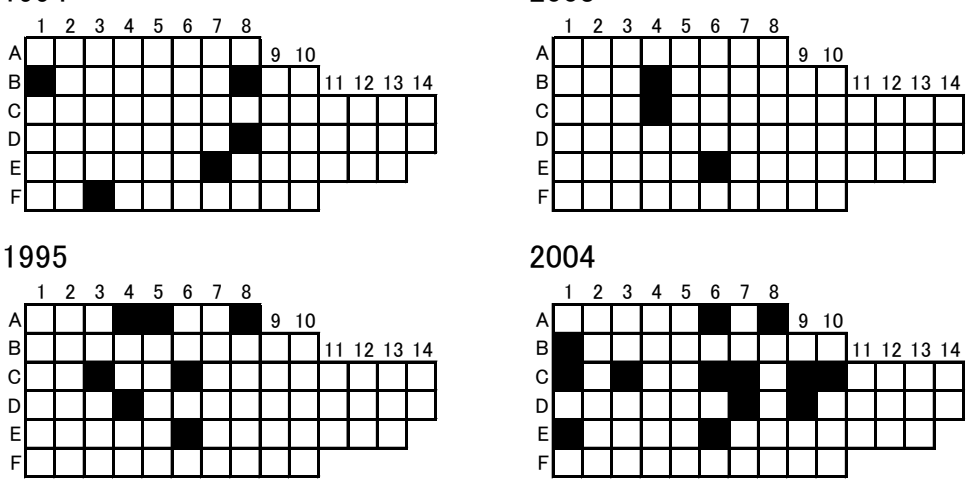

2004

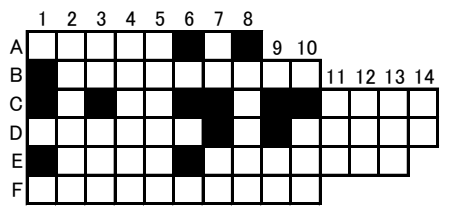

1996

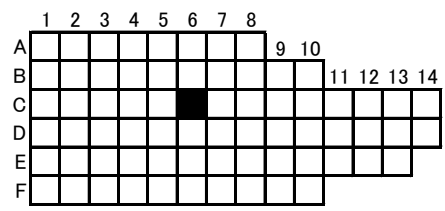

2005

1997
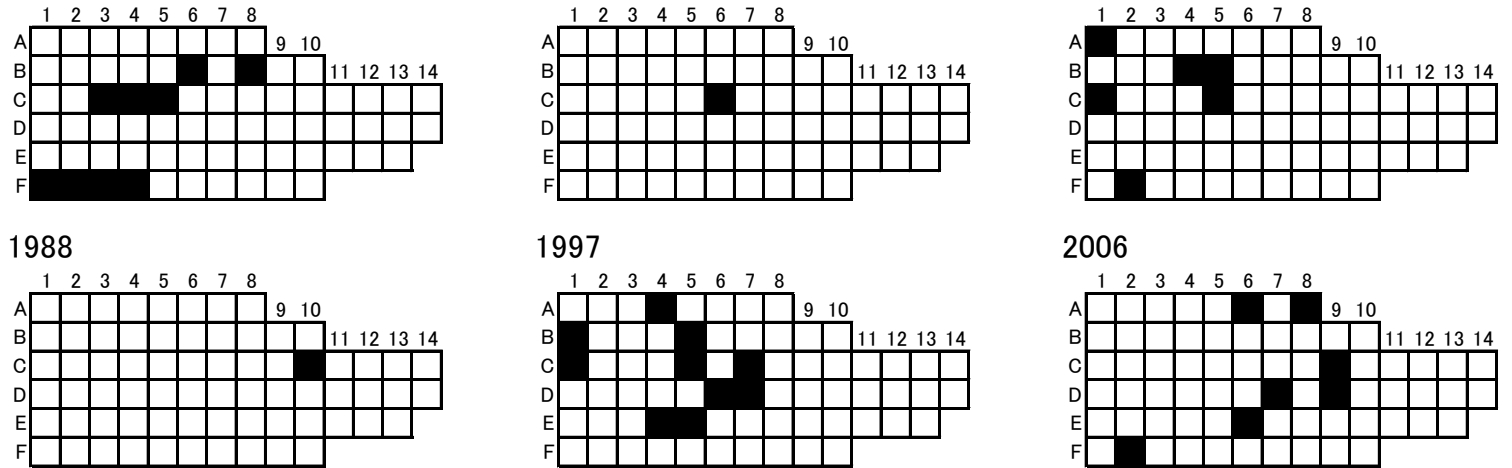

2006

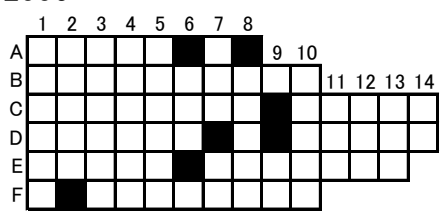

1989

1998
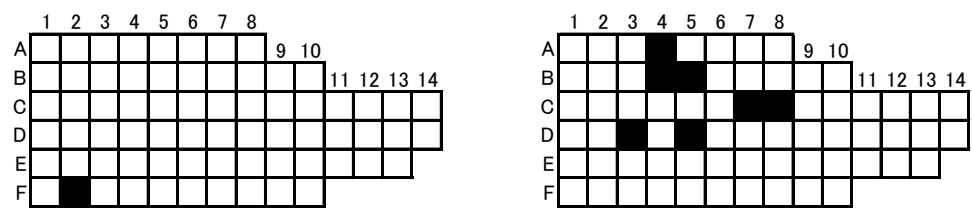

2007
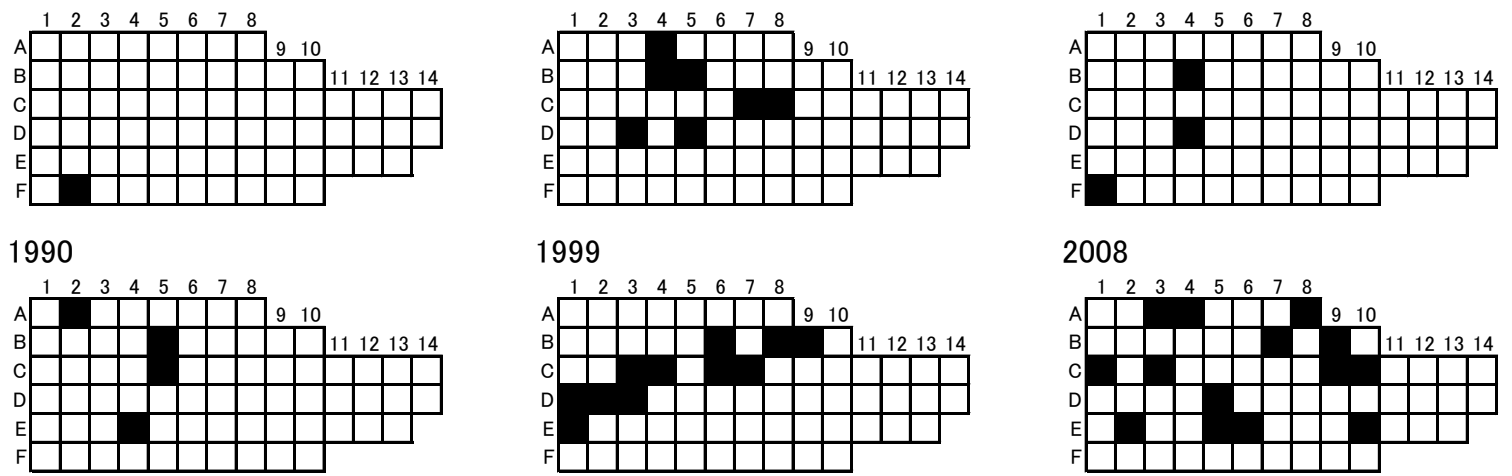

1999

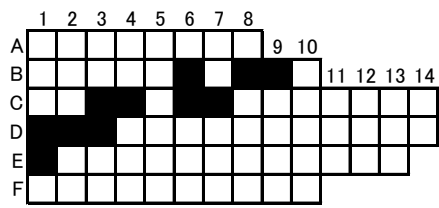

2008

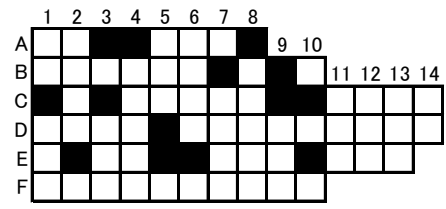

1991

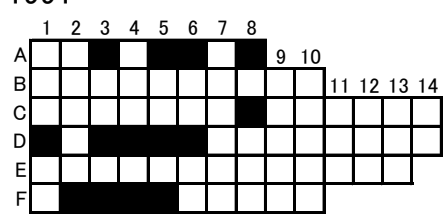

2000

2009
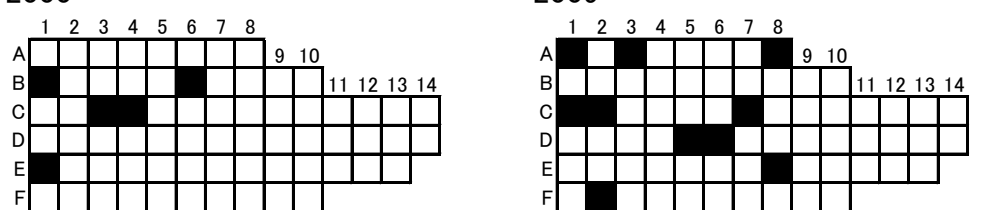

1992

2001
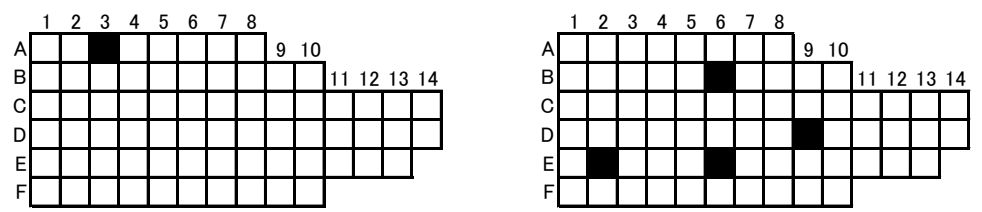

2010
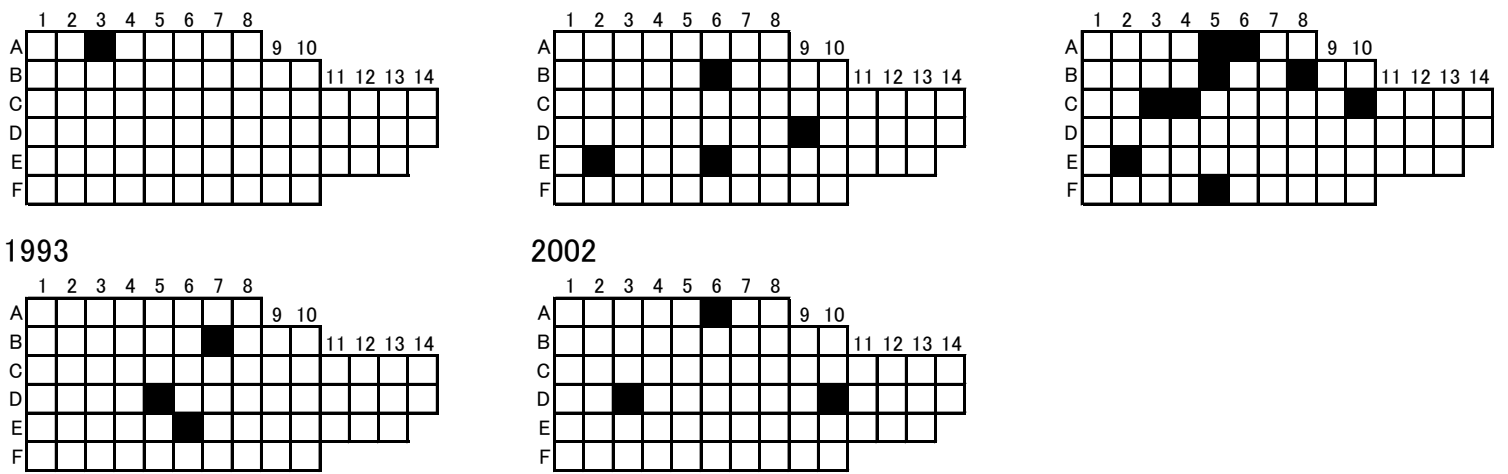

\section{2}

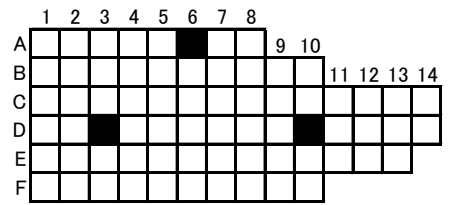




\section{Littorina brevicula タマキビ}

1985

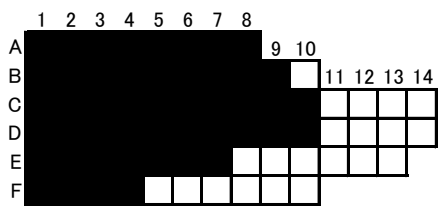

1986

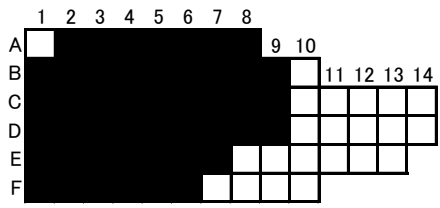

1987

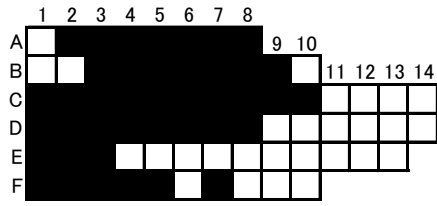

1988

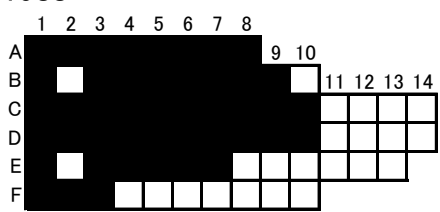

1989

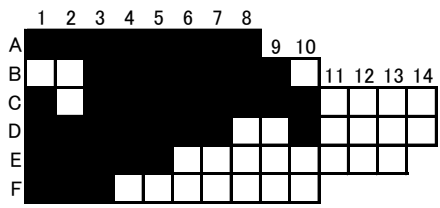

1990

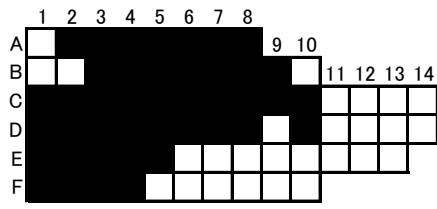

1991

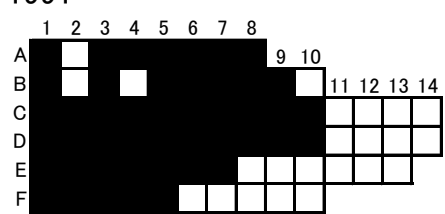

1992

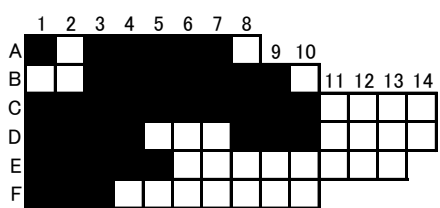

1993

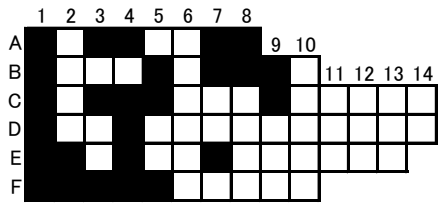

1994

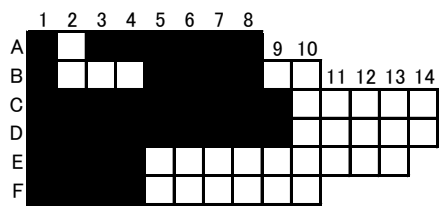

1995

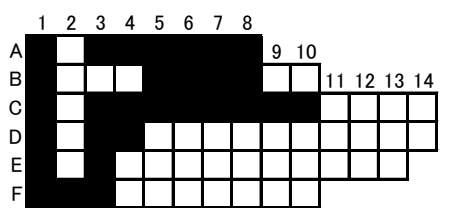

1996

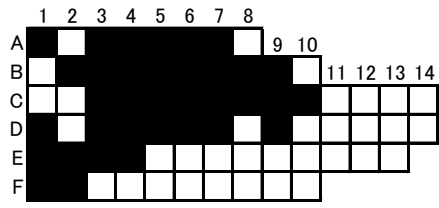

1997

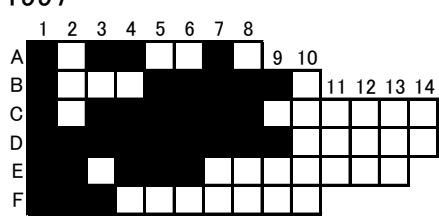

1998

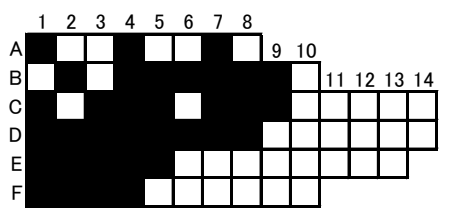

1999

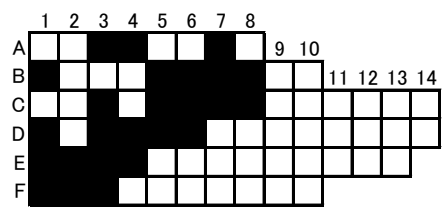

2000

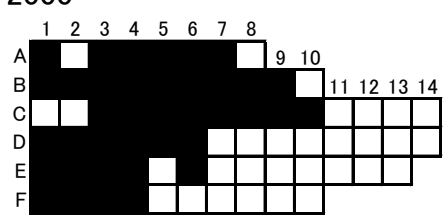

2001

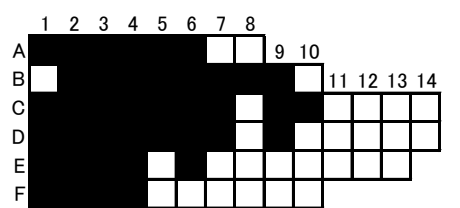

2002

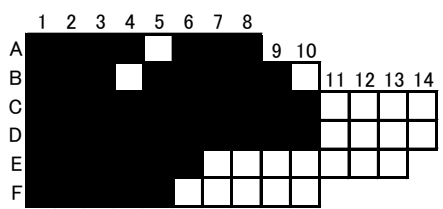

2003

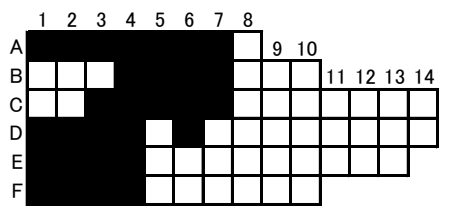

2004

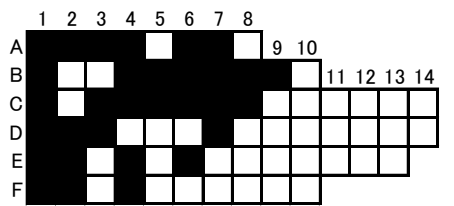

2005

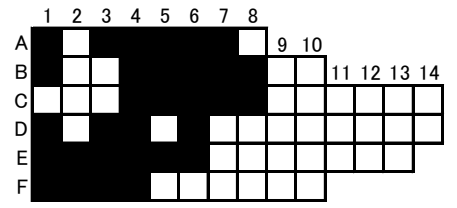

2006

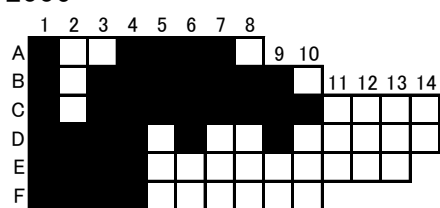

2007

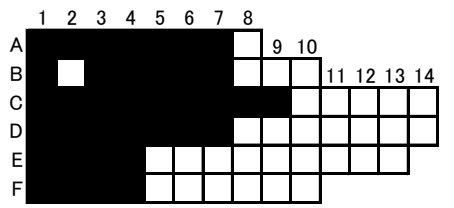

2008

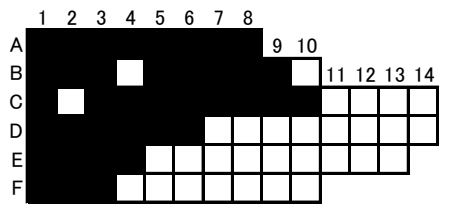

2009

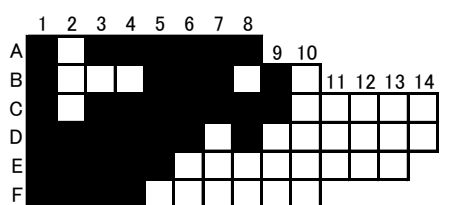

2010

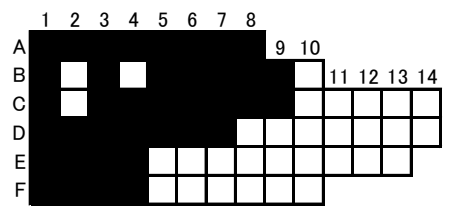


82

Barleeia angustata

1985

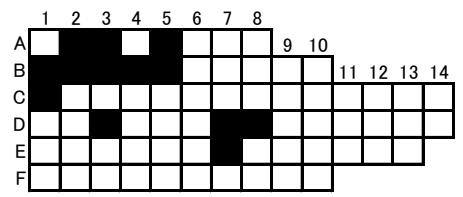

1986

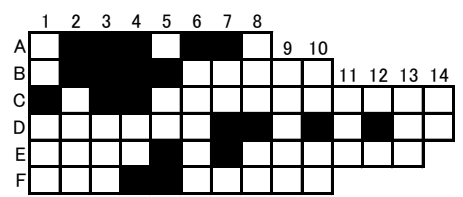

1987

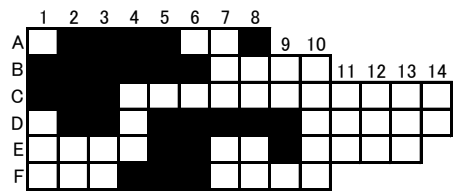

1988

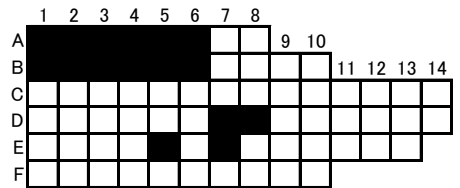

1989

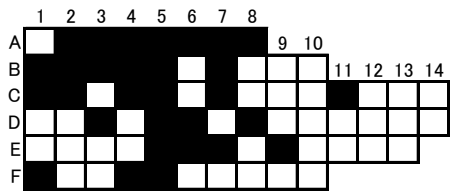

1990

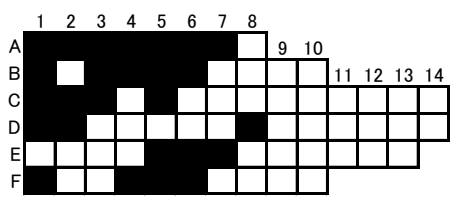

1991

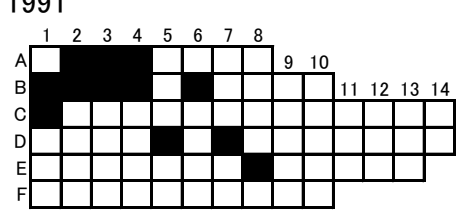

1992

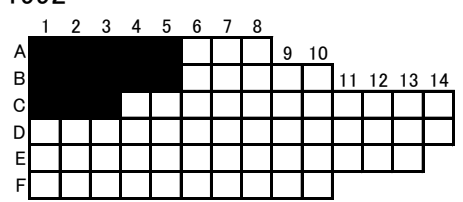

1993

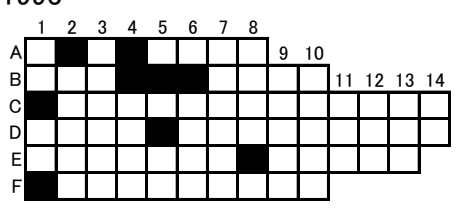

チャツボ

1994

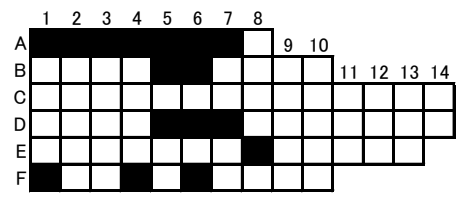

1995

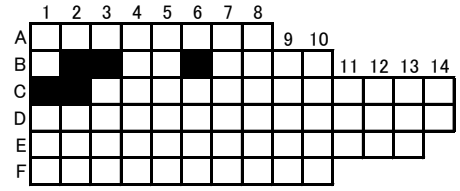

1996

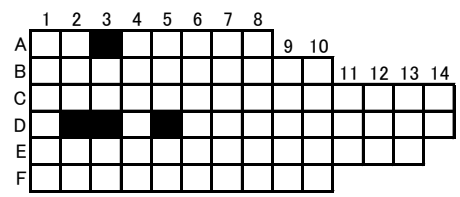

1997

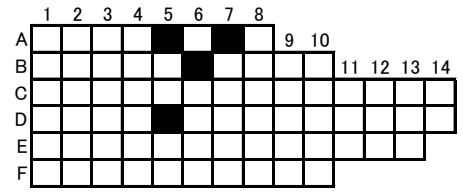

1998

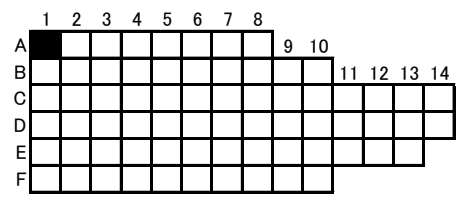

1999

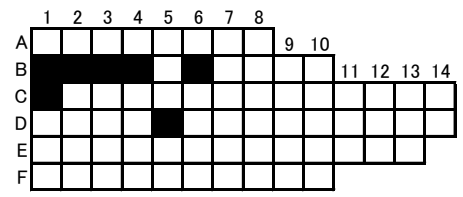

2000

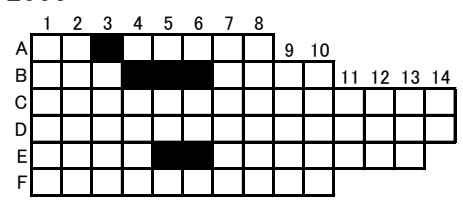

2001

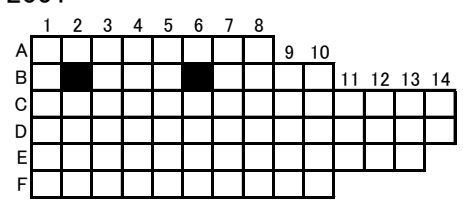

2002

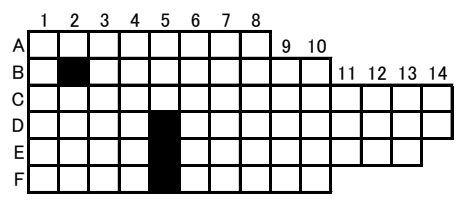

2003

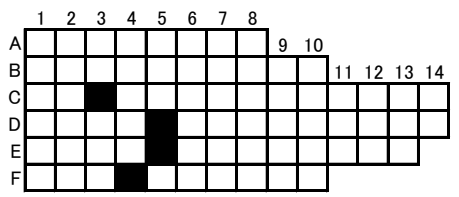

2004

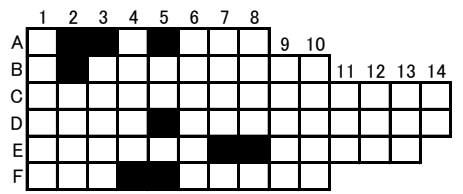

2005

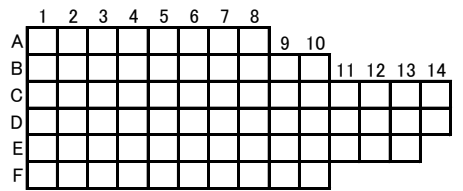

2006

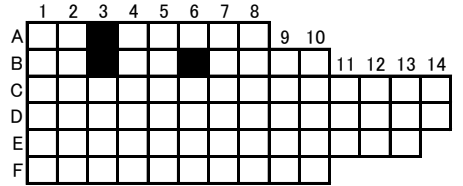

2007

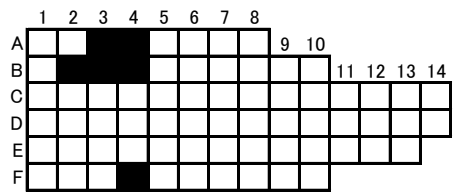

2008

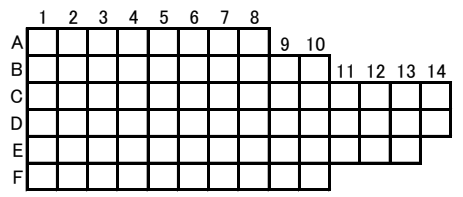

2009

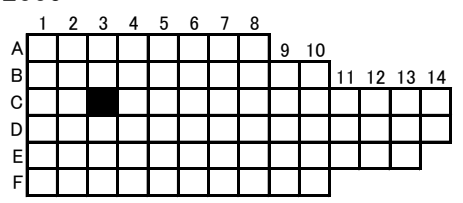

2010

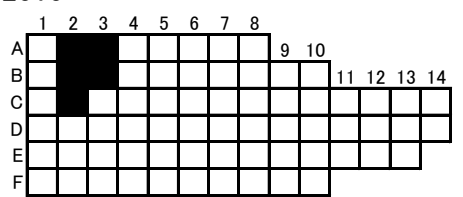


キクスズメ

1985

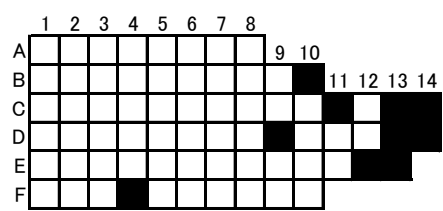

1986

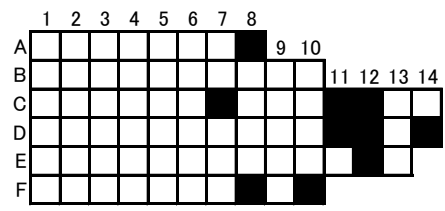

1987

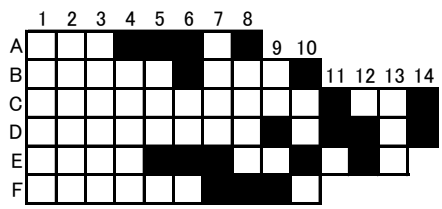

1988

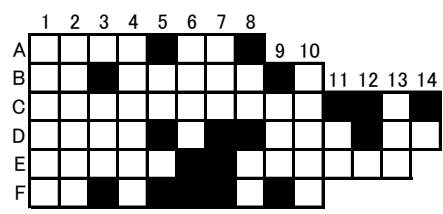

1989

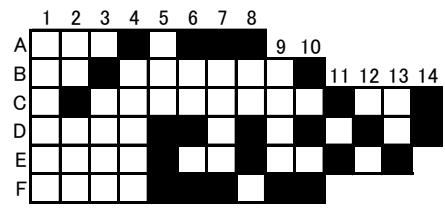

1990

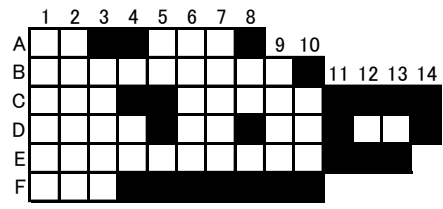

1991

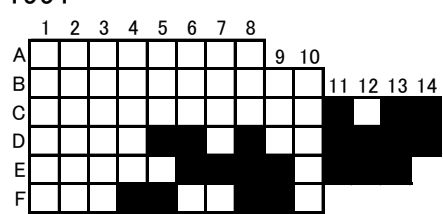

1992

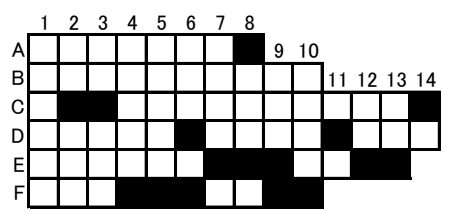

1993

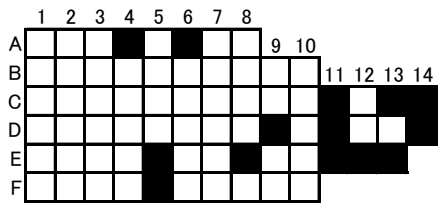

1994

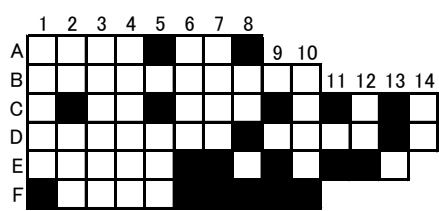

1995

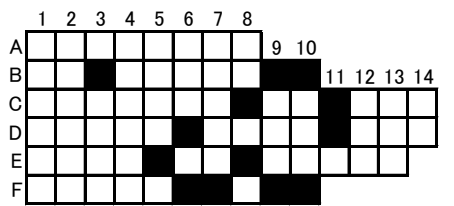

1996

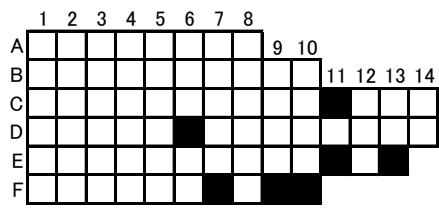

1997

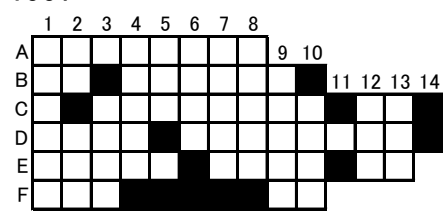

1998

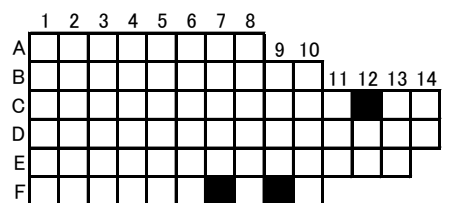

1999

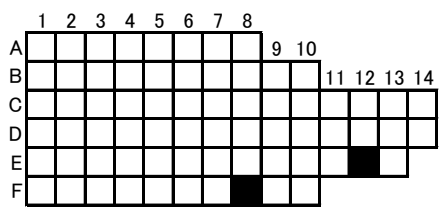

2000

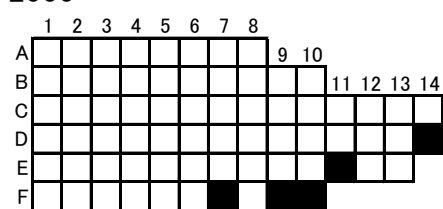

2001

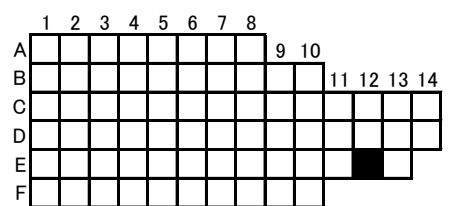

2002

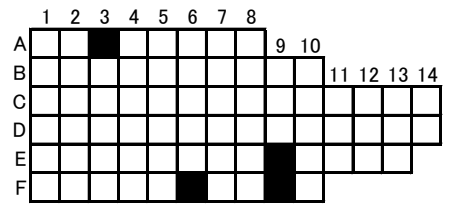

2003

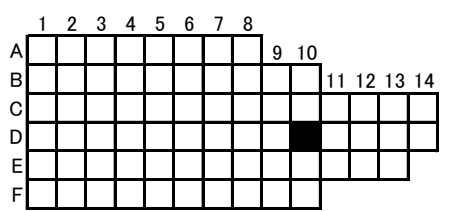

2004

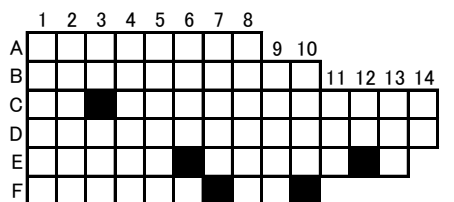

2005

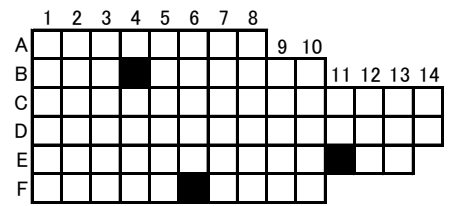

2006

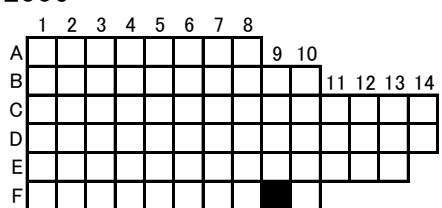

2007

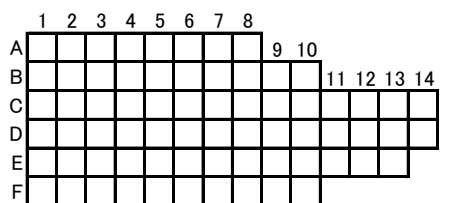

2008

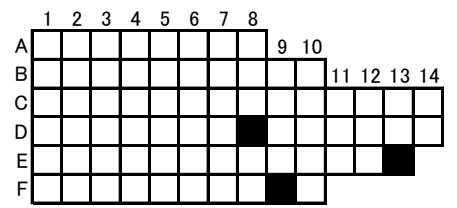

2009

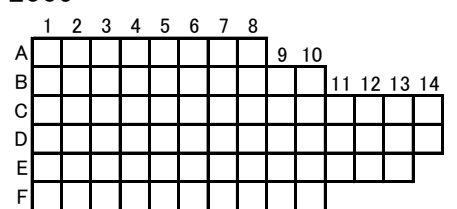

2010

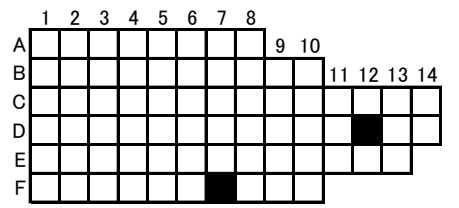


87 Hipponix foliacea カワチドリ

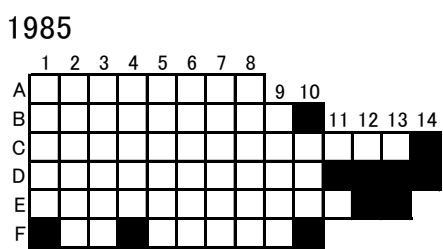

1986

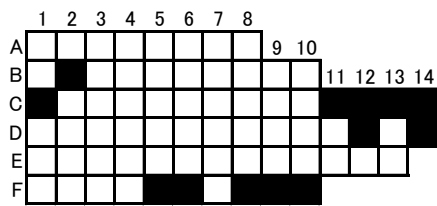

1987

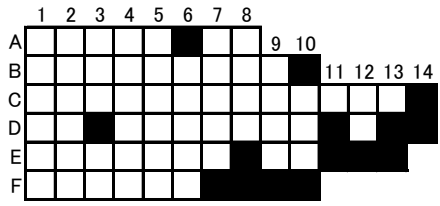

1988

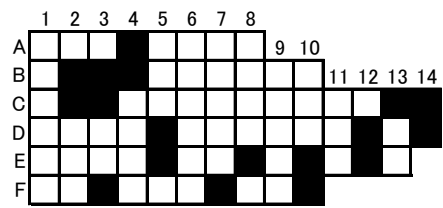

1989

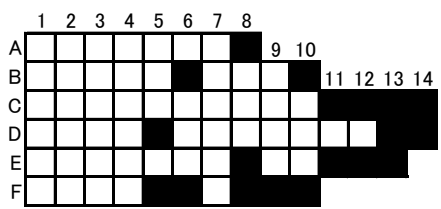

1990

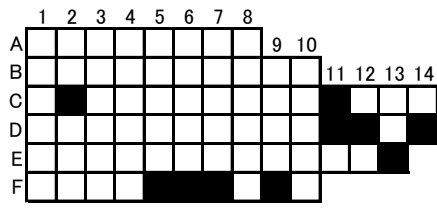

1991

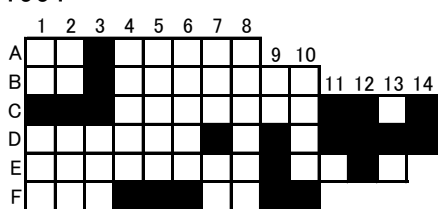

1992

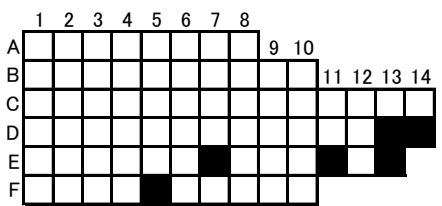

1993

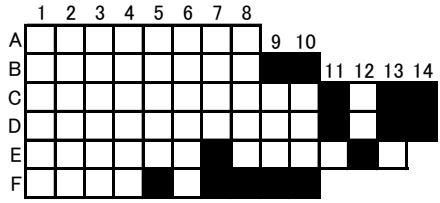

1994

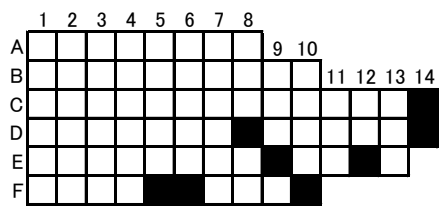

1995

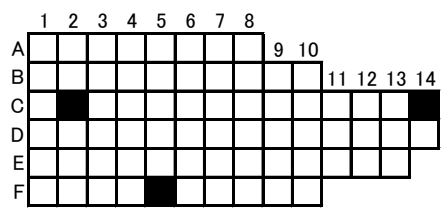

1996

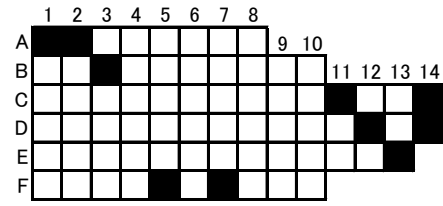

1997

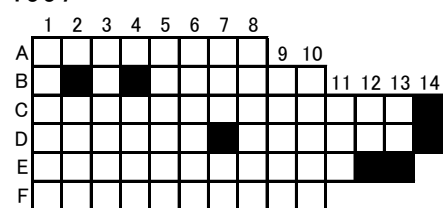

1998

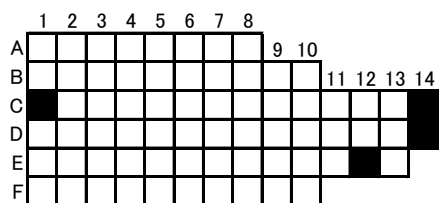

1999

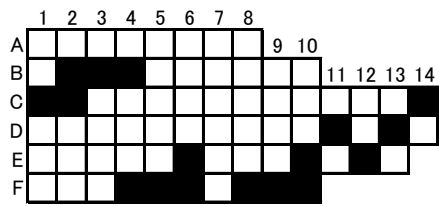

2000

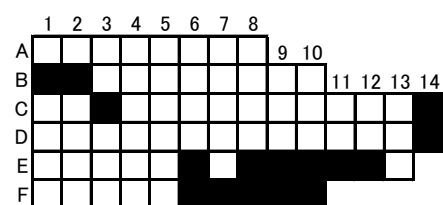

2001

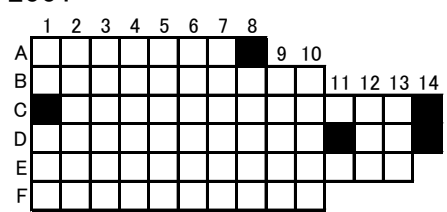

2002

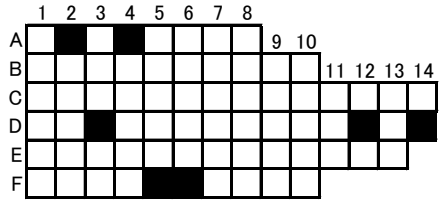

2003

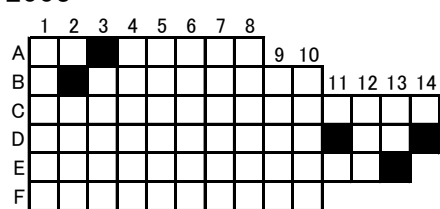

2004

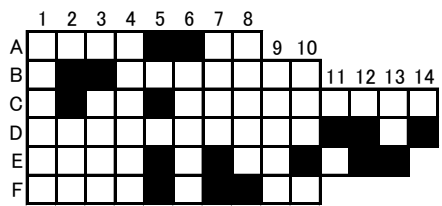

2005

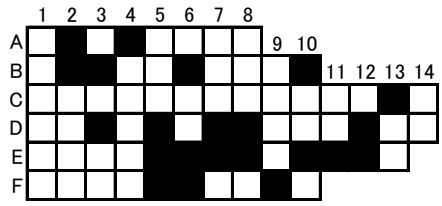

2006

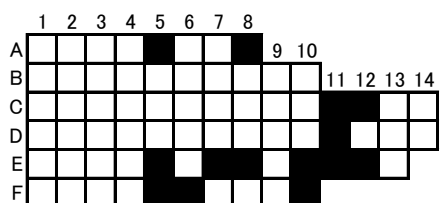

2007

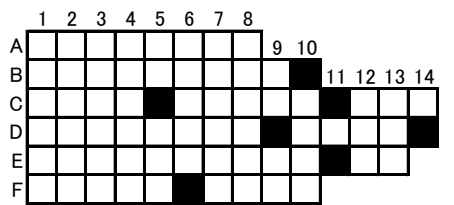

2008

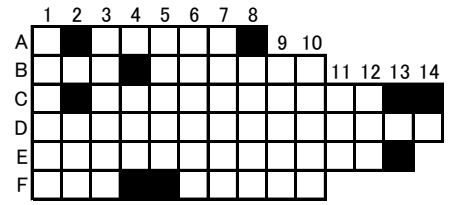

2009

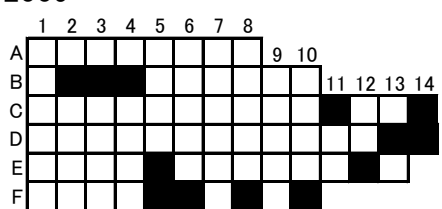

2010

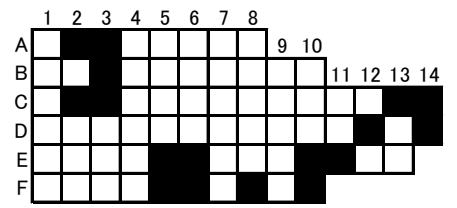


88 Hipponix trigona

1985

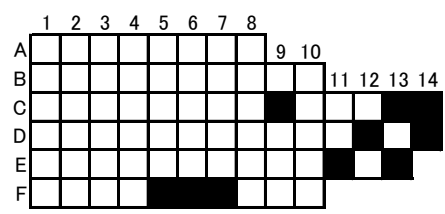

1986

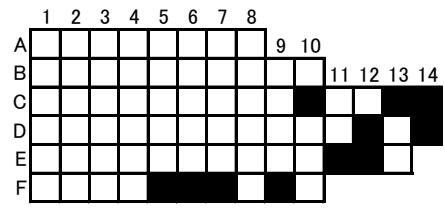

1987

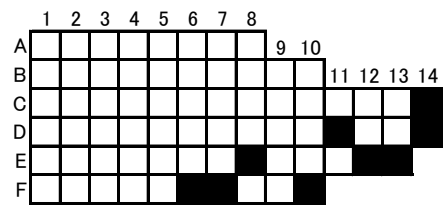

1988

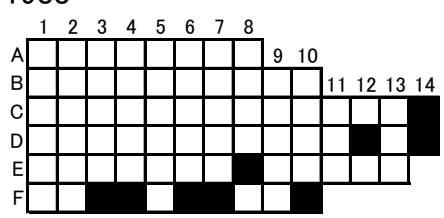

1989

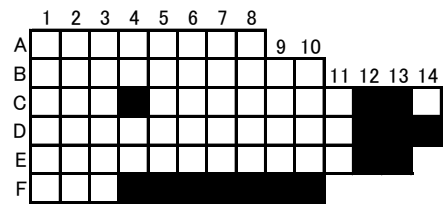

1990

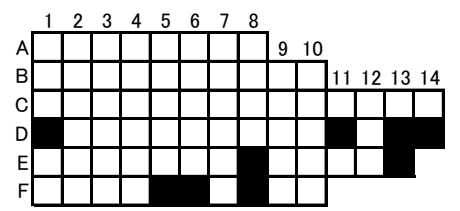

1991

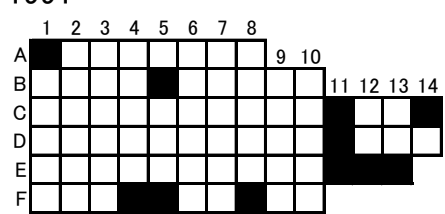

1992

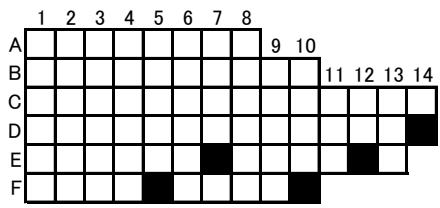

1993

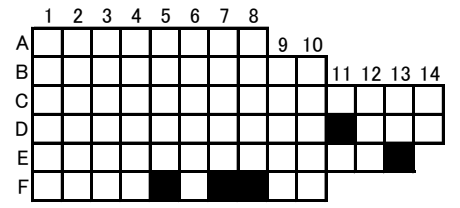

スズメガイ

1994

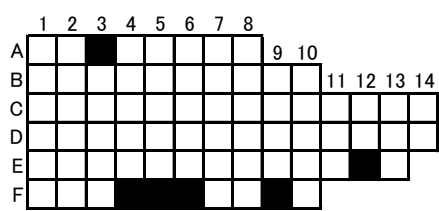

1995

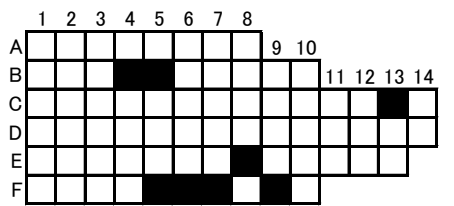

1996

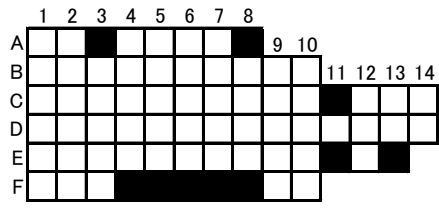

1997

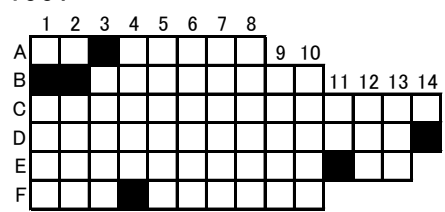

1998

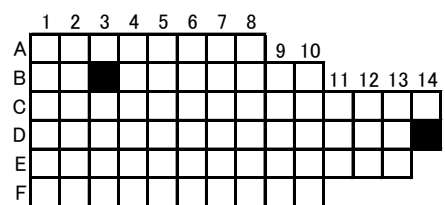

1999

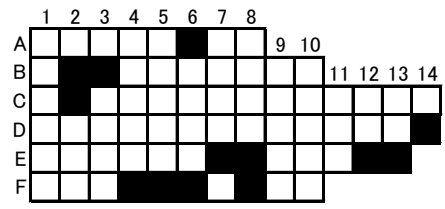

2000

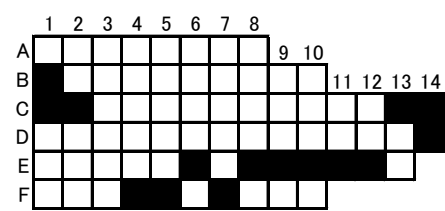

2001

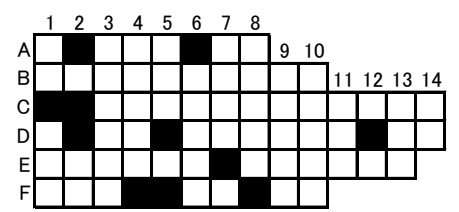

2002

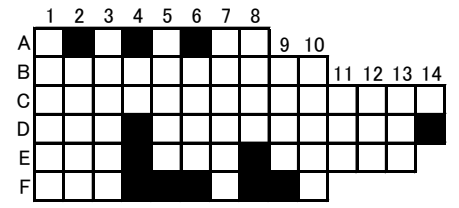

2003

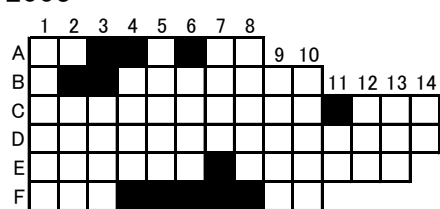

2004

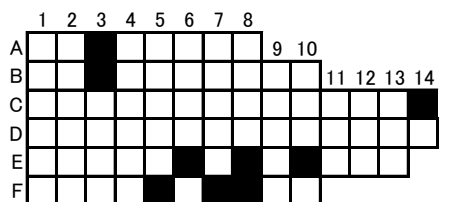

2005

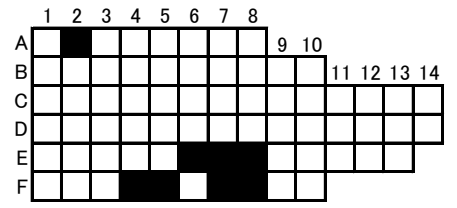

2006

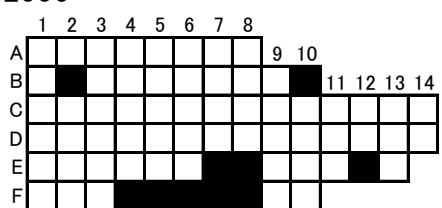

2007

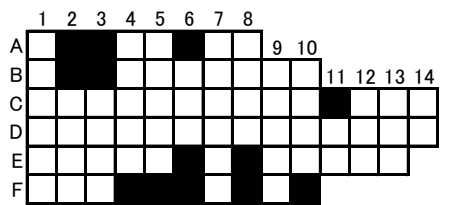

2008

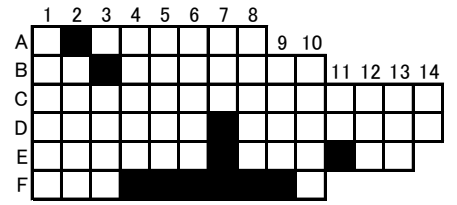

2009

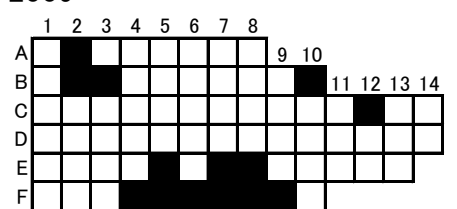

2010

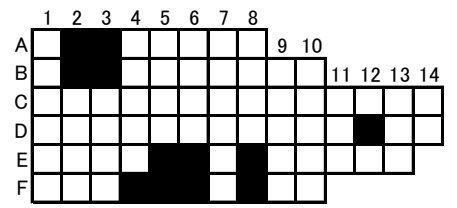



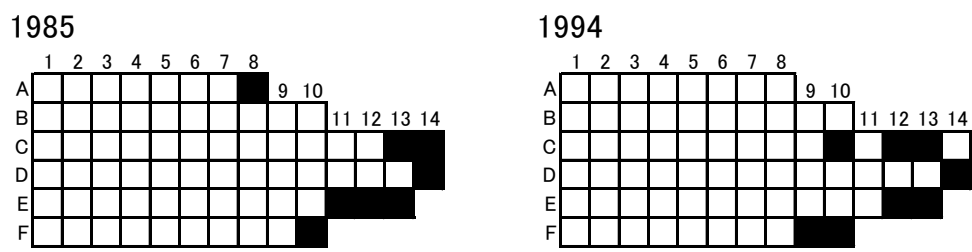

2003

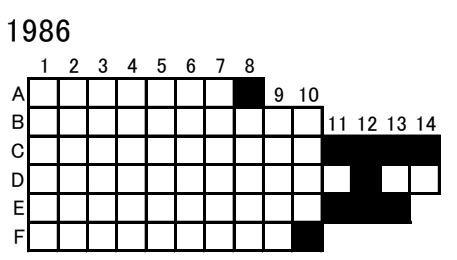

1995
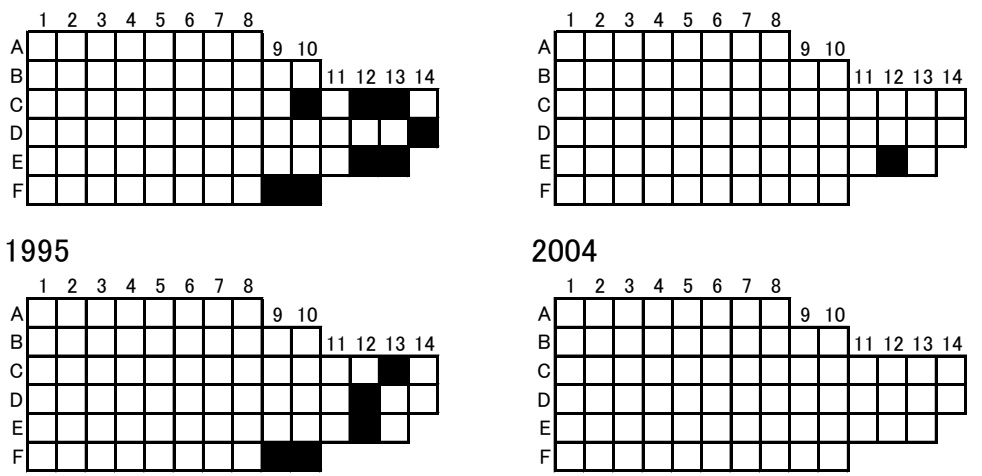

2004

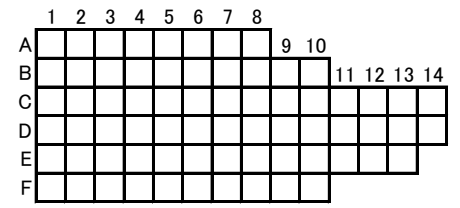

1987

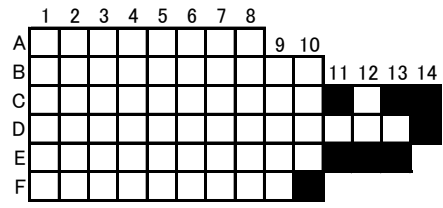

1996

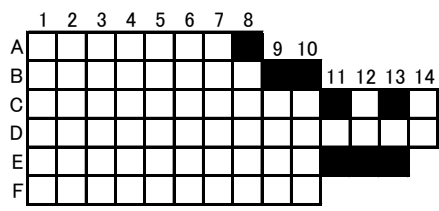

2005

1988

1997
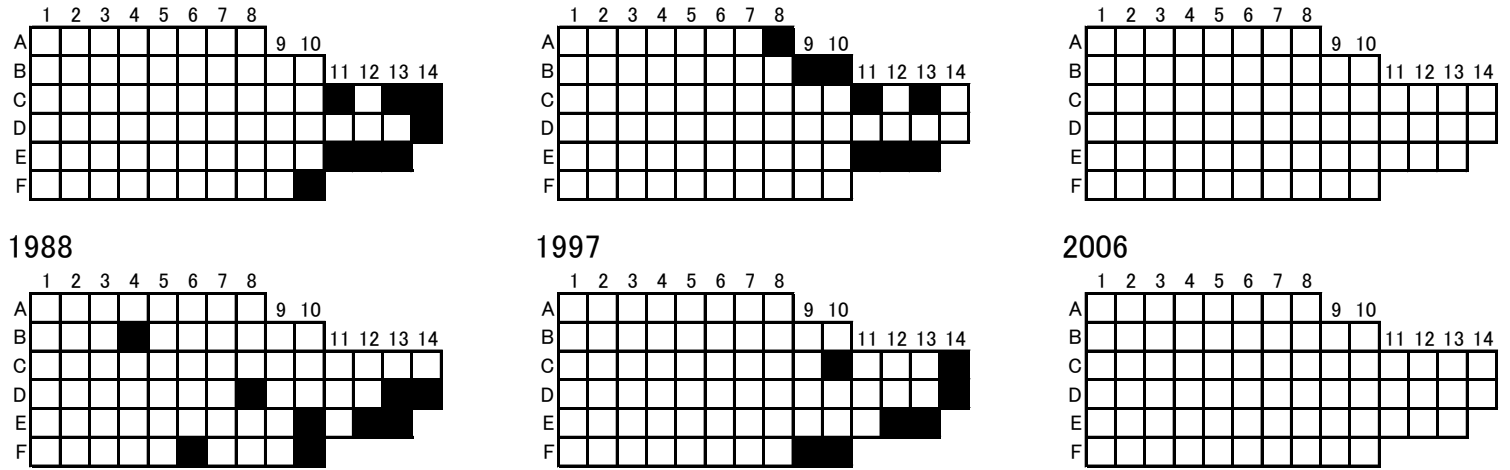

2006

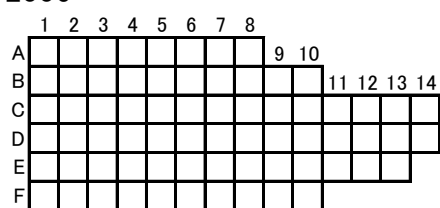

1989

1998
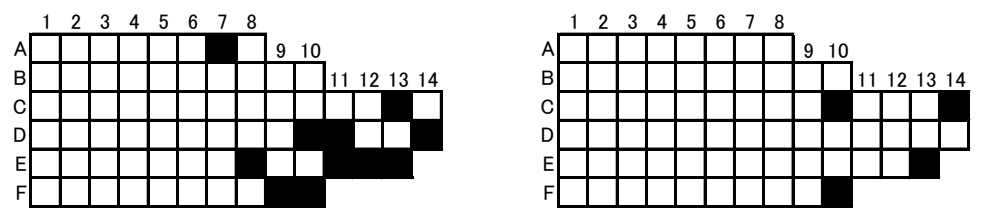

2007
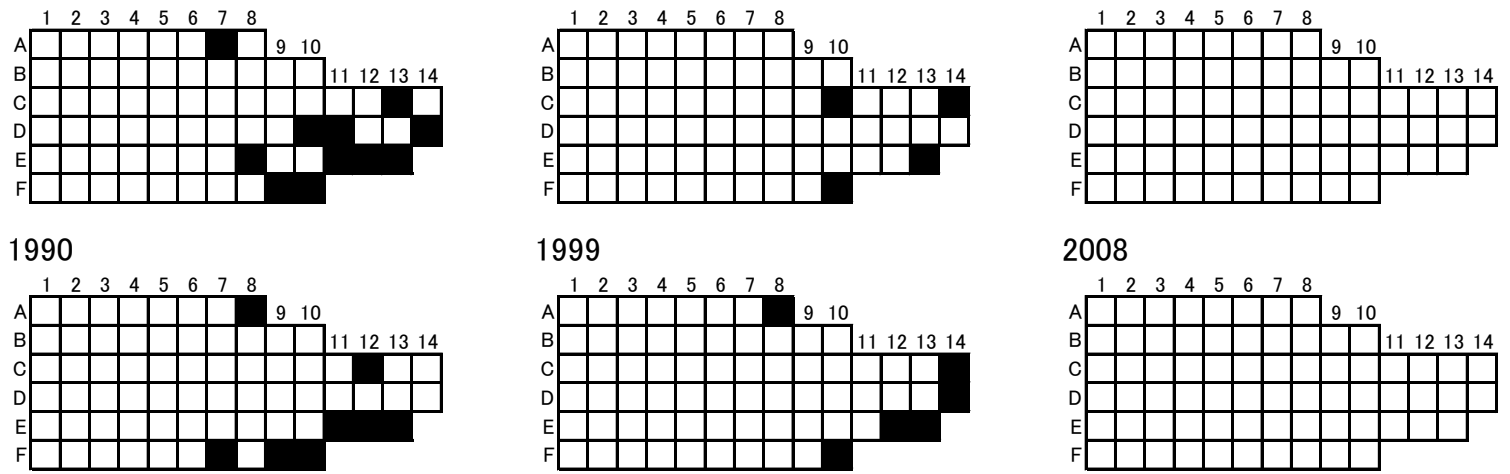

1999

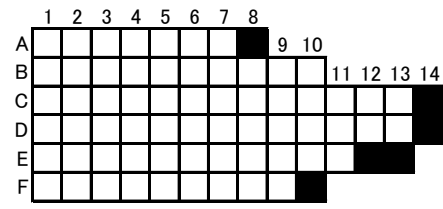

2008

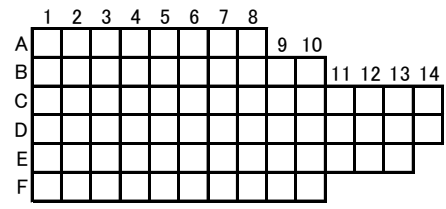

1991

2000

2009
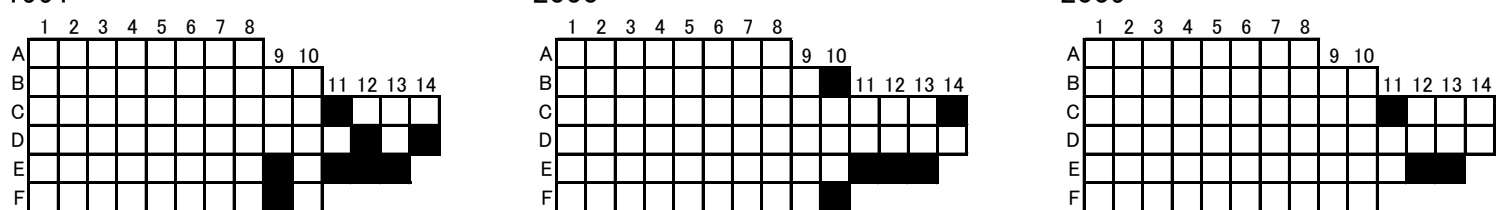

1992

2001
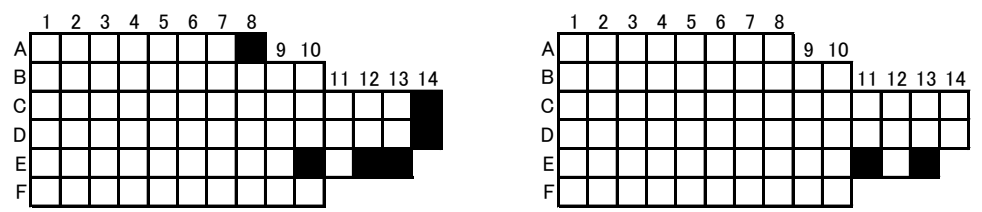

2010

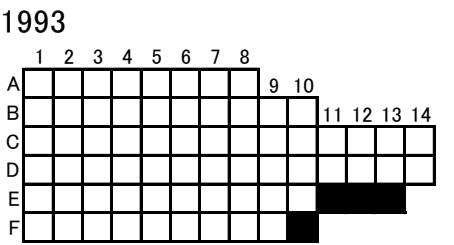

2002
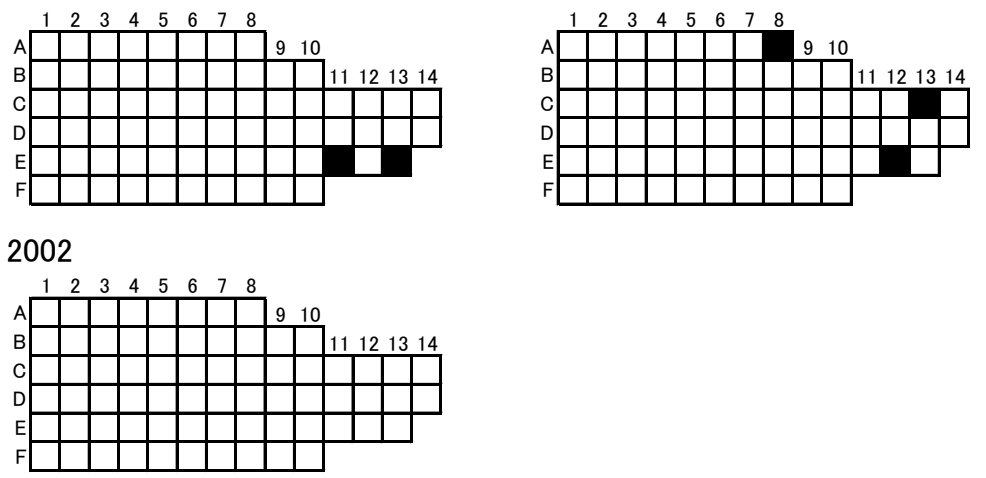
91 Dendropoma dragonella タッノコヘビガイ
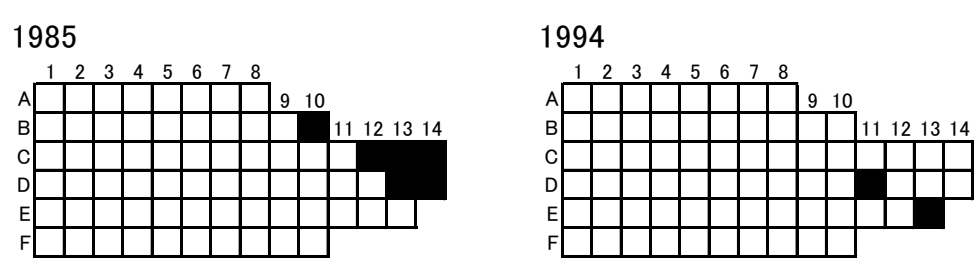

2003

1986

1995
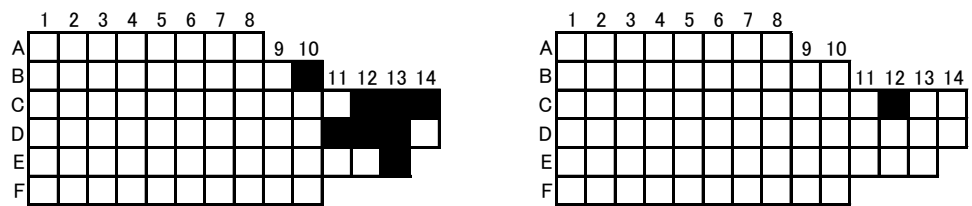

1987

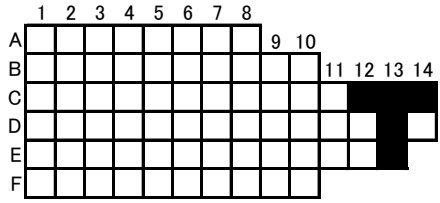

1996

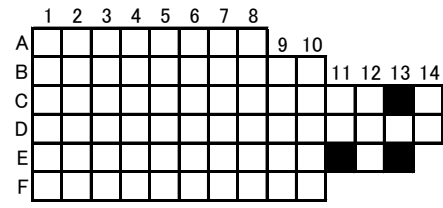

1988

1997
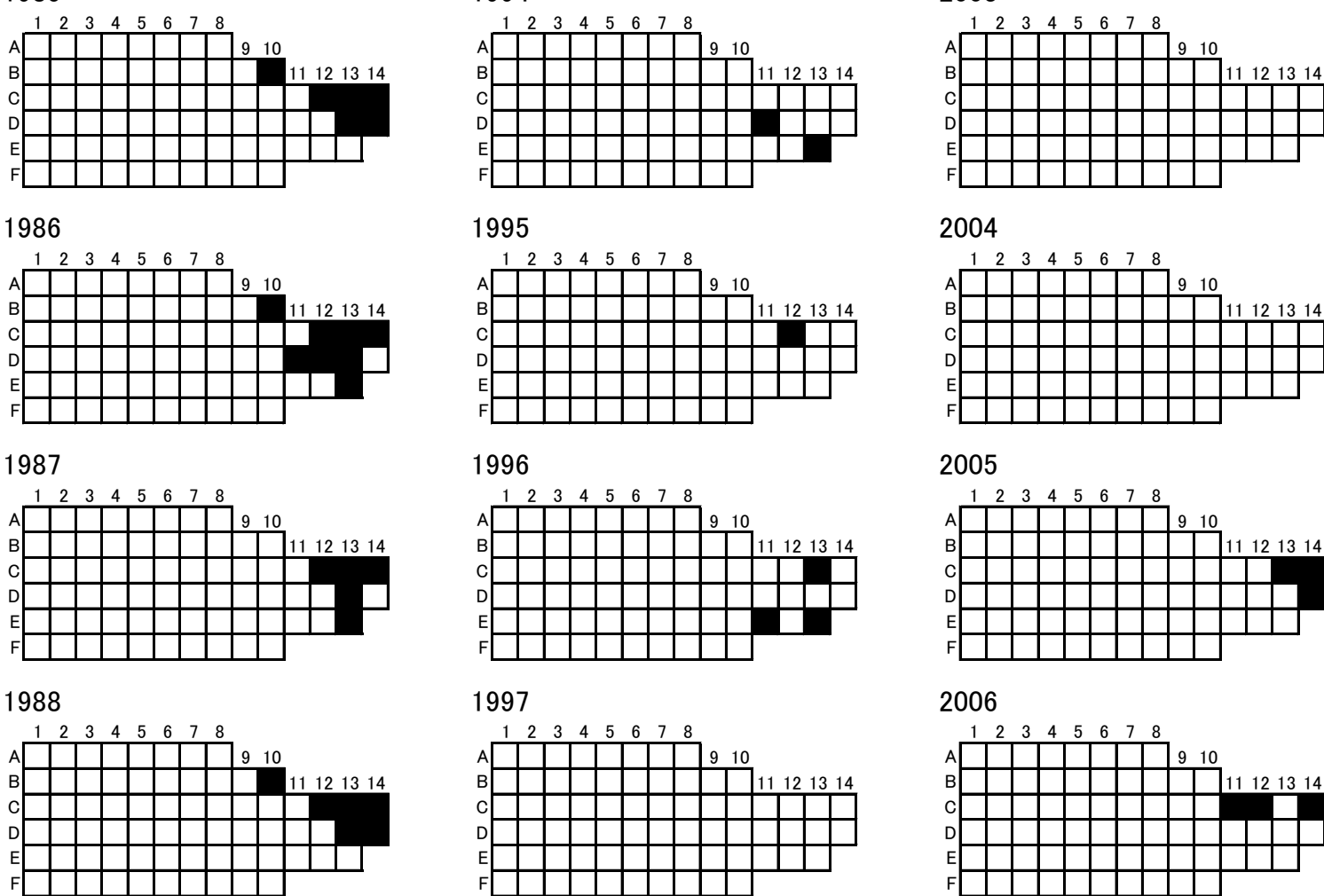

2004

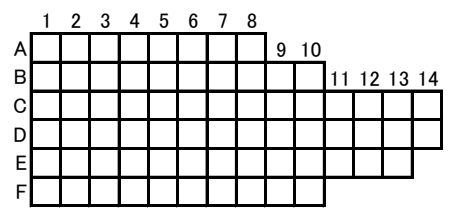

2005

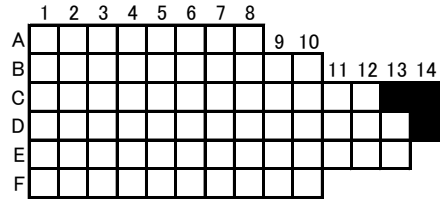

2006

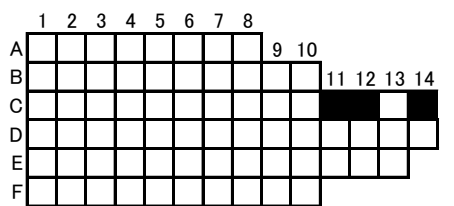

1989

1998
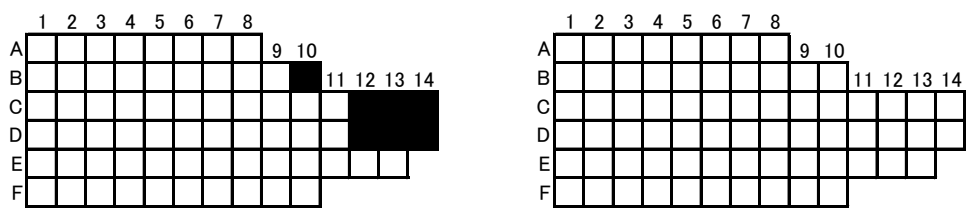

2007
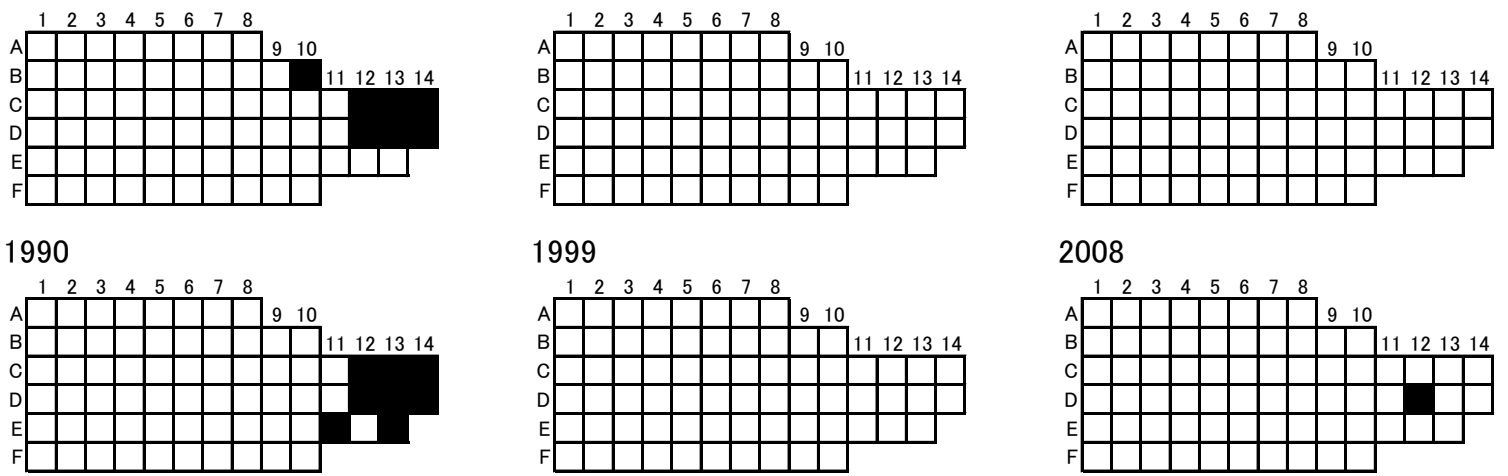

1999

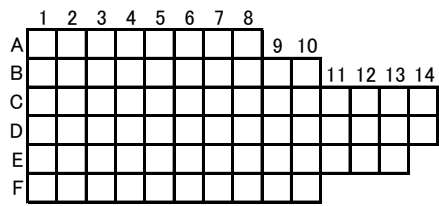

2008

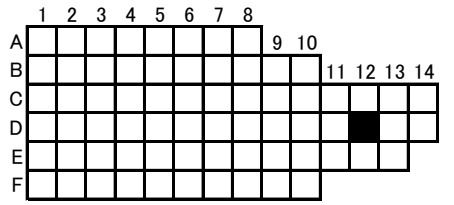

1991

2000
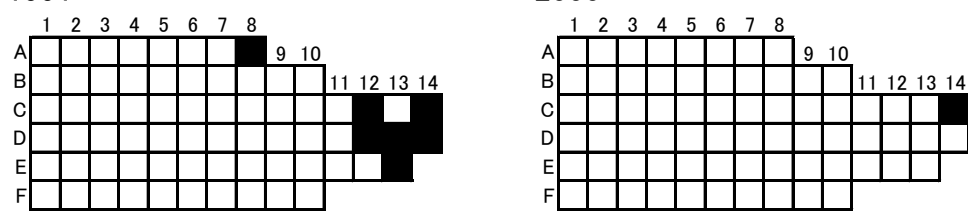

2009

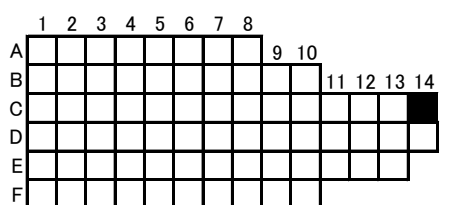

1992

2001
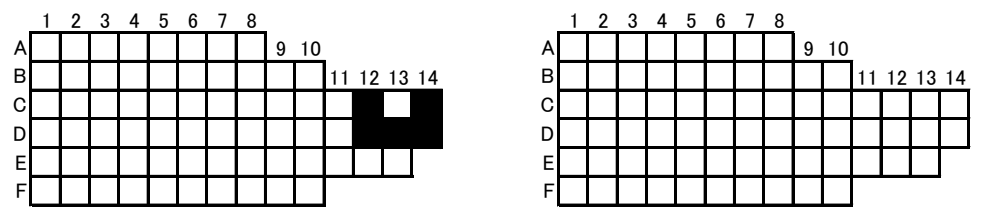

2010

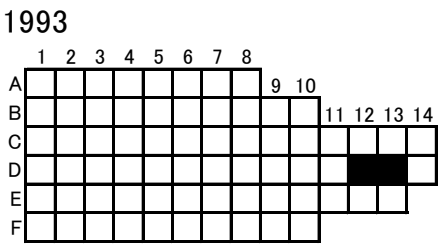

2002

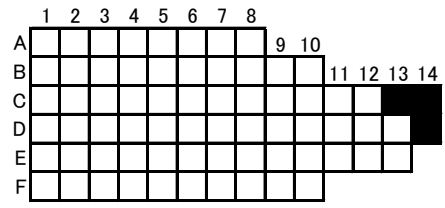

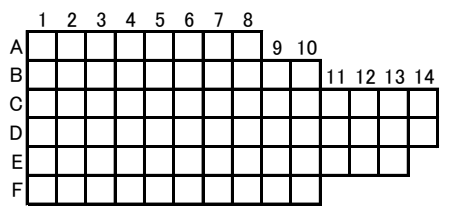


94 Serpulorbis imbricatus オオヘビガイ

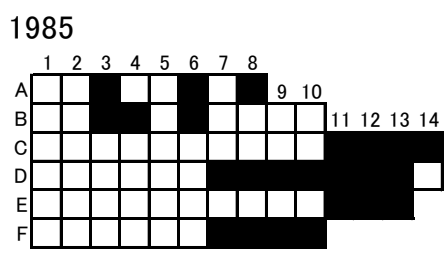

1994

2003
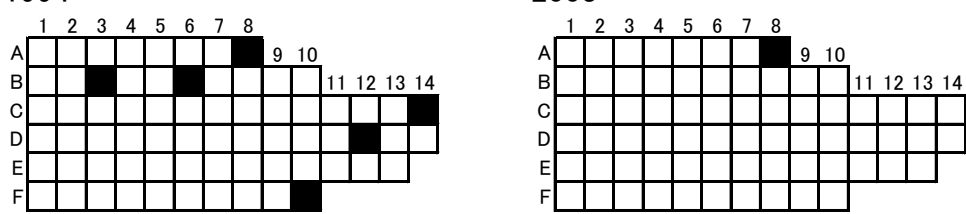

1986

1995
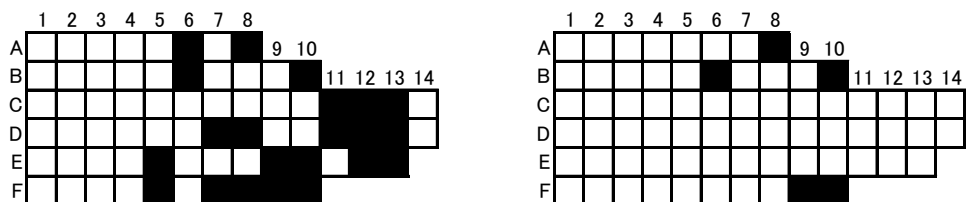

2004

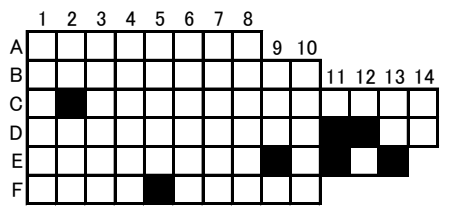

1987

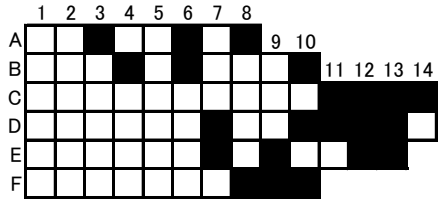

1996

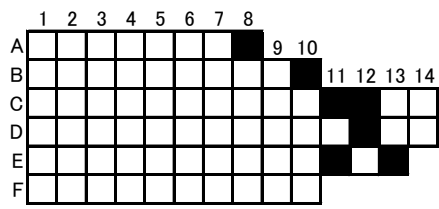

2005

1988

1997
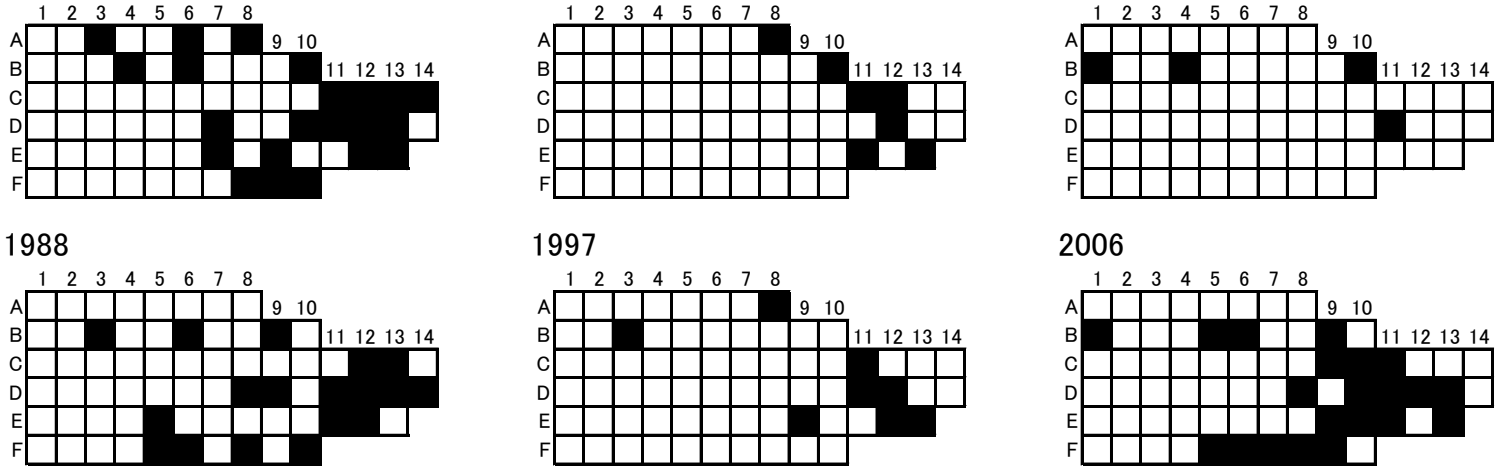

1998

1989

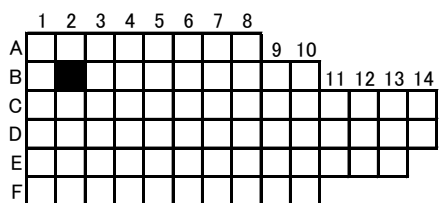

2006
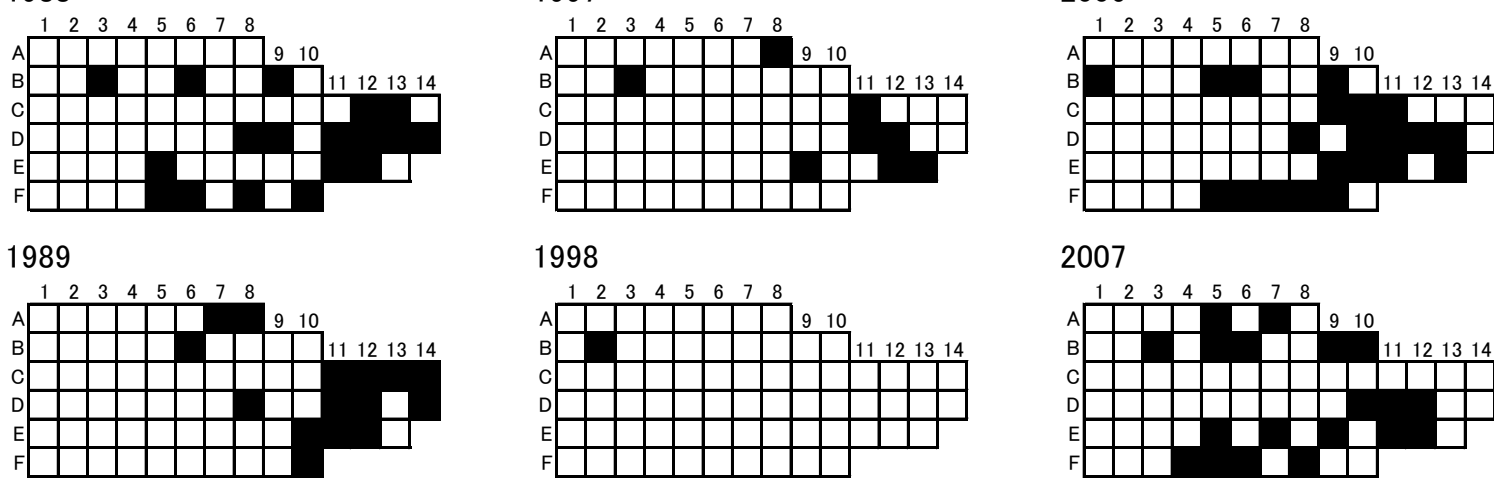

1999
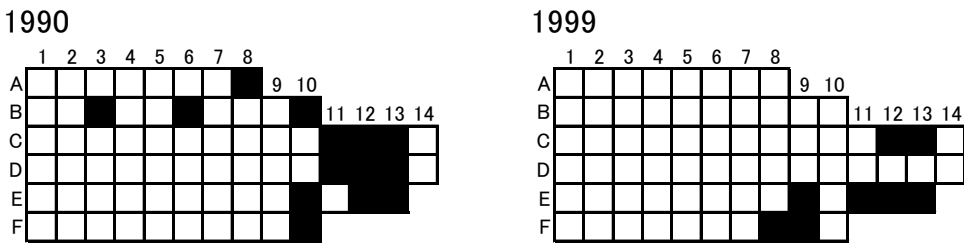

2007

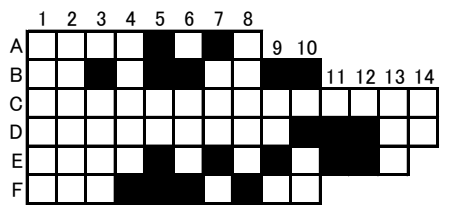

2008

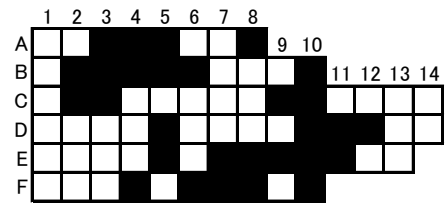

1991

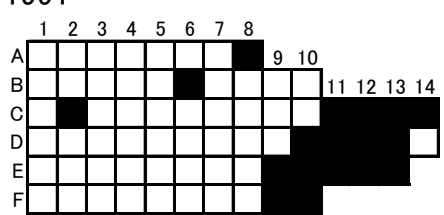

2000

2009
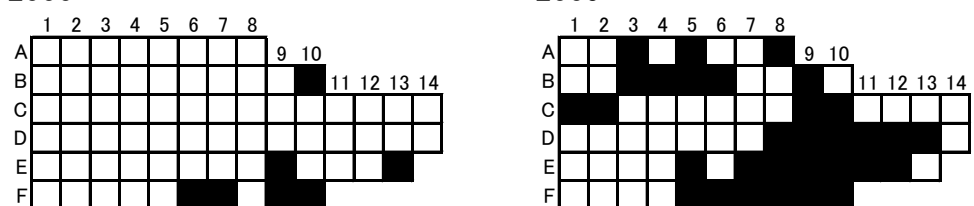

1992

2001
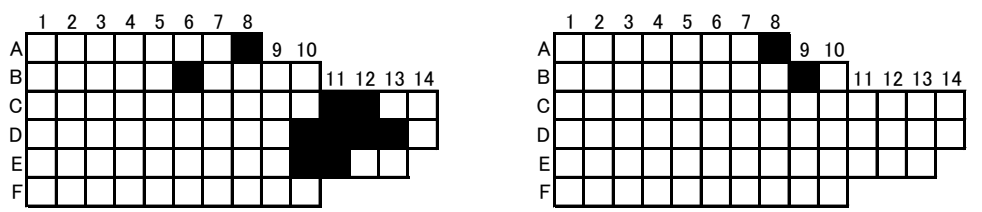

2010
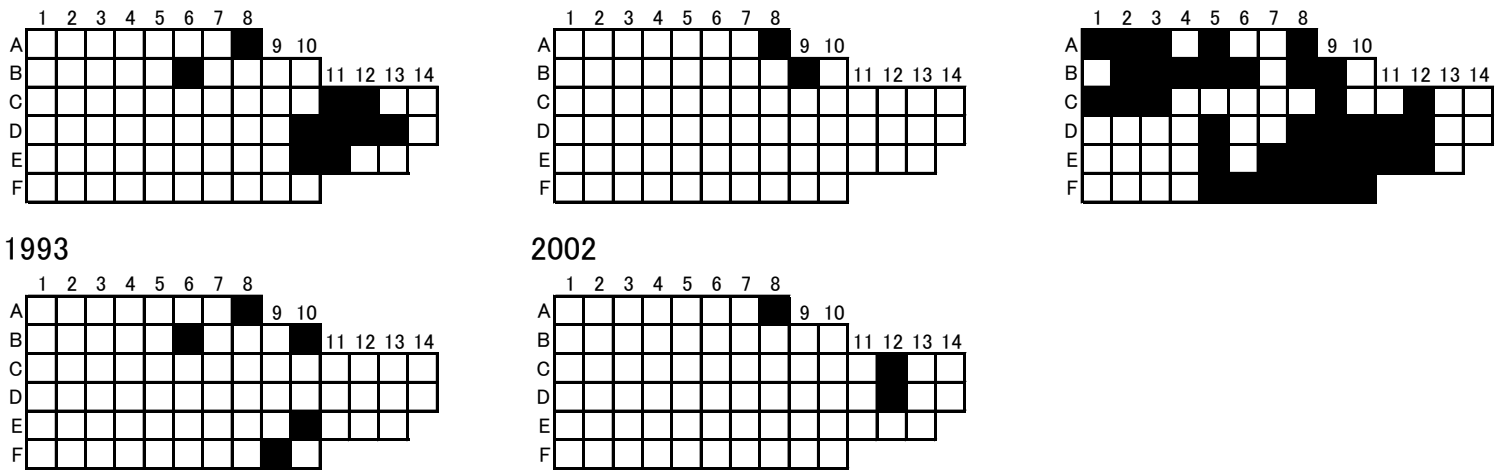

2002

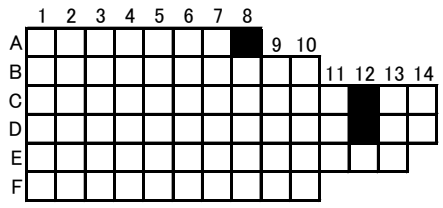



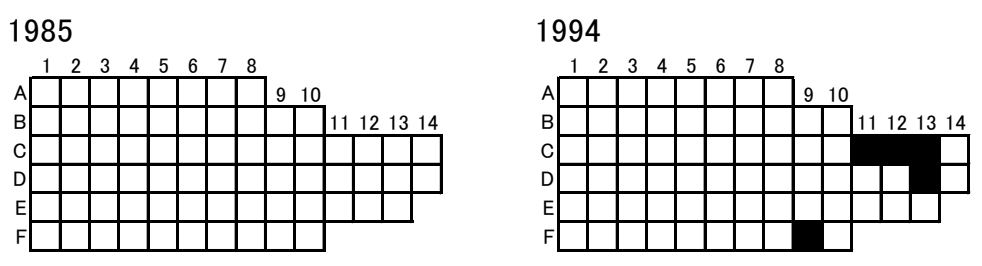

2003

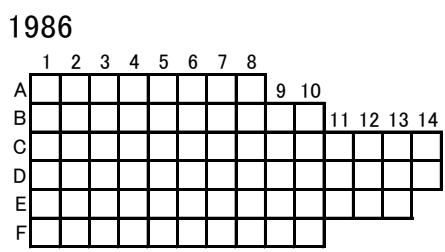

1995
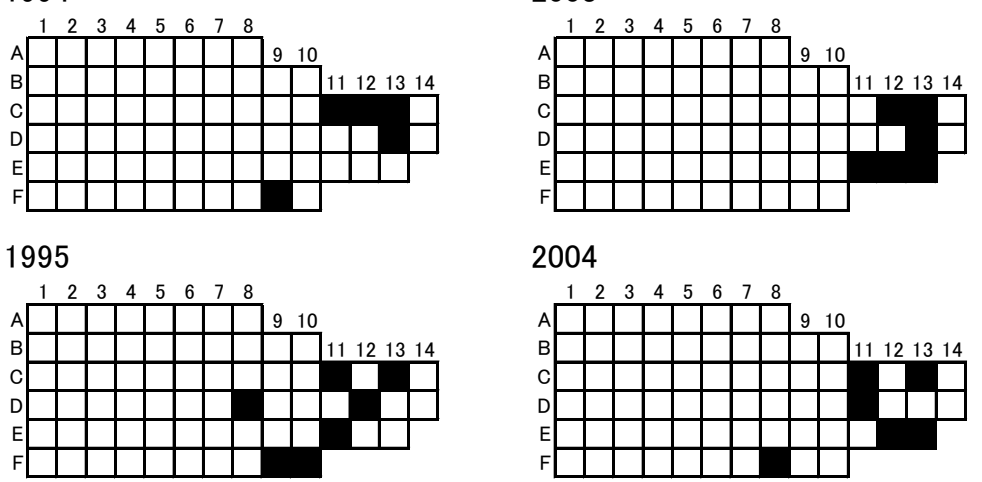

2004

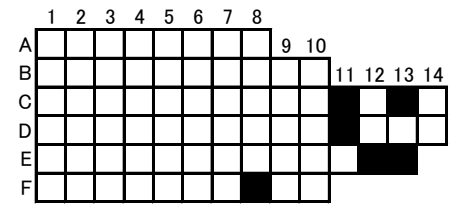

1987

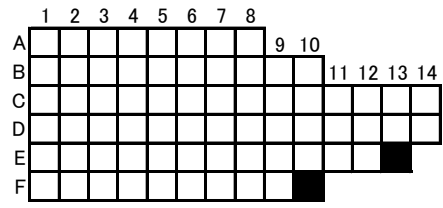

1996

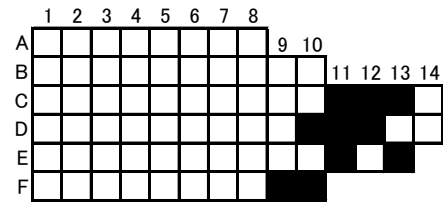

2005

1988

1997
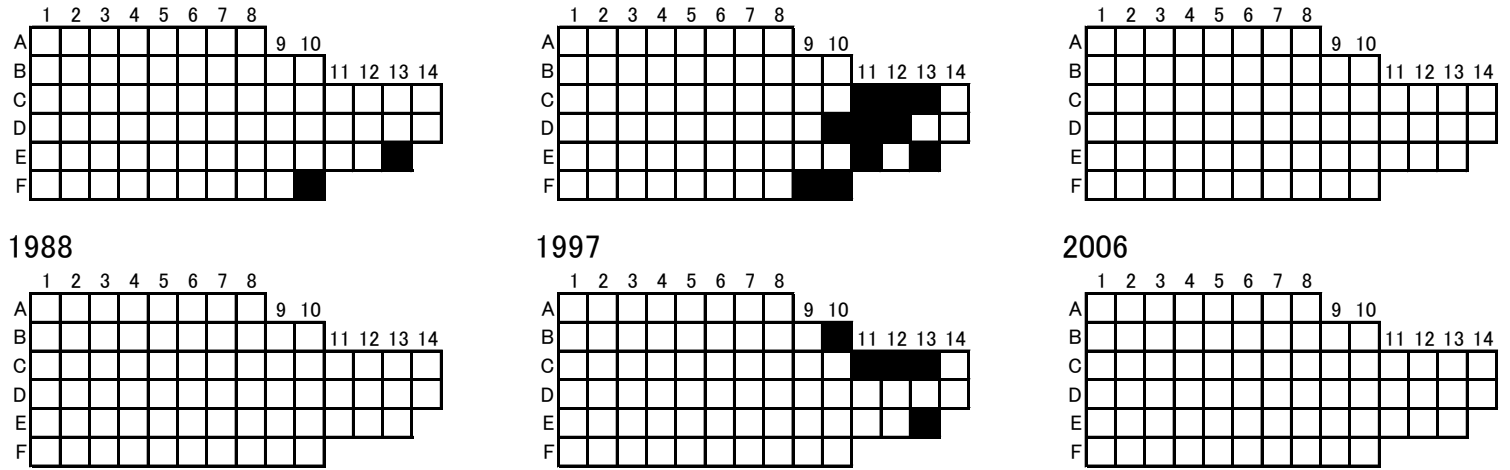

2006

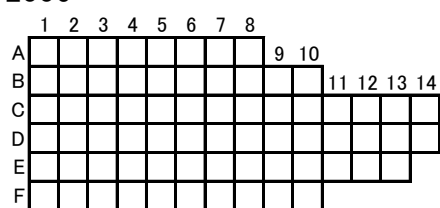

1989

1998
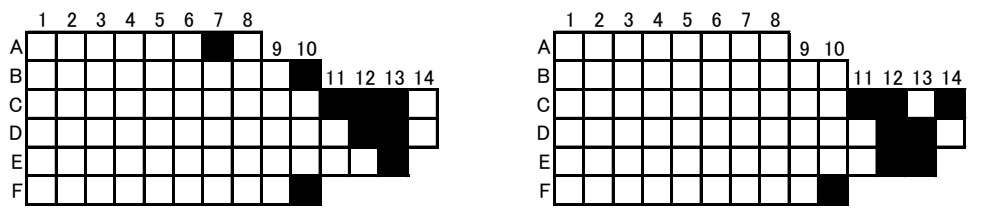

2007
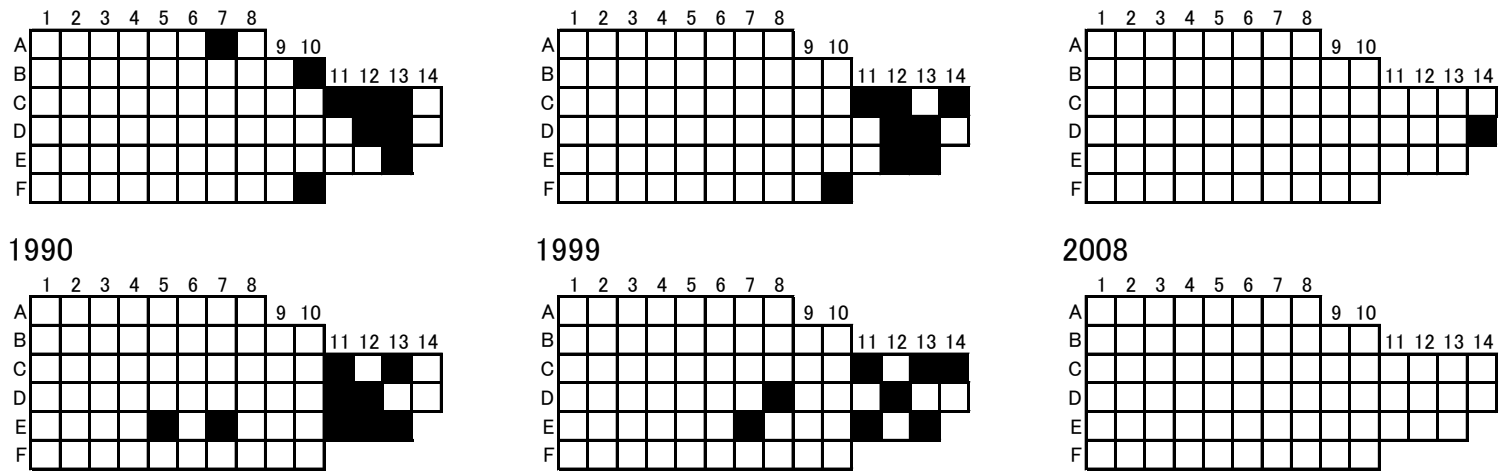

1999

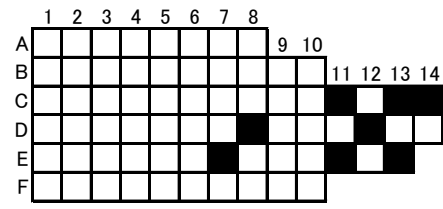

2008

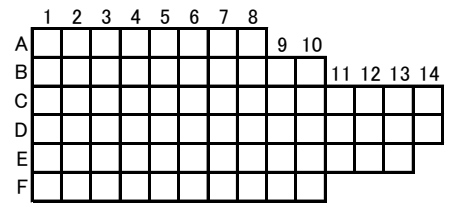

1991

2000

2009
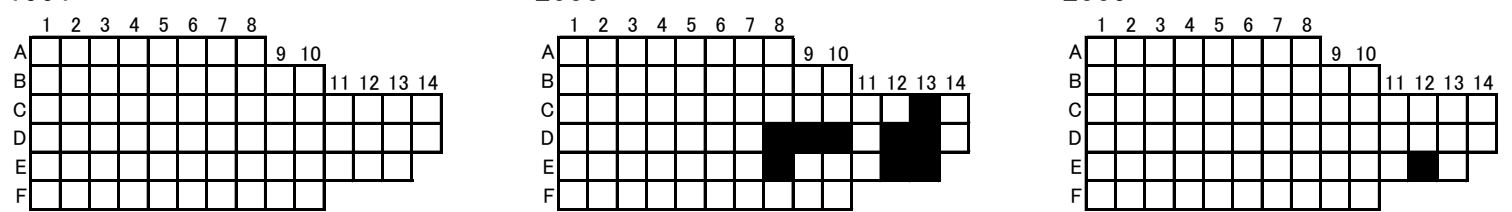

1992

2001
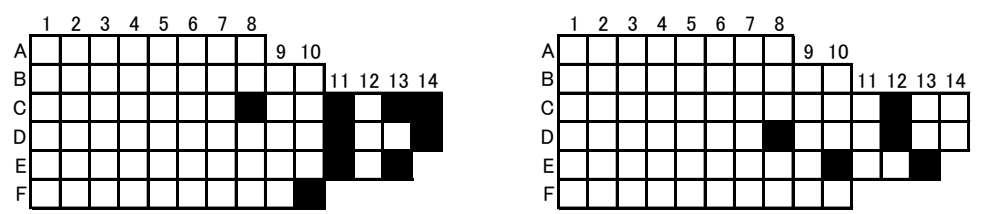

2010

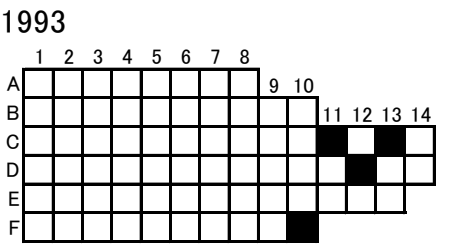

2002

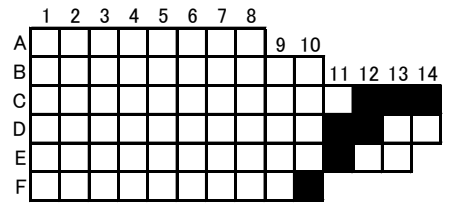

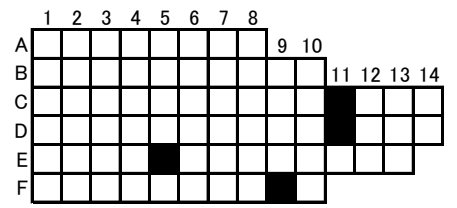


103 Cypraea gracilis

1985

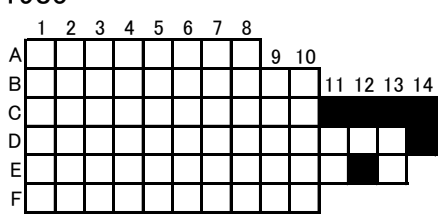

1986

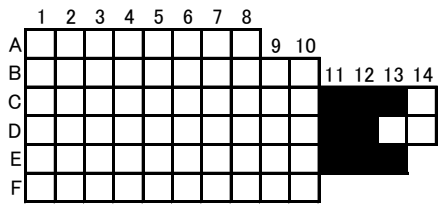

1987

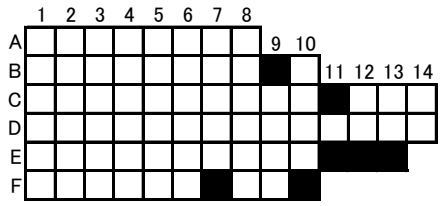

1988

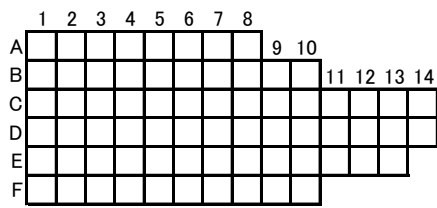

1989

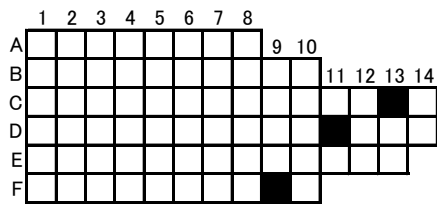

1990

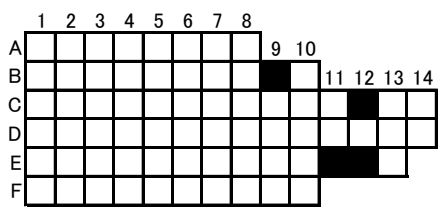

1991

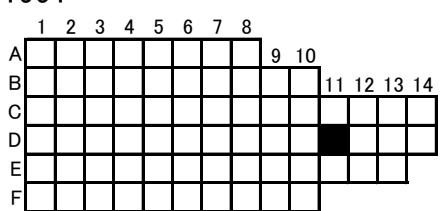

1992

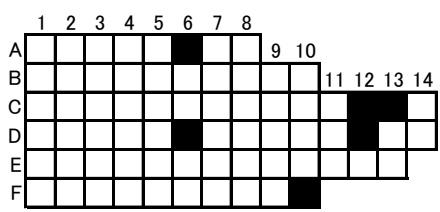

1993

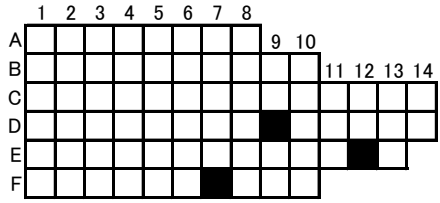

メダカラ

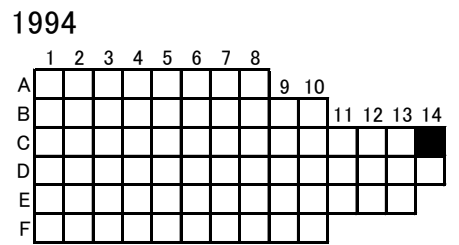

2003

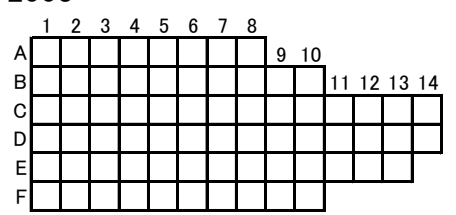

1995

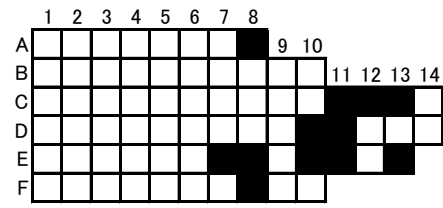

1996

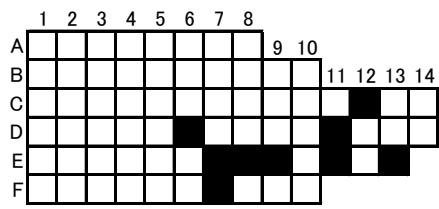

1997

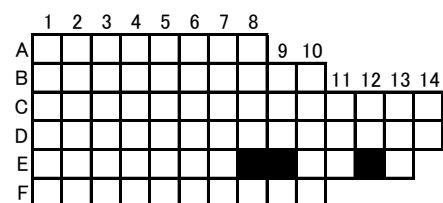

1998

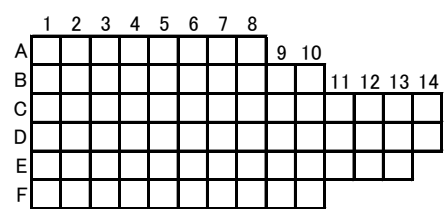

1999

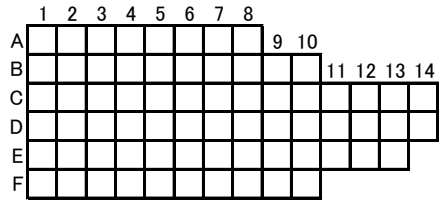

2000

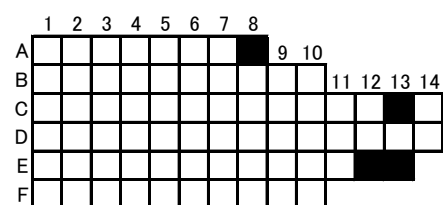

2001

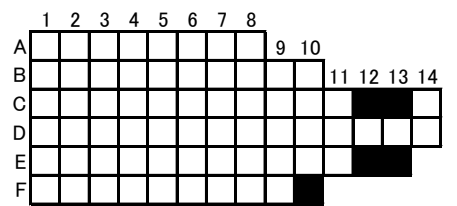

2002

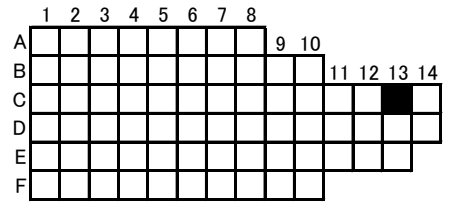

2004

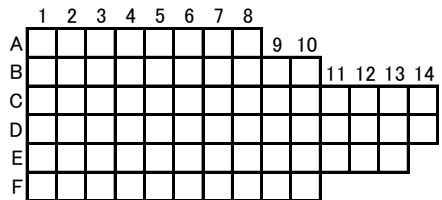

2005

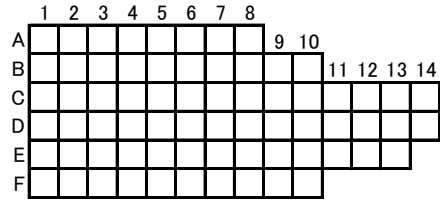

2006

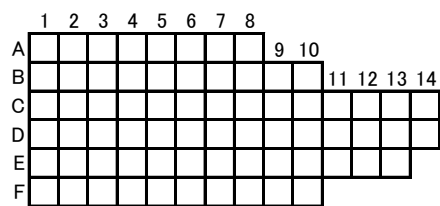

2007

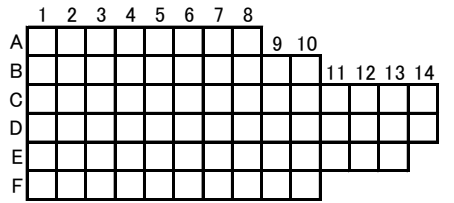

2008

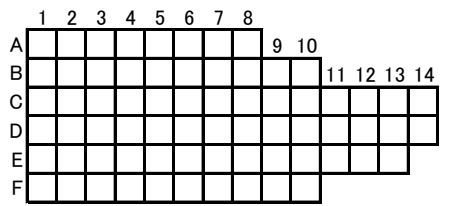

2009

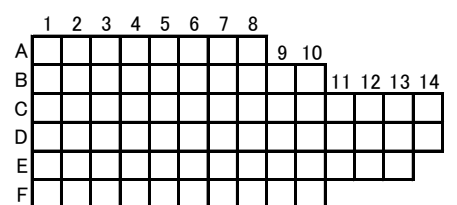

2010

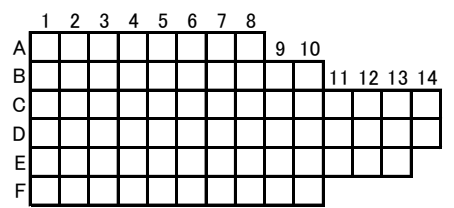


115 Gyroscala lamellosa ネジガイ
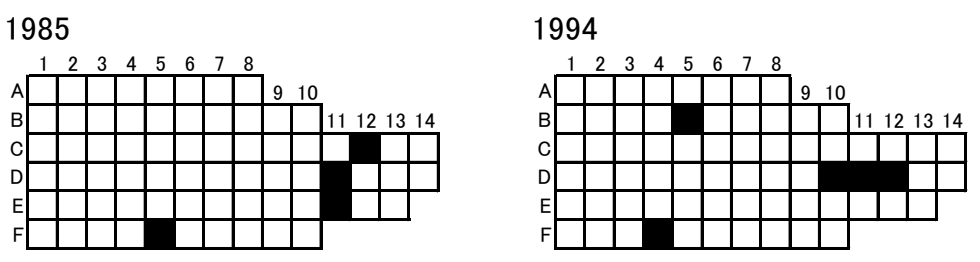

2003

1986

1995
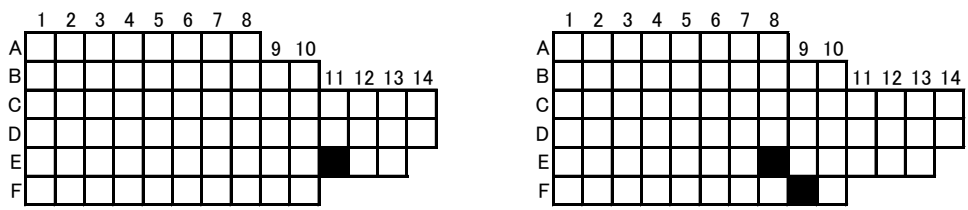

1987

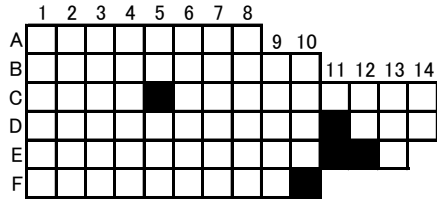

1996

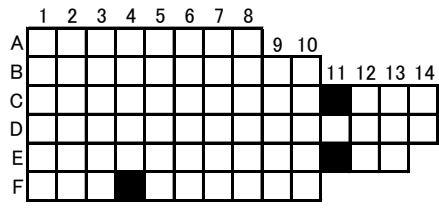

1988

1997
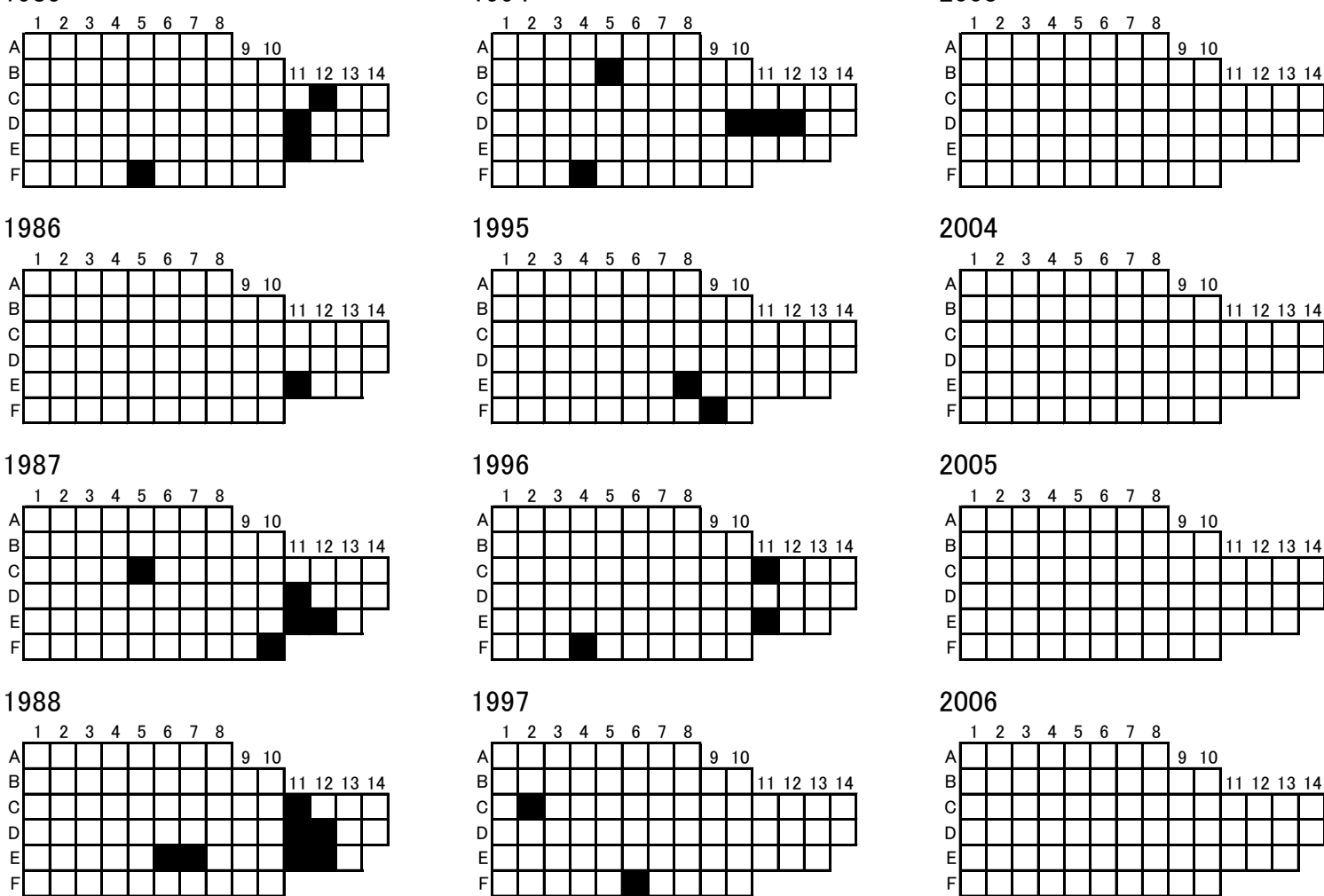

2004

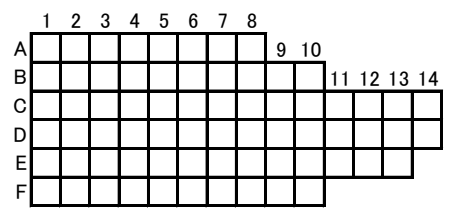

2005

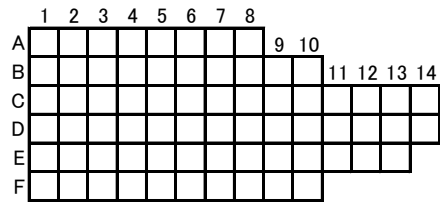

2006

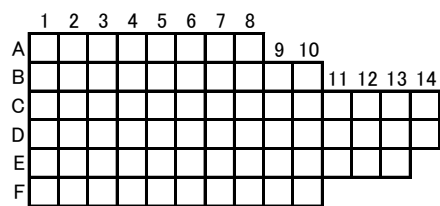

1989

1998
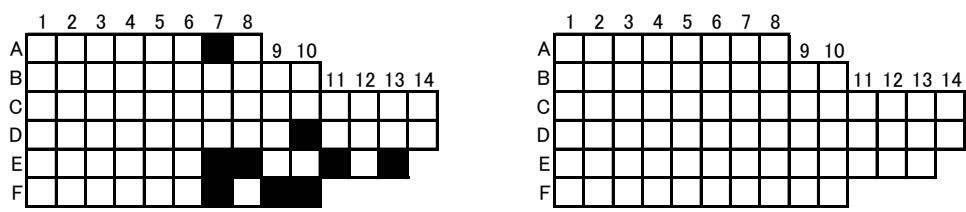

2007

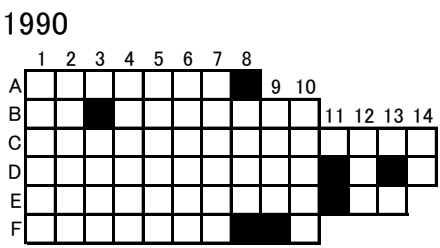

1999

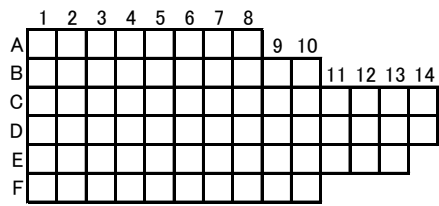

1991

2000
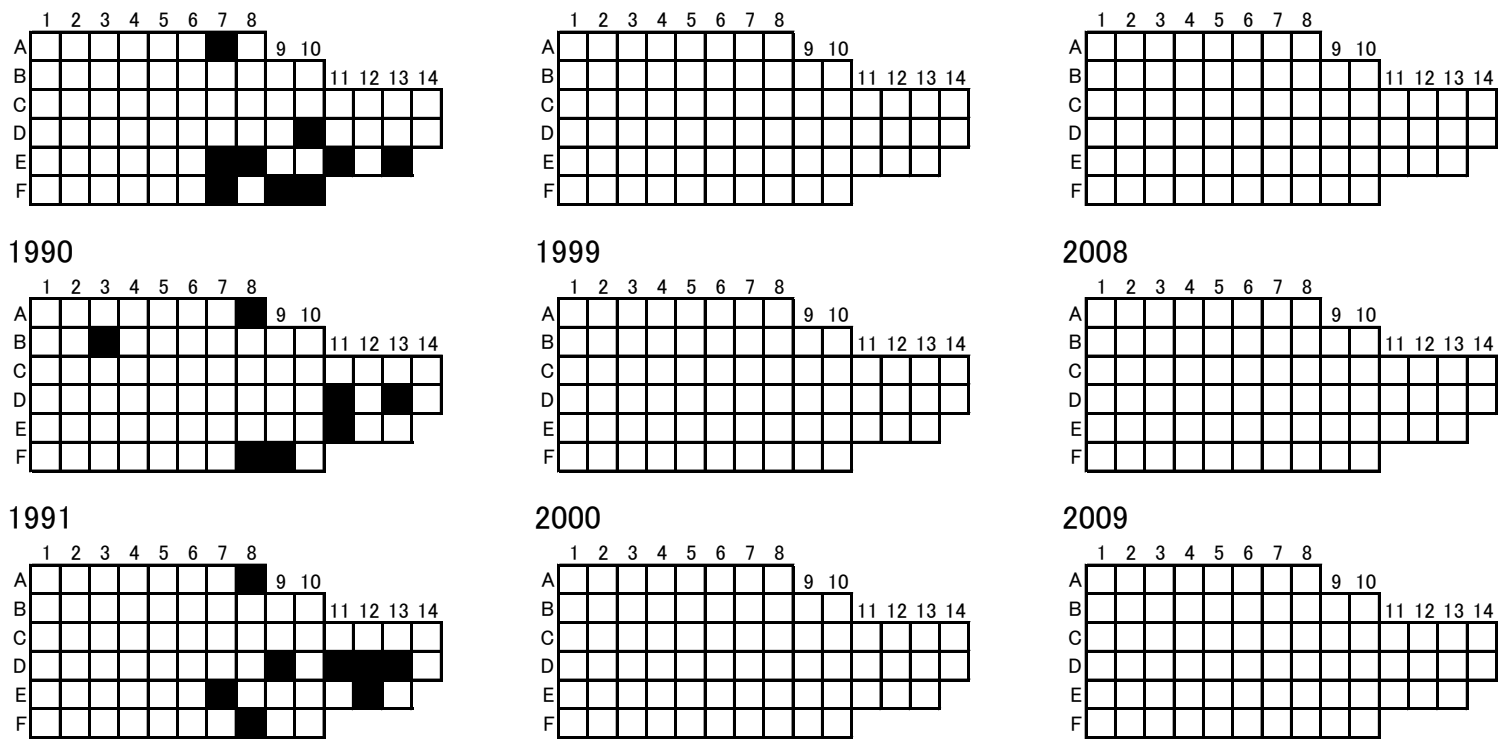

2008

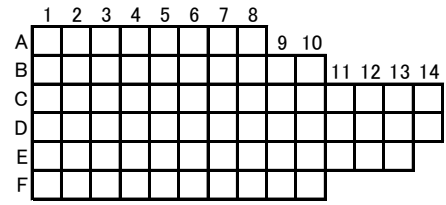

2009

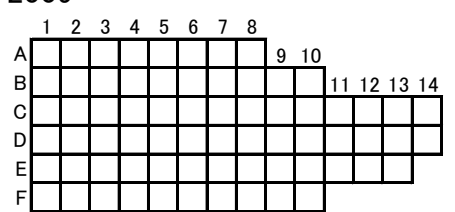

1992

2001
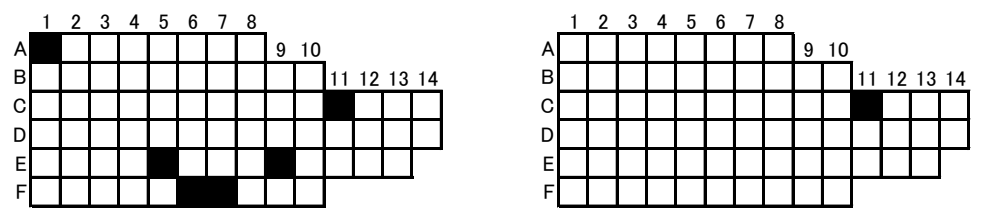

2010

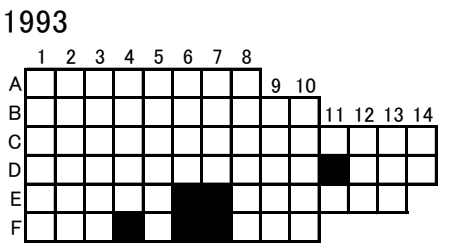

2002

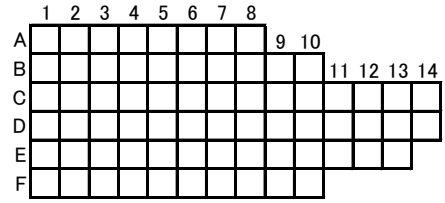

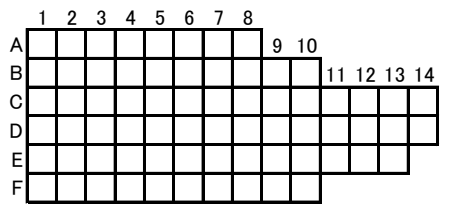


116 Epitonium japonicum
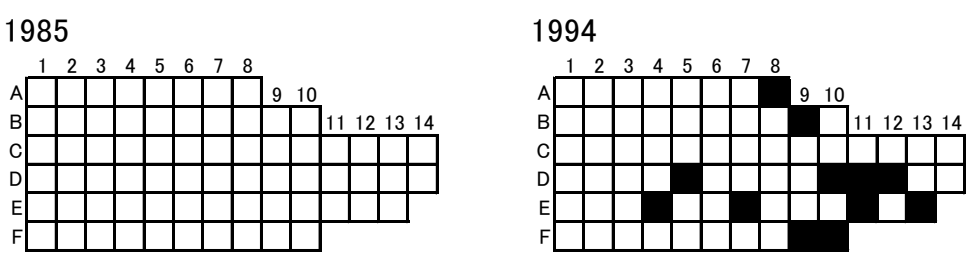

2003

1986

1995
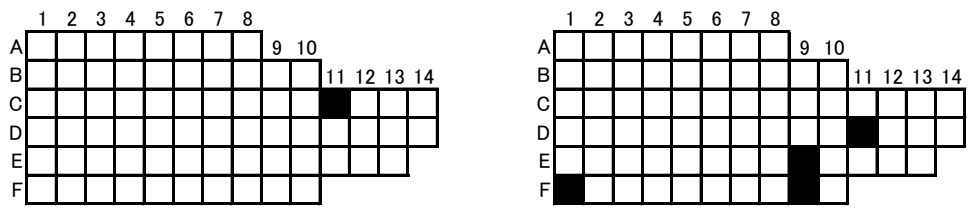

1987

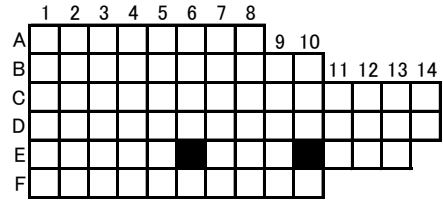

1996
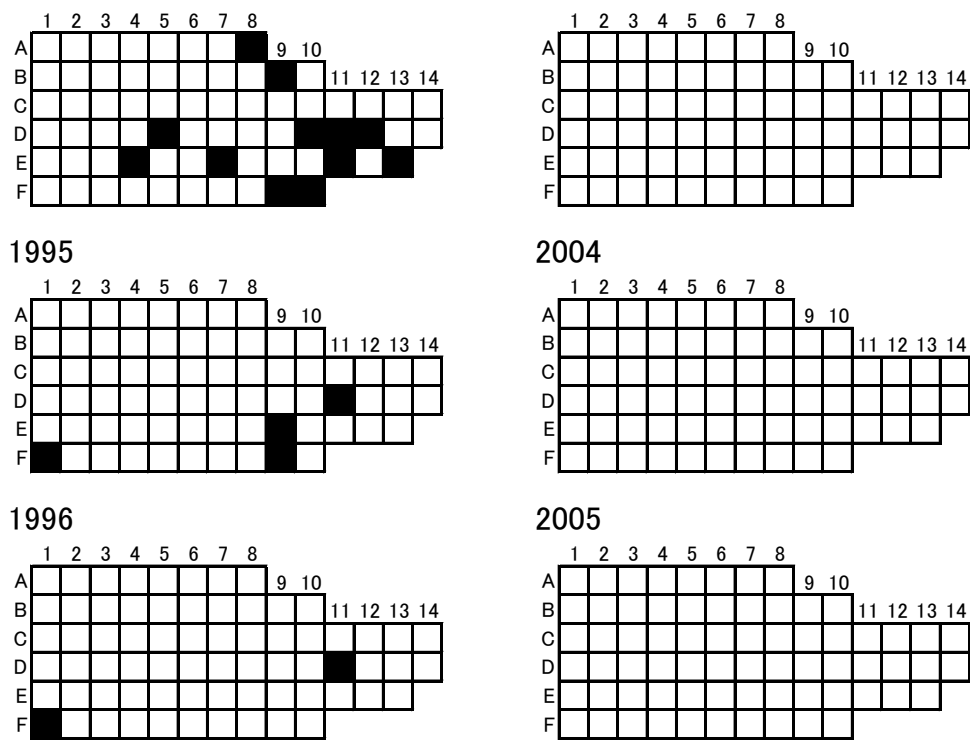

2004

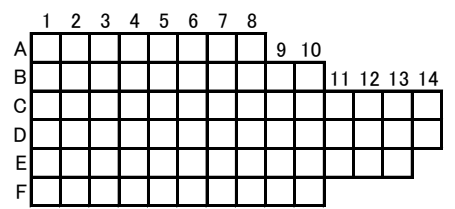

2005

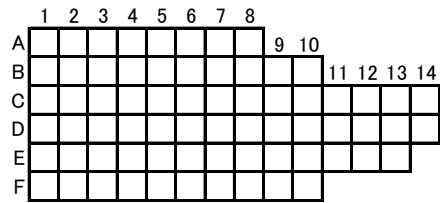

1988

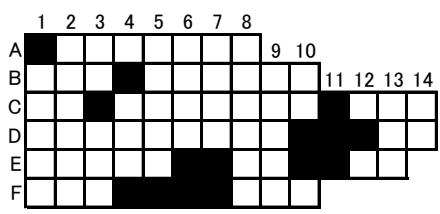

1997

2006
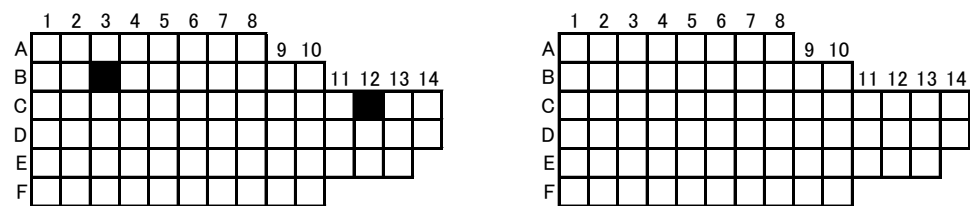

1989

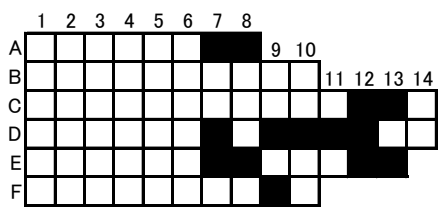

1998

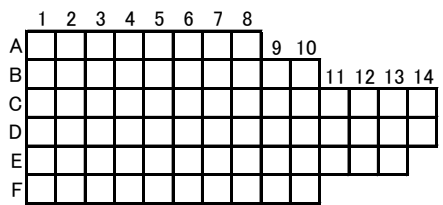

2007
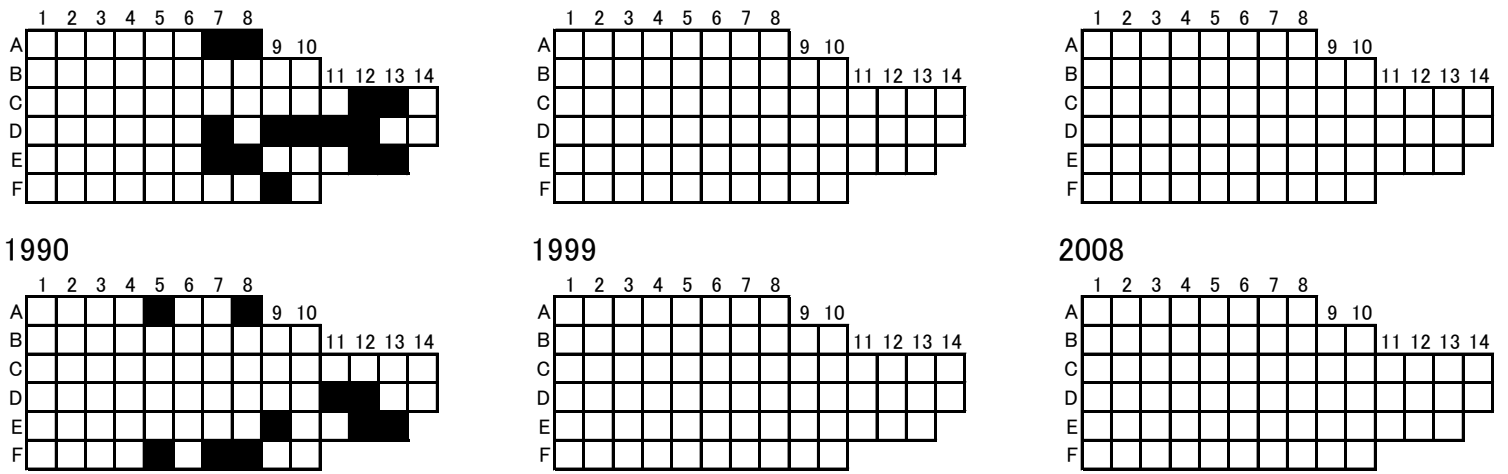

1999

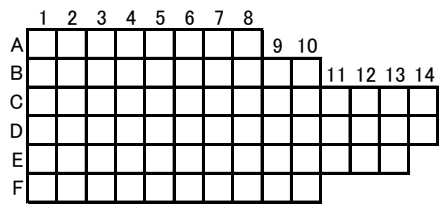

2008

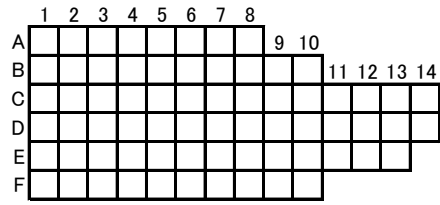

1991

2000
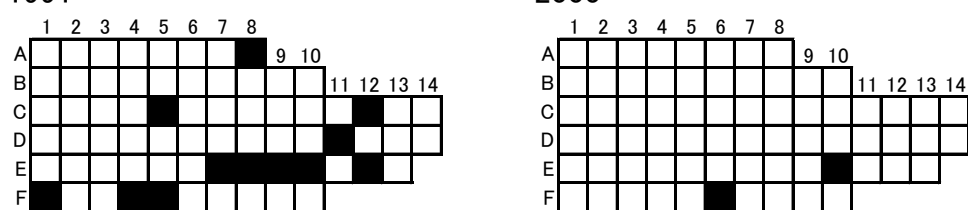

2009

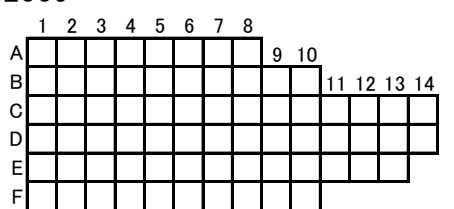

1992

2001
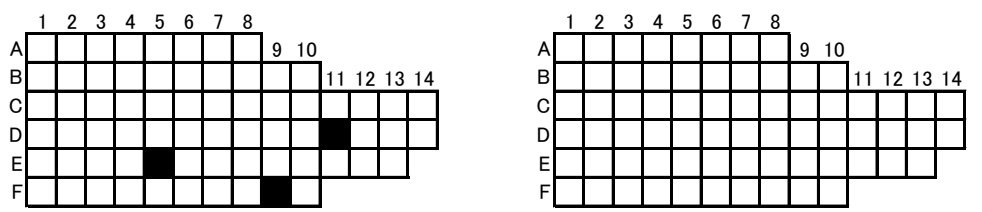

2010

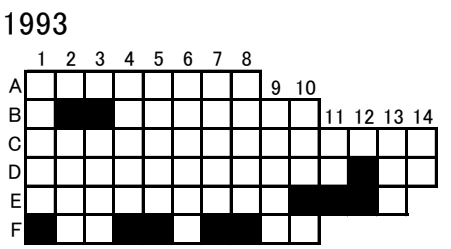

2002

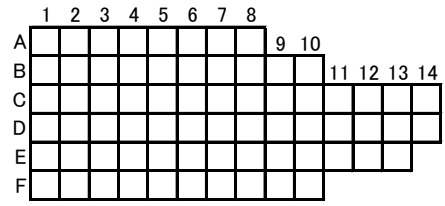

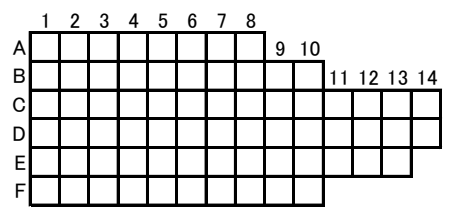


キンイロセトモノガイ

1985

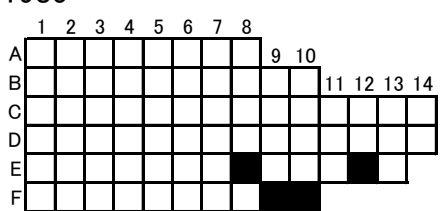

1986

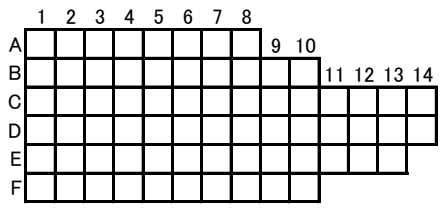

1987

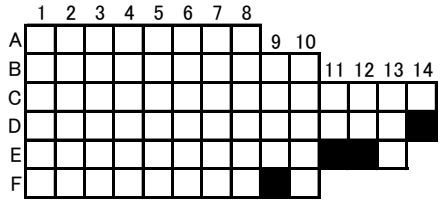

1988

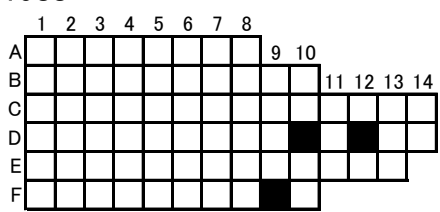

1989

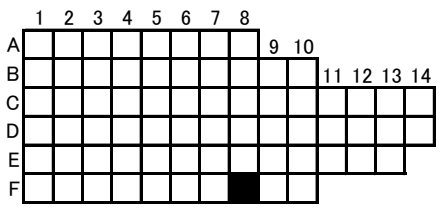

1990

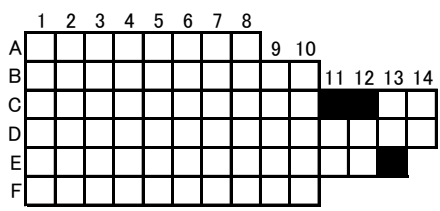

1991

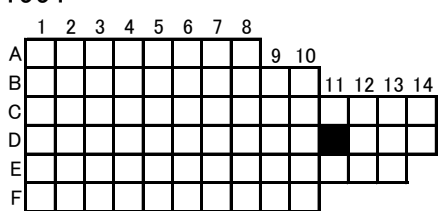

1992

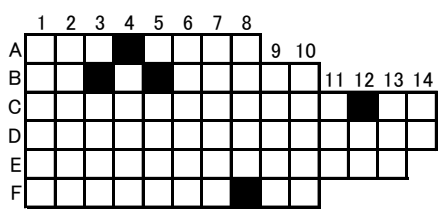

1993

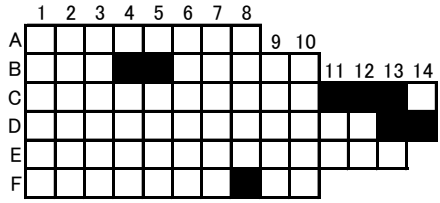

1994

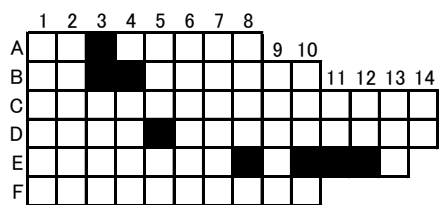

1995

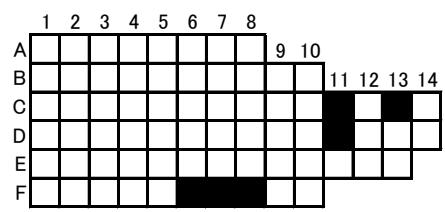

1996

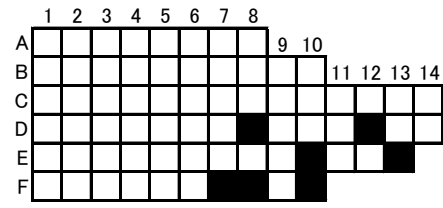

1997

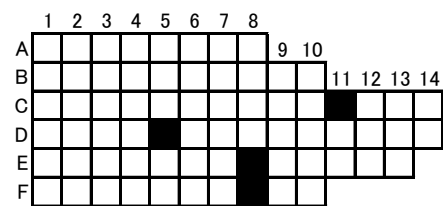

1998

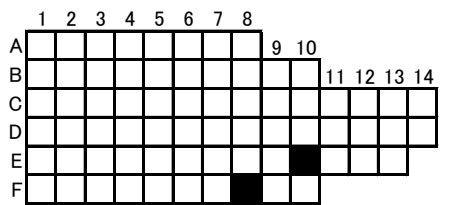

1999

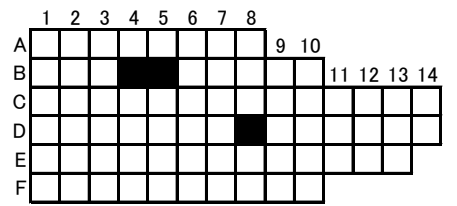

2000

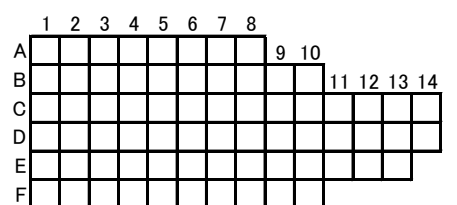

2001

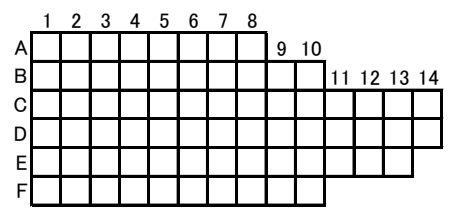

2002

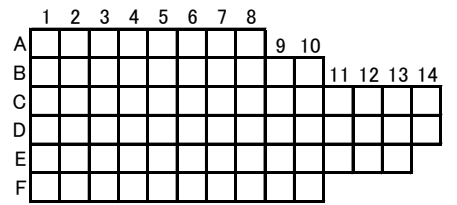

2003

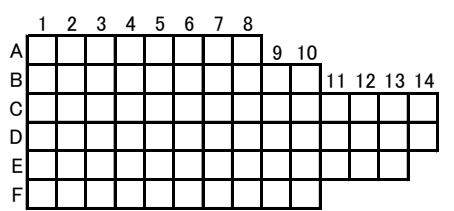

2004

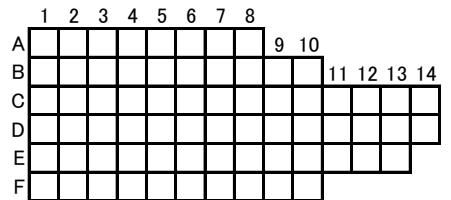

2005

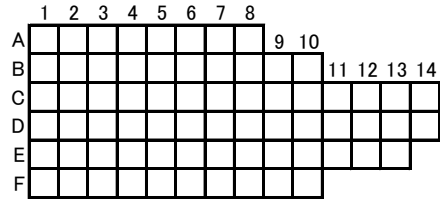

2006

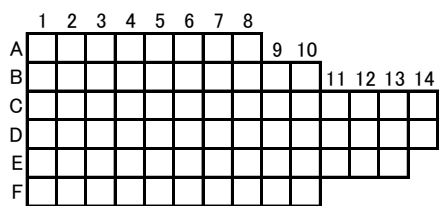

2007

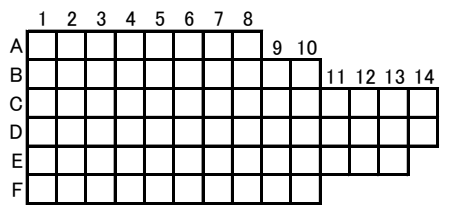

2008

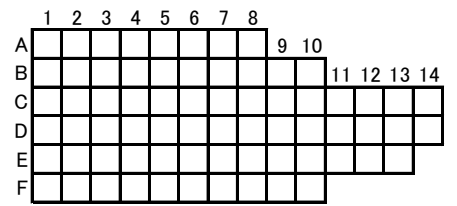

2009

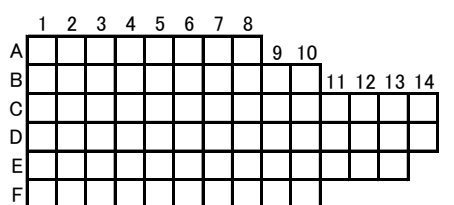

2010

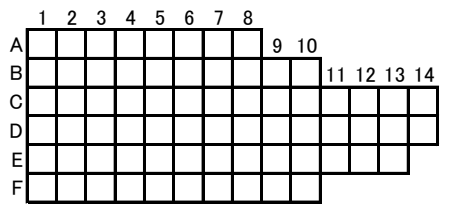


122 Cronia margariticola ウネレイシダマシ

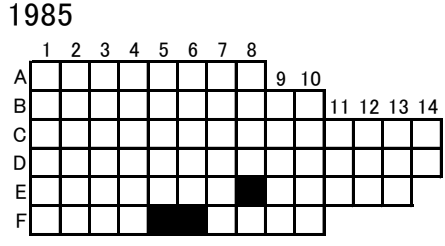

1986

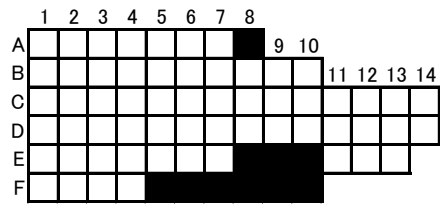

1987

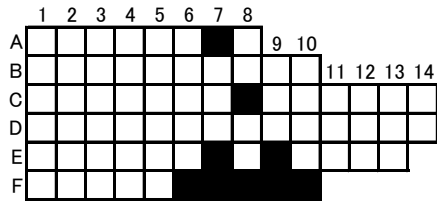

1988

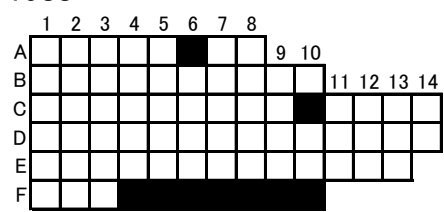

1989

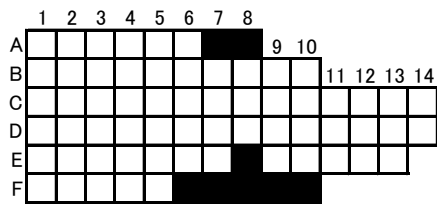

1990

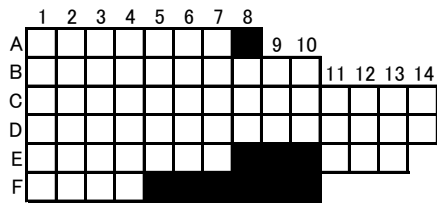

1991

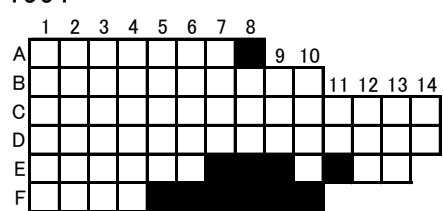

1992

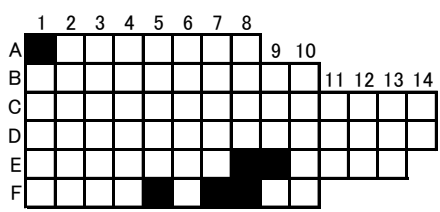

1993

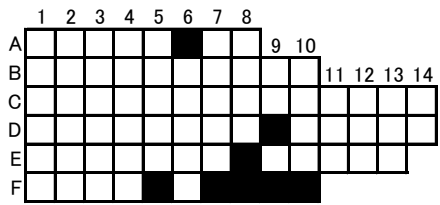

1994

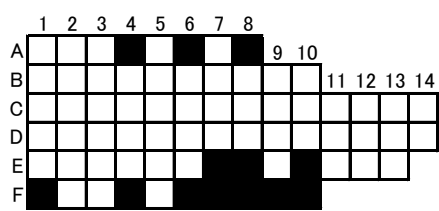

1995

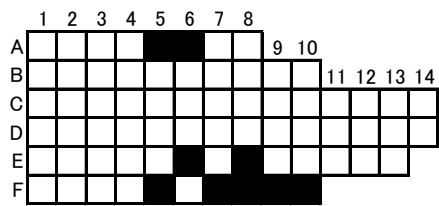

1996

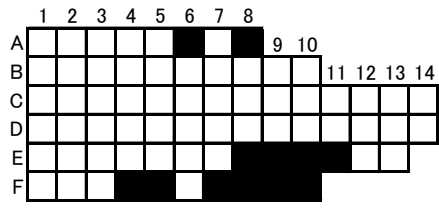

1997

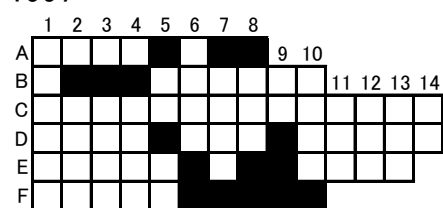

1998

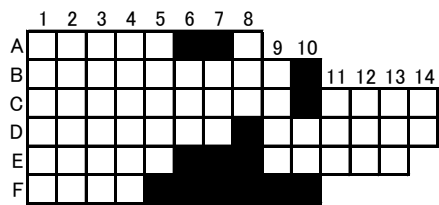

1999

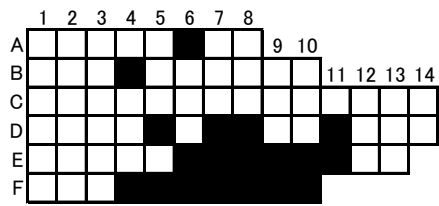

2000

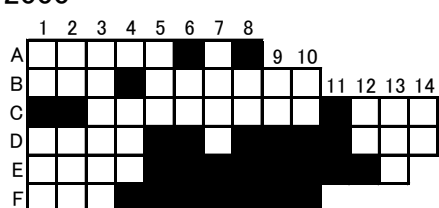

2001

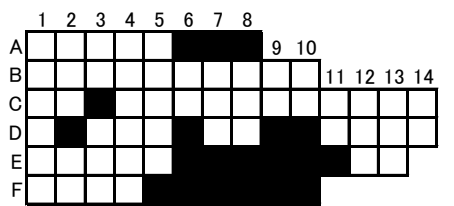

2002

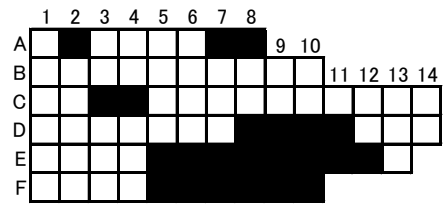

2003

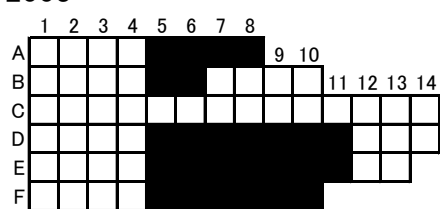

2004

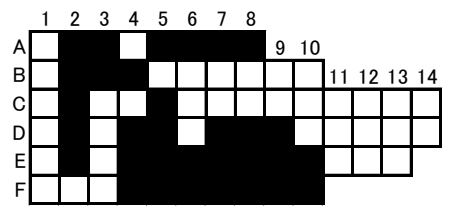

2005

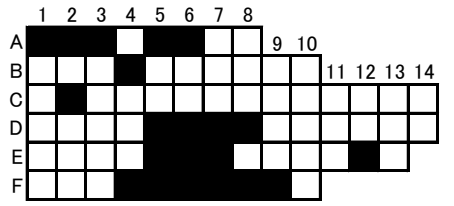

2006

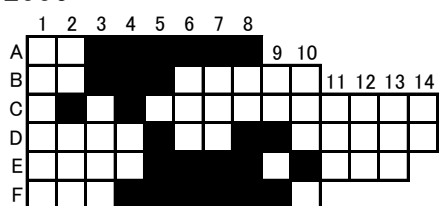

2007

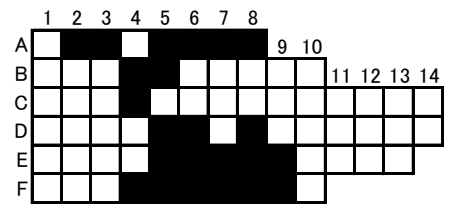

2008

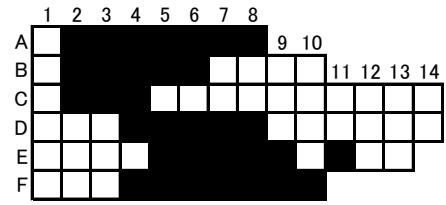

2009

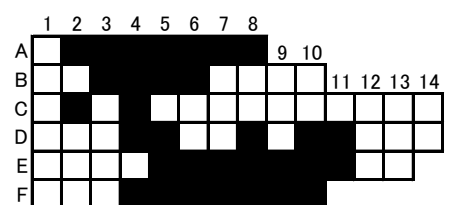

2010

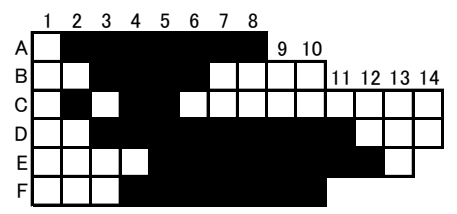




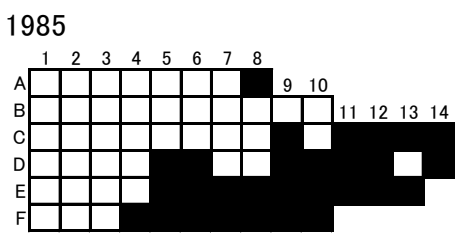

1986

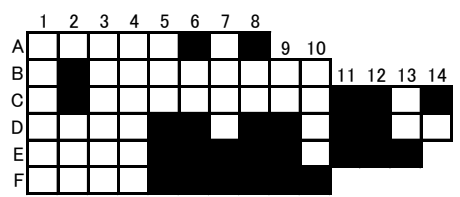

1987

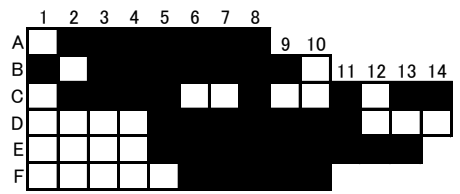

1988

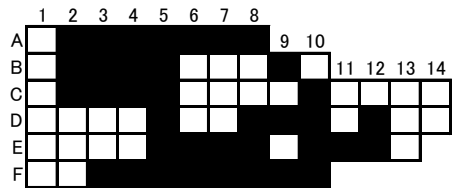

1989

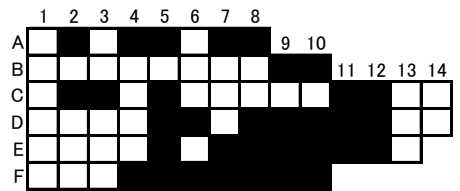

1990

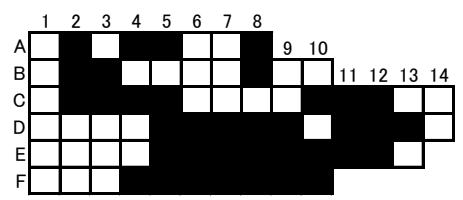

1991

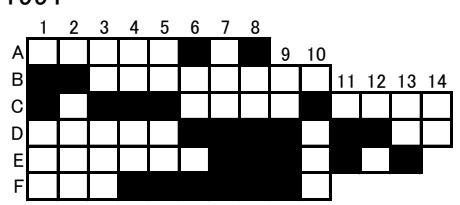

1992

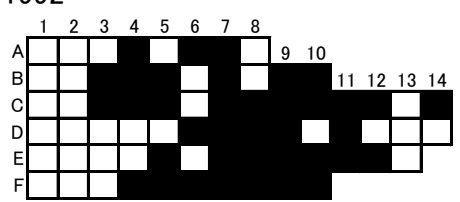

1993

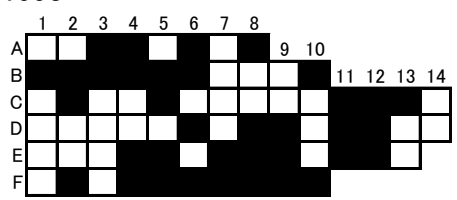

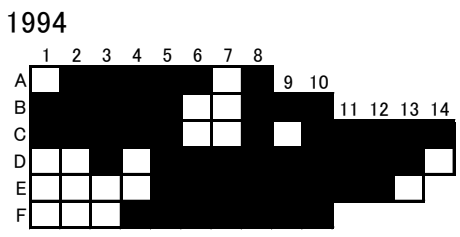

1995

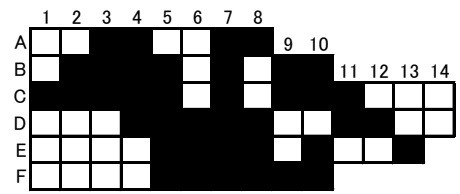

1996

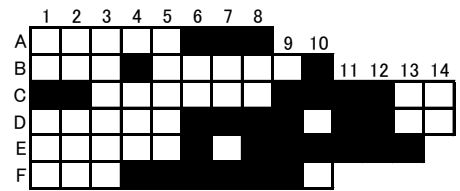

1997

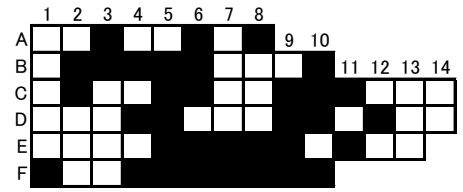

1998

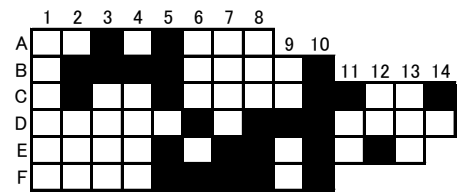

1999

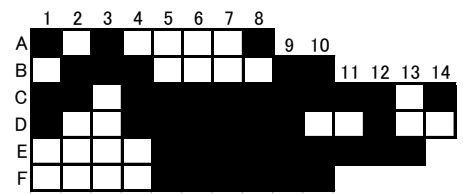

2000

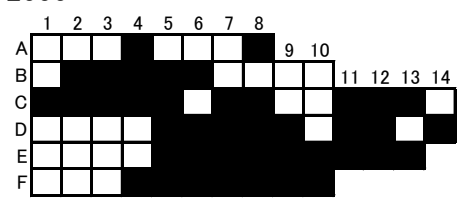

2001

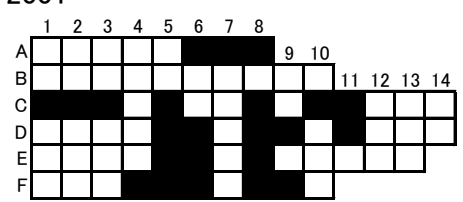

2002

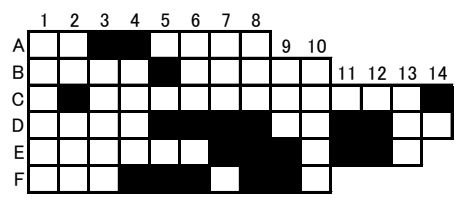

2003

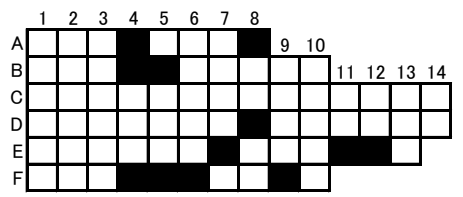

2004

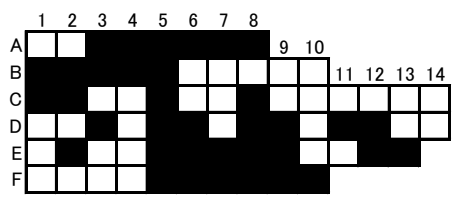

2005

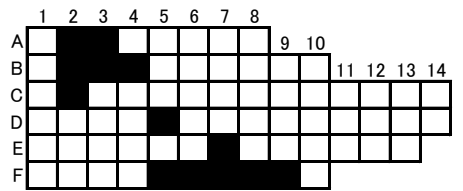

2006

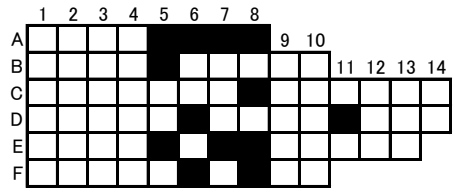

2007

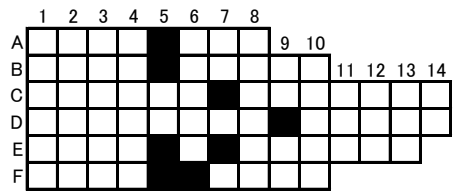

2008

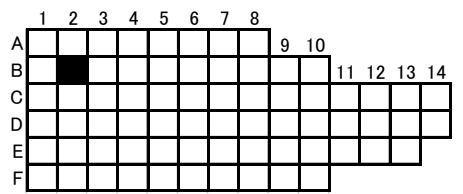

2009

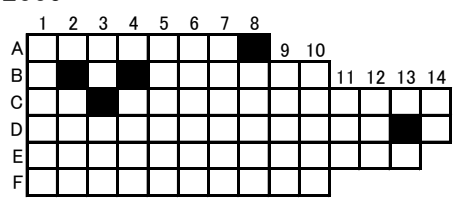

2010

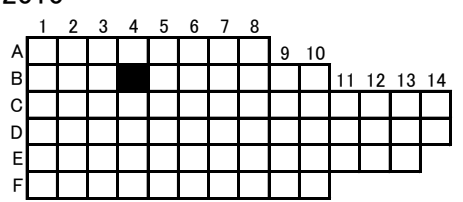



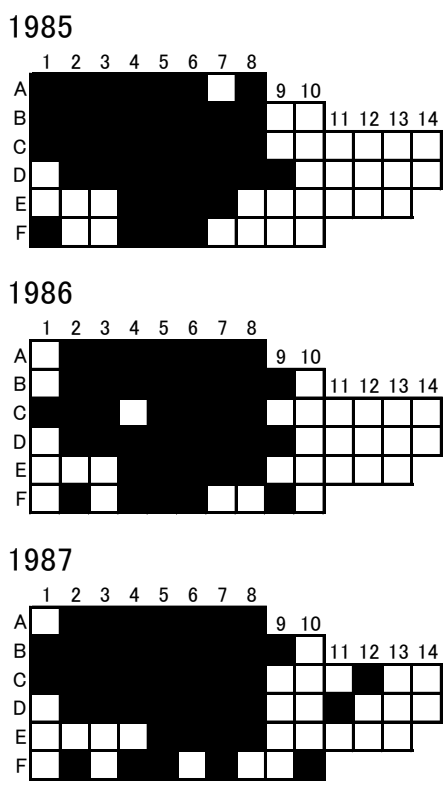

1988

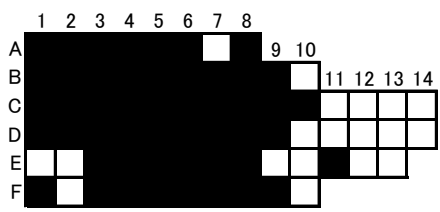

1989

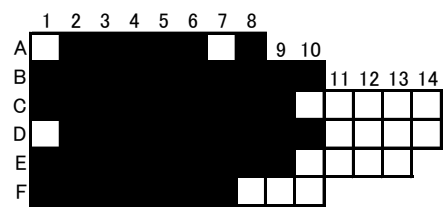

1990

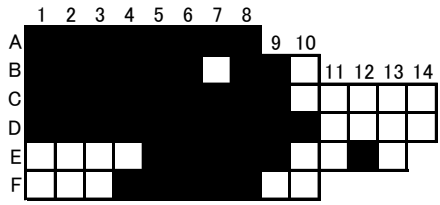

1991

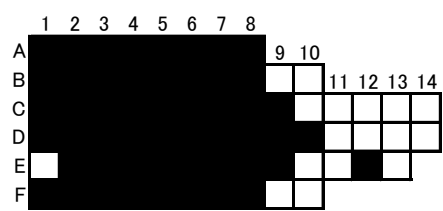

1992

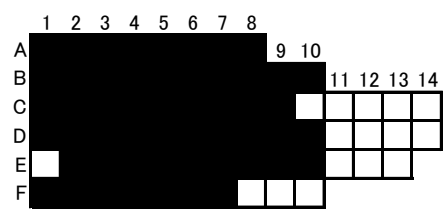

1993

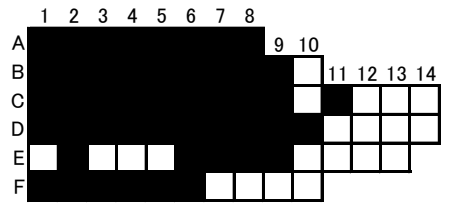

1994

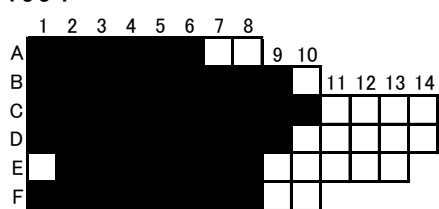

1995

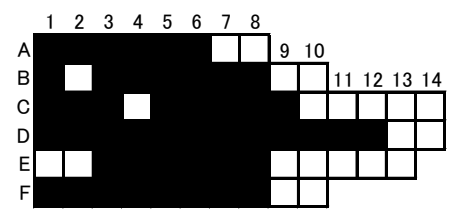

1996

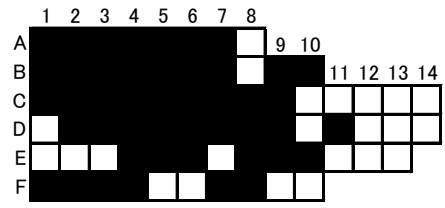

1997

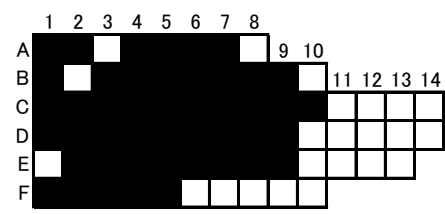

1998

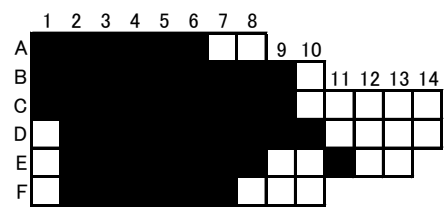

1999

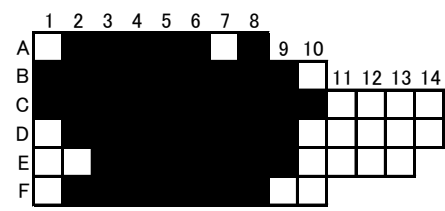

2000

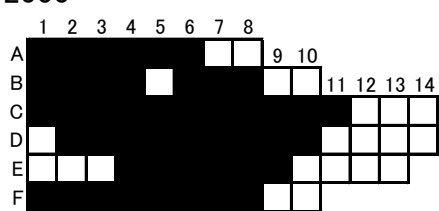

2001

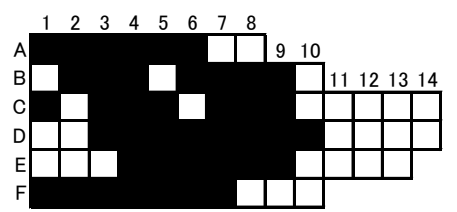

2002

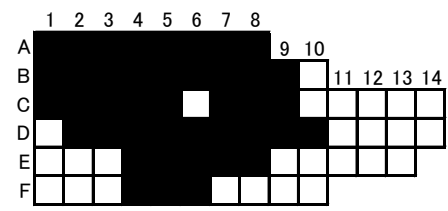

2003

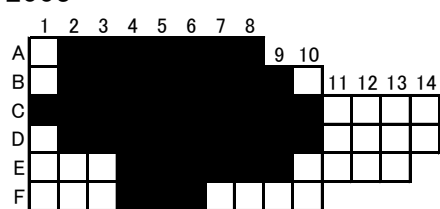

2004

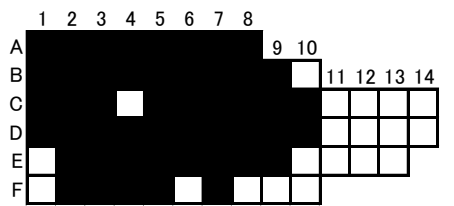

2005

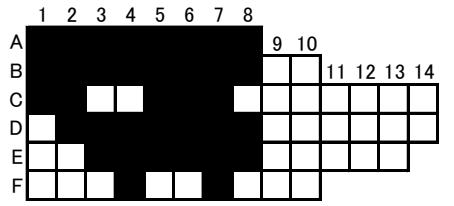

2006

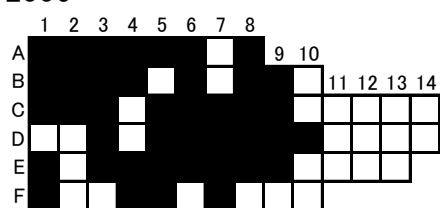

2007

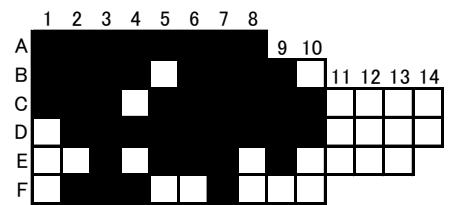

2008

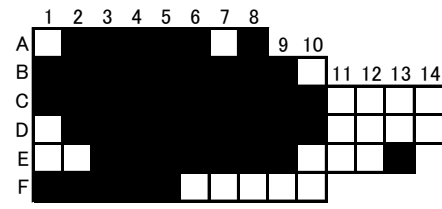

2009

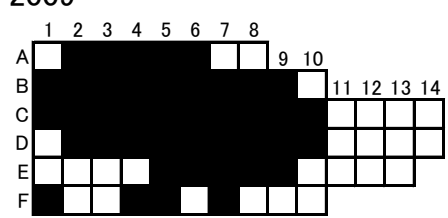

2010

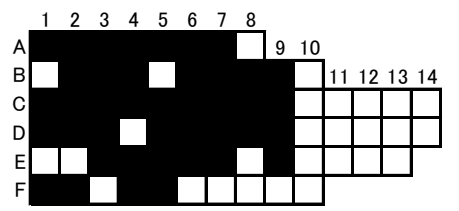


125 Muricodrupa sp. コウシレイシダマシ
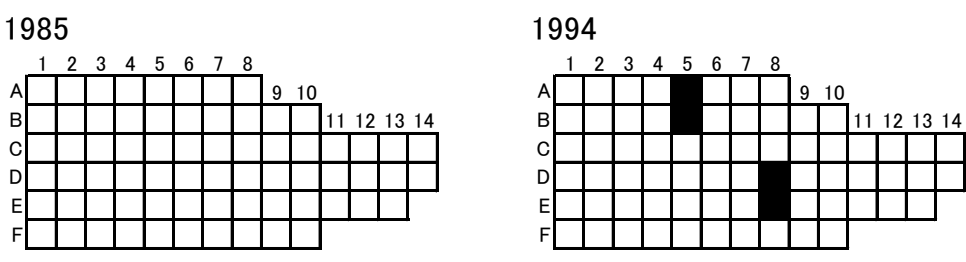

2003

1986

1995
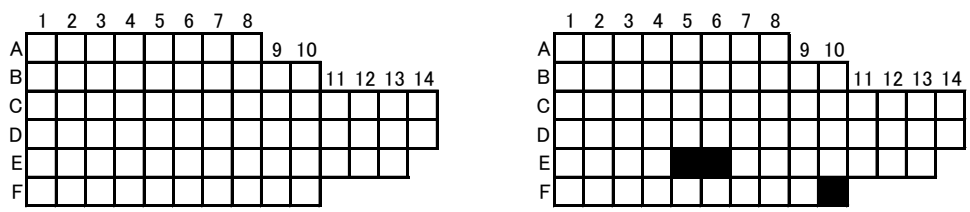

1987

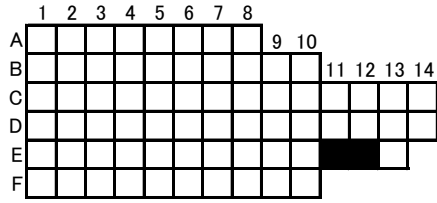

1996
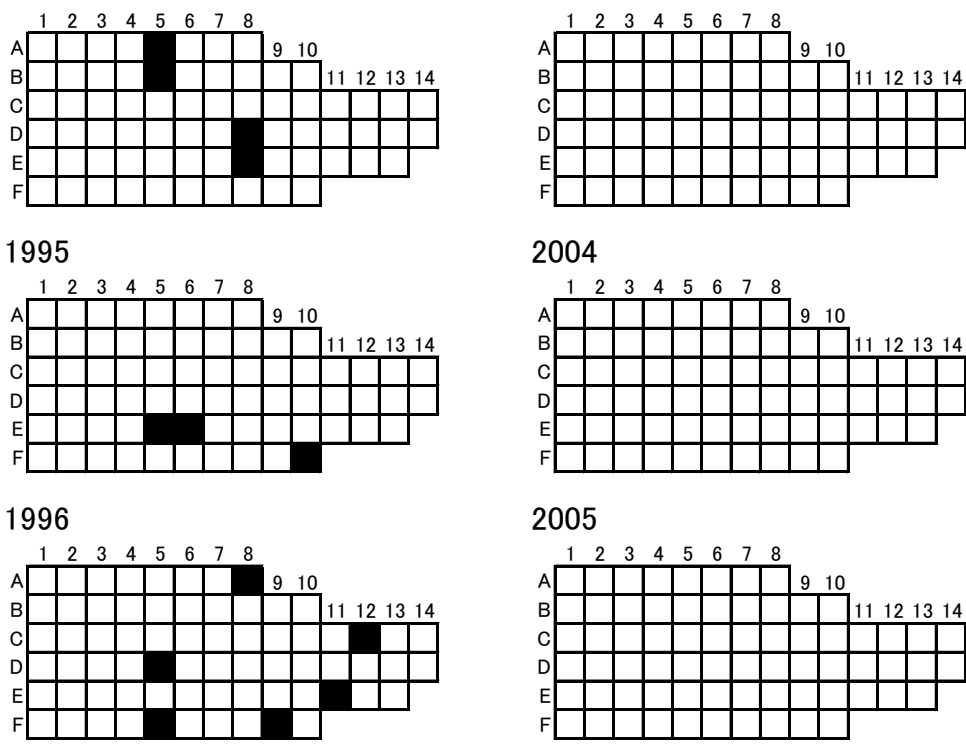

2004

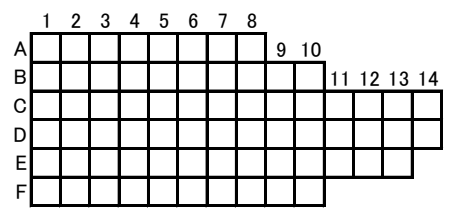

1988

1997
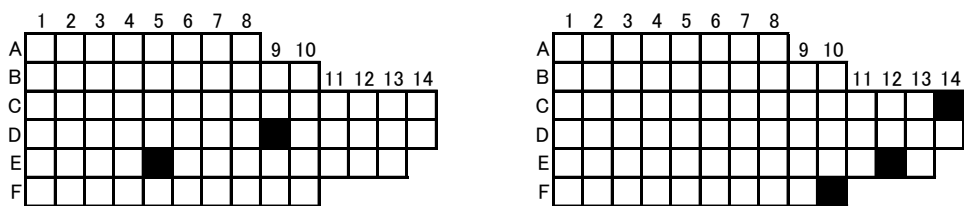

2005

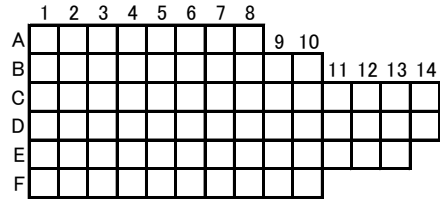

2006

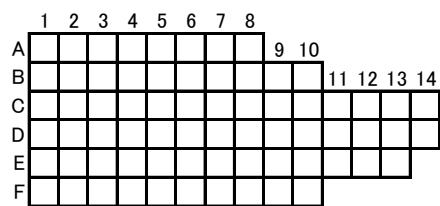

1989

1998
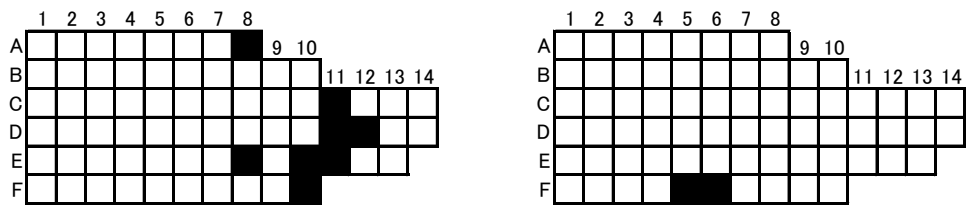

2007
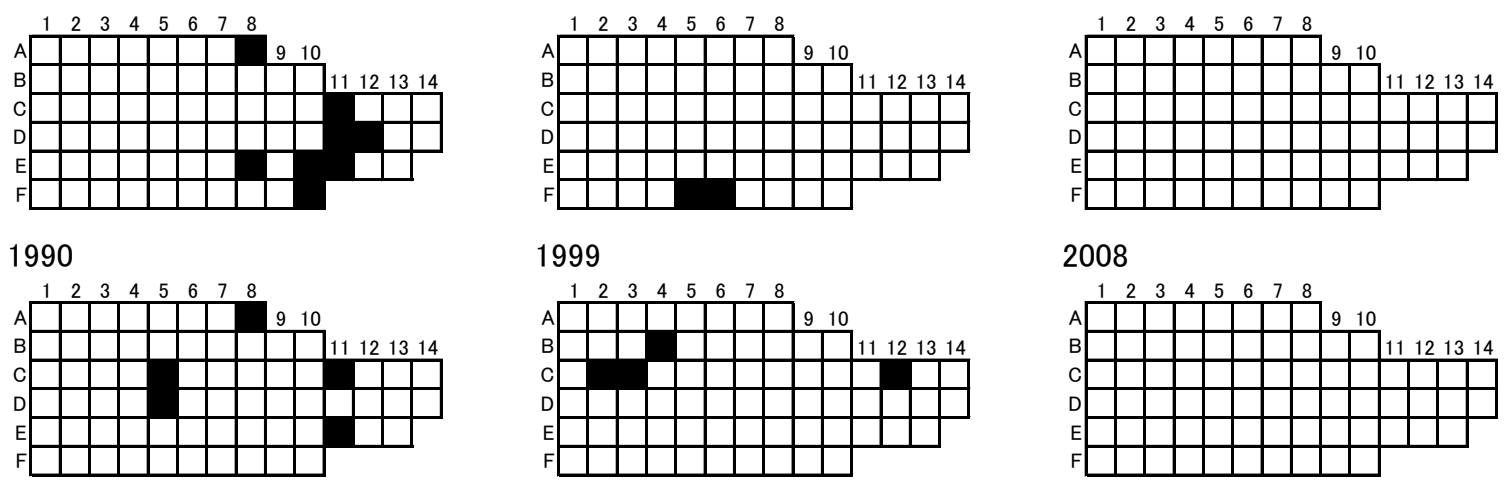

1999

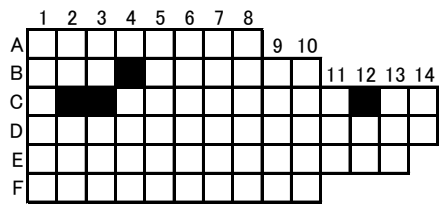

2008

1991

2000
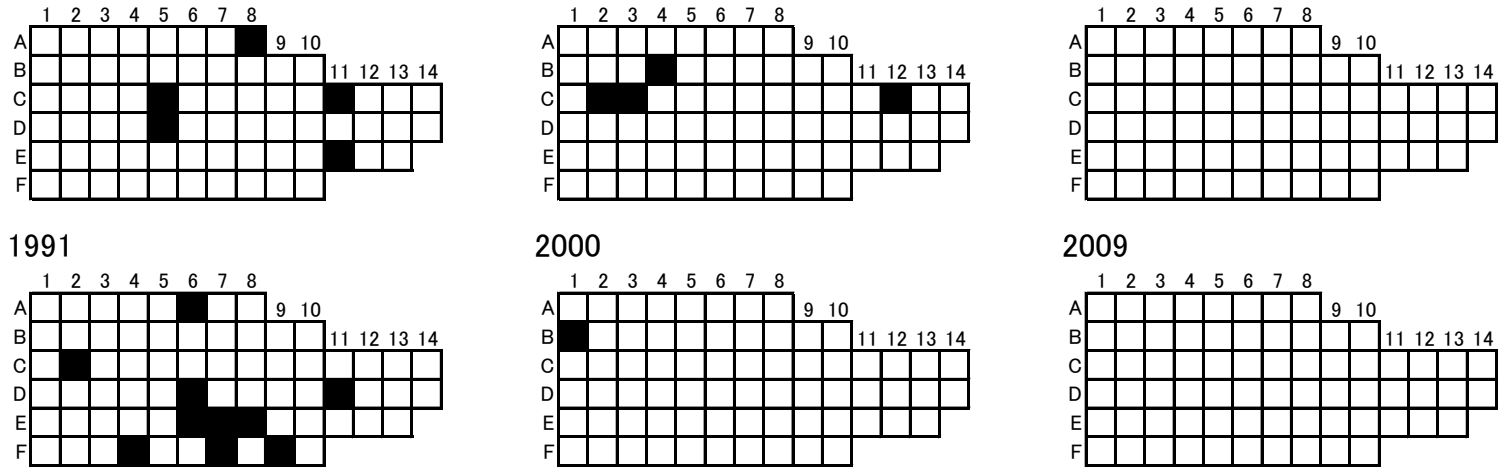

2009

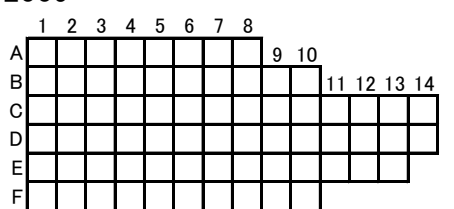

1992

2001
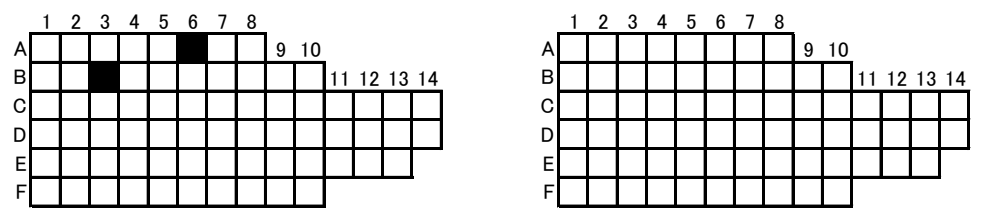

2010

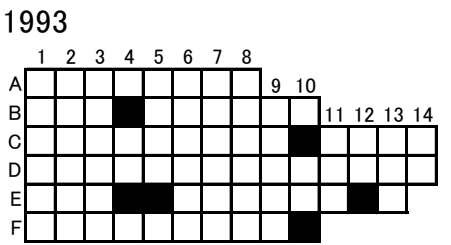

2002

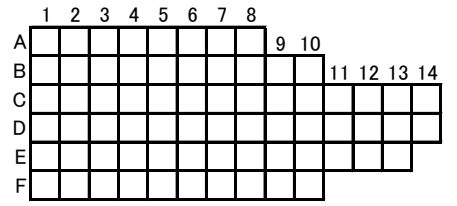

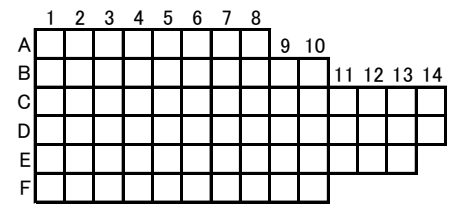




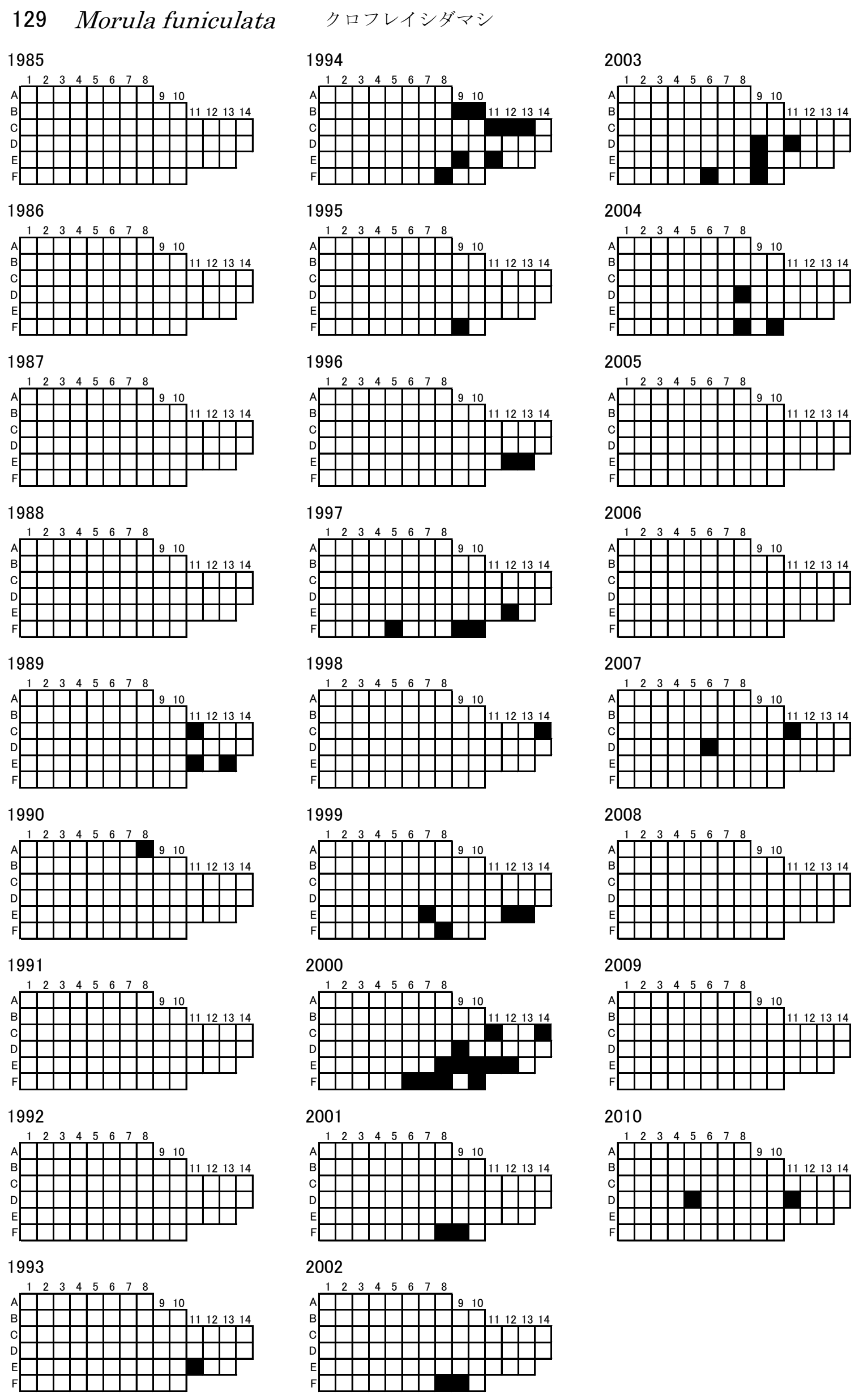


1985

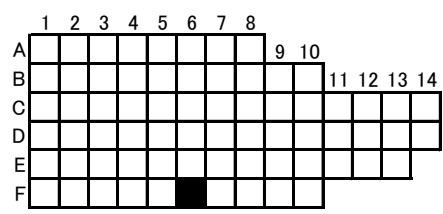

1986

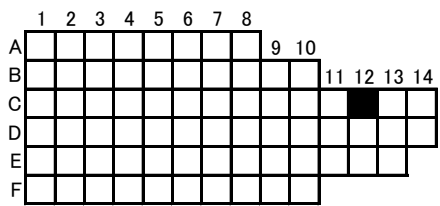

1987

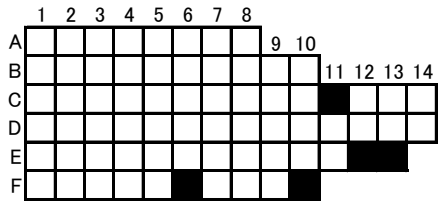

1988

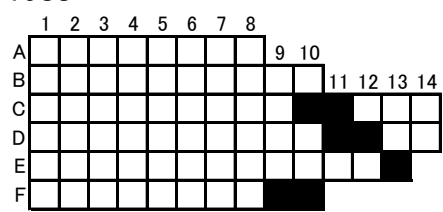

1989

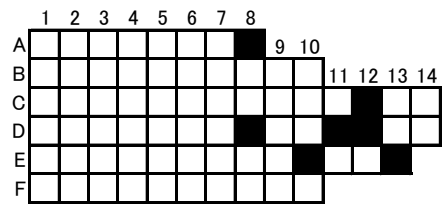

1990

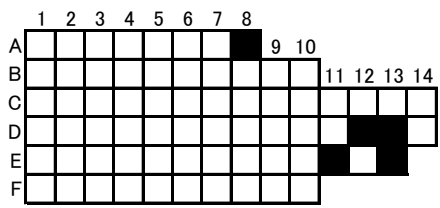

1991

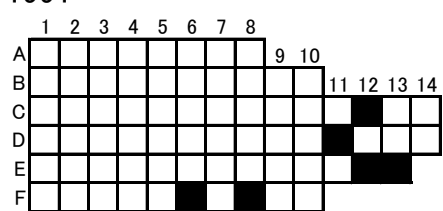

1992

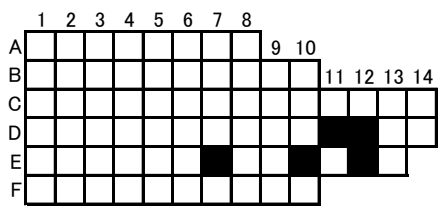

1993

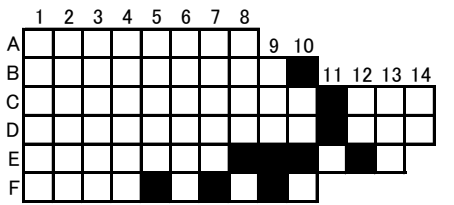

1994

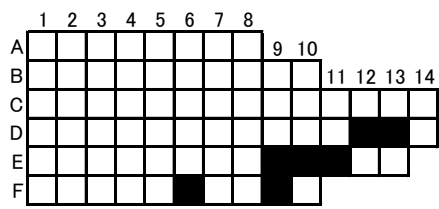

1995

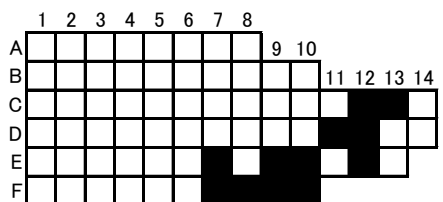

1996

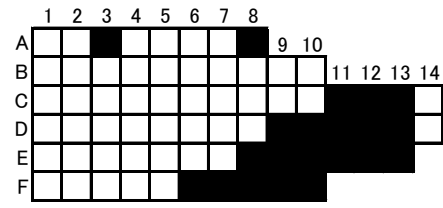

1997

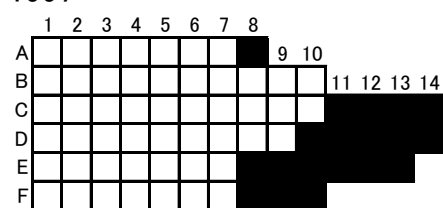

1998

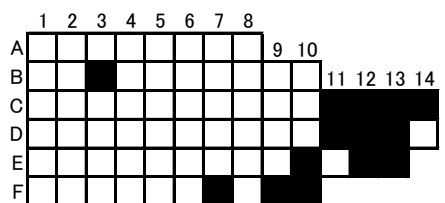

1999

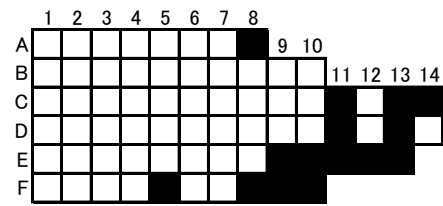

2000

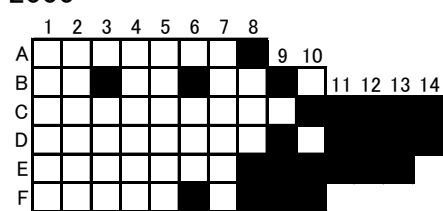

2001

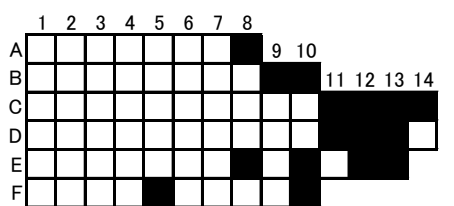

2002

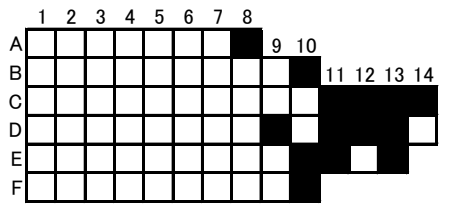

2003

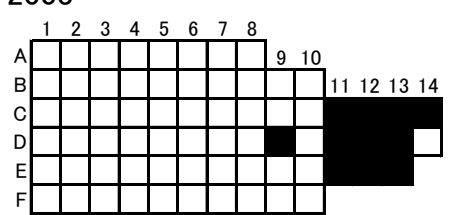

2004

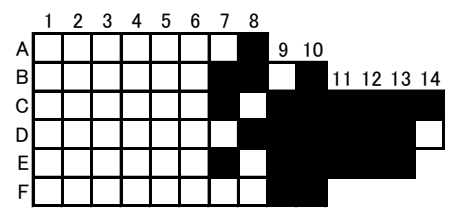

2005

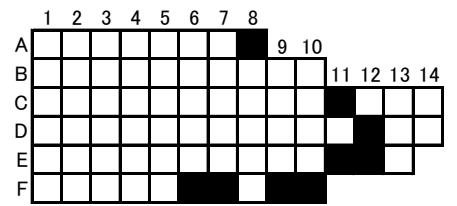

2006

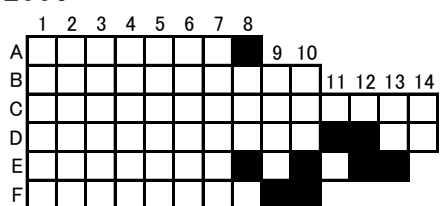

2007

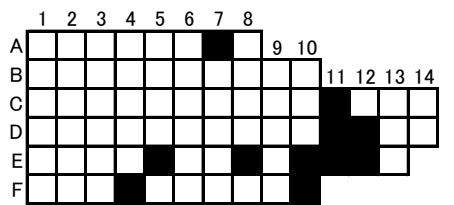

2008

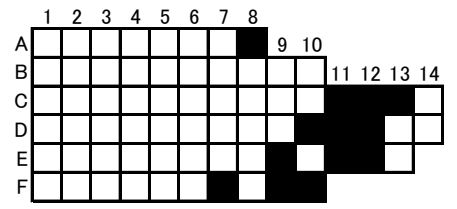

2009

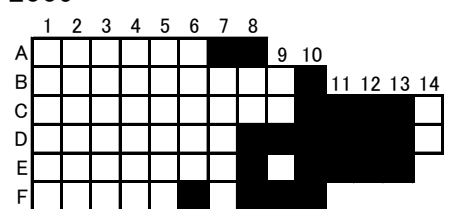

2010

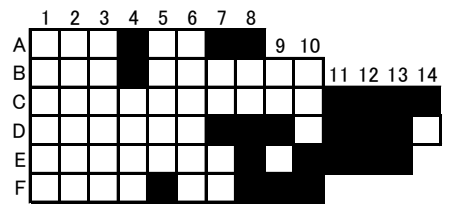




\section{Morula iostoma イトマキレイシダマシ}

1985

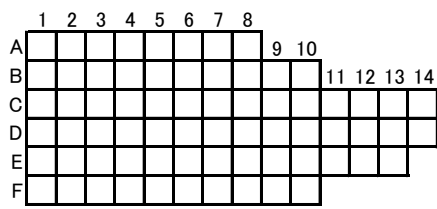

1986

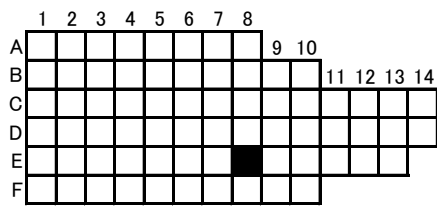

1987

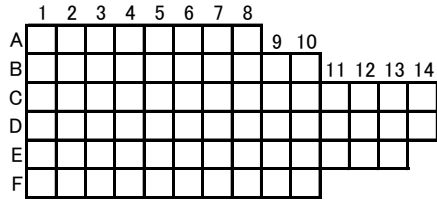

1988

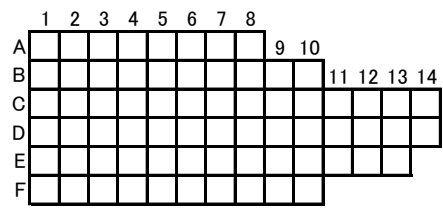

1989

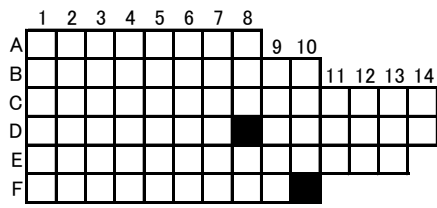

1990

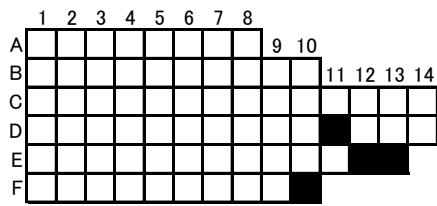

1991

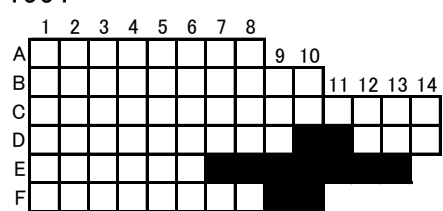

1992

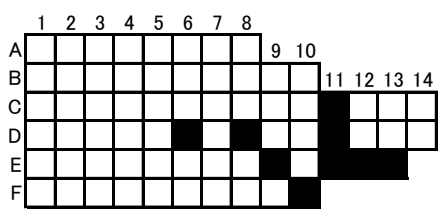

1993

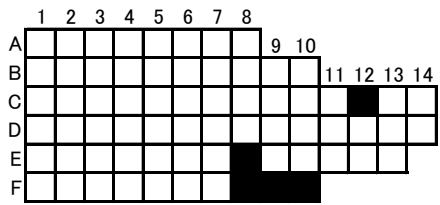

1994

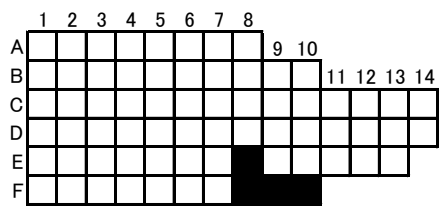

1995

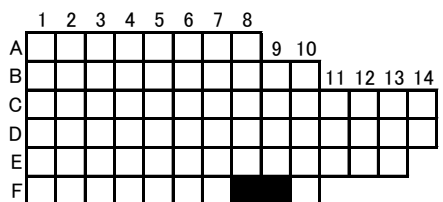

1996

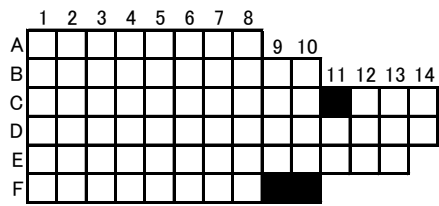

1997

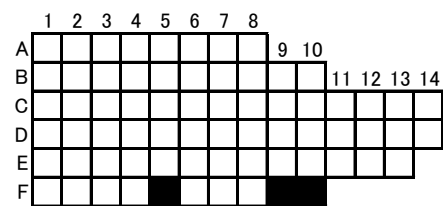

1998

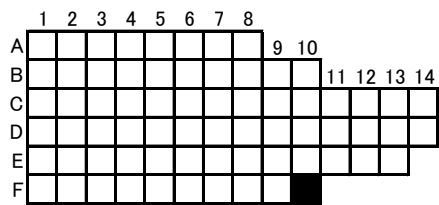

1999

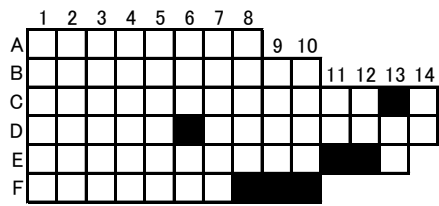

2000

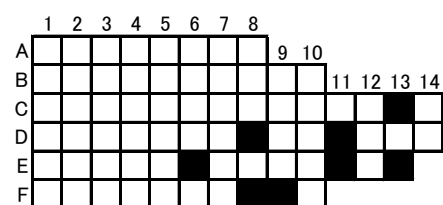

2001

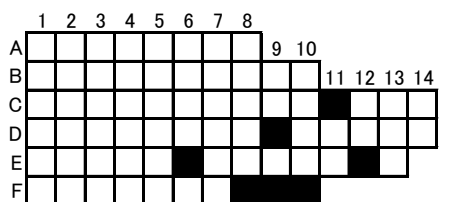

2002

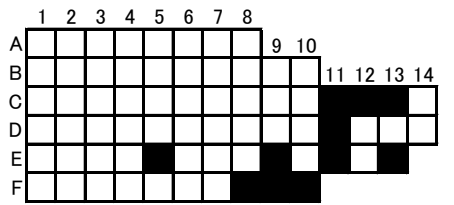

2003

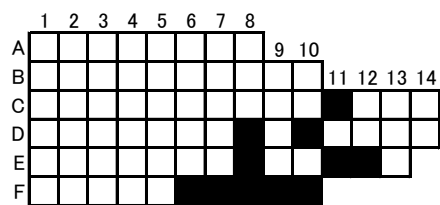

2004

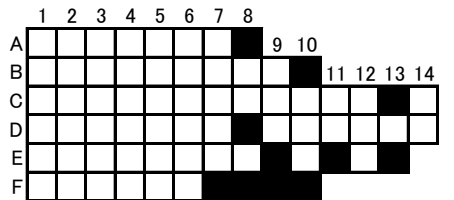

2005

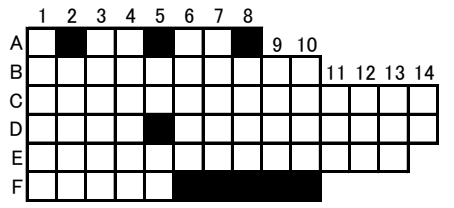

2006

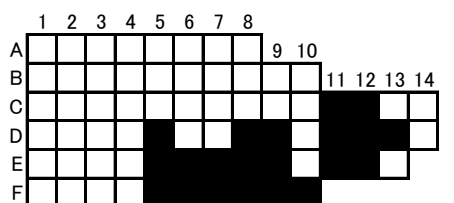

2007

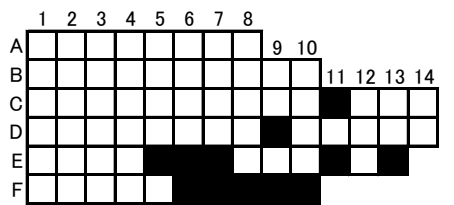

2008

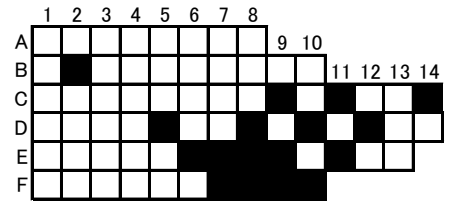

2009

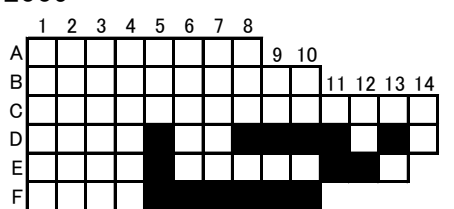

2010

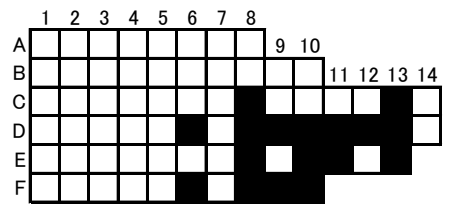


1985

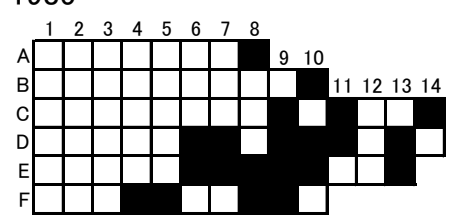

1986

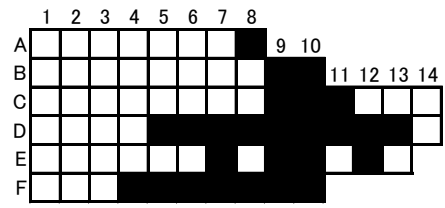

1987

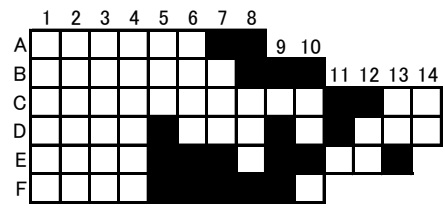

1988

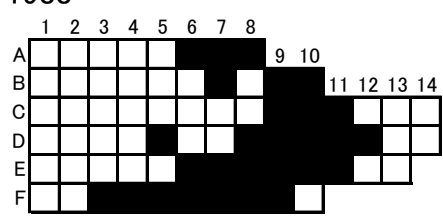

1989
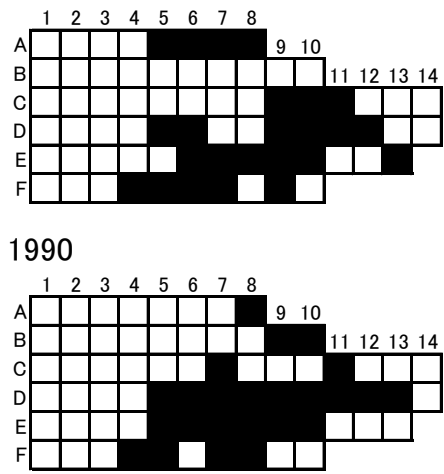

1991

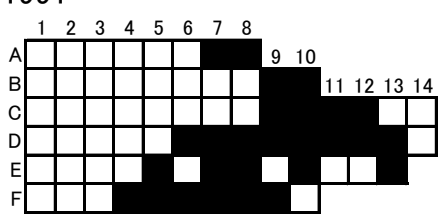

1992

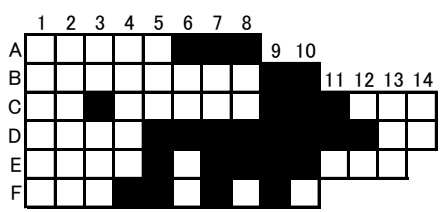

1993

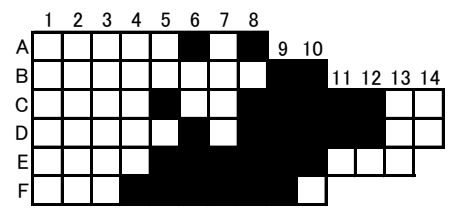

1994

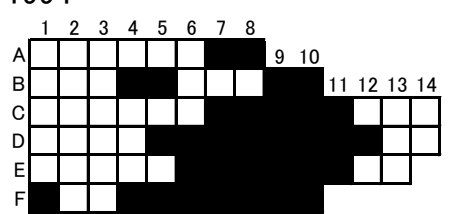

1995

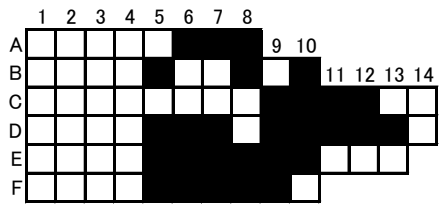

1996

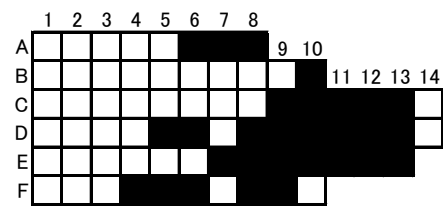

1997

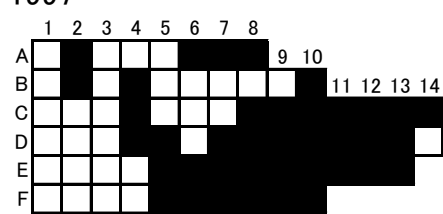

1998

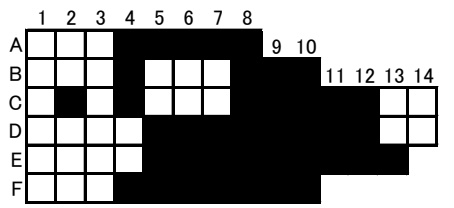

1999

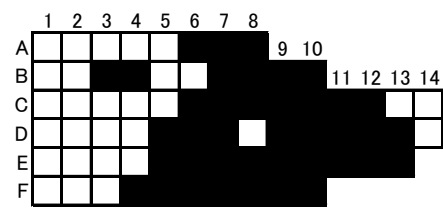

2000

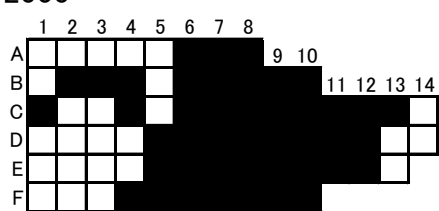

2001

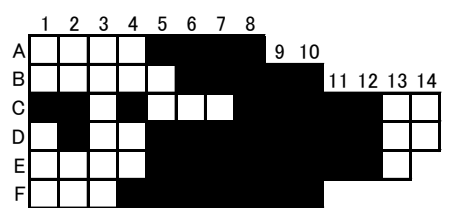

2002

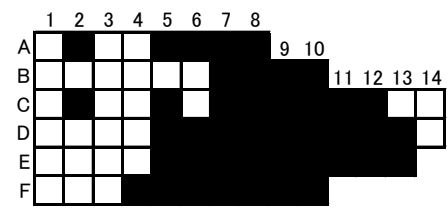

2003

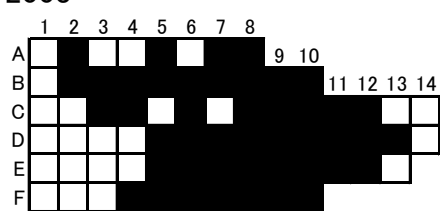

2004

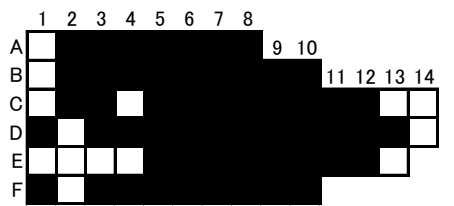

2005

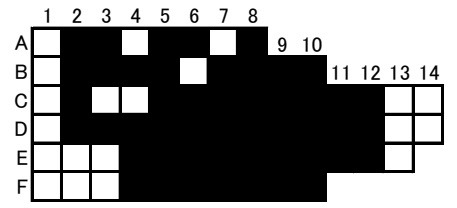

2006

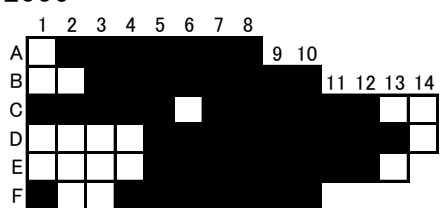

2007

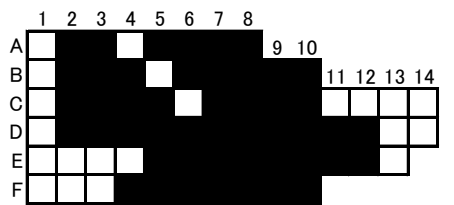

2008

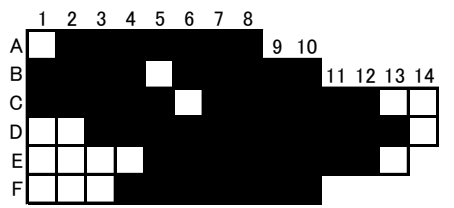

2009

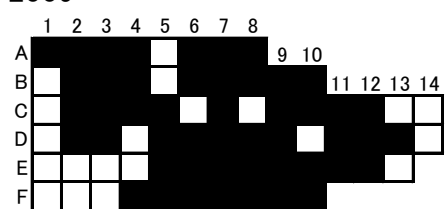

2010

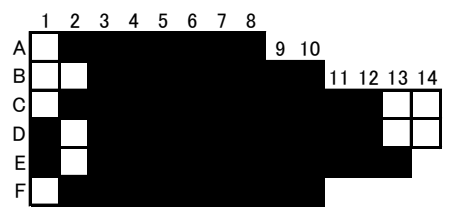


1985

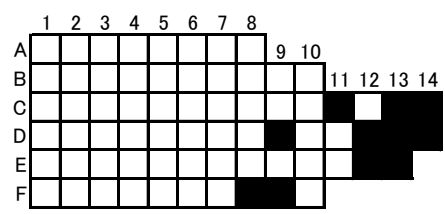

1986

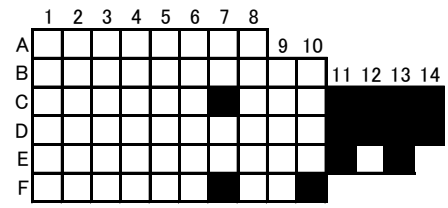

1987

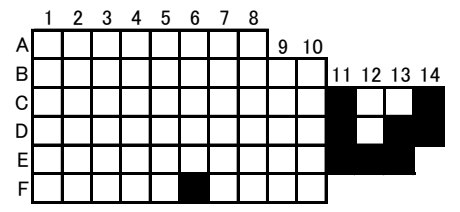

1988

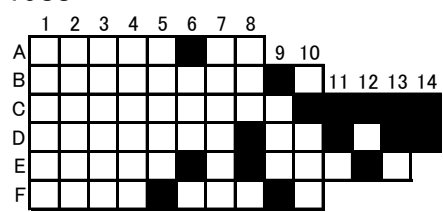

1989

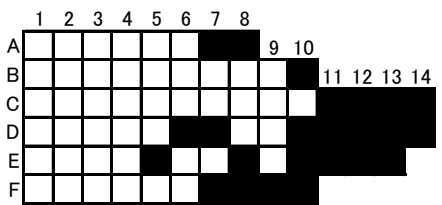

1990

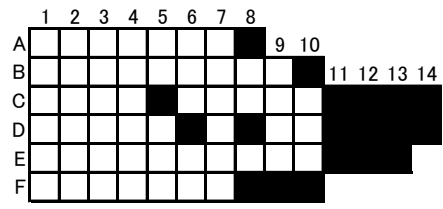

1991

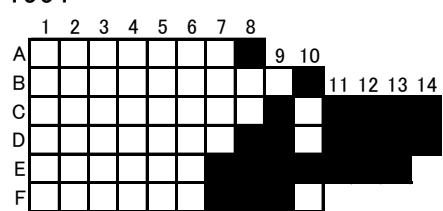

1992

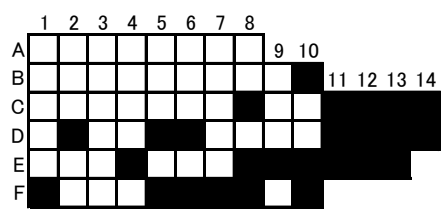

1993

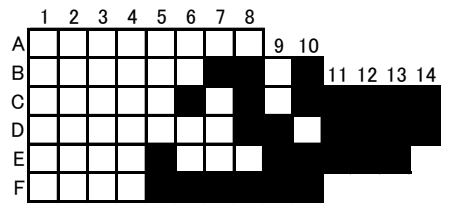

1994

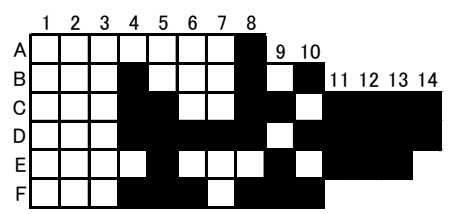

1995

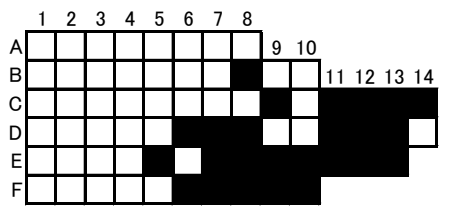

1996

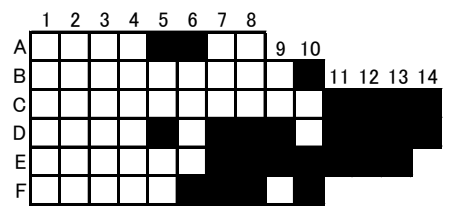

1997

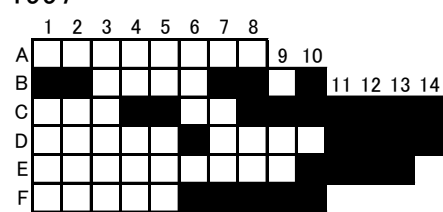

1998

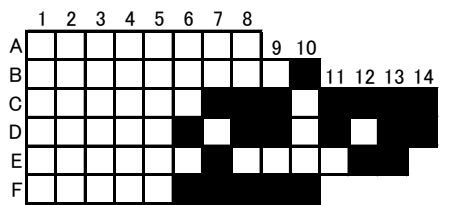

1999

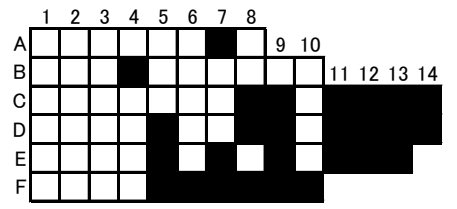

2000

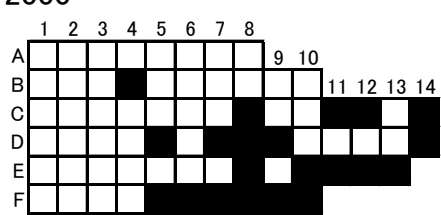

2001

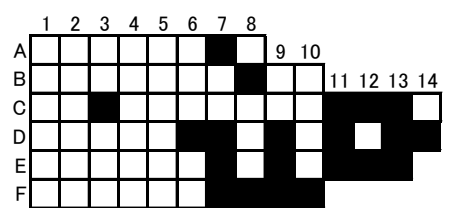

2002

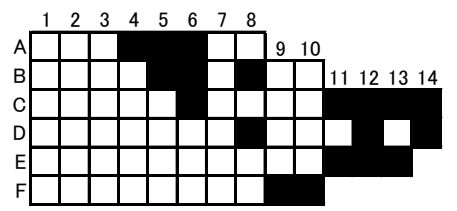

2003

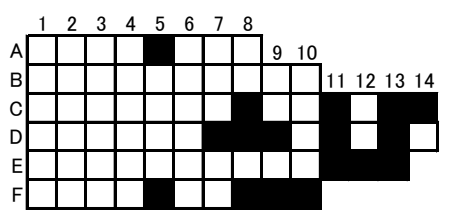

2004

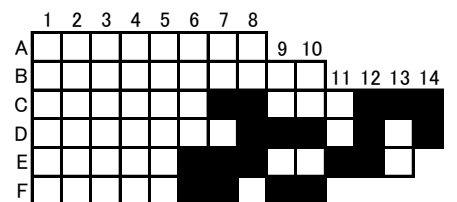

2005

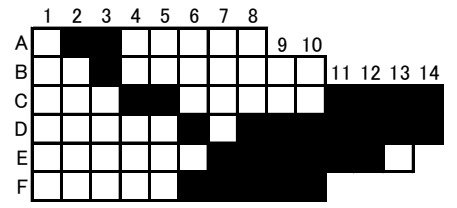

2006

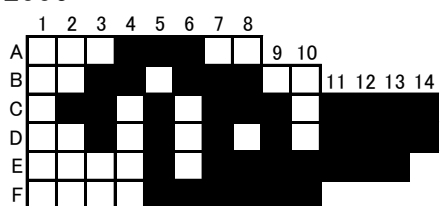

2007

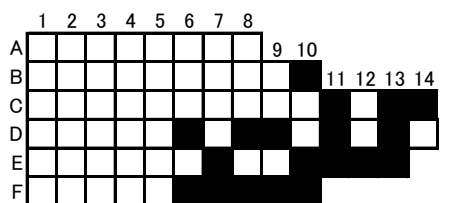

2008

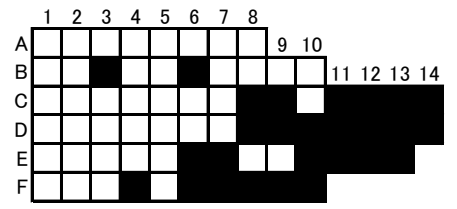

2009

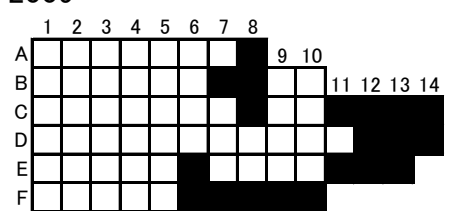

2010

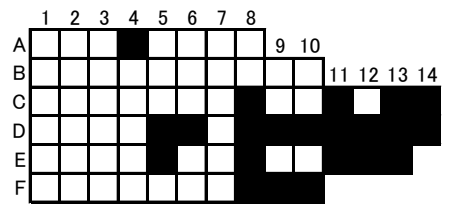


1985

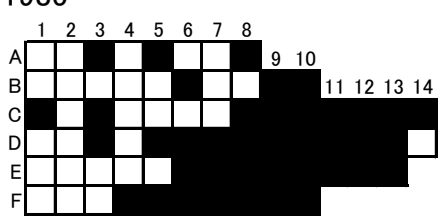

1986

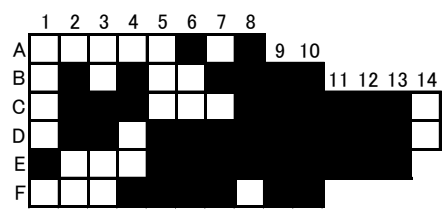

1987

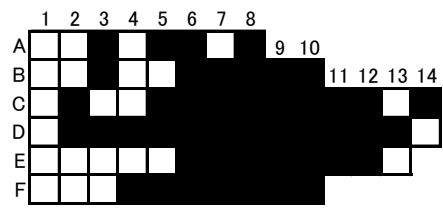

1988

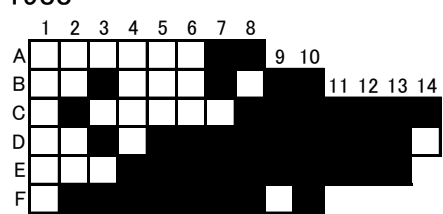

1989
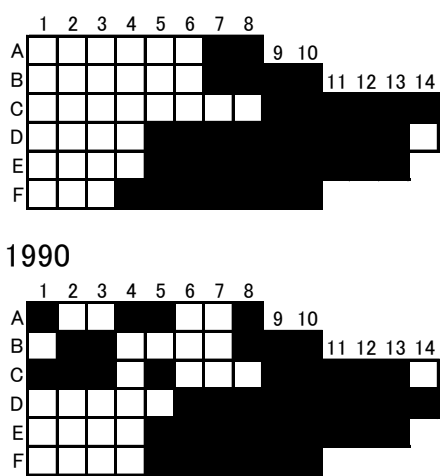

1991

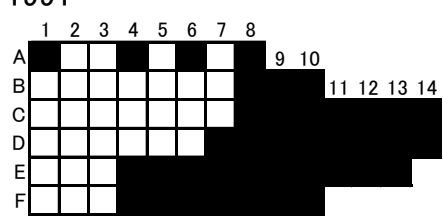

1992

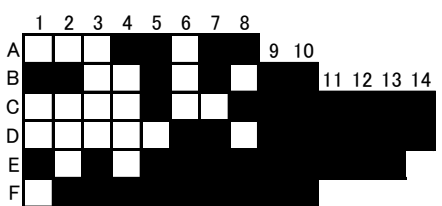

1993

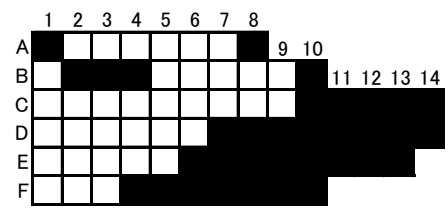

1994

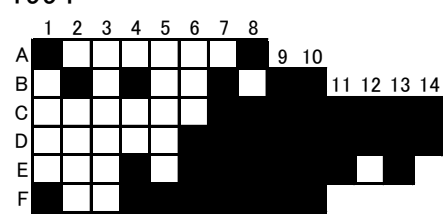

1995

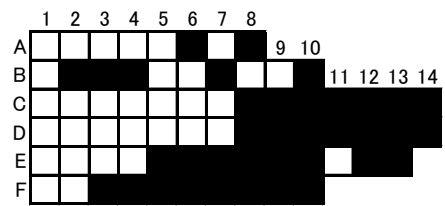

1996

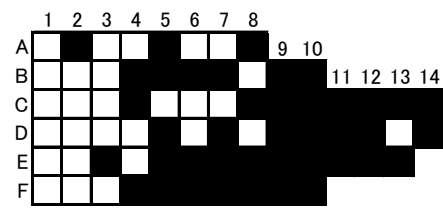

1997

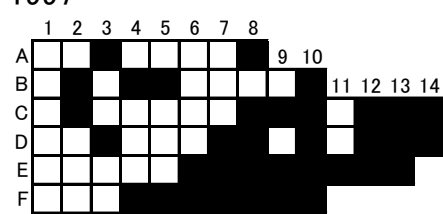

1998

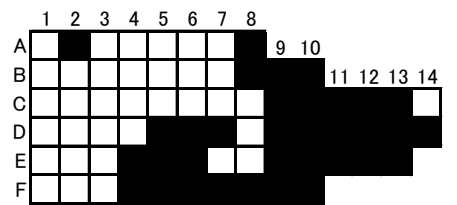

1999

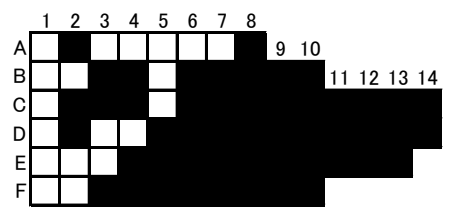

2000

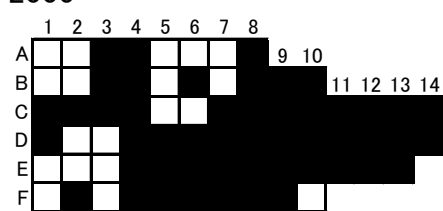

2001

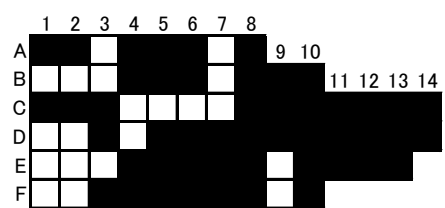

2002

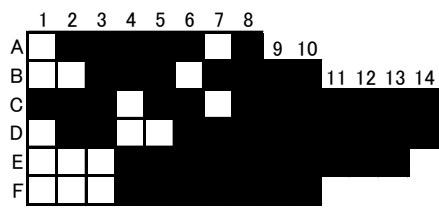

2003

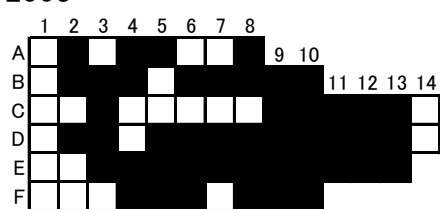

2004

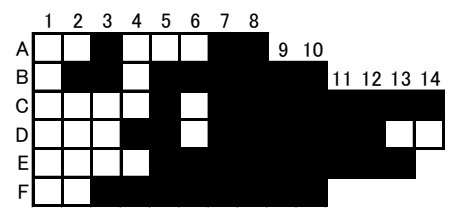

2005

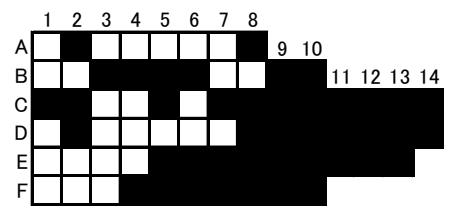

2006

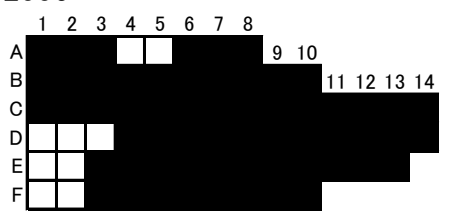

2007

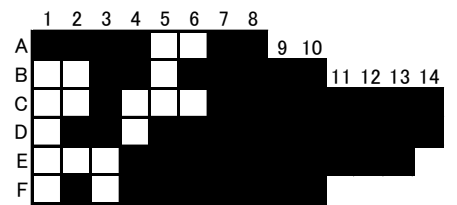

2008

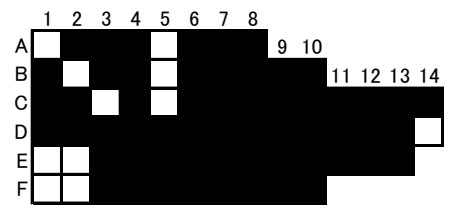

2009

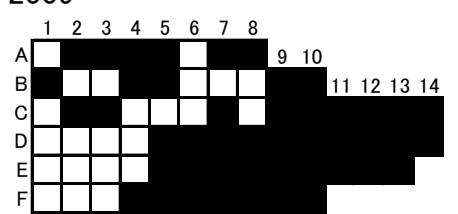

2010

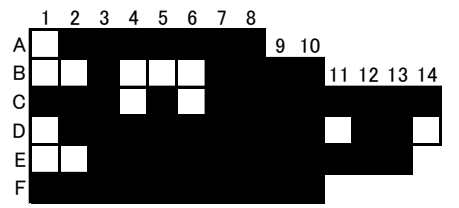


1985

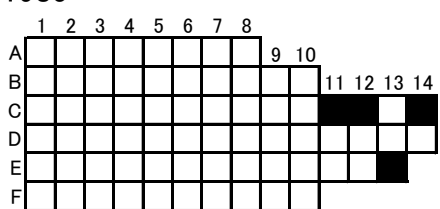

1986

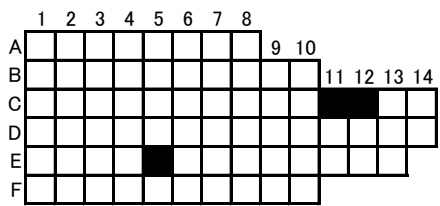

1987

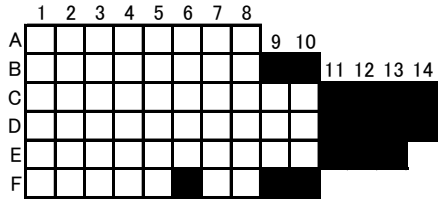

1988

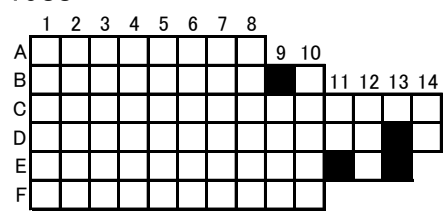

1989

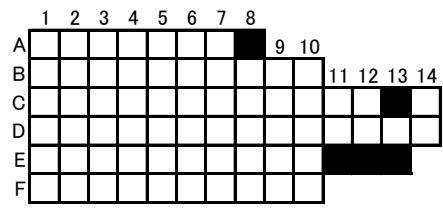

1990

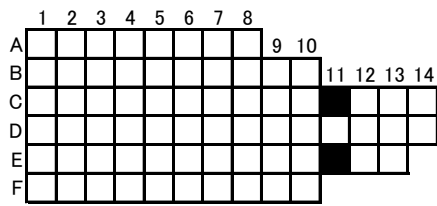

1991

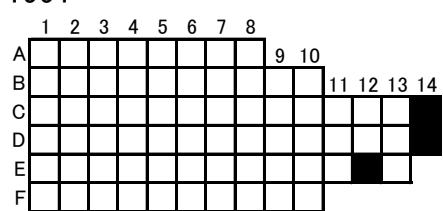

1992

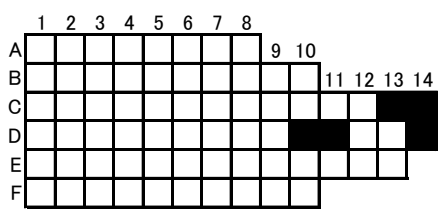

1993

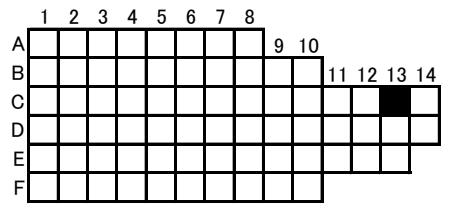

1994

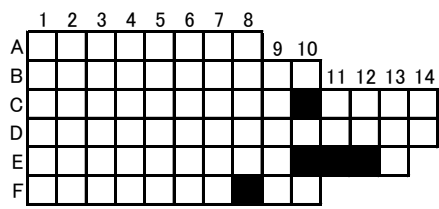

1995

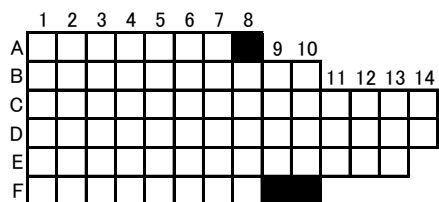

1996

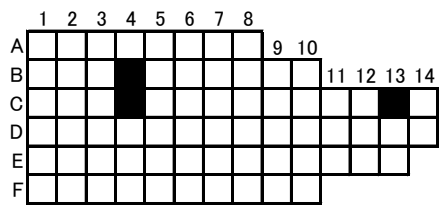

1997

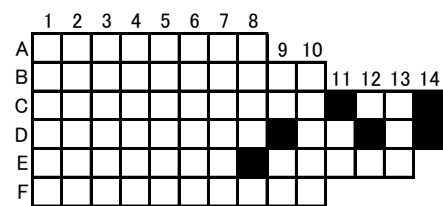

1998

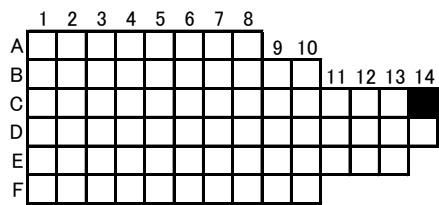

1999

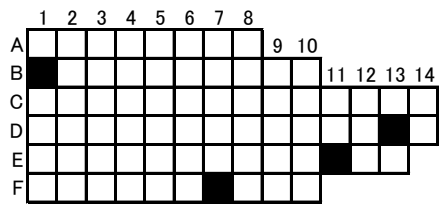

2000

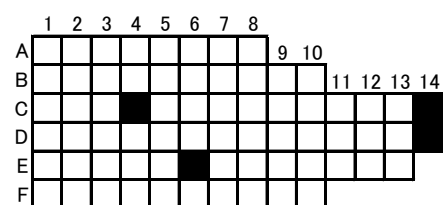

2001

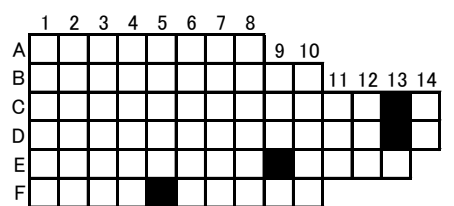

2002

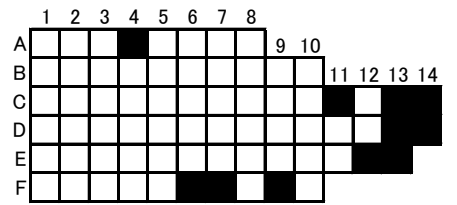

2003

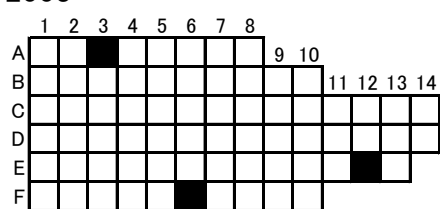

2004

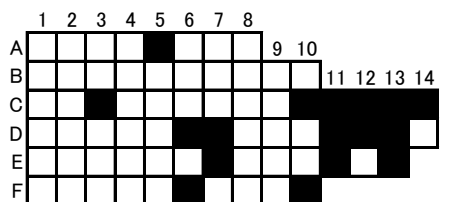

2005

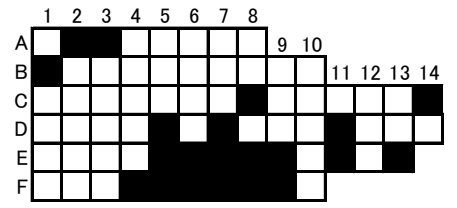

2006

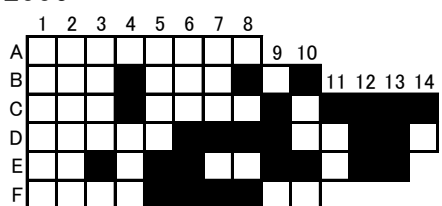

2007

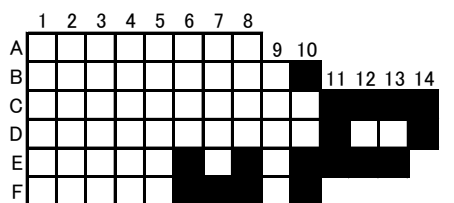

2008

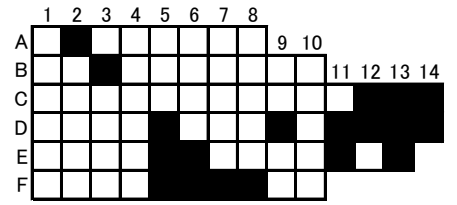

2009

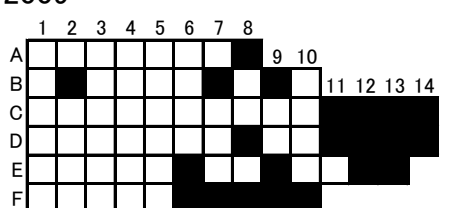

2010

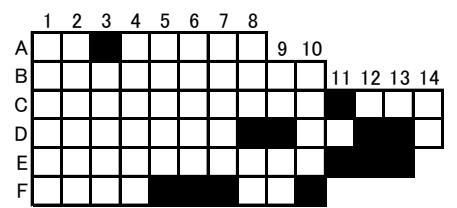


144 Coralliophila squamosissimaカゴメサンゴヤドリ

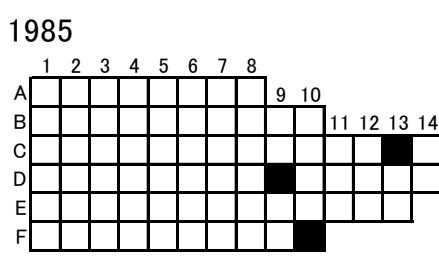

1994

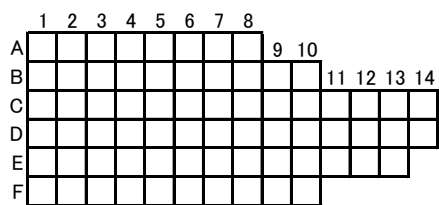

1986

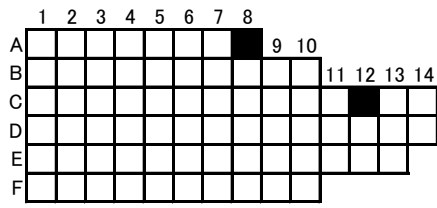

1987

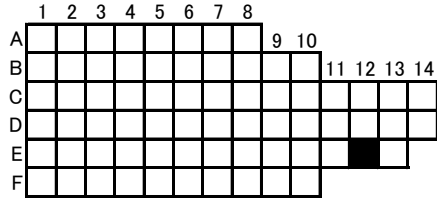

1988

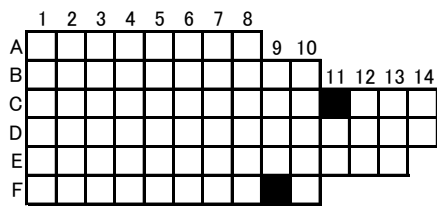

1989

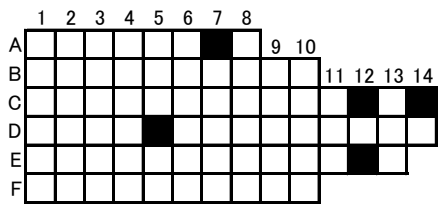

1990

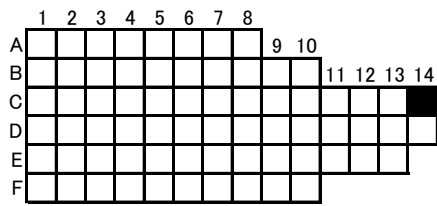

1991

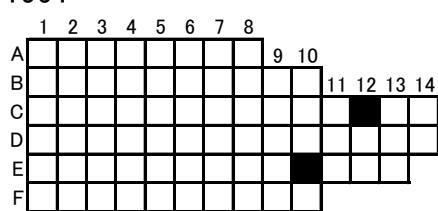

1992

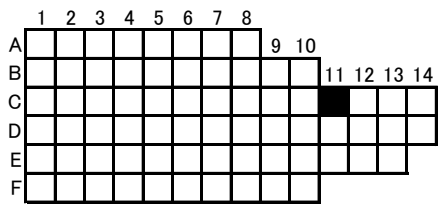

1993

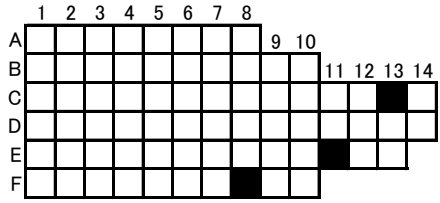

1995

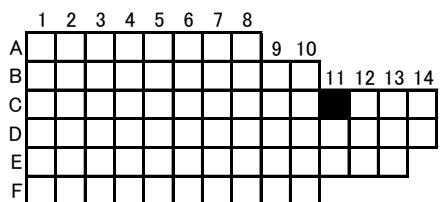

1996

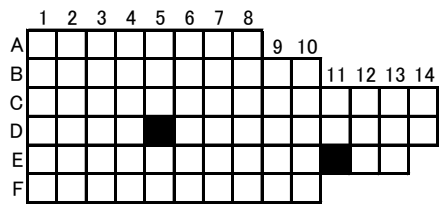

1997

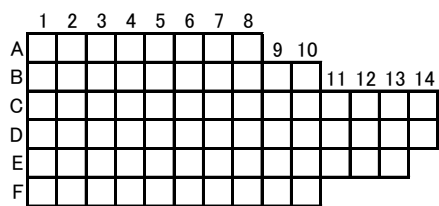

1998

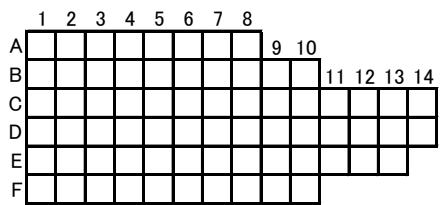

1999

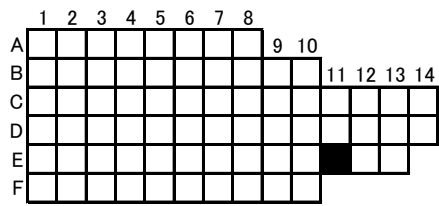

2000

2001

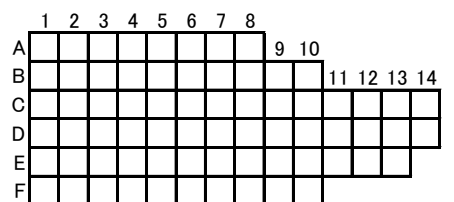

2002

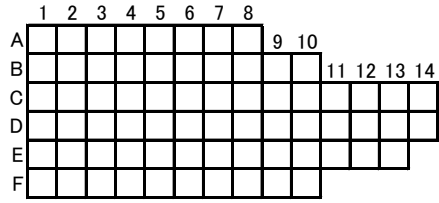

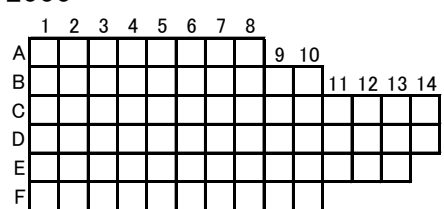

2003

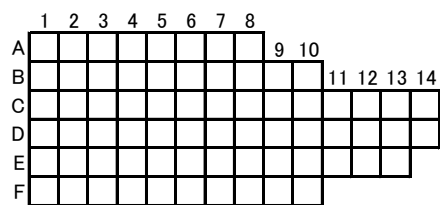

2004

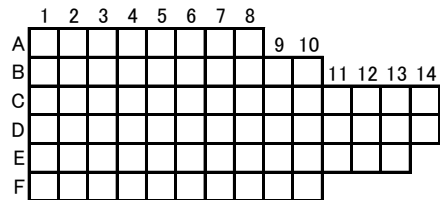

2005

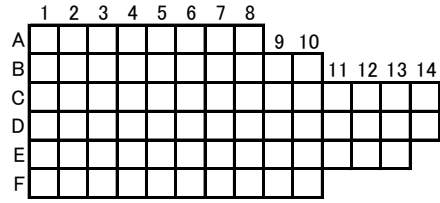

2006

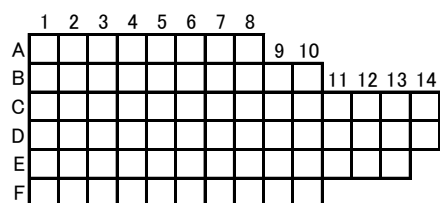

2007

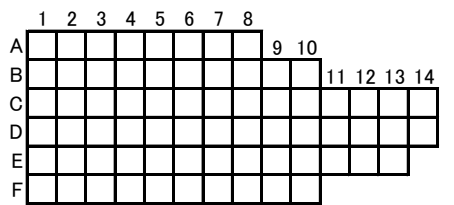

2008

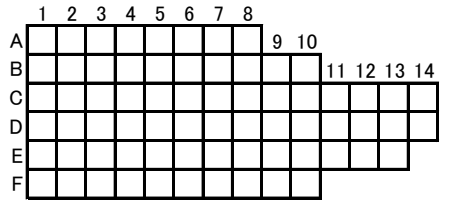

2009

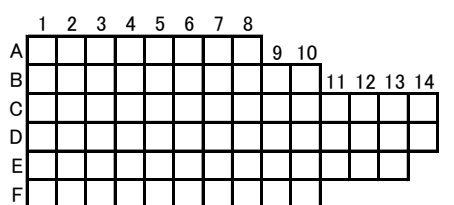

2010

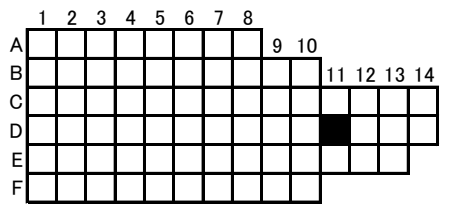


1985

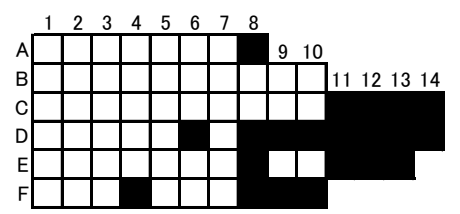

1986

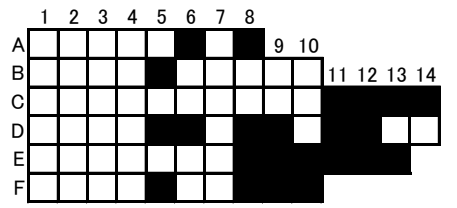

1987

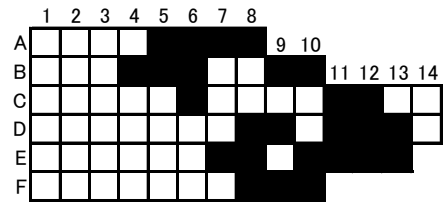

1988

ב

1989

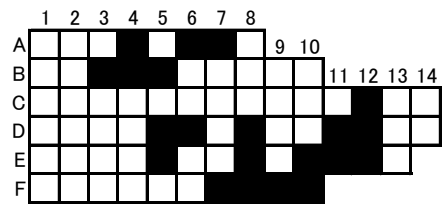

1990

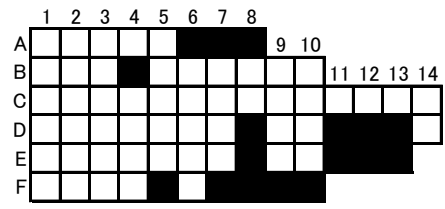

1991

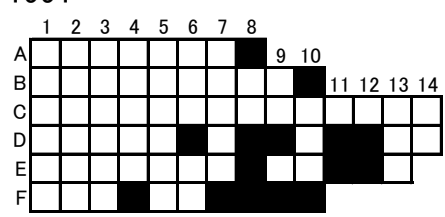

1992

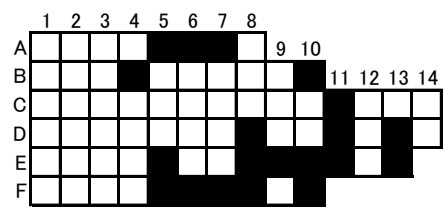

1993

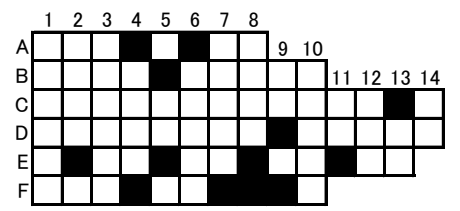

1994

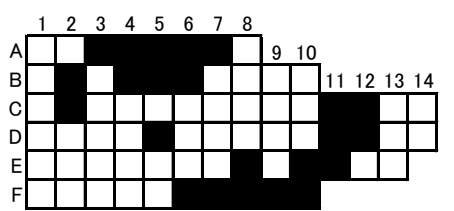

1995

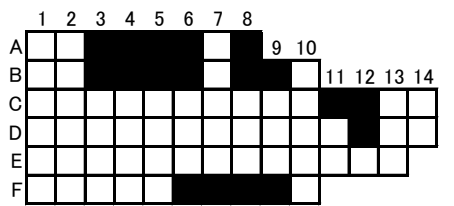

1996

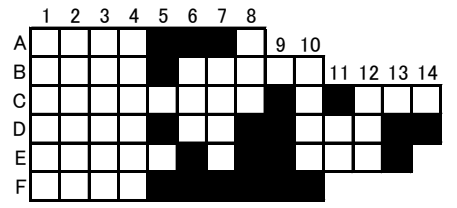

1997

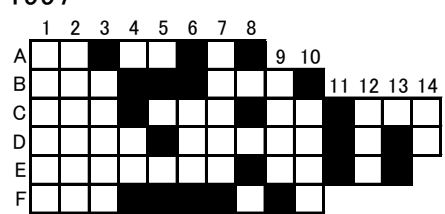

1998

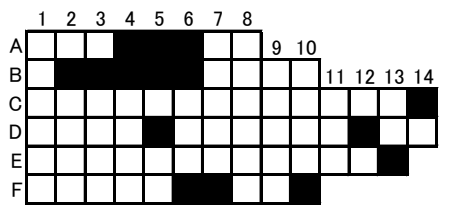

1999

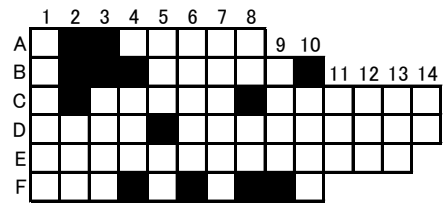

2000

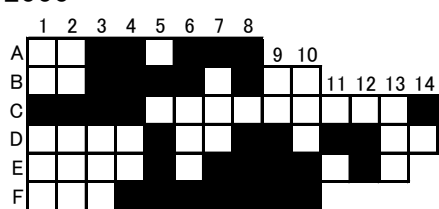

2001

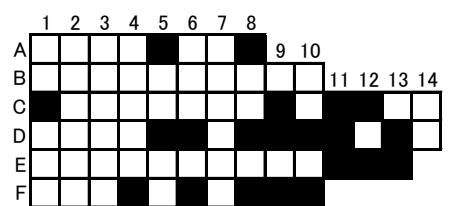

2002

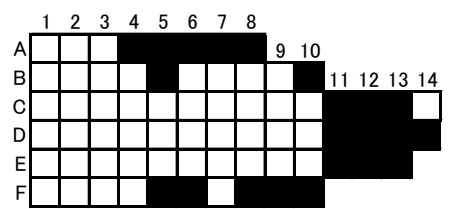

2003

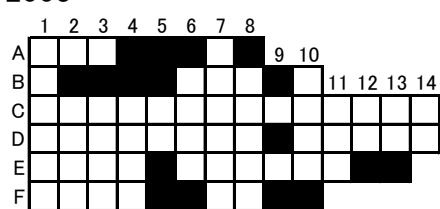

2004

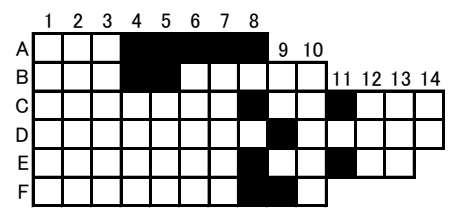

2005

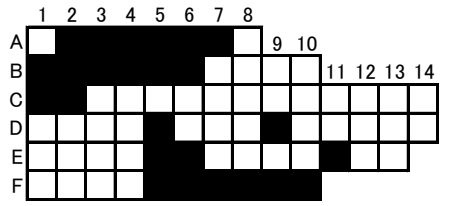

2006

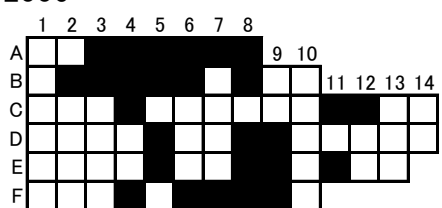

2007

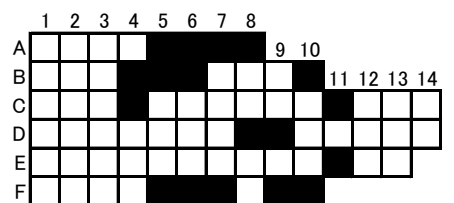

2008

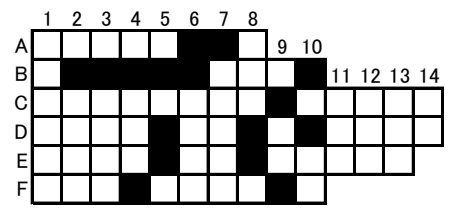

2009

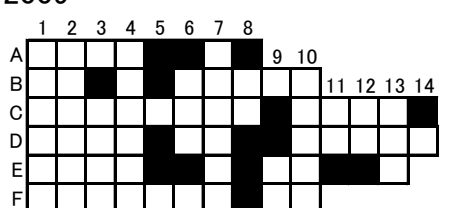

2010

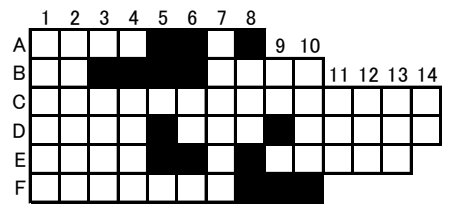


146 Anachis misera misera ボサツガイ
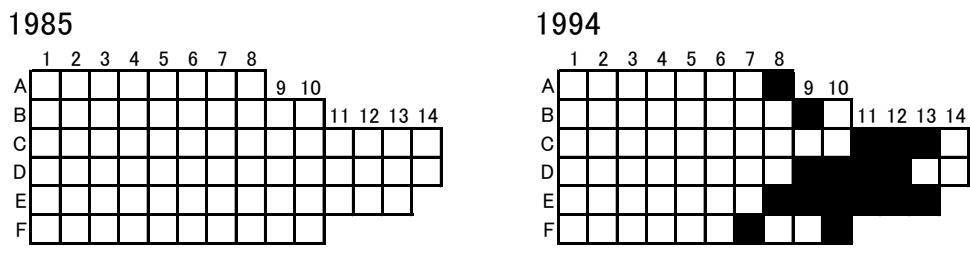

2003

1986

1995
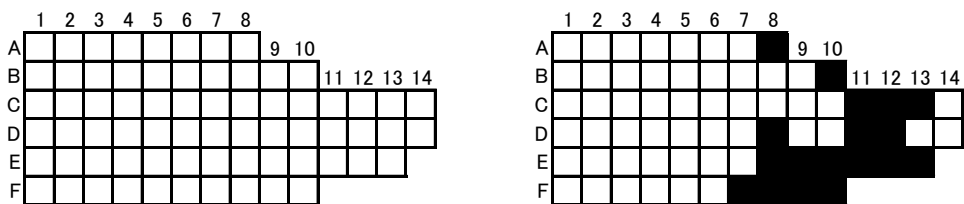

1987

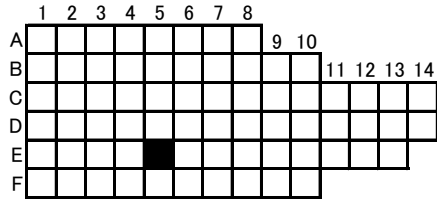

1996
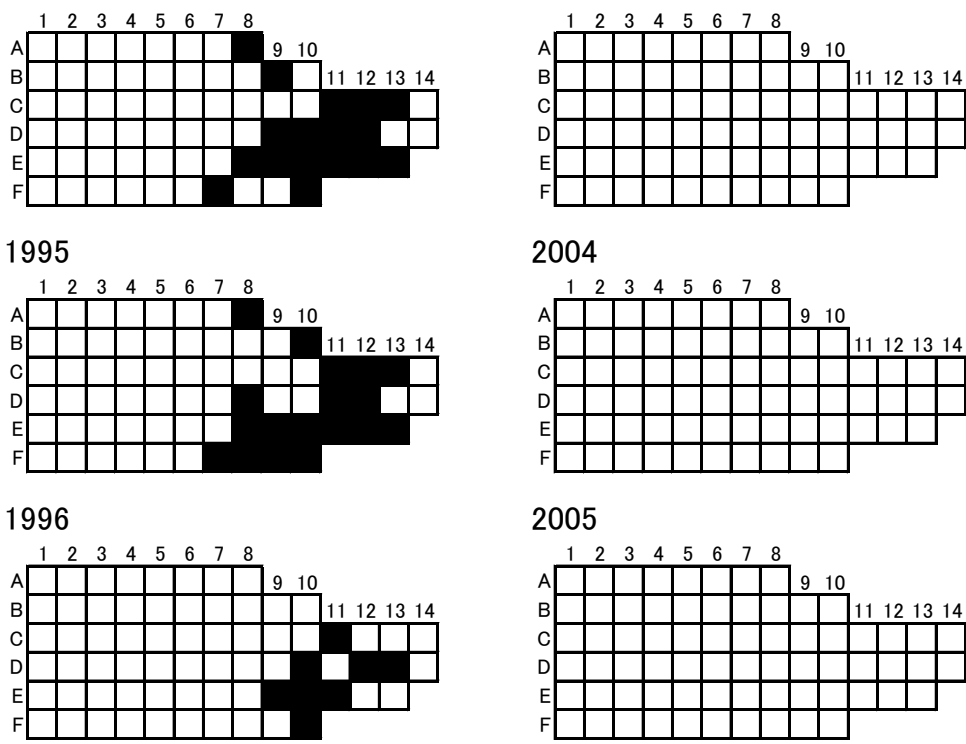

2004

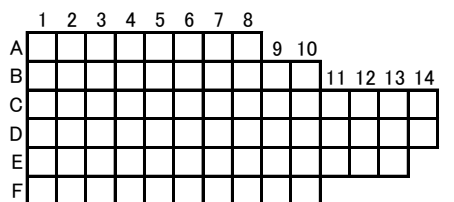

2005

1988

1997
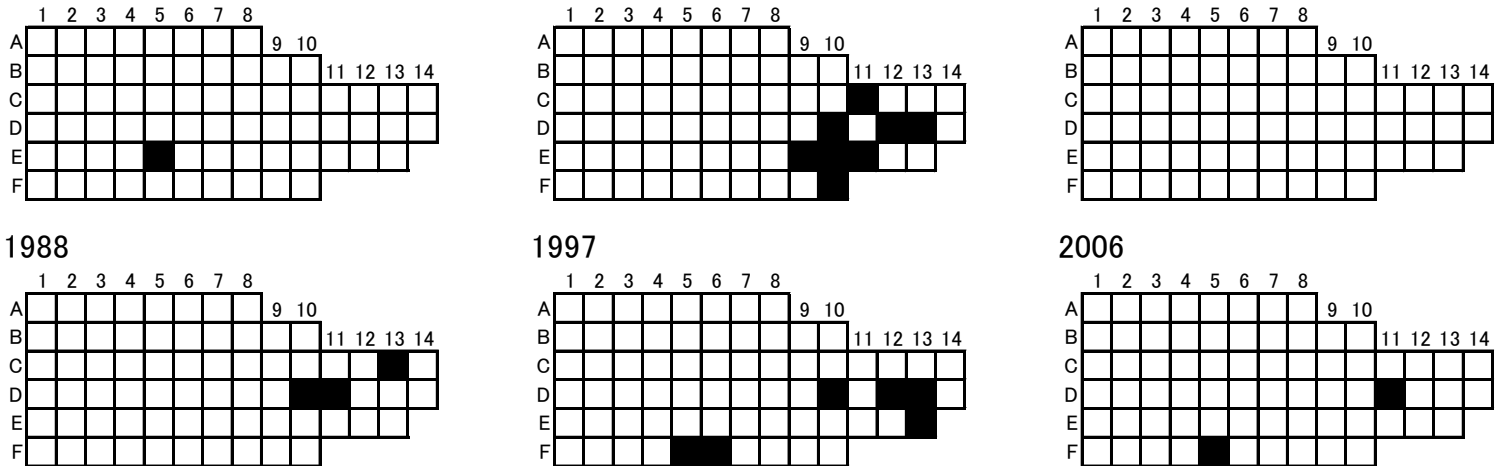

2006

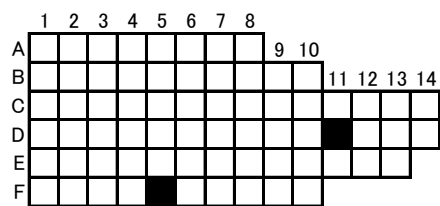

1989

1998
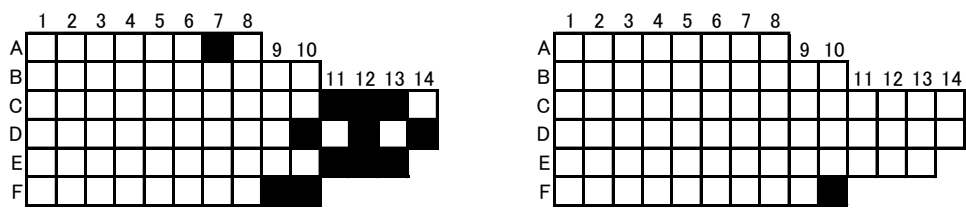

2007
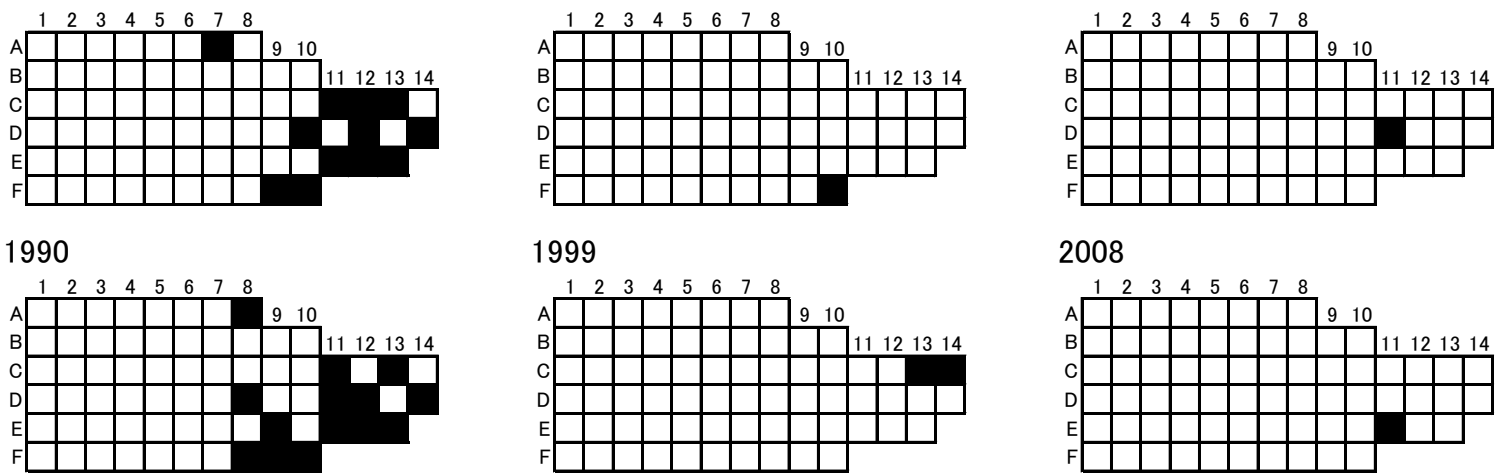

1999

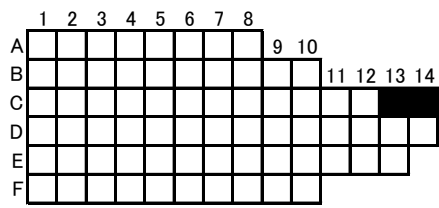

2008

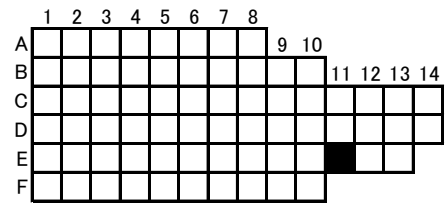

1991

2000
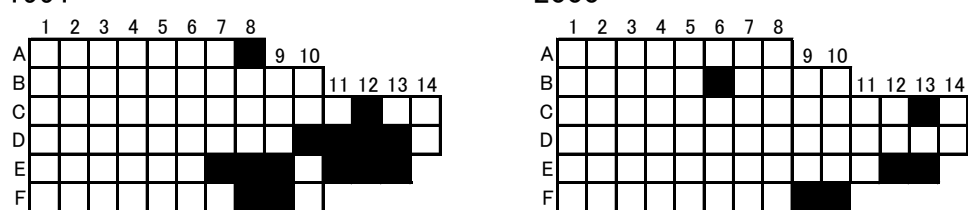

2009

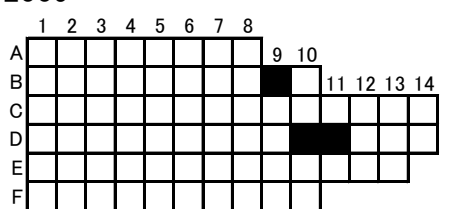

1992

2001
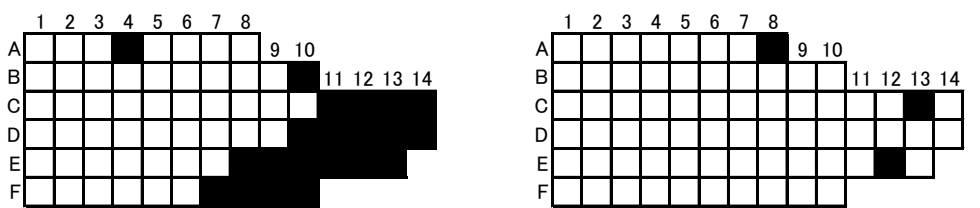

2010

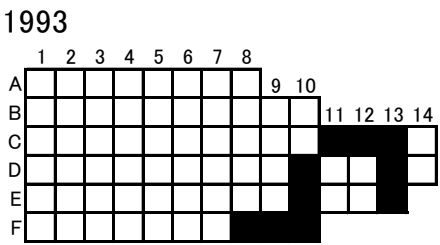

2002
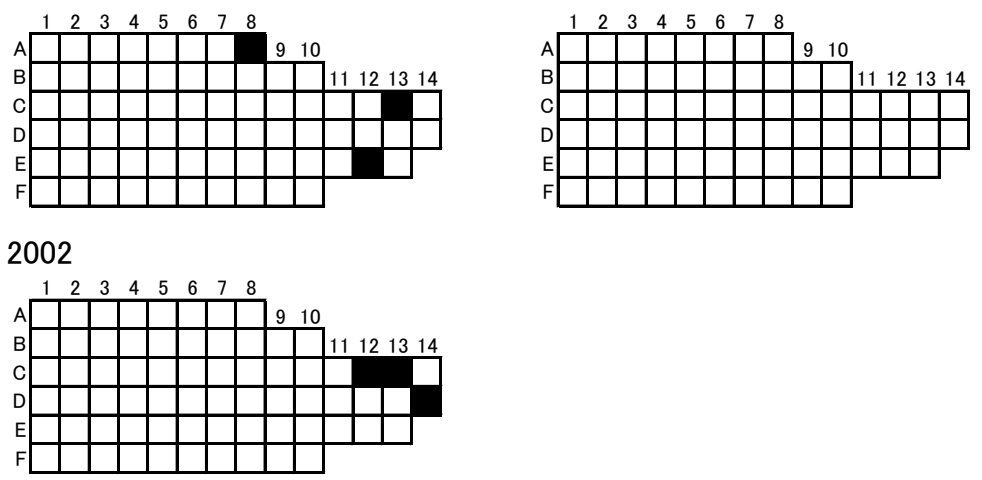
Mitrella bicincta ムギガイ

1985

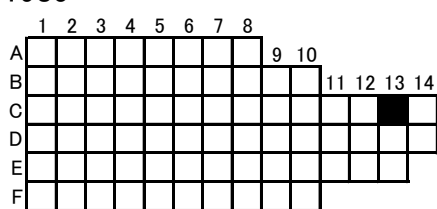

1986

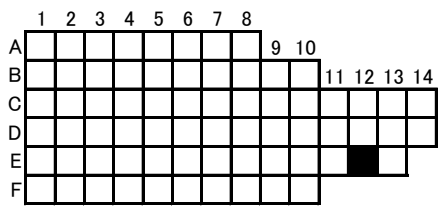

1987

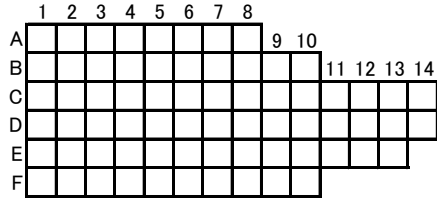

1988

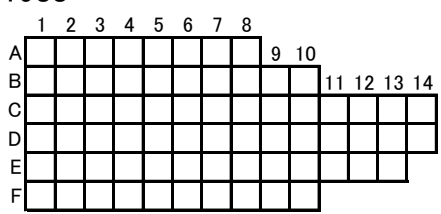

1989

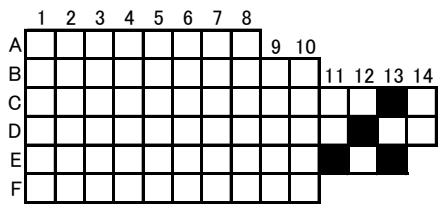

1990

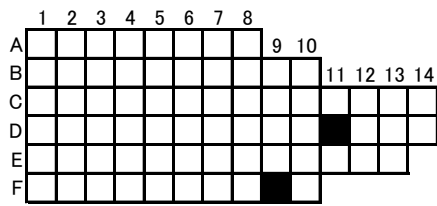

1991

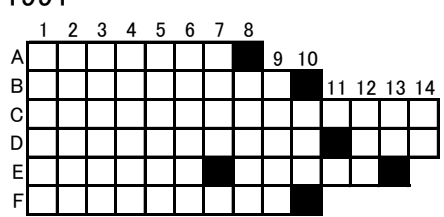

1992

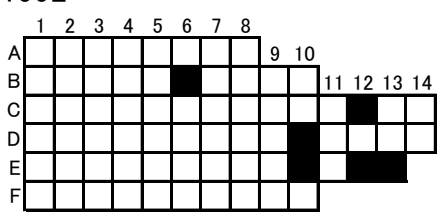

1993

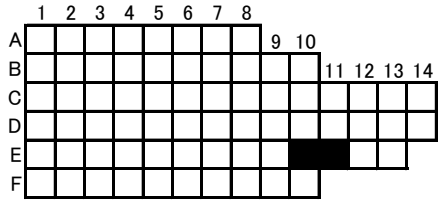

1994

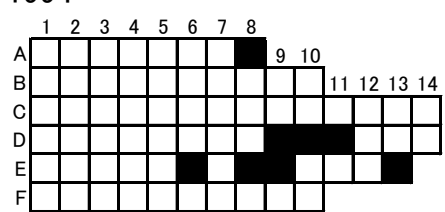

1995

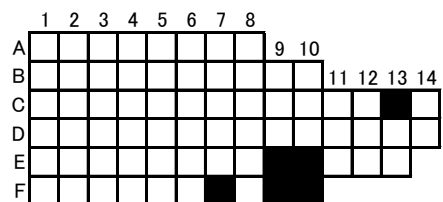

1996

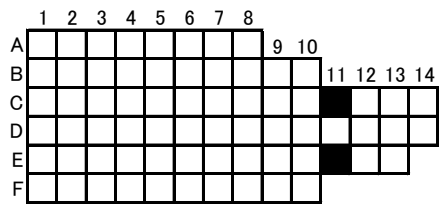

1997

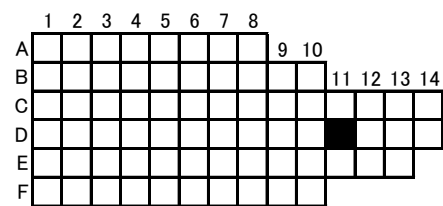

1998

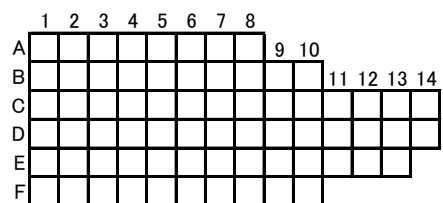

1999

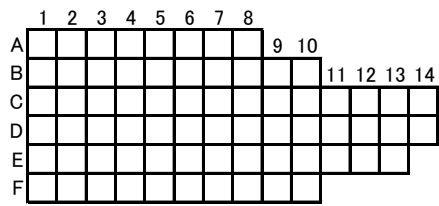

2000

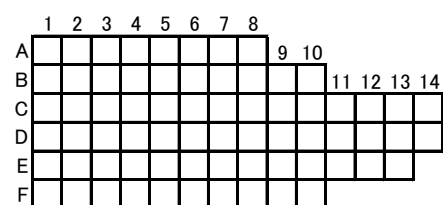

2001

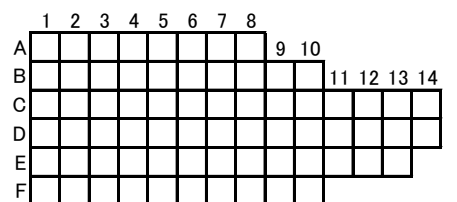

2002

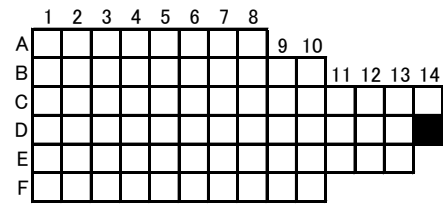

2003

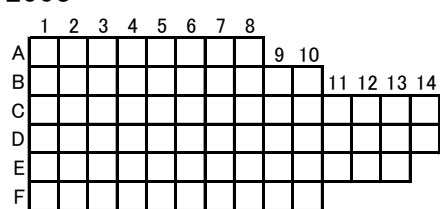

2004

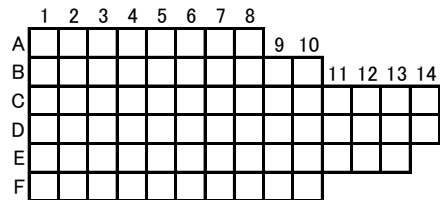

2005

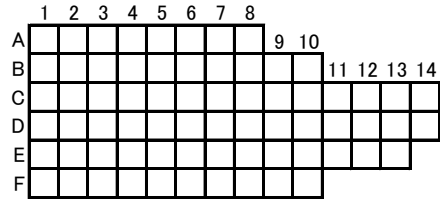

2006

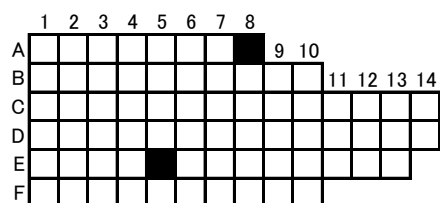

2007

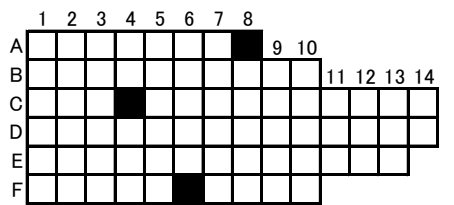

2008

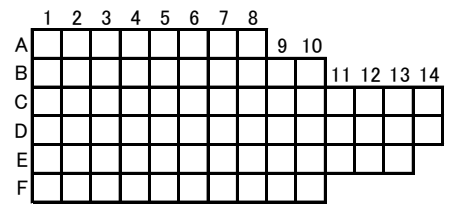

2009

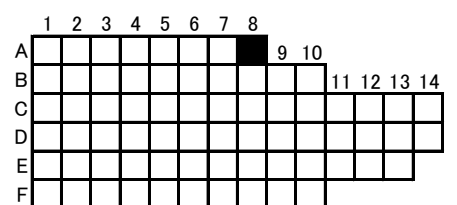

2010

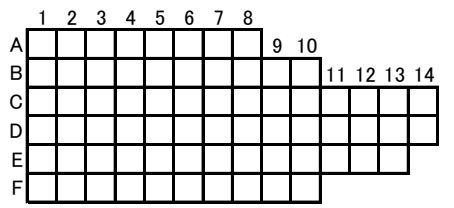




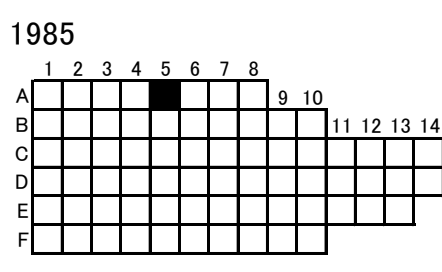

1986

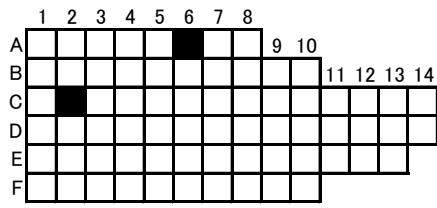

1987

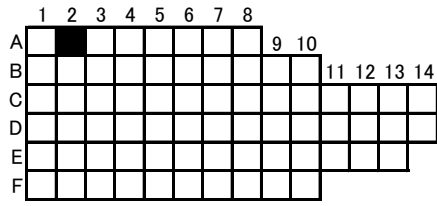

1988

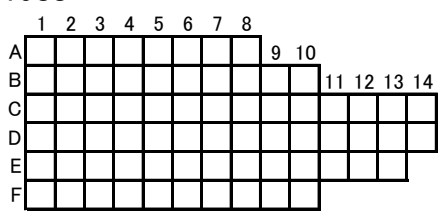

1989

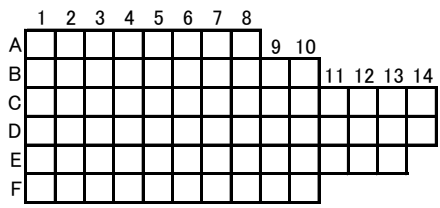

1990

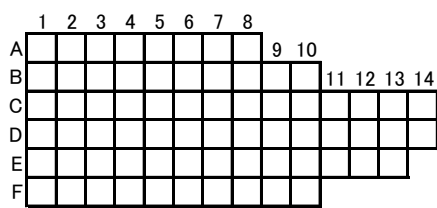

1991

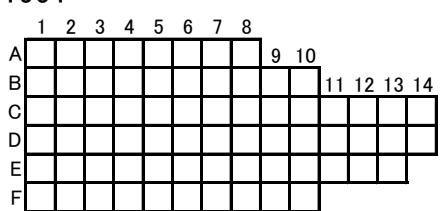

1992

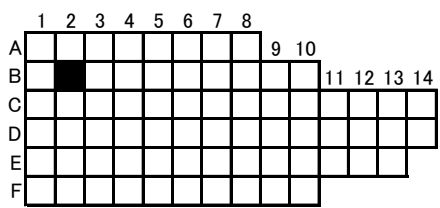

1993

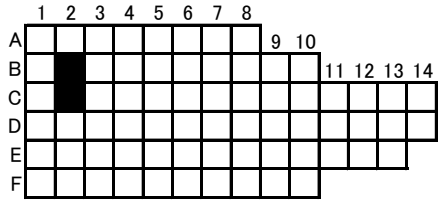

1994

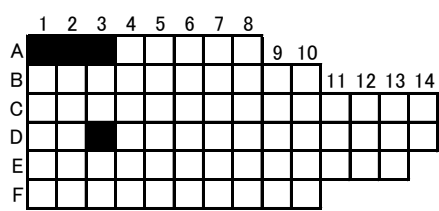

1995

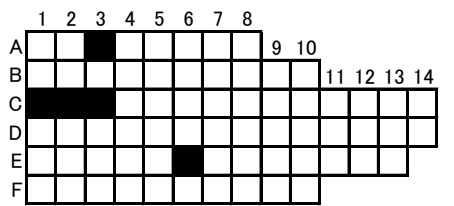

1996

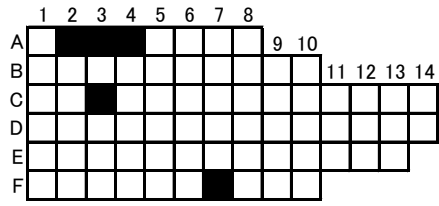

1997

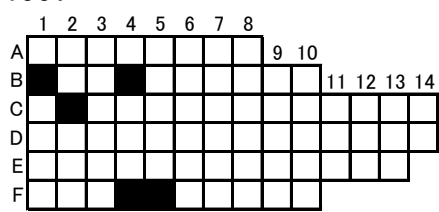

1998

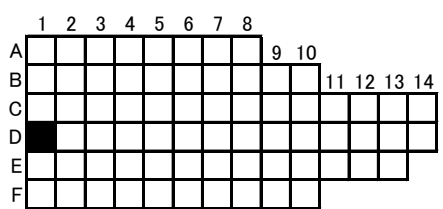

1999

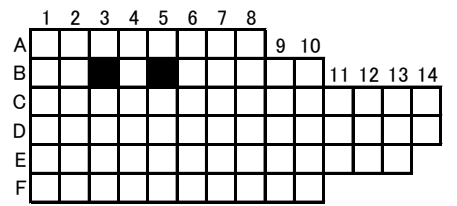

2000

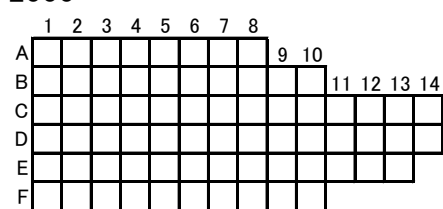

2001

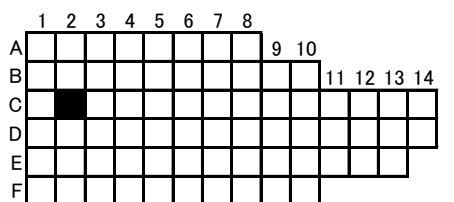

2002

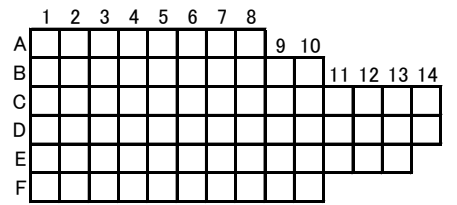

2003

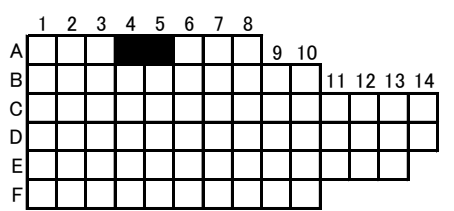

2004

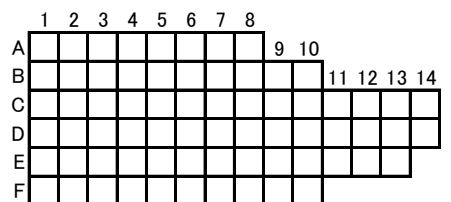

2005

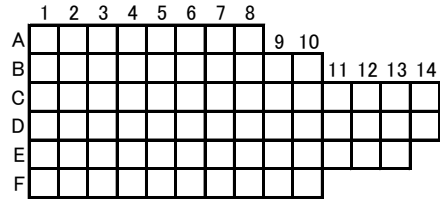

2006

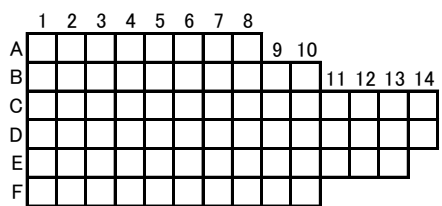

2007

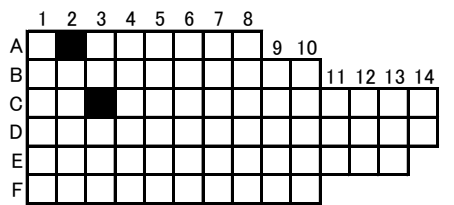

2008

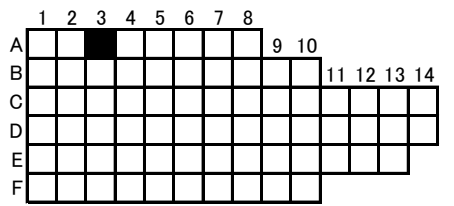

2009

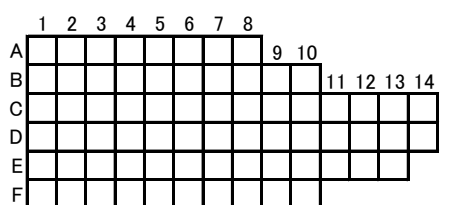

2010

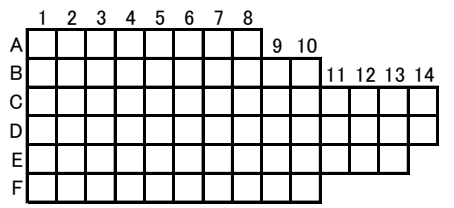


1985

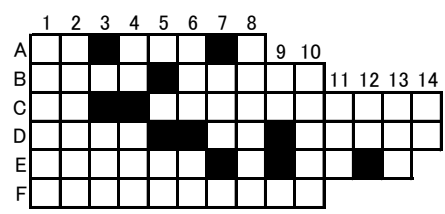

1986

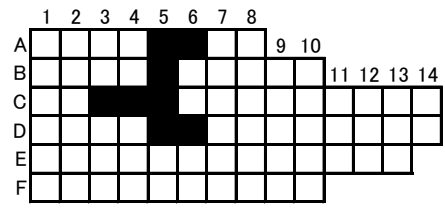

1987

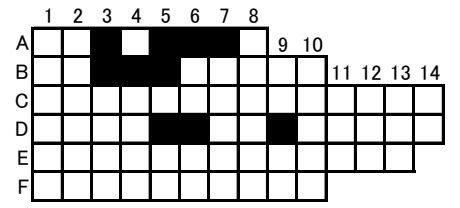

1988

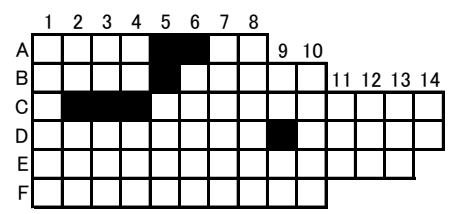

1989

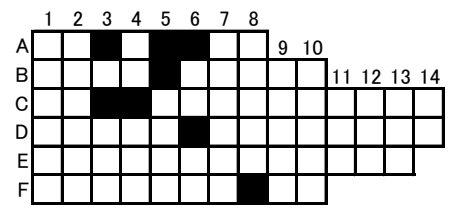

1990

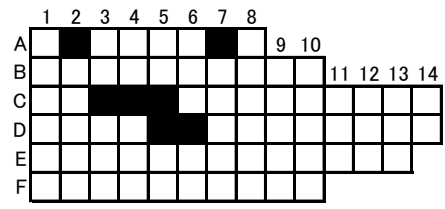

1991

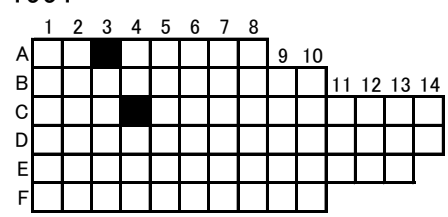

1992

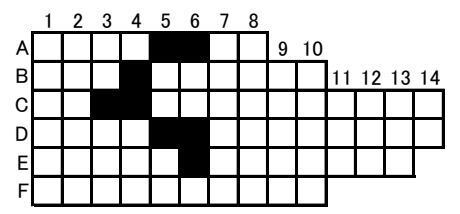

1993

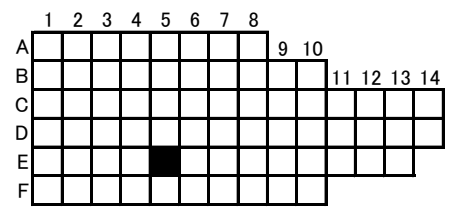

1994

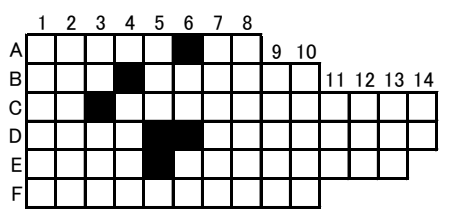

1995

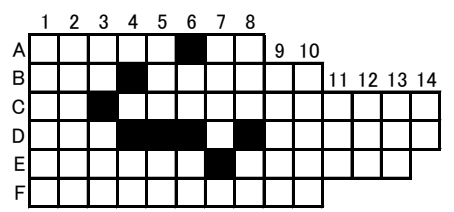

1996

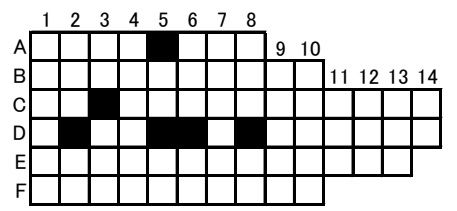

1997

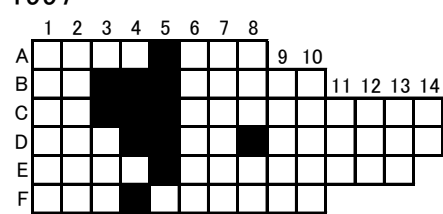

1998

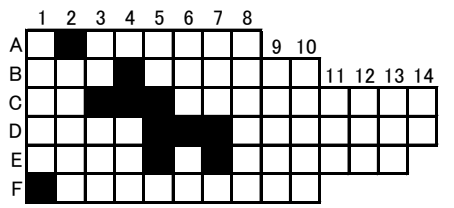

1999

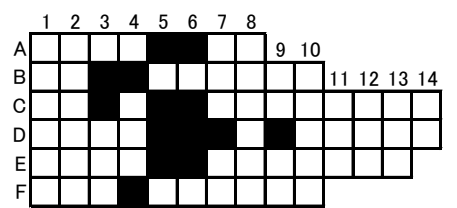

2000

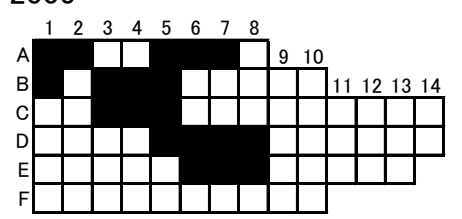

2001

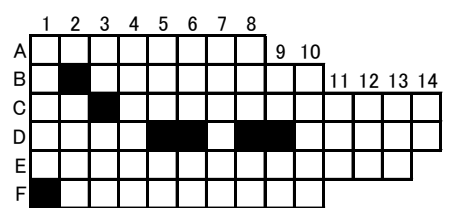

2002

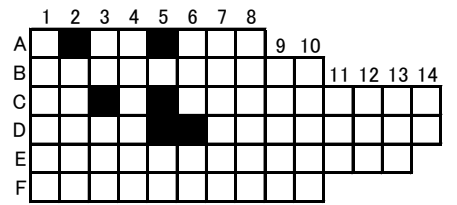

2003

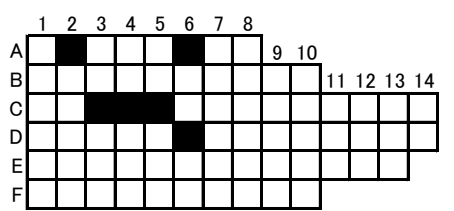

2004

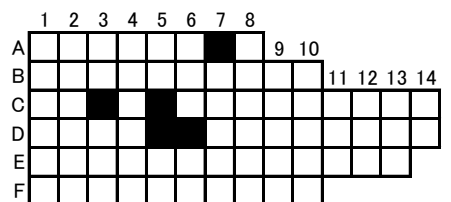

2005

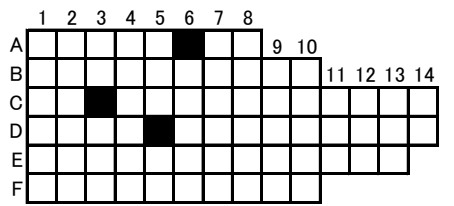

2006

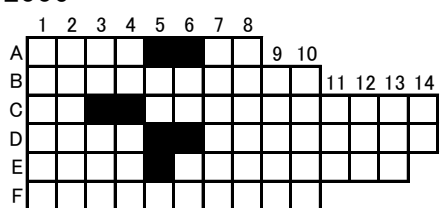

2007

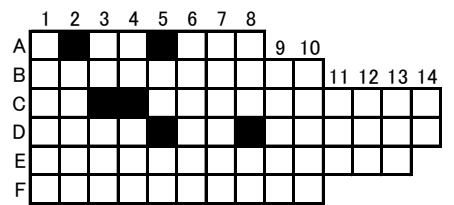

2008

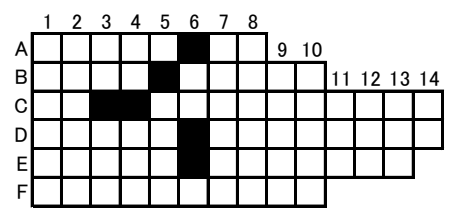

2009

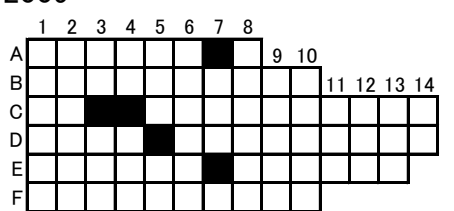

2010

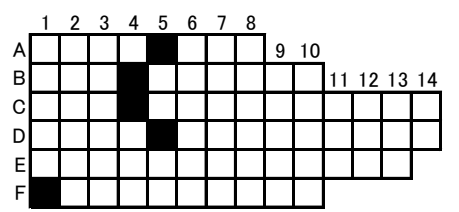


161 1985

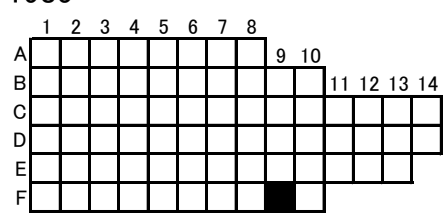

1986

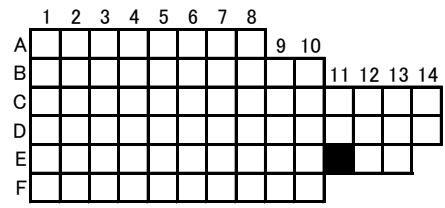

1987

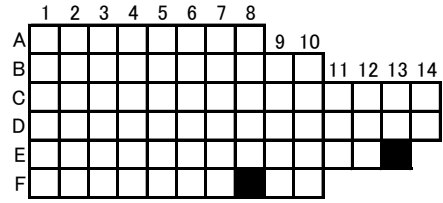

1988

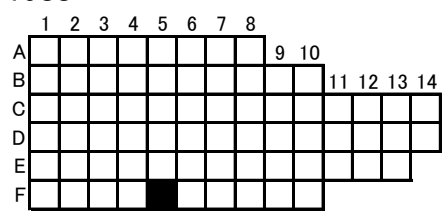

1989

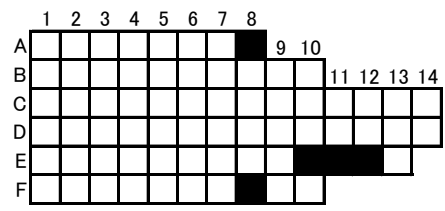

1990

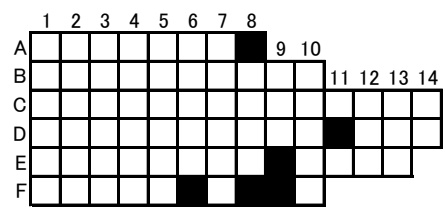

1991

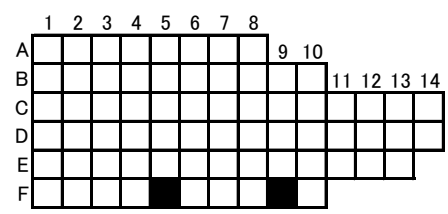

1992

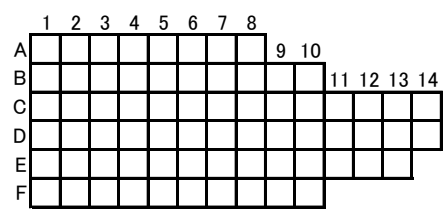

1993

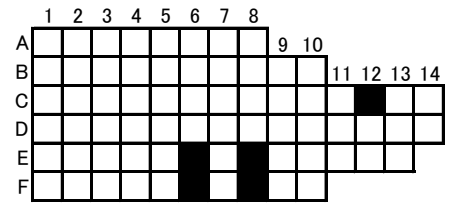

1994

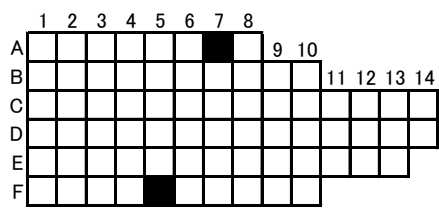

1995

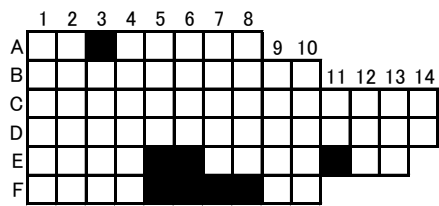

1996

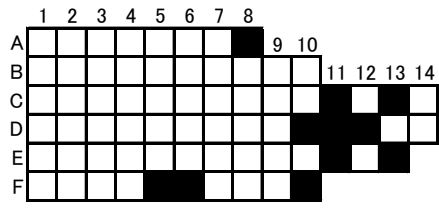

1997

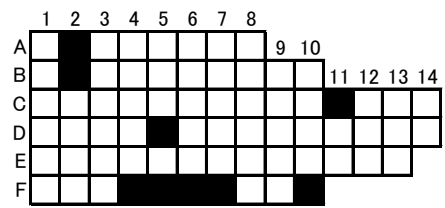

1998

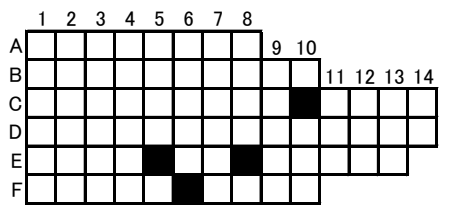

1999

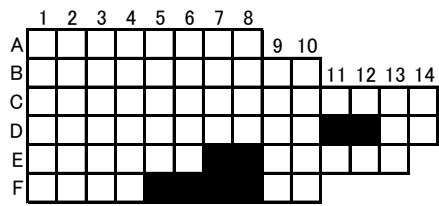

2000

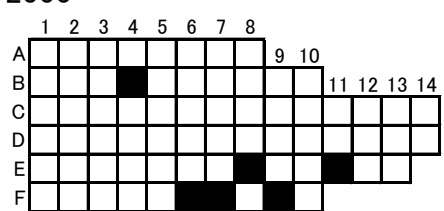

2001

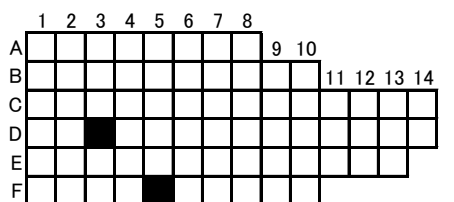

2002

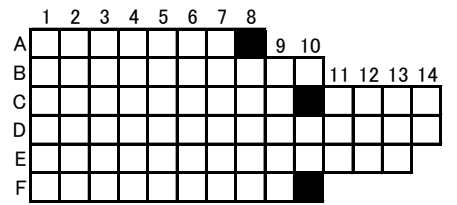

2003

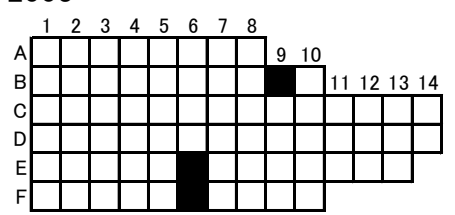

2004

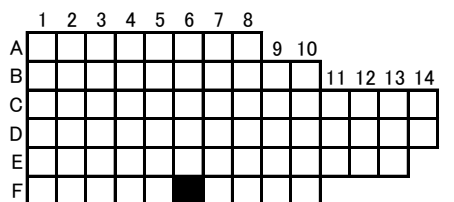

2005

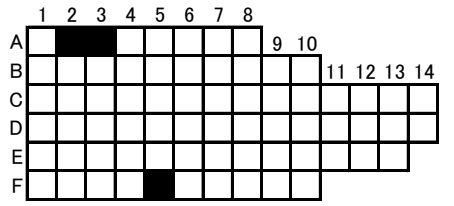

2006

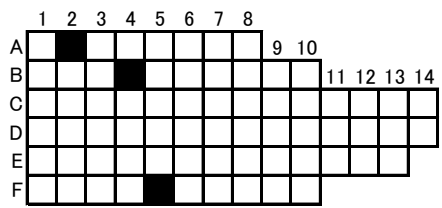

2007

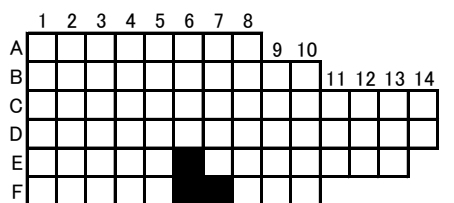

2008

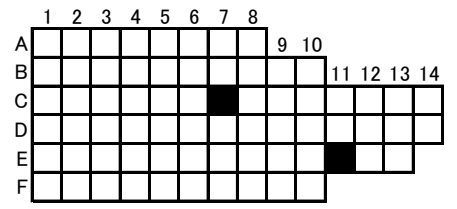

2009

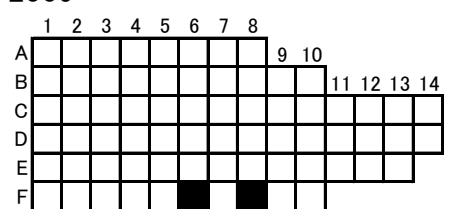

2010

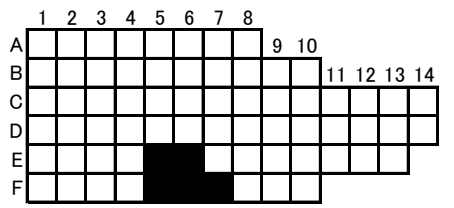




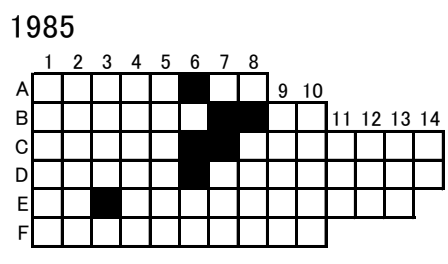

1986

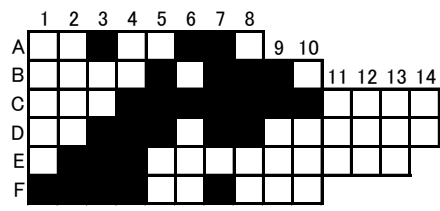

1987

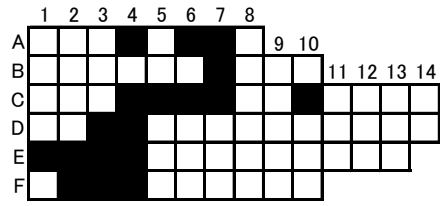

1988

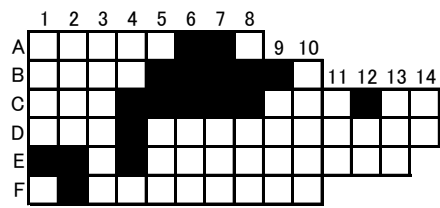

1989

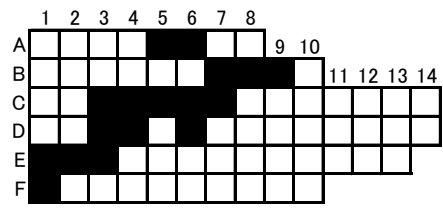

1990

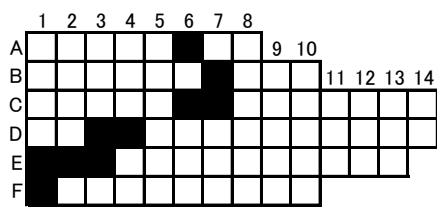

1991

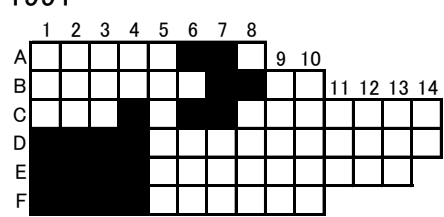

1992

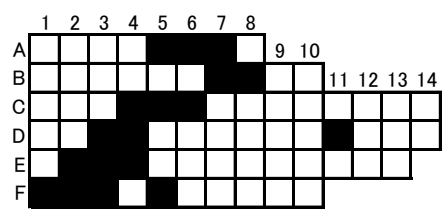

1993

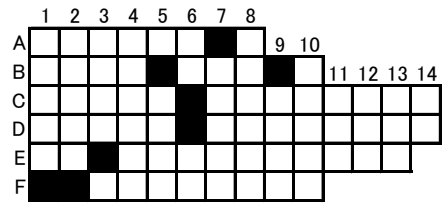

1994

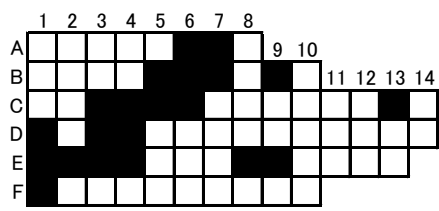

1995

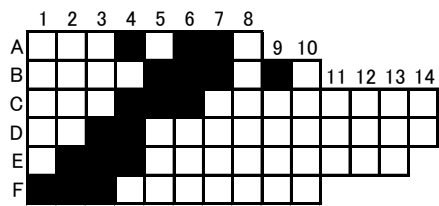

1996

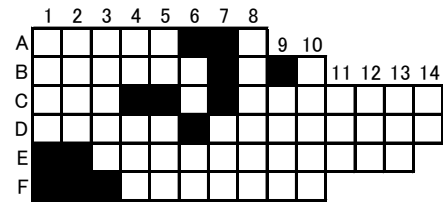

1997

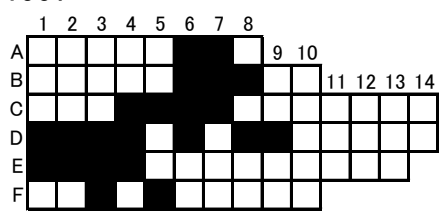

1998

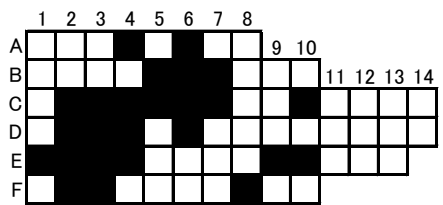

1999

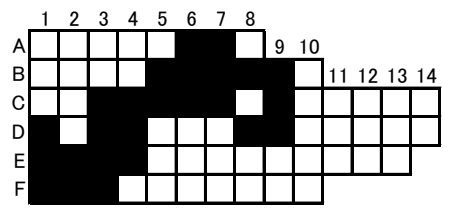

2000

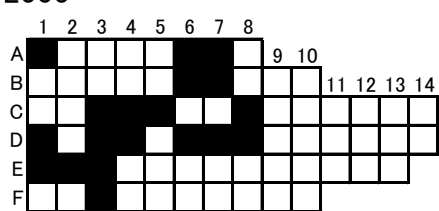

2001

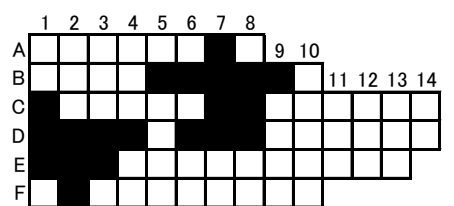

2002

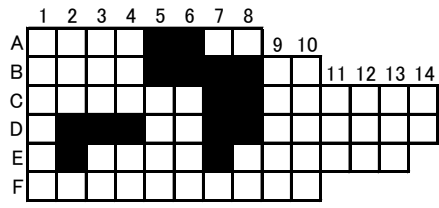

2003

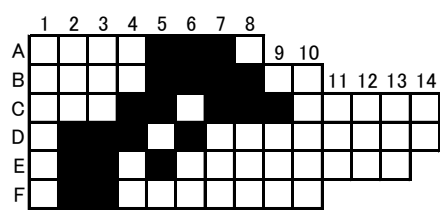

2004

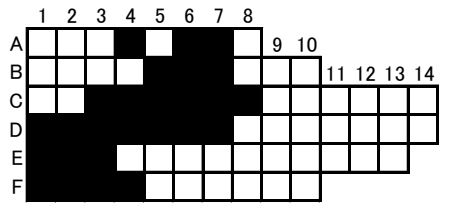

2005

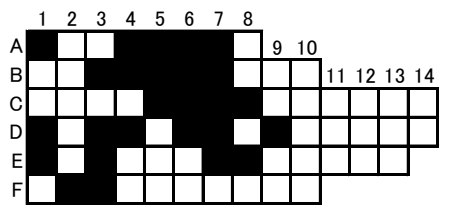

2006

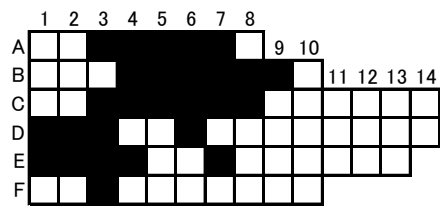

2007

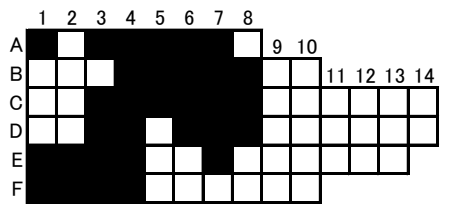

2008

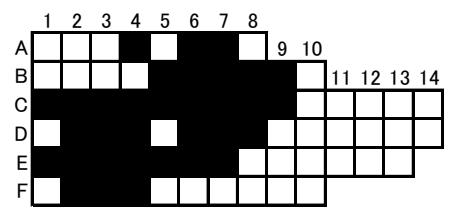

2009

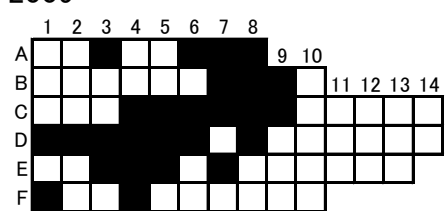

2010

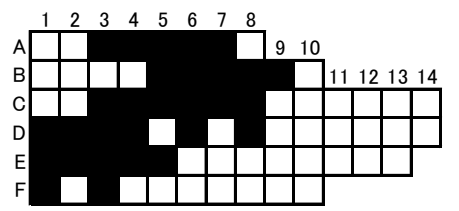


カラマツガイ

1985
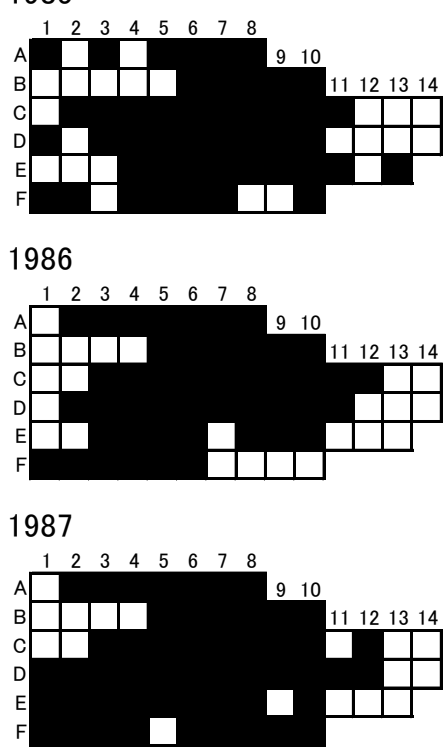

1988

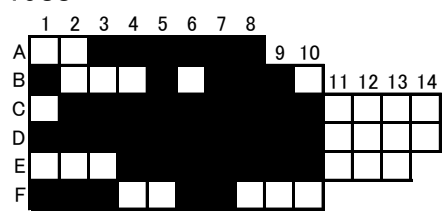

1989

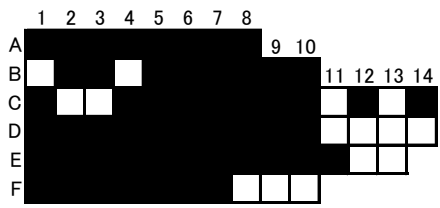

1990

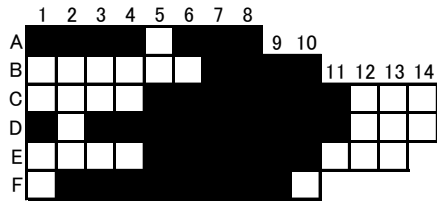

1991

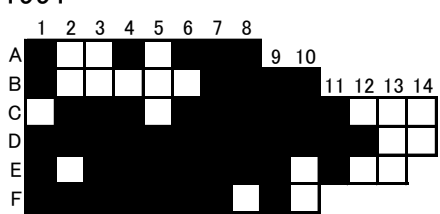

1992

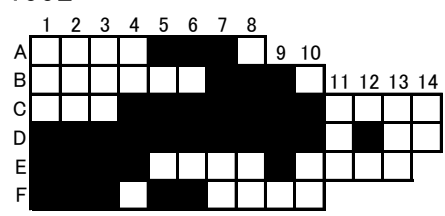

1993

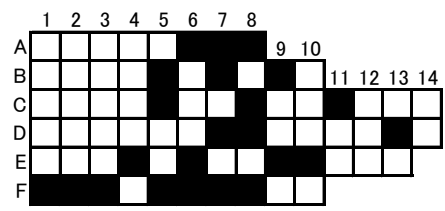

1994

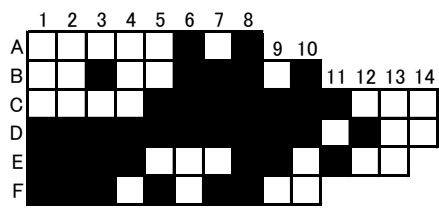

1995

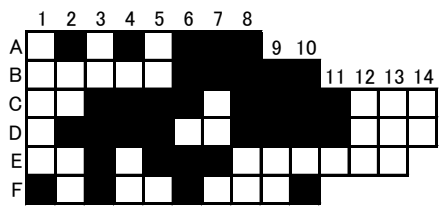

1996

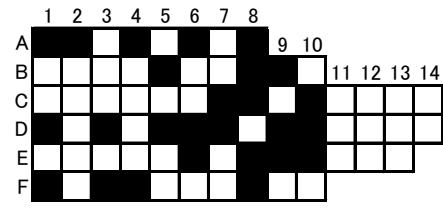

1997

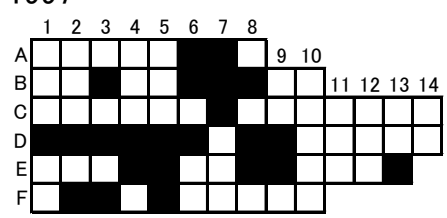

1998

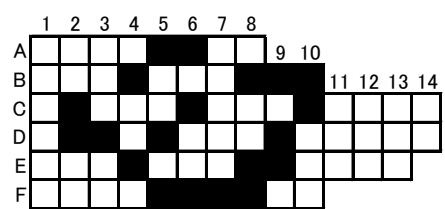

1999

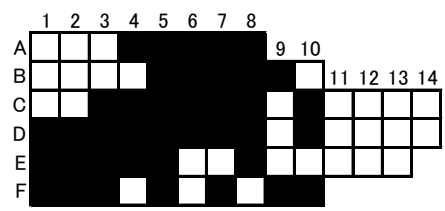

2000

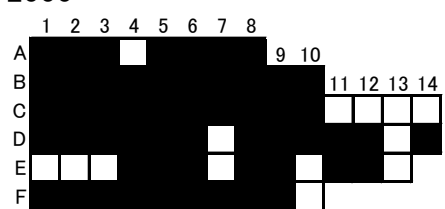

2001

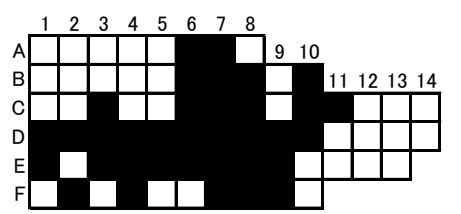

2002

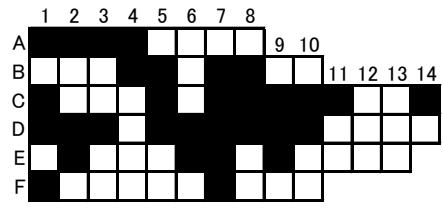

2003

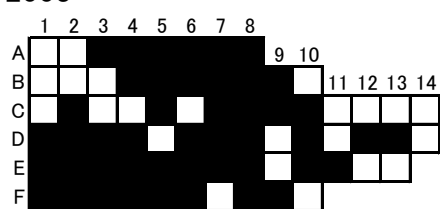

2004

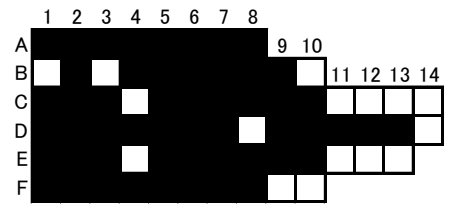

2005

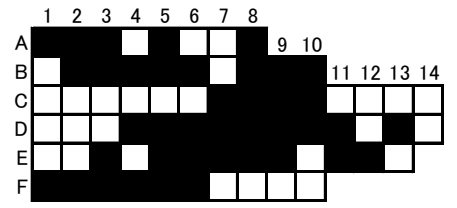

2006

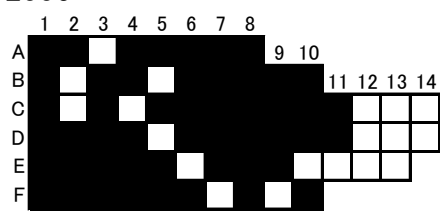

2007

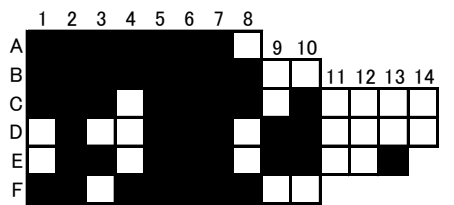

2008

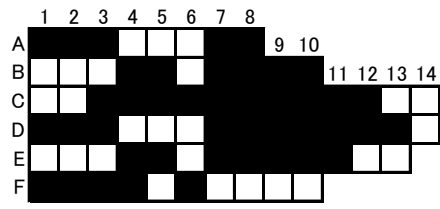

2009

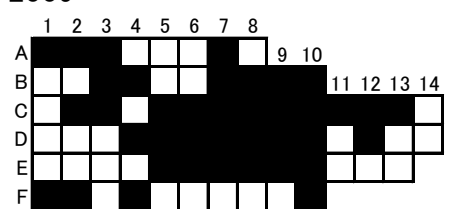

2010

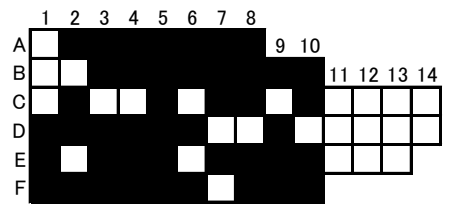


キクノハナガイ

1985

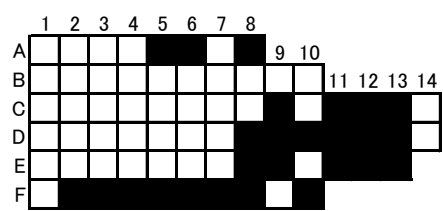

1986

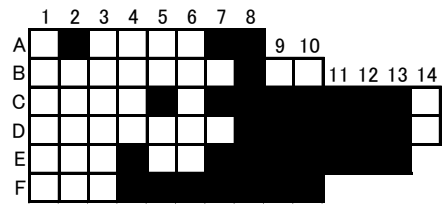

1987

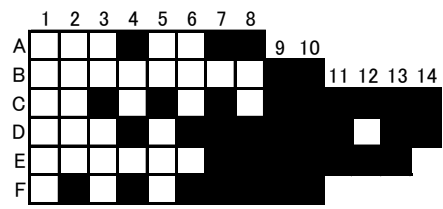

1988

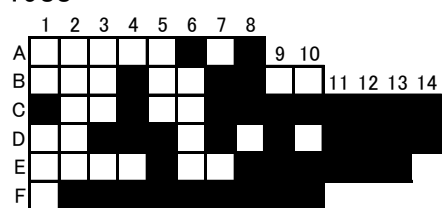

1989
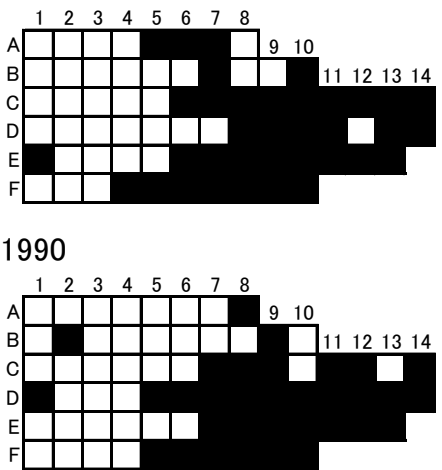

1991

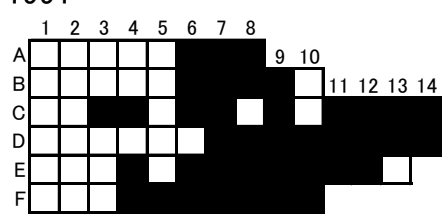

1992

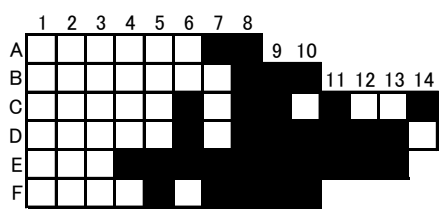

1993

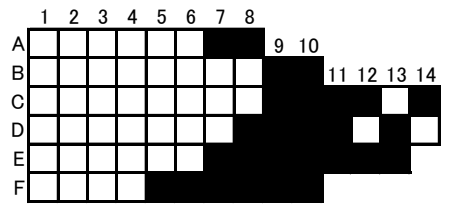

1994

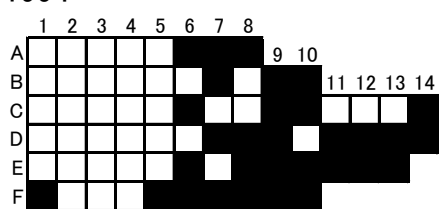

1995

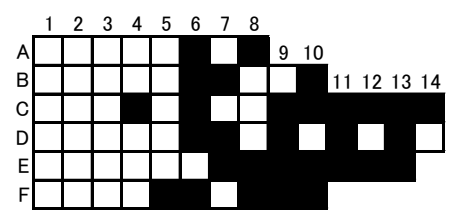

1996

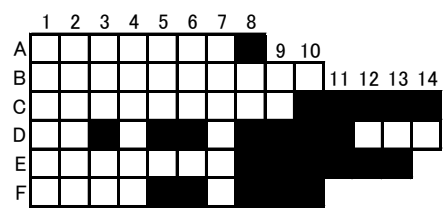

1997

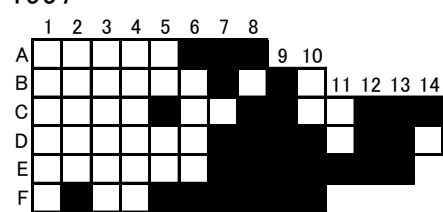

1998

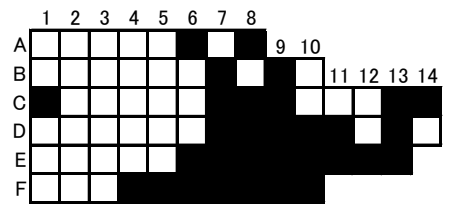

1999

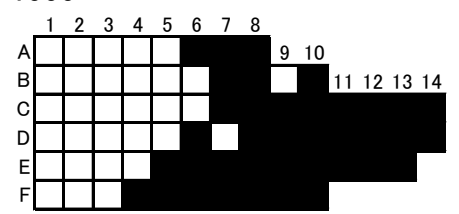

2000

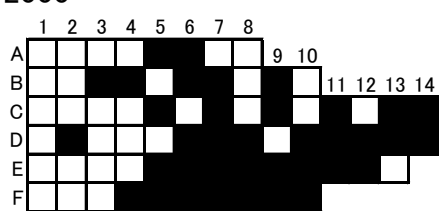

2001

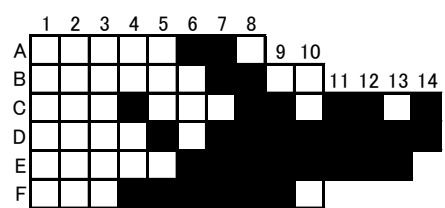

2002

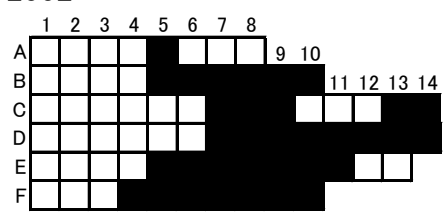

2003

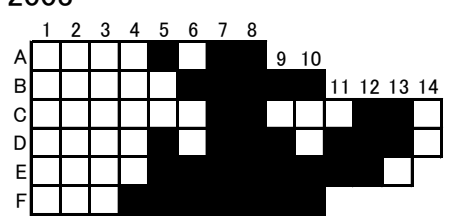

2004

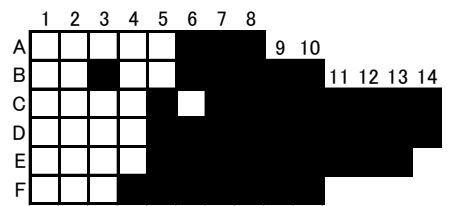

2005

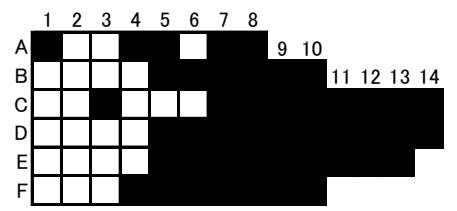

2006

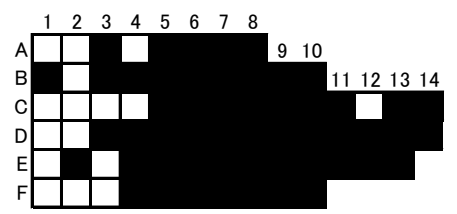

2007

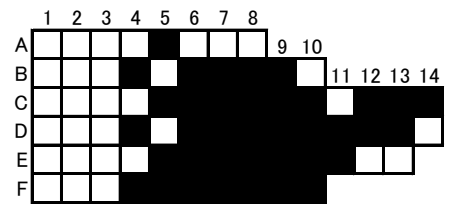

2008

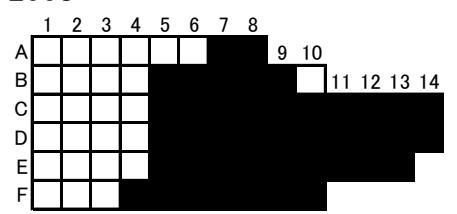

2009

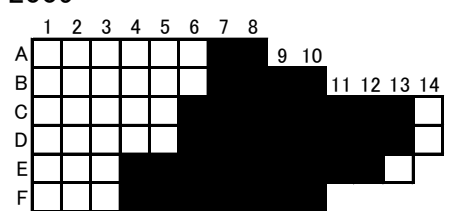

2010

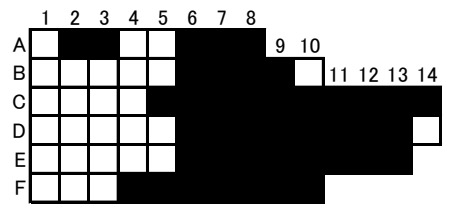




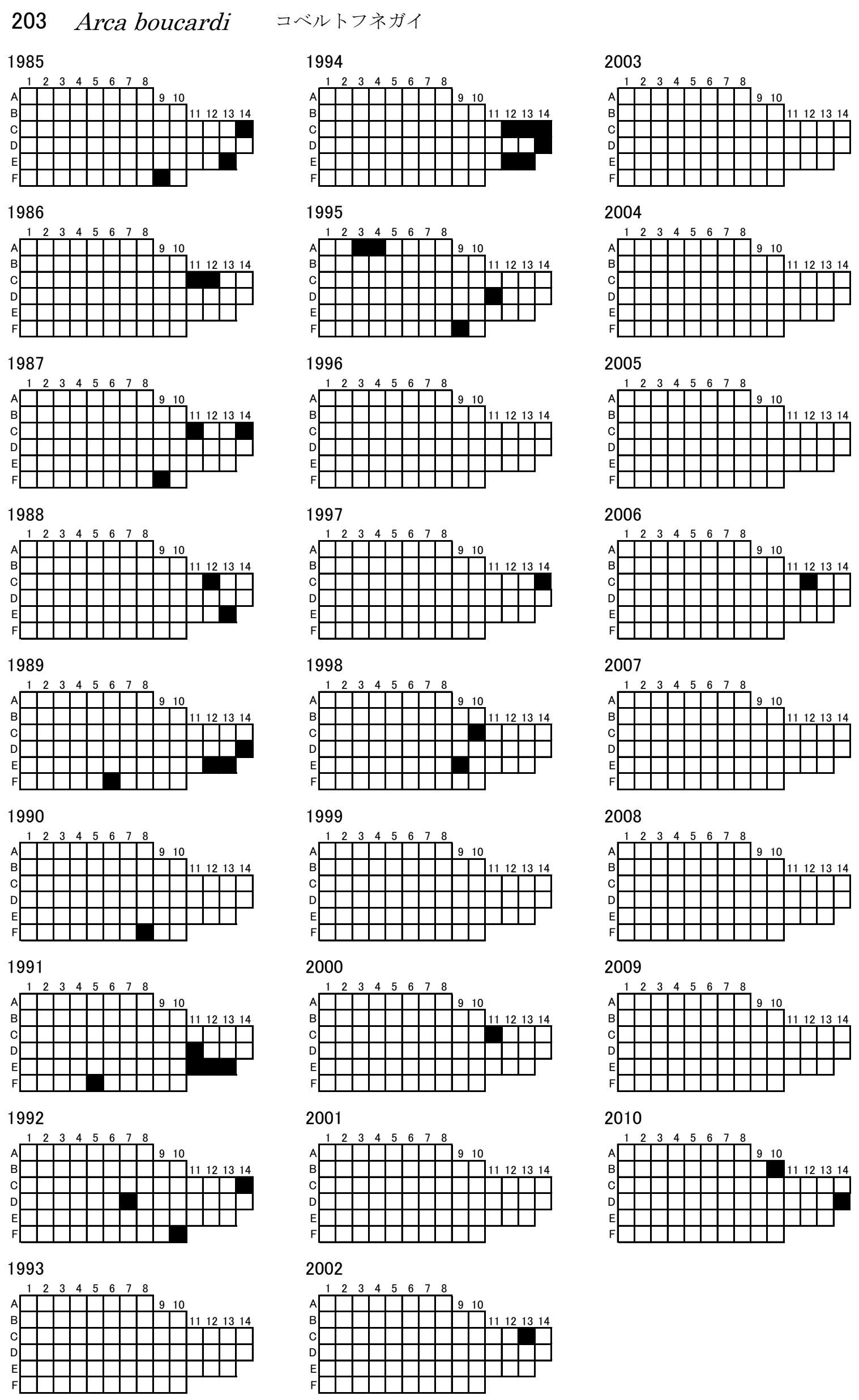


1985

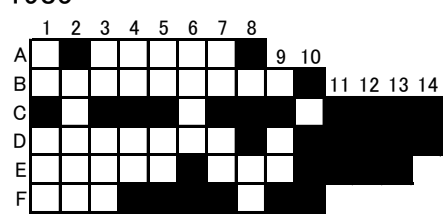

1986

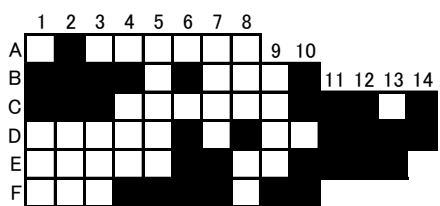

1987

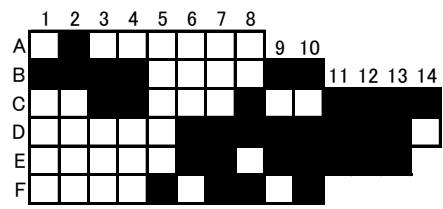

1988

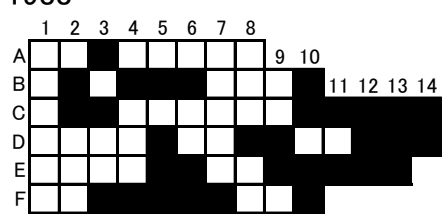

1989

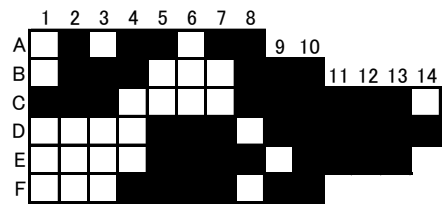

1990

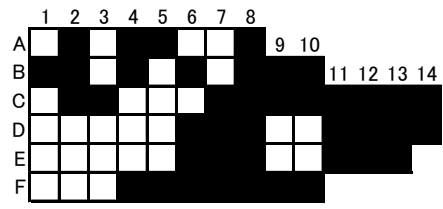

1991

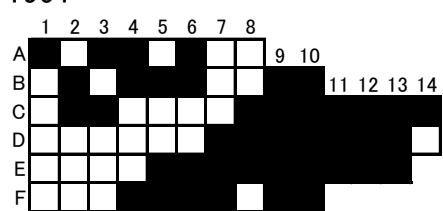

1992

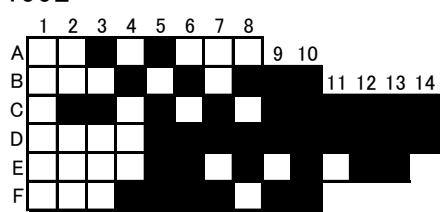

1993

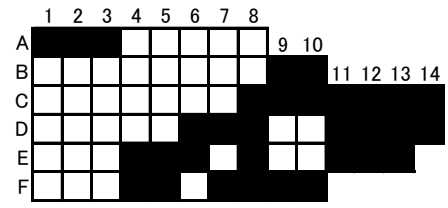

1994

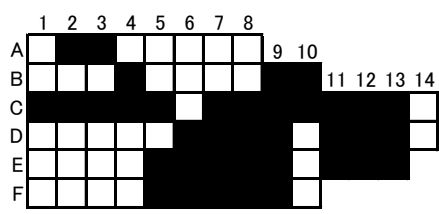

1995

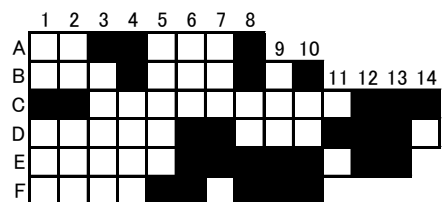

1996

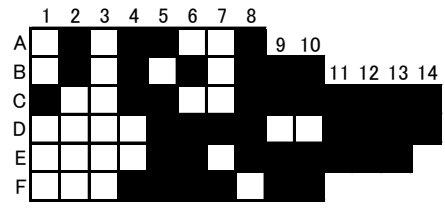

1997

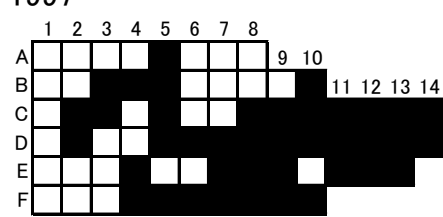

1998

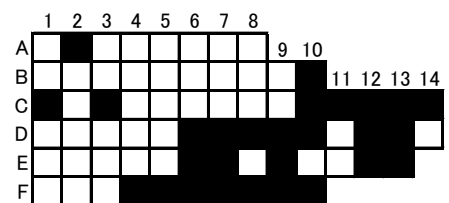

1999

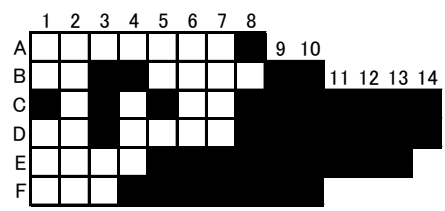

2000

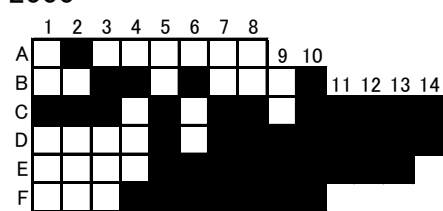

2001

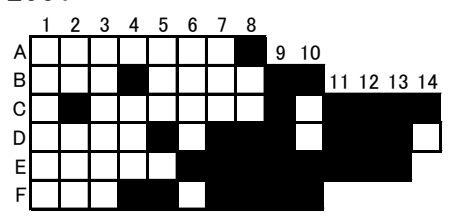

2002

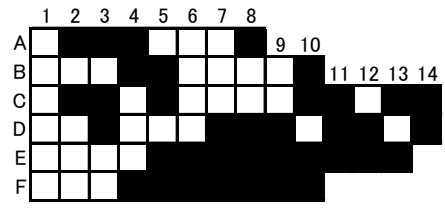

2003

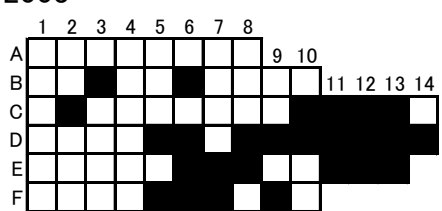

2004

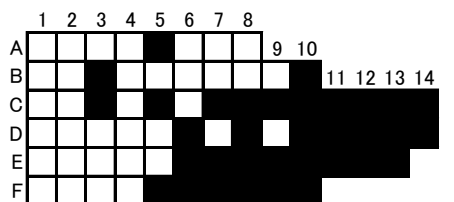

2005

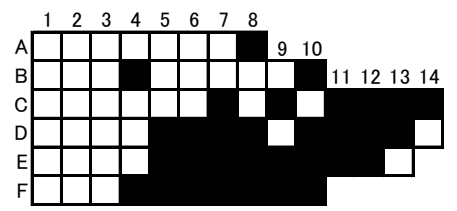

2006

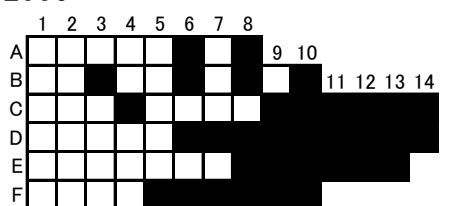

2007

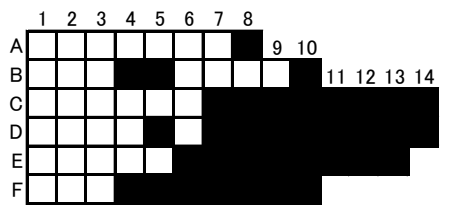

2008

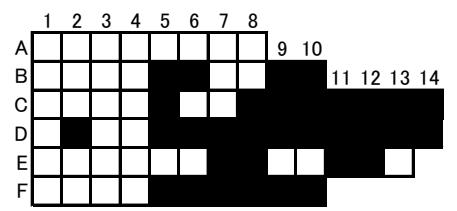

2009

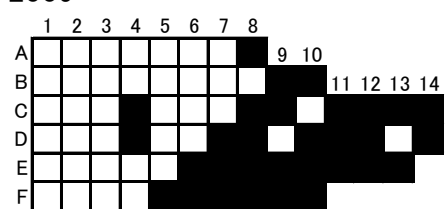

2010

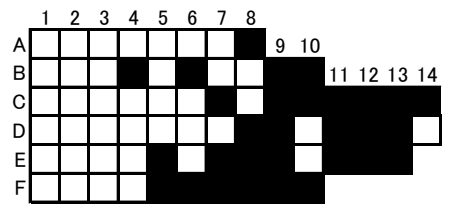


210 Mytilus galloprovincialis ムラサキイガイ
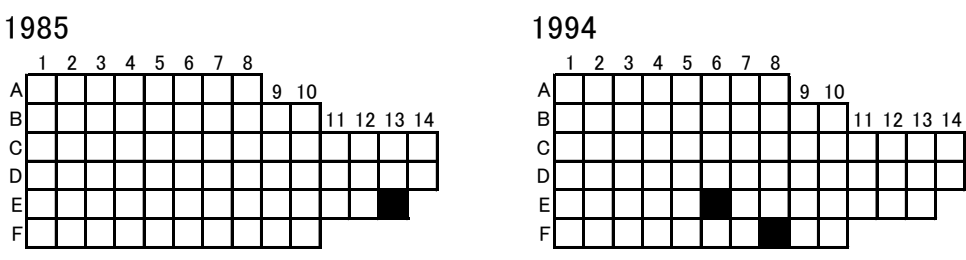

2003

1986

1995
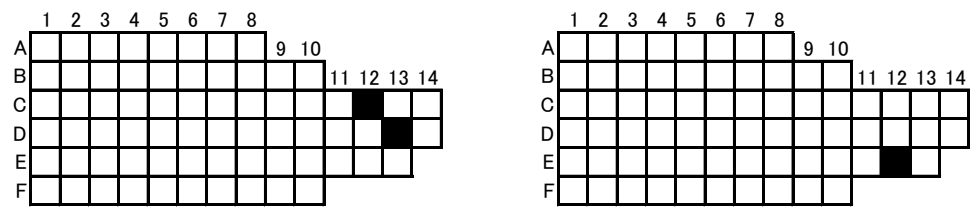

1987

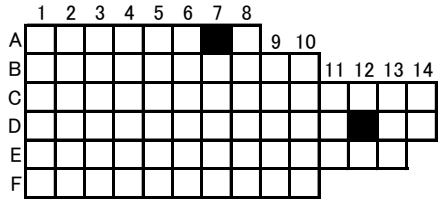

1996
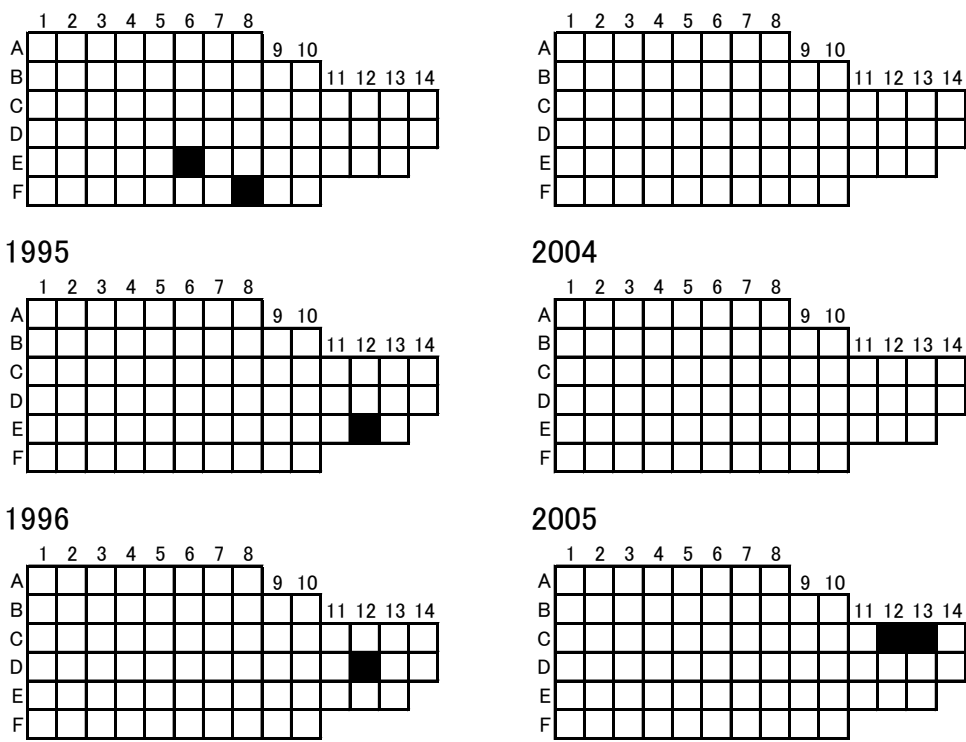

2004

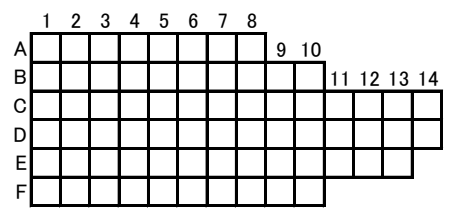

2005

1988

1997
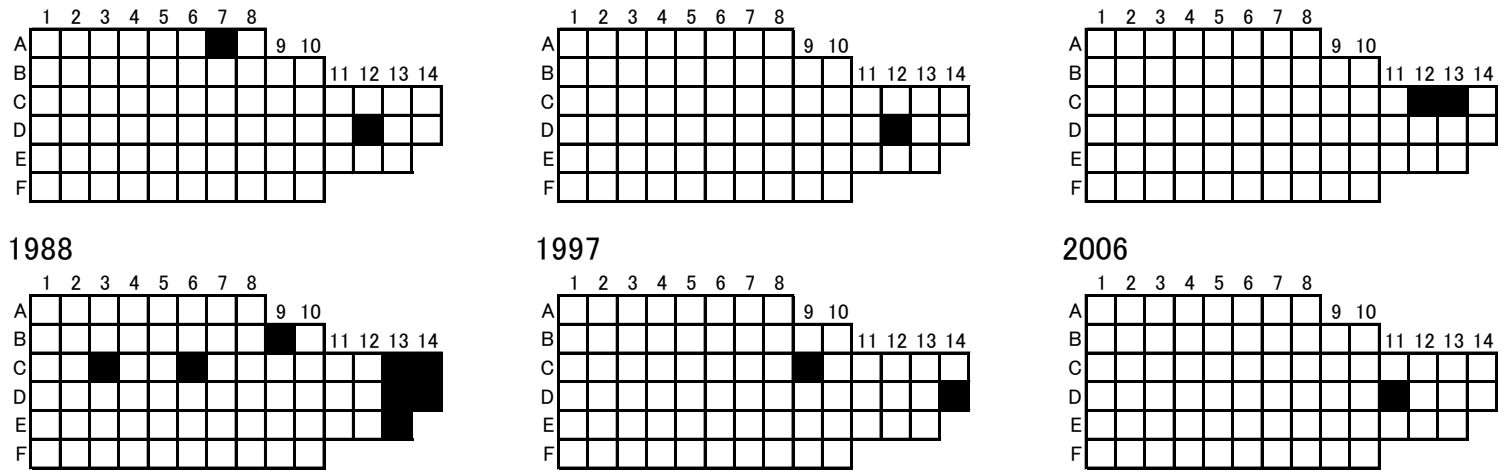

2006

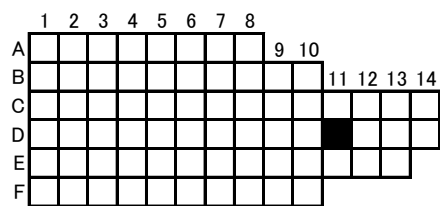

1989

1998
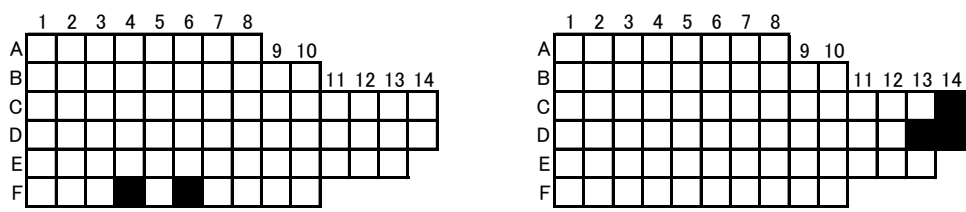

2007
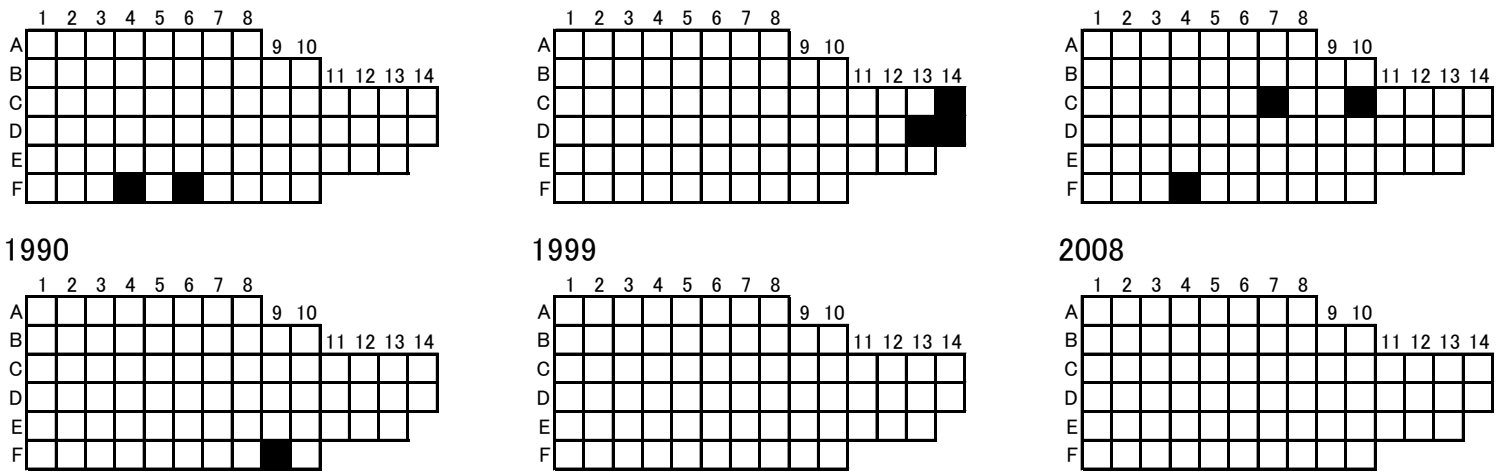

1999

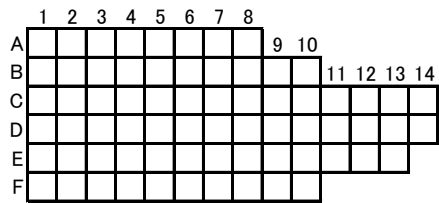

2008

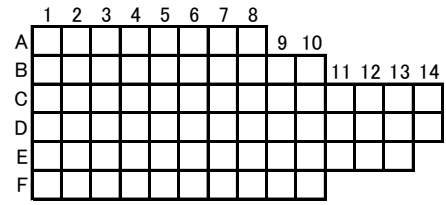

1991

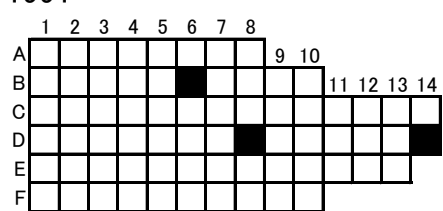

2000

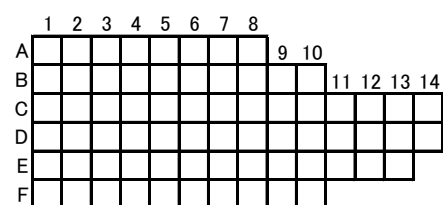

2009

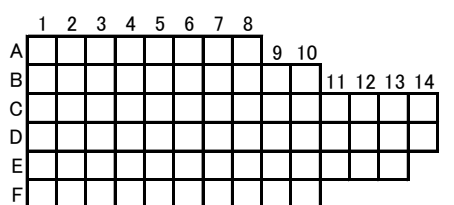

1992

2001
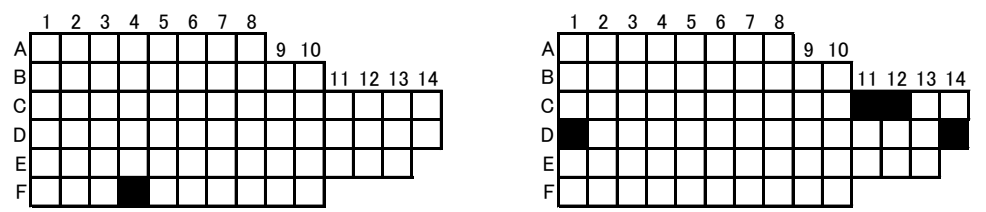

2010

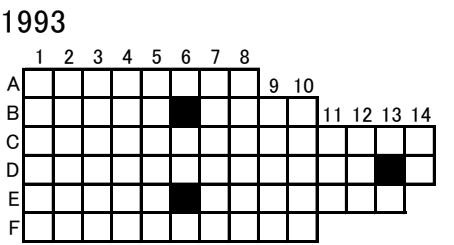

2002

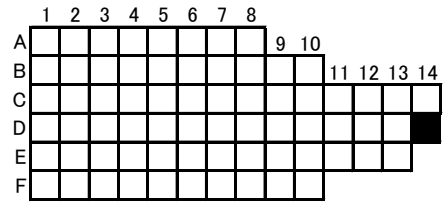

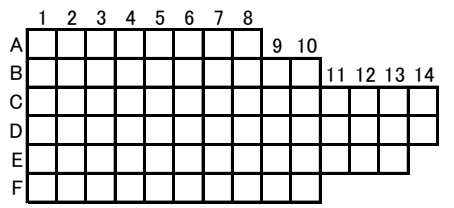


211 Xenostrobus atratus クログチ

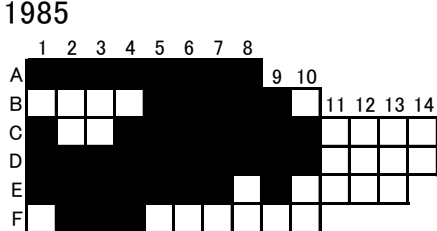

1986

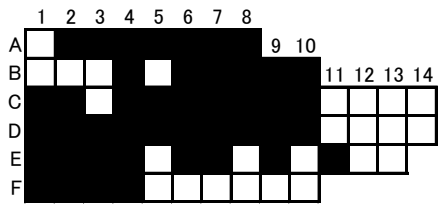

1987

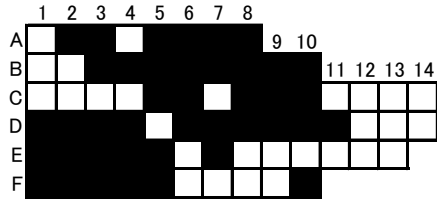

1988

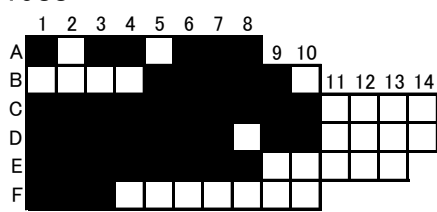

1989

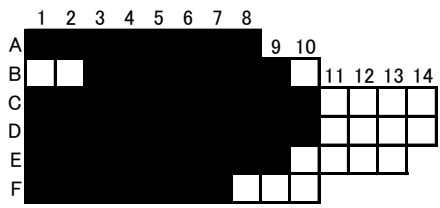

1990

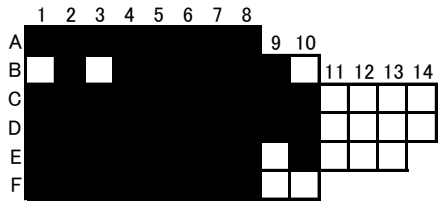

1991

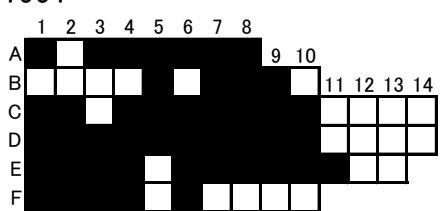

1992

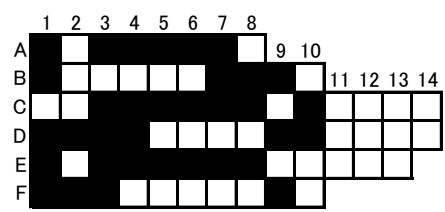

1993

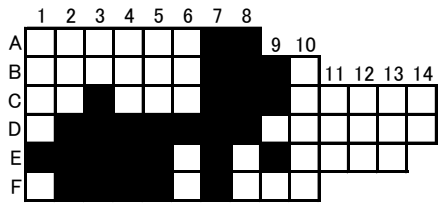

1994

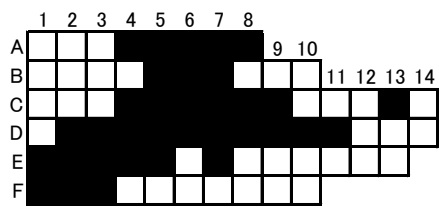

1995

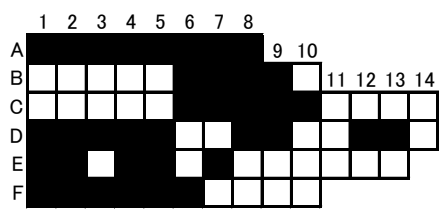

1996

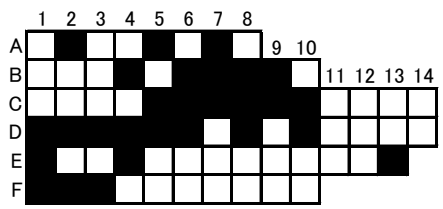

1997

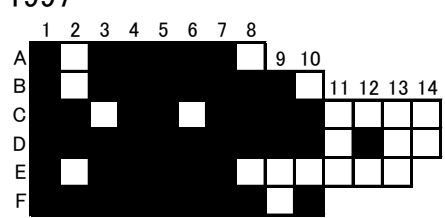

1998

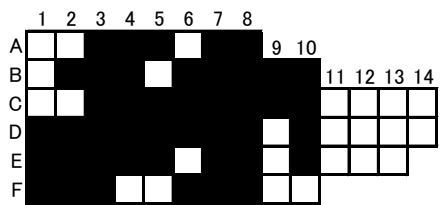

1999

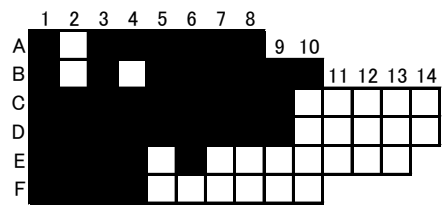

2000

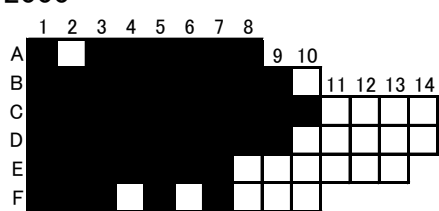

2001

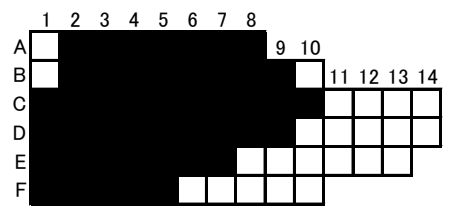

2002

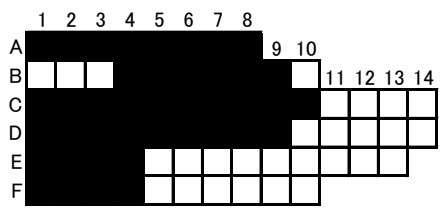

2003

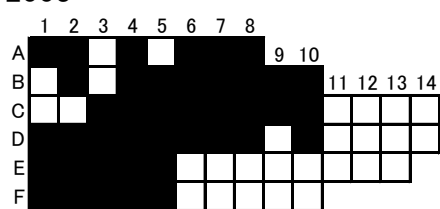

2004

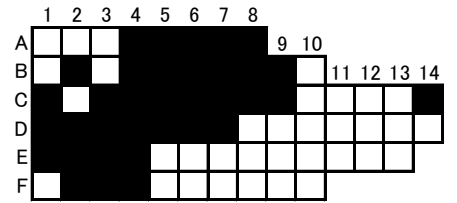

2005

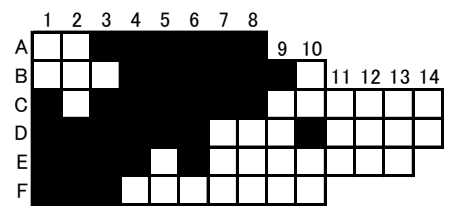

2006

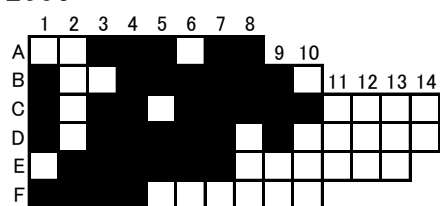

2007

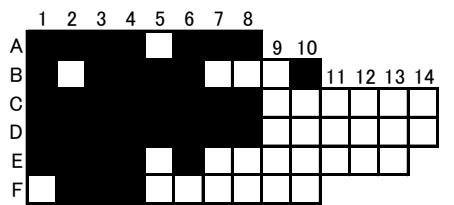

2008

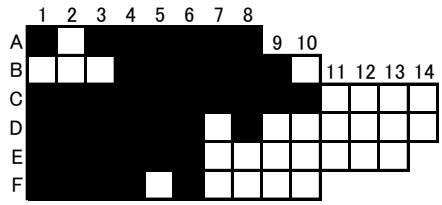

2009

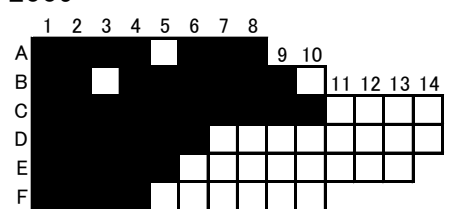

2010

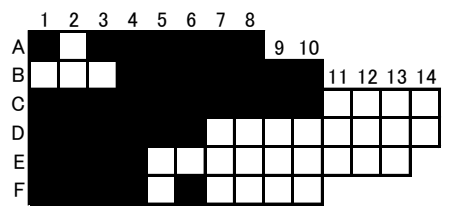


212 Hormomya mutabilis ヒバリガイモドキ

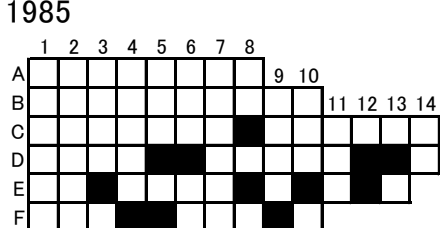

1986

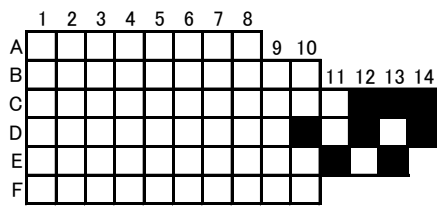

1987

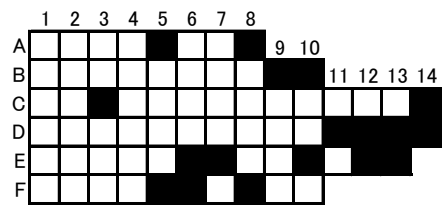

1988

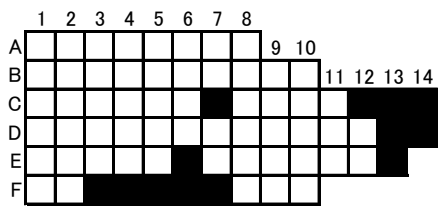

1989

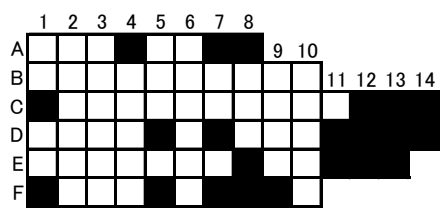

1990

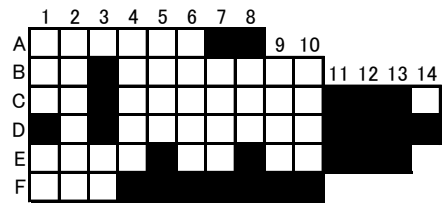

1991

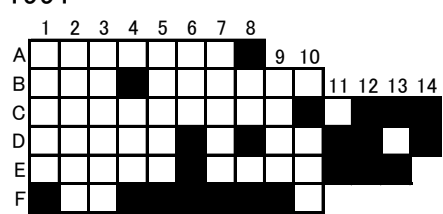

1992

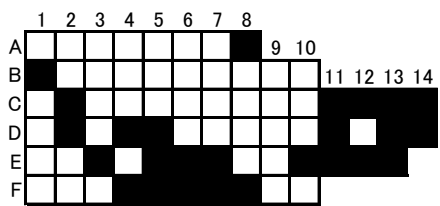

1993

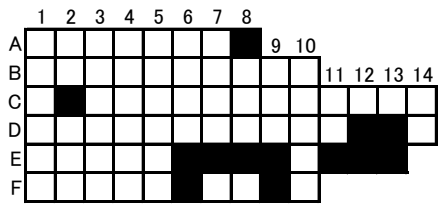

1994

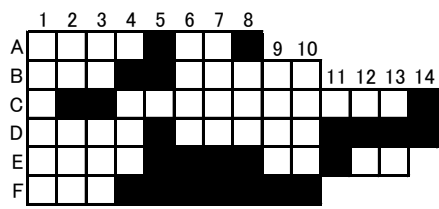

1995

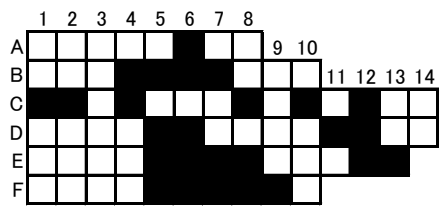

1996

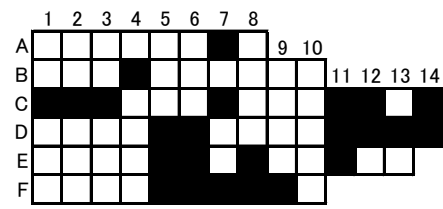

1997

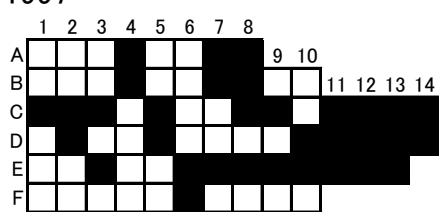

1998

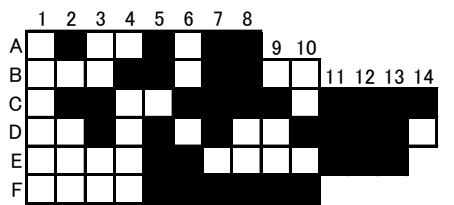

1999

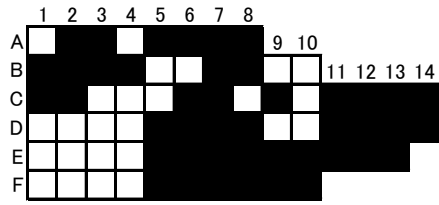

2000

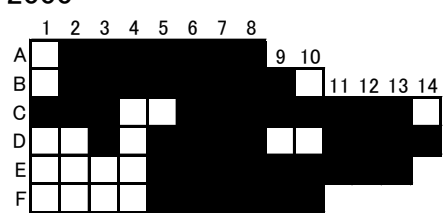

2001

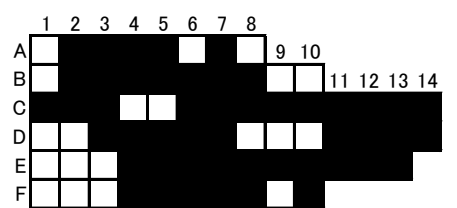

2002

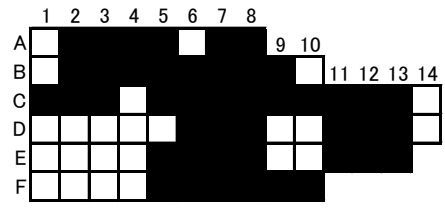

2003

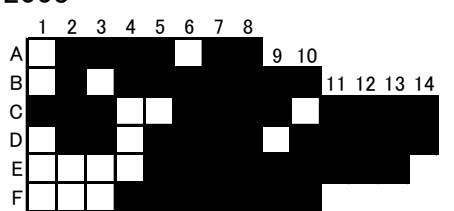

2004

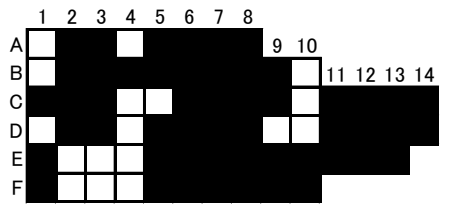

2005

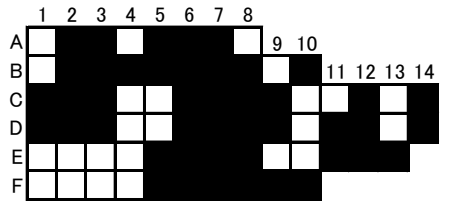

2006

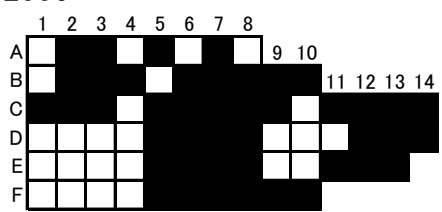

2007

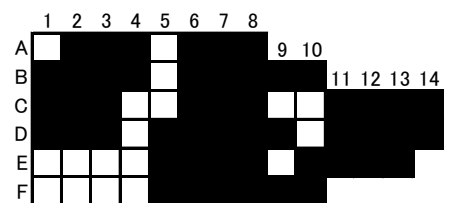

2008

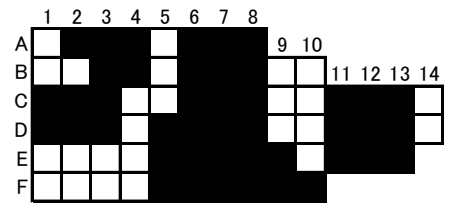

2009

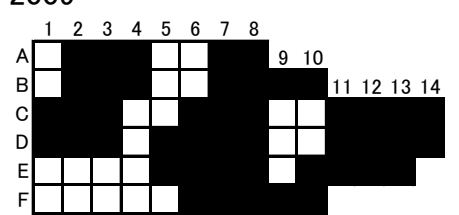

2010

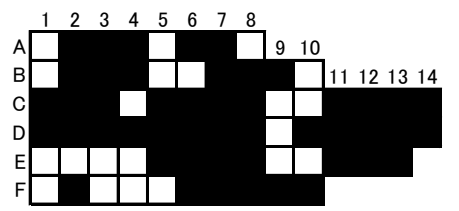


213 Septifer bilocularis クジャクガイ

1985

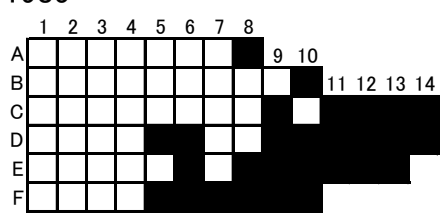

1986

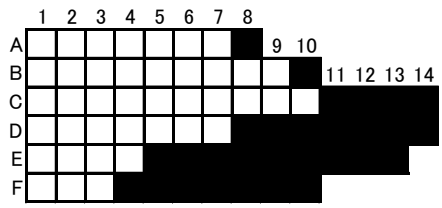

1987

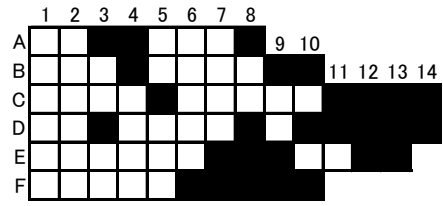

1988

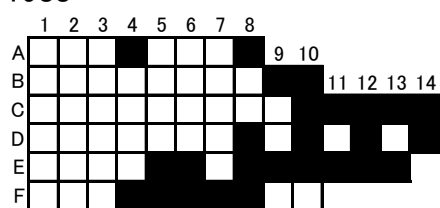

1989

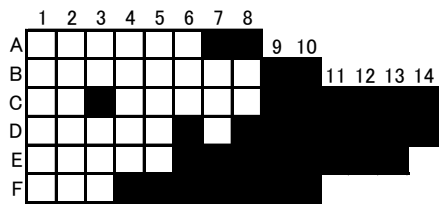

1990

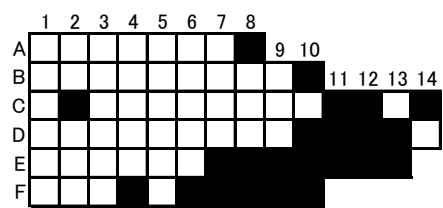

1991

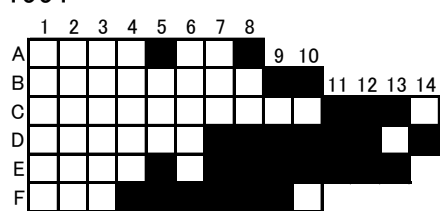

1992

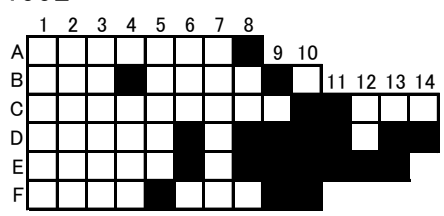

1993

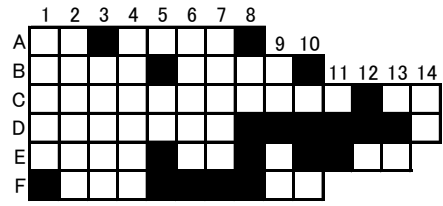

1994

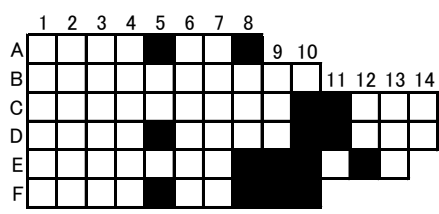

1995

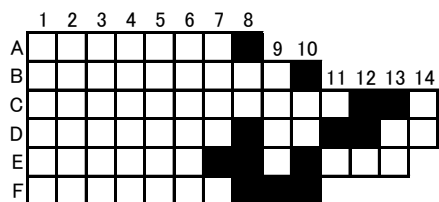

1996

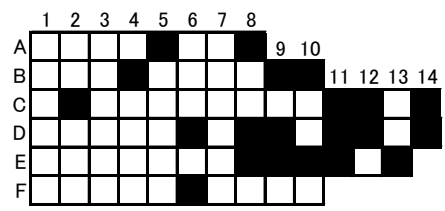

1997

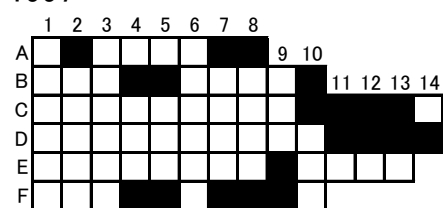

1998

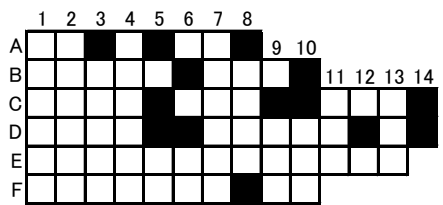

1999

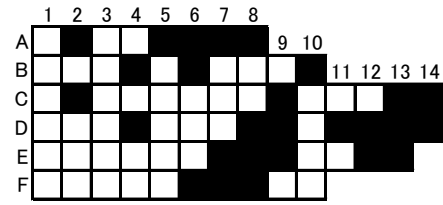

2000

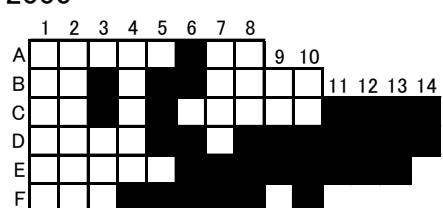

2001

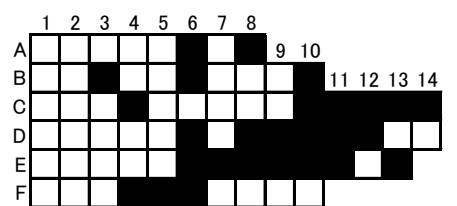

2002

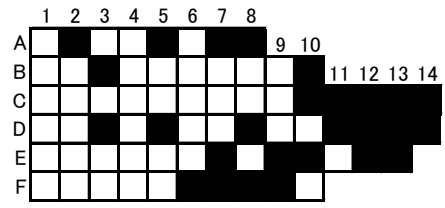

2003

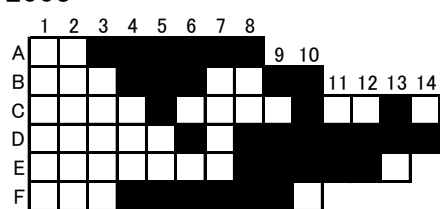

2004

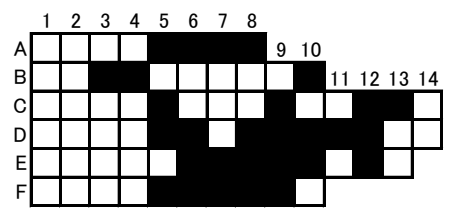

2005

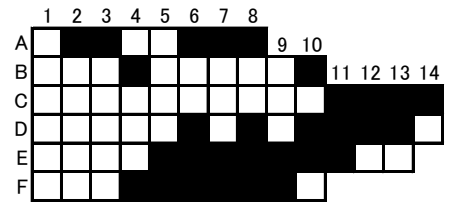

2006

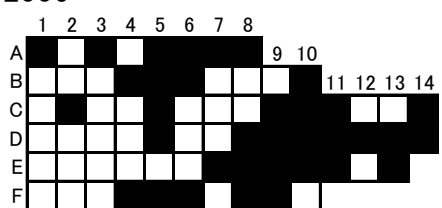

2007

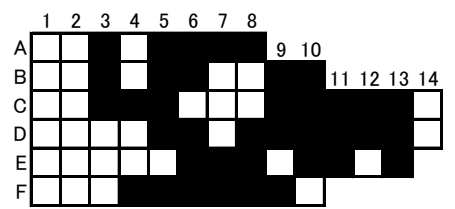

2008

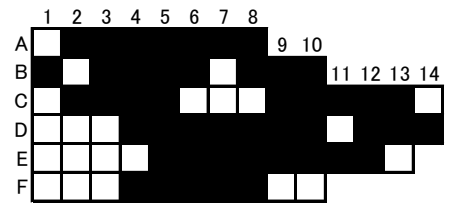

2009

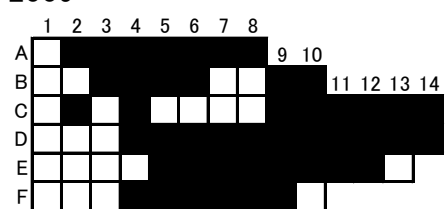

2010

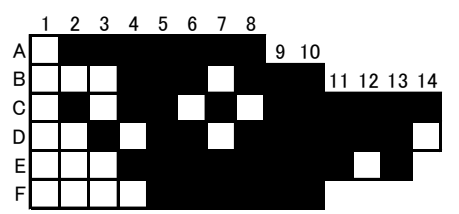


1985

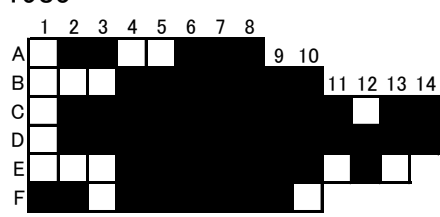

1986

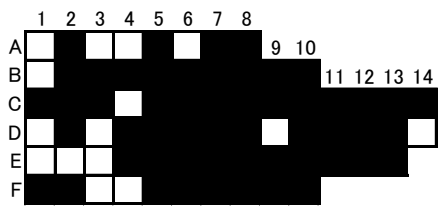

1987

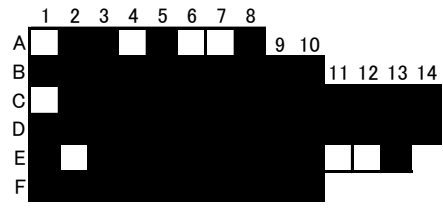

1988

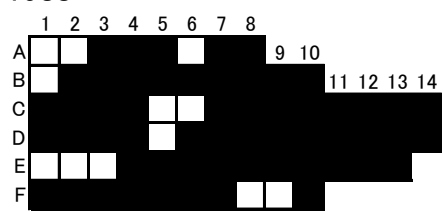

1989

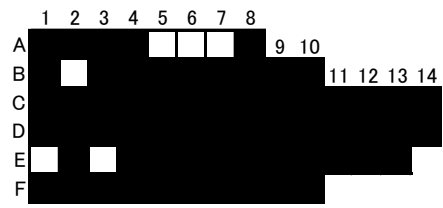

1990

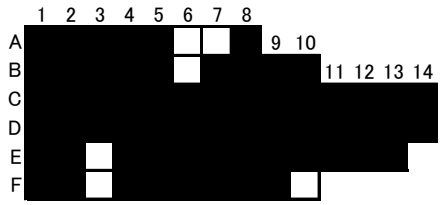

1991

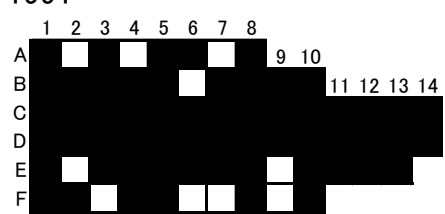

1992

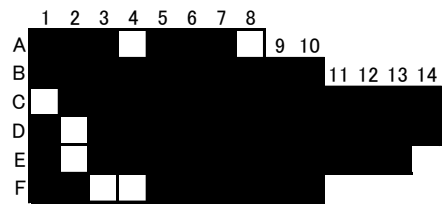

1993

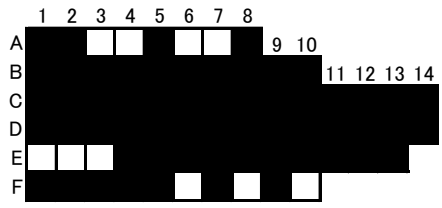

1994

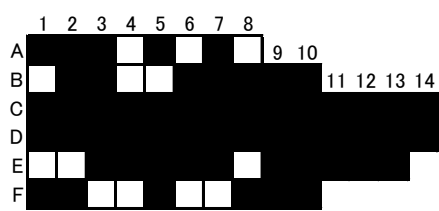

1995

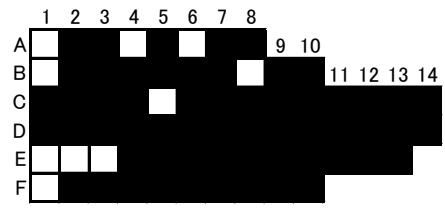

1996

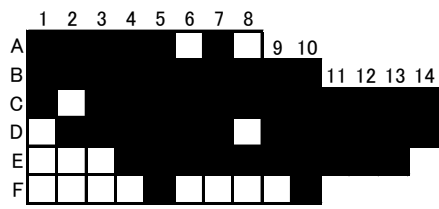

1997

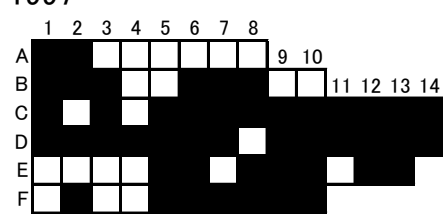

1998

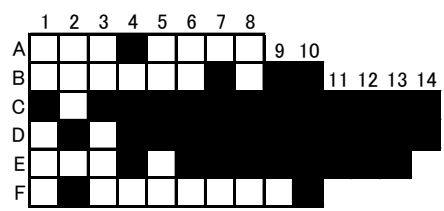

1999

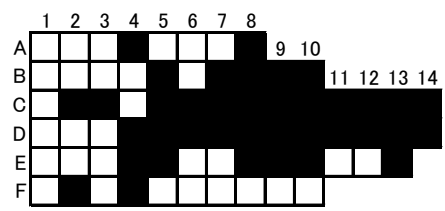

2000

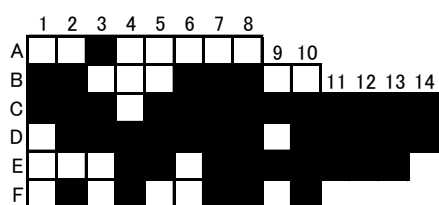

2001

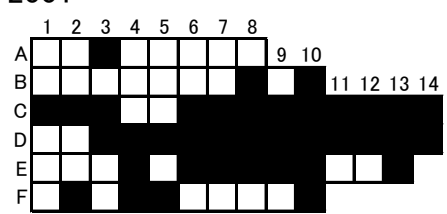

2002

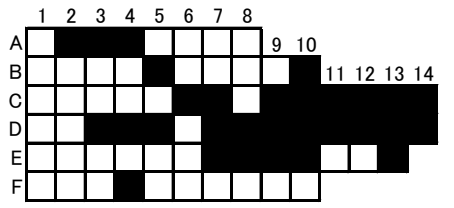

2003

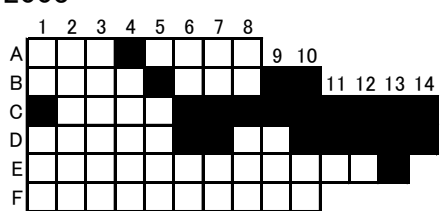

2004

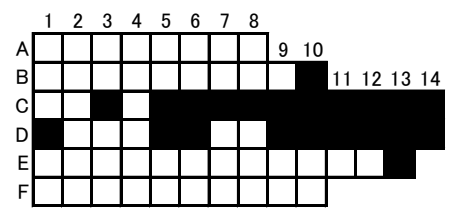

2005

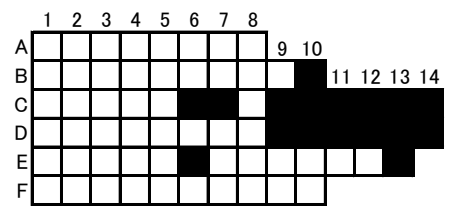

2006

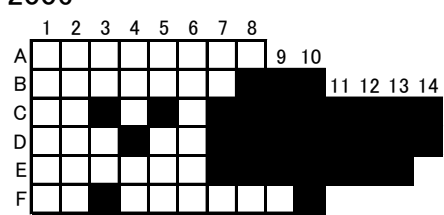

2007

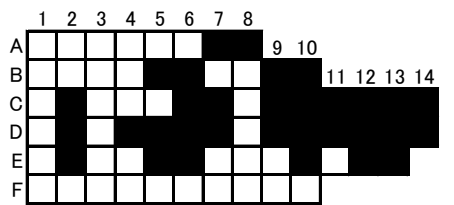

2008

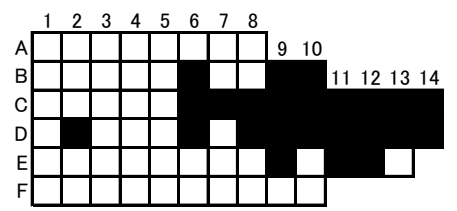

2009

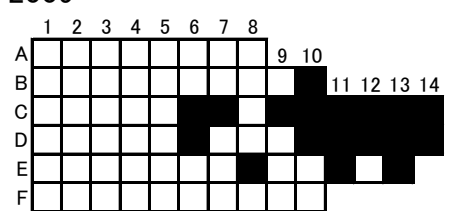

2010

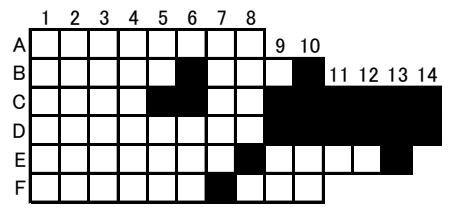




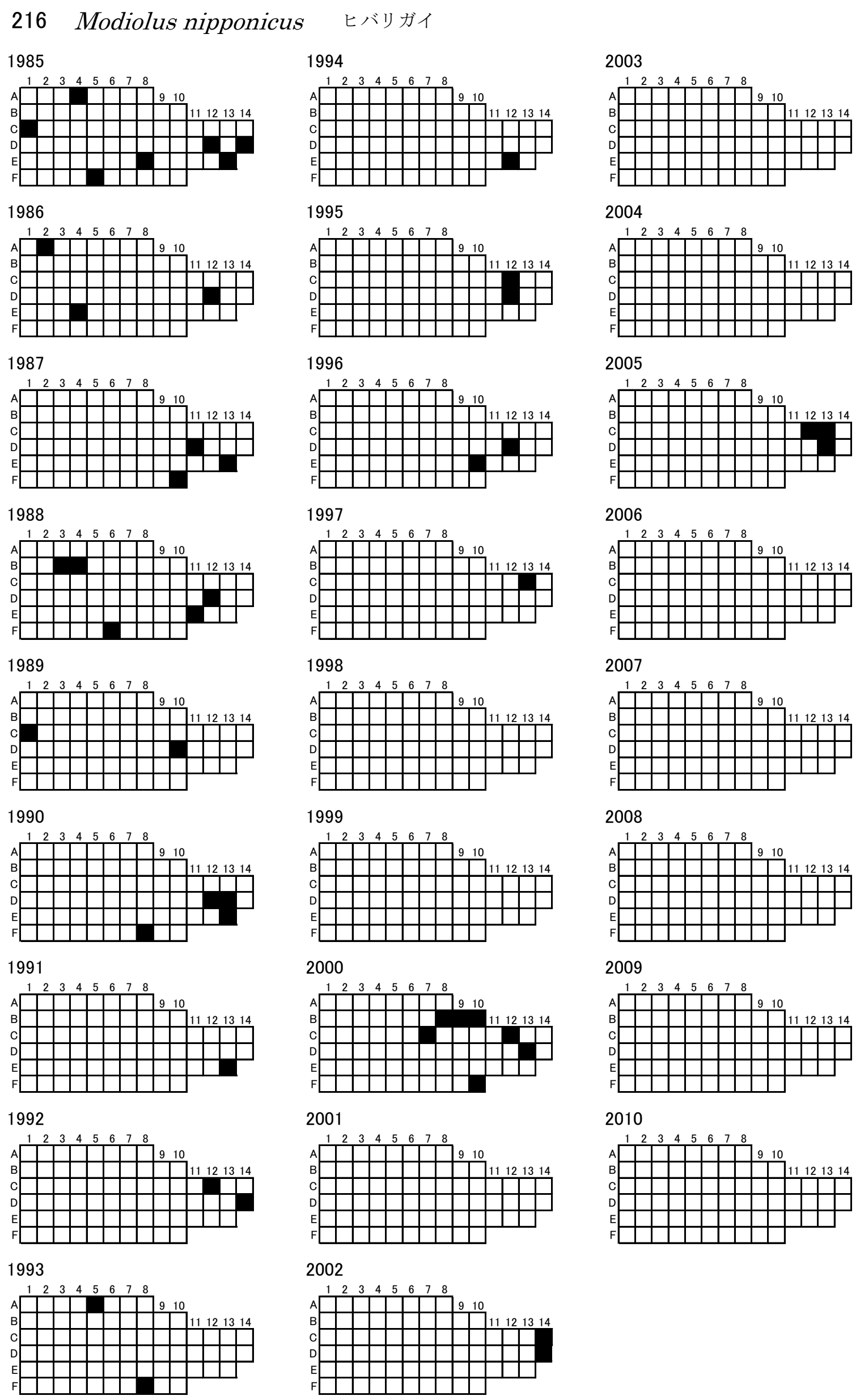




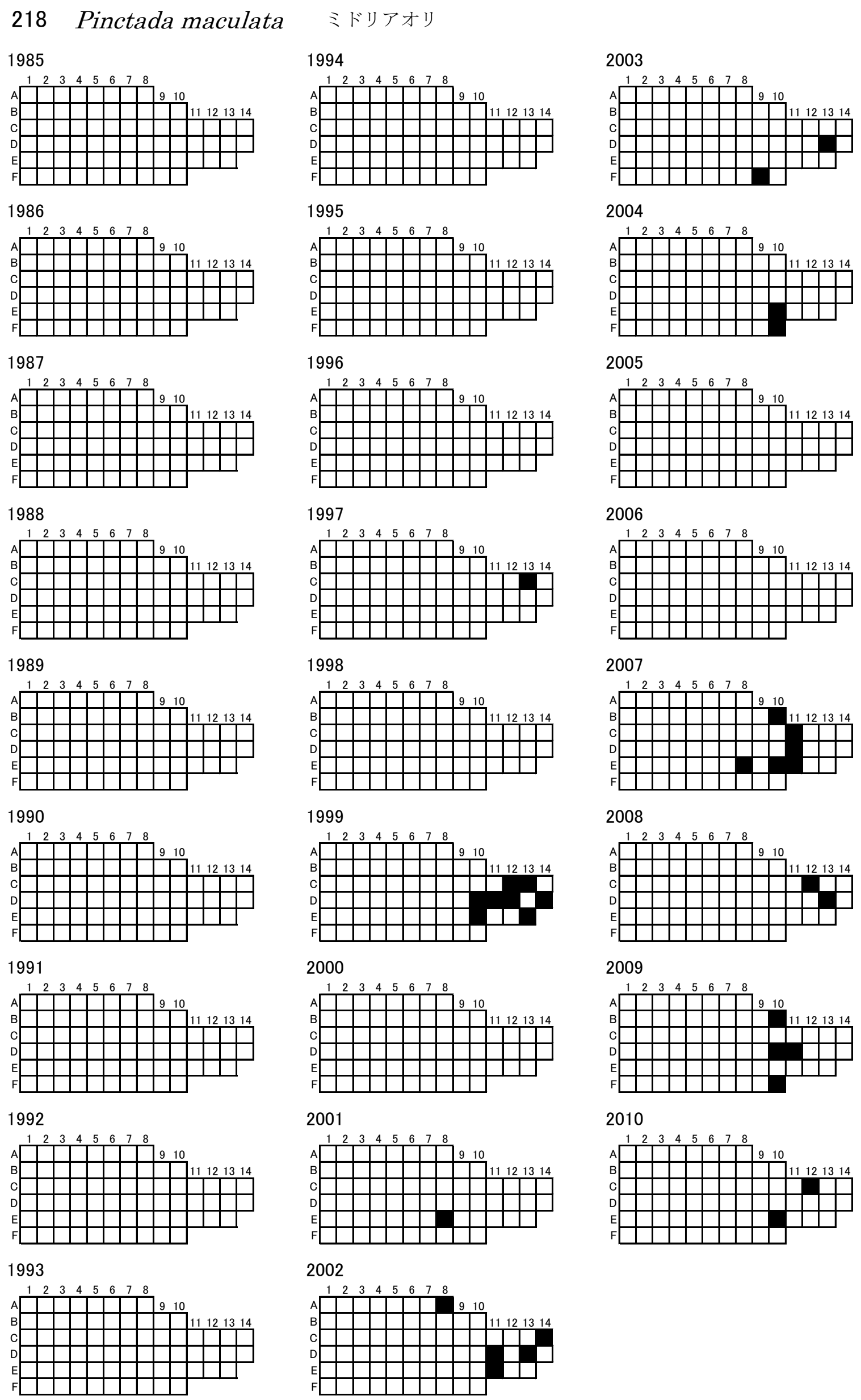




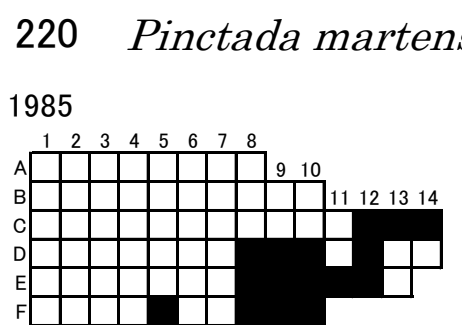

アコヤガイ
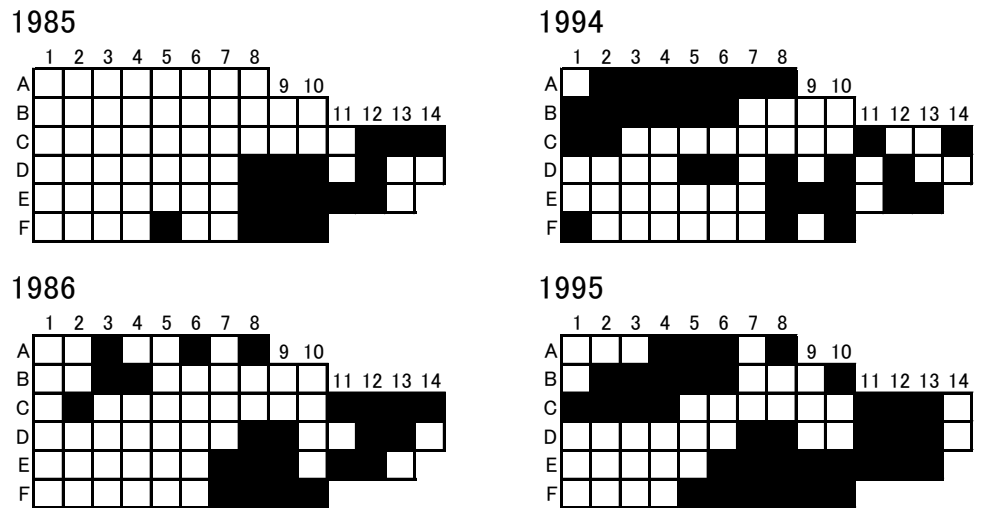

2003

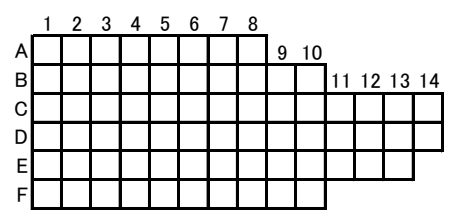

1995

2004
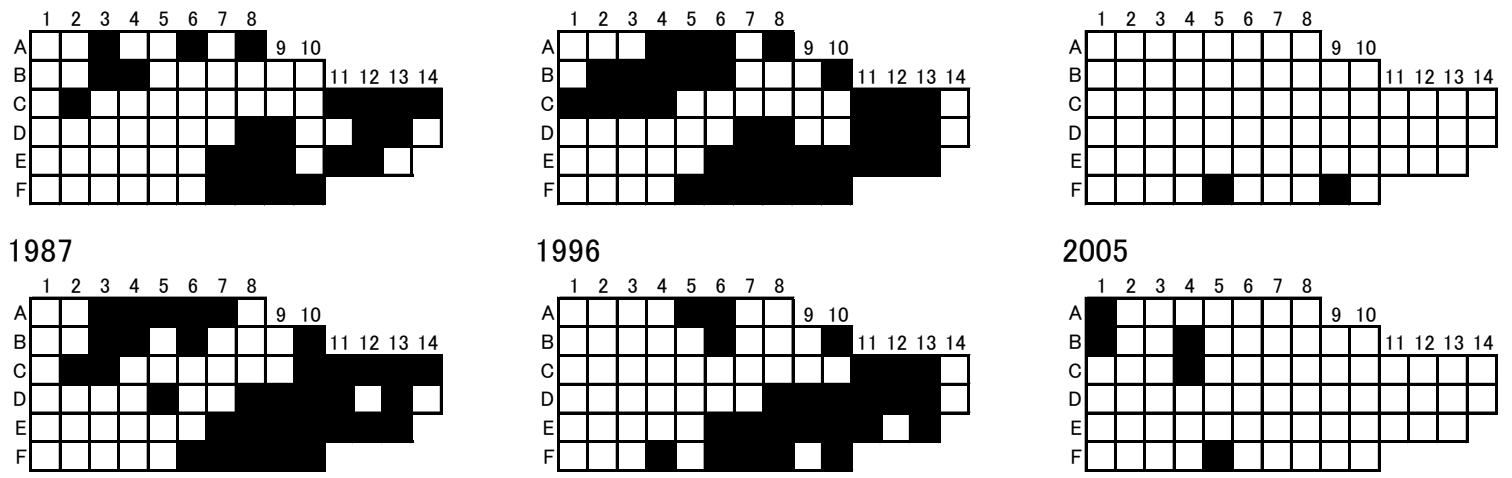

1996

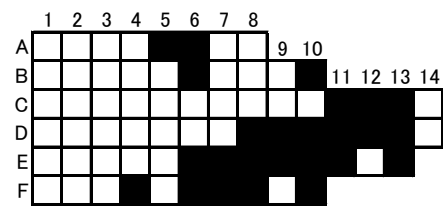

2005

1988

1997
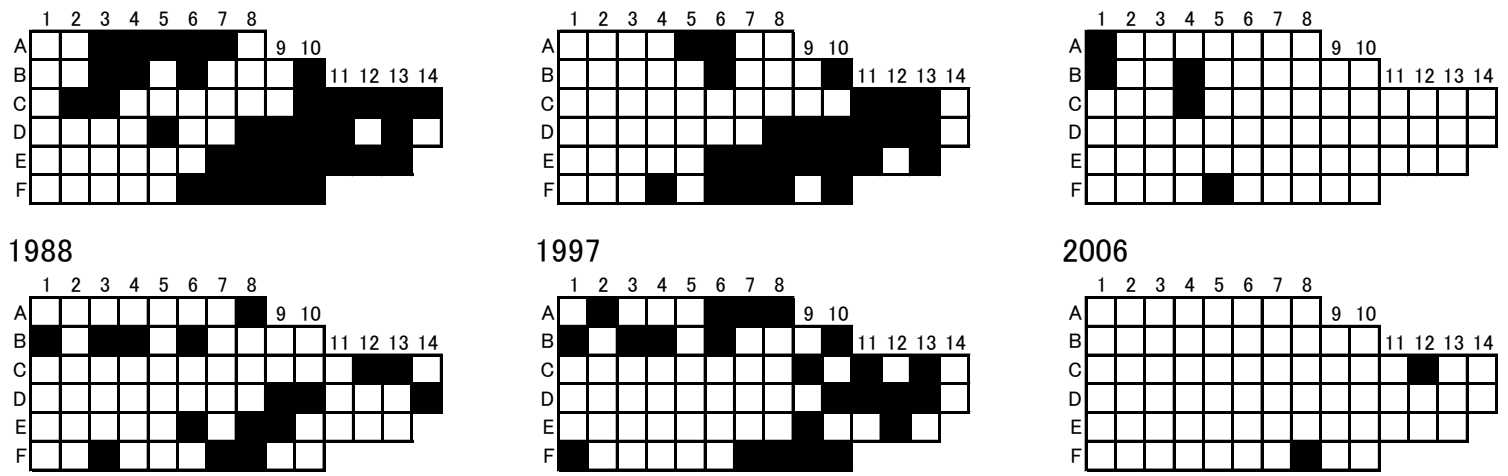

2006

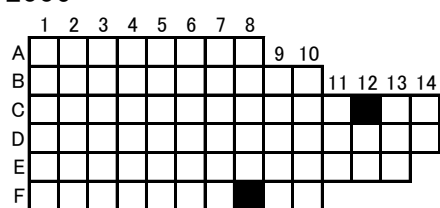

1989

1998
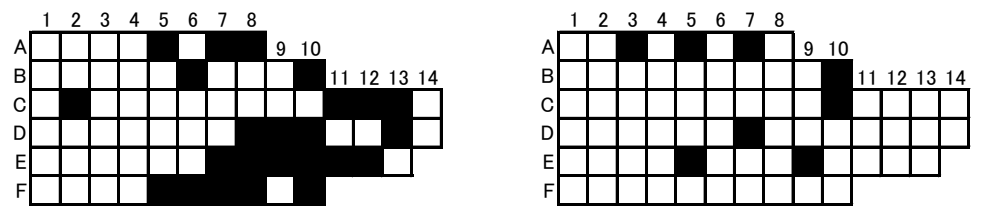

2007
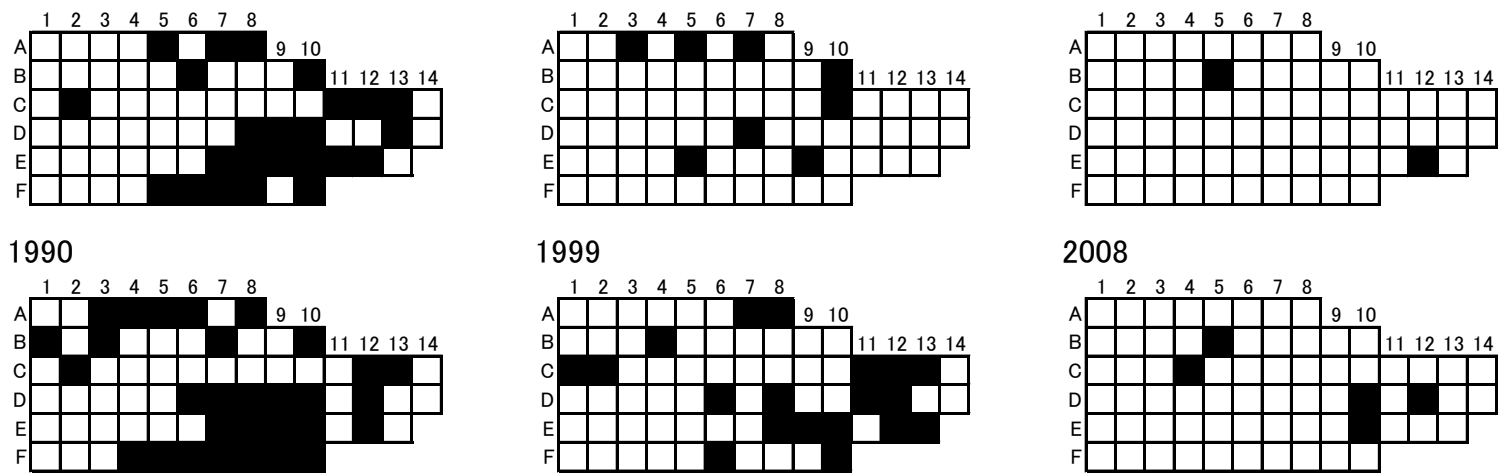

1999

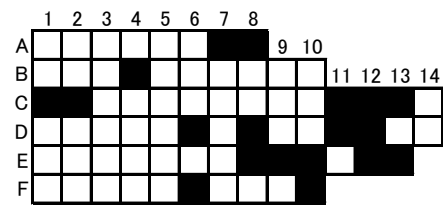

2008

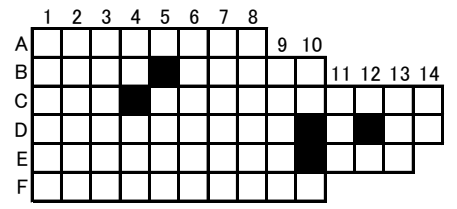

1991

2000

2009
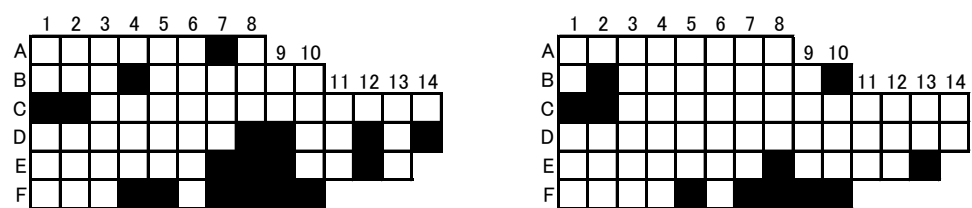

1992

2001
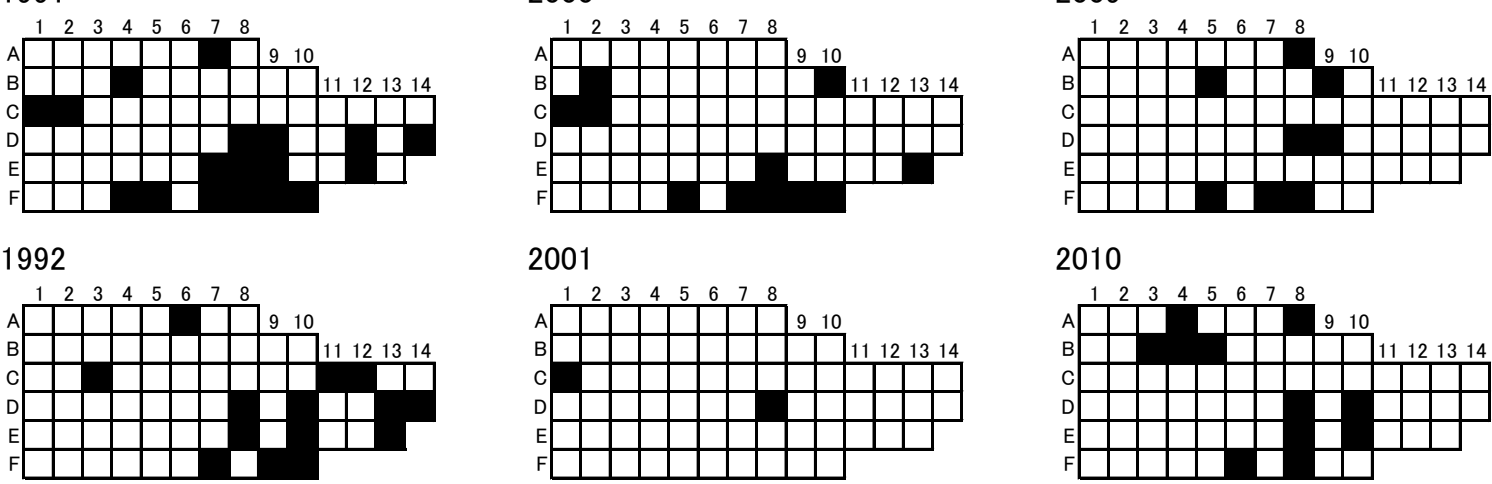

2010
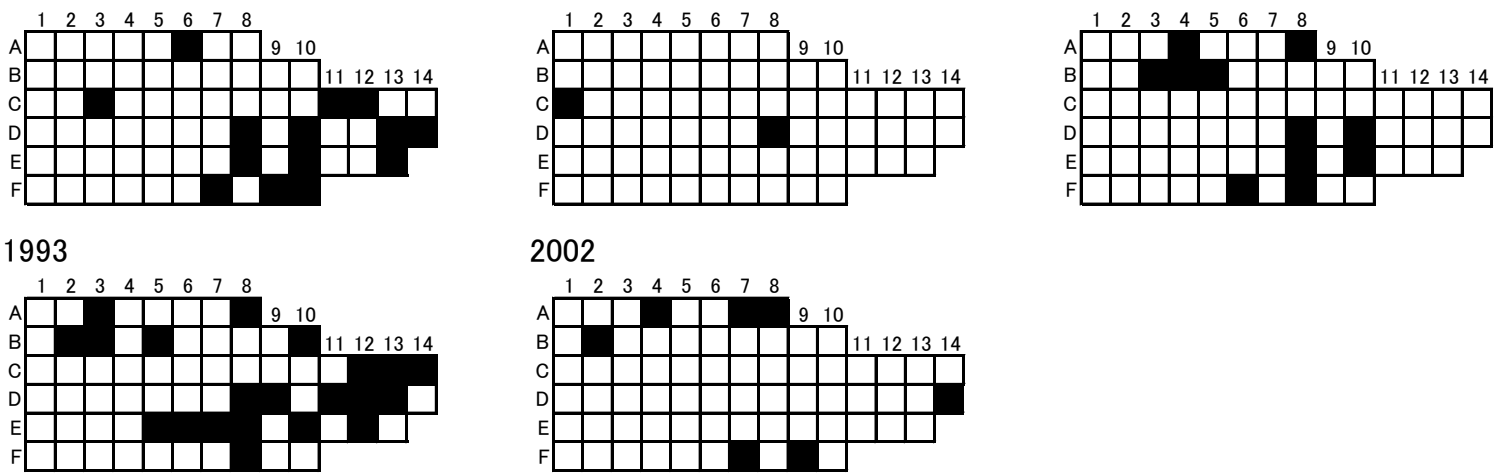

2002

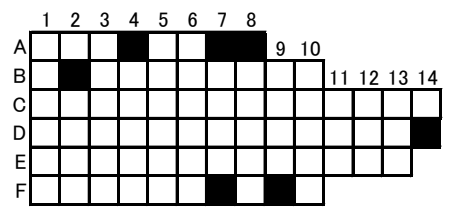


221 Isognomon acutirostris ヘリトリアオリ

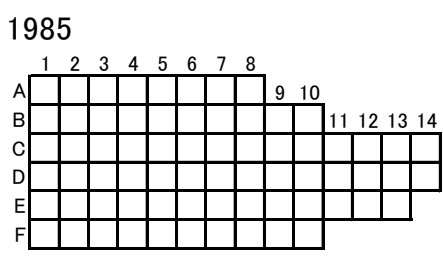

1994

2003

1986
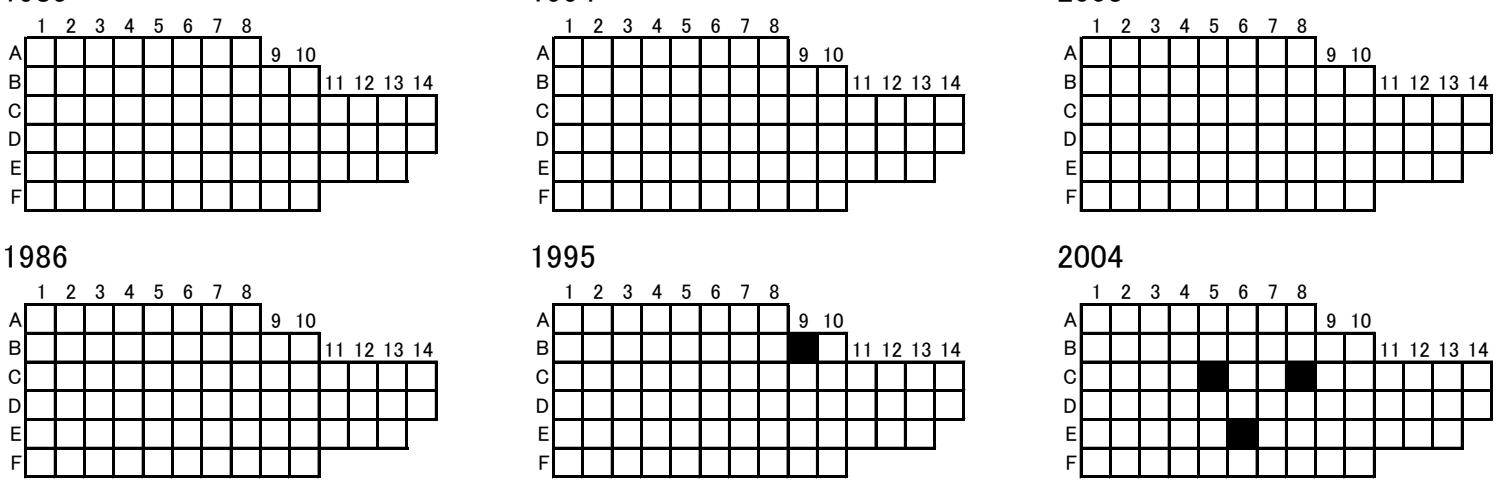

1995

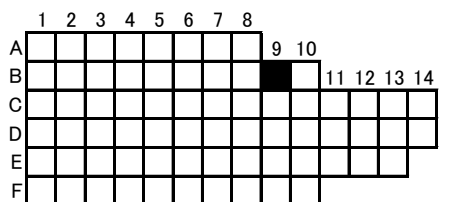

2004

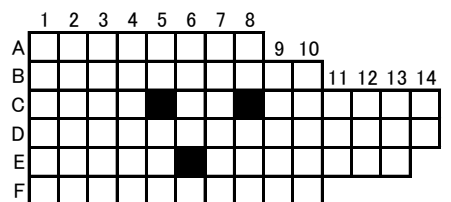

1987

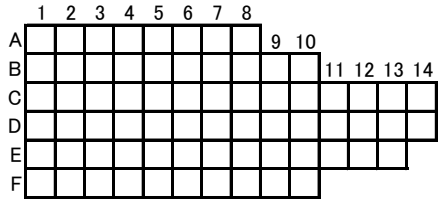

1996

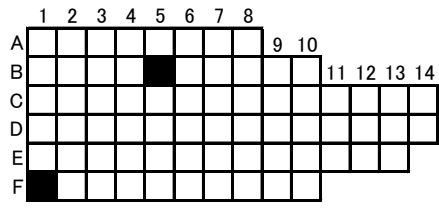

2005

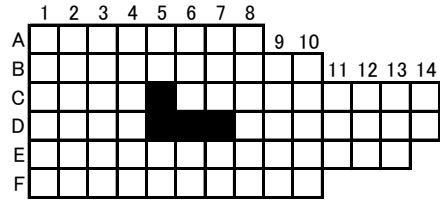

1988

1997
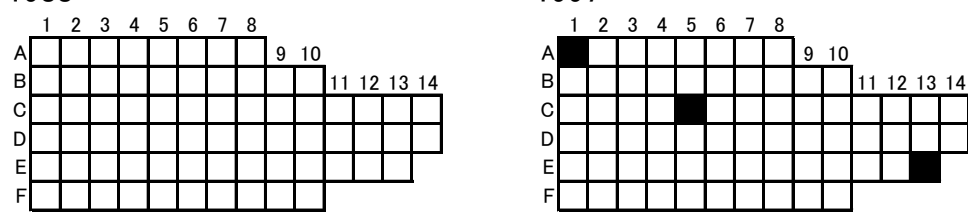

2006

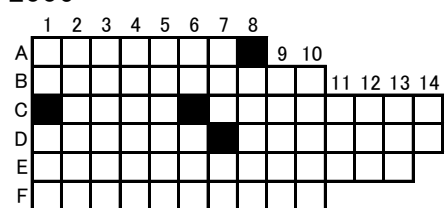

1989

1998
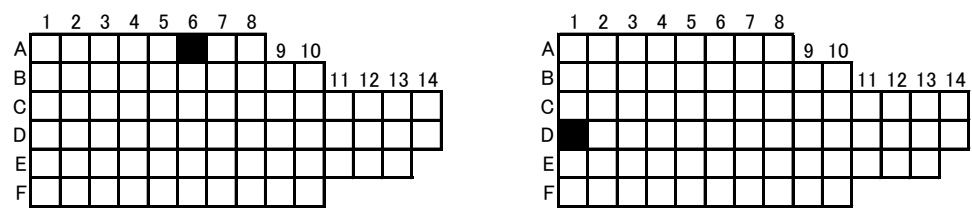

2007
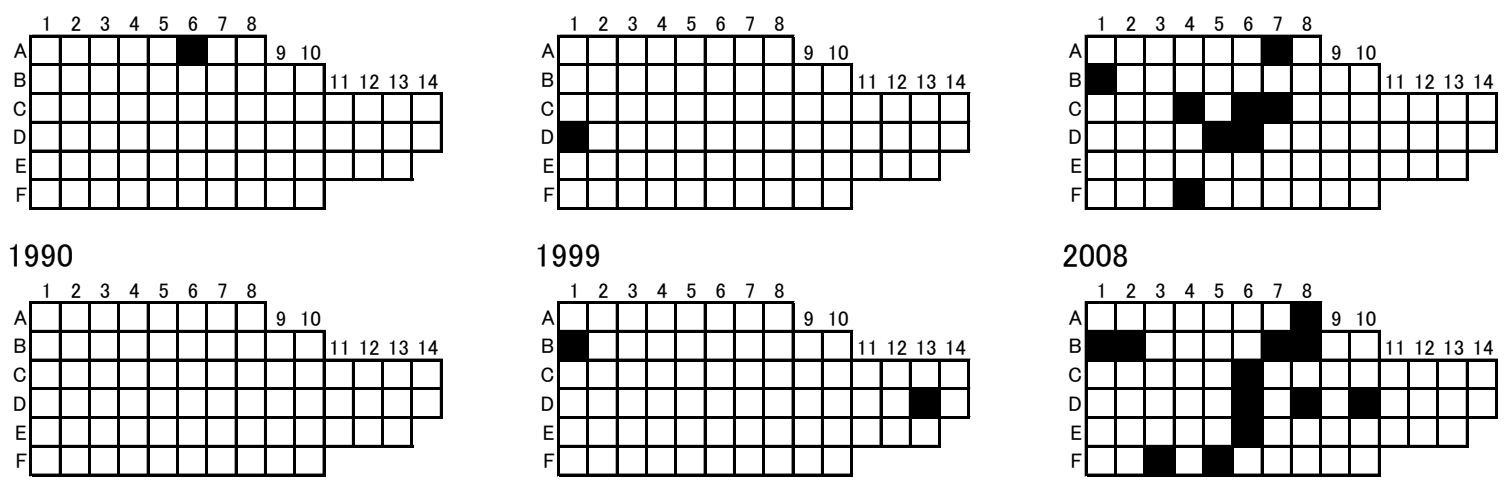

1999

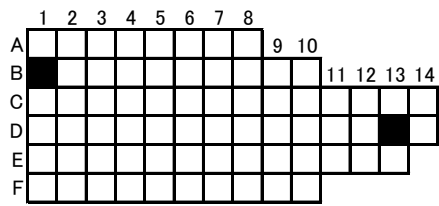

2008

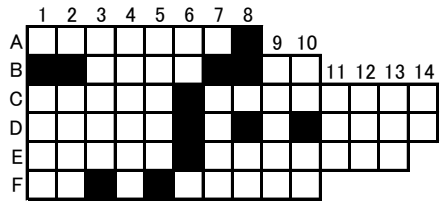

1991

2000
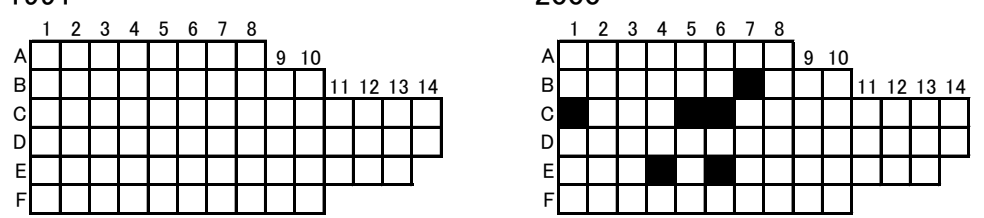

2009

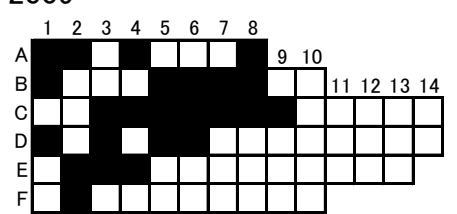

1992

2001
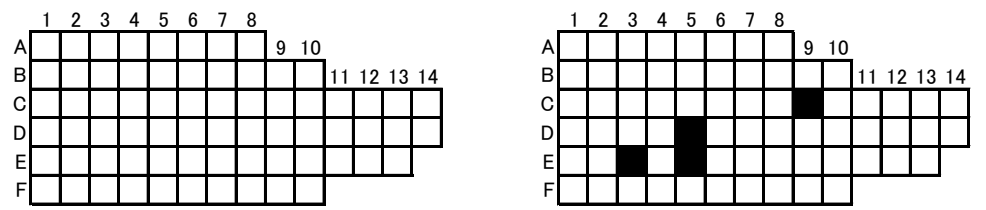

2010

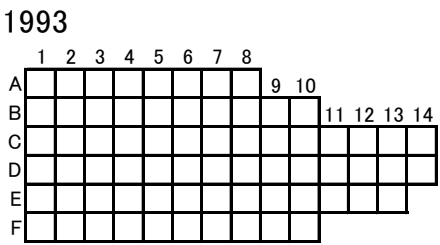

2002
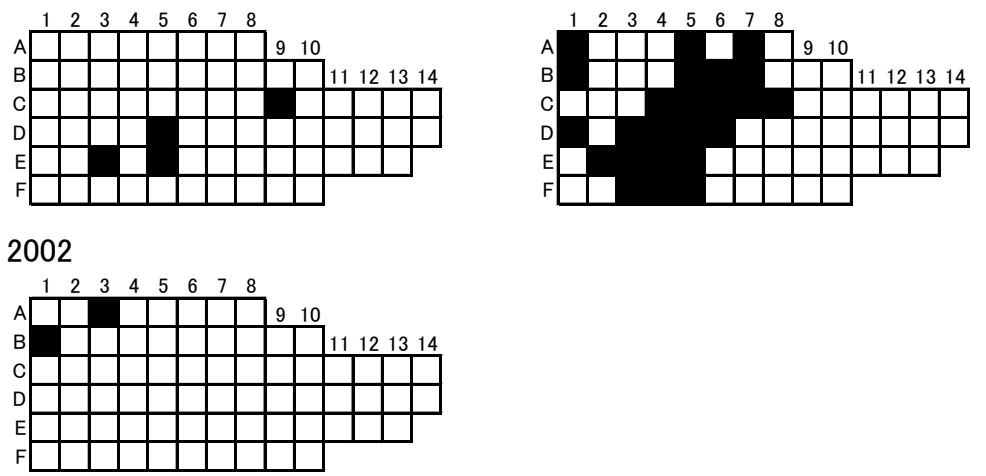


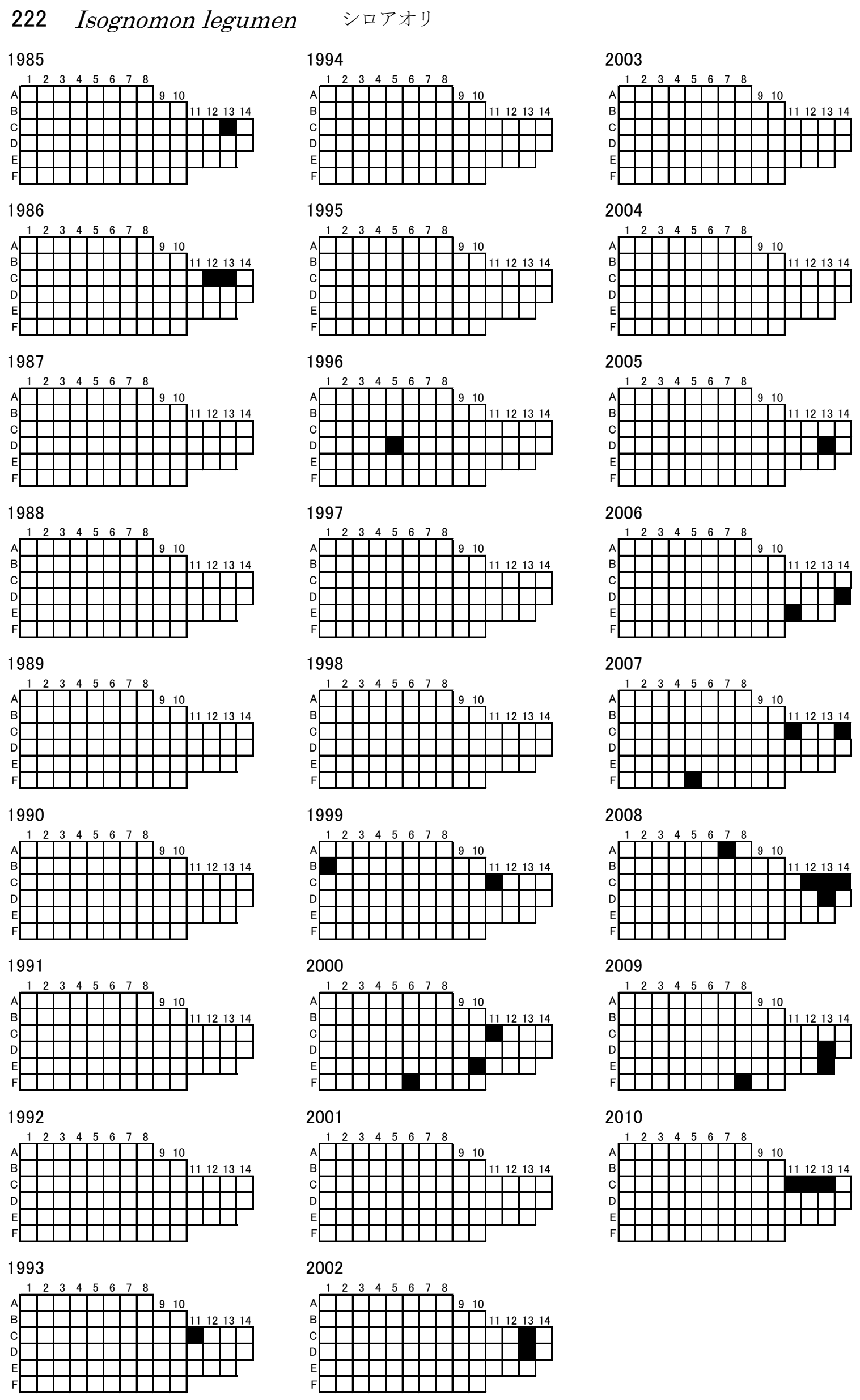


227 Crassostrea gigas マガキ
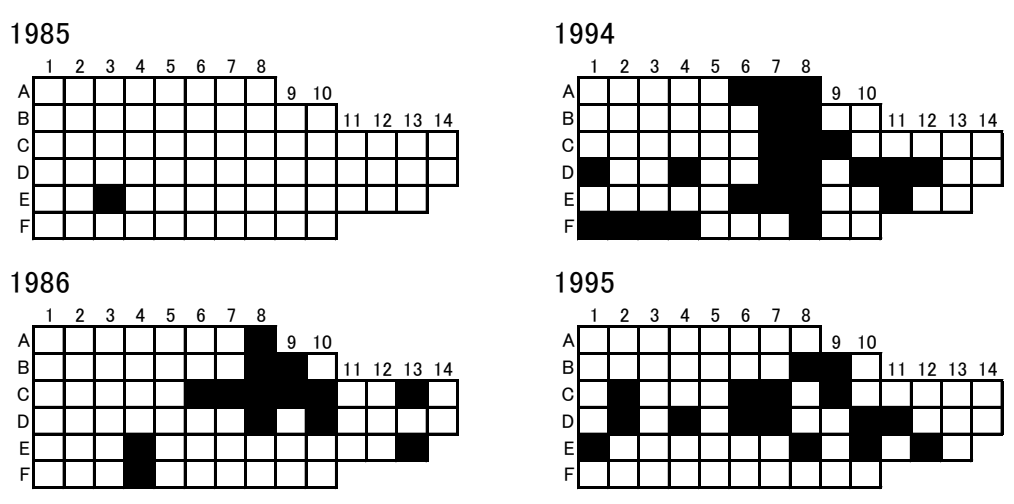

2003
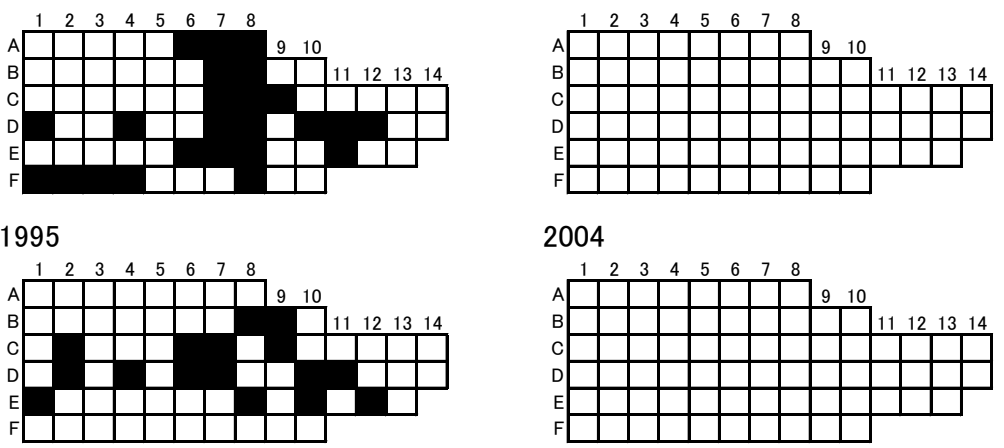

2004

1987

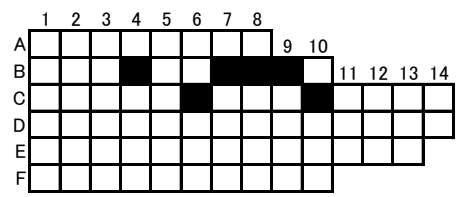

1996
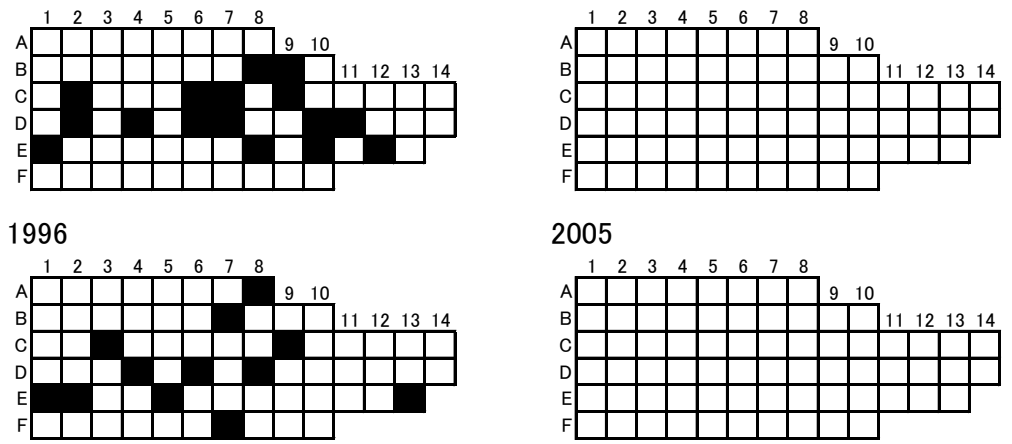

2005

1988

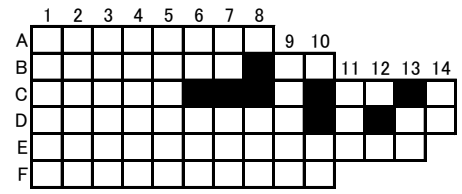

1997
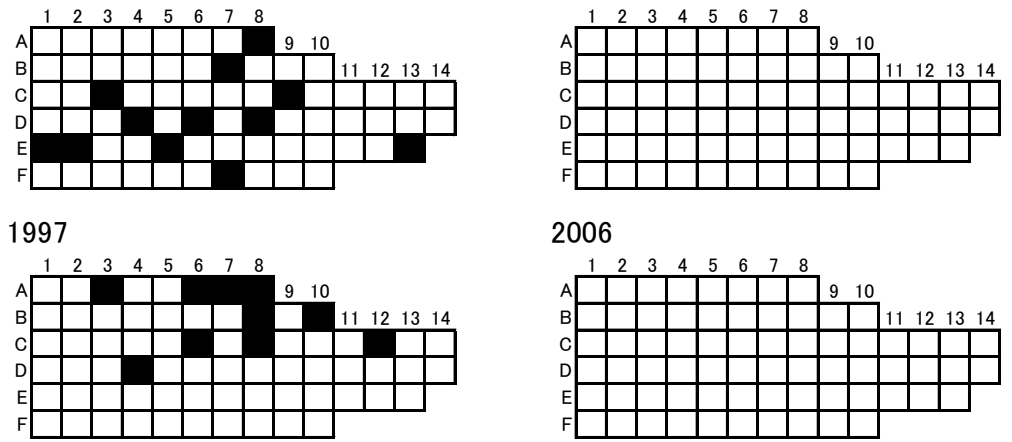

2006
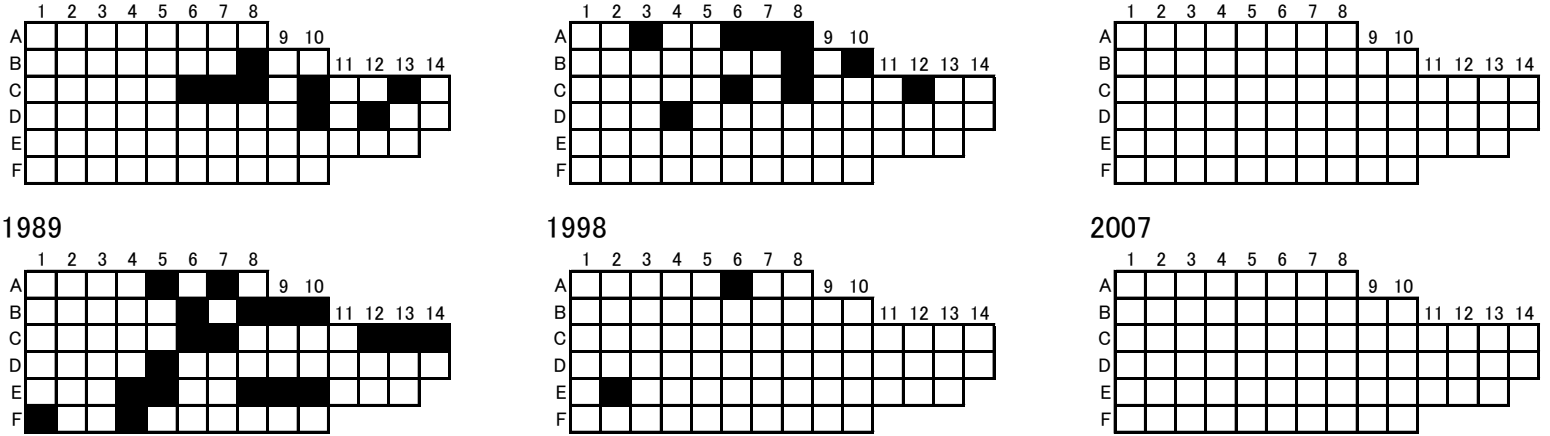

2007

1990

1999
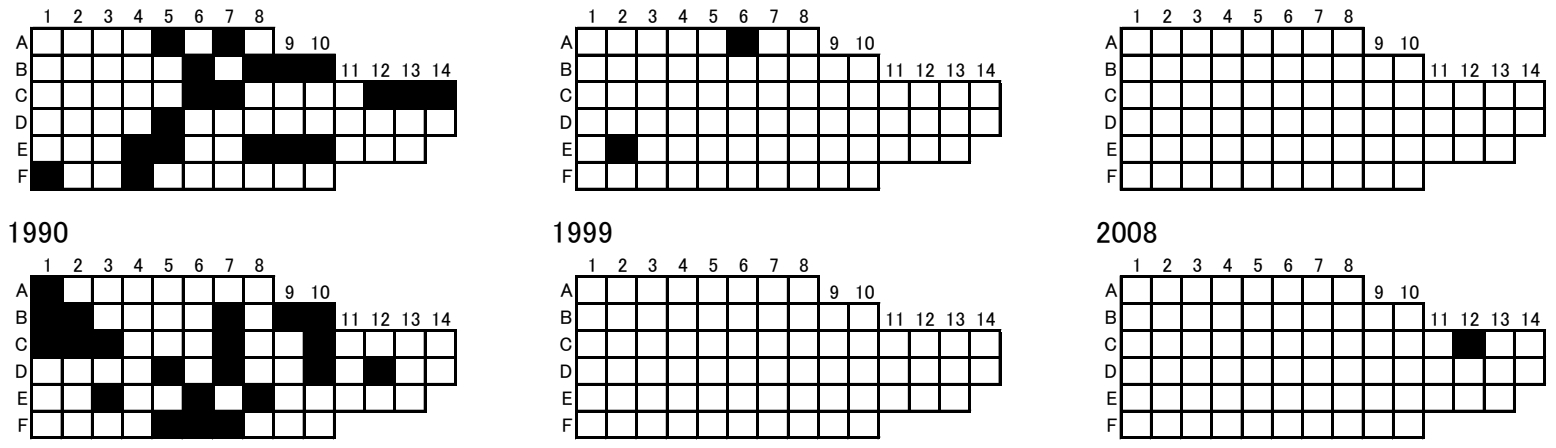

2008

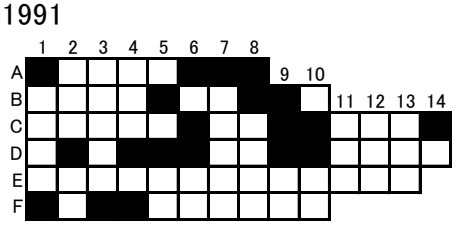

2000
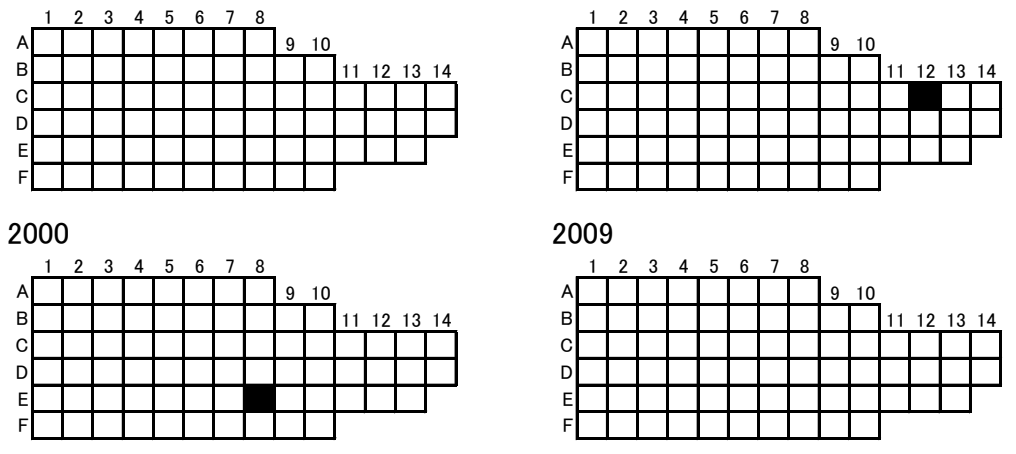

1992

2001
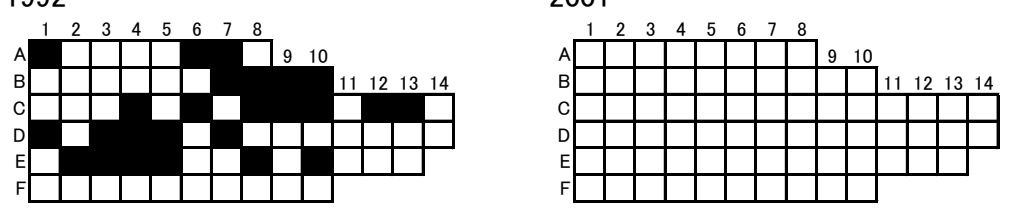

2010

1993

2002
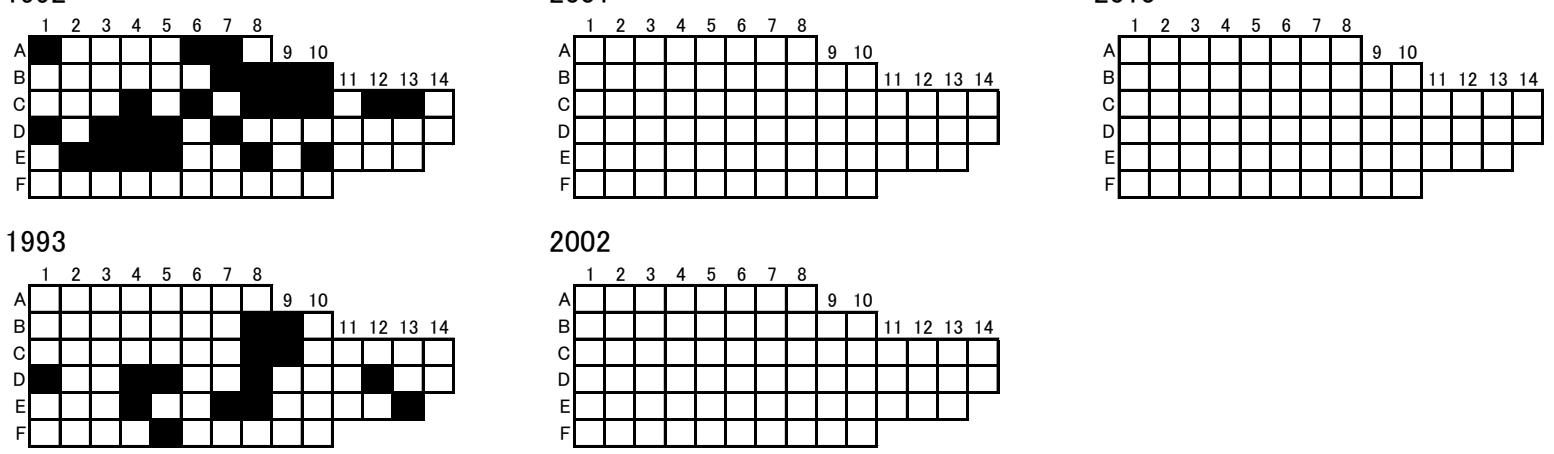
Saccostrea kegaki ケガキ

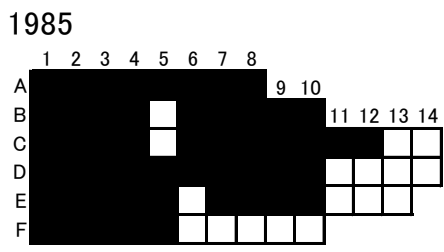

1994

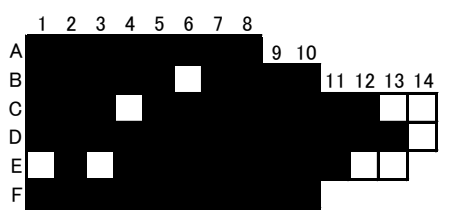

1986

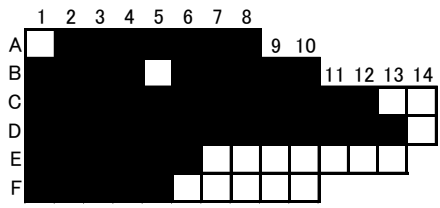

1987

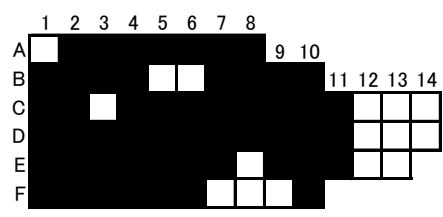

1988

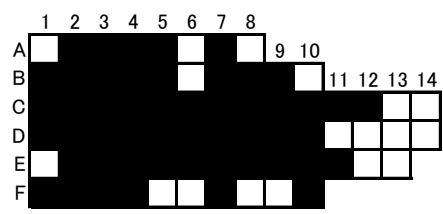

1989
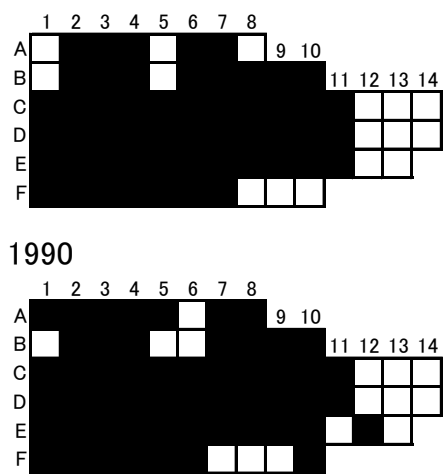

1991

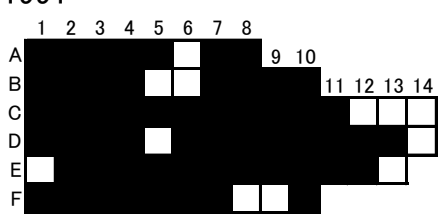

1992

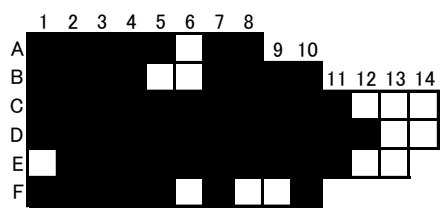

1993

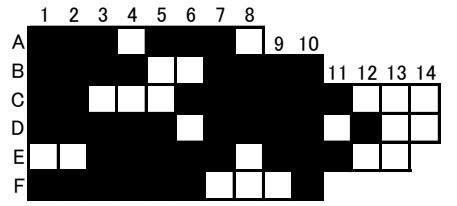

1995

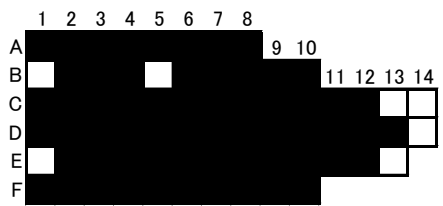

1996

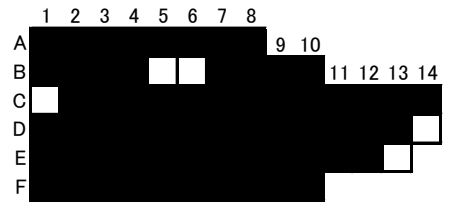

1997

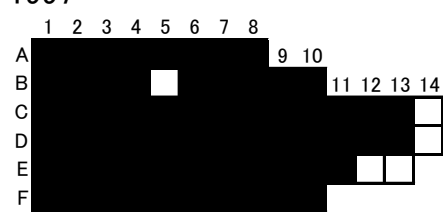

1998

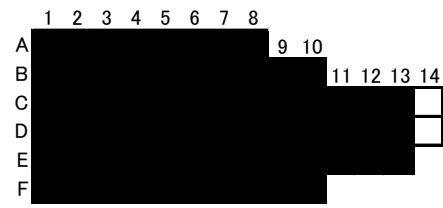

1999

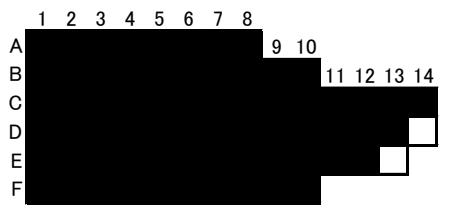

2000

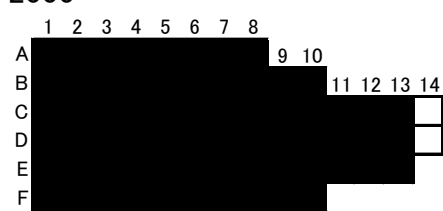

2001

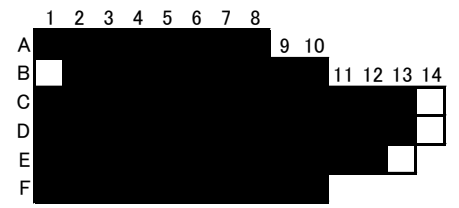

2002

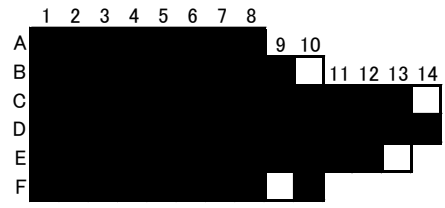

2003

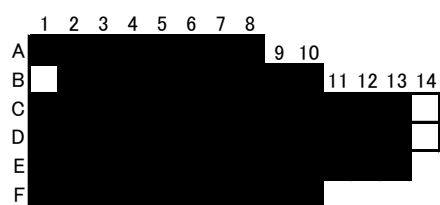

2004

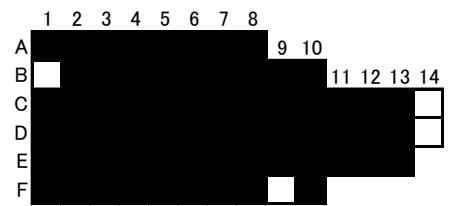

2005

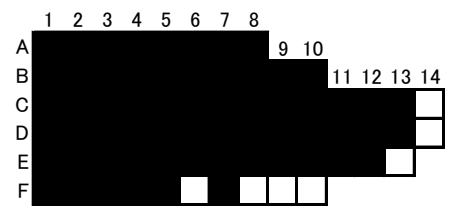

2006

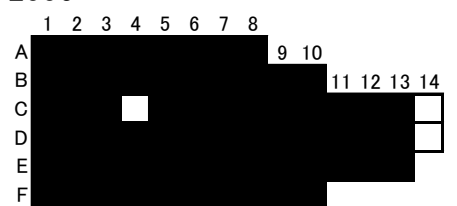

2007

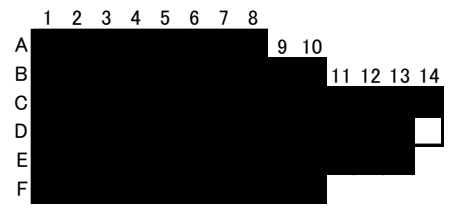

2008

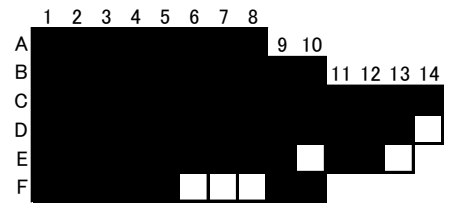

2009

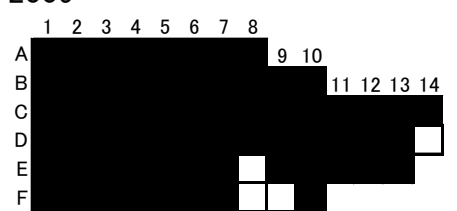

2010

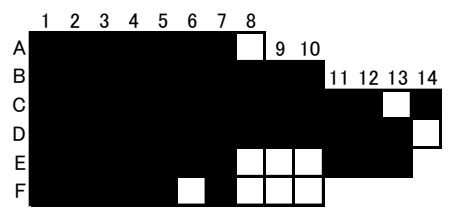


オハグロガキ
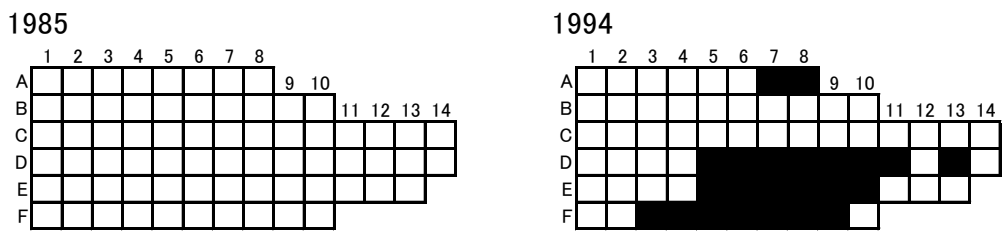

2003

1986

1995
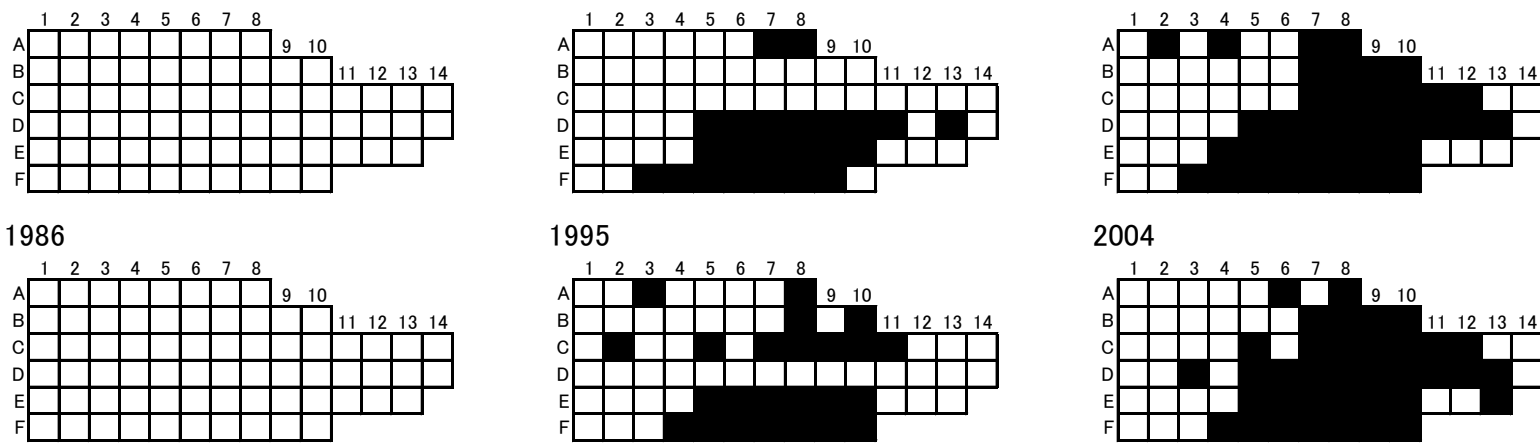

2004

1987

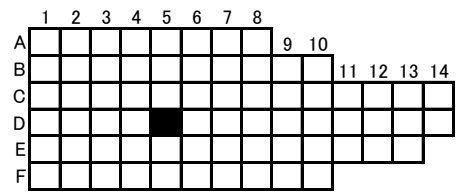

1996
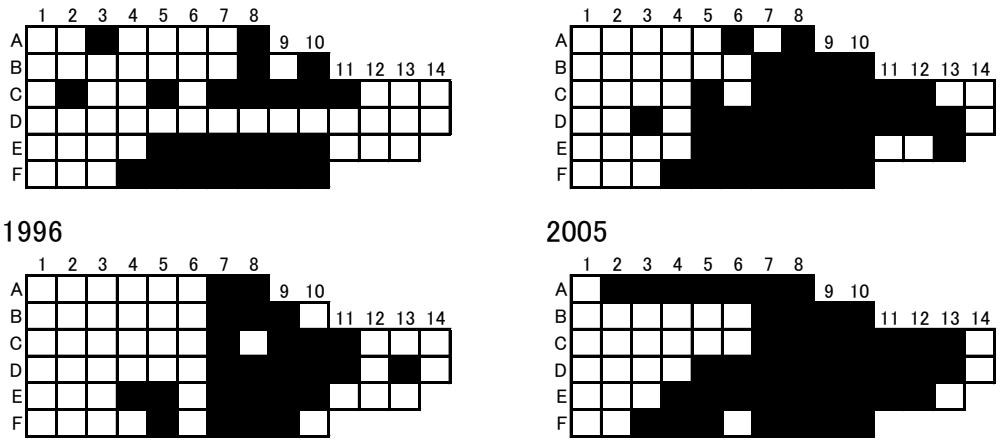

2005

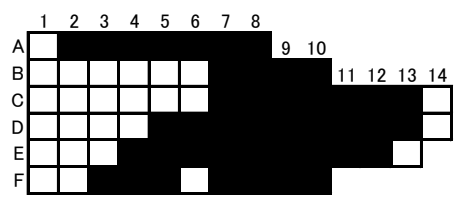

1988

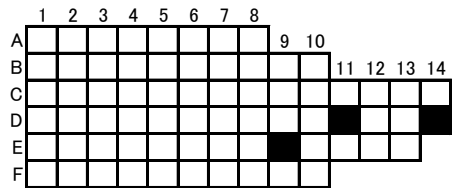

1997

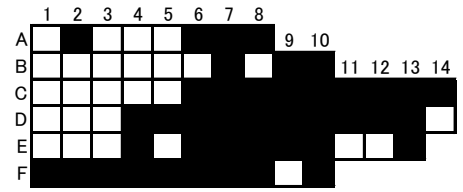

2006

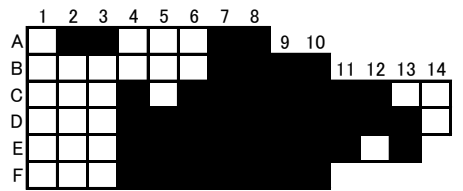

1989

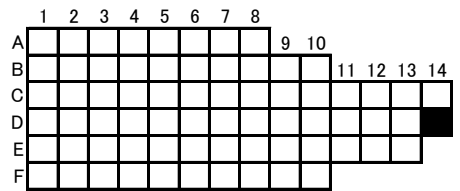

1998

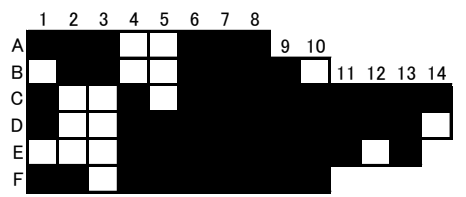

2007

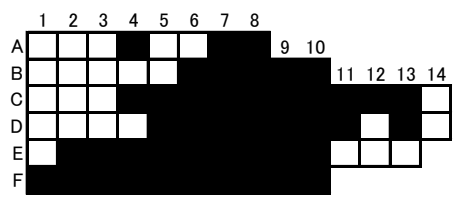

1990

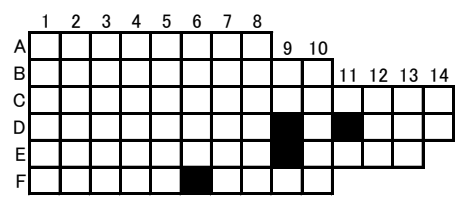

1999

2008
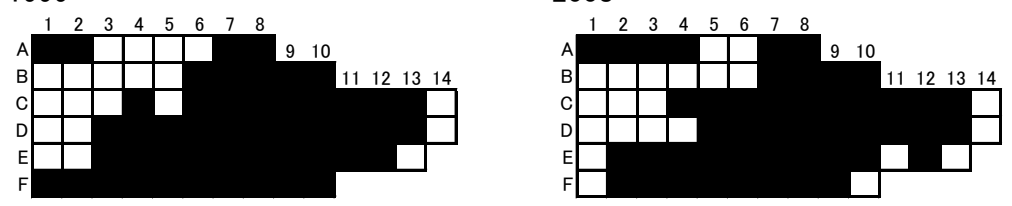

1991
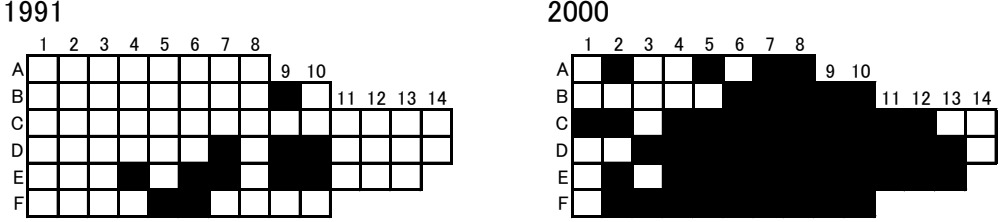

2009

1992

2001
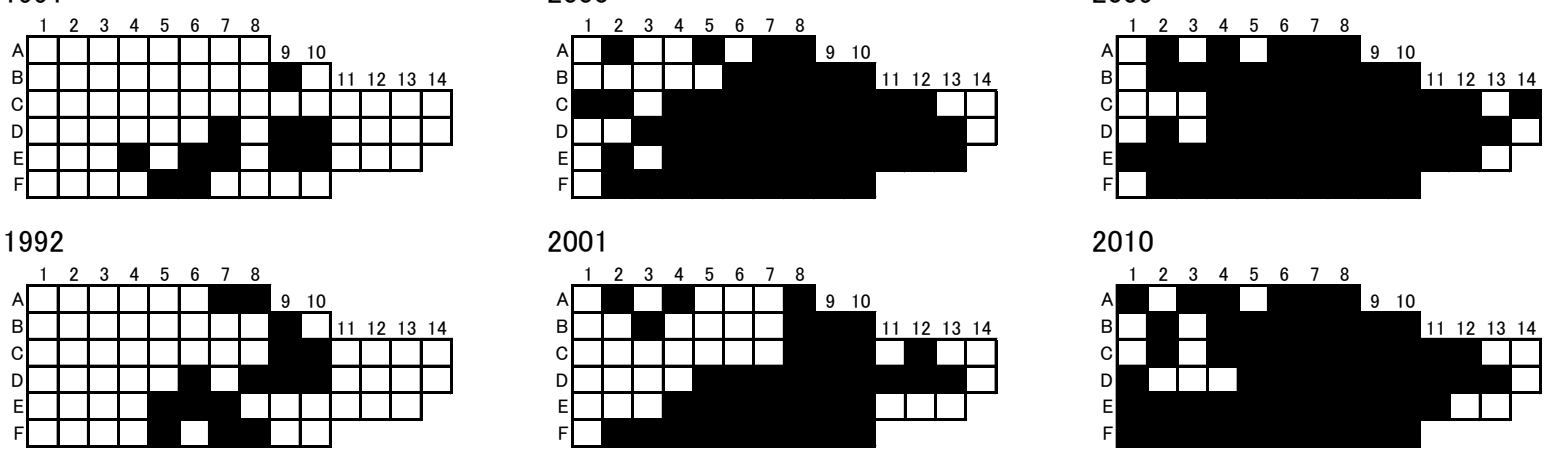

1993

2002
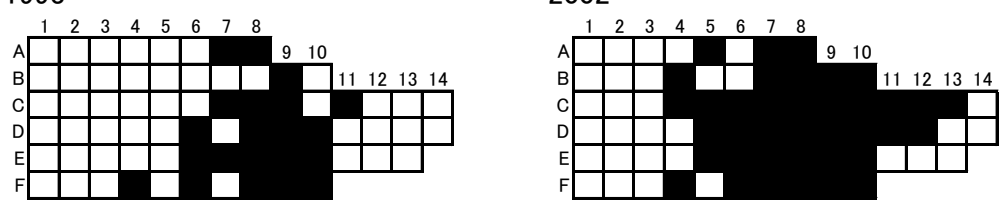


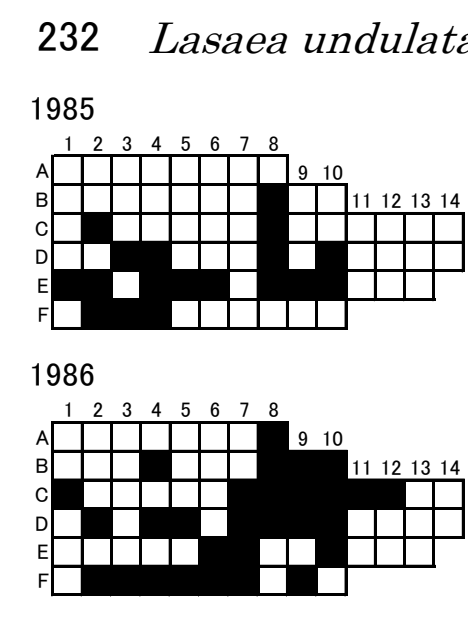

チリハギガイ
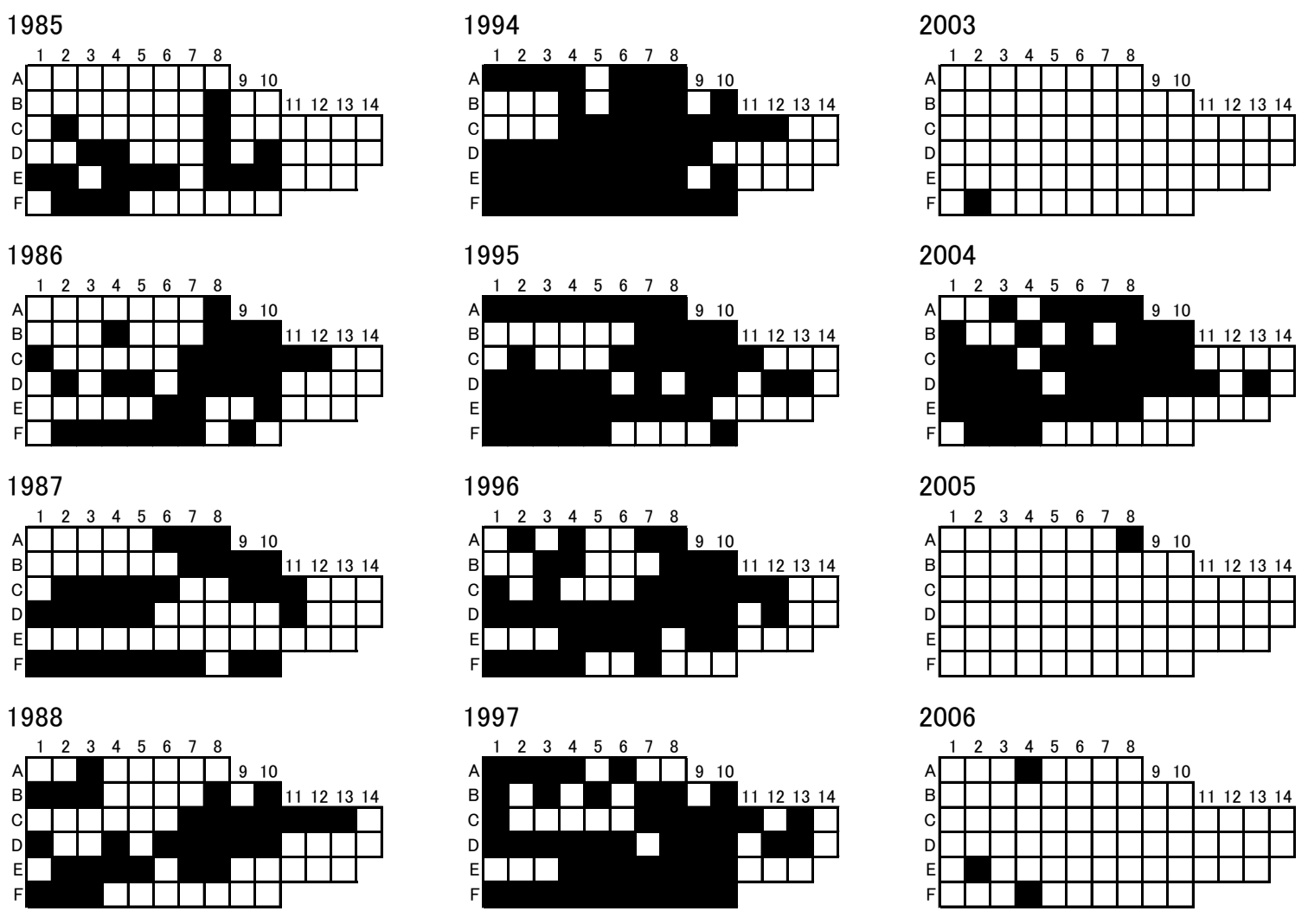

1997

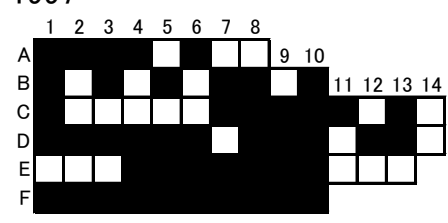

2006
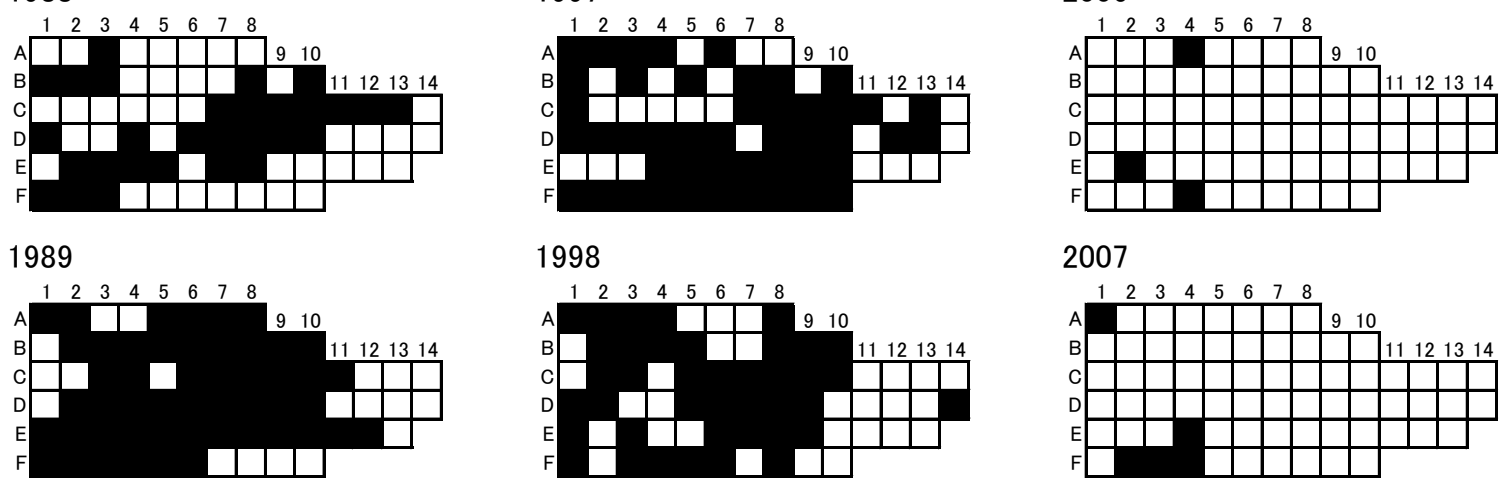

2007
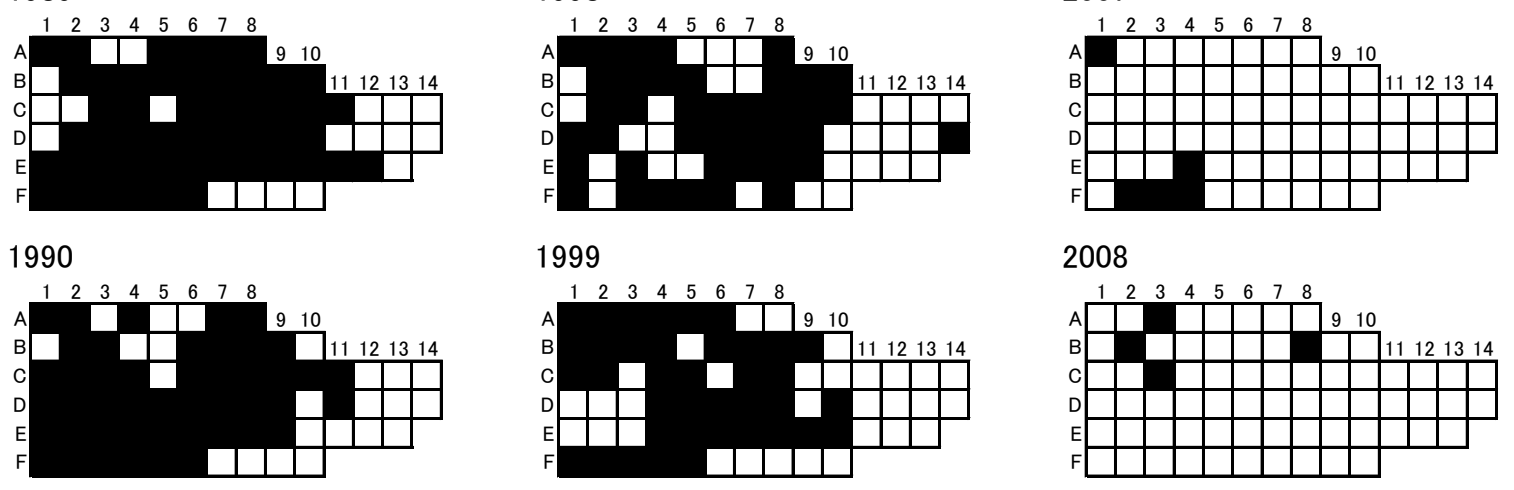

1999

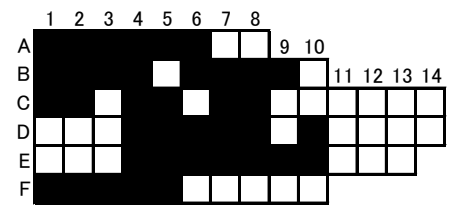

2008

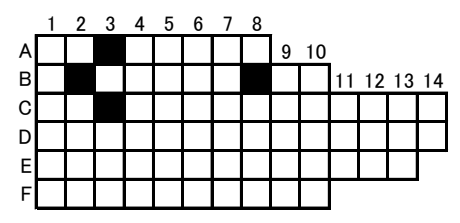

1991

2000

2009
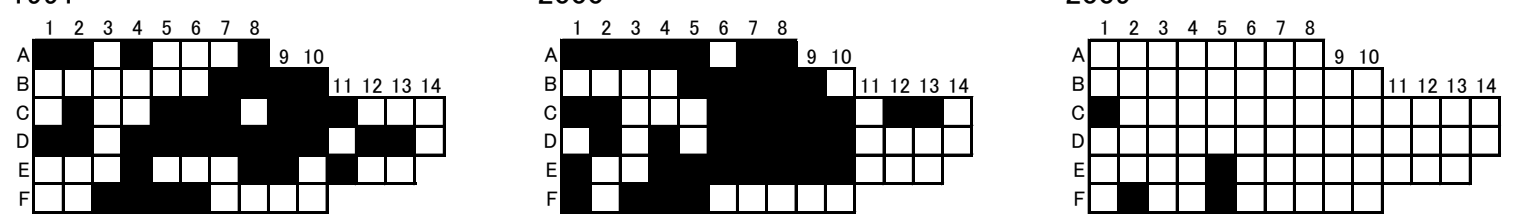

1992

2001
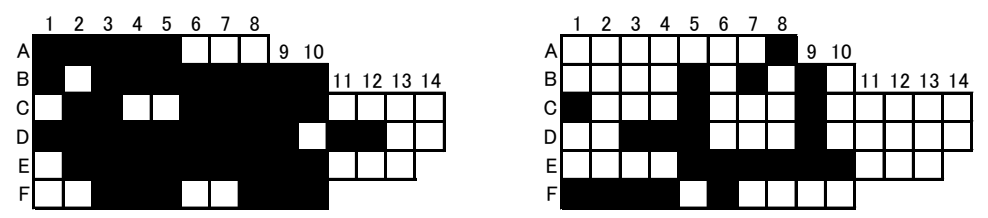

2010
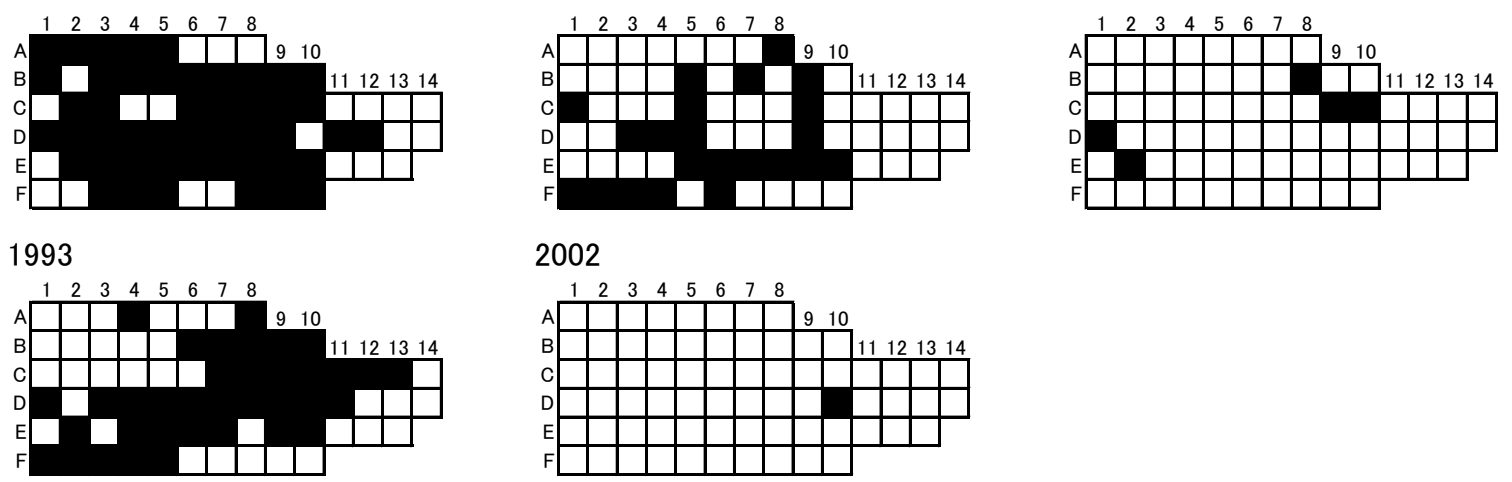
233 Cardita leana トマヤガイ
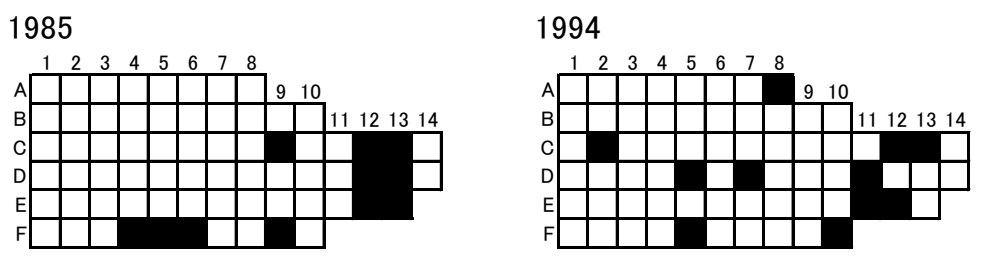

2003

1986

1995
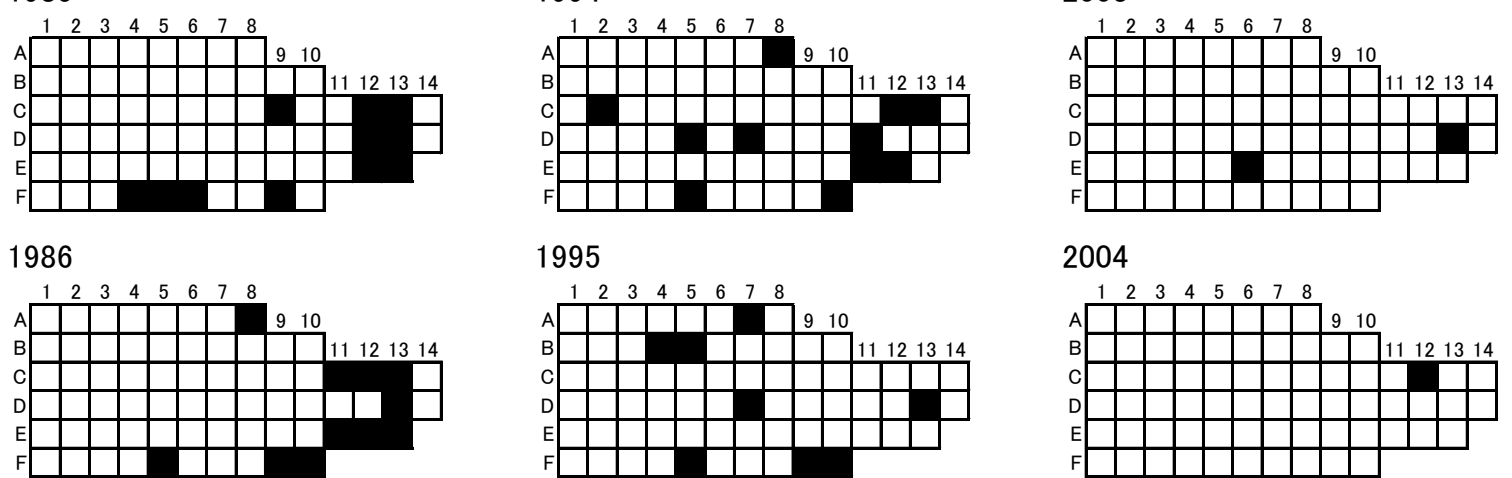

2004

1987

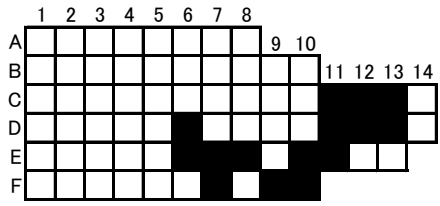

1996
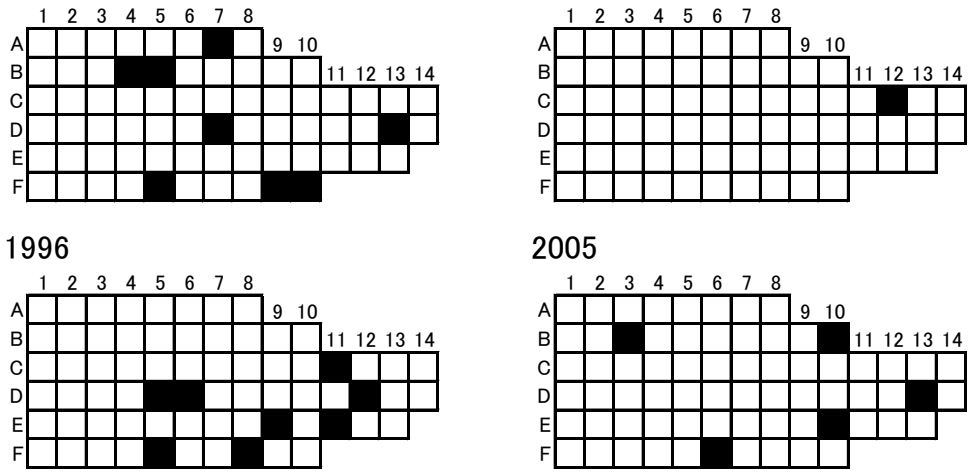

1988

1997
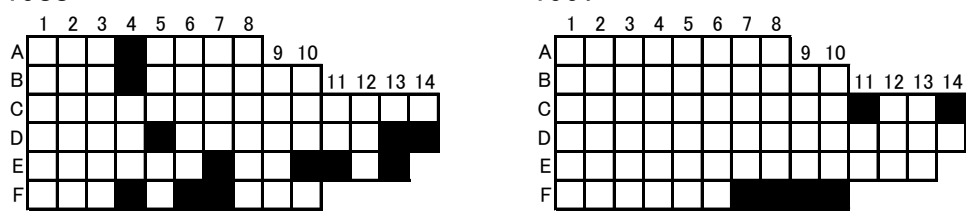

2005

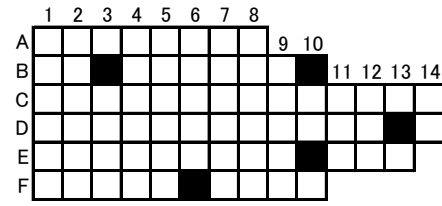

2006

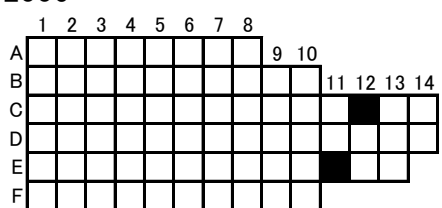

1989

1998

2007
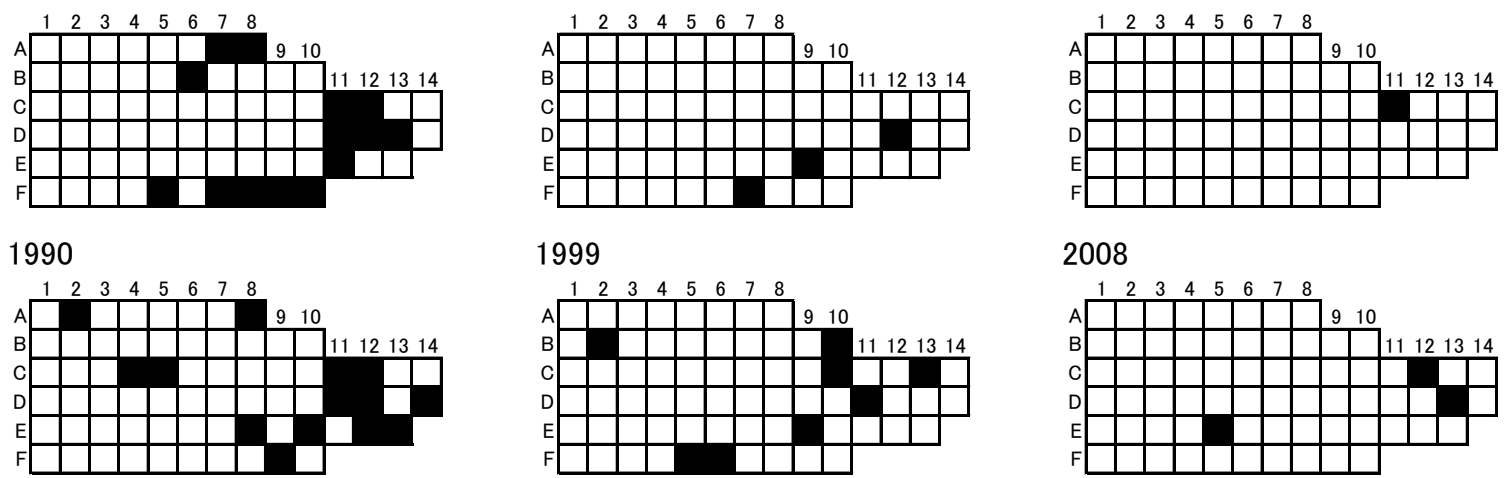

1999

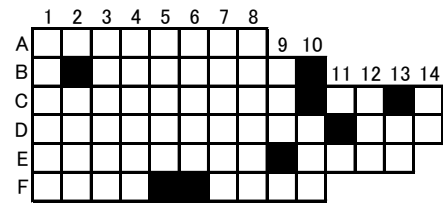

2008

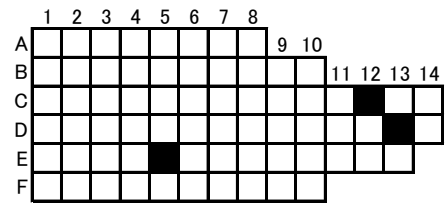

1991

2000
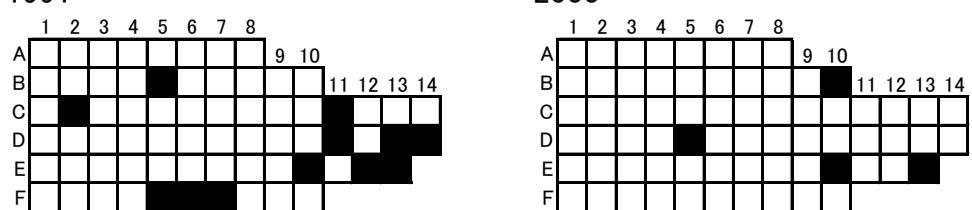

2009

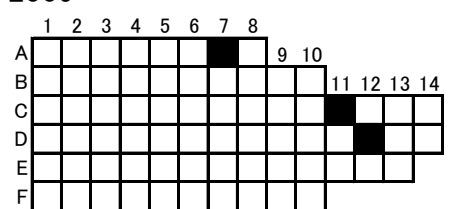

1992

2001
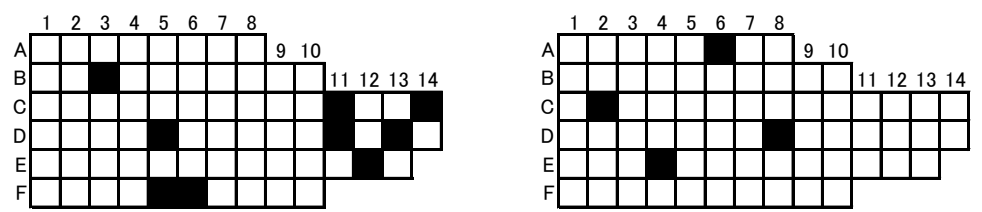

2010

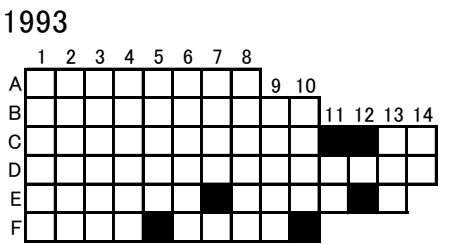

2002

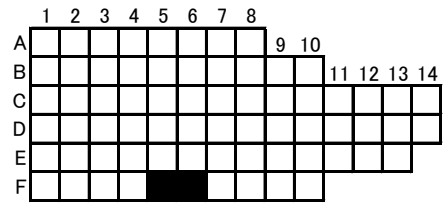

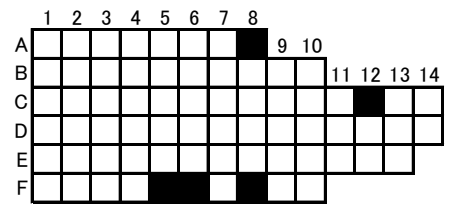


234 Chama japonica キクザル
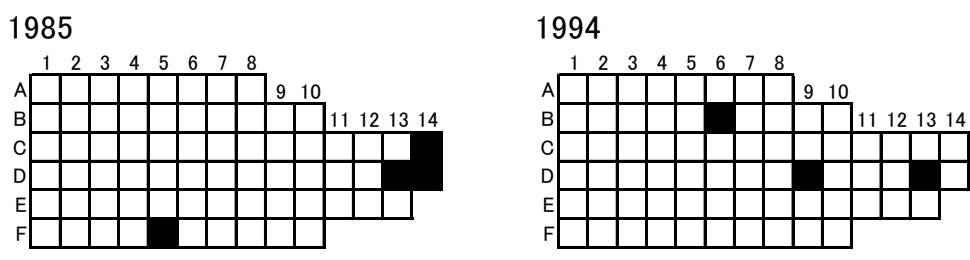

2003

1986

1995
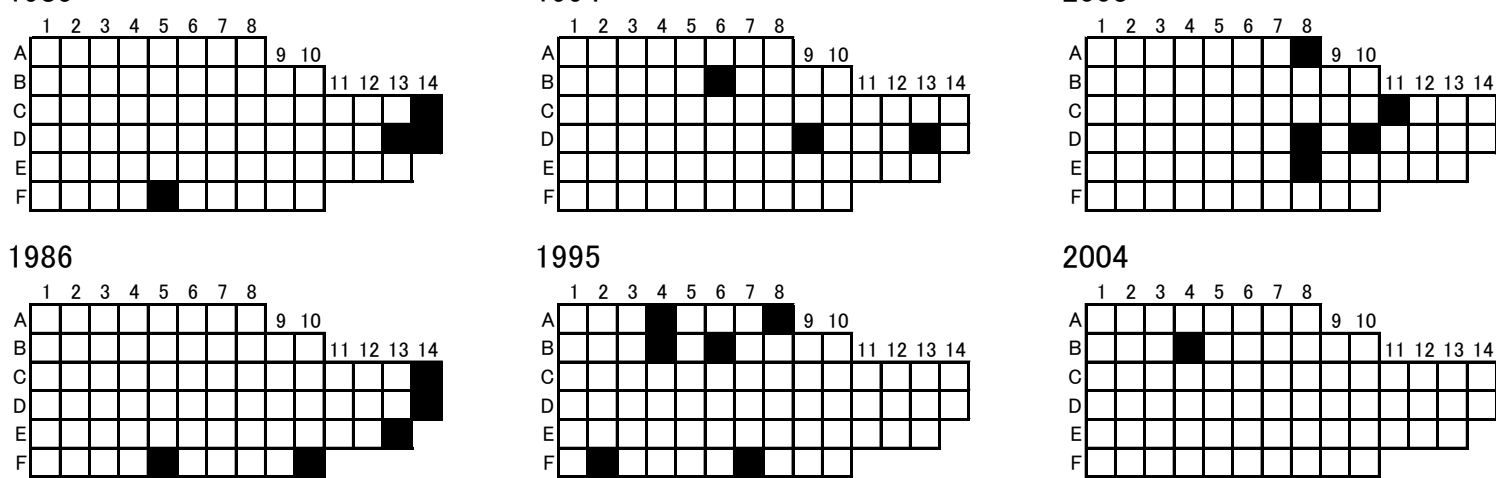

2004

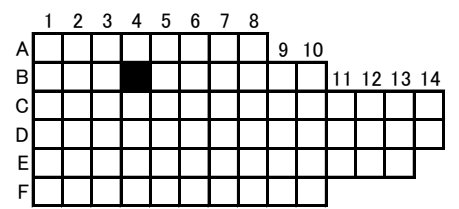

1987

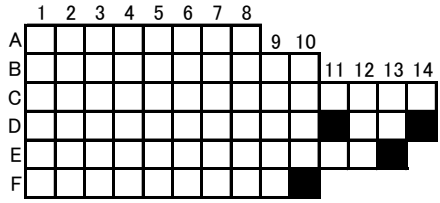

1996

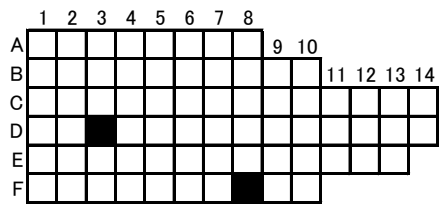

2005

1988

1997
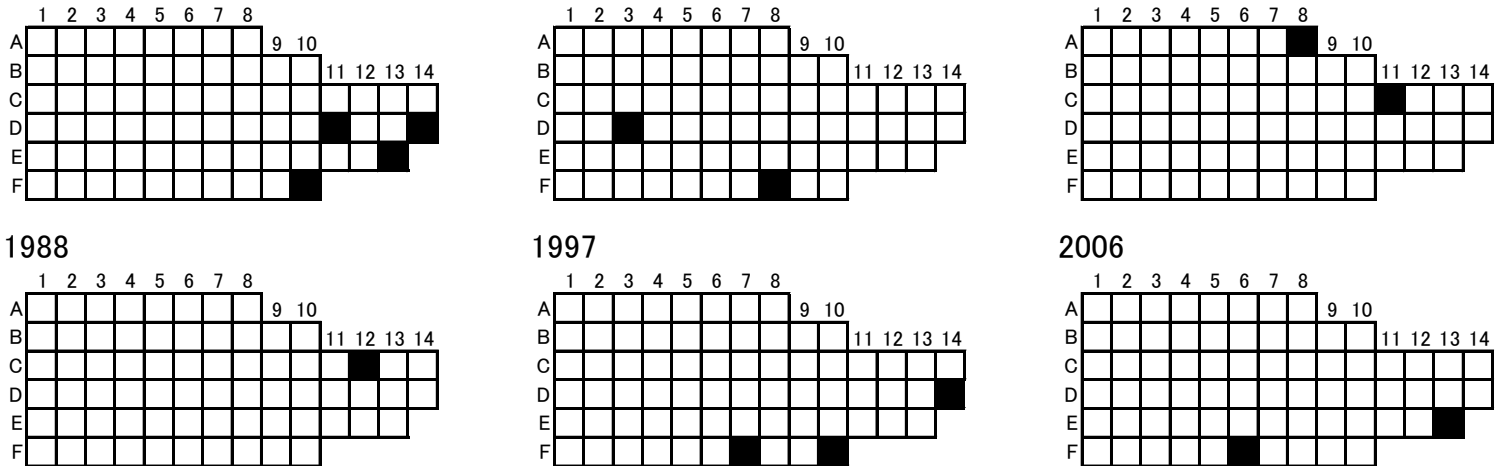

2006

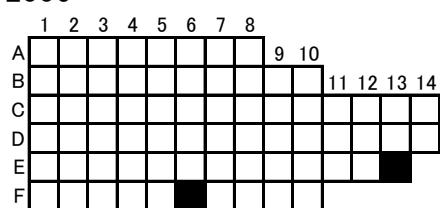

1989

1998
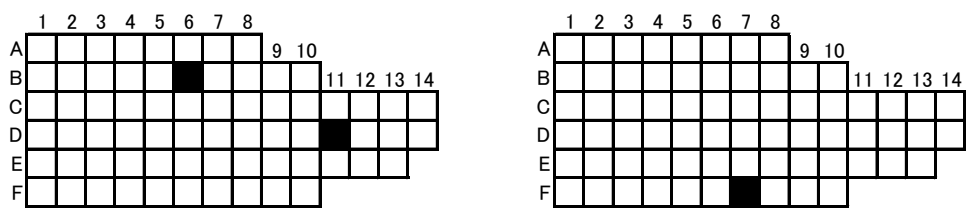

2007
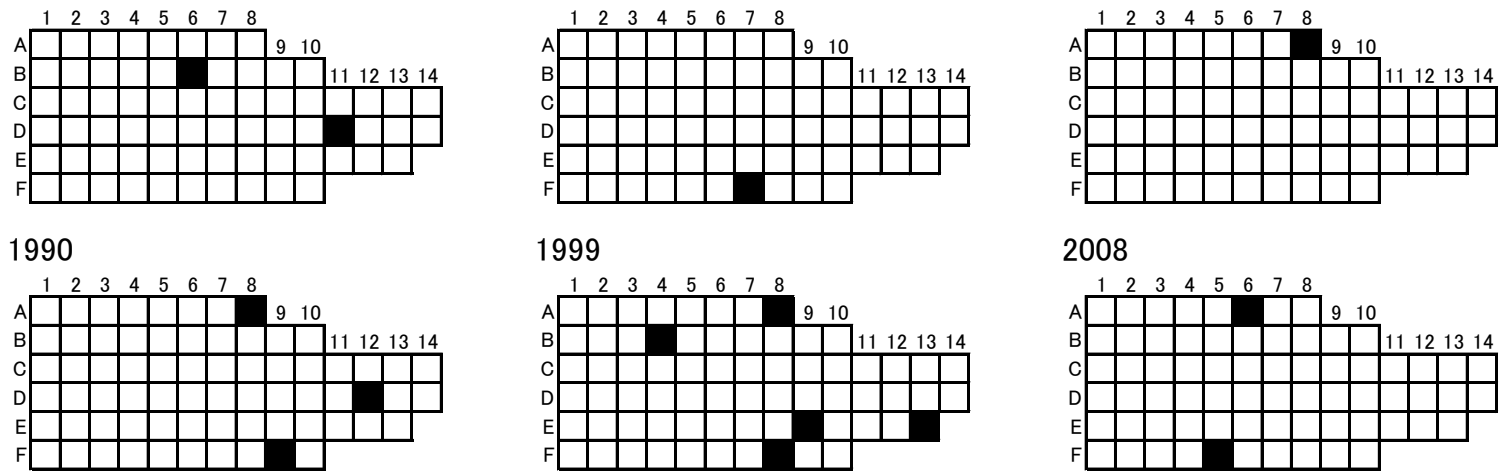

1999

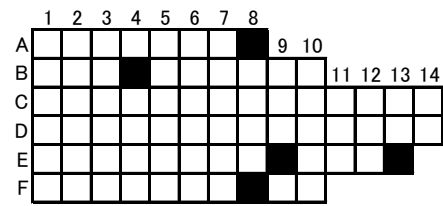

2008

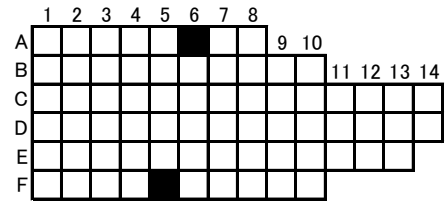

1991

2000
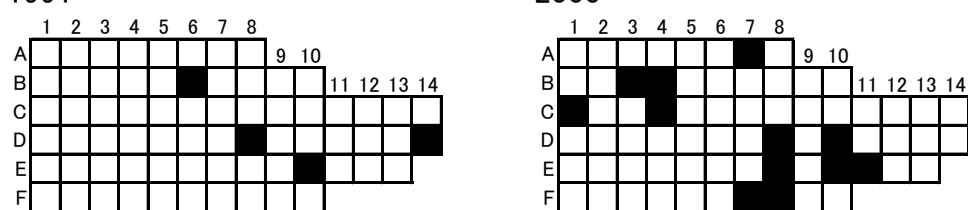

2009

1992

2001
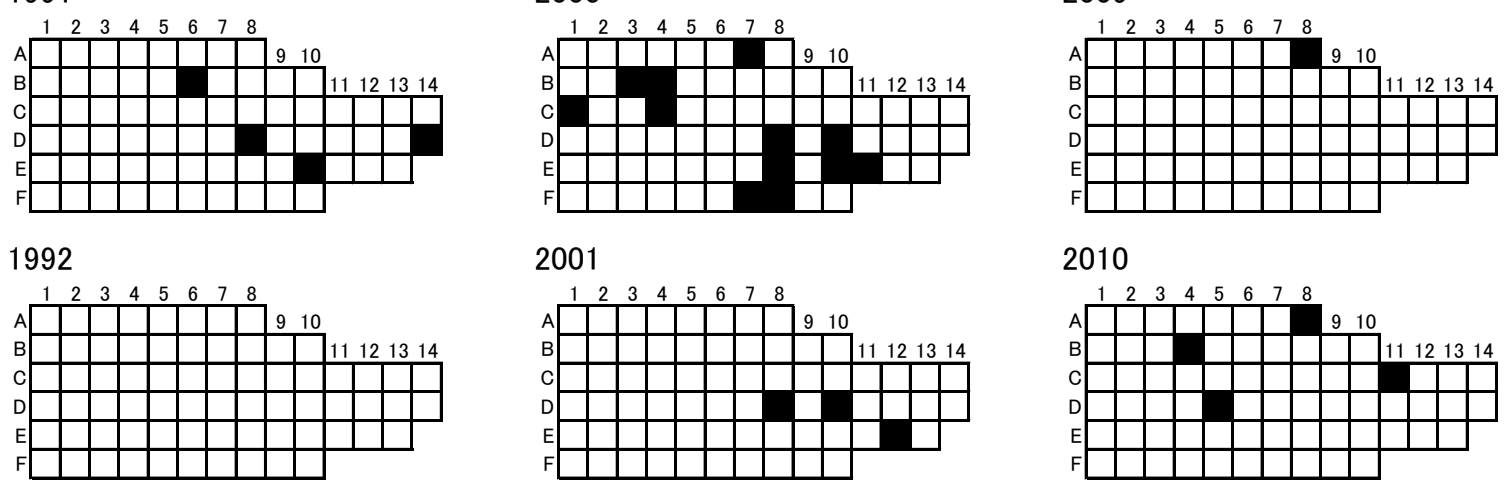

2010

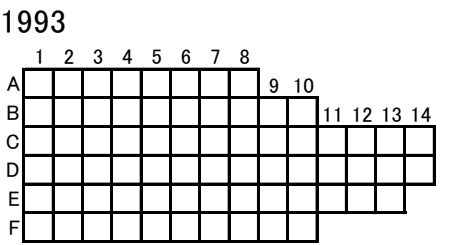

2002
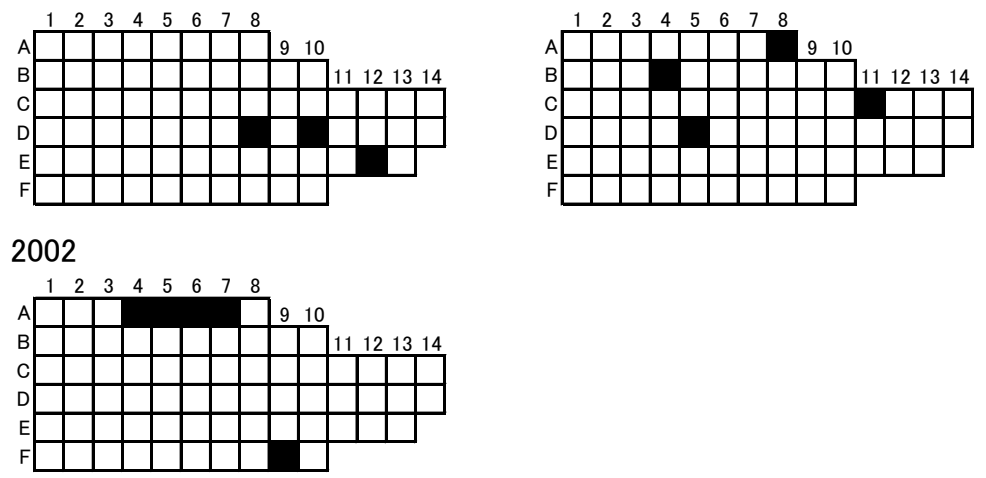
1985

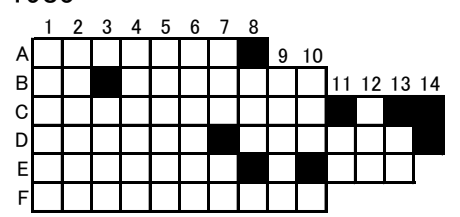

1986

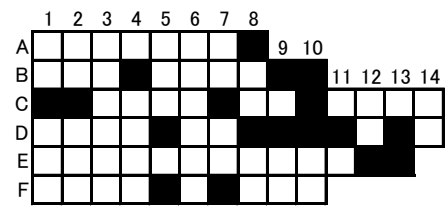

1987

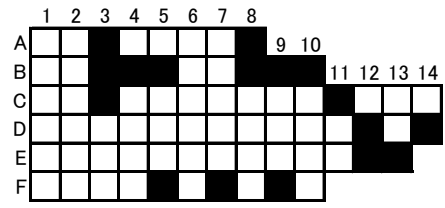

1988

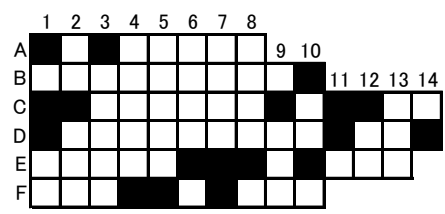

1989

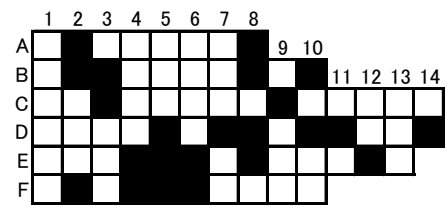

1990

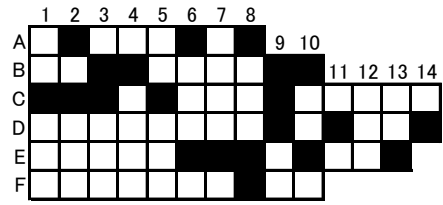

1991

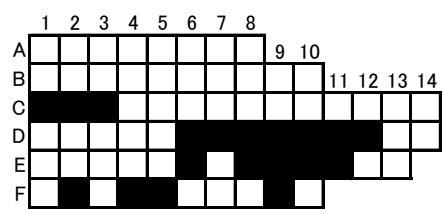

1992

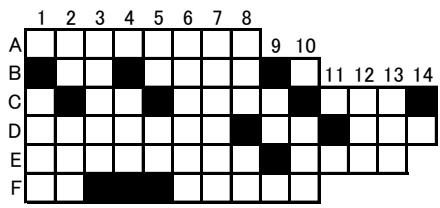

1993

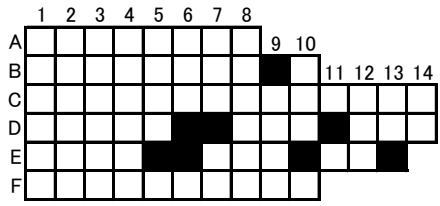

1994

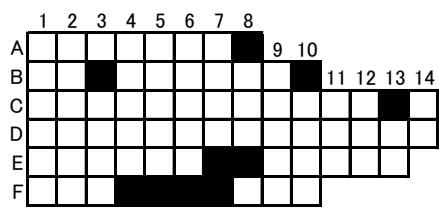

1995

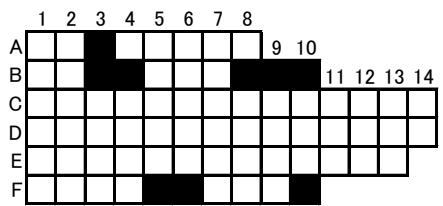

1996

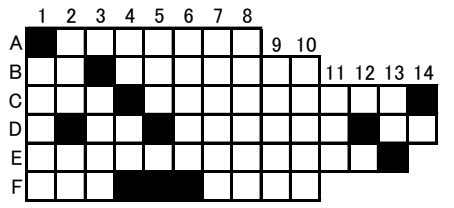

1997

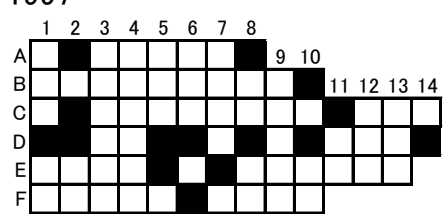

1998

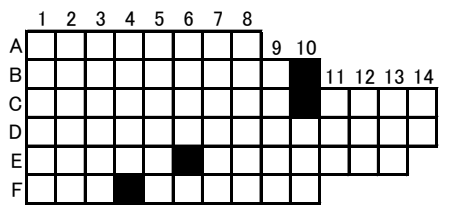

1999

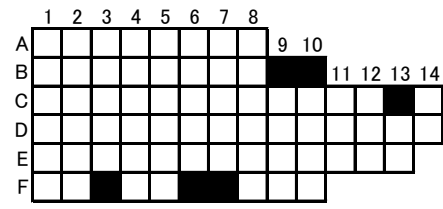

2000

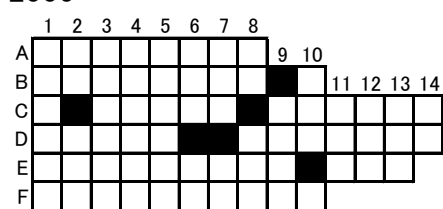

2001

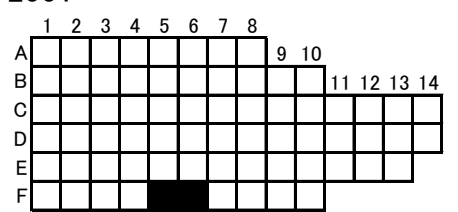

2002

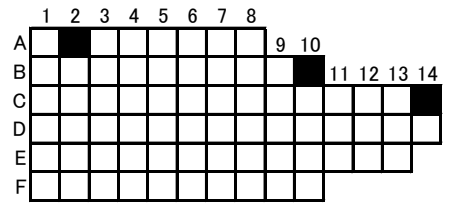

2003

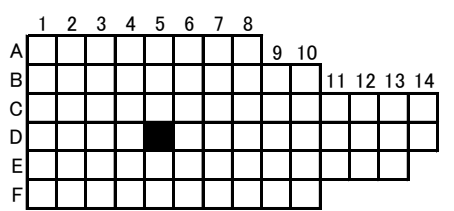

2004

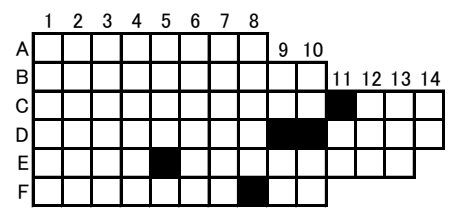

2005

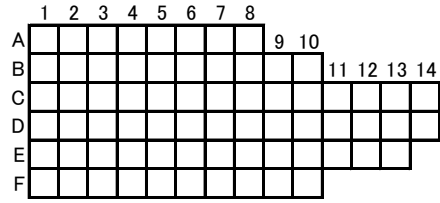

2006

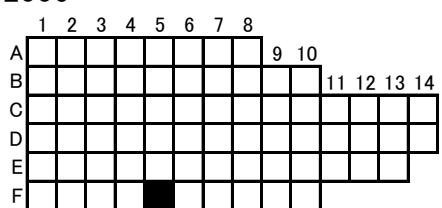

2007

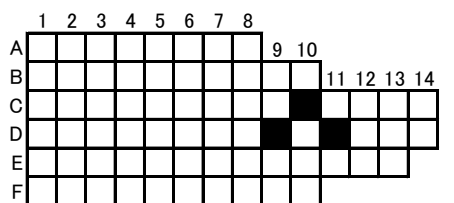

2008

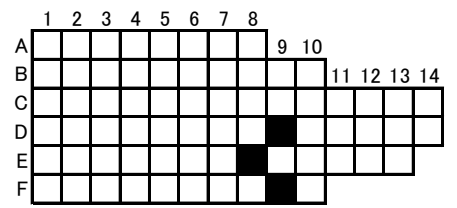

2009

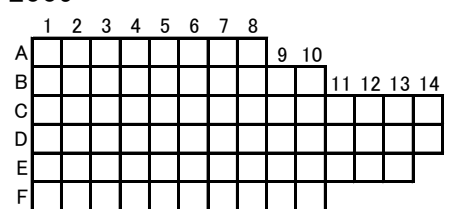

2010

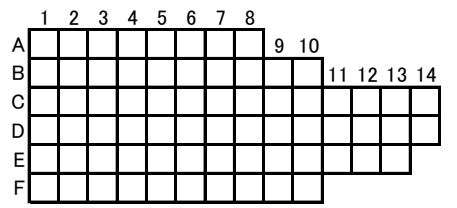


5-2. Cumulative distribution patterns of the 242 species

Figure 3.

Distribution of all of the species recorded in the study area during the 25-year period (1985 to 2010). The cumulative number of years when each species was present is shown for each quadrat. A numeral attached to a species name corresponds to the species code in the List of recorded species (Section 2). 
1 Ischnochiton boninensis

ホソウスヒザラガイ

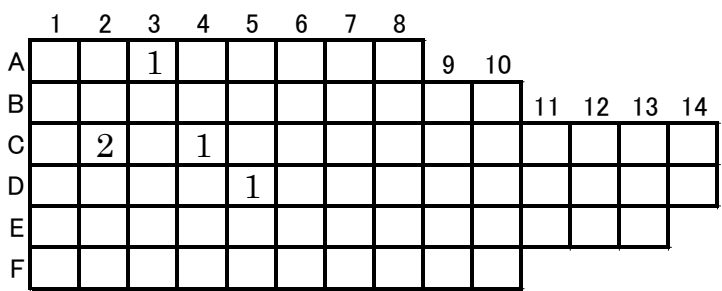

\section{Ischnochiton comptus}

ウスヒザラガイ

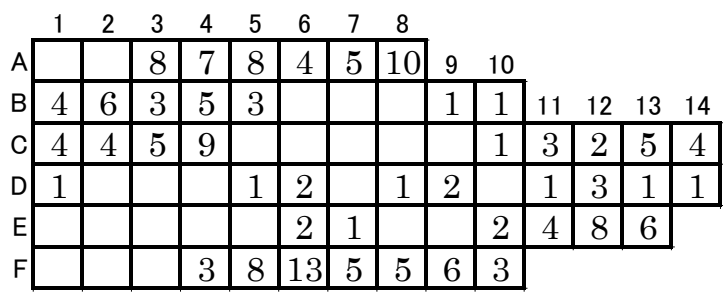

\section{Placiphorella stimpsoni}

ババガセ

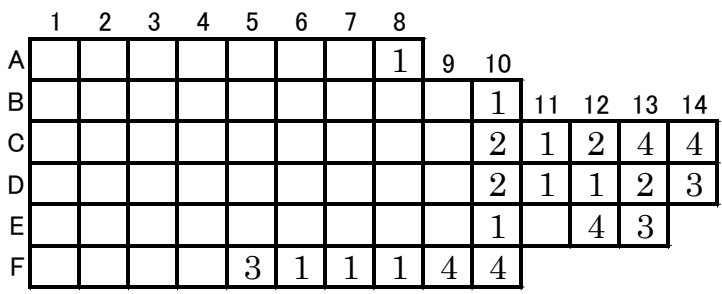

\section{Acanthopleura japonica} ヒザラガイ

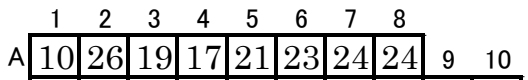

\begin{tabular}{l|l|l|l|l|l|l|l|l|l|l|llll}
\hline 8 & 16 & 24 & 23 & 16 & 18 & 16 & 25 & 26 & 26 & 11 & 12 & 13 & 14 \\
\hline
\end{tabular} C 10 \begin{tabular}{l|c|c|c|c|c|c|c|c|c|c|c|c|}
\hline 12 & 17 & 12 & 17 & 9 & 24 & 21 & 25 & 25 & 22 & 24 & 21 & 8 \\
\hline
\end{tabular} \begin{tabular}{ll|l|l|l|l|l|l|l|l|l|l|l|l|l|}
\hline $\mathrm{D}$ & 5 & 5 & 9 & 20 & 21 & 26 & 25 & 25 & 26 & 26 & 26 & 25 & 24 & 9 \\
\hline
\end{tabular} \begin{tabular}{|l|l|l|l|l|l|l|l|l|l|l|l|l|}
\hline & & & 21 & 26 & 26 & 25 & 26 & 25 & 24 & 25 & 19 & 16 \\
\hline
\end{tabular} \begin{tabular}{|l|l|l|l|l|l|l|l|l|l|}
\hline 1 & 3 & 13 & 26 & 26 & 26 & 26 & 25 & 24 & 23 \\
\hline
\end{tabular}

\section{Acanthopleura loochooana \\ リュウキュウヒザラガイ}

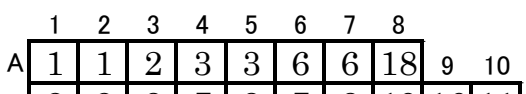

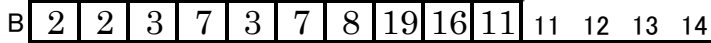
c \begin{tabular}{l|l|l|l|l|l|l|l|l|l|l|l|l|l|}
\hline 1 & & 2 & 2 & 6 & 4 & 13 & 16 & 17 & 16 & 8 & 12 & 5 & 5 \\
\hline
\end{tabular} \begin{tabular}{|l|l|l|l|l|l|l|l|l|l|l|l|l|l|}
\hline $\mathrm{D}$ & 1 & 4 & 3 & 7 & 14 & 14 & 15 & 16 & 18 & 15 & 12 & 12 & 3 \\
\hline
\end{tabular}

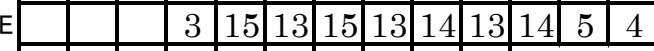

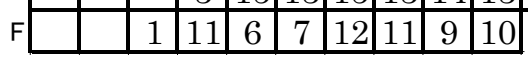

6 Onithochiton hirasei

ニシキヒザラガイ

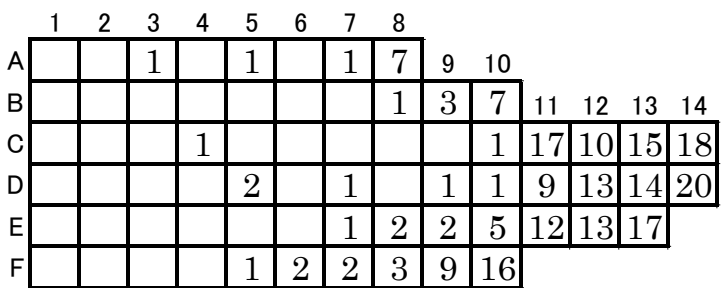

7 Acanthochitona achates

ヒメケハダヒザラガイ

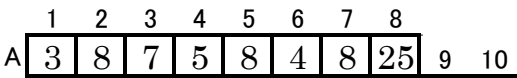

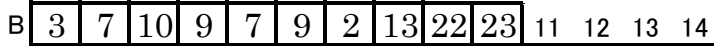

c \begin{tabular}{l|l|l|l|l|l|l|l|l|l|l|l|l|l|}
\hline & 2 & 3 & 3 & 5 & 2 & 10 & 19 & 24 & 19 & 23 & 20 & 23 & 21 \\
\hline
\end{tabular}

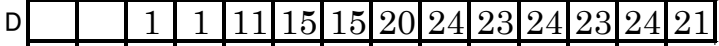

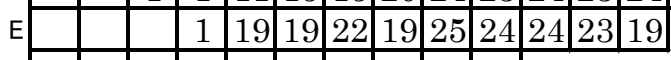

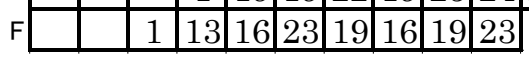

\section{8}

Acanthochitona dissimilis

ビロウドヒザラガイ

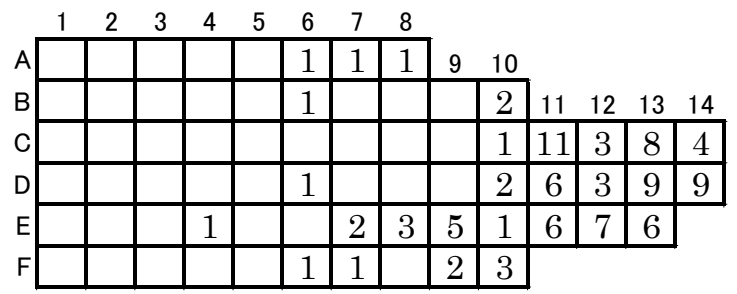

\section{Cryptoplax japonica}

ケムシヒザラガイ

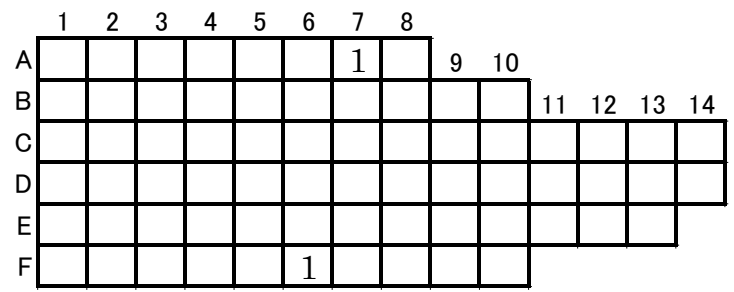

10 Scutellastra flexuosa

ツ夕ノ八

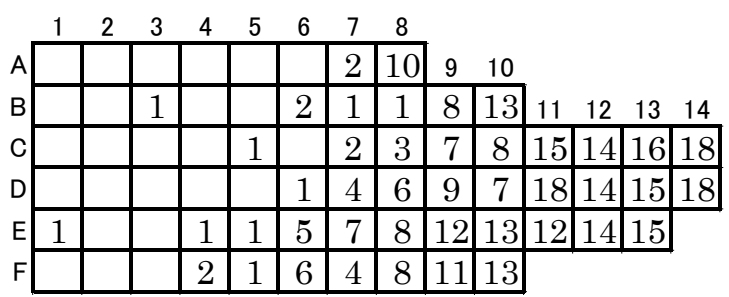


11

Cellana grata

ベッコウガサ

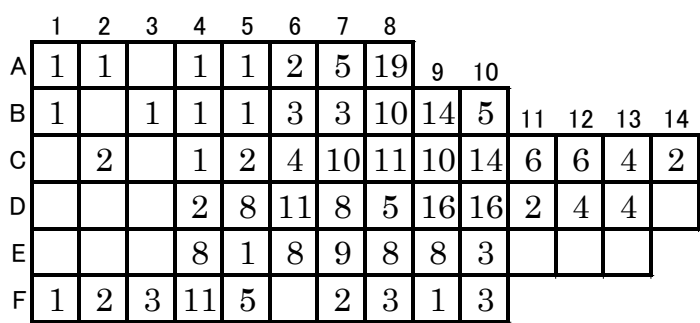

12 Cellana nigrolineata

マツバガイ

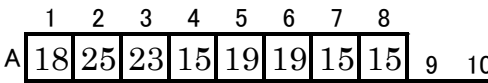
B \begin{tabular}{l|l|l|l|l|l|l|l|l|l|llll}
\hline 20 & 22 & 21 & 23 & 20 & 19 & 11 & 21 & 20 & 1 & 11 & 12 & 13 & 14 \\
\hline
\end{tabular} C \begin{tabular}{l|l|l|l|l|l|l|l|l|l|l}
19 & 15 & 19 & 19 & 20 & 10 & 20 & 24 & 23 & 3 & 1 \\
\hline
\end{tabular} D 7 \begin{tabular}{c|c|c|c|c|c|c|c|c|c|c|} 
& 10 & 11 & 14 & 26 & 23 & 25 & 21 & 23 & 13 & 2 \\
\hline
\end{tabular}

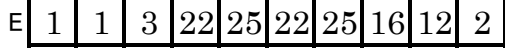
F \begin{tabular}{lllllllll|l|l|l|}
13 & 10 & 17 & 24 & 17 & 4 & 14 & 5 & 2 & 1 \\
\hline
\end{tabular}

13

Cellana toreuma

ヨメガカサ

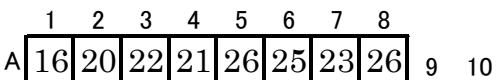
в 1 \begin{tabular}{llllllll|l|l|l|llll}
16 & 24 & 25 & 26 & 22 & 24 & 16 & 25 & 25 & 15 & 11 & 12 & 13 & 14
\end{tabular} c \begin{tabular}{r|l|l|l|l|l|l|l|l|l|l|l|l|l|}
16 & 20 & 20 & 18 & 20 & 9 & 23 & 23 & 25 & 20 & 17 & 23 & 17 & 20 \\
\hline
\end{tabular} \begin{tabular}{ll|l|l|l|l|l|l|l|l|l|l|l|l|l|}
$\mathrm{D}$ & 2 & 16 & 21 & 15 & 25 & 25 & 26 & 26 & 24 & 26 & 19 & 23 & 23 & 20 \\
\hline
\end{tabular}

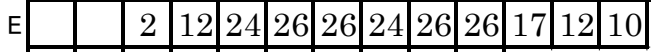
\begin{tabular}{lllllll|l|l|l|l|l|}
$\mathrm{F}$ & 7 & 2 & 7 & 25 & 25 & 25 & 24 & 26 & 25 & 20 \\
\hline
\end{tabular}

14 Patelloida pygmaea heroldi ヒメコザラ

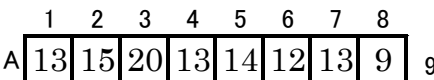

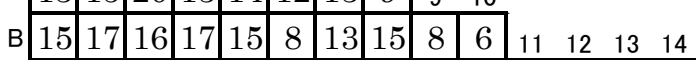
c \begin{tabular}{l|l|l|l|l|l|l|l|l|l|l|l|l|l|}
17 & 22 & 21 & 17 & 15 & 12 & 17 & 14 & 10 & 9 & 4 & 7 & 3 & 3 \\
\hline
\end{tabular}

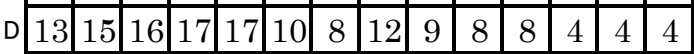

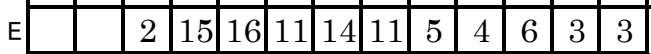
F 10 \begin{tabular}{lllllll|l|l|l|l|} 
& 7 & 6 & 14 & 9 & 13 & 12 & 6 & 5 & 6 \\
\hline
\end{tabular}

15 Patelloida saccharina lanx ウノアシ

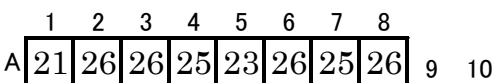

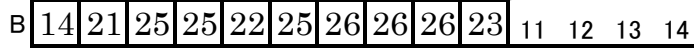
c \begin{tabular}{l|l|l|l|l|l|l|l|l|l|l|l|l|l|}
17 & 20 & 23 & 24 & 22 & 23 & 26 & 26 & 26 & 25 & 19 & 23 & 15 & 7 \\
\hline
\end{tabular}

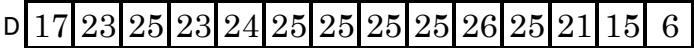
E 9 \begin{tabular}{llllllllll|l|l|l|l|l} 
& 9 & 12 & 20 & 25 & 26 & 26 & 26 & 26 & 25 & 25 & 24 & 20 & 8
\end{tabular} F \begin{tabular}{|l|l|l|l|l|l|l|l|l|l|}
21 & 22 & 24 & 24 & 25 & 24 & 25 & 26 & 25 & 23 \\
\hline
\end{tabular}
16 Lottia langfordi

キクコザラ

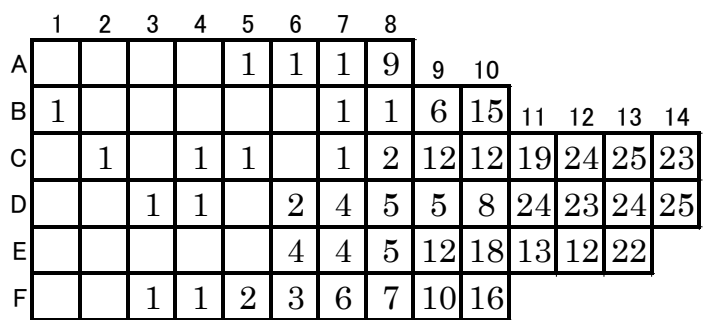

17 Lottia kogamogai

コガモガイ

$\begin{array}{rrrrrrrr}1 & 2 & 3 & 4 & 5 & 6 & 7 & 8\end{array}$

A \begin{tabular}{l|l|l|l|l|l|l|l|ll}
10 & 20 & 18 & 10 & 10 & 10 & 23 & 24 & 9 & 10 \\
\hline
\end{tabular}

в 10 \begin{tabular}{l|l|l|l|l|l|l|l|l|llll}
14 & 15 & 14 & 14 & 9 & 16 & 22 & 26 & 18 & 11 & 12 & 13 & 14 \\
\hline
\end{tabular}

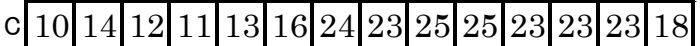

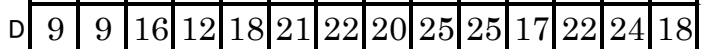

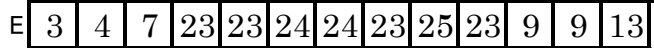

F \begin{tabular}{|l|l|l|l|l|l|l|l|l|l|}
9 & 15 & 17 & 24 & 22 & 16 & 18 & 19 & 19 & 19 \\
\hline
\end{tabular}

18

Lottia tenuisculpta

コモレビコガモガイ

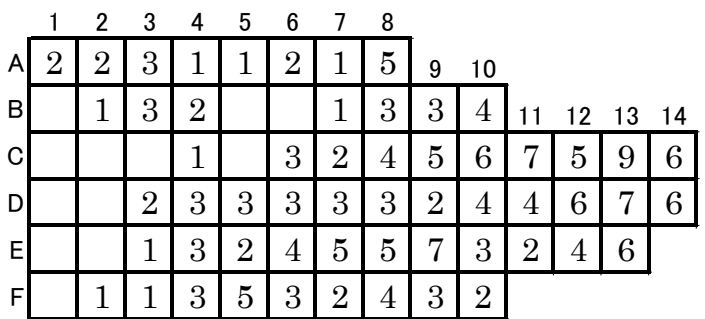

19 Lottia lindbergi

オボロヅキコガモガイ

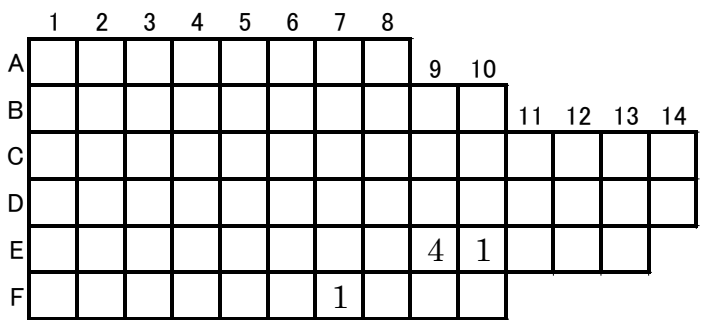

20 Nipponacmea fuscoviridis

クサイロアオガイ

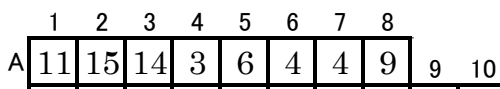

В 10 \begin{tabular}{llllllllll|l|l|llll}
\hline 10 & 7 & 12 & 7 & 4 & & & 2 & 5 & 4 & 11 & 12 & 13 & 14
\end{tabular}

\begin{tabular}{c|c|c|c|c|c|c|c|c|c|c|c|c|c|c|}
$\mathrm{C}$ & 9 & 9 & 15 & 7 & 11 & 2 & 7 & 8 & 3 & 3 & 2 & 2 & & \\
\hline $\mathrm{n}$ & 6 & 5 & 4 & 5 & 12 & 19 & 14 & 11 & 15 & 6 & 1 & 1 & & 1 \\
\hline
\end{tabular}

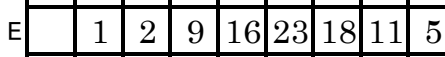

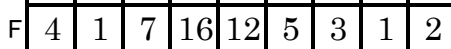


21

Nipponacmea gloriosa

サクラアオガイ

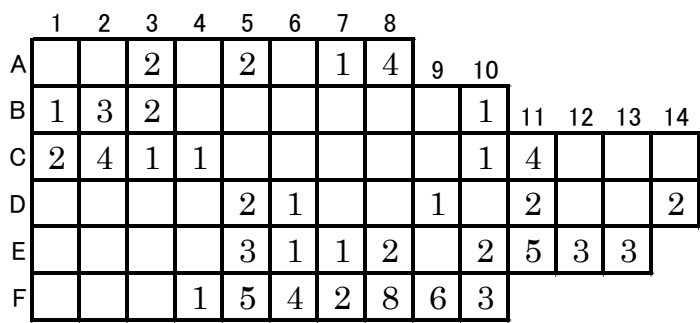

$22 \begin{aligned} & \text { Nipponacmea nigrans } \\ & \text { クモリアオガイ }\end{aligned}$

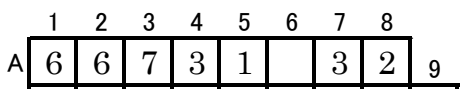

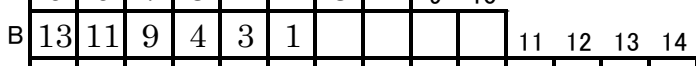

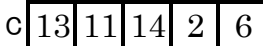

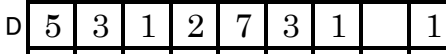

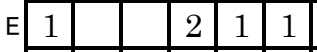

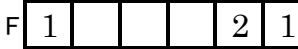

23 Nipponacmea schrenckii

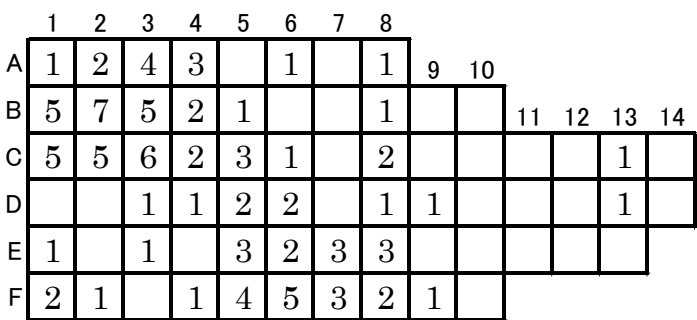

24 Haliotis discus discus

クロアワビ

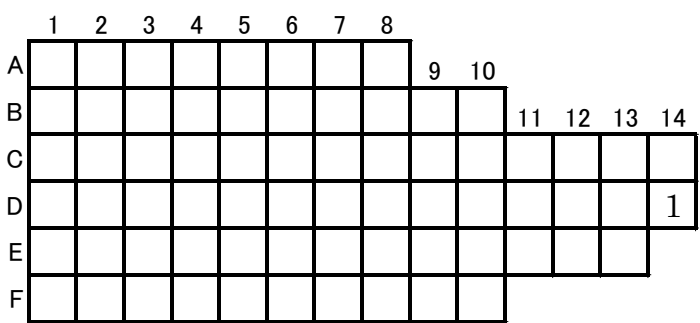

$25 \begin{aligned} & \text { Haliotis diversicolor aquatilis } \\ & \text { トコブシ }\end{aligned}$

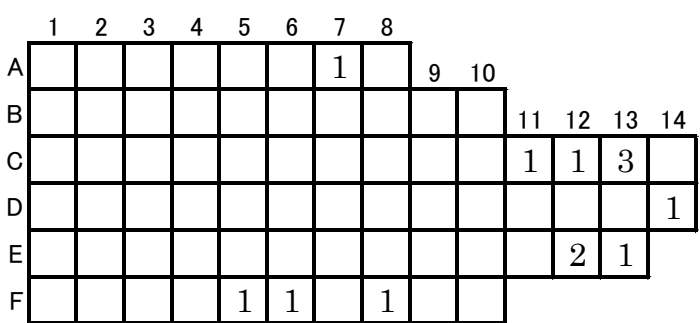

26

Haliotis varia

イボアナゴ

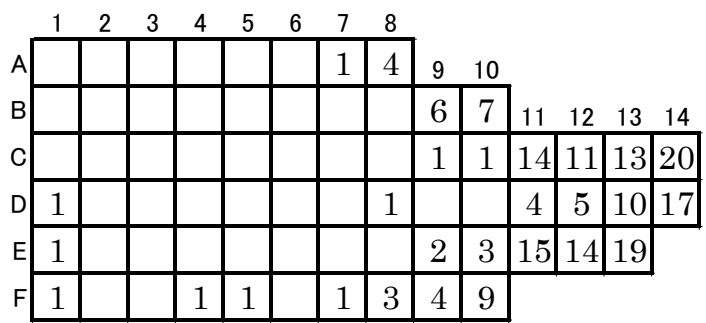

27 Tugali decussata

シロスソカケガイ

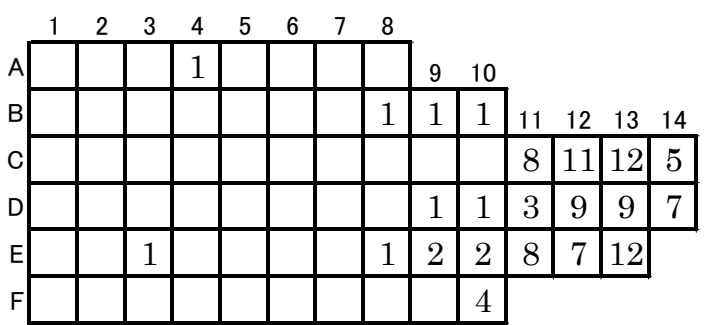

28 Montfortula picta

スソカケガイ

A \begin{tabular}{c|c|c|c|c|c|c|c|cc} 
& 1 & 2 & 3 & 4 & 5 & 6 & 7 & 8 & \\
\hline 2 & 1 & 2 & 1 & 2 & 7 & 6 & 24 & 9 & 10
\end{tabular}

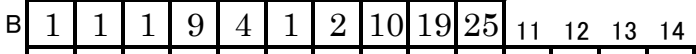

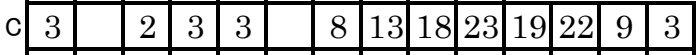

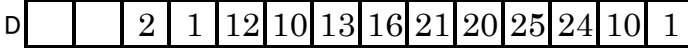
Е $\quad$\begin{tabular}{lllllll|l|l|l|l|l|l|}
\hline & & & 1 & 6 & 9 & 12 & 19 & 22 & 24 & 18 & 16 & 9 \\
\hline
\end{tabular}

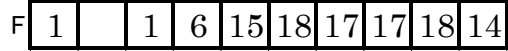

29 Macroschisma dilatatum ヒラスカシガイ

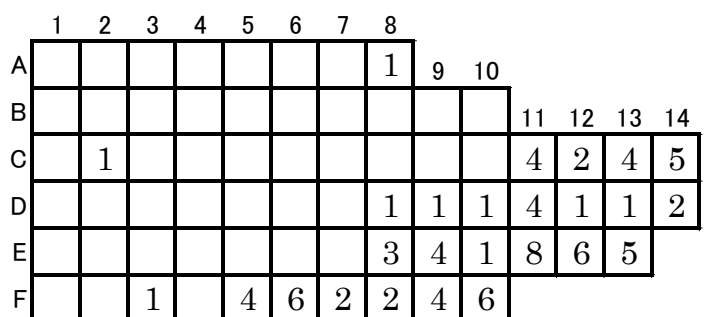

30 Macroschisma sinense スカシガイ

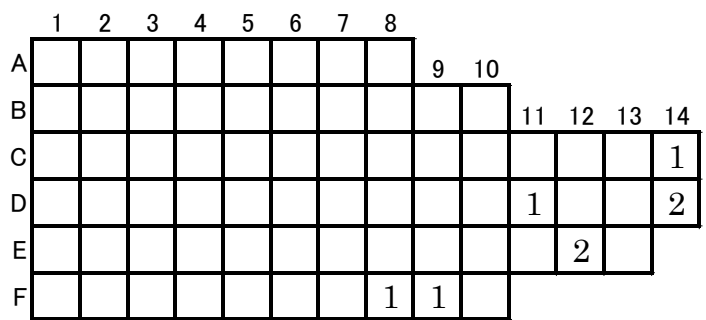


31

Chlorostoma lischkei

クボガイ

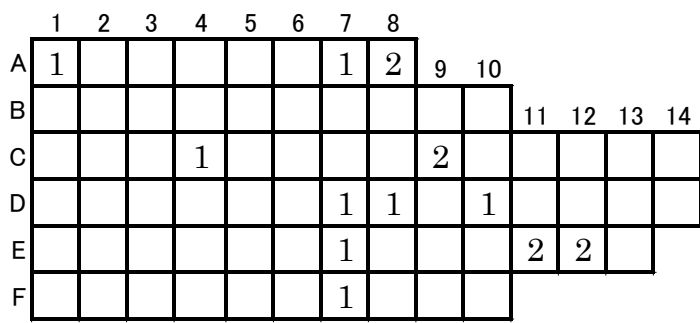

32 Chlorostoma turbinatum

ヘソアキクボガイ

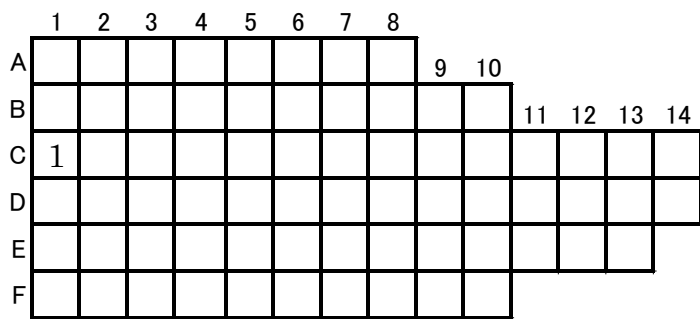

33 Chlorostoma xanthostigma

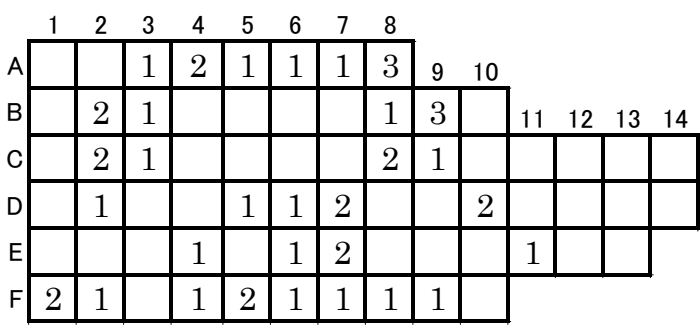

34 Omphalius nigerrimus ヒメクボガイ

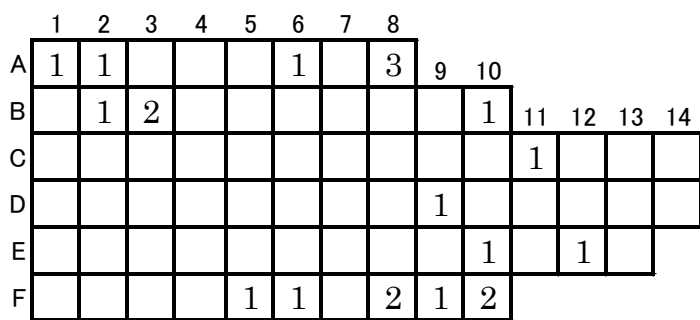

35 Omphalius pfeifferi バテイラ

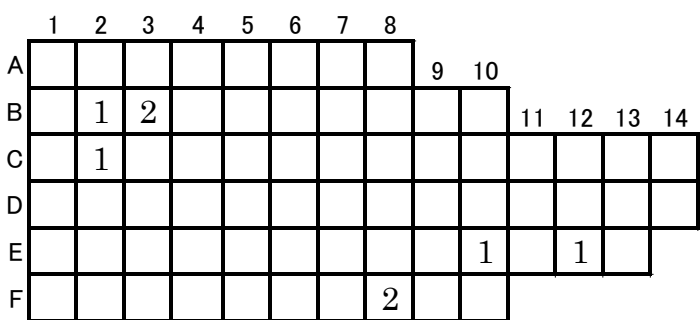

36 Omphalius rusticus

コシダカガンガラ

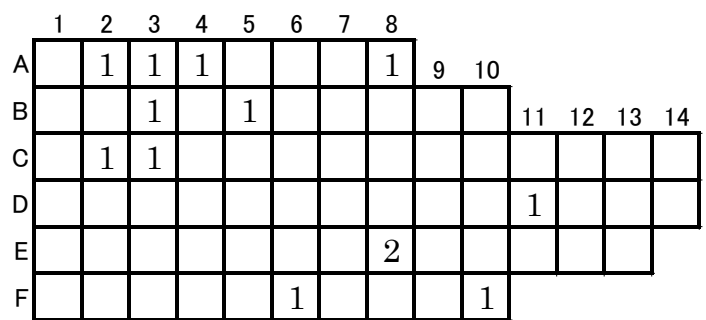

37 Trochus histrio

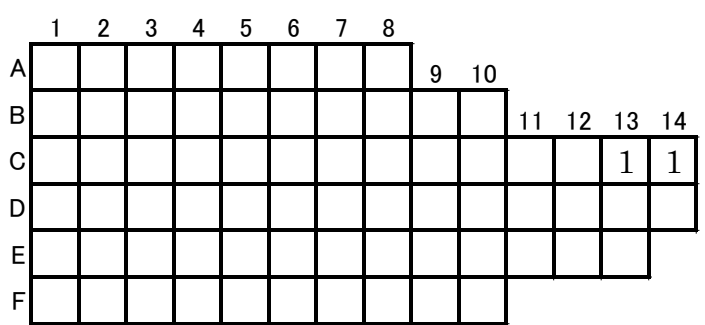

38 Trochus maculatus ニシキウズ

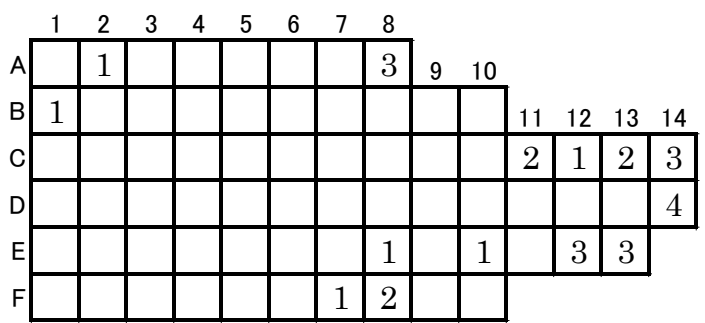

39 Trochus rota

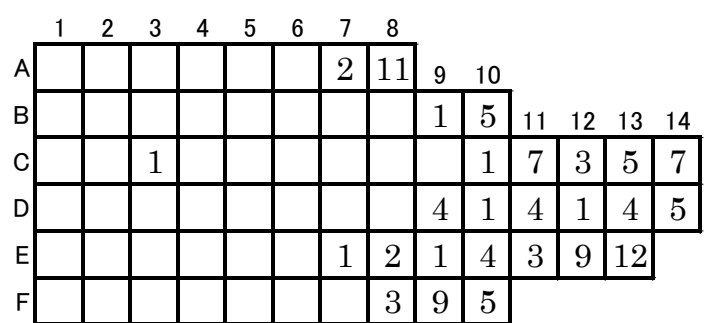

40 Tectus conus

ベニシリダカ

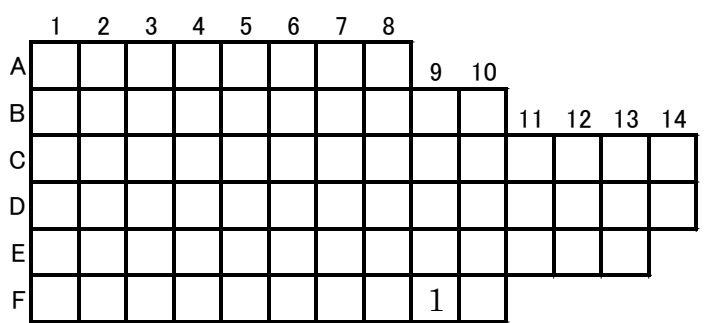


41

Tectus pyramis

ギンタカハマ

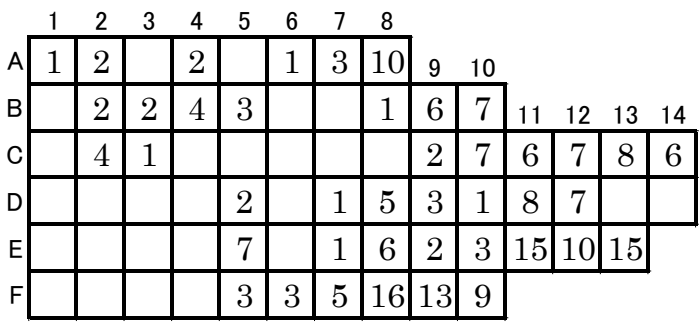

$42 \begin{aligned} & \text { Eurytrochus cognatus } \\ & \text { クルマチグサ }\end{aligned}$

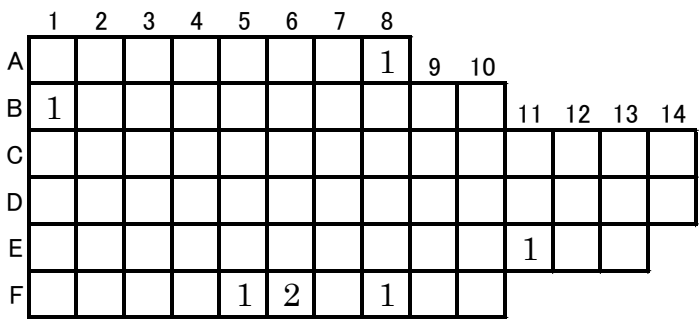

$43 \begin{aligned} & \text { Fossarina picta } \\ & \text { チビアシヤ }\end{aligned}$

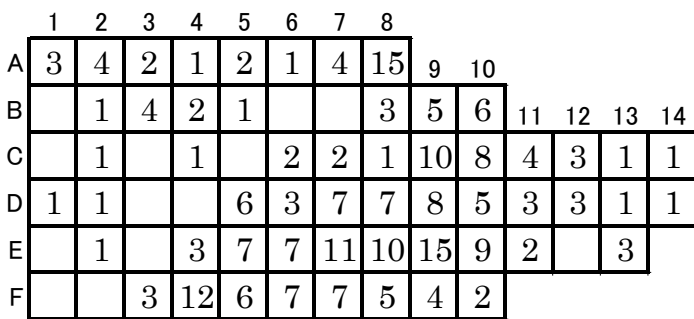

44 Monodonta labio confusa

イシダタミ

\begin{tabular}{c|cccccccc|c}
1 & 2 & 3 & 4 & 5 & 6 & 7 & 8 & \\
A 22 & 25 & 26 & 24 & 18 & 19 & 21 & 16 & 9 & 10 \\
\hline
\end{tabular}

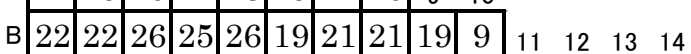
c \begin{tabular}{l|l|l|l|l|l|l|l|l|l|l|l}
25 & 25 & 26 & 26 & 25 & 21 & 24 & 23 & 23 & 19 & 7 & \\
\hline
\end{tabular}

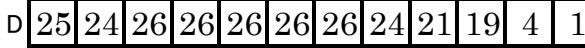
E \begin{tabular}{l|l|l|l|l|l|l|l|l|l|l|l|l}
18 & 16 & 19 & 24 & 24 & 24 & 24 & 17 & 16 & 10 & & 1 & 1 \\
\hline
\end{tabular} F \begin{tabular}{|l|l|l|l|l|l|l|l|l|l|}
24 & 25 & 21 & 25 & 19 & 6 & 9 & 4 & 1 & 1 \\
\hline
\end{tabular}

45 Monodonta perplexa perplexa クビレクロジケ

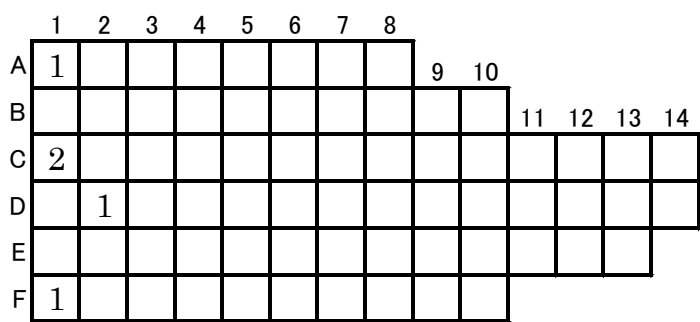

46

Cantharidus callichroa

ハナチグサ

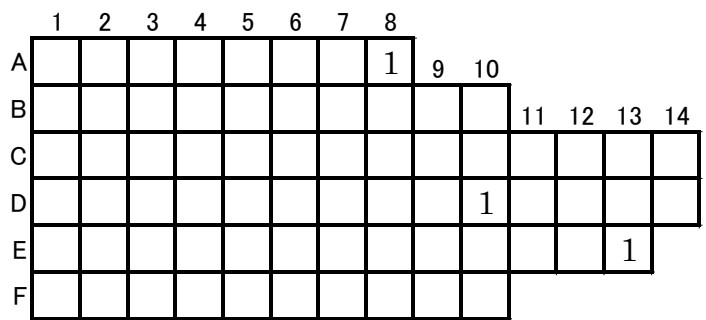

47 Cantharidus japonicus

チグサガイ

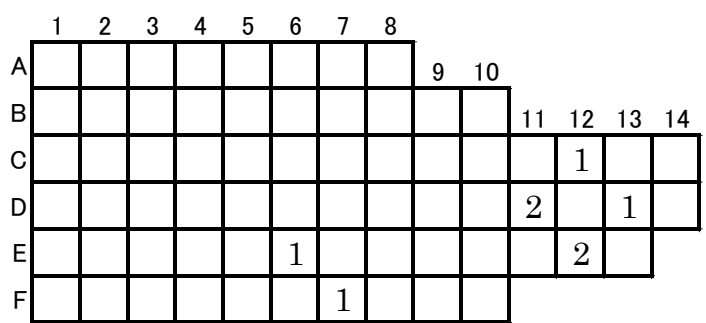

48

Diloma suavis

メクラガイ

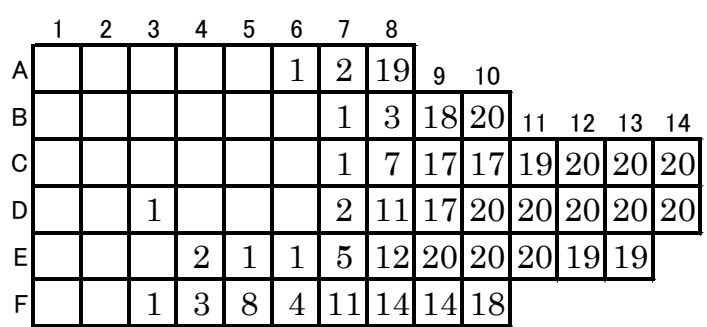

49

Broderipia iridescens

ハナザラ

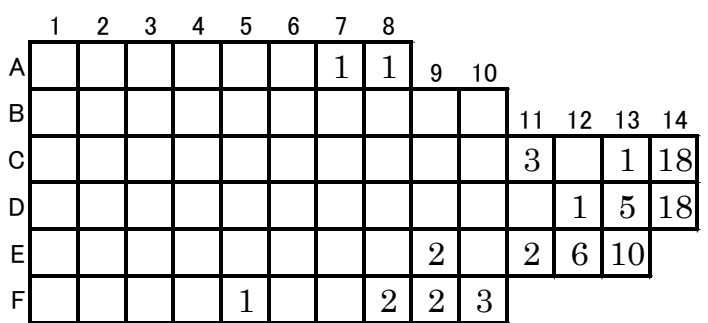

50 Stomatella impertusa

ヒメアワビ

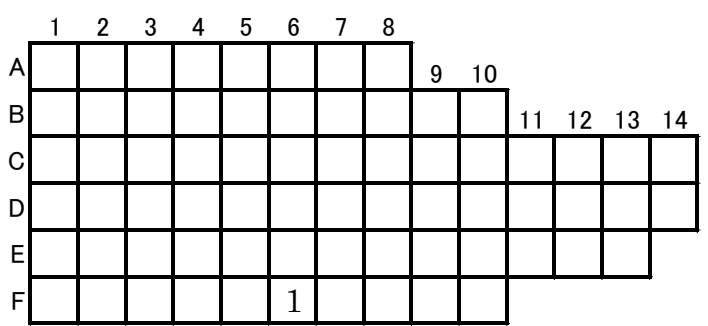


51 Thalotia attenuatus

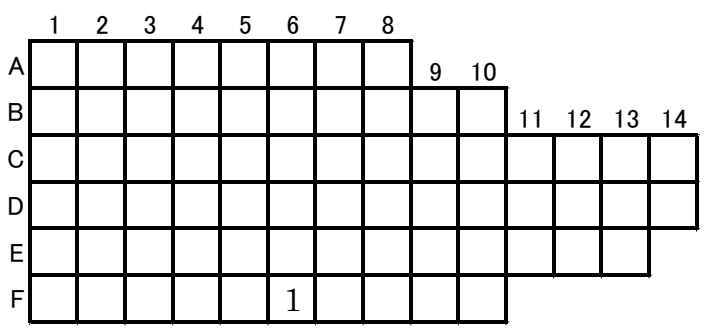

52 Calliostoma unicum

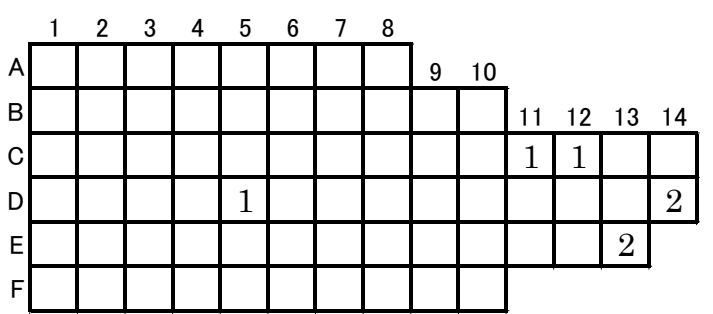

53 Conotalopia mustelina

アワジチグサ

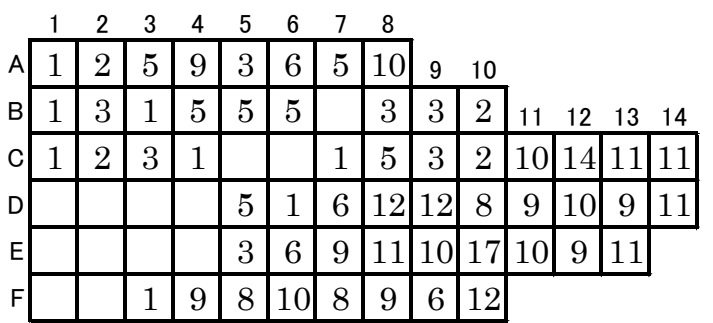

54 Angaria neglecta

カタベガイ

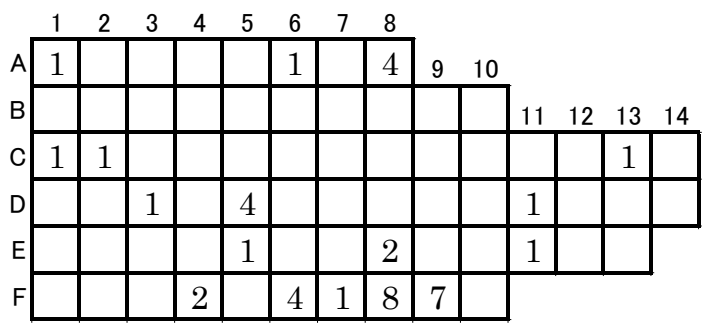

55 Collonista amakusaensis

シラタマサンショウスガイ

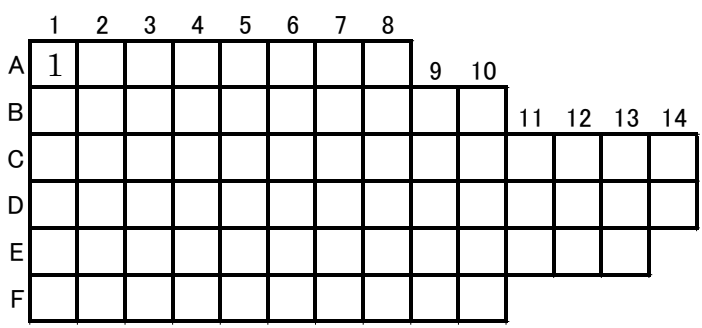

56 Collonista glareosa

コダマサンショウスガイ

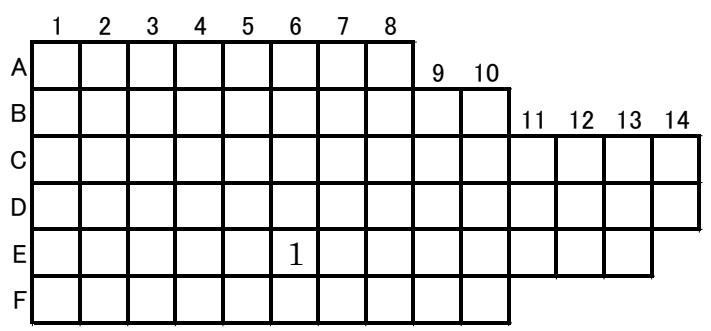

$57 \begin{aligned} & \text { Bothropoma pilulum } \\ & \text { サンショウスガイ }\end{aligned}$

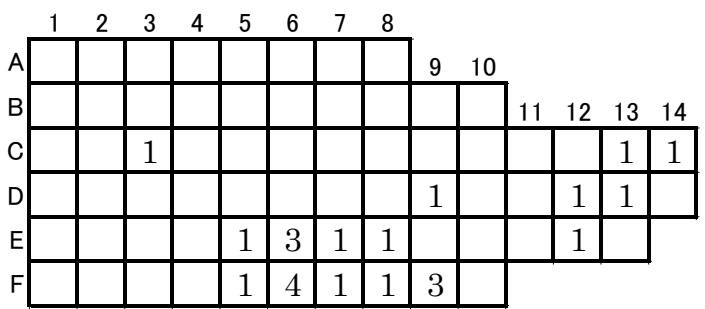

58 Astralium haematragum

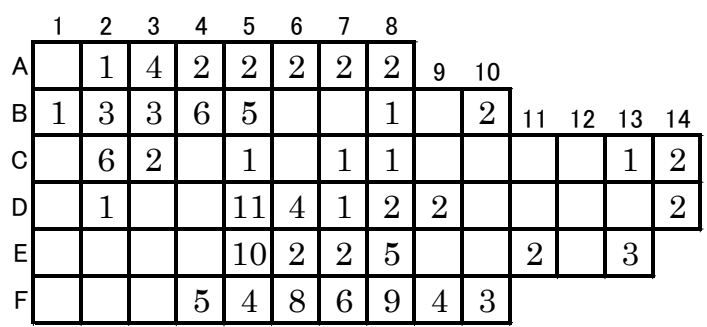

59 Astralium heimburgi

カサウラウズ

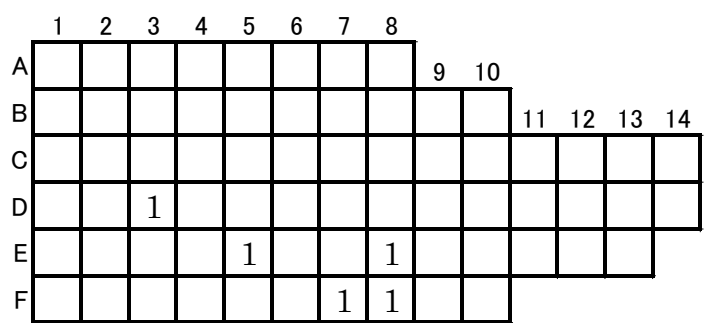

60 Turbo coronatus coreensis スガイ

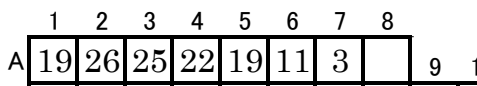

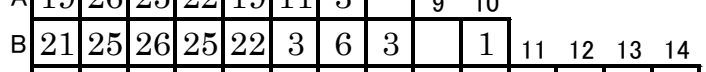

c \begin{tabular}{l|l|l|l|l|l|l|l|l|l|}
25 & 25 & 22 & 20 & 14 & & 5 & 6 & 2 & 1 \\
\hline
\end{tabular}

\begin{tabular}{l|l|l|l|l|l|l|l|l|l|l|}
$\mathrm{D}$ & 13 & 19 & 21 & 7 & 17 & 8 & 9 & 9 & 1 & 2 \\
\hline
\end{tabular}

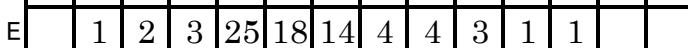

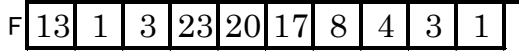




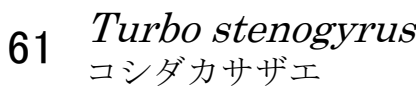

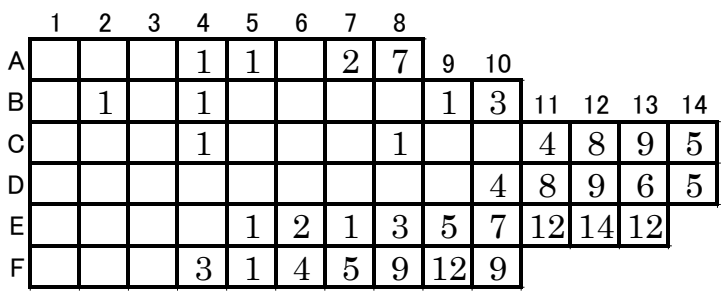

62 Phasianella solida

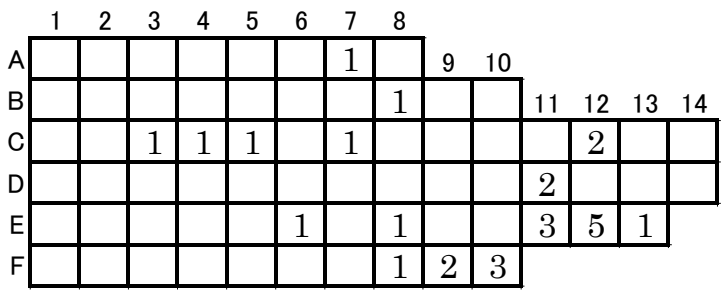

$63 \begin{aligned} & \text { Nerita albicilla } \\ & \text { アマオブネガイ }\end{aligned}$

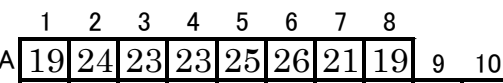
\begin{tabular}{ll|l|l|l|l|l|l|l|l|l|llll}
\hline $\mathrm{2} 1$ & 24 & 26 & 26 & 21 & 20 & 23 & 24 & 22 & 2 & 11 & 12 & 13 & 14 \\
\hline
\end{tabular} c c \begin{tabular}{ll|l|l|l|l|l|l|l|l|l|l|l|}
\hline & 25 & 25 & 22 & 21 & 23 & 23 & 22 & 23 & 22 & 16 & 1 \\
\hline
\end{tabular}

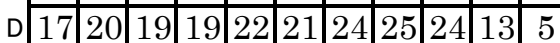

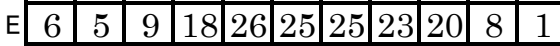
$\mathrm{F}$\begin{tabular}{|l|l|l|l|l|l|l|l|l|l|}
\hline 18 & 18 & 14 & 21 & 21 & 16 & 20 & 15 & 5 & 1 \\
\hline
\end{tabular}

\section{Nerita japonica}

アマガイ

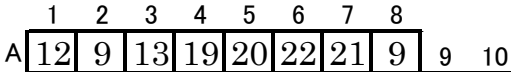

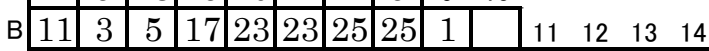
C \begin{tabular}{l|l|l|l|l|l|l|l|l|}
20 & 6 & 22 & 24 & 26 & 26 & 26 & 23 & 5 \\
\hline
\end{tabular}

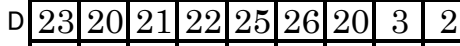

E \begin{tabular}{l|l|l|l|l|l|l|l|l|l}
16 & 15 & 13 & 24 & 12 & 10 & 4 & 2 & 1 \\
\hline
\end{tabular}

$\mathrm{F}$\begin{tabular}{|l|l|l|l|l|l|l|l|l|l}
24 & 22 & 20 & 20 & 4 & 1 & & 1 & & \\
\hline
\end{tabular}

\section{Nerita plicata キバアマガイ}

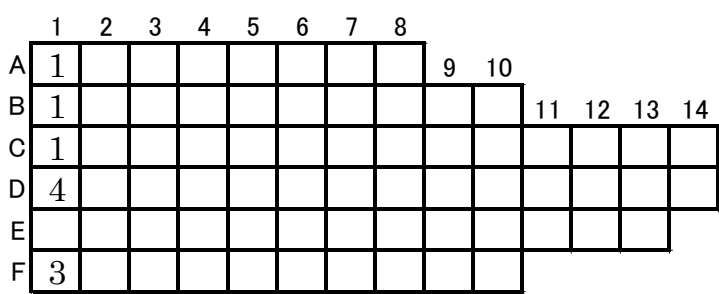

66

Phenacolepas unguiformis

ツメナリミヤコドリ

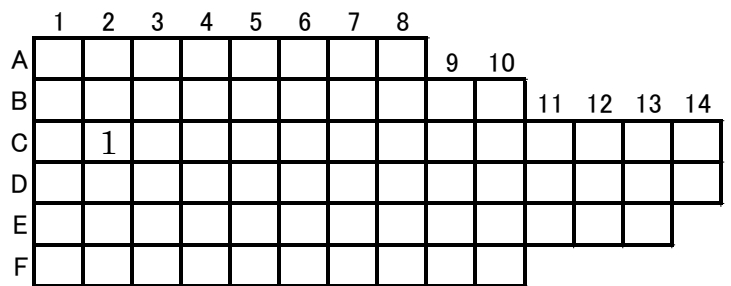

\section{Cerithium citrinum \\ キイロカニモリ}

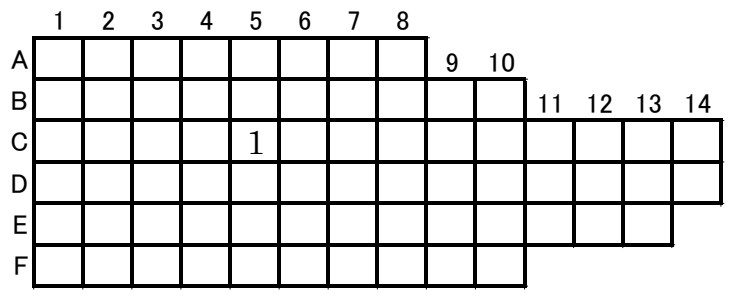

68 Cerithium lifuense

ヨロイツノブエ

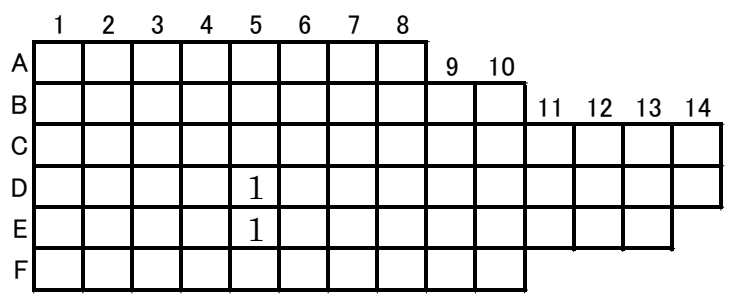

\section{Cerithium variegatum}

マダラチビカニモリ

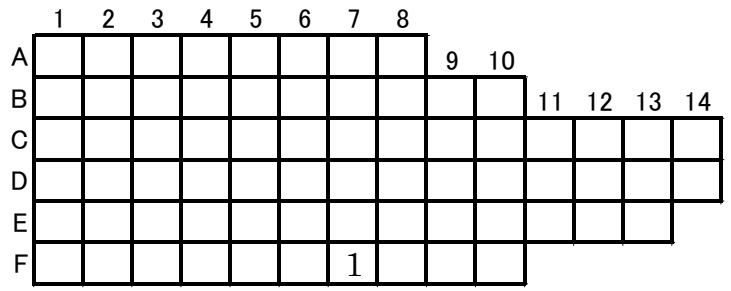

\section{Clypeomorus bifasciata カヤノミカニモリ}

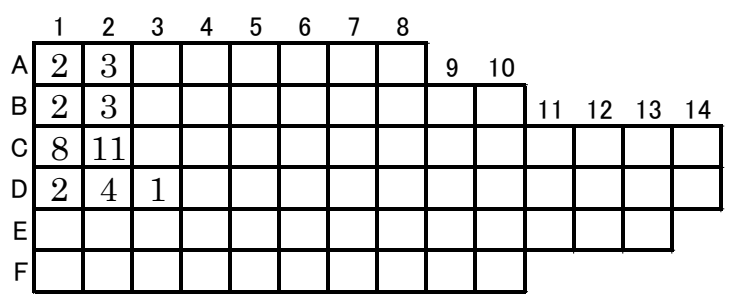




\section{Ittibittium parcum}

\begin{tabular}{c|c|c|c|c|c|c|c|c|}
\hline & 2 & 3 & 4 & 5 & 6 & 7 & 8 \\
\hline
\end{tabular}

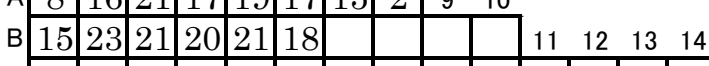
c \begin{tabular}{l|l|l|l|l|l|l} 
& 17 & 12 & 11 & 5 & 1 \\
\hline
\end{tabular}

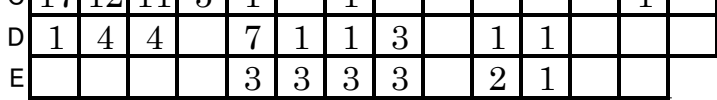

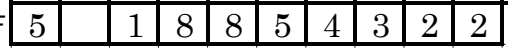

72 Diala semistriata

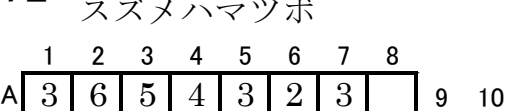

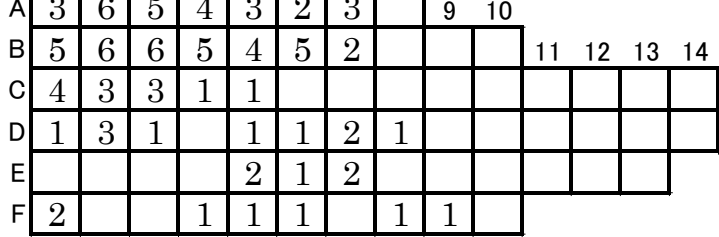

73 Planaxis sulcatus

ゴマフニナ

\begin{tabular}{ccccccccc|c|c}
1 & 2 & 3 & 4 & 5 & 6 & 7 & 8 & & \\
$\mathrm{~A}$ & 24 & 26 & 26 & 23 & 23 & 23 & 18 & 9 & 9 & 10
\end{tabular}

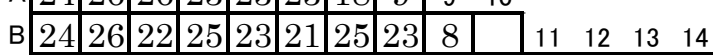

c \begin{tabular}{lllllll|l|l|l|l|l}
26 & 22 & 24 & 26 & 25 & 25 & 24 & 19 & 10 & 2 \\
\hline
\end{tabular}

D 26 \begin{tabular}{llllllllllllll}
\hline 26 & 26 & 26 & 25 & 26 & 26 & 17 & 13 & 1 \\
\hline
\end{tabular}

E 24 \begin{tabular}{lllllll|l|l|l|l|}
24 & 24 & 26 & 26 & 26 & 23 & 12 & 4 & 1 \\
\hline
\end{tabular}

F \begin{tabular}{|l|l|l|l|l|l|l|l|l|l|}
26 & 26 & 26 & 25 & 21 & 4 & 6 & & 1 & \\
\hline
\end{tabular}

\section{Fossarus trochlearis} トリデニナ

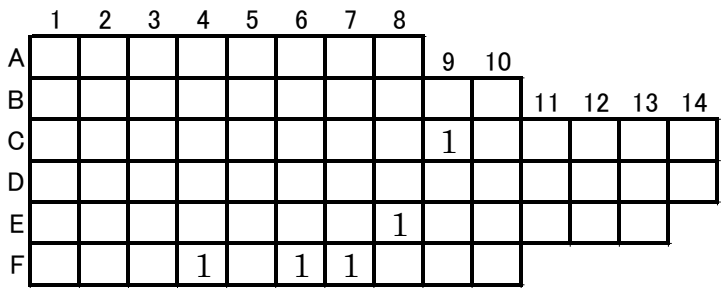

75 Littoraria pintado

コウダカタマキビ

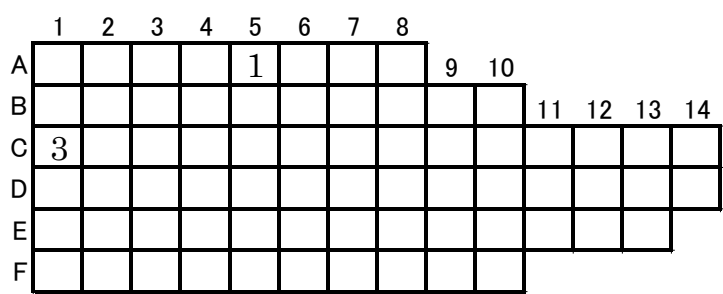

76

Littoraria undulata

ホソスジウズラタマキビ

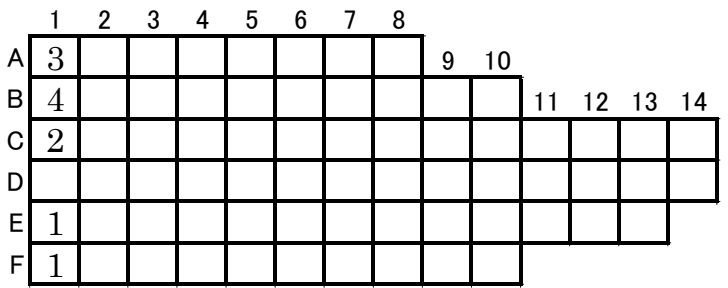

77 Peasiella habei

コビトウラウズガイ

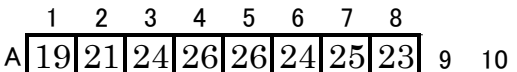

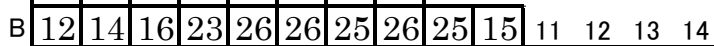

c c \begin{tabular}{l|l|l|l|l|l|l|l|l|l|l|l|l|l}
22 & 17 & 22 & 24 & 25 & 25 & 26 & 23 & 23 & 23 & 5 & 2 & 5 & \\
\hline
\end{tabular}

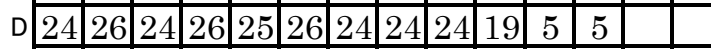

E \begin{tabular}{|l|l|l|l|l|l|l|l|l|l|l|l|l|}
23 & 26 & 25 & 23 & 25 & 22 & 19 & 17 & 18 & 13 & 2 & 2 & 1 \\
\hline
\end{tabular}

$\mathrm{F}$\begin{tabular}{|l|l|l|l|l|l|l|l|l|l|}
\hline 26 & 26 & 26 & 25 & 24 & 8 & 11 & 4 & 5 & 2 \\
\hline
\end{tabular}

\section{Nodilittorina radiata}

アラレタマキビ

\begin{tabular}{|c|c|c|c|c|c|c|c|c|c|}
1 & 2 & 3 & 4 & 5 & 6 & 7 & 8 & & \\
\hline 20 & 5 & 17 & 26 & 25 & 25 & 25 & 26 & 9 & 10 \\
\hline 13 & 3 & 4 & 19 & 26 & 26 & 26 & 24 & 25 & 3
\end{tabular}

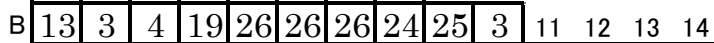

C \begin{tabular}{l|l|l|l|l|l|l|l|l|l|l|}
23 & 7 & 25 & 26 & 26 & 26 & 26 & 26 & 25 & 23 & 1 \\
\hline
\end{tabular}

D \begin{tabular}{|l|l|l|l|l|l|l|l|l|l|}
26 & 24 & 26 & 26 & 25 & 26 & 20 & 21 & 24 & 23 \\
\hline
\end{tabular}

E 26 \begin{tabular}{lllllll|l|l|l|l|} 
& 26 & 26 & 25 & 18 & 15 & 11 & 3 & 7 & 6 \\
\hline
\end{tabular}

$\mathrm{F}$\begin{tabular}{|l|l|l|l|l|l|l|l|l|l|}
26 & 23 & 25 & 22 & 5 & & & & 1 & \\
\hline
\end{tabular}

79 Nodilittorina trochoides

イボタマキビ

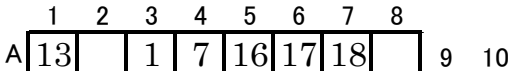

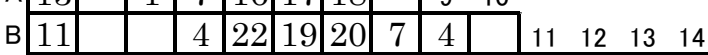

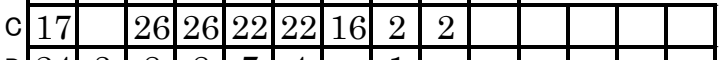

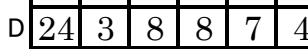

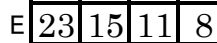

F 24 \begin{tabular}{l|l|l|l|}
\hline 24 & 8 & 4 & 4 \\
\hline
\end{tabular}

\section{Nodilittorina vidua \\ タイワンタマキビ}

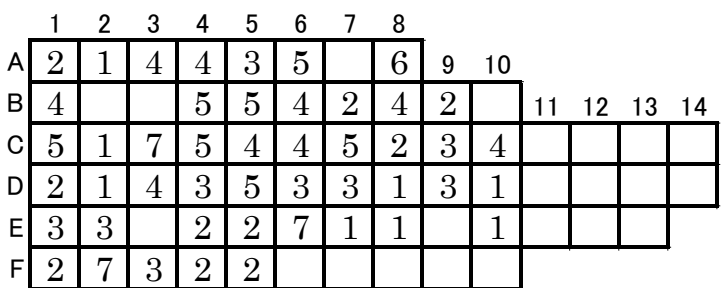




\section{Littorina brevicula}

タマキビ

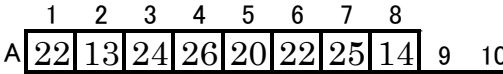

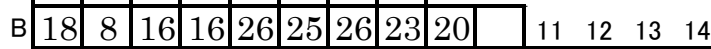
c \begin{tabular}{l|l|l|l|l|l|l|l|l|l}
21 & 11 & 25 & 25 & 26 & 24 & 25 & 23 & 21 & 14 \\
\hline
\end{tabular}

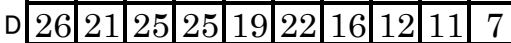
E 26 \begin{tabular}{l|l|l|l|l|l|}
24 & 23 & 24 & 12 & 10 & 5 \\
\hline
\end{tabular}

F 26 \begin{tabular}{l|l|l|l|l|l}
26 & 24 & 18 & 5 & 1 & 1 \\
\hline
\end{tabular}

\section{Barleeia angustata}

チャツボ

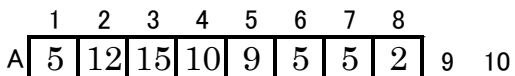
B \begin{tabular}{lllllllllll|l|l|llll} 
& 8 & 14 & 13 & 12 & 10 & 12 & 1 & & & & 12 & 13 & 14 \\
\hline
\end{tabular} \begin{tabular}{|c|c|c|c|c|c|c|c|c|c|c|c|c|c|c|}
\hline \\
\cline { 2 - 13 }
\end{tabular} \begin{tabular}{llllllllllll}
\hline $\mathrm{F}$ & & & & & 8 & 4 & 6 & 4 & 2 & \\
\hline
\end{tabular}

83 Schwartziella zeltnerioides ハスメチョウジガイ

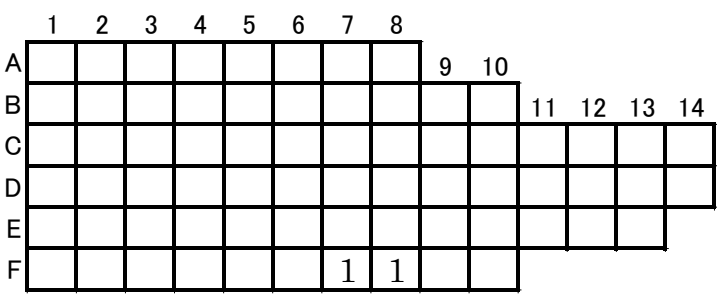

\section{Strombus luhuanus マガキガイ}

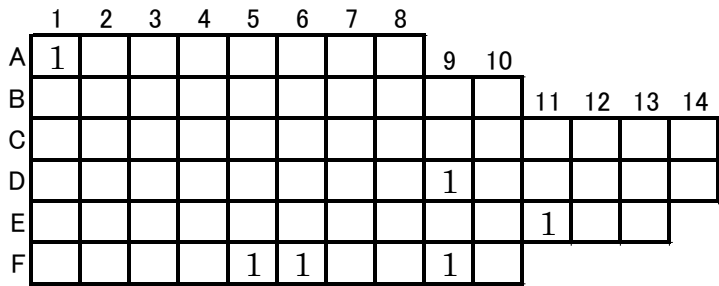

85

Strombus mutabilis

ムカシタモ卜

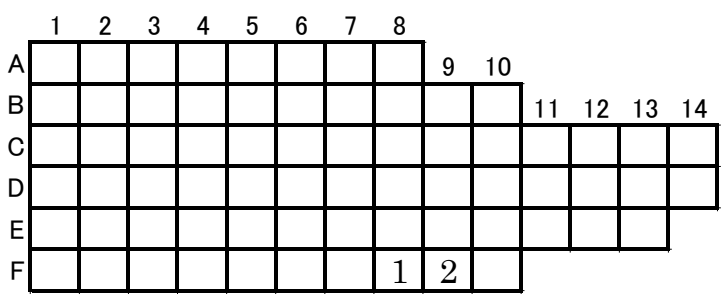

86 Hipponix conica

キクスズメ

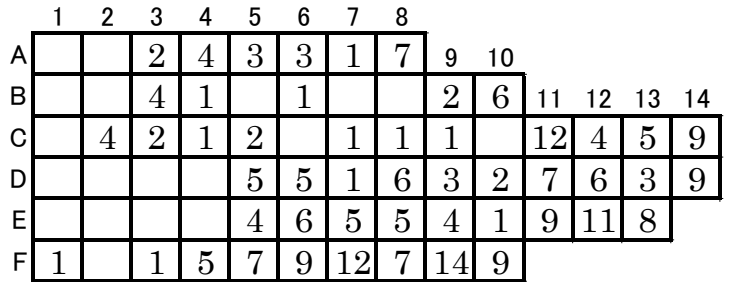

87 Hipponix foliacea

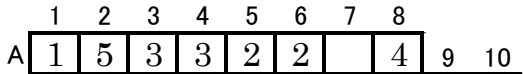

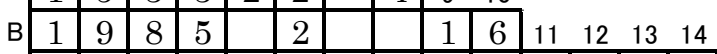
\begin{tabular}{c|c|c|c|c|c|c|c|c|c|c|c|c|c|c|}
$\mathrm{C}$ & 5 & 8 & 4 & & 2 & & & & & & 9 & 4 & 7 & 18 \\
\hline & & 3 & & 3 & & 3 & 2 & 2 & & 10 & 10 & 8 & 21 \\
\hline
\end{tabular} E \begin{tabular}{lllllllll|l|l|l|l|l|}
\hline & & & & 6 & 4 & 5 & 6 & 3 & 7 & 8 & 15 & 10 \\
\hline
\end{tabular}

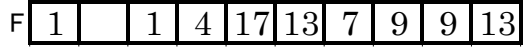

88 Hipponix trigona

スズメガイ

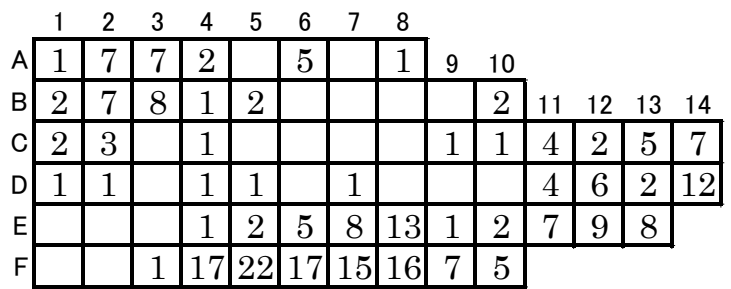

89 Crepidula gravispinosus アワブネ

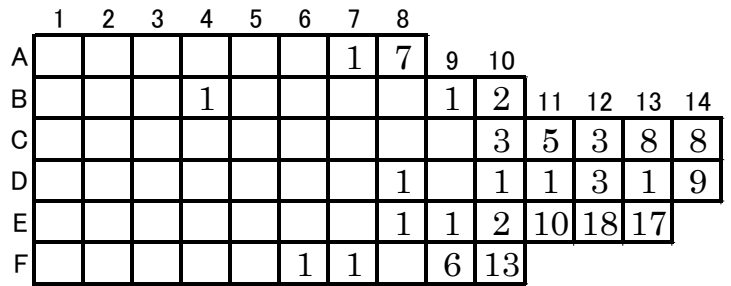

90 Crepidula onyx

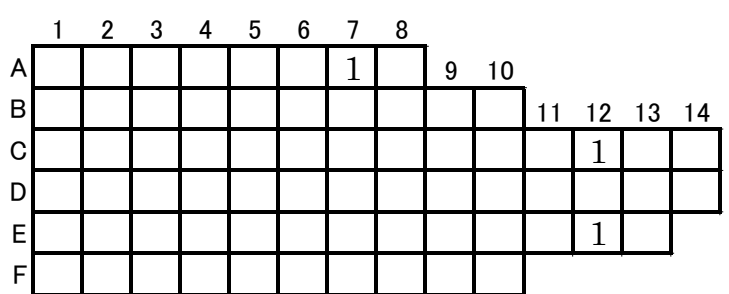


91 Dendropoma dragonella

タツノコヘビガイ

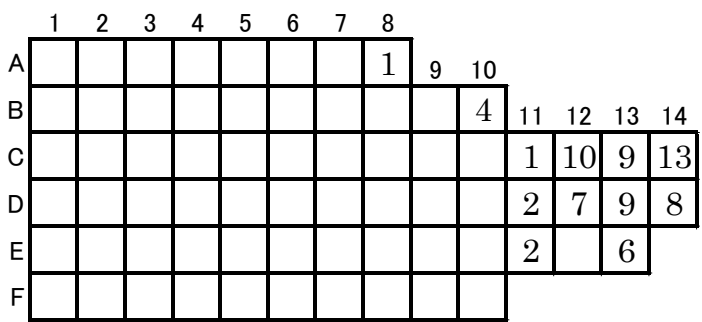

92 Dendropoma planorbis

ミジンムカデガイ

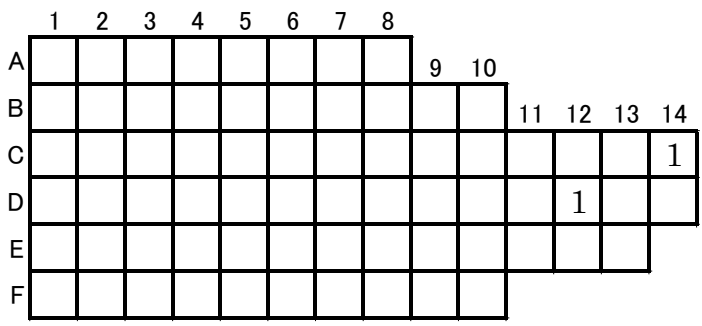

93 Serpulorbis daidai オレンジヘビガイ

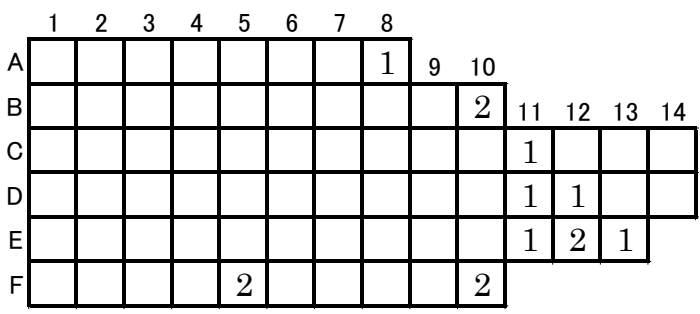

\section{Serpulorbis imbricatus}

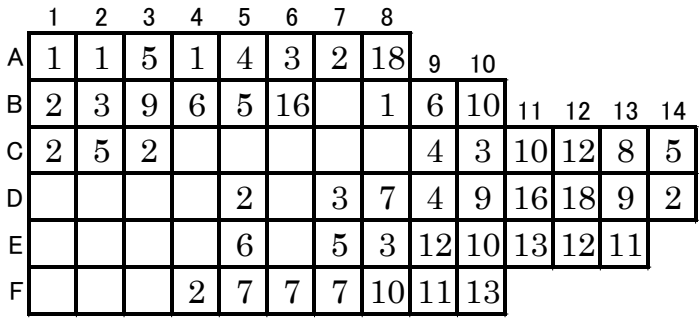

\section{Cypraea annulus}

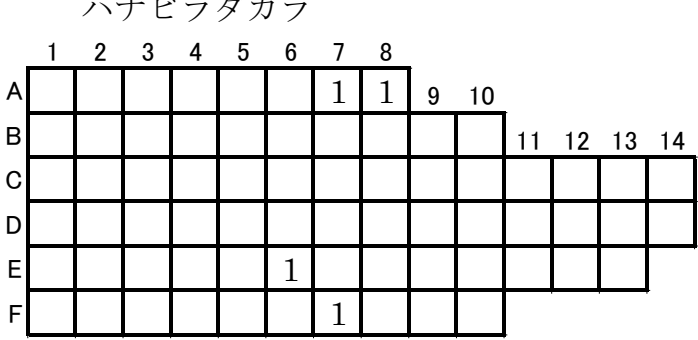

96 Cypraea arabica asiatica ヤクシマダカラ

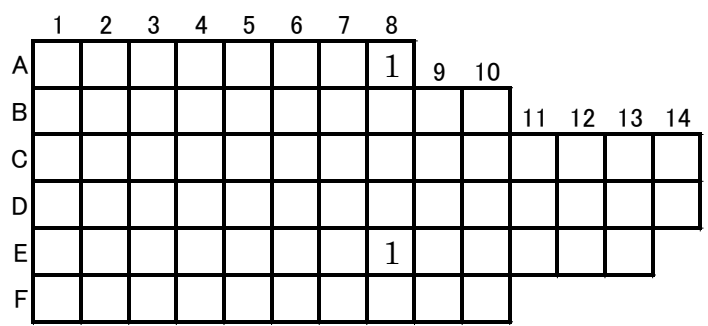

97 Cypraea artuffeli

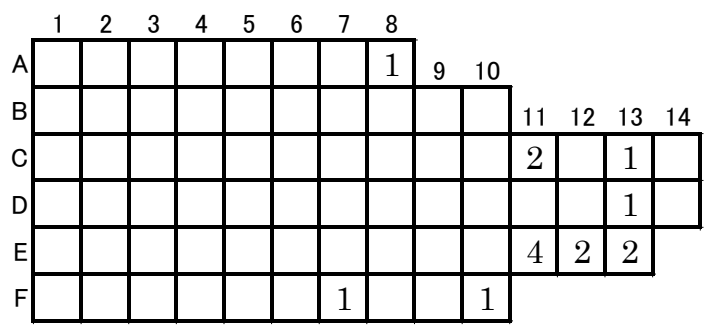

98 Cypraea boivinii

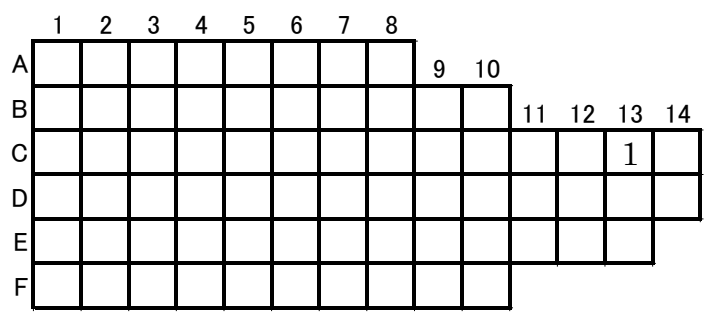

99 Cypraea caputserpentis

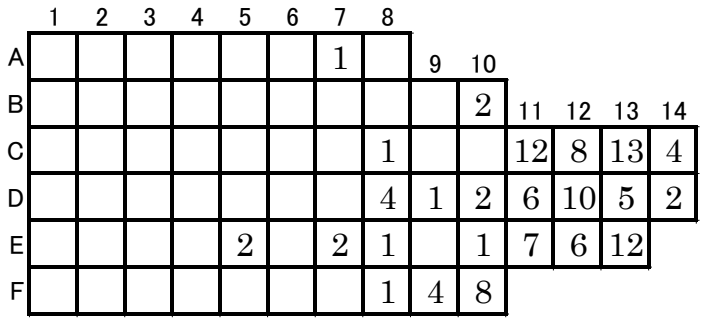

100 Cypraea clandestina clandestina

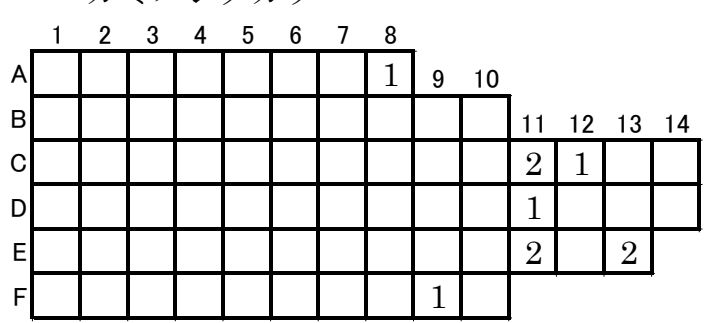


101 Cypraea errones errones ナツメモドキ

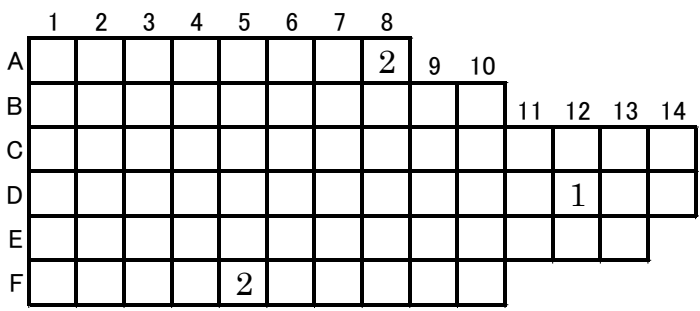

102

Cypraea fimbriata fimbriata

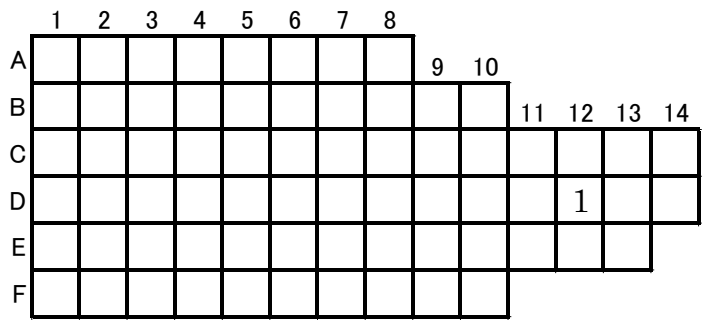

103 Cypraea gracilis

メダカラ

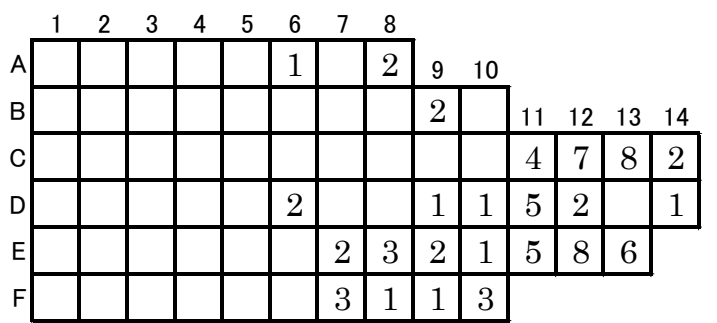

104 Cypraea helvola helvola

カモンダカラ

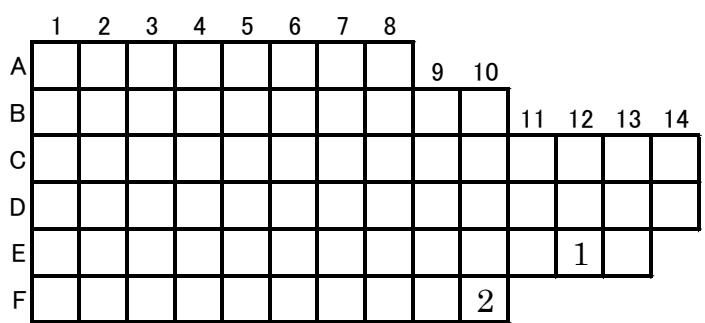

105 Cypraea labrolineata

ナシジダカラ

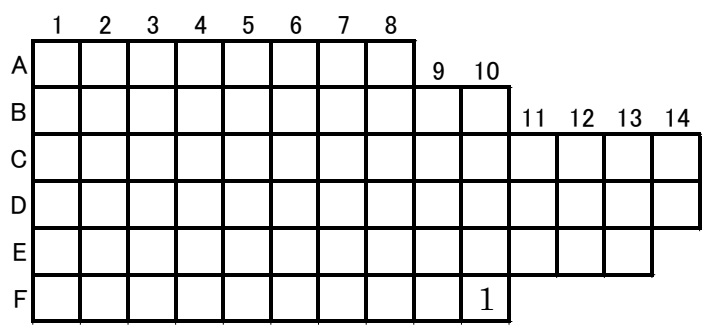

$106 \begin{aligned} & \text { Cypraea limacina limacina } \\ & \text { シボリダカラ }\end{aligned}$

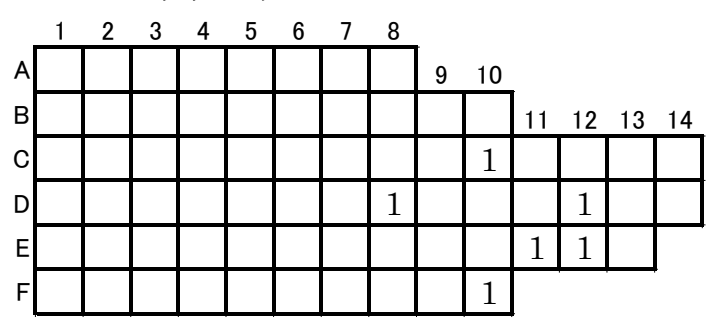

\section{Cypraea listeri}

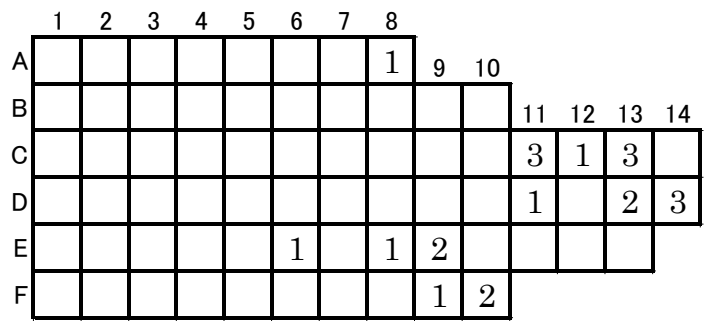

$108 \begin{aligned} & \text { Cypraea moneta } \\ & \text { キイロダカラ }\end{aligned}$

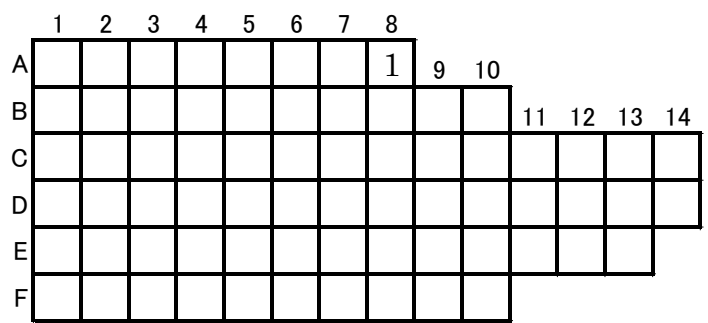

109 Cypraea poraria

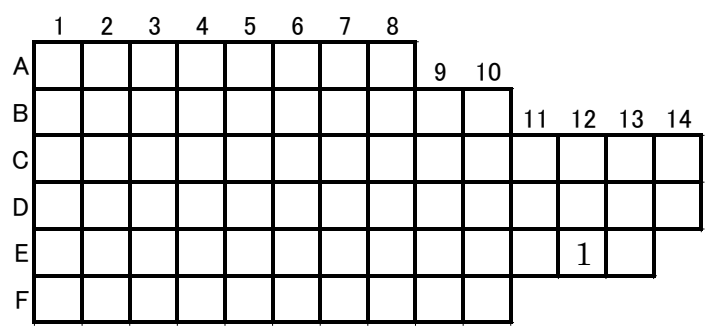

$110 \begin{aligned} & \text { Cypraea vitellus } \\ & \text { ホシキヌタ }\end{aligned}$

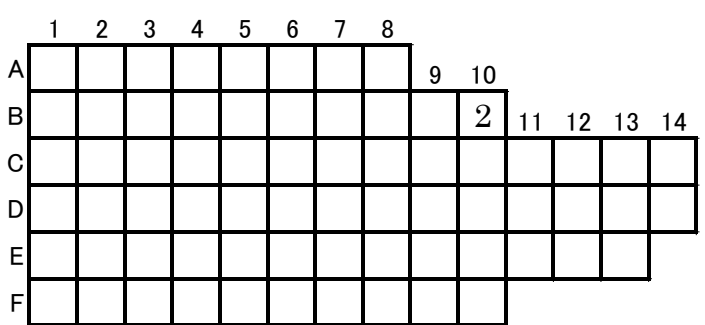


$111 \begin{aligned} & \text { Erato callosa } \\ & \text { ザクロガイ }\end{aligned}$

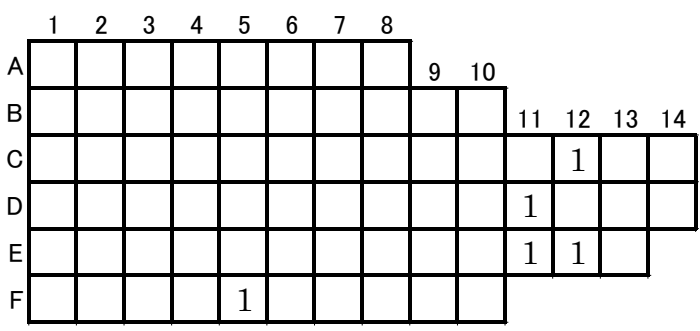

112 Lamellaria kiiensis

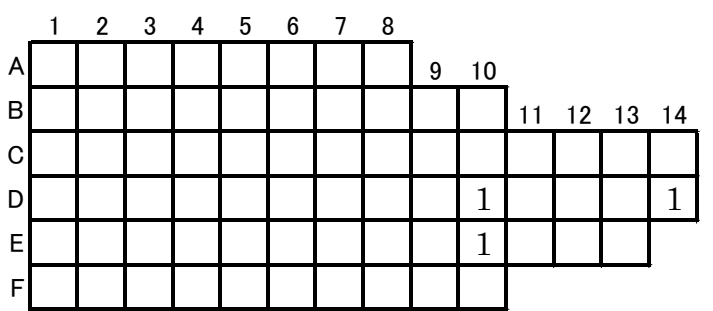

113 Natica gualteriana

ホウシュノタマ

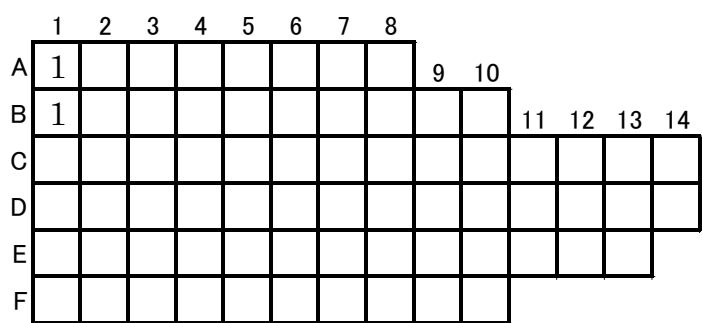

114 Charonia lampas sauliae ボウシュウボラ

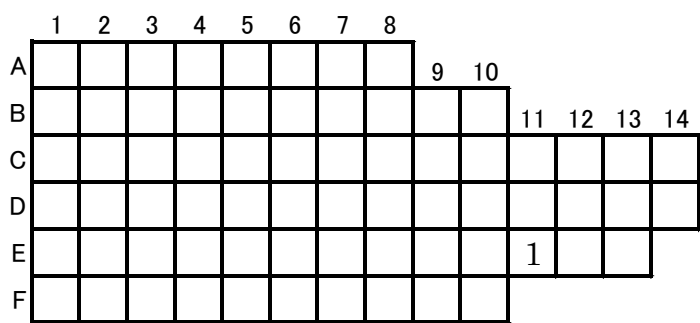

115 Gyroscala lamellosa

ネジガイ

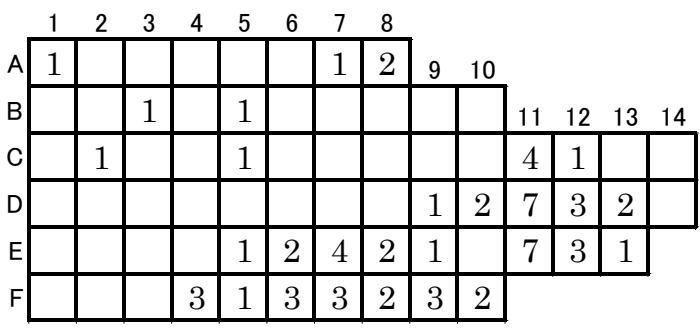

116 Epitonium japonicum

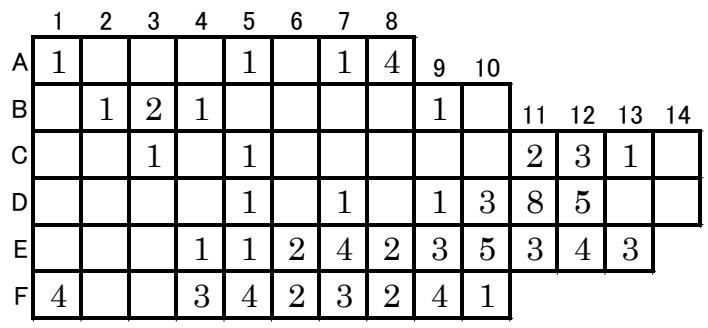

\section{Epitonium vigintifoliatum} ハタエイトカケ

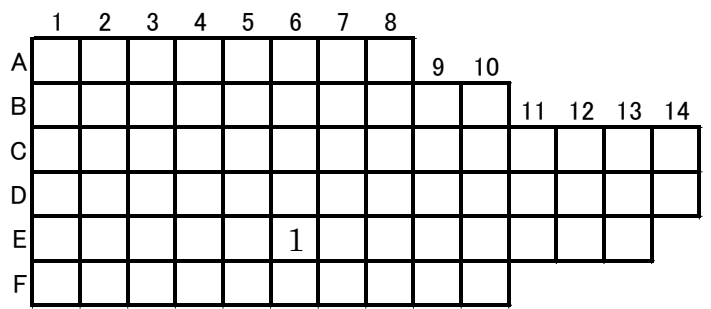

118 Alexania inazawai

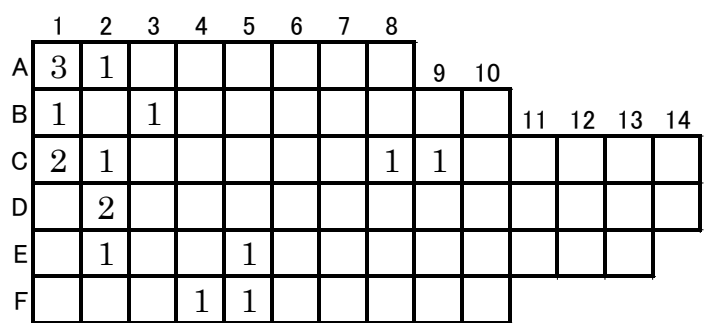

119 Vitreolina auratas キンイロセトモノガイ

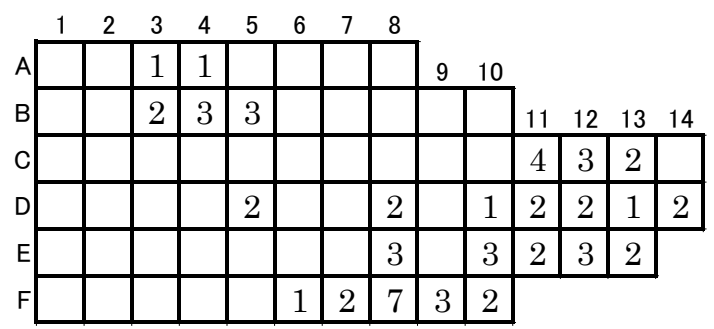

\section{Vitreolina langfordi ムラサキウニヤドリニナ}

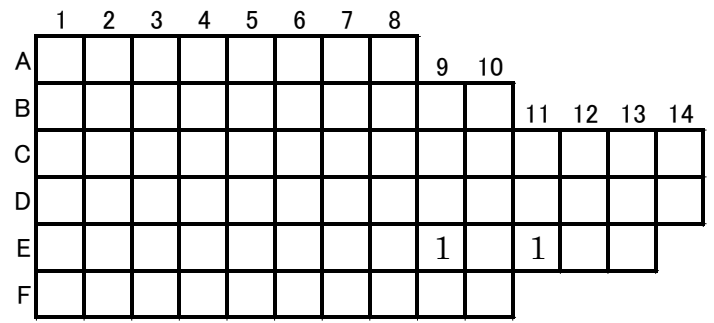


121 Apicalia habei

ヤツデヒトデヤドリニナ

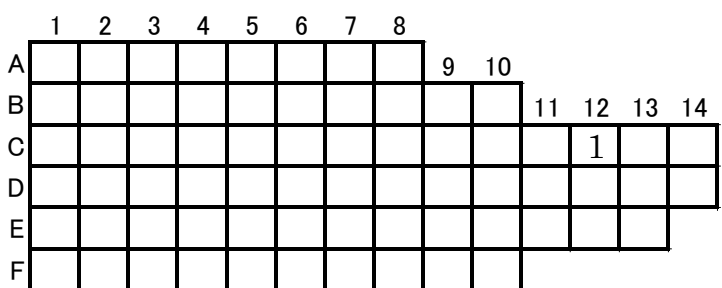

122 Cronia margariticola

ウネレイシダマシ

A \begin{tabular}{c|c|c|c|c|c|c|c|c|c|c}
1 & 2 & 3 & 4 & 5 & 6 & 7 & 8 & \\
\hline & 2 & 7 & 7 & 5 & 10 & 17 & 13 & 17 & 9 & 10
\end{tabular}

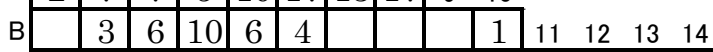

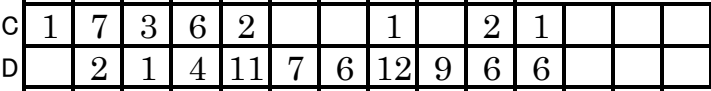
\begin{tabular}{|l|l|l|l|l|l|l|l|l|l|l|l|l}
\hline & 1 & & 1 & 10 & 15 & 16 & 23 & 17 & 13 & 10 & 4 & \\
\hline
\end{tabular} \begin{tabular}{ll|l|l|l|l|l|l|l|l|l|l|}
\hline $\mathrm{F}$ & $\mathrm{F}$ & & & 12 & 22 & 22 & 25 & 25 & 24 & 21 \\
\hline
\end{tabular}

123

\section{Ergalatax contractus}

ヒメヨウラク

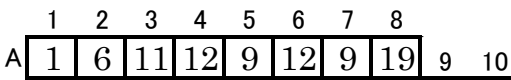

\begin{tabular}{llllll|lllllll|l|llll}
\hline $\mathrm{B}$ & 5 & 15 & 13 & 16 & 14 & 4 & 3 & 3 & 7 & 9 & 11 & 12 & 13 & 14 \\
\hline
\end{tabular}

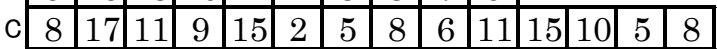

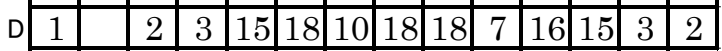
E \begin{tabular}{ll|llllllllllllllll} 
& & 1 & & 1 & 18 & 13 & 21 & 20 & 15 & 12 & 16 & 16 & 9 \\
\hline
\end{tabular} F \begin{tabular}{l|l|l|l|l|l|l|l|l|l|}
\hline 1 & 1 & 1 & 14 & 21 & 23 & 18 & 21 & 20 & 15 \\
\hline
\end{tabular}

\section{Muricodrupa fusca}

レイシダマシモドキ

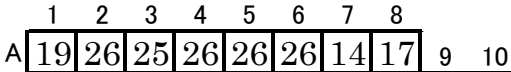

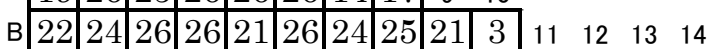
c \begin{tabular}{l|l|l|l|l|l|l|l|l|l|l|l}
26 & 25 & 25 & 20 & 26 & 24 & 26 & 25 & 22 & 10 & 2 & 1 \\
\hline
\end{tabular}

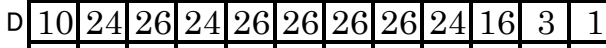
E \begin{tabular}{lllllllllllllllllll} 
& 2 & 8 & 15 & 21 & 25 & 26 & 25 & 23 & 17 & 2 & 2 & 2 & 1 \\
\hline
\end{tabular} $\mathrm{F}$\begin{tabular}{|l|l|l|l|l|l|l|l|l|l|}
\hline 16 & 18 & 16 & 26 & 23 & 16 & 18 & 8 & 2 & 1 \\
\hline
\end{tabular}

\section{5}

Muricodrupa sp.

コウシレイシダマシ

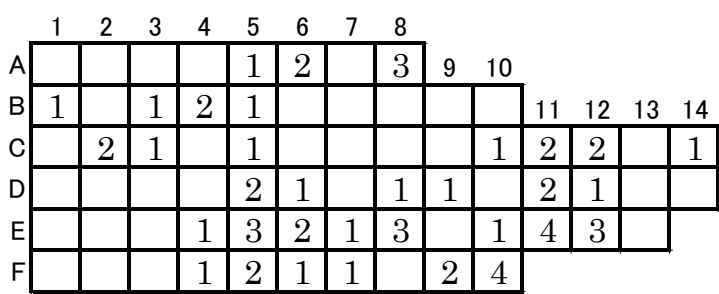

$126 \begin{aligned} & \text { Maculotriton serriale } \\ & \text { ゴマフヌカボラ }\end{aligned}$

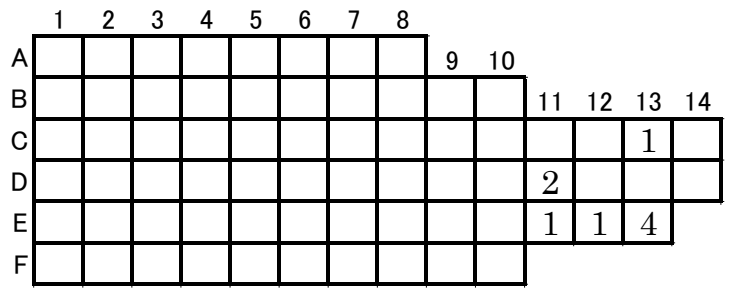

\section{Drupella fragum}

ヒメシロレイシダマシ

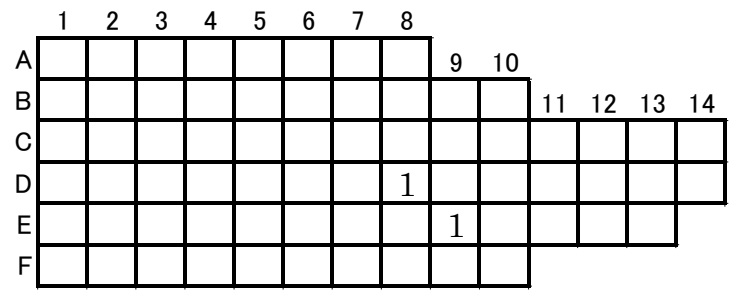

$128 \begin{aligned} & \text { Morula anaxeres } \\ & \text { ウネシロレイシダマシ }\end{aligned}$

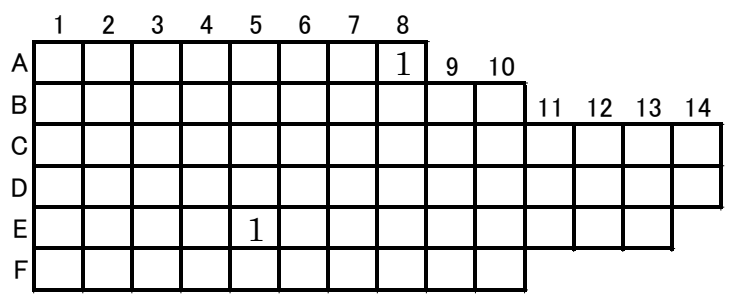

129 Morula funiculata

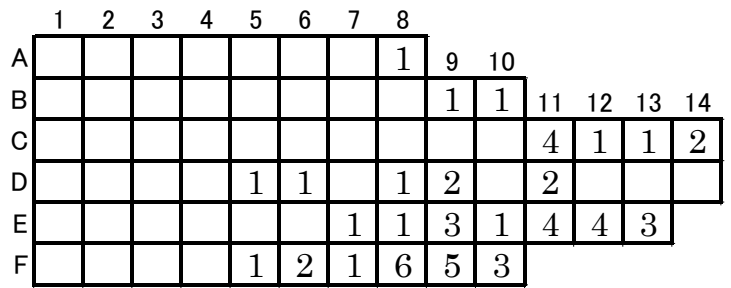

130 Morula granulata

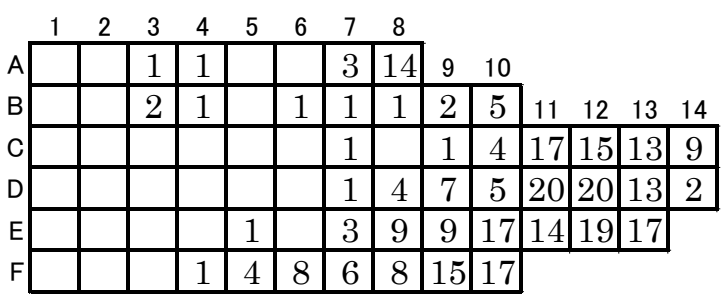


131

Morula iostoma

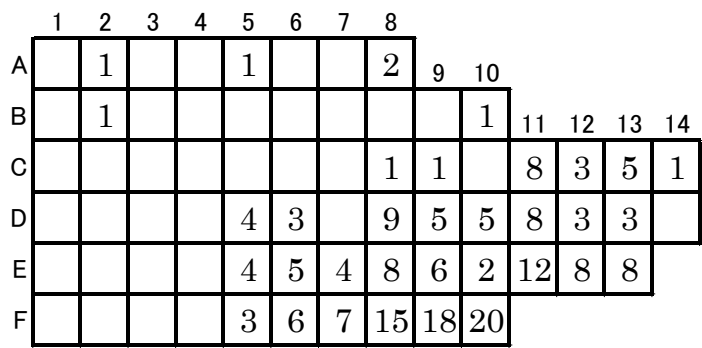

132

Morula musiva

シマレイシダマシ

A \begin{tabular}{c|c|c|c|c|c|c|c|c|c|c|c|} 
& \multicolumn{1}{l}{1} & 2 & 3 & 4 & 5 & 6 & 7 & 8 & \\
\hline & 1 & 10 & 7 & 6 & 11 & 19 & 21 & 26 & 9 & 10
\end{tabular}

в 1 \begin{tabular}{llllllllllll|l|llll}
\hline 1 & 8 & 10 & 13 & 7 & 9 & 13 & 15 & 21 & 25 & 11 & 12 & 13 & 14
\end{tabular}

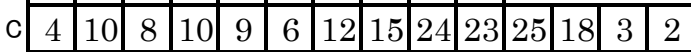

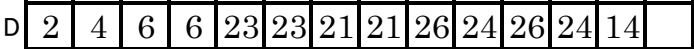

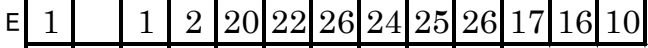

\begin{tabular}{lllllllll|l|l|l|l|}
$\mathrm{F}$ & 3 & 1 & 3 & 23 & 26 & 23 & 24 & 24 & 25 & 16 \\
\hline
\end{tabular}

133 Morula sp.

ニッポンレイシダマシ

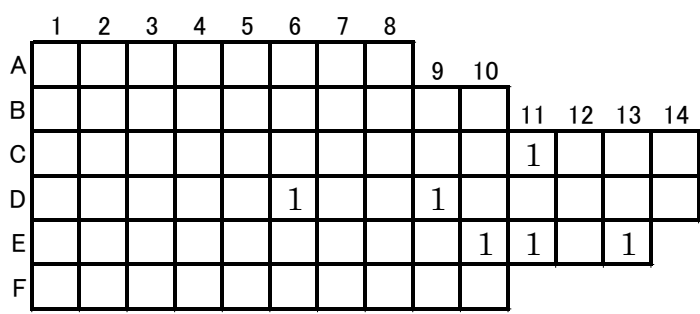

\section{Habromorula spinosa}

トゲレイシダマシ

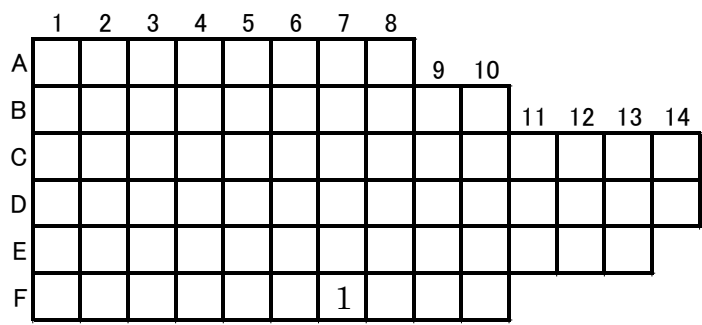

135

Drupa ricinus hadari

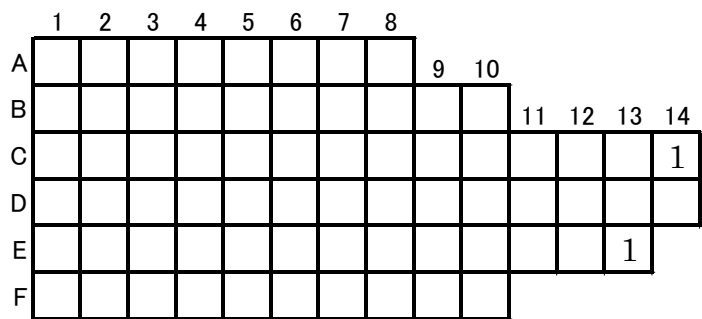

136 Mancinella bufo

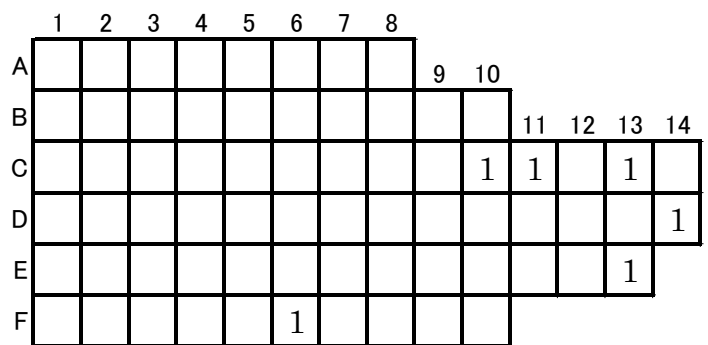

137 Mancinella echinata ウニレイシ

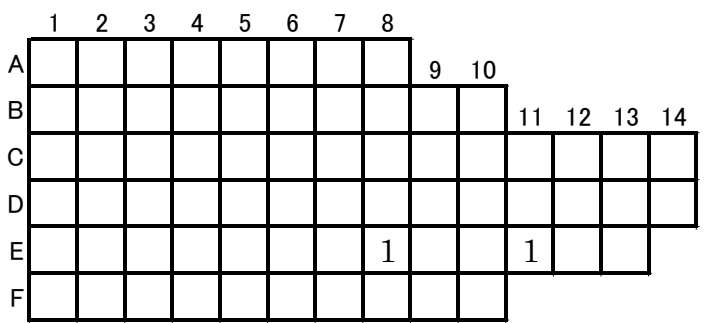

138 Mancinella mancinella キナレイシ

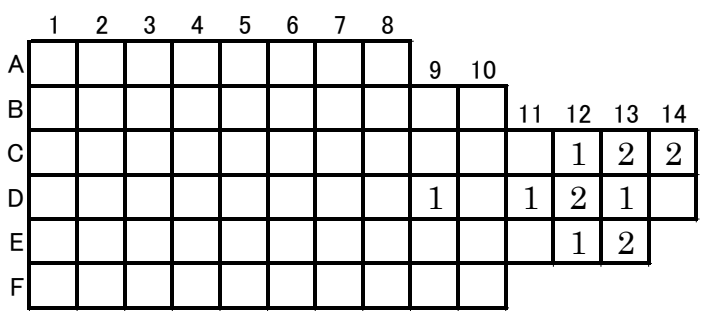

139 Mancinella tuberosa

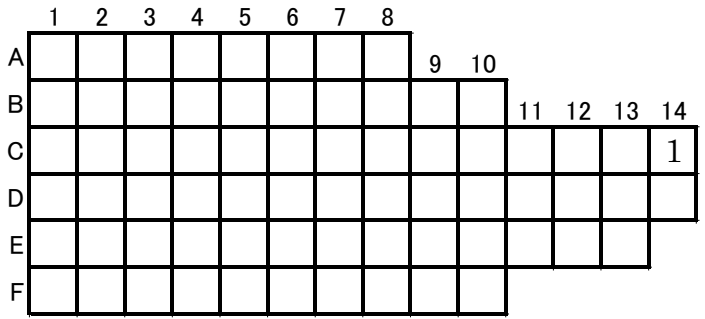

140 Purpula panama

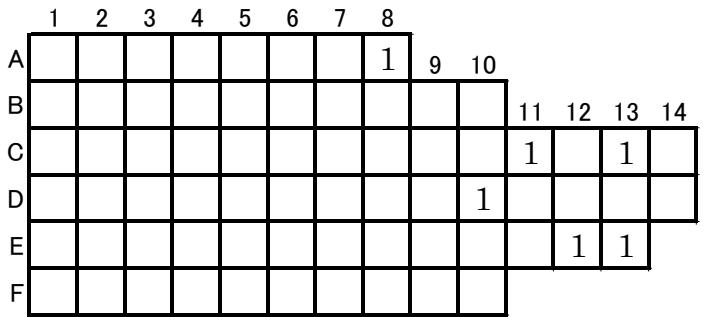


141

Thais bronni

レイシガイ

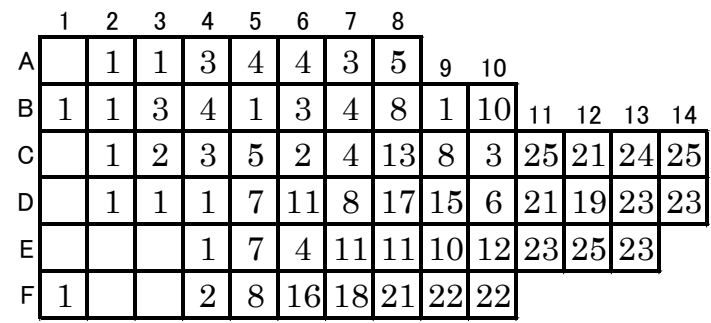

142

Thais clavigera

イボニシ

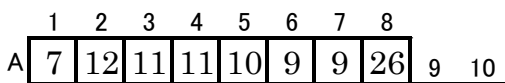

В 4 \begin{tabular}{llllll|l|l|l|l|l|llll} 
& 4 & 10 & 15 & 16 & 9 & 12 & 16 & 16 & 23 & 26 & 11 & 12 & 13 & 14
\end{tabular}

C 9 \begin{tabular}{llllll|l|l|l|l|l|l|l|l|l|}
9 & 14 & 12 & 6 & 8 & 5 & 11 & 20 & 25 & 26 & 25 & 26 & 25 & 22 \\
\hline
\end{tabular}

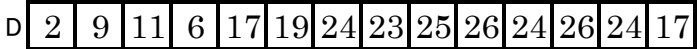

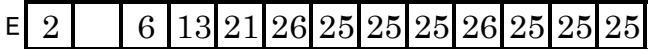

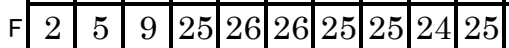

143

Thais luteostoma

クリフレイシ

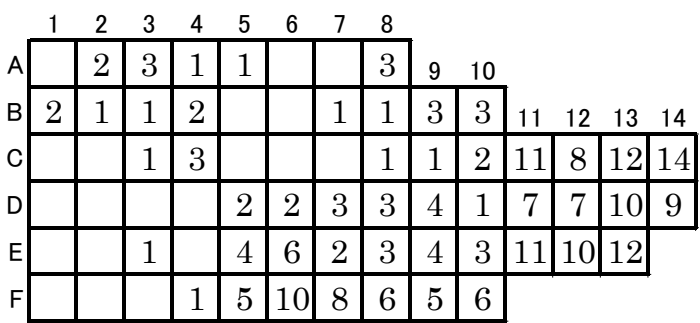

144 Coralliophila squamosissima カゴメサンゴヤドリ

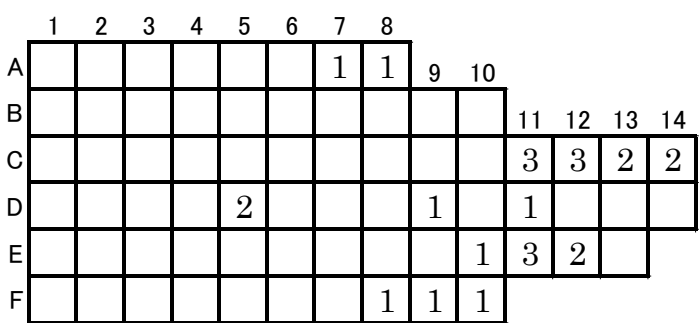

\section{Euplica scripta}

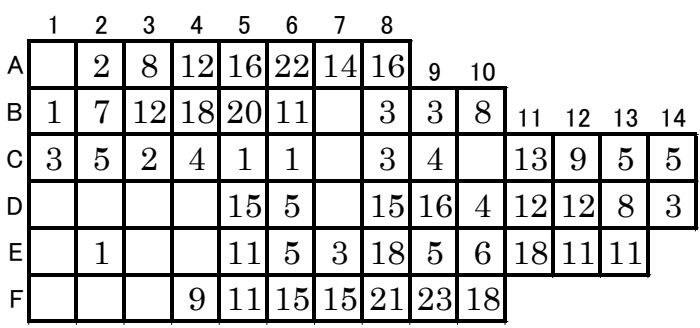

146 Anachis misera misera

ボサツガイ

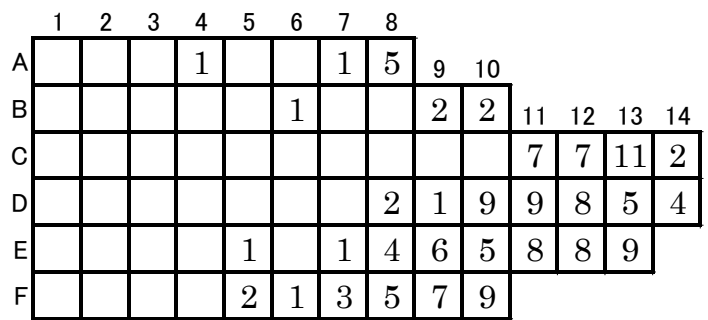

Pyrene flava
ムシエビ

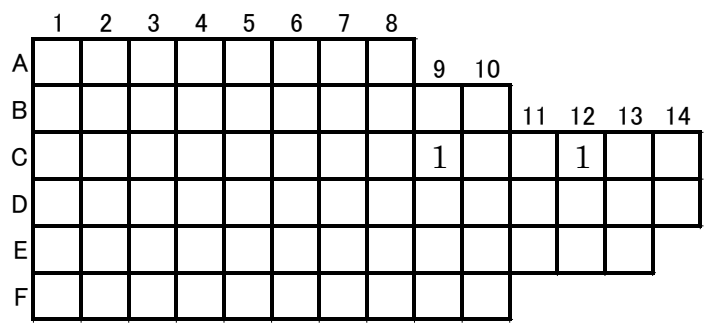

148 Pyrene testudinaria tylerae マツムシ

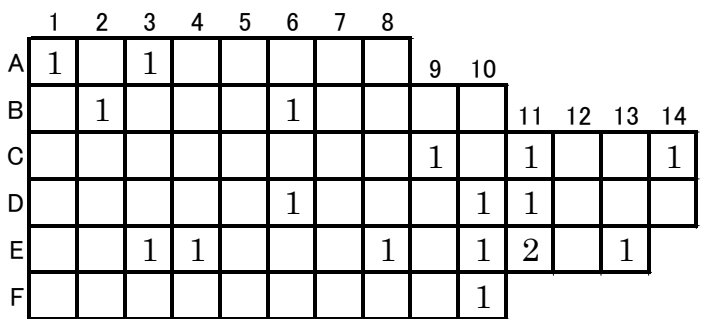

149 Mitrella bicincta ムギガイ

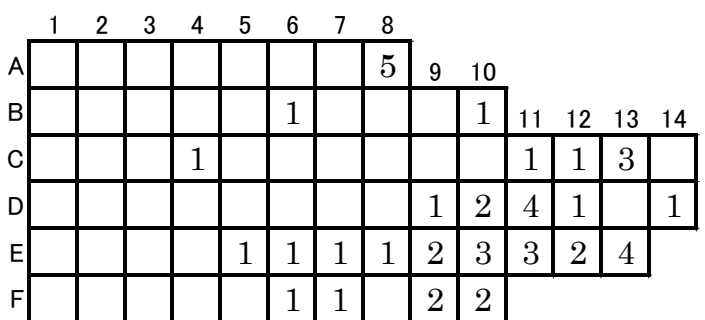

150 Zafra pumila

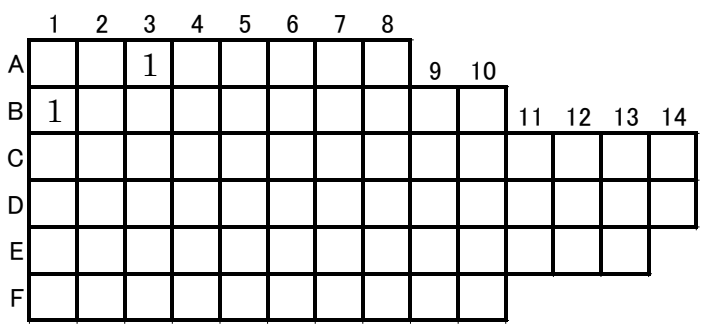


151

Zafra sinensis

ケシマツムシ

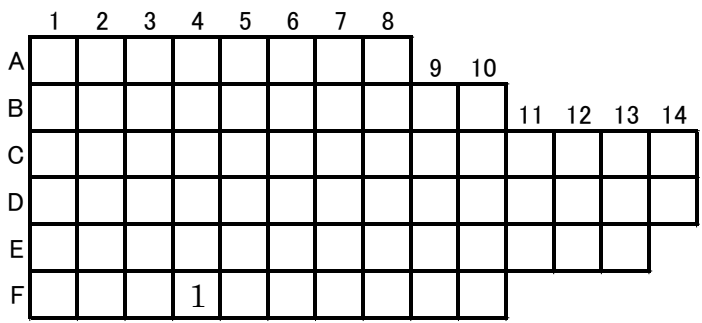

152 Niotha livescens

ムシロガイ

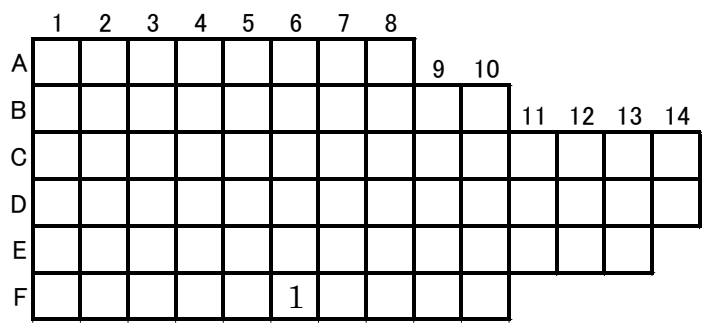

153 Niotha semisulcata

アツムシロ

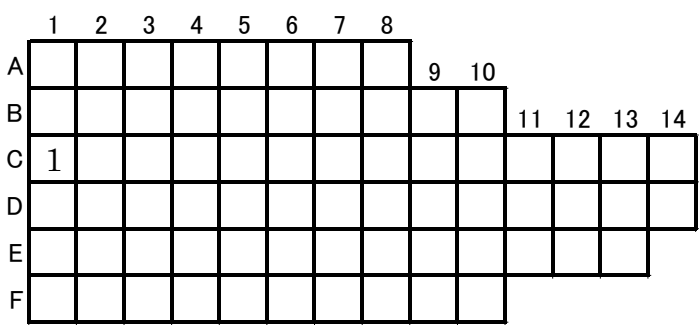

154 Telasco sufflatus ヨフバイ

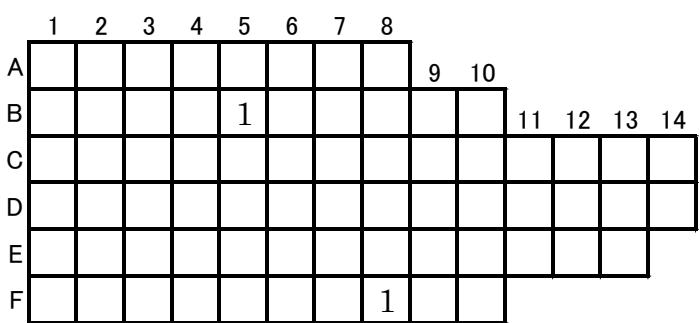

\section{$155 \begin{aligned} & \text { Telasco velatus } \\ & \text { シイノミョフバイ }\end{aligned}$}

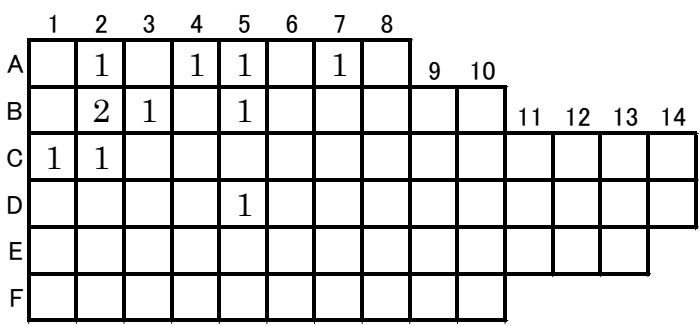

156 Reticunassa fratercula

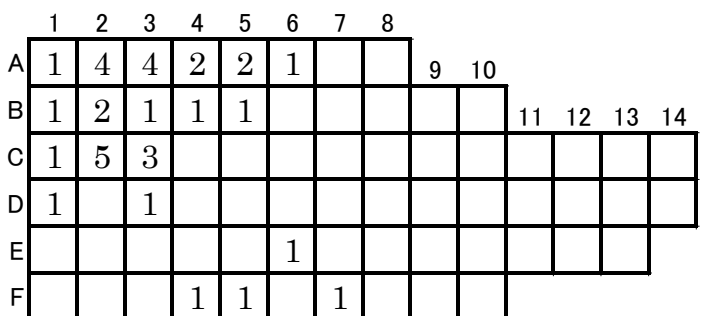

\section{Enzinopsis menkeana \\ ナガゴマフホラダマシ}

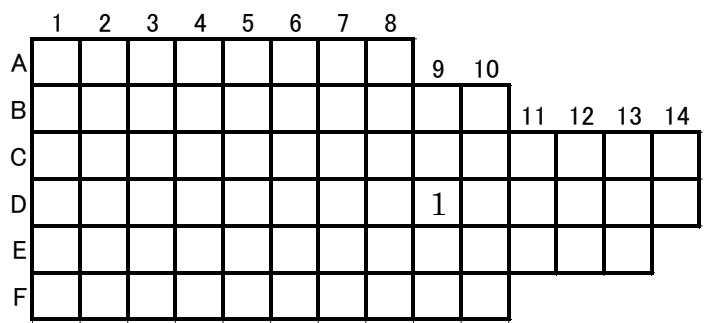

158 Japeuthria ferrea

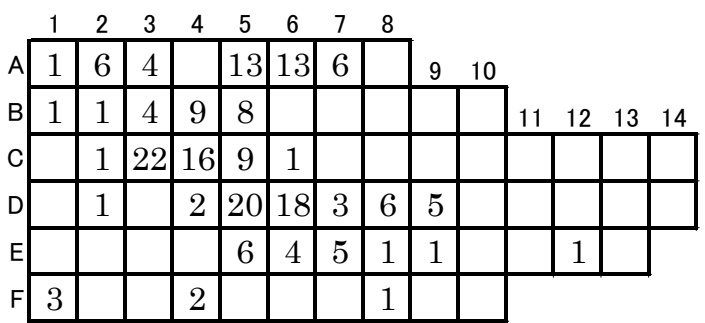

159 Strigatella litterata

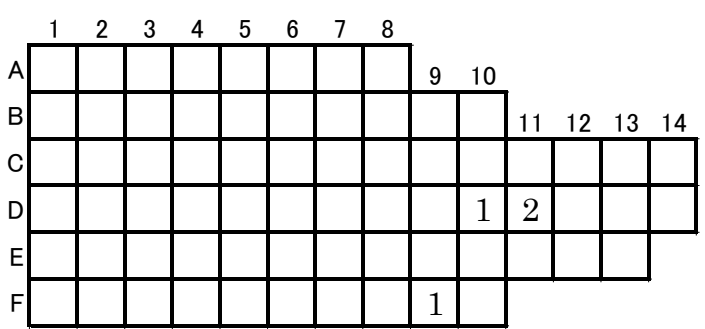

$160 \begin{aligned} & \text { Strigatella paupercula } \\ & \text { ナガシマヤタテ }\end{aligned}$

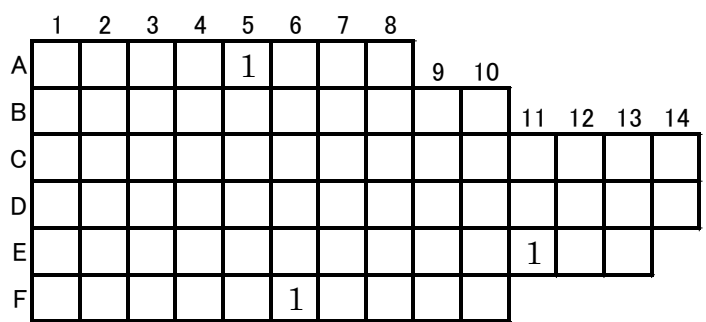


161

Strigatella scutulata

ヤタテガイ

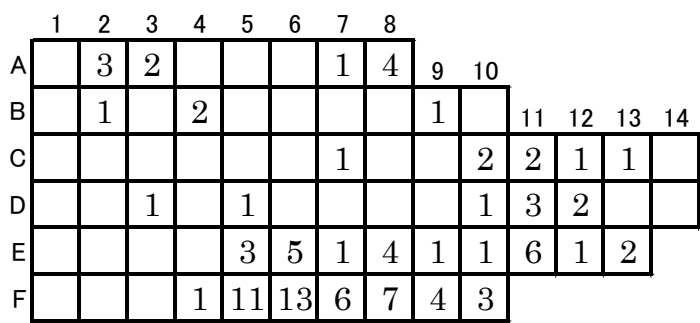

162 Conus coronatus

ジュズカケサヤガタイモ

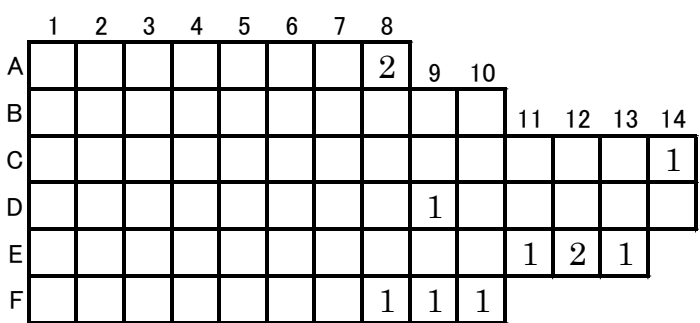

$163 \begin{aligned} & \text { Conus miliaris } \\ & \text { サヤガタイモ }\end{aligned}$

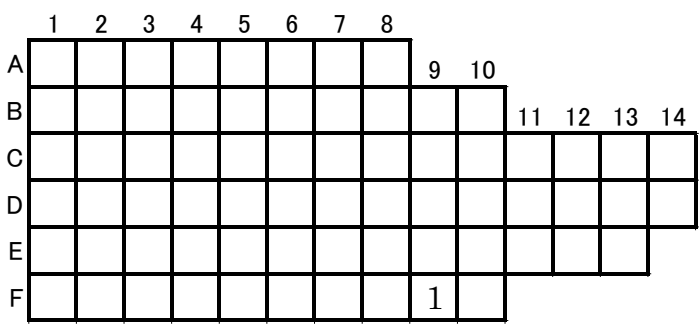

164 Conus ebraeus

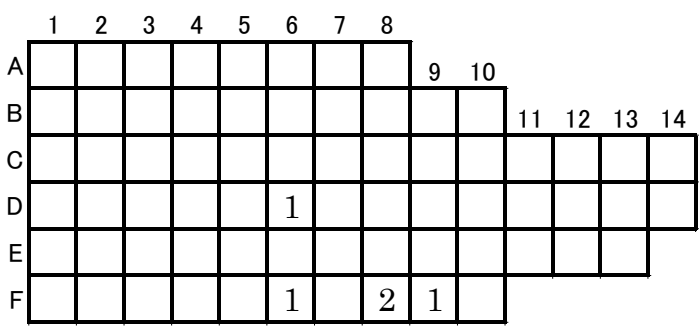

165

Conus lividus

イボシマイモ

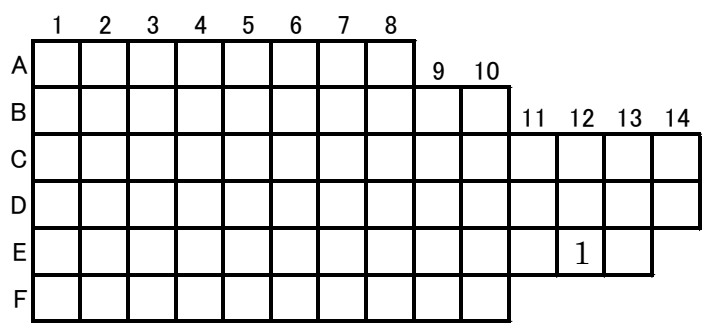

166 Conus musicus

ガクフイモ

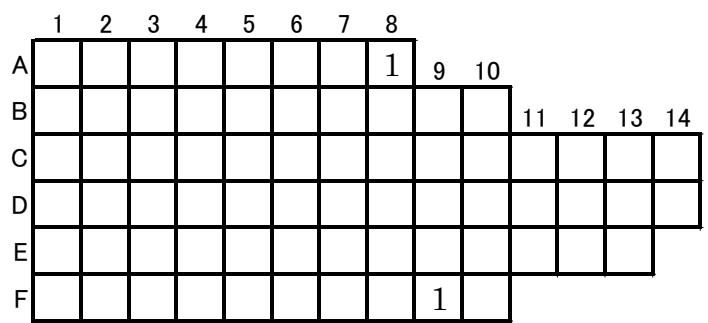

167 Conus sponsalis

セイロンイモ

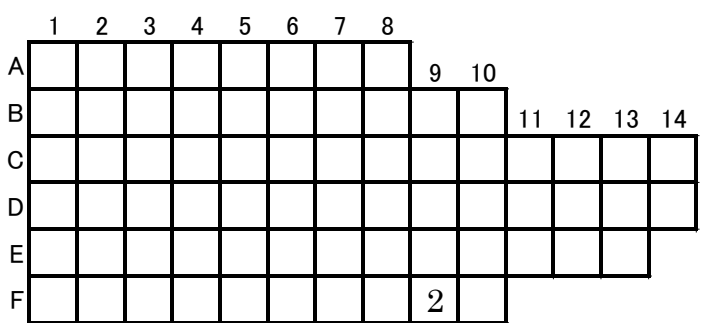

$168 \begin{aligned} & \text { Hemicythara octangulata } \\ & \text { ハッカクフタナシシャジク }\end{aligned}$

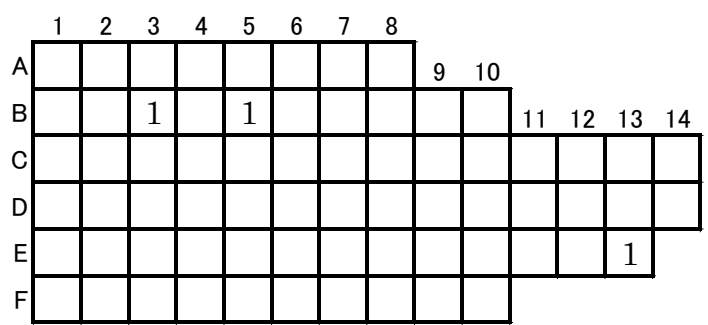

169 Lienardia malleti

モモイロフタナシジジク

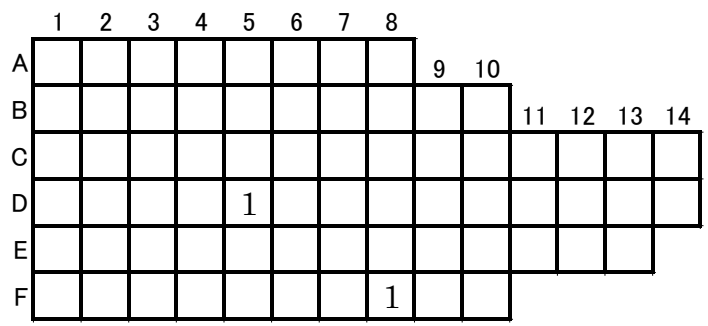

$170 \begin{aligned} & \text { Heliacus enoshimensis } \\ & \text { ナワメグルマ }\end{aligned}$
ナワ

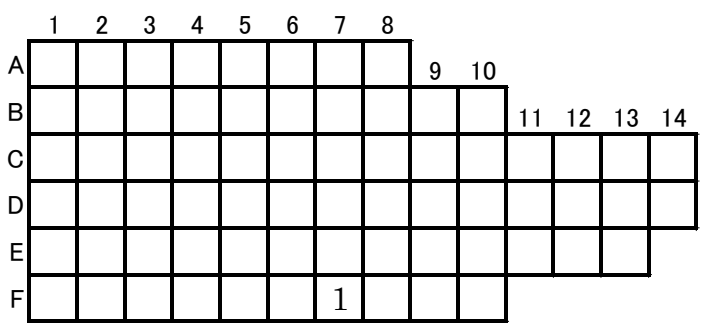


171

Paracingulina triarata

ミスジョコイトカケギリ

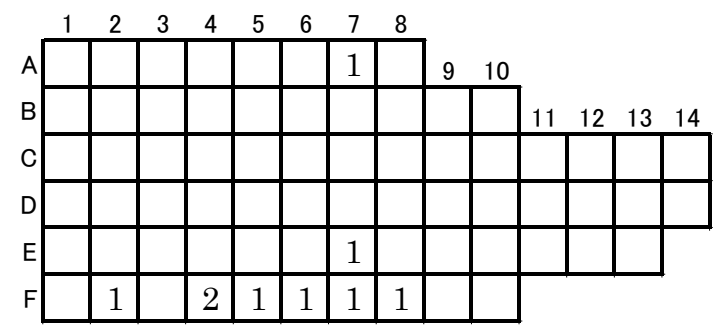

172 Bullina lineata

ベニシボリガイ

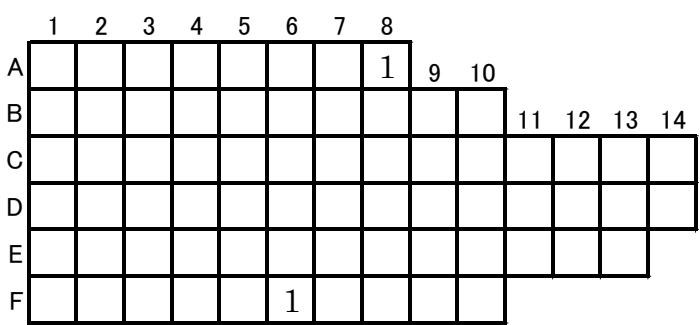

173 Hydatina physis

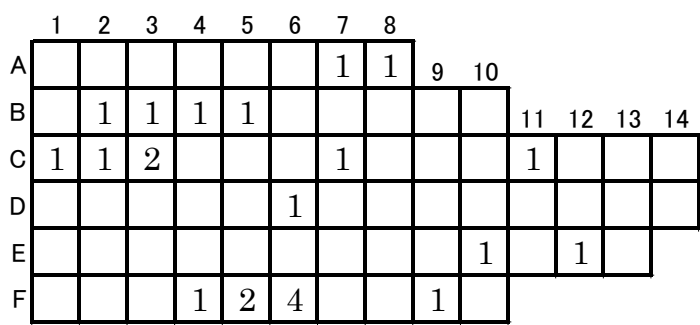

174

Chelidonura inornata

オハグロツバメガイ

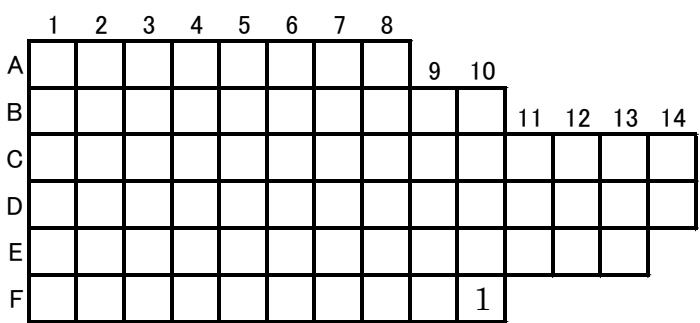

$175 \begin{aligned} & \text { Haloa japonica } \\ & \text { ブドウガイ }\end{aligned}$

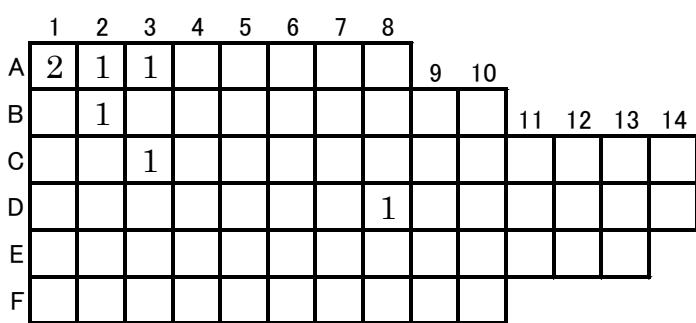

176 Smaragdinella sieboldi

タテジワミドリガイ

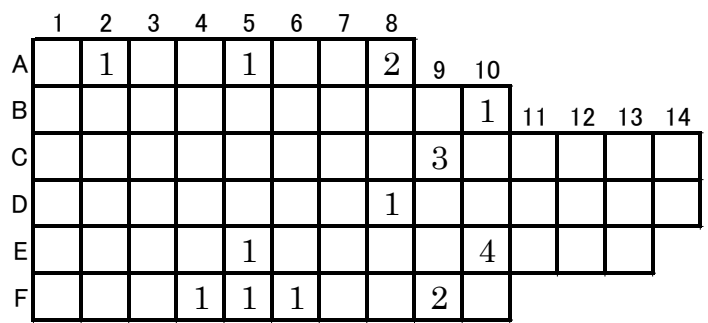

$177 \begin{aligned} & \text { Bulla ventricosa } \\ & \text { ナツメガイ }\end{aligned}$

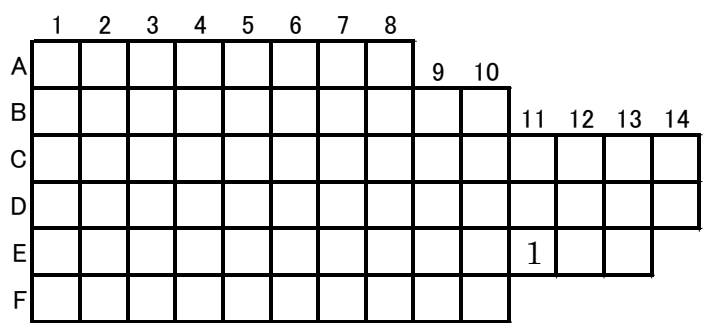

$178 \begin{aligned} & \text { Ercolania boodleae } \\ & \text { アリモウミウシ }\end{aligned}$

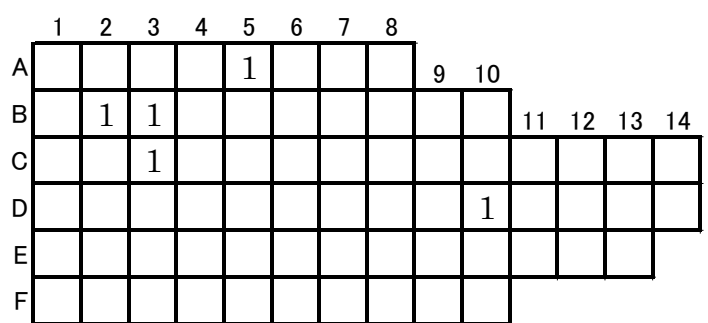

179 Aplysia dactylomela

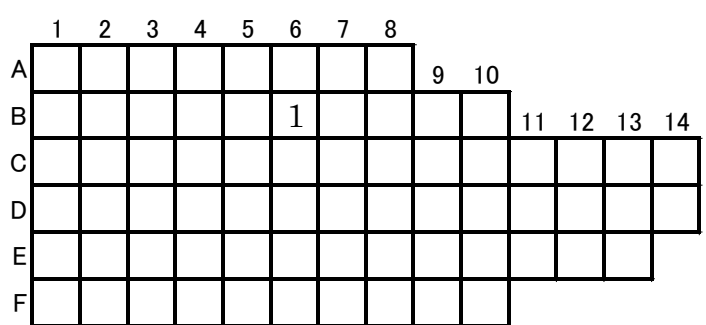

$180 \begin{aligned} & \text { Aplysia juliana } \\ & \text { アマクサアメフラシ }\end{aligned}$

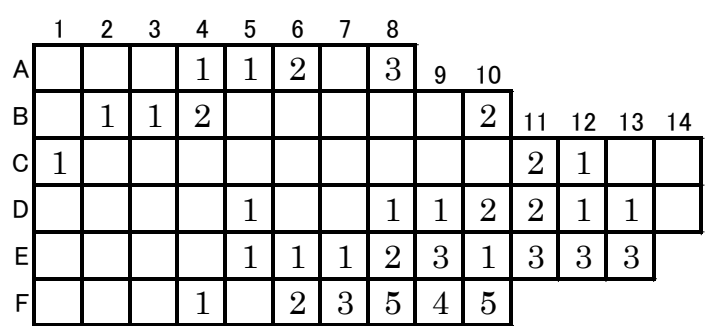


181 Aplysia kurodai

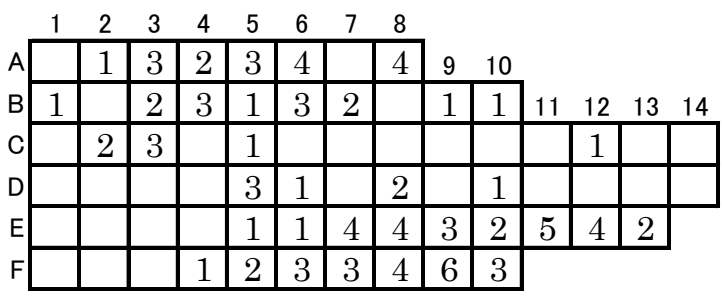

182 Aplysia oculifera

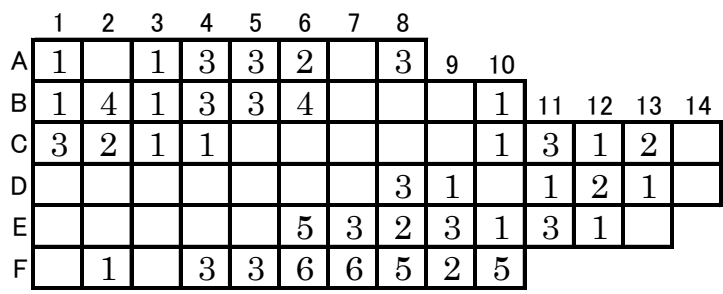

$183 \begin{aligned} & \text { Aplysia parvula } \\ & \text { クロヘリアメフラシ }\end{aligned}$

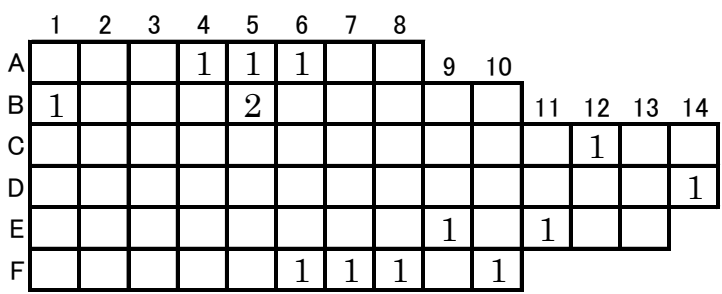

184 Dolabella auricularia

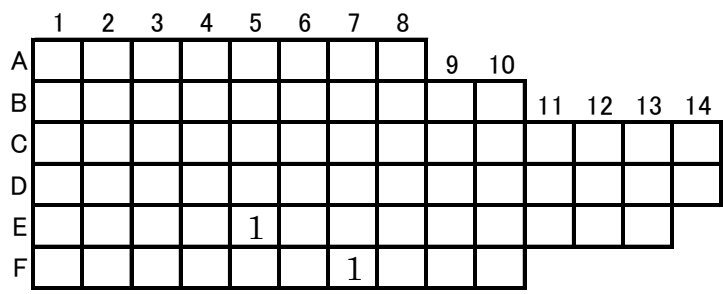

185 Goniodoris castanea

ネコジタウミウシ

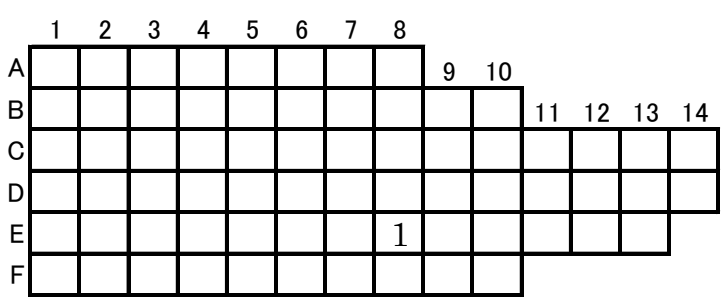

$186 \begin{aligned} & \text { Kalinga ornata } \\ & \text { ハナデンシャ }\end{aligned}$

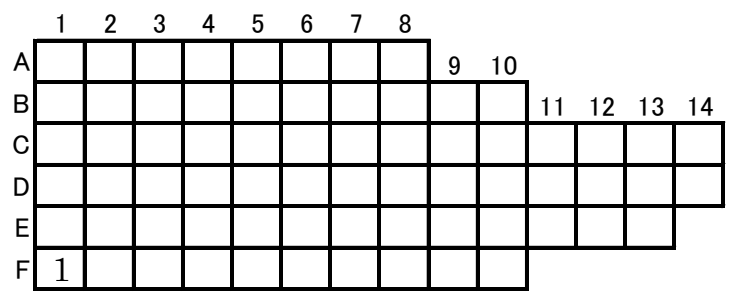

187 Hypselodoris festiva

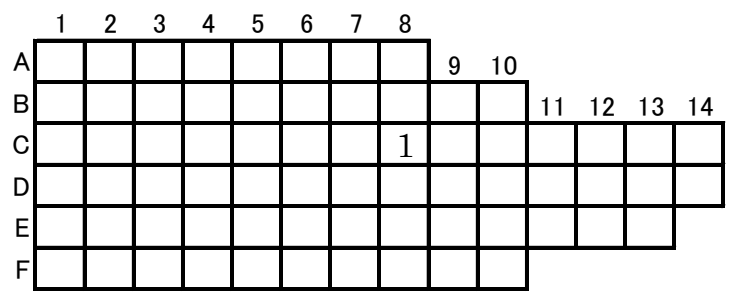

188 Discodoris concinna

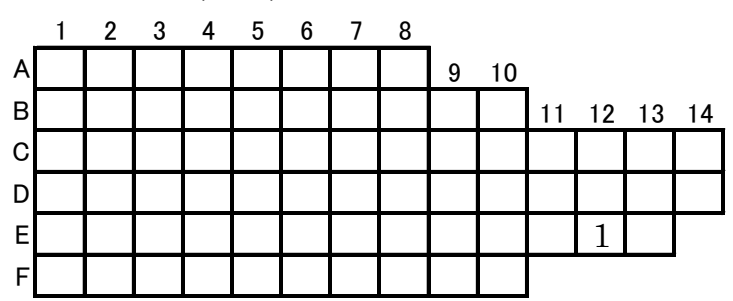

189 Doriopsis granulosa

キイロクシエラウミウシ

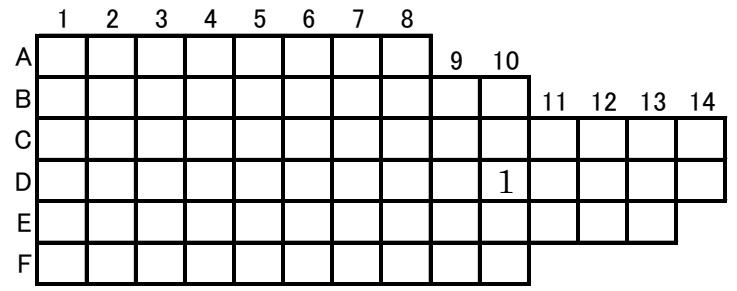

$190 \begin{aligned} & \text { Platydoris speciosa } \\ & \text { クモガタウミウシ }\end{aligned}$

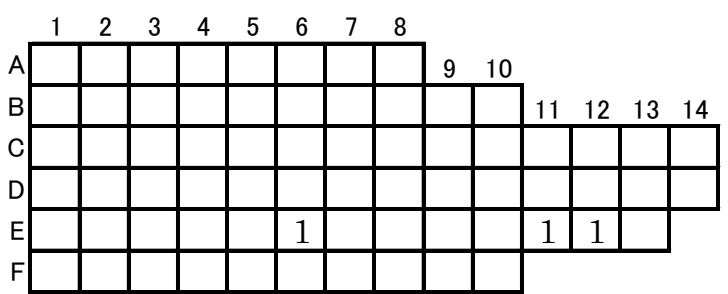


191

Platydoris tabulata

ネズミウミウシ

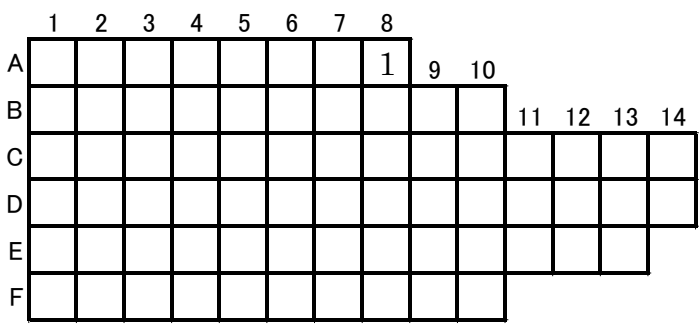

192

Dendrodoris arborescens

クロシタナシウミウシ

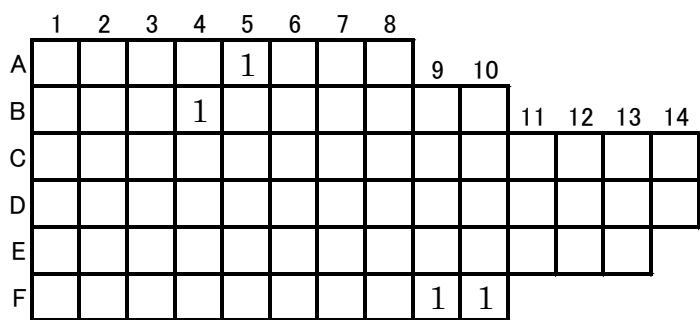

193

Doriopsilla miniata

ダイダイウミウシ

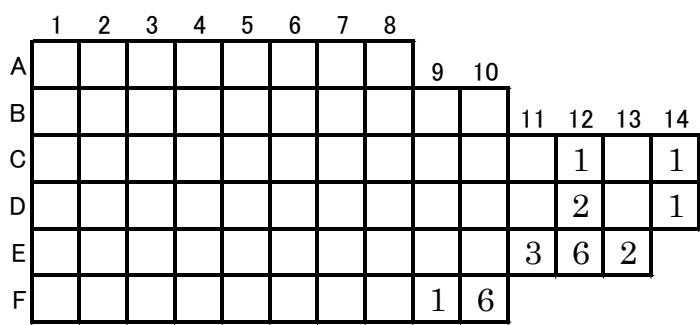

194 Melibe papillosa

メリベウミウシ

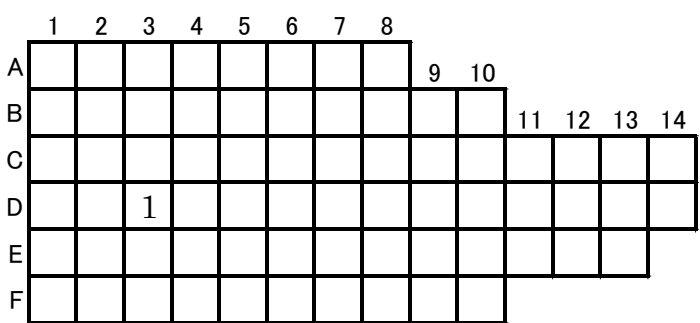

195 Spurilla chromosoma

イロミノウミウシ

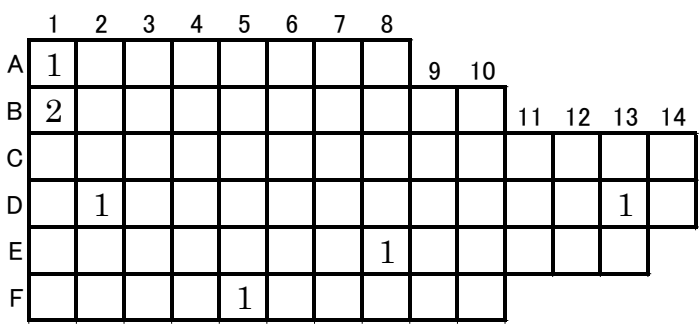

196

Onchidella kurodai

ヒメアワモチ

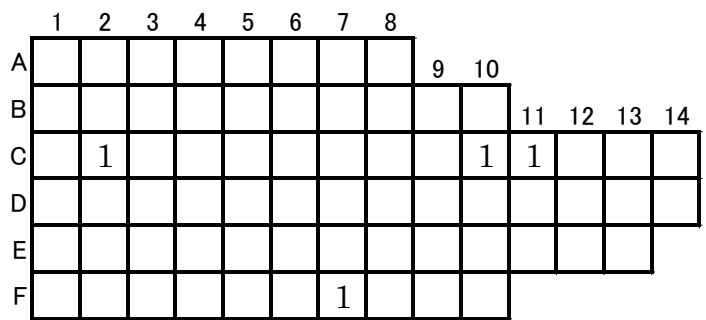

197 Peronia sp.

イソアワモチ近似種

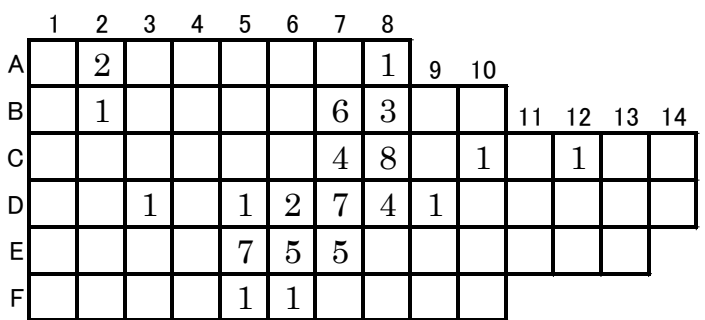

198 Siphonaria acmaeoides

シロカラマツガイ

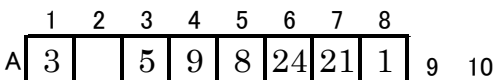

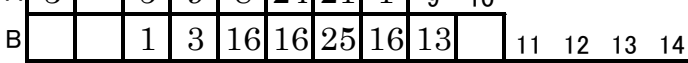

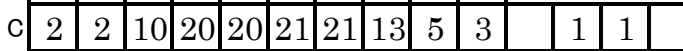

\begin{tabular}{l|l|l|l|l|l|l|l|l|l|l|l|}
$\mathrm{D}$ & 11 & 11 & 22 & 22 & 3 & 16 & 8 & 10 & 3 & & 1 \\
\hline
\end{tabular}

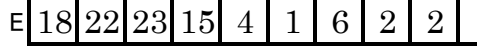

\begin{tabular}{lll|l|l|l|l|l|l|l|l|}
\hline $\mathrm{F}$ & 14 & 16 & 17 & 7 & 2 & & 1 & 1 & & \\
\hline
\end{tabular}

199

Siphonaria japonica

カラマツガイ

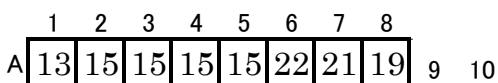

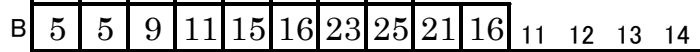

c \begin{tabular}{l|l|l|l|l|l|l|l|l|l|l|l|l|l|}
\hline 6 & 10 & 14 & 11 & 20 & 19 & 23 & 24 & 18 & 24 & 12 & 5 & 1 & 2 \\
\hline
\end{tabular}

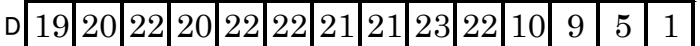

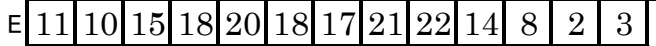

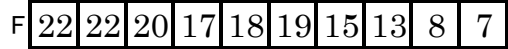

200 Siphonaria sirius

キクノハナガイ

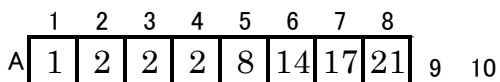

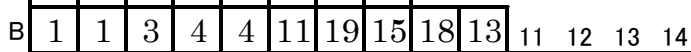

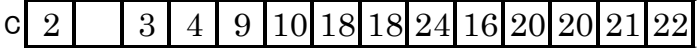

\begin{tabular}{llllllllllllllllllll|}
$\mathrm{D}$ & 1 & 1 & 3 & 4 & 9 & 14 & 19 & 24 & 25 & 22 & 25 & 20 & 25 & 14 \\
\hline
\end{tabular}

E \begin{tabular}{llllllllllllllllll}
\hline 1 & 1 & & 5 & 12 & 17 & 22 & 26 & 26 & 25 & 26 & 24 & 20 \\
\hline
\end{tabular}

$\mathrm{F}$\begin{tabular}{ll|l|l|l|l|l|l|l|l|l|}
\hline 1 & 4 & 2 & 19 & 25 & 25 & 24 & 26 & 25 & 25 \\
\hline
\end{tabular} 

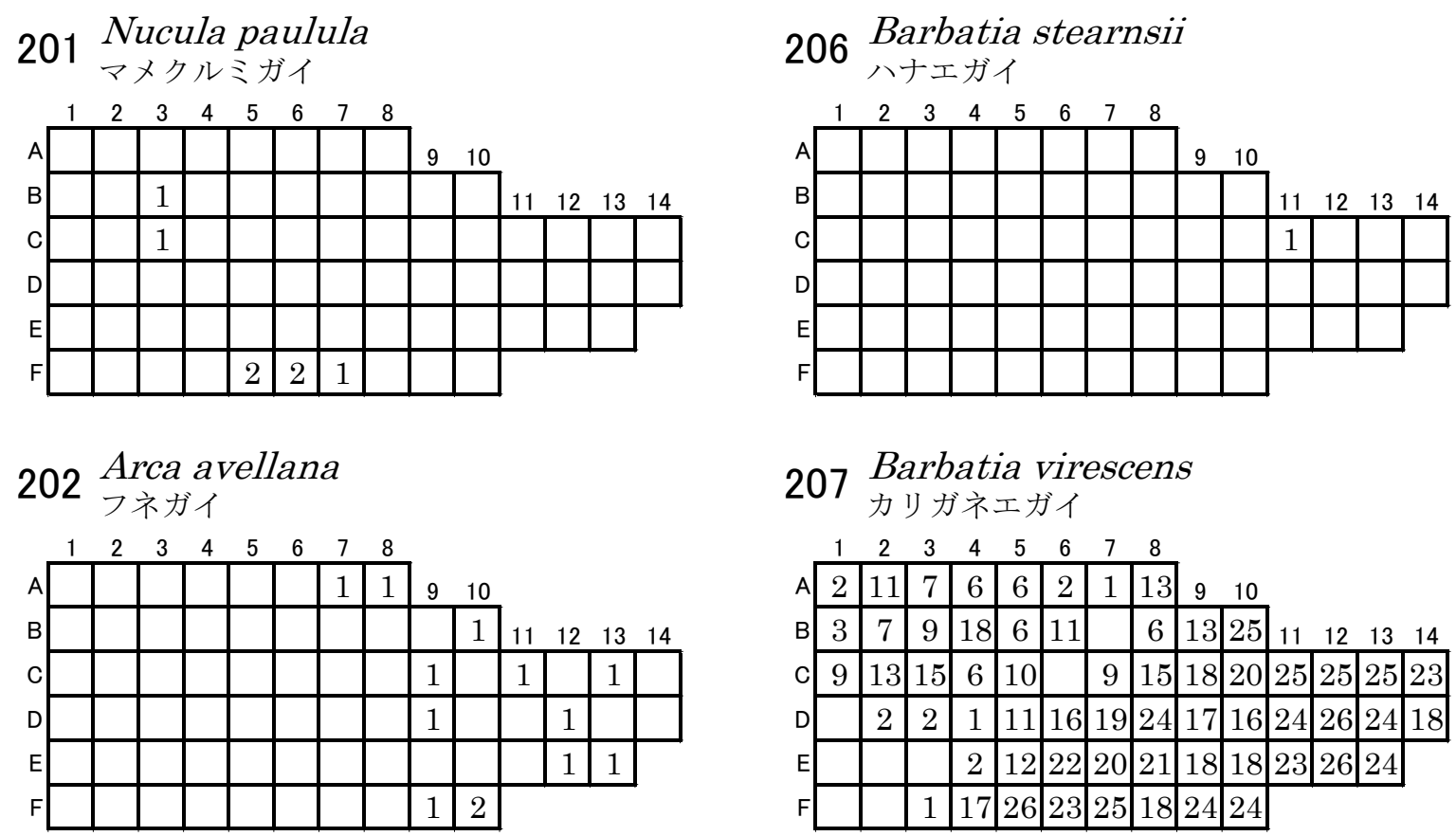

$207 \begin{aligned} & \text { Barbatia virescens } \\ & \text { カリガネエガイ }\end{aligned}$

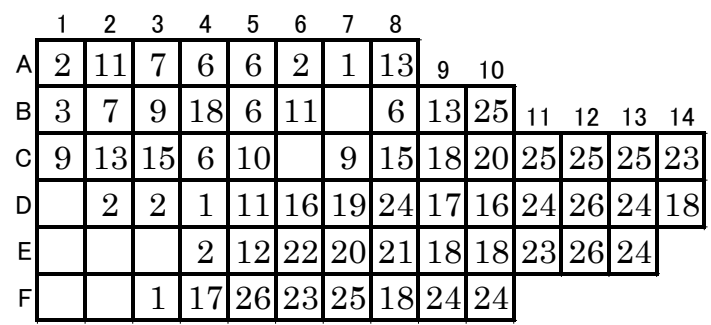
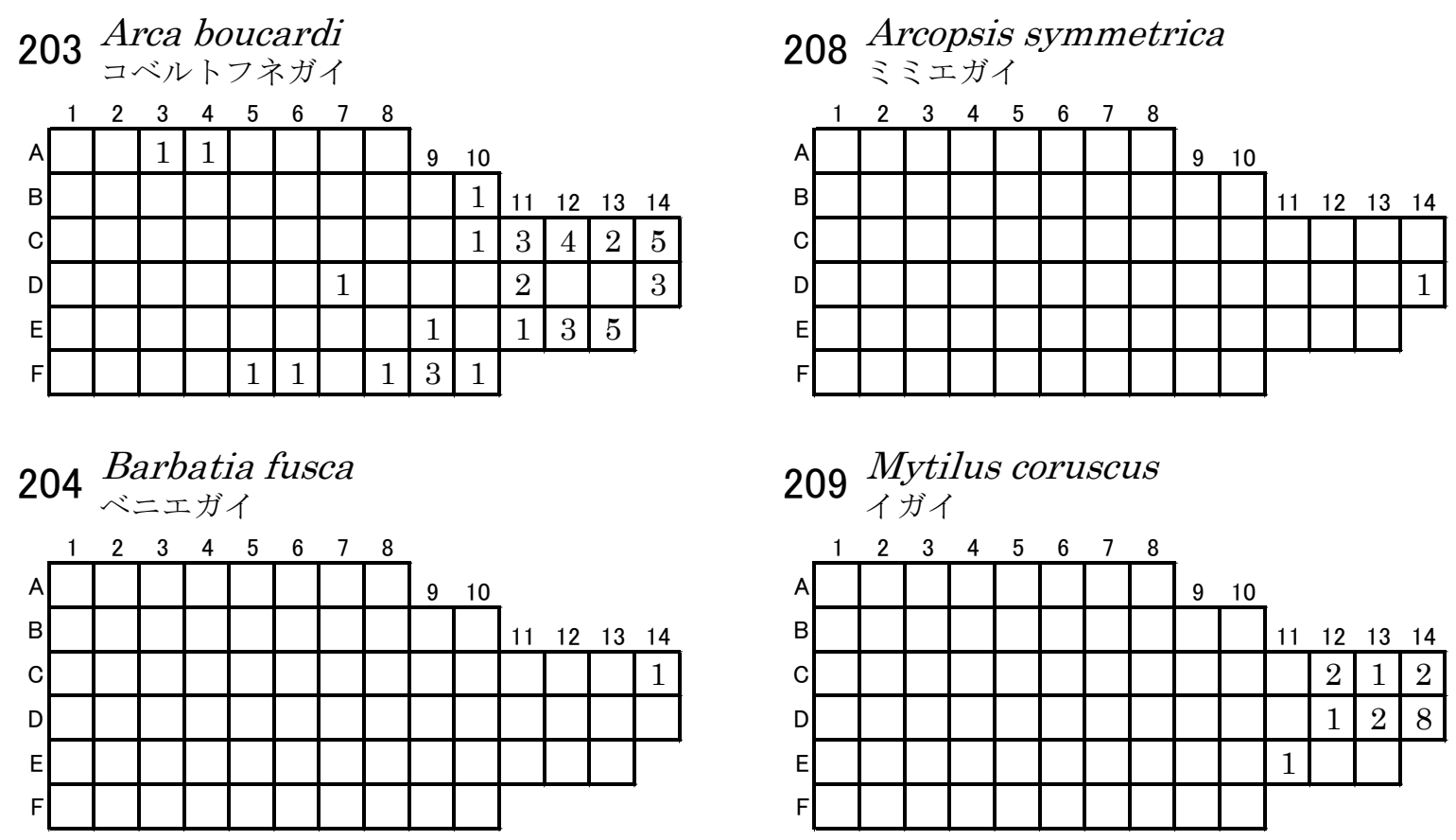

\section{$205 \begin{aligned} & \text { Barbatia lima } \\ & \text { エガイ }\end{aligned}$}

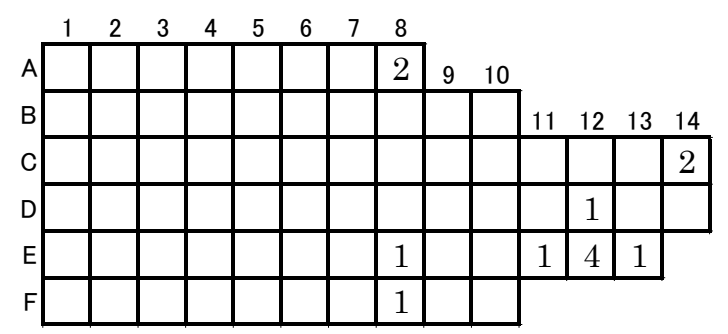


211

Xenostrobus atratus

クログチ

A \begin{tabular}{c|c|c|c|c|c|c|c|c|c}
1 & 2 & 3 & 4 & 5 & 6 & 7 & 8 & \\
16 & 12 & 21 & 23 & 21 & 22 & 26 & 23 & 9 & 10
\end{tabular}

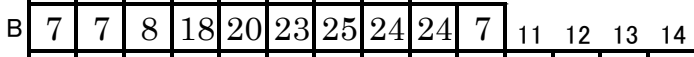
c \begin{tabular}{llllllllllll|l|l|l|l|}
18 & 14 & 18 & 22 & 23 & 24 & 25 & 26 & 23 & 20 & & & 1 & 1 \\
\hline
\end{tabular}

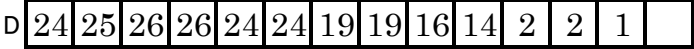
E 25 \begin{tabular}{lllllllllllllllll}
25 & 23 & 24 & 26 & 17 & 15 & 16 & 6 & 5 & 3 & 2 & & 1 \\
\hline
\end{tabular}

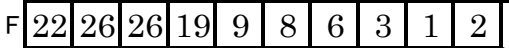

212

Hormomya mutabilis

ヒバリガイモドキ

A \begin{tabular}{|c|c|c|c|c|c|c|c|c|c|}
1 & 2 & 3 & 4 & 5 & 6 & 7 & 8 \\
& 13 & 12 & 10 & 11 & 8 & 17 & 17 & 9
\end{tabular}

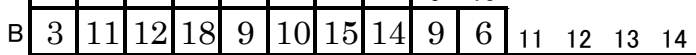
c \begin{tabular}{r|r|r|r|l|l|l|l|l|l|l|l|l|l|}
\hline 16 & 19 & 17 & 1 & 4 & 13 & 15 & 15 & 10 & 5 & 16 & 22 & 19 & 19 \\
\hline
\end{tabular}

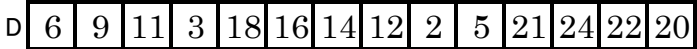

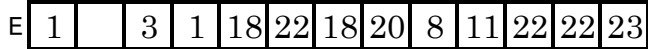
\begin{tabular}{llllllllll|l|l|l|}
$\mathrm{F}$ & 3 & 1 & 1 & 8 & 21 & 23 & 21 & 21 & 20 & 15 \\
\hline
\end{tabular}

213 Septifer bilocularis

クジャクガイ

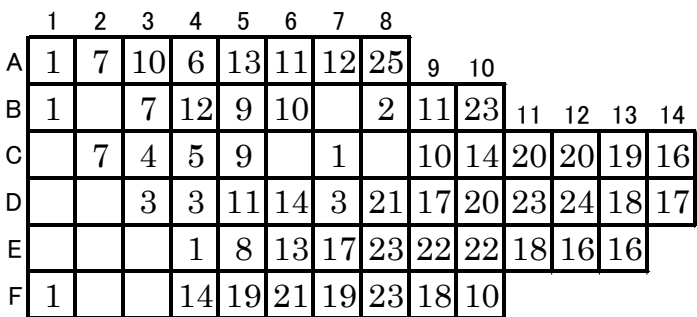

214 Septifer virgatus

ムラサキインコ

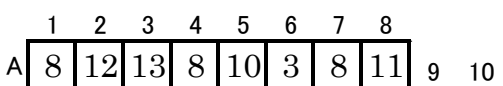

В \begin{tabular}{l|l|l|l|l|l|l|l|l|l|llll}
\hline 9 & 12 & 12 & 11 & 15 & 15 & 16 & 16 & 18 & 24 & 11 & 12 & 13 & 14
\end{tabular} C \begin{tabular}{l|l|l|l|l|l|l|l|l|l|l|l|l|l|}
14 & 15 & 19 & 12 & 17 & 24 & 25 & 21 & 26 & 26 & 26 & 25 & 26 & 26 \\
\hline
\end{tabular}

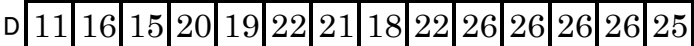
E 4 \begin{tabular}{llllll|l|l|l|l|l|l|l|l|} 
& 4 & 3 & 4 & 16 & 16 & 17 & 17 & 20 & 19 & 20 & 15 & 17 & 24 \\
\hline
\end{tabular} F \begin{tabular}{r|r|r|r|r|r|r|r|r|r|}
10 & 16 & 6 & 12 & 14 & 9 & 12 & 11 & 10 & 14 \\
\hline
\end{tabular}

\section{Modiolus auriculatus}

リュウキュウヒバリガイ

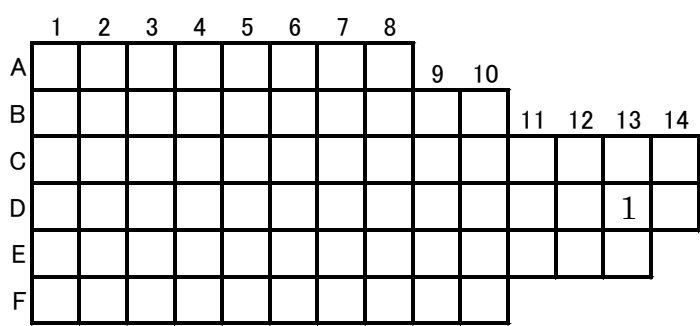

216 Modiolus nipponicus

ヒバリガイ

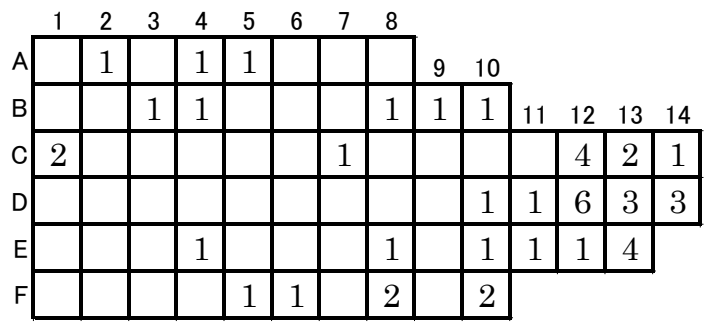

217 Musculus pusio

チビタマエガイ

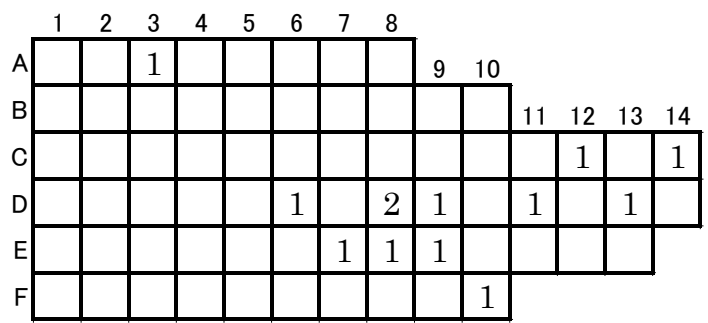

218 Pinctada maculata

ミドリアオリ

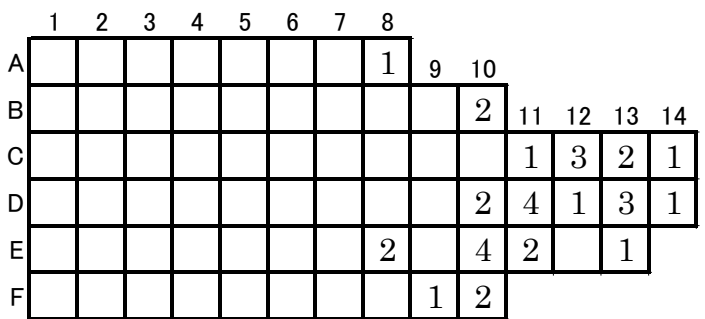

219 Pinctada margaritifera

クロチョウガイ

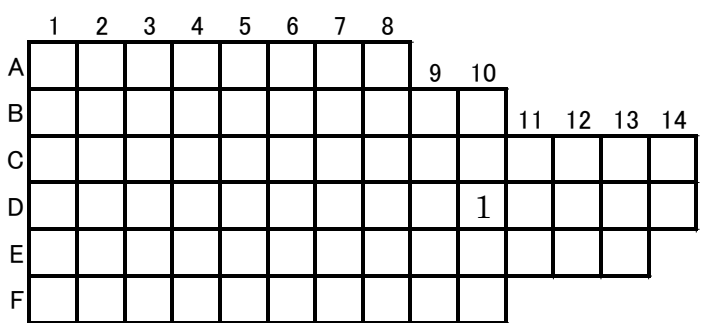

$220 \begin{aligned} & \text { Pinctada martensii } \\ & \text { アコヤガイ }\end{aligned}$

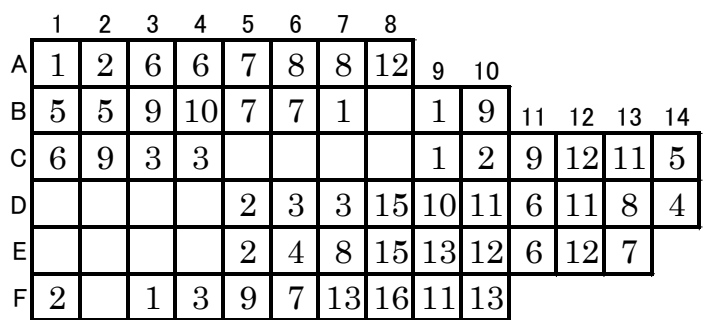


$221 \begin{aligned} & \text { ISognomon acutirostris } \\ & \text { ヘリトリアオリ }\end{aligned}$

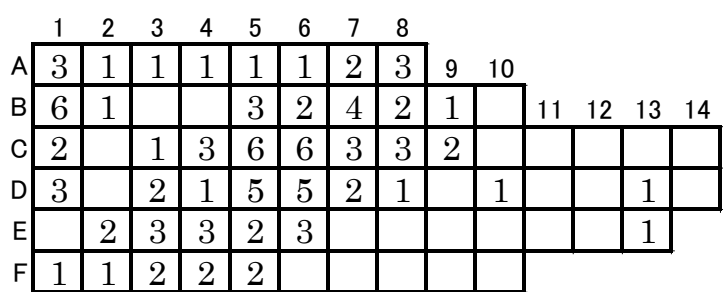

\section{Isognomon legumen}

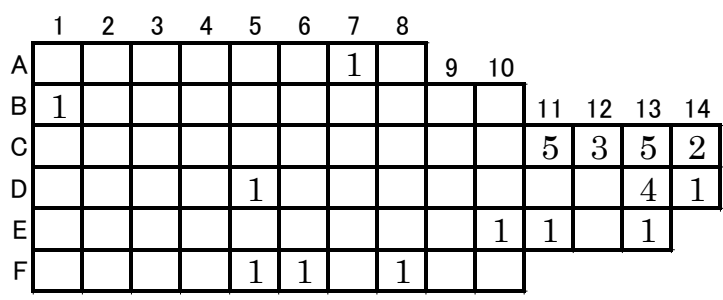

\section{Lima vulgaris}

ミノガイ

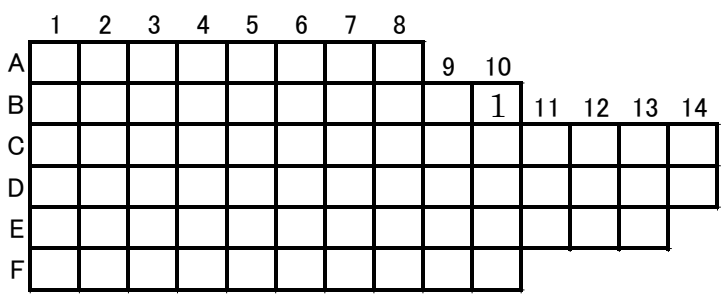

\section{Spondylus barbatus}

ウミギク

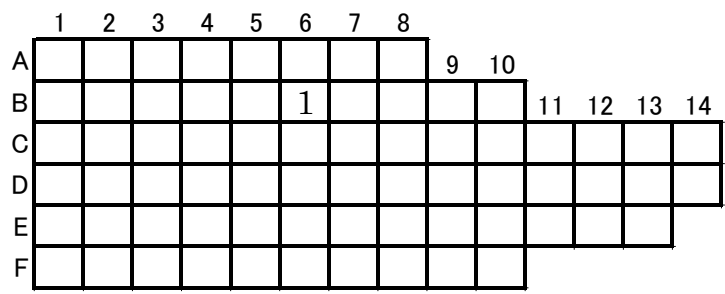

\section{Plicatula australis}

カスリイシガキモドキ

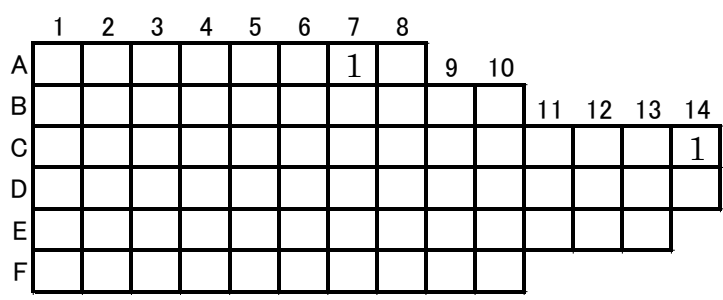

$226 \begin{aligned} & \text { Hyotissa chemnitzi } \\ & \text { ベニガキ }\end{aligned}$

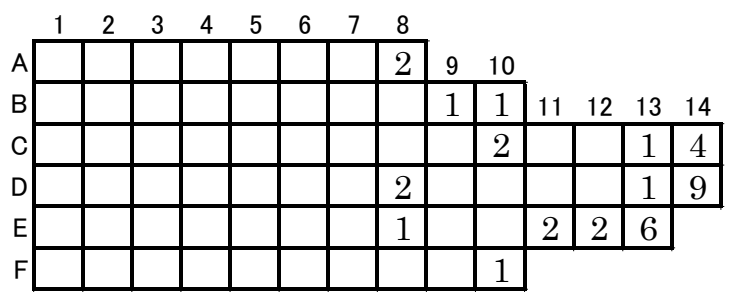

\section{Crassostrea gigas \\ マガキ}

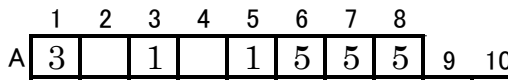
В 1 \begin{tabular}{lllllllllll|l|lll}
\hline 1 & 1 & & 1 & 1 & 1 & 5 & 10 & 8 & 4 & 11 & 12 & 13 & 14 \\
\hline & 1 & 2 & 2 & 1 & & 8 & 6 & 6 & 7 & 6 & & 4 & 4 & 2 \\
\hline
\end{tabular}

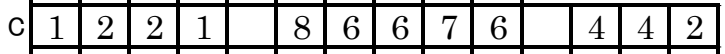

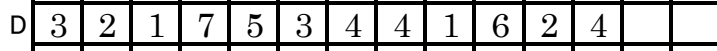
E \begin{tabular}{lllllllllllll|l|l|} 
& 3 & 3 & 3 & 4 & 3 & 2 & 2 & 7 & 1 & 3 & 1 & 1 & 3 \\
\hline
\end{tabular} $\mathrm{F}$\begin{tabular}{|l|l|l|l|l|l|l|l|l|l|l}
\hline 3 & 1 & 2 & 4 & 2 & 1 & 2 & 1 & & & \\
\hline
\end{tabular}

$228 \begin{aligned} & \text { Crassostrea nippona } \\ & \text { イワガキ }\end{aligned}$

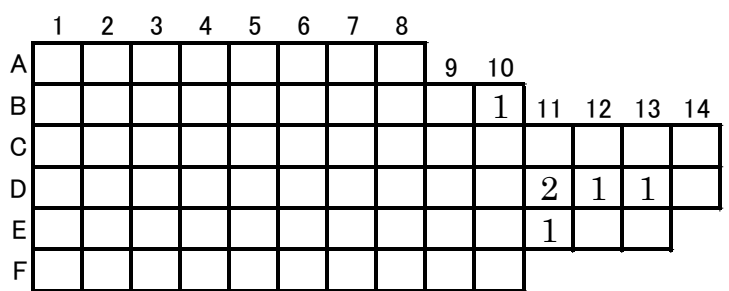

\section{Saccostrea kegaki \\ 厅ガキ}

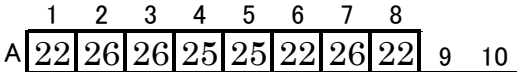

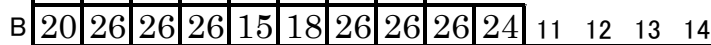
c \begin{tabular}{|l|l|l|l|l|l|l|l|l|l|l|l|l|l|}
25 & 26 & 24 & 23 & 24 & 26 & 26 & 26 & 26 & 26 & 26 & 20 & 14 & 6 \\
\hline
\end{tabular} D 26 \begin{tabular}{llllllllllllll|l|l|}
\hline 26 & 26 & 26 & 25 & 25 & 26 & 26 & 26 & 26 & 23 & 21 & 19 & 1 \\
\hline
\end{tabular} E 20 \begin{tabular}{l|l|l|l|l|l|l|l|l|l|l|l|}
\hline 25 & 25 & 26 & 26 & 25 & 25 & 21 & 24 & 23 & 23 & 17 & 8 \\
\hline
\end{tabular} \begin{tabular}{ll|l|l|l|l|l|l|l|l|l|}
\hline 26 & 26 & 26 & 26 & 25 & 19 & 20 & 13 & 12 & 21 \\
\hline
\end{tabular}

\section{Saccostrea mordax} オハグロガキ

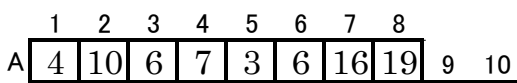
В \begin{tabular}{lllllllll|l|l|l|llll}
\hline & 3 & 3 & 3 & 2 & 6 & 14 & 15 & 18 & 14 & 11 & 12 & 13 & 14
\end{tabular}

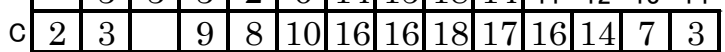

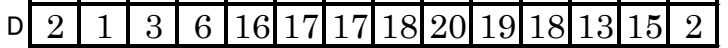

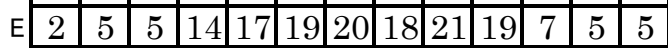
$\mathrm{F}$\begin{tabular}{|l|l|l|l|l|l|l|l|l|l|}
\hline 5 & 9 & 11 & 17 & 18 & 18 & 18 & 19 & 17 & 15 \\
\hline
\end{tabular} 
Dendostrea crenulifera

ノコギリガキ

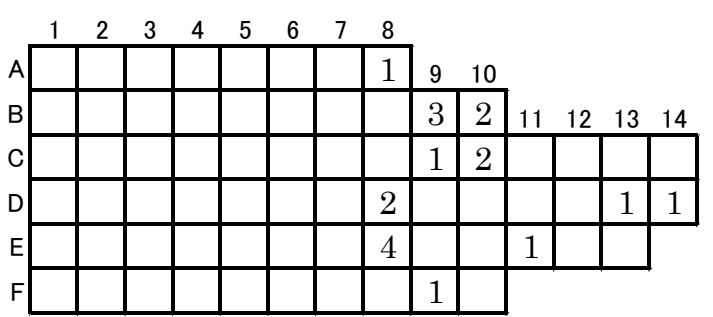

$232 \begin{aligned} & \text { Lasaea undulata } \\ & \text { チリハギガイ }\end{aligned}$

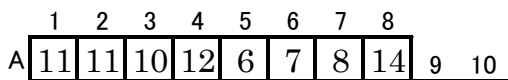
в \begin{tabular}{l|l|l|l|l|l|l|l|l|l|llll}
\hline 5 & 6 & 8 & 8 & 6 & 8 & 12 & 19 & 14 & 13 & 11 & 12 & 13 & 14 \\
\hline
\end{tabular}

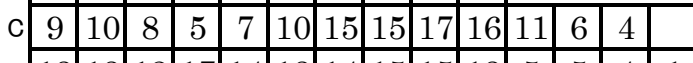
\begin{tabular}{l|l|l|l|l|l|l|l|l|l|l|l|l|l|l|}
$\mathrm{D}$ & 13 & 13 & 12 & 17 & 14 & 13 & 14 & 15 & 15 & 13 & 5 & 5 & 4 & 1 \\
\hline
\end{tabular} \begin{tabular}{|l|l|l|l|l|l|l|l|l|l|l|l|l|}
\hline 8 & 11 & 8 & 15 & 15 & 15 & 15 & 14 & 13 & 11 & 2 & 1 & \\
\hline
\end{tabular} F \begin{tabular}{|l|l|l|l|l|l|l|l|l|l|}
13 & 17 & 19 & 19 & 14 & 9 & 5 & 4 & 5 & 5 \\
\hline
\end{tabular}

\section{Cardita leana \\ トマヤガイ}

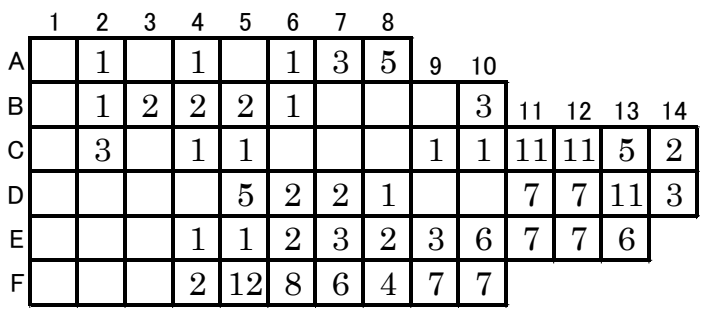

234 Chama japonica キクザル

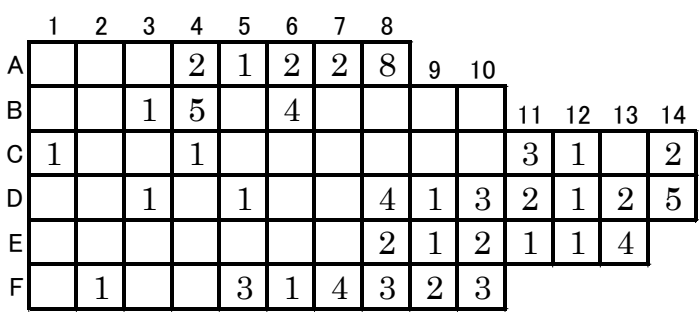

\section{Claudiconcha japonica} セミアサリ

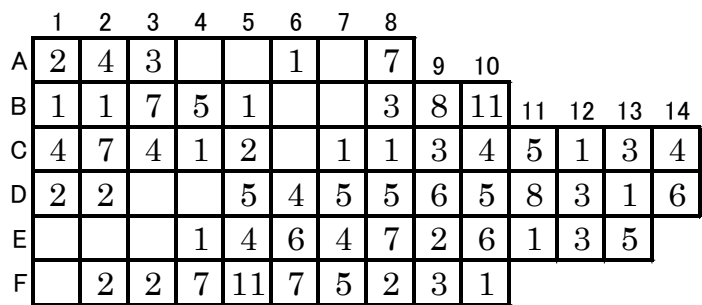

236

Gafrarium dispar

イナミガイ

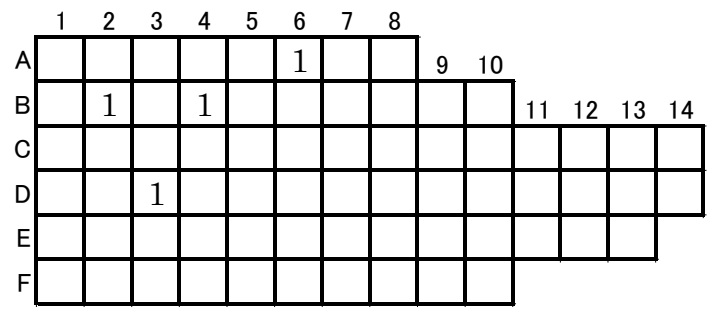

237 Gafrarium divaricatum

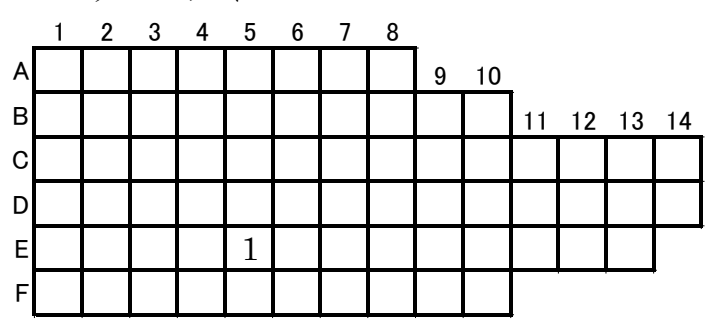

238 Protothaca jedoensis

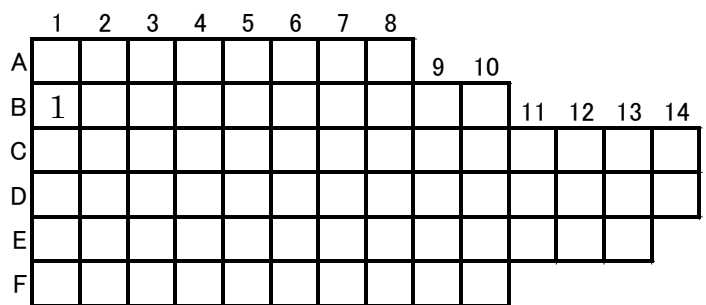

239 Ruditapes variegatus ヒメアサリ

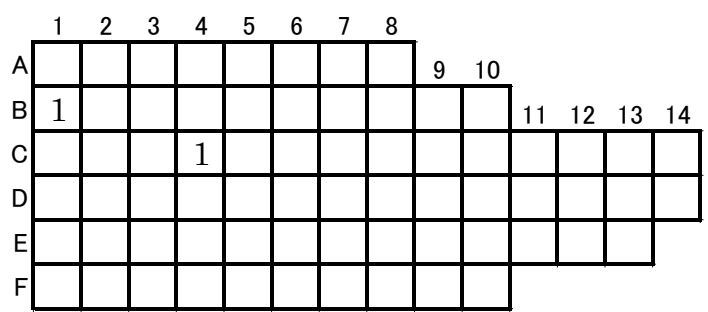

\section{Irus mitis}

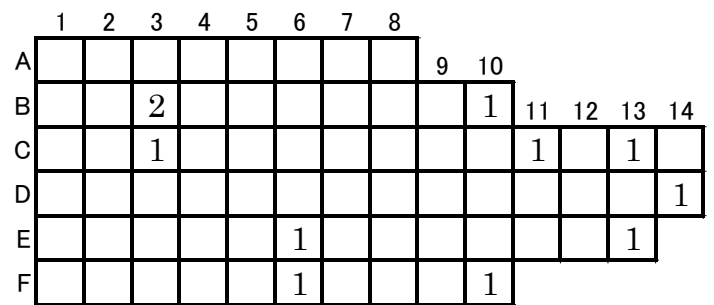


241 Irus macrophyllus

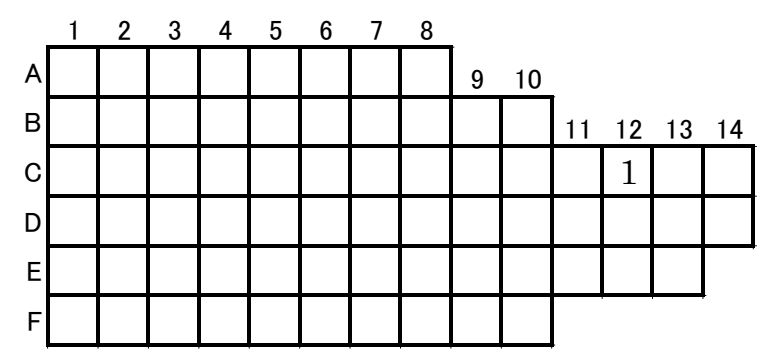

\section{Hiatella orientalis}

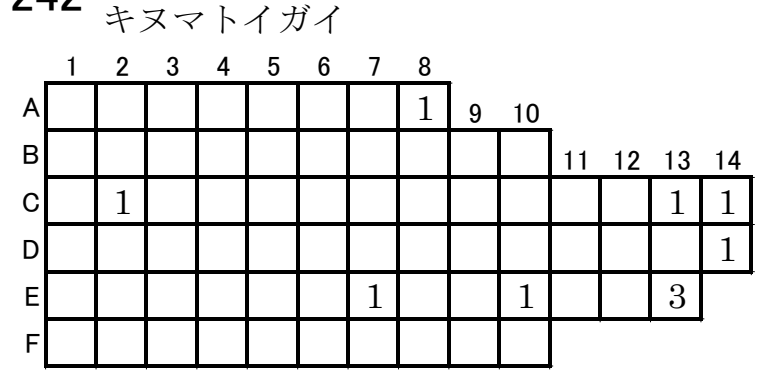


5-3. Inter-annual variation in the abundance of the 242 species

Table 2.

The number of quadrats in which each species occurred each year. Italic numerals in the uppermost row indicate the lower two figures of the years in A.D. (e.g., 05 means 2005) SC, species codes in the List of recorded species (Section 2). NY, number of years when the species appeared. CQ, cumulative number of quadrats occupied by the species during the 25-year period. -, no data; when this symbol is included in the row of a species, the values of $\mathrm{NY}$ and $\mathrm{CQ}$ are in parentheses. 


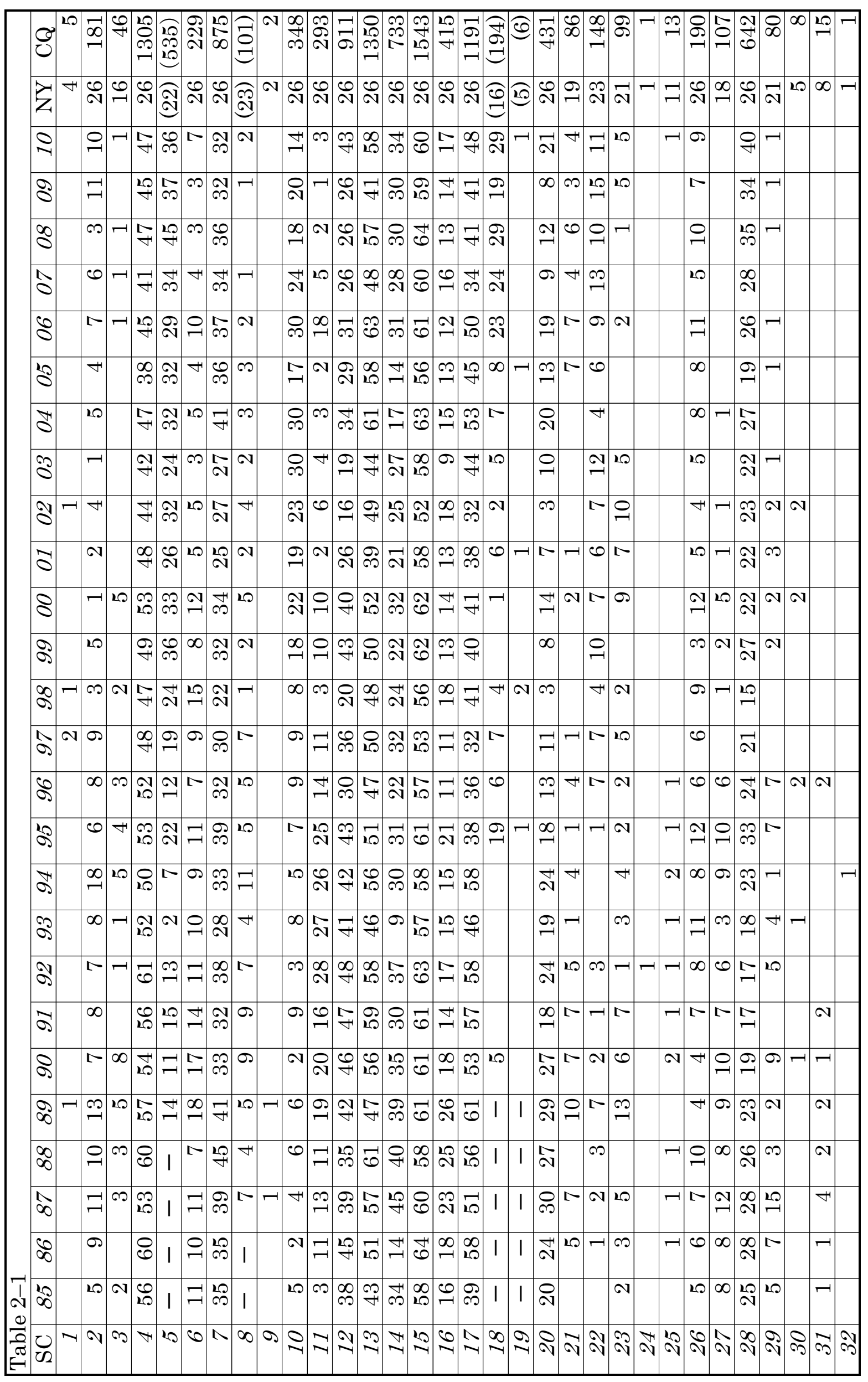




\begin{tabular}{|c|c|c|c|c|c|c|c|c|c|c|c|c|c|c|c|c|c|c|c|c|c|c|c|c|c|c|c|c|c|c|}
\hline 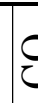 & & & & & 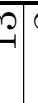 & & $\begin{array}{c}7 \\
7\end{array}$ & $\Rightarrow$ & 오 & & \begin{tabular}{l|}
$\infty$ \\
$\stackrel{+}{+}$ \\
|
\end{tabular} & \begin{tabular}{|c|}
\multirow{2}{*}{} \\
$\stackrel{2}{\text { s }}$ \\
\end{tabular} & & & & 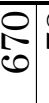 & & $\bar{r}$ & & & & & & & & $\begin{array}{l}\mathcal{N} \\
\mathbb{1} \\
\mathbb{0}\end{array}$ & & & & \\
\hline & & 4 & & 0 & 0 & -19 & $\theta \sqrt{\sigma}$ & S & $\rightarrow \underset{\sim}{ }$ & 0 & $\stackrel{10}{\mathrm{~N}}$ & : & 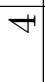 & & 0 & 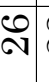 & ลึ & -1 & -1 & 0 & o) & - & $-1-1$ & & ล & ${ }^{*} \stackrel{\bullet}{\ominus}$ & $\stackrel{\Omega}{-}$ & $\stackrel{0}{-1}$ & $\stackrel{\leftrightarrow}{\sim}$ & 今ి \\
\hline & 4 & & & & & & $\sqrt{9}$ & & $\infty$ & $N$ & $\sigma$ & $\underset{q}{*}$ & & & & $\begin{array}{c}\infty \\
\stackrel{N}{N}\end{array}$ & $N$ & & & & N & 4 & & & 20 & 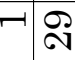 & -1 & & $\underset{+}{0}$ & की \\
\hline 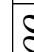 & & & & & & & +6 & $\mathrm{v}$ & $\underset{\square}{\nabla}$ & & $\sigma$ & $\begin{array}{l}\infty \\
\infty\end{array}$ & & & & $\vec{\sim}$ & N & & -1 & & $\infty$. & -1 & & & & ט) & 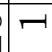 & & $\stackrel{\mathscr{P}}{+}$ & ली \\
\hline c & & & & & & & & & 6 & & 10 & ח) & & & & ลง & & & & & $\infty c$ & $\infty$ & & & $\infty$ & ஜ & - & -1 & $f$ & $\stackrel{\vec{N}}{\mathrm{~N}}$ \\
\hline 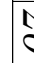 & & & & & -1 & & & t & $\infty 2$ & & 익 & $\underset{⿱ 中}{\infty}$ & & & & ลิ & & & & & 6 . & -1 & & & -1 & ח2 & & & $\stackrel{10}{7}$ & $\widehat{\widehat{N}}$ \\
\hline$\delta$ & & 16 & & & -1 & & & -1 & $N$ & & $\sigma$ & $\underset{\sim}{\infty}$ & & & & ๓ื & N & & & & $\infty$, & -1 & & & 20 & $\stackrel{\odot}{\circ}$ & & & & $\widehat{\infty}$ \\
\hline 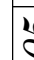 & & & & & & & -1 & & N & & 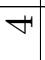 & $\vec{n}$ & & & & $\widehat{N}$ & N & & & & $\sigma 7$ & -1 & & & $\nabla$ & $\stackrel{\Omega}{-1}$ & & & $\widetilde{f}$ & $\begin{array}{l}\infty \\
\stackrel{N}{*}\end{array}$ \\
\hline & 5 & & & & & & & -1 & $\infty$ & & $\infty$ & $\frac{10}{4}$ & & & & $\stackrel{\mathrm{N}}{\mathrm{N}}$ & & & & & 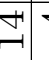 & 4 & & & 0 & $\stackrel{\infty}{\stackrel{N}{N}}$ & -1 & $\infty$ & 81 & के \\
\hline 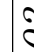 & & & & & & & & & $\stackrel{0}{\circ}$ & & 10 & $\frac{20}{4}$ & & & & $\overrightarrow{\mathrm{N}}$ & N & & & & 100 & $m$ & & & $\infty$ & $\ddot{\infty}$ & & -1 & $g$ & ๓ి \\
\hline & & & & & & & $\sqrt{3}$ & & $\sigma$ & -1 & + & $\underset{\forall}{P}$ & -1 & & & $\underset{\sim}{\infty}$, & $\neg$ & & & & م & -1 & & -1 & $\Gamma$ & 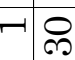 & & -1 & מొ & 잉 \\
\hline 8 & & & & & & & & & 6 & & $\infty$ & ले & & & & $\stackrel{N}{N}$ & $\mathrm{~N}$ & & & & -17 & -1 & & & $\mathrm{~N}$ & $\widehat{N}$ & $N$ & -1 & $\begin{array}{l}30 \\
10\end{array}$ & ले \\
\hline 0 & & & & & & & $\partial \pi$ & & 6 & & $\infty$ & $\underset{\forall}{P}$ & & & & $\stackrel{\mathbb{N}}{\mathrm{N}}$ & -1 & & & & $\underline{v}$ & $\infty$ & & -1 & 0 & $\begin{array}{ll}\sigma \\
\stackrel{L}{N}\end{array}$ & 0 & 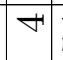 & t' & ๓े \\
\hline 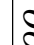 & & & & & & & & -1 & $\sigma$ & & + & I & & & & 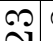 & $\infty$ & & & & $\mp$ & 4 & & & 工 & $\neg \infty$ & $N$ & -1 & t & 0 \\
\hline ? & & & & & & & $c$ & & $\infty$ & & $\infty$ & $\vec{\infty}$ & & & & 20 & 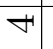 & & & & 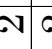 & $v$ & & & $\infty$ & $\sqrt{-1}$ & & -1 & $\sqrt{1}$ & t \\
\hline & & & & & & & 025 & & 10 & & $\sigma$ & 0 & & & -1 & +1 & 10 & & & & 01 & - & & & 10 & o & & -1 & 잉 & $\infty$ \\
\hline & & & & & & & & & & & & & & & & & & & & & & & & & & & & & & \\
\hline c & & & & & & & & $\mathrm{N} / \mathrm{T}$ & 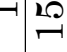 & & $\stackrel{N}{\sim}$ & 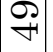 & & & & $\stackrel{\bigcirc}{\circ}$ & 10 & & & & ما & -1 & -1 & -1 & -1 & $\stackrel{+}{N}$ & 6 & $\infty$ & $\begin{array}{l}0 \\
10\end{array}$ & $\stackrel{\infty}{\stackrel{D}{N}}$ \\
\hline 3 & & & & & -1 & 7 & & t & $\vec{N}$ & & $\stackrel{N}{r}$ & 20 & & & & ט) & $\nabla$ & & & -72 & $\Omega 7$ & -1 & & $\theta$ & $m$ & $\infty$ & I & -1 & 20 & $N$ \\
\hline & & $\sqrt{2}$ & & & 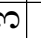 & & & & $\infty$ & & 10 & $\sim$ & & & -1 & $\circ$ & $\Gamma$ & & & & $\rightarrow 0$ & $v$ & & -1 & $\sigma$ & $\sigma$ & $\infty$ & $N$ & $\rho$ & 0 \\
\hline & & & & & & & & & & & & & & & & & & & & & & & & & & & & & & \\
\hline ¿ & & & & & v & & & & $m$ & & $\stackrel{\sim}{\sim}$ & 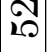 & & & -1 & 恶 & $\infty$ & & & -1 & 7 & -1 & & $\neg$ & $\infty$ & $\stackrel{\theta}{-}$ & $\stackrel{N}{\sim}$ & -1 & 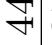 & 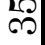 \\
\hline 8 & & -17 & & & $v$ & & & 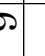 & $\infty$ & & 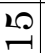 & (1) & & & $\infty$ & $\stackrel{\mathrm{N}}{\mathrm{S}}$ & $\infty$ & -1 & & \begin{tabular}{c|c}
0 \\
0
\end{tabular} & $\begin{array}{l}\text { ov } \\
\text { के }\end{array}$ & & & & 0 & $\infty$ & $\infty$ & 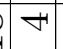 & 0 & म \\
\hline c & & 6 & 56 & 27 & -1 & 6 & 9 & & $\stackrel{N}{-}$ & & $\infty$ & iv & & -1 & -1 & $\stackrel{\mathrm{N}}{\mathrm{S}}$ & N & & & -7 & $\sqrt{\mathrm{v}}$ & & & -1 & $\infty$ & ๓ & $\sigma$ & & $\stackrel{m}{\sim}$ & m \\
\hline & & 8 & & $\sqrt{10}$ & $\mathrm{~N}$ & 6 & 27 & -1 & -1 & & $\infty$ & $\infty$ & -1 & & & $\widehat{\Lambda}$ & $1 \Omega$ & & & & 0 & & & 10 & $\infty$ & $\ddot{0}$ & $\infty$ & -1 & 9 & $m$ \\
\hline & & & & & & & & & & & & & & & & & & & & & & & & & & & & & & \\
\hline$\delta$ & & $t^{\circ} 6$ & $\mathrm{~J} / \mathrm{r}$ & -1 & & 7 & $-1 ?$ & - & $m$ & -1 & $\underline{0}$ & $\begin{array}{l}10 \\
10\end{array}$ & & $\sim$ & & $\stackrel{10}{\mathrm{~N}}$ & $\infty$ & & & & "r & $\Gamma$ & -1 & & 0 & $\stackrel{\infty}{N}$ & 6 & & $\stackrel{\sigma}{\sigma}$ & $\stackrel{N}{\Delta}$ \\
\hline \& & & & & -1 & & 7 & -16 & & $\infty$ & 7 & 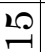 & $\underset{\forall}{\operatorname{Pa}}$ & & & -1 & ) & + & & & & 0 & & & & 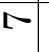 & $\widehat{N}$ & $\mathcal{N}$ & & N & $\infty$ \\
\hline 5 & & & & -1 & & 6 & $\sqrt{ } \propto$ & & 工 & -1 & $\infty$ & 20 & $N$ & & & $g$ & 10 & & & 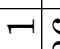 & 0 & & & & 0 & $\widehat{\curvearrowright}$ & $\mathfrak{N}$ & -1 & $\sqrt{v}$ & $\mathfrak{N}$ \\
\hline & & & & & & & & & & & & & & & & & & & & & & & & & & & & & & \\
\hline 5 & & $\sigma$ & & & & & & + & 6 & -1 & 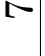 & | & & & & $\stackrel{+}{\mathrm{N}}$ & N & & & -15 & 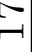 & & & & -1 & 거 & $\stackrel{N}{-1}$ & & מ & 요 \\
\hline & & D & & & & $v$ & $\sigma$ & $\mathrm{v}$ & $\infty$ & & & 드 & -1 & & & ลึ & + & & & & 0 & & & 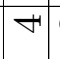 & $\infty$ & 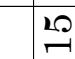 & $\infty$ & & $\vec{\omega}$ & 尺) \\
\hline 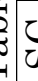 & & & & & & 6 & 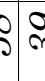 & b & 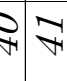 & & $\mathscr{P}$ & 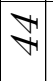 & 4 & $\notin 1$ & $\pi$ & $\infty$ & \& & 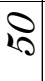 & & हैं। & D. & tr & 960 & $\hat{0}$ & 10 & $\therefore 8$ & 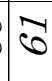 & है & 0 & 6 \\
\hline
\end{tabular}




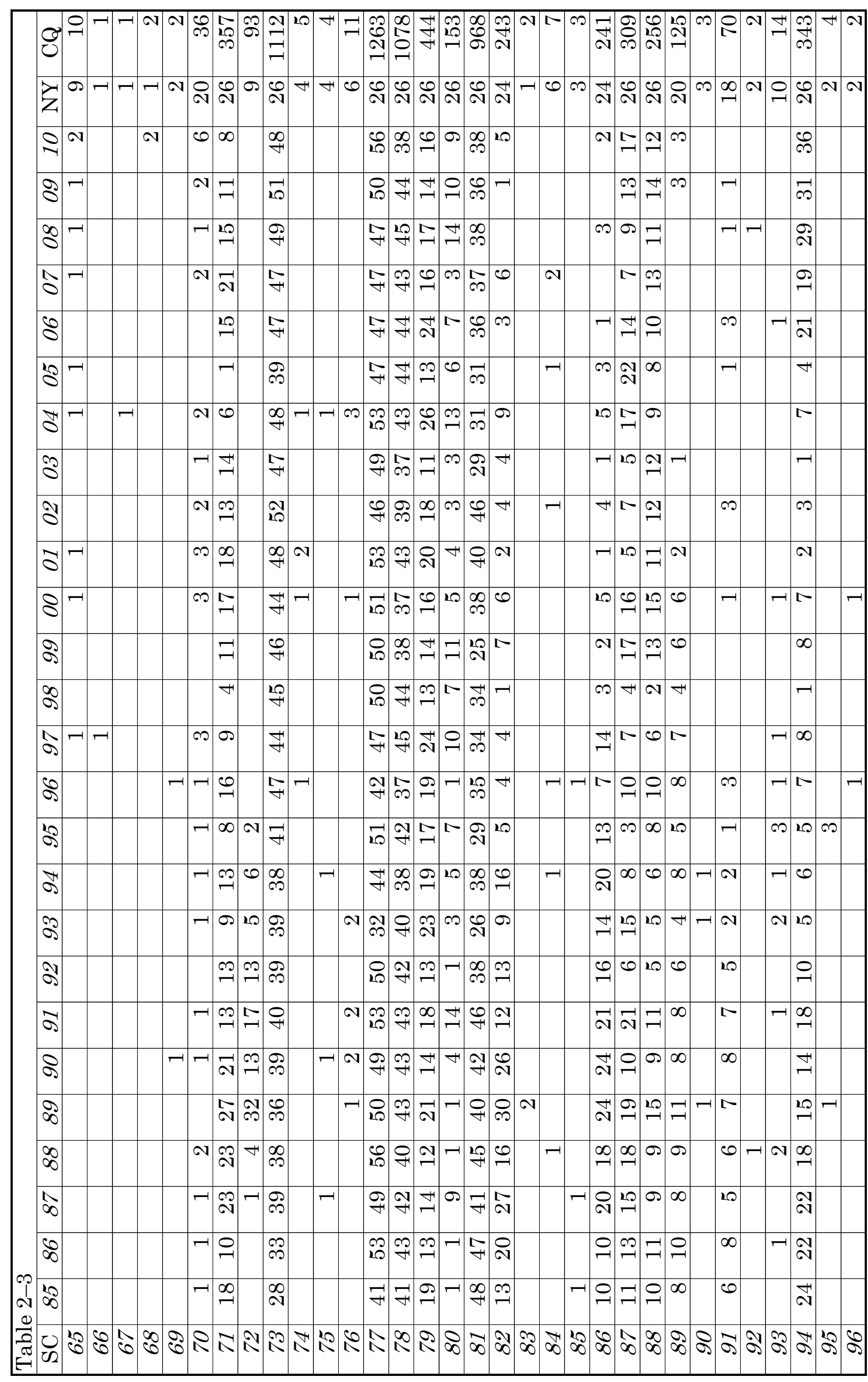




\begin{tabular}{|c|c|c|c|c|c|c|c|c|c|c|c|c|c|c|c|c|c|c|c|c|c|c|c|c|c|c|c|c|c|c|c|c|c|}
\hline & ช & \begin{tabular}{|l|}
$\Omega$ \\
\\
\end{tabular} & $\Gamma$ & 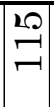 & $\stackrel{\circ}{\circ}$ & 10 & -1 & $\mathbb{N}$ & $\infty$ & -1 & 0 & 건 & -1 & -1 & N & 10 & $m$ & N & 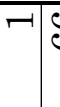 & $\begin{array}{l}0 \\
0\end{array}$ & ๑) & $\neg$ & $\sqrt{\sim}$ & $\begin{array}{ll}0 \\
10\end{array}$ & \begin{tabular}{l|r}
$\mathbf{N}$ & $\mathrm{r}$
\end{tabular} & 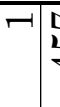 & 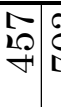 & \begin{tabular}{lll}
$m$ & 1 \\
\hdashline & 1 \\
\hdashline & 1
\end{tabular} & $\begin{array}{ll}+ & \alpha \\
I & \\
F & \end{array}$ & & $\sigma 6$ & & $\mathrm{~N}$ \\
\hline & $z^{2}$ & $\stackrel{0}{-1}$ & $\neg$ & $\stackrel{\rho}{\sigma}$ & $\infty$ & H & -1 & $\begin{array}{l}0 \\
-1\end{array}$ & $\infty$ & -1 & +4 & 득 & -1 & -1 & N & 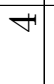 & N & -1 & -1 & $\underset{-1}{+}$ & $\stackrel{\infty}{\sim}$ & -1 & $\infty$ & $\underset{\square}{+1}$ & $\neg r$ & -1 & $\stackrel{0}{\circ}$ & $\begin{array}{lll}0 & c & c\end{array}$ & \begin{tabular}{c|c}
0 & \multicolumn{1}{c}{} \\
&
\end{tabular} & $\nabla c$ & 60 & $\mathrm{~N}$ & $N$ \\
\hline & $\stackrel{1}{2}$ & & & 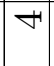 & & & & & -1 & & & & & & & & & & & & & & & & & & $\begin{array}{l}\infty \\
\infty\end{array}$ & -1 & $\not$ & & & & \\
\hline & 3 & & & -1 & & & & & & & & -1 & & & & & & & & & & & & & & & ஸै & 10 & $\underset{f}{+}$ & & & & \\
\hline & $\infty$ & & & & & & & & & & & & & & & & & & & & & & & & & & m. & -1 & + & & & & -1 \\
\hline & $\widehat{O}$ & & & -1 & & & & & & & & & & & & & & N & & & & & & & & & $\stackrel{m}{\mathfrak{N}}$ & $\infty ?$ & $\stackrel{\infty}{+}$ & & & & \\
\hline & 8 & & & & & & & & & & & -1 & & & & & & & & & & & & & & & \begin{tabular}{l|l}
10 & 6 \\
$\mathrm{~N}$ & $\mathrm{r}$
\end{tabular} & $\stackrel{2}{\sim}$ & $\not 1$ & & & & \\
\hline & 20 & & & & & -1 & & & & & & & & & & & & & & & & & & & & & 穴 & $\stackrel{c}{\sim}$ & $\begin{array}{l}0 \\
0 \\
\mathrm{n}\end{array}$ & & & & \\
\hline & $\sigma^{+1}$ & & & 0 & & & & & & & & & & & & & & & & & & & & & & & ஸै & ल) & F & & & & \\
\hline & $\dddot{2}$ & & & 0 & -1 & & & -1 & & & & & & & & & & & & & & & & & & & $\stackrel{\mathrm{N}}{6}$ & $\stackrel{\text { N }}{\sim}$ & $\stackrel{9}{q}$ & & & & \\
\hline & כิ & -1 & & $\Gamma$ & & & & -1 & -1 & & & -1 & & & -1 & & & & & & & & & & & & ๑) & 거 & $\stackrel{\leftrightarrow}{*}$ & & & & \\
\hline & 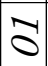 & & & 10 & & & & 10 & & & & & & & & & & & & -1 & & & -1 & & & & ণ & $\stackrel{\leftrightarrow}{\sim}$ & $\vec{F}$ & & & & \\
\hline & 8 & N & & $\sigma$ & & & & $F$ & & & & N & -1 & -1 & & & & & & & N & & $\neg$ & & & & $\stackrel{\sim}{\sim}$ & FI & ${ }_{\vec{H}}^{N}$ & -1 & & & \\
\hline & హ) & $\neg$ & & $\infty$ & & & & & & & & 10 & & & & & & & & & & & & $m$ & & & $\stackrel{\sigma}{\sigma}$ & $\stackrel{m}{q}$ & $N_{f}$ & $\begin{aligned}+1 \\
\end{aligned}$ & -1 & & \\
\hline & $\begin{array}{l}\infty \\
0\end{array}$ & & & $\infty$ & & & & & & & -1 & & & & & & & & & & & & $\neg$ & N & & & $\underset{-1}{+}$ & $\begin{array}{ll}0 \\
\stackrel{N}{N}\end{array}$ & $F_{+} \sigma$ & ov & & & \\
\hline & $\widehat{\widehat{S}}$ & & & 10 & & -1 & & $\infty$ & -1 & & & N & & & & -1 & & & & N & N & & 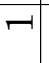 & $F$ & & & $\stackrel{0}{0}$ & ल) & 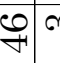 & $\infty$ & & $\neg$ & \\
\hline & 6) & $m$ & & $\stackrel{0}{\circ}$ & -1 & N & & $\sigma$ & & & & -1 & & & -1 & & & & & $\infty$ & N & & $\neg$ & $\Gamma$ & & & N) & $\stackrel{\leftrightarrow}{\circ}$ & $\underset{+}{0} 0$ & \begin{tabular}{c|c}
6 & 6
\end{tabular} & $\mathrm{~N}$ & & \\
\hline & 20 & & & $\Gamma$ & & -1 & & $\stackrel{\sim}{\sim}$ & & & $\mathrm{N}$ & 20 & & & & & $\neg$ & & & N & 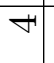 & & & 0 & & & $\sigma$ & ळ) & ${ }_{\forall}$ & $\infty 1$ & -1 & & \\
\hline & హ) & $\Gamma$ & & 10 & -1 & & & -1 & & & & -1 & & & & -1 & & & & 10 & 금 & & 10 & $\infty$ & $\mathrm{N}$ & & $m_{-1}$ & 용 & $\underset{f}{P}$ & +1 & & & \\
\hline & ๙่ & & & $F$ & -1 & & & $\infty$ & & & & & & & & & & & $-1 c$ & 0 & 듣 & & $\infty$ & $\infty$ & & -10 & $\infty$ & అం: & $\underset{+}{\infty}$ & 0 & & & -1 \\
\hline & ô & $\Gamma$ & -1 & 0 & N & & & 0 & & & $N$ & -1 & & & & N & $\mathrm{N}$ & & & 0 & $\infty$ & & $F$ & 10 & & & $\begin{array}{lll}0 & 0\end{array}$ & $\begin{array}{c}\infty \\
\text { m } \\
\end{array}$ & \begin{tabular}{ll} 
& 0 \\
\hdashline
\end{tabular} & ov & & & \\
\hline & $\widehat{a s}$ & & & & -1 & & & -1 & & & & & & & & & & & & $\infty$ & 금 & & & -1 & & & 可 & 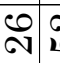 & \begin{tabular}{l|l}
$\mathrm{N}$ & \multicolumn{1}{c}{} \\
$\mathrm{S}$ &
\end{tabular} & $\underset{\sim}{\circ} \odot$ & N & & \\
\hline & ๑) & -1 & & $a$ & & & & 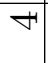 & & & -1 & & & & & -1 & & & & $N$ & $\stackrel{-}{\circ}$ & & & $\infty$ & & & $\stackrel{0}{\circ}$ & $\hat{\infty}$ & $\underset{f}{0} 10$ & م & $\mathrm{N}$ & -1 & \\
\hline & $\infty$ & -1 & & $\sigma$ & N & & & $\infty$ & & -1 & & -1 & & & & & & & & $\sigma$ & 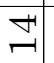 & & & -1 & & & $\infty$ & ल) & 잉 & $\infty$ & & & \\
\hline & $\begin{array}{l}\infty \\
\infty\end{array}$ & & & & & & & & & & & & & & & & & & & $\Gamma$ & 足 & & & $\infty$ & & & $\sigma$ & m) & $\begin{array}{lll}0 & 0 \\
& 0\end{array}$ & \begin{tabular}{l|l}
$\mathrm{N}$ & 7
\end{tabular} & -1 & & \\
\hline & $\infty$ & & & N & & & & $\Gamma$ & & & & & & & & & & & & 10 & N & $\neg$ & & $\forall$ & & & $\sigma$ & $\underset{7}{4}$ & $\underset{\forall}{\stackrel{f}{*}} \odot$ & ov & & & \\
\hline & $\infty$ & N & & & & & & $\infty$ & & & & & & & & & & & & -1 & $\neg$ & & & & & & $\stackrel{\circ}{\circ}$ & $\widehat{N}$ & $\stackrel{0}{\circ}$ & & & & \\
\hline $\mid \begin{array}{c}1 \\
\sim \\
0\end{array}$ & $\infty$ & N & & & -1 & & -1 & 0 & & & & & & & & & & & & H & & & & 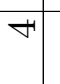 & & & $\infty$ & จে & న & & & & \\
\hline 光 & $\underset{\mho}{0}$ & $\hat{\sigma}$ & $\infty$ & 3) & $\stackrel{8}{-1}$ & $\stackrel{v}{-1}$ & $\begin{array}{l}0 \\
0 \\
-1\end{array}$ & 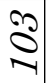 & $\sigma^{2}$ & $\begin{array}{l}20 \\
-1 \\
-1\end{array}$ & 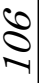 & $\widehat{\nabla}$ & $\begin{array}{l}\infty \\
0 \\
-1\end{array}$ & $\stackrel{2}{-1}$ & $\stackrel{ }{-1}$ & $\bar{N}$ & $\begin{array}{l}\mathcal{N} \\
-1\end{array}$ & $\stackrel{m}{-}$ & $\underset{N}{N}$ & $\begin{array}{l}0 \\
-1 \\
-1\end{array}$ & $\begin{array}{l}0 \\
-1 \\
-1\end{array}$ & $\stackrel{N}{-1}$ & $\begin{array}{l}\infty \\
-1\end{array}$ & $\begin{array}{l}2 \\
\sim\end{array}$ & 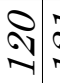 & సै & $\stackrel{े}{\mathrm{~N}}$ & 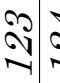 & \begin{tabular}{l|l}
$*$ & 5 \\
- & 5
\end{tabular} & $\begin{array}{lll}5 & 5 \\
V & 5\end{array}$ & 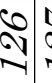 & $\widehat{N}$ & $\infty$ \\
\hline
\end{tabular}




\begin{tabular}{|c|c|c|c|c|c|c|c|c|c|c|c|c|c|c|c|c|c|c|c|c|c|c|c|c|c|c|c|c|c|c|c|c|c|}
\hline & ช & \begin{tabular}{|l|}
10 \\
20
\end{tabular} & $\begin{array}{l}\boldsymbol{N} \\
\boldsymbol{n}\end{array}$ & $\vec{\sigma}$ & $\begin{array}{l}0 \\
\\
\end{array}$ & 0 & -1 & N & 6 & ov & \begin{tabular}{|l|}
0 \\
-1
\end{tabular} & -1 & 6 & \begin{tabular}{|l|}
$\infty$ \\
$\infty$ \\
$\infty$ \\
10
\end{tabular} & 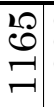 & \begin{tabular}{l|l} 
& \\
\multirow{N}{N}{} & \\
N &
\end{tabular} & \begin{tabular}{c|c|}
\multirow{2}{*}{} & \\
$\mathrm{N}$ & \\
\end{tabular} & 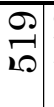 & 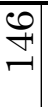 & N & $\underset{-\infty}{\infty}$ & $\underset{+}{0}$ & $\mathbf{N}$ & $\begin{array}{ll}r \\
\end{array}$ & $\vec{r}$ & 70 & \begin{tabular}{l|l}
$\boldsymbol{N}$ & 7
\end{tabular} & & \begin{tabular}{l|l}
0 \\
0
\end{tabular} & 7 & S' & 10 & $m$ \\
\hline & $\bar{z}$ & $\begin{array}{c}0 \\
-1\end{array}$ & $\begin{array}{c}0 \\
\text { N }\end{array}$ & ๙2 & 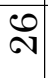 & $\forall$ & -1 & N & 10 & N & $\Gamma$ & -1 & 0 & $\stackrel{0}{\mathrm{~N}}$ & $\stackrel{0}{\mathrm{~N}}$ & $\stackrel{0}{\stackrel{0}{N}}$ & $\infty_{1}$ & $\stackrel{0}{\mathrm{~N}}$ & $\stackrel{\mathrm{N}}{\mathrm{N}}$ & -1 & $\infty$ & ${ }_{10}^{20}$ & $\mathbf{N}$ & -1 & $\neg r$ & -10 & O $C$ & 04 & T & -1 & $\begin{array}{c}0 \\
\mathrm{~N}\end{array}$ & $\forall$ & $m$ \\
\hline & $\stackrel{-1}{-1}$ & N & ๙2 & N & $\begin{array}{l}\infty \\
10\end{array}$ & & & & -1 & & & & -1 & $\stackrel{N}{\mathrm{~N}}$ & $\begin{array}{l}0 \\
10\end{array}$ & $\stackrel{\infty}{-1}$ & -1 & $\mid \begin{array}{ll}10 \\
-1\end{array}$ & & & & & & & & & & & & & 10 & & 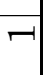 \\
\hline & ชి & & ヘิ & 10 & $\underset{7}{\sigma}$ & & & & -1 & & N & & & ㅇำ & $\stackrel{0}{+}$ & N & & అ्व & $\infty$ & & & 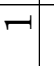 & & & & $\neg$ & & -1 & & & 10 & & \\
\hline & $\infty$ & & $\infty_{1}$ & 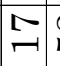 & ڤ & & & & N & & 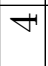 & & & $\widehat{N}$ & $\begin{array}{l}\infty \\
10\end{array}$ & $\stackrel{\Omega}{\sim}$ & & $\underline{\bullet}$ & -1 & & & & -1 & & & & & & -1 & & 0 & $\neg 1$ & \\
\hline & $\hat{\sigma}$ & N & 二 & $\stackrel{\sim}{\sim}$ & $\stackrel{\infty}{\rightarrow+}$ & & & & & & -1 & & -1 & 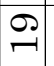 & $\begin{array}{l}\text { No } \\
\text { No }\end{array}$ & $\sqrt{-1}$ & & $\infty$ & -1 & & & $m$ & & & & & & $\begin{array}{lll} & 6\end{array}$ & $\mathrm{~N}$ & & 0 & & \\
\hline & 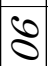 & & $\sigma$ & $\overrightarrow{\mathrm{N}}$ & 20 & & & & & -1 & & & & $\stackrel{\circ}{\circ}$ & 8 & $\stackrel{0}{\mathrm{~N}}$ & & $\widehat{N}$ & $\mathrm{~N}$ & & & $\mathbf{N}$ & & & & & & -1 & & & $r$ & & \\
\hline & 10 & & $\sigma$ & 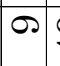 & $\stackrel{\rho}{\rightarrow}$ & & & & $\Gamma$ & -1 & & & & $\stackrel{\infty}{\sim}$ & $\underset{\forall}{\infty}$ & $\overrightarrow{\mathrm{N}}$ & & $\stackrel{20}{N}$ & & & & & & & & & & & & & $\infty$ & & \\
\hline & $\sigma^{*}$ & $\infty$ & $\stackrel{10}{\mathrm{~N}}$ & 元1 & \begin{tabular}{|l|}
10 \\
10
\end{tabular} & & & & & & & & & 穴 & $\stackrel{10}{7}$ & 근 & & $\underset{\square}{+}$ & & & & & -1 & & & & & & & & $2 \Omega$ & & \\
\hline & 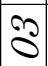 & 10 & 二 & 元 & 10 & -1 & & & & & $\infty$ & & & 금 & $\stackrel{0}{+}$ & $m$ & & 담 & & & & & & & & & & $m 0$ & \begin{tabular}{l|l} 
& 7
\end{tabular} & -16 & (0) & & \\
\hline & כै & $\nabla$ & $\underset{-1}{+}$ & 元 & $\stackrel{\sim}{\forall}$ & & & & & & $\infty$ & & & 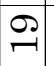 & ๓ి & 二 & & $\stackrel{N}{\mathrm{~N}}$ & $\infty$ & & & -1 & & & & & & $m$ & & & 0 & & \\
\hline & $\hat{\sigma}$ & N & $\begin{array}{l}0 \\
-1\end{array}$ & $\Gamma$ & 가 & & & & & & N & & & 건 & $\underset{\forall}{\sigma}$ & +1 & & $\overrightarrow{\mathrm{N}}$ & $m$ & & & & & & & & & & -1 & & $N$ & & \\
\hline & 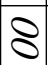 & $\stackrel{N}{\sim}$ & $\stackrel{+}{\mathrm{N}}$ & $\infty$ & F & & & & -1 & & & & & 넌 & $\stackrel{\circ}{\circ}$ & $\nabla$ & & $\infty$ & 0 & & -1 & & & & -1 & & & & & & $\stackrel{\Omega}{\sigma}$ & & -1 \\
\hline & వి & 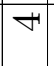 & $\log _{1}$ & $\Gamma$ & $\stackrel{9}{9}$ & $\boldsymbol{N}$ & & & & & -1 & & -1 & N & $\stackrel{\circ}{\circ}$ & + & -1 & $\stackrel{m}{-1}$ & $\mathrm{~N}$ & N & & & & & & & & & $\mathrm{N}$ & & \pm & & \\
\hline & $\begin{array}{l}\infty \\
0\end{array}$ & $\neg$ & $\underset{\sim}{+}$ & $\neg$ & $\stackrel{\bigcirc}{+}$ & -1 & & -1 & & & & & & $\stackrel{N}{\mathrm{~N}}$ & की & -1 & & $\stackrel{20}{10}$ & -1 & & & & & & & & & & -1 & & 드 & & \\
\hline & $\widehat{\widehat{J}}$ & 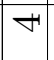 & $\boldsymbol{\sigma}$ & $\infty$ & م & & & -1 & & & & -1 & & $\begin{array}{l}\infty \\
\sim \\
N\end{array}$ & $\stackrel{\circ}{\infty}$ & 6 & & 거 & 0 & & & -1 & & & & & & -12 & 20 & & N & & \\
\hline & 6) & N & 겅 & $\infty$ & จ & $\mathbf{N}$ & & . & & & & & & $\stackrel{\bullet}{\bullet}$ & F & $\infty$ & $\boldsymbol{N}$ & 거 & $\infty$ & & & N & & & & & & & 20 & & 0 & -1 & -1 \\
\hline & 20 & -1 & $\stackrel{N}{\sim}$ & $\infty$ & ๙ & & & & & & & & & م) & $\tilde{\infty}$ & $\infty$ & $\neg$ & $\infty$ & $\underset{\sim-1}{\infty}$ & & & 0 & & & & & & & ס & & $\infty$ & N & \\
\hline & $\sigma^{*}$ & $\infty$ & $\Gamma$ & + & $\infty$ & & & & & & & & & m & 암 & 10 & & ஸి & $\sqrt{-1}$ & & N & $\infty$ & & & & & & & $\vec{r}$ & & 0 & & \\
\hline & ڤి & $\neg$ & $\stackrel{0}{\circ}$ & 10 & $\begin{array}{l}\infty \\
\sim \\
\sim\end{array}$ & & & & & & & & & $\stackrel{\infty}{\infty}$ & के & -1 & $\infty$ & $\underset{\sim}{\infty}$ & $\stackrel{0}{\circ}$ & & & $\mathrm{N}$ & & & & & & & $\mathrm{N}$ & & -1 & -1 & \\
\hline & ô & & 10 & 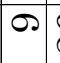 & $\stackrel{0}{\sim}$ & & & & & & & & & $\stackrel{0}{\circ}$ & $\underbrace{0}_{+1}$ & 10 & -1 & $\stackrel{\circ}{\circ}$ & 거 & & -1 & 6 & & & & & -1 & & 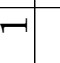 & & $\infty$ & & \\
\hline & $\widehat{a s}$ & & 0 & 二 & $\widehat{\widehat{N}}$ & & & & & & & & -1 & $\stackrel{\infty}{*}$ & ఠ & $\infty$ & N & L & $\underset{-1}{+}$ & & $F$ & 0 & & & & & & & & & $\mathrm{~N}$ & & \\
\hline & ๑) & $\neg$ & 10 & $\nabla$ & $\stackrel{+}{\sim}$ & & -1 & & & & & & -1 & 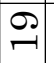 & Fै & N & -1 & $\widetilde{\sim}$ & $\underset{-1}{+}$ & & & N & & & & & & & & & $N$ & & \\
\hline & $\infty$ & $\infty$ & $\Gamma$ & N & $\stackrel{+}{\sim}$ & & & & & & & & -1 & $\stackrel{+}{\sim}$ & $\widehat{\infty}$ & 10 & 10 & $\overrightarrow{\mathrm{N}}$ & N & & -1 & $\nabla$ & & & & & -1 & & & & $\infty$ & & \\
\hline & $\begin{array}{l}\infty \\
\infty\end{array}$ & & $\Gamma$ & & $\begin{array}{l}\infty \\
\sim \\
\sim\end{array}$ & & & & & & & & & $\stackrel{0}{-1}$ & $\stackrel{\sim}{\forall}$ & 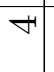 & N & $\stackrel{\infty}{\sim}$ & $m$ & & 0 & & & & & & & & & & $N$ & & \\
\hline & $\infty$ & & 10 & & 건 & & & & & & & & & $\sigma$ & $\underset{7}{0}$ & $\begin{array}{l}0 \\
0 \\
-1\end{array}$ & -1 & $\stackrel{0}{\stackrel{N}{N}}$ & -1 & & N & & & & & & & & -1 & & $\stackrel{0}{0}$ & & \\
\hline & $\infty$ & & -1 & $\neg$ & 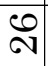 & & & & & & & & & $m_{-1}$ & $\underset{+}{+}$ & $\infty$ & $N$ & $\stackrel{\leftrightarrow}{\sim}$ & & & & -1 & & & & & & & $\mathrm{~N}$ & & $\infty$ & & \\
\hline$\left|\begin{array}{c}0 \\
1 \\
N \\
0\end{array}\right|$ & $\infty$ & & -1 & & 건 & & & & & & & & & 거 & 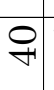 & $F$ & $\infty$ & $\vec{N}$ & & & $\Gamma$ & -1 & & $\neg 1$ & & & & & -1 & & 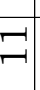 & & \\
\hline 光 & $\underset{\mho}{0}$ & $\begin{array}{l}\stackrel{2}{*} \\
-1\end{array}$ & ヘิ & ઝิ & ले & ๗ิ) & م) & ڤิ) & $\begin{array}{l}\hat{\jmath} \\
\text { พิ-1 }\end{array}$ & $\begin{array}{l}\hat{⿵} \\
-1\end{array}$ & $\begin{array}{l}\infty \\
-\infty \\
-1\end{array}$ & ๙ે) & $\underset{7}{7}$ & $\underset{y}{J}$ & $\underset{y}{\nu}$ & $\underset{m}{2}$ & 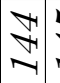 & $\frac{2}{2}$ & 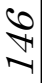 & $\underset{N}{N}$ & $\begin{array}{l}\infty \\
+ \\
-1\end{array}$ & $\underset{7}{7}$ & $\begin{array}{l}0 \\
-1 \\
7\end{array}$ & 20 & $\begin{array}{l}0 \\
-1\end{array}$ & & $\begin{array}{ll}2+1 \\
-1\end{array}$ & $\begin{array}{ll}10 & 5 \\
-1 & 4\end{array}$ & \begin{tabular}{lll}
0 & 1 \\
\hdashline & 1
\end{tabular} & $\widehat{v}_{1}$ & $\begin{array}{l}\infty \\
1 \\
-1\end{array}$ & $\begin{array}{l}0 \\
-1\end{array}$ & $\because$ \\
\hline
\end{tabular}




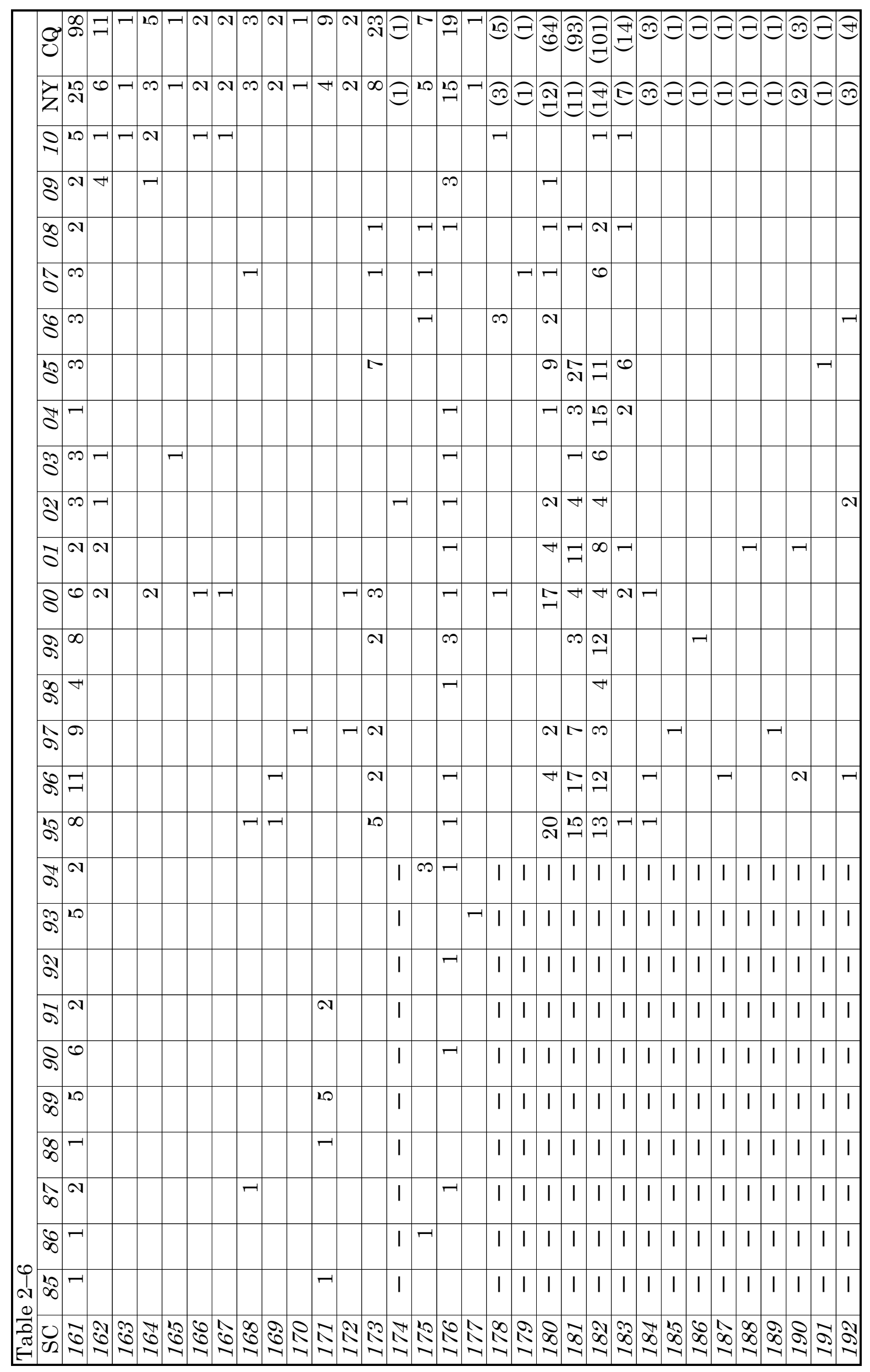




\begin{tabular}{|c|c|c|c|c|c|c|c|c|c|c|c|c|c|c|c|c|c|c|c|c|c|c|c|c|c|c|c|c|c|c|c|c|}
\hline & & & & & & & & & 3 & & 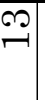 & $F$ & & $\stackrel{\infty}{-1}$ & $\Gamma$ & \begin{tabular}{l} 
m \\
\hdashline \\
8
\end{tabular} & $\sqrt{-1}$ & & & 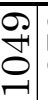 & & & $\begin{array}{l}\text { N } \\
\text { ב } \\
\end{array}$ & & & & & & & & & 17 \\
\hline & & & & 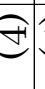 & 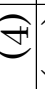 & $E$ & ט. & ט) & 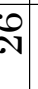 & 0 & $\sigma$ & $\begin{array}{l}0 \\
-1\end{array}$ & -1 & 엄 & -1 & $\stackrel{\leftrightarrow}{)}$ & -1 & $\stackrel{\mathcal{N}}{\sim}$ & $\stackrel{\rho}{\sim}$ & $\stackrel{\mathrm{v}}{\mathrm{v}}$ & $\stackrel{\mathrm{v}}{\mathrm{N}}$ & $\stackrel{\leftrightarrow}{\circ}$ & $\stackrel{\leftrightarrow}{*}$ & -1 & 莗 & $\infty$ & 穴 & -1 & & 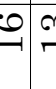 & & 17 \\
\hline & $\begin{array}{r}7 \\
\end{array}$ & & & & -1 & $\underline{\theta}$ & $\mathcal{S}$ & +4 & ov & & & $\boldsymbol{N}$ & & -1 & & $\stackrel{\circ}{\circ}$ & & & & & $\underset{\sim}{\infty}$ & $F$ & $\stackrel{\Omega}{\sim}$ & & & & $\mathrm{N}$ & & - & $\stackrel{+}{\Delta}$ & & \\
\hline & & & & & & - & .) & D & $\begin{array}{l}\infty \\
\cdots \\
m\end{array}$ & & & & & & & $\vec{\sigma}$ & & & & 아 & $\begin{array}{l}0 \\
71\end{array}$ & $\begin{array}{l}0 \\
\not+1\end{array}$ & $\stackrel{\infty}{\infty}$ & & & & $\forall$ & 0 & $\infty$ & $\nabla^{\circ}$ & & \\
\hline 8 & & & & & & 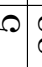 & $m$ & $+\infty$ & 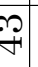 & & & & & -1 & & ๓ి & & -1 & & F & $f$ & F & $\stackrel{\vec{N}}{*}$ & & & & $\mathrm{~N}$ & & م & $->16$ & & \\
\hline & & & & & & m & $m$ & 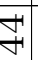 & $\begin{array}{l}\infty \\
-\infty \\
-\infty\end{array}$ & & & & & & & êم & & & & $\widehat{\sigma}$ & $\overrightarrow{0}$ & $\begin{array}{l}\infty \\
\infty\end{array}$ & ले & & & & 6 & & $v$ & $\infty \mathrm{cr}$ & & \\
\hline & $8{ }^{\circ}$ & $\mathrm{v}$ & & -1 & & S & $\widehat{\sigma}$ & 足 & קి & & & -1 & & -1 & & ली & & $\infty$ & & $\widehat{\infty}$ & $f^{\prime}$ & ది & $\vec{\infty}$ & & & & & & & +6 & & \\
\hline 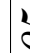 & $r$ & & & & & $v$ & , & 아 & $\begin{array}{l}0 \\
y\end{array}$ & & & & & & & ָָ & & & $N$ & के & $\stackrel{20}{4}$ & ભ & $\sqrt{-1}$ & & $\infty$ & & & & م6 & 4 & & \\
\hline & 5 & & & & & $v$ & $\widehat{N}$ & ס & + & & & & & & & $\vec{m}$ & & & & 20 & ט) & จ & ง & & & & $\mathrm{N}$ & & & & & \\
\hline & & & & & & v & $\sqrt{3}$ & 0 & +4 & & & & & & & 0 & & & & $\mp$ & N & $m$ & $\boldsymbol{N}$ & & & & $\mathbf{N}$ & & & & & \\
\hline & & & & & & & & & & & & & & & & & & & & & स० & & & & & & & & & & & \\
\hline & $\mathrm{S}^{\mathrm{r}}$ & & & & & 81 & ه & $\vec{\infty}$ & r & & & -1 & & -1 & & $\widehat{\infty}$ & & & -1 & $F$ & $\frac{10}{7}$ & $\widehat{N}$ & $\stackrel{\leftrightarrow}{\circ}$ & & $\mathrm{N}$ & & 10 & & T & 60 & & \\
\hline & $y$ & -1 & -1 & & & 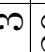 & o & 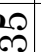 & m & & & & & & & $\bar{\infty}$ & & & 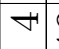 & 0 & g & $\widehat{\curvearrowright}$ & $\infty$ & & & & -1 & & & + & & \\
\hline & & & & & $\mathrm{N}$ & o & S & (O) & - & & & -1 & & & & -1 & & 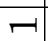 & & $\Sigma$ & 0 & $\infty$ & 10 & & $\Gamma$ & & & & & $6 \mathrm{cr}$ & & \\
\hline & & & & & & & & & & & & & & & & & & & & & & & & & & & & & & & & \\
\hline$\delta$ & & & & ov & & $m$ & טֶ) & هి & $\begin{array}{c}\infty \\
\cdots \\
\cdots \\
\cdots\end{array}$ & & & & & & -1 & ल) & & & & 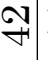 & $\stackrel{\sharp}{\forall}$ & $\widehat{N}$ & $\begin{array}{c}\infty \\
\infty \\
\infty\end{array}$ & & & & $\infty$ & & $\Omega$ & $\sigma o$ & & \\
\hline 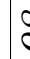 & & v & & & & $v 1$ & ט) & $\stackrel{\mathrm{N}}{\mathrm{O}}$ & $\vec{b}$ & & & $N$ & & & & $\begin{array}{l}\infty \\
N\end{array}$ & & & $\infty$ & Ft & હ) & $\underset{\sim}{+}$ & 악 & & & & & & $\infty$. & 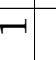 & & \\
\hline & 7 & -1 & & & -1 & $v$ & ov & $\stackrel{\leftrightarrow}{\circ}$ & 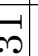 & -1 & $\mathrm{~N}$ & -1 & & & & 우 & & & $N$ & $\stackrel{\infty}{+}$ & क् & $\stackrel{\curvearrowright}{\circ}$ & $\tau_{\forall}$ & & -1 & & - & -16 & & $\infty$ & & \\
\hline & 01 & & & $\mathrm{~N}$ & & $v 0$ & $m$ & 6 & 4 & & -1 & & & $\mathrm{~N}$ & & N & & 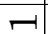 & $\pi$ & $\infty$ & +1 & $\sqrt{-1}$ & $\infty$ & & & -1 & & & & $\mathrm{~N}$ & & \\
\hline & & & & & & & & & & & & & & & & & & & & 64 & & & & & & & & & & & & \\
\hline$y$ & & & & ov & & $m$ & $\infty$ & ס & D. & -1 & & + & & & & $\stackrel{\infty}{N}$ & & & -1 & $\widehat{\infty}$ & 이 & m & 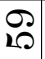 & & $\mathrm{N}$ & & & & है & -1 & & \\
\hline & +4 & & 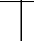 & 1 & 1 & 1 & -1 & $\infty$ & 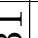 & -1 & & 0 & & & & $\Sigma$ & & -1 & $N$ & 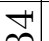 & I & 10 & 0 & & -1 & $\infty$ & & & o & & & \\
\hline & & & & & & & & & & & & & & & & & & & & & & & & & & & & & & & & \\
\hline 8 & s. & & 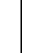 & I & | & | & $\infty$ & 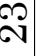 & 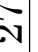 & & $\infty$ & & & -1 & & ๓ి & & & $\infty$ & $\stackrel{\infty}{\mathrm{N}}$ & 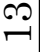 & ㅇำ & مి & & N & & & & $\vec{v}$ & & & \\
\hline & v & & 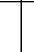 & I & I & | & 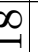 & $\begin{array}{c}+1 \\
\mathrm{~m}\end{array}$ & טै & & -1 & $\infty$ & -1 & -1 & & s & & $\neg$ & -1 & m & 0 & $\stackrel{N}{*}$ & $\begin{array}{l}\mathcal{N} \\
0\end{array}$ & & $\mathrm{~N}$ & & & & $t$ & & & \\
\hline & & & & & & & & & & & & & & & & & & & & & & & & & & & & & & & & \\
\hline & 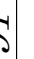 & & 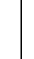 & I & I & | & 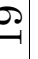 & D) & מֶ & -1 & -1 & 10 & & & & F & & -1 & $\infty$ & 踪 & $\stackrel{N}{N}$ & $\stackrel{\infty}{\stackrel{N}{N}}$ & ฉి & -1 & -1 & $\Omega$ & & & D. & & & \\
\hline$\delta$ & & & 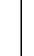 & I & I & | & $\underline{-1}$ & $\underset{\forall}{*}$ & 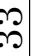 & & $\mathrm{N}$ & -1 & & $\sqrt{1}$ & & F & & & -1 & ำ & $\stackrel{\mathrm{N}}{\mathrm{N}}$ & $\stackrel{9}{\stackrel{9}{*}}$ & $\mathscr{8}$ & & +1 & & & & $\vec{n}$ & & & \\
\hline 8 & $D$ & & 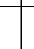 & | & -1 & $m$ & $=$ & 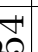 & 0 & -1 & -1 & $F^{\prime}$ & & $\mathrm{N}$ & & $\mathscr{P}$ & & -1 & $N$ & 5 & $\stackrel{N}{N}$ & $\vec{m}$ & $\mathscr{\infty}$ & & $\mathrm{N}$ & & & & $\begin{array}{l}4 \\
7\end{array}$ & -1 & & - \\
\hline & & & & & & & & & & & & & & & & & & & & & & & & & & & & & & & & \\
\hline$g$ & $\begin{array}{l}0 \\
0\end{array}$ & & 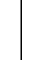 & I & I & | & 我 & oy & ? & N & -1 & N & & & & ๙ิ & & -1 & $\infty$ & F & $\stackrel{\infty}{-1}$ & ڤै & مَ & & 10 & & & & - & & & \\
\hline 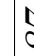 & & & 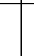 & I & I & I & 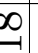 & טֶ) & 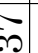 & & -1 & $\infty$ & & $N$ & & $\begin{array}{c}\infty \\
\infty \\
\infty\end{array}$ & 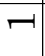 & N & $N$ & 가 & $\stackrel{\infty}{\infty}$ & $\begin{array}{l}\infty \\
N \\
N\end{array}$ & $\overrightarrow{6}$ & & $\infty$ & & & & 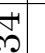 & & & \\
\hline & & & & 1 & 1 & | & $=$ & 0 & $\infty$ & & & $N$ & & & & $N$ & & $N$ & $N$ & 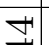 & $\infty$ & $\Omega$ & 4 & & $\infty$ & & & & $?$ & & & \\
\hline & & & & & & & & & & & & & & & & & & & & & & & & & & & & & & & & \\
\hline & & & & I & I & | & 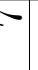 & $\begin{array}{c}0 \\
y\end{array}$ & 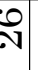 & & & $\infty$ & & & & $\vec{\sigma}$ & & $N$ & -1 & $\stackrel{\text { N }}{+}$ & $\stackrel{\stackrel{N}{\sim}}{\sim}$ & $\begin{array}{l}\infty \\
\stackrel{N}{N}\end{array}$ & ח̊ & & 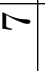 & & & & 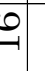 & & & \\
\hline to & & & & 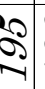 & $\begin{array}{c}0 \\
2 \\
-1\end{array}$ & 5 & & & & & & & రీ & $\begin{array}{c}20 \\
\curvearrowright \\
\curvearrowright\end{array}$ & & $\widehat{\widehat{\vartheta}}$ & $\infty$ & 2 & $\begin{array}{l}0 \\
\vec{v}\end{array}$ & $\underset{ה}{ה}$ & จิ & 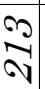 & $\frac{\pi}{v}$ & $\begin{array}{l}10 \\
\Delta\end{array}$ & $\begin{array}{l}0 \\
\frac{0}{v}\end{array}$ & $\widehat{N}$ & \begin{tabular}{l}
$\infty$ \\
\multirow{2}{*}{}
\end{tabular} & $\stackrel{د}{\Delta}$ & : val & $\sqrt{*} \cdot 1$ & v & $\sqrt{ }$ \\
\hline
\end{tabular}




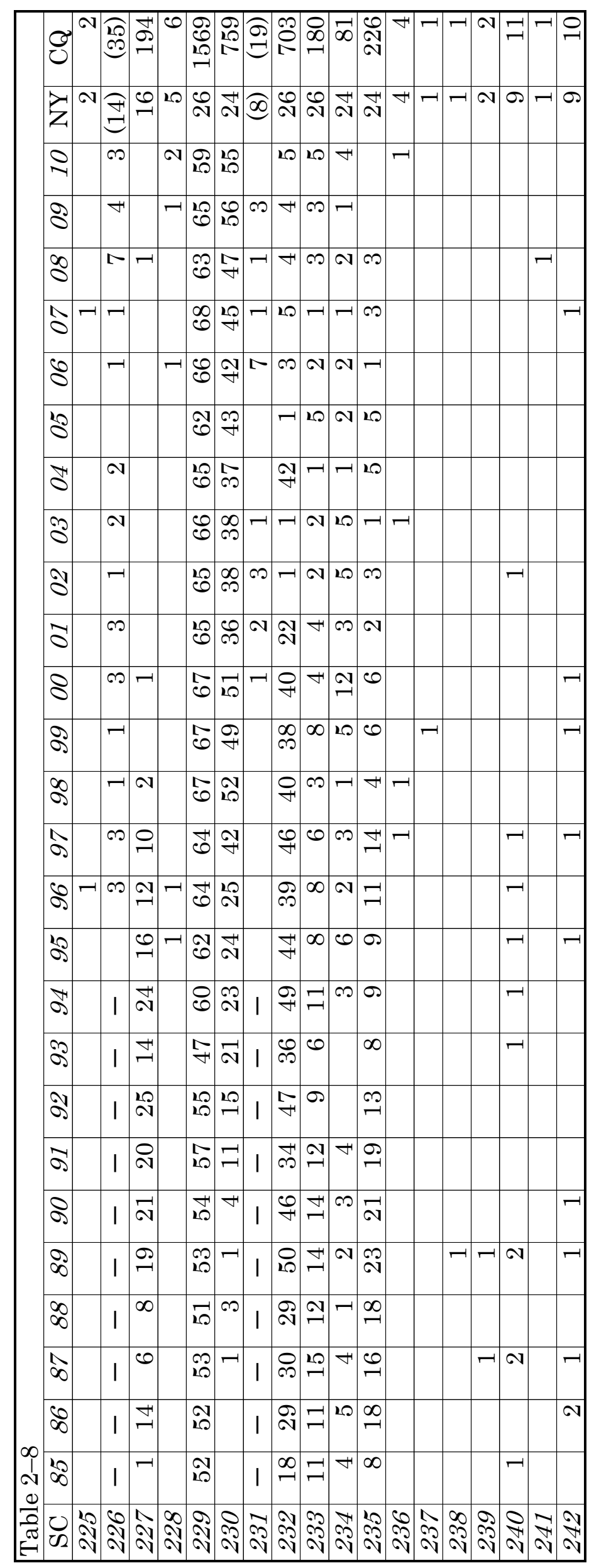

